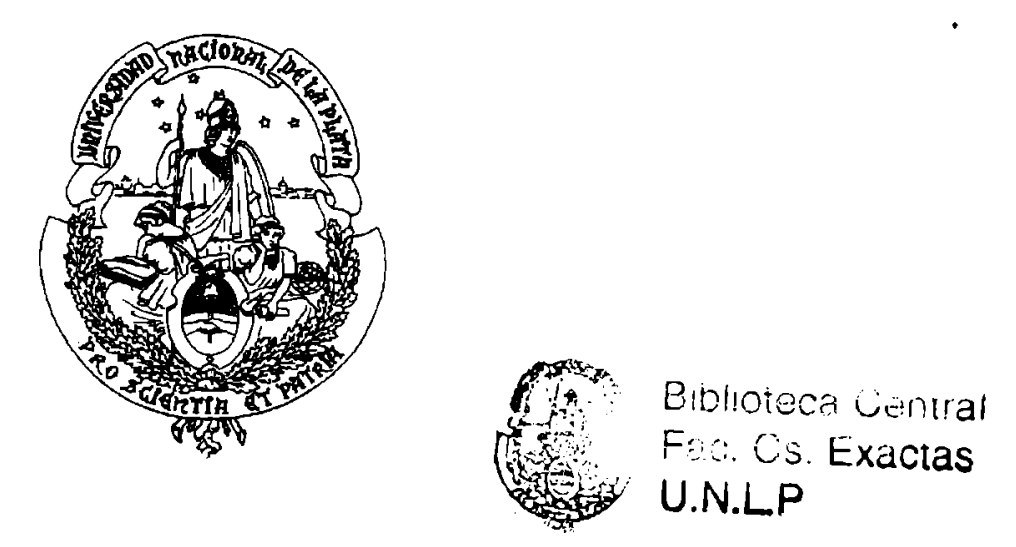

UNIVERSIDAD NACIONAL DE LA PLATA

FACULTAD DE CIENCIAS EXACTAS

DEPARTAMENTO DE QUIMICA

\title{
MODOS DE CRECIMIENTO EN LA
}

\section{ELECTROCRISTALIZACION DE METALES}

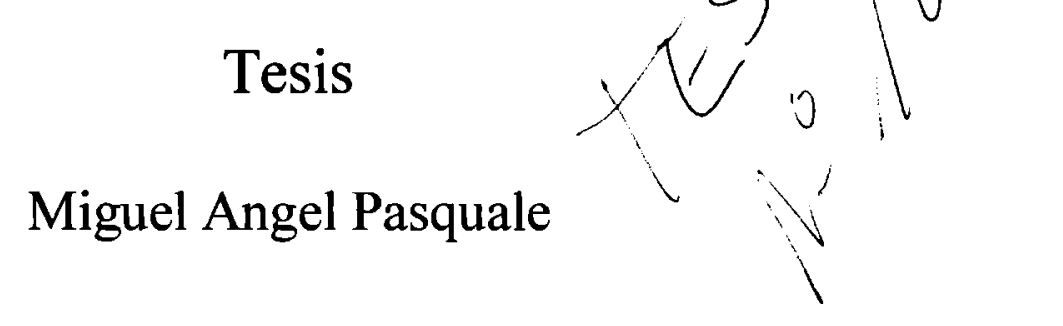

2004

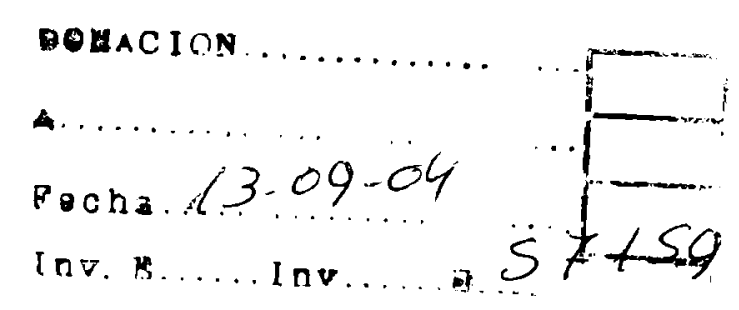


El presente trabajo de Tesis se realizó bajo la dirección de la Ing. Susana L. Marchiano y el Dr. Alejandro. J. Arvia, en el Instituto de Investigaciones Fisicoquímicas Teóricas y Aplicadas del Departamento de Química de la Facultad de Ciencias Exactas, Universidad Nacional de La Plata. Se presenta a consideración de las autoridades de dicha Facultad para acceder al grado académico de Doctor de la Facultad de Ciencias Exactas. 


\section{Agradecimientos}

A mis directores Ing. Susana L. Marchiano y Dr. Alejandro J. Arvia por la dirección de este trabajo.

A las autoridades del INIFTA, Dr. A. J. Arvia y E. Castro (actual director), por permitir la realización de este trabajo.

Al Prof. D. Barkey de la Universidad de New Hampshire, por las fructiferas discusiones.

Al Dr. E. Albano y al Lic. C. Horowitz por los trabajos realizados en conjunto sobre la caracterización de los electrodepósitos.

Al Dr. A. Bolzán, por la ayuda en los experimentos voltamperométricos.

A la Dra. M. Mirifico y el Dr. Carán, por asistencia en el uso de espectrómetro IR.

Al Lic. Fernando Amarilla por la colaboración en las determinaciones de viscosidad.

A todo el personal de taller, electrónica, vitroplastía, biblioteca y secretaría del INIFTA.

A la Facultad de Ciencias Exactas y a sus docentes.

A la Cátedra de Fisicoquímica $I$.

Al Dr. Garavaglia (CIOP) y al Ing. Sacchetto (UTN) por la colaboración en el diseño y construcción de diversos materiales.

A La Comisión de Investigaciones Cientificas de la provincia de Buenos Aires, por otorgarme una beca de entrenamiento para realizar tareas de investigación en el INIFTA.

A la Agencia Nacional de Promoción Cientifica y Tecnológica por otorgarme una beca de postgrado y al Consejo Nacional de Investigaciones Cientificas y Técnicas (CONICET), por otorgarme la beca doctoral.

A mis amigos.

A mi familia.

Este trabajo fue financiado por la Agencia Nacional de Promoción Cientifica y Tecnológica y por el Consejo Nacional de Investigaciones Cientificas y Técnicas (CONICET). 
A la mamma, 


\section{INDICE}

\section{CAPITULO 1}

$\begin{array}{lll}1.1 & \text { Introducción } & 1\end{array}$

$\begin{array}{lll}1.2 & \text { Ordenación del trabajo } & 2\end{array}$

CAPITULO 2

Recopilación bibliográfica y conceptos 5

$2.1 \quad$ Sistemas electroquímicos 5

$\begin{array}{lll}2.1 .1 & \text { Equilibrio electroquímico } & 6\end{array}$

$\begin{array}{lll}2.1 .2 & \text { La reacción electroquímica } & 7\end{array}$

$\begin{array}{lll}\text { 2.1.3 Transporte de materia } & 10\end{array}$

$\begin{array}{lll}\text { 2.1.3.1 Electrolito binario } & 12\end{array}$

$\begin{array}{lll}\text { 2.1.3.2 Electrolito soporte } & 13\end{array}$

$\begin{array}{lll}2.2 & \text { Formación de metales por vía electroquímica } & 13\end{array}$

2.3 Electrodeposición de plata 14

$\begin{array}{lll}\text { 2.3.1 } & \mathrm{La} \text { reacción } \mathrm{Ag}^{+} / \mathrm{Ag} & 14\end{array}$

2.3.2 Características cinéticas para la reacción de trasferencia de carga 15

$2.4 \quad$ Morfología de depósitos (objetos) 16

$\begin{array}{lll}2.4 .1 & \text { Clasificación morfológica } & 17\end{array}$

$\begin{array}{ll}\text { 2.4.2 Técnicas usadas en el estudio de interfases } & 19\end{array}$

$\begin{array}{lll}2.4 .2 .1 & \text { Escalado dinámico } & 19\end{array}$

$\begin{array}{lll}\text { 2.4.2.2 } & \text { Modelos de crecimiento de las interfases }\end{array}$

2.4.3 Clases de universalidad 23

$\begin{array}{lll}2.4 .4 & \text { Geometría fractal } & 23\end{array}$

2.4.4.1 Autosimilaridad y autoafinidad 24

2.4.4.2 Dimensión fractal 24

2.4.4.3 Tipos de fractales 26

$\begin{array}{lll}\text { 2.4.4.4 Métodos para determinar la dimensión fractal } & 27\end{array}$

$2.5 \quad$ Formación de una fase en un medio desordenado 29 
2.6 Trabajos previos seleccionados en relación con la tesis

\section{CAPITULO 3}

\section{Parte Experimental}

3.1 Técnicas electroquímicas

3.1.1 Equipos y materiales

3.1.1.1 Potenciostatos

3.1.1.2 Electrodos de referencia

$\begin{array}{lll}\text { 3.1.1.3 Celdas electroquímicas } & 38\end{array}$

3.1.1.4 Celdas empleadas en los experimentos con gradientes de temperatura 41

3.1.1.5 Celdas utilizadas para estudiar el efecto de un gradiente térmico y la 42

3.1.1.6 Celda empleada para realizar el estudio estadístico de la estructura 42

3.2 Soluciones empleadas

3.2.1 Soluciones empleadas en la electrodeposición de plata 43

3.3 Sistema de seguimiento y observación del electrodepósito 44

3.4 Sistema de termostatización de electrodos en celdas quasibidimensionales y tridimensionales

$\begin{array}{lll}3.4 .1 & \text { Sensores de temperatura } & 46\end{array}$

3.4.2 Sistema de calentamiento, medida y control de temperatura 48

3.5 Descripción del procedimiento experimental en la electrodeposición 51

3.5.1 Influencia de la agarosa en la electrodeposición de plata en celdas 52

3.6 Métodos ópticos empleados para estudiar perfiles de velocidad del 52

3.7 Estudio de las propiedades electroquímicas de la interfase $\mathrm{Pt} /$ solución y $\mathrm{Ag}$ / solución conteniendo agarosa

3.7.1 Adsorción de agarosa sobre platino 53

3.7.2 Utilización de la celda de flujo 54

$\begin{array}{lll}\text { 3.7.3 Adsorción de agarosa sobre plata } & 55\end{array}$

\section{CAPITULO 4}

Electrodepósitos ramificados de plata $\quad 57$

4.1 Electrodeposición de plata en celdas quasi-bidimensionales 
4.1.1 Electrodeposición de plata utilizando la solución I en la celda 57 circular A

4.1.2 Electrodeposición de plata utilizando la solución I en la celda rectangular BIII quasi bidimensional

4.1.3 Electrodeposición de plata utilizando la solución II $+\mathrm{H}_{2} \mathrm{SO}_{4} \quad 0,5 \mathrm{M}$

4.1.4 Electrodeposición de plata utilizando la solución II

4.2 Experimentos galvanostáticos

4.3 Crecimientos aciculares

4.3.1 Descripción macro y microscópica de los electrodepósitos aciculares

4.3.2 Dinámica de crecimiento de los electrodepósitos aciculares

4.4 Análisis e interpretación de resultados

4.4.1 Electrodeposición en celdas electroquímicas quasi-bidimensionales 90

4.4.1.1 Celda circular y celda rectangular 93

4.4.2 Influencia de la migración, convección y difusión en la producción de electrodepósitos ramificados y crecimientos aciculares

4.4.3 Estudio de los transitorios de corriente en la electrodeposición de plata en celdas quasi-bidimensionales controlada por transporte de materia

4.4.3.1 Análisis de transitorios potenciostáticos de corriente 100

$\begin{array}{lll}\text { 4.4.3.2 } & \text { Aplicación a los datos experimentales } & 101\end{array}$

4.4.3.2.1 Transitorios de corriente para la celda circular con la solución I 104

4.4.3.2.2 Transitorios de corriente para la celda rectangular con la solución I 106

4.4.3.2.3 Transitorios de corriente para la celda rectangular con solución II $+\quad 106$

$\begin{array}{ll}\text { 4.4.4 Corriente en la punta de los crecimientos aciculares } & 108\end{array}$

\section{CAPITULO 5}

Teoría de estabilidad de Mullins - Sekerka 114

$\begin{array}{ll}5.1 & \text { Inestabilidad de Mullins - Sekerka } \\ & 114\end{array}$

5.1.1 La teoría de estabilidad en la electrodeposición de metales 116

$\begin{array}{lll}\text { 5.1.2 Teoría de la estabilidad y crecimiento dendrítico } & 119\end{array}$

$\begin{array}{lll}5.2 & \text { Relación entre el radio de la punta de los electrodepósito aciculares y } & 124\end{array}$

$\begin{array}{lll}5.3 & \text { Análisis de estabilidad lineal } & 127\end{array}$ 


\section{CAPITULO 6}

Convección natural en celdas quasi - bidimensionales

$\begin{array}{lll}6.1 & \text { Convección natural en sistemas electroquímicos } & 133\end{array}$

$\begin{array}{lll}6.2 & \text { Electrodos planos verticales } & 134\end{array}$

6.2.1 Aproximación de la película límite y solución de Levich 134

$\begin{array}{lll}6.3 & \text { Convección natural no isotérmica } & 137\end{array}$

$\begin{array}{lll}6.4 & \text { Resultados del estudio de la convección natural en celdas quasi- } \quad 140\end{array}$

6.4.1 Verificación de la ecuación general de difusión convectiva en 141

6.4.2 Posibles interferencias en el proceso de difusión convectiva 149

$\begin{array}{lll}\text { 6.4.2.1 } & 149\end{array}$

$\begin{array}{lll}\text { 6.4.2.2 Distancia cátodo-ánodo } & 151\end{array}$

6.5 Datos complementarios e interpretación de resultados 152

$\begin{array}{lll}\text { 6.5.1 Correlación general } & 152\end{array}$

$\begin{array}{lll}\text { 6.5.2 Comparación de la correlación general propuesta con datos de otros } & 154\end{array}$ autores

\section{CAPITULO 7}

Efecto de gradientes de temperatura en la electrodeposición de $\quad 157$

$\begin{array}{lll}7.1 & \text { Transiciones morfológicas } & 157\end{array}$

$\begin{array}{lll}\text { 7.1.1 Efecto de la concentración de electrolito soporte, el potencial } 161 & 16\end{array}$

$\begin{array}{lll}7.2 & \text { Descripción de la evolución de los electrodepósitos que presentan } & 164\end{array}$ $\begin{array}{ll}\text { transición morfológica } & 172 \\ \text { Parámetros relacionados con las transiciones morfológicas } & 164\end{array}$

7.3 Parámetros relacionados con las transiciones morfológicas $\quad 172$

$\begin{array}{lll}7.4 & \text { Datos complementarios e interpretación de resultados } & 180\end{array}$

$\begin{array}{lll}7.4 .1 & \text { Perfiles de velocidad del fluido } & 181\end{array}$

$\begin{array}{ll}\text { 7.4.1.1 Electrodeposición en condiciones isotérmicas } & 182\end{array}$

$\begin{array}{lll}\text { 7.4.1.2 Influencia del gradiente térmico } & 183\end{array}$ 


\section{CAPITULO 8}

Simulaciones y caracterización de los electrodepósitos

8.1 Simulaciones

8.1.1 Características del modelo

$\begin{array}{lll}\text { 8.1.2 } & \text { Ecuaciones para un campo difusional } & 186\end{array}$

$\begin{array}{lll}\text { 8.1.3 Efecto de la incorporación de la convección y la migración en un } & 187\end{array}$

$\begin{array}{lll}8.2 & \text { Caracterización de los electrodepósitos } & 191\end{array}$

$\begin{array}{lll}\text { 8.2.1 } & \text { Escalado dinámico } & 192\end{array}$

8.2.2 Análisis de la estructura interna de los electrodepósitos de plata de la región II (denso)

8.2.2.1 Resultados experimentales

\section{CAPITULO 9}

\section{Efecto del agregado de aditivos}

9.1 Electrodeposición de plata empleando soluciones de sulfato de plata en presencia y ausencia de electrolito soporte, conteniendo distintas concentraciones de agarosa

9.2 Medidas de potencial de reposo 209

9.3 Deposición a subpotencial de plomo y electrodisolución anódica (upd/anodic stripping) sobre plata

9.4 Interacción agarosa - platino

9.4.1 Voltamperometría sobre platino

9.4.2 Experimentos voltamperométricos realizados empleando la celda de flujo

9.5 Espectros infrarrojos

9.6 Propiedades fisicoquímicas de las soluciones. Medidas del tiempo de escurrimiento

$9.7 \quad$ Interpretación de resultados

\section{CAPITULO 10}

Electrodeposición en medios estructurados desordenados

10.1 Estructura de los geles

10.2 Efecto de la agarosa en la electrodeposición de plata en celdas circulares quasi-2D, empleando solución II sin electrolito soporte 
10.2.2 Características morfológicas de los electrodepósitos 232

10.3 Efecto de la agarosa en la electrodeposición de plata en celdas 234

$\begin{array}{lll}\text { 10.3.1 } & \text { circulares quasi-2D, empleando solución I, con electrolito soporte } & 234\end{array}$

10.3.2 Características morfológicas de los electrodepósitos 236

10.4 Experimentos realizados en la celda quasi-2D de geometría 238

$\begin{array}{lll} & \text { rectangular } & \\ \text { 10.4.1 Curvas de polarización } & 238\end{array}$

$\begin{array}{lll}\text { 10.4.2 Transitorios de corriente } & 239\end{array}$

10.4.3 Características morfológicas de los electrodepósitos 241

$10.5 \quad$ Movilidad de los pequeños aglomerados de agarosa 245

10.6 Influencia de la concentración de la especie electroactiva en la 247

$\begin{array}{lll}10.7 & \text { Interpretación de los resultados } & 249\end{array}$

\section{CAPITULO 11}

Conclusiones generales $\quad 255$

$\begin{array}{ll}\text { Bibliografía } & 258\end{array}$

$\begin{array}{ll}\text { Apéndice A } & 267\end{array}$

Apéndice B $\quad 269$

$\begin{array}{ll}\text { Apéndice C } & 275\end{array}$

Apéndice D 276

$\begin{array}{ll}\text { Apéndice E } & 280\end{array}$ 


\section{CAPITULO 1}

\subsection{Introducción}

En este trabajo se estudia la formación electroquímica de una fase sólida. Se intenta conocer el efecto de las distintas variables involucradas en los mecanismos de formación de fases sólidas con determinada morfología y, consecuentemente en las propiedades características, tales como, densidad, fractalidad, transiciones morfológicas, etc.

El conocimiento de las variables que afectan la formación de una fase sólida, es esencial para el desarrollo de la ingeniería de los materiales, y dentro de ella, diseñar procesos de fabricación de superficies con estructuras y composición apropiadas para su uso optimizado en catálisis heterogénea, esto es, procesos tan diversos como la síntesis de compuestos químicos en múltiples escalas, procesos vinculados con sistemas de conversión y almacenamiento limpio de energía, procesos de descontaminación, etc. Abarca también, las tecnologías basadas en el empleo de semiconductores que demandan la obtención, a partir de medios fundido o en solución, de sustancias y compuestos de muy alta pureza y con caracteristicas cristalográficas particulares, según el uso al que se los destine.

Por otro lado, durante la formación de una fase sólida aparecen fenómenos de evolución de la interfase y de crecimiento de agregados que presentan particular interés para su estudio teórico y elaboración de modelos. A partir del advenimiento de los conceptos de geometría fractal para la descripción de morfologías complejas y su relación con las leyes de escala que describen la dinámica de la formación de agregados, se presta mucha atención a los modelos de agregación y a los de evolución de las interfases, y su clasificación dentro de las clases de universalidad. Resulta de fundamental importancia disponer entonces, de datos experimentales confiables para contrastar esos modelos. De la misma manera, los datos experimentales pueden servir de estimulo para mejorar los modelos existentes y desarrollar nuevos modelos.

Interesa conocer tanto las propiedades estáticas de las interfases, las que han recibido hasta ahora mayor atención, como las propiedades dinámicas. Estas últimas se refieren a su evolución como consecuencia de la acumulación de un gran número de eventos que ocurren de acuerdo a determinadas reglas. En el mejor de los casos, hasta ahora, las propiedades de las interfase en evolución, son solo parcialmente conocidas. El estudio de la dinámica de crecimiento de agregados y las correspondientes interfases constituyen temas de frontera que justifican atención. Para poder llevar a cabo esta clase de estudio, se requiere disponer de técnicas de caracterización de los agregados y de 
seguimiento de las interfases correspondientes, con el fin de disponer de elementos que permitan la contrastación entre modelos y experimentos diseñados a priori o situaciones reales que se presentan en la naturaleza. Entre estas técnicas se pueden mencionar, el escalado dinámico, el análisis de la estructura interna y el cálculo de las dimensiones fractales.

En este trabajo se estudia la formación de plata metálica por via electroquímica, empleando celdas electroquímicas "quasi-bidimensionales" de distintas geometrías y de diferentes diseños, modificando las propiedades de las soluciones acuosas con la adición de electrolito soporte y de sustancias que modifican la estructura del medio. Se analiza la dinámica de crecimiento de los electrodepósitos o agregados y se aplican modelos de crecimiento para entender el proceso. Se intenta también, explicar algunas características morfológicas a escala micro y meso métrica.

Se utiliza la electrodeposición de plata para generar los agregados, pues esta reacción constituye una de las reacciones electroquímica más rápidas conocidas. Esto permite prescindir de los procesos de transferencia electrónica en el análisis de los resultados, ya que la cinética global de electrodeposición está controlada por el transporte de materia hacia la interfase. Precisamente, como se verá en la presentación, los fenómenos de transporte juegan un papel preponderante en la selección de las morfologías de los agregados.

\subsection{Ordenación del trabajo}

El trabajo está ordenado de la siguiente manera. En Capítulo 2, se reúnen distintos conceptos básicos, requeridos para la presentación y análisis de los resultados en capítulos posteriores. Se acompaña también una extensa recopilación bibliográfica. La primera sección trata en forma sucinta los fundamentos de la electroquímica, incluyendo la definición de sistema electroquímico, las consideraciones de equilibrio, el origen de los sobrepotenciales y los fenómenos de transporte. Se destacan las características de la cupla plata/ión plata en solución acuosa.

En la segunda sección se aborda, primero en forma general, el tema de la formación de estructuras en condiciones apartadas del equilibrio y luego haciendo colación del papel que juega la electroquímica al respecto. Se definen los parámetros que permiten caracterizar agregados e interfases, y se describen las técnicas de caracterización mostrando varios ejemplos. Finalmente, el Capítulo 2 se concluye realizando una 
recopilación de trabajos previos en los que se emplean celdas electroquímicas "quasibidimensionales", relacionándolos a los temas mencionados en las secciones anteriores.

El Capítulo 3 se dedica a la parte experimental, se describen las rutinas de electrodeposición, las celdas electroquímicas, y el sistema de adquisición y tratamiento de imágenes. Se muestra y ocasionalmente se esquematizan los distintos instrumentos y circuitos empleados para controlar la temperatura y la magnitud del gradiente térmico adicionado al sistema. También se incluye la descripción del instrumental y de las rutinas empleadas en las técnicas voltamperométricas.

Los resultados y su análisis se muestran en los Capítulos 4 -9. En primer lugar se describen los distintos electrodepósitos que resultan de emplear celdas de distintas geometrías, diferentes rutinas de potencial, y soluciones acuosas de distinta composición. Se analizan los transitorios de corriente y se estudia la cinética de formación de los distintos electrodepósitos. Se introduce el análisis adimensional para discriminar las contribuciones de los distintos sobrepotenciales y la participación de fenómenos convectivos. Para escalas de tiempo relativamente pequeñas y longitudes características pequeñas, comparadas con el tamaño de la película de transferencia asociada con el transporte de materia, se aplica la teoría de estabilidad lineal con el fin de dar cuenta de la estructura fina de los electrodepósitos a escala micrométrica. Según esta teoría, la formación de una fase sólida, involucra la competencia de un proceso de relajación que estabiliza el crecimiento, e incluye la tensión interfacial y otro que desestabliza y que tiene en cuenta la difusión de reactivo hacia la interfase. La velocidad de este último proceso es proporcional al gradiente de concentración de reactivo entre el seno de la solución y la interfase.

En el Capítulo 4 se analizan con cuidado los distintos transitorios de corriente y se propone un método para inferir sobre los distintos mecanismos de transportes más probables que tienen lugar en distintas escalas de tiempo, y el efecto del cambio en el área activa en el transitorio. Se discuten los procesos convectivos que pueden tener lugar en el proceso de electrodeposición, involucrando no solo la velocidad de desplazamiento del fluido electrolítico sino también la velocidad de desplazamiento del frente que crece. Se trata a la electrodeposición como un problema de Stefan, que implica la resolución de la ecuación de difusión con una frontera móvil como condición de contorno.

En los Capítulos 6-7, teniendo en cuenta la presencia de los fenómenos convectivos en celdas "quasi-bidimensionales", se incorpora un gradiente térmico de magnitud variable, se aplica y comprueba la validez de la correlación general deducida por Marchiano-Arvia para la convección libre no isotérmica. Se relacionan las transiciones 
morfológicas observadas en los electrodepósitos a las distintas contribuciones de los fenómenos de transporte.

En el Capítulo 8 se muestran resultados cualitativos de simulaciones numéricas basadas en el modelo DLA (diffusion limited aggregation), con la incorporación de convección libre isotérmica. Además, se utilizan técnicas para caracterizar la dinámica de la interfase y se relaciona la electrodepocición de plata en diferentes condiciones con modelos teóricos.

En los Capítulos 9-10, se trata la electroformación de plata en geles de agarosa. Los geles eliminan la convección y proporcionan un medio desordenado que se opone al avance del frente del electrodepósito en crecimiento. Estos experimentos se analizan con los mismos métodos descriptos y empleados en los capítulos anteriores. En el Capítulo 9 se presenta un estudio sistemático de la química de soluciones de agarosa y su interacción con distintas superficies metálicas. En el capítulo 10 se estudian las características estructurales de los electrodepósitos de plata obtenidos en soles y geles de agarosa.

Finalmente en el capítulo 11 se elaboran las conclusiones. 


\section{CAPITULO 2}

\section{Conceptos y recopilación bibliográfica}

\subsection{Sistemas electroquímicos}

Un proceso electroquímico involucra transferencia de carga eléctrica. Los procesos electroquímicos ocurren, generalmente, a través de la interfase formada por dos conductores eléctricos de distinta naturaleza (iónico y electrónico) constituyendo distintas fases. Una de las fases es un electrolito, que transporta carga por movimiento de iones (especies cargadas). Los electrolitos pueden ser soluciones acuosas, sales fundidas, o sólidos conductores tales como la alúmina sódica que posee iones sodio $\left(\mathrm{Na}^{+}\right)$. La otra fase puede ser un electrodo sólido o líquido, que transporta la carga por electrones; pueden ser metales o semiconductores, sólidos o líquidos.

Entre dos fases de distinta composición en contacto se establece una diferencia de potencial eléctrico. Esta diferencia de potencial eléctrico ocurre prácticamente en la interfase, comprendida en una distancia muy pequeña $\left(10^{-7} \mathrm{~cm}\right.$ aproximadamente) respecto al tamaño de la fase. En consecuencia, aún para bajos potenciales aplicados (1V aproximadamente), se generará un campo eléctrico muy elevado, del orden de $10^{7} \mathrm{~V} \mathrm{~cm}^{-1}$, en la región interfacial. Este potencial determina la dirección de desplazamiento de los portadores de carga.

Un sistema electroquímico es un diseño experimental de fases en contacto, una de ellas es impermeable a los electrones. Puede funcionar como celda galvánica o como celda electroquímica. La primera produce energía eléctrica a partir de reacciones electroquímicas que ocurren espontáneamente. Las celdas electroquímicas, dependiendo del potencial aplicado entre los electrodos, impulsan ciertas reacciones químicas que son de interés para producir sustancias diversas en forma selectiva.

Controlar el potencial del electrodo de trabajo, es equivalente a controlar la energía de los electrones en el electrodo [1]. Llevando el potencial a valores más negativos, la energía de los electrones aumenta y alcanza un nivel suficientemente alto para ocupar estados vacantes en las especies químicas del electrolito. En este caso, se produce un flujo de electrones desde el electrodo hacia el electrolito (corriente catódica o de reducción). En forma similar, la energía de los electrones se puede disminuir imponiendo un potencial más positivo que produce transferencia electrónica desde la solución hacia el electrodo (corriente anódica o de oxidación).

Se conoce como potencial de equilibrio $\Delta \mathrm{E}^{0}$ para un sistema $\mathrm{M} / \mathrm{M}^{2}$ aquel en el que 
la velocidad de la transferencia de electrones desde el electrodo a la solución es igual a la de la transferencia en sentido opuesto, de forma que la corriente total de electrones en el sistema es nula. En esta situación de equilibrio dinámico, la corriente se denomina corriente de intercambio $\left(I_{0}\right)$ de la cupla $\mathrm{M} / \mathrm{M}^{\mathrm{z}}$.

\subsubsection{Equilibrio electroquímico}

Para un sistema electroquímico cerrado, la condición de equilibrio de fases entre dos fases, $\mathbf{M}$ (conductor electrónico) y $\mathbf{S}$ (conductor electrolítico) en contacto, para la especie i es

$$
\mu_{\mathrm{i}}^{\mathrm{M}}=\mu_{\mathrm{i}}^{\mathrm{S}}
$$

donde $\mu$ es el potencial electroquímico.

La expresión de equilibrio de reacción es

$$
\sum_{\mathrm{i}} v_{\mathrm{i}} \mu_{\mathrm{i}}=0
$$

siendo $v_{\mathrm{i}}$ los coeficientes estequiométricos de la reacción.

Los potenciales electroquímicos se expresan como:

$$
\begin{gathered}
\mu_{\mathrm{i}}^{\mathrm{M}}=\mu_{\mathrm{i}}^{\mathrm{M}}+z_{\mathrm{i}} \mathrm{F} \phi_{\mathrm{M}} \\
\mu_{\mathrm{i}}^{\mathrm{S}}=\mu_{\mathrm{i}}^{\mathrm{S}}+z_{\mathrm{i}} \mathrm{F} \phi_{\mathrm{S}}
\end{gathered}
$$

donde $\mu_{\mathrm{i}}$ es el potencial químico; $\phi_{\mathrm{M}}$ y $\phi_{\mathrm{S}}$ son los potenciales eléctricos en la fases $\mathrm{M}$ y $\mathrm{S}$ respectivamente, que son consecuencia de la carga eléctrica, $z_{\mathrm{i}}$ es la valencia de la especie $\mathrm{i}$ y F es la constante de Faraday.

Reemplazando (2.3) y (2.4) en (2.1) y reordenando, se obtiene la condición de equilibrio para una especie que se encuentra en las dos fases:

$$
z_{\mathrm{i}} \mathrm{F}\left(\phi^{\mathrm{M}}-\phi^{\mathrm{s}}\right)=\mu_{\mathrm{i}}^{\mathrm{s}}-\mu_{\mathrm{i}}^{\mathrm{M}}
$$

Sea la condición (2.2), aplicada a un electrodo de plata sumergido en una solución de iones plata $\left(\mathrm{Ag}^{+}{ }_{\mathrm{aq}}\right)$ en equilibrio:

$$
\mathrm{Ag}_{\text {aq }}^{+}+\mathrm{e}^{-} \Leftrightarrow \mathrm{Ag}^{0}
$$

La suma de los potenciales químicos de las especies involucradas multiplicados por sus respectivos coeficientes estequiométricos, que es el cambio de energía libre molar de la reacción, se compensa con el trabajo eléctrico $\mathrm{F}\left(\phi^{\mathrm{M}}-\phi^{\mathrm{S}}\right)$ : 


$$
\begin{gathered}
\mu_{\mathrm{Ag}}-\mu_{\mathrm{Ag}^{+}}^{0}-\mathrm{R} T \ln a_{\mathrm{Ag}^{+}}-\mathrm{F} \phi^{S}+\mu_{\mathrm{e}^{-}}+\mathrm{F} \phi^{\mathrm{M}}=0 \\
-\mathrm{F}\left(\phi^{\mathrm{M}}-\phi^{\mathrm{S}}\right)=\mu_{\mathrm{Ag}}+\mu_{\mathrm{e}^{-}}-\mu_{\mathrm{Ag}^{+}}^{0}-\mathrm{R} T \ln a_{\mathrm{Ag}^{+}} \\
\left(\phi^{\mathrm{M}}-\phi^{\mathrm{S}}\right)=\mathrm{E}_{\mathrm{Ag}^{+} / \mathrm{Ag}}=\mathrm{E}^{0}+{ }_{\mathrm{F}}^{\mathrm{R} T} \ln a_{\mathrm{Ag}^{+}}
\end{gathered}
$$

donde $a_{\mathrm{Ag}+}$ es la actividad de los iones $\mathrm{Ag}^{+}, \mathrm{E}_{\mathrm{Ag}+/ \mathrm{Ag}}$ es el potencial reversible del par plata/ ión plata, $\mathrm{E}^{0}$ es una constante igual al potencial reversible cuando la actividad del ión plata $a_{\mathrm{Ag}^{+}}$es $1 ; \mathrm{R}$ la constante de los gases y $T$ la temperatura absoluta.

El potencial de un electrodo aislado ( $\mathrm{E}$, en la ecuación (2.8)) no se puede medir. Por tal razón el potencial de electrodo es la diferencia de potencial medida a circuito abierto (fuerza electromotríz) en una pila formada por el electrodo en cuestión y uno de referencia. Se utiliza, así la escala arbitraria del electrodo normal de hidrógeno (ENH), en donde esta interfase se utiliza como referencia. En este último la actividad de los protones y la fugacidad del hidrógeno gaseoso son unitarias, y su potencial se considera igual a cero a todas las temperaturas. Para fijar la escala de potenciales, además, se conviene que en el electrodo de hidrógeno ocurre la reacción de oxidación. Así el potencial de electrodo de cualquier par electroquímico resulta $\Delta E^{\prime}=E_{M+M}^{\prime}-E_{E N H}=E_{M+M}$.

\subsubsection{La reacción electroquímica}

Para el estudio de la cinética de los procesos electroquímicos alejados del equilibrio es conveniente utilizar celdas electroquimicas con tres electrodos, esto es, un electrodo de trabajo ET donde ocurre el proceso en estudio, un electrodo de referencia ER, utilizado para seguir los cambios de potencial del ET y un electrodo auxiliar o contraelectrodo $\mathrm{CE}$ que cierra el circuito con el ET permitiendo el pasaje de corriente por la celda. El diseño y ubicación del ER es tal que no circula corriente a través de él, por lo que se asegura que la diferencia de potencial ER/solución permanezca constante.

Las reacciones electroquímicas, constituyen un caso especial de reacciones heterogéneas. En general, proceden a través de un mecanismo que involucra por lo menos tres etapas, como se muestra en el esquema de la Figura 2.1. La primer etapa es el transporte de la especie reactiva, $\left(\mathrm{O}_{\mathrm{r}}\right)$ hacia la interface, luego según la complejidad del mecanismo puede existir una reacción en la cual $\mathrm{O}_{\mathrm{r}}$ se transforma en $\mathrm{O}^{\prime}$, que a su vez se adsorbe en la superficie del electrodo $\left(\mathrm{O}_{\mathrm{ads}}{ }^{\prime}\right)$ y participa en una transferencia de carga generando el producto $\mathrm{R}_{\mathrm{ads}}$ ', que se desorbe y se desplaza hacia el seno de la solución. 
En una reacción electroquímica se puede producir la descarga de iones que quedan en solución o la formación de una nueva fase, ya sea gaseosa o sólida.

La electrodeposición metálica consiste en la formación de una nueva fase sólida conductora sobre el ET, partiendo de una solución electrolítica o de una sal fundida que tiene los iones reactivos [2]. El proceso consta de una serie de pasos sucesivos [3]:

1) Transporte de reactivos desde el seno del conductor iónico hacia el electrodo (migración, difusión y convección);

2) Adsorción de reactivos y transferencia electrónica (catódica) desde el cátodo a los reactivos;

3) Difusión superficial de los adiones o adátomos, y nucleación y crecimiento de una nueva fase.

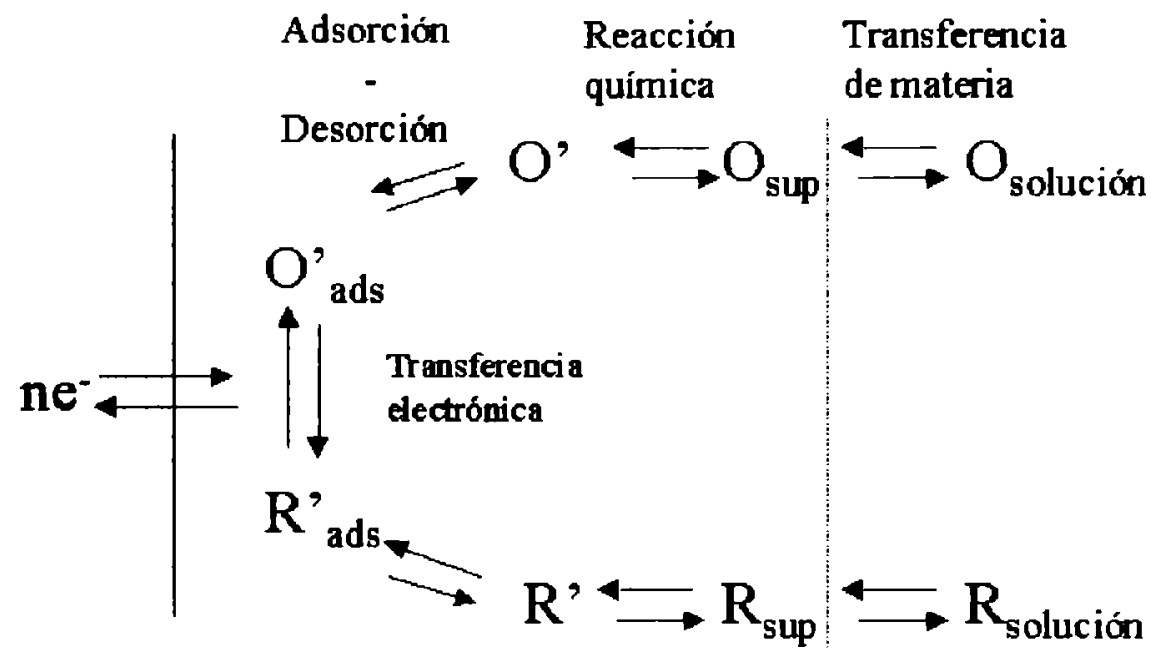

Figura 2.1. Esquema de una reacción electroquímica

La velocidad de la reacción (anódica o catódica) se controla aportando un exceso de energía con respecto al potencial reversible o de equilibrio $\Delta \mathrm{E}^{0}$. Ese exceso de energía se denomina sobrepotencial $(\eta)$ y se expresa como la diferencia entre el potencial que se debe aplicar para que circule una densidad de corriente $j$ y el potencial de equilibrio; esto es $\eta=\left|\Delta \mathrm{E}(j)-\Delta \mathrm{E}^{0}\right|$. La magnitud de $\eta$ es una medida del apartamiento del sistema de las condiciones de equilibrio cuando circula corriente por la celda. Este apartamiento se denomina polarización. De esta manera, el potencial total aplicado $(\Delta \mathrm{E})$ entre ET y CE, para que el proceso electroquímico ocurra con una densidad de corriente $j$ es:

$$
\Delta \mathrm{E}=\Delta \mathrm{E}^{0}+\Delta \varphi_{\mathrm{ohm}}+\eta(j)
$$


$\Delta \varphi_{\text {ohm }}$ es la caída de potencial óhmico en la solución, que es función la intensidad de corriente y de la resistencia eléctrica de la solución $R$. También aparecen efectos óhmicos cuando entre el ET o CE y el electrolito se halla una capa poco conductora, como es el caso de la formación de óxidos.

Cuando la causante principal de la polarización es $\Delta \varphi_{\text {ohm }}$ la reacción electroquímica está bajo control óhmico, y la relación entre la corriente que circula $(I)$, y el potencial aplicado $(\triangle \mathrm{E})$ está dada por de la ley de Ohm:

$$
I=\Delta E / R
$$

La aparición de un sobrepotencial $\eta(j)$ en la interfase de un electrodo de primera especie, $\mathrm{M}$ / Solución $\mathrm{M}^{2+}$, se puede deber a varios procesos que requieren energía para que se realicen (figura 2.1). El sobrepotencial de la interfase puede tener varios componentes y en general considerando una sola interfase $\eta(j)$ se puede descomponer así:

$$
\eta(j)=\eta_{\mathrm{t}}+\eta_{\mathrm{c}}+\eta_{\mathrm{crist}}
$$

donde $\eta_{1}$ es el sobrepotencial de transferencia de carga, asociado a la lentitud del proceso de transferencia electrónica; $\eta_{\mathrm{c}}$ es el sobrepotencial de concentración, que se lo puede separar en un sobrepotencial de transferencia de materia y uno de reacción química; $\eta_{\text {crist }}$ es el sobrepotencial de cristalización de una nueva fase.

El sobrepotencial de transferencia de carga $\eta_{\mathrm{t}}$ está relacionado con la densidad de corriente por la ecuación de Butler-Volmer :

$$
j=j_{0}\left[e^{(1-\beta) \mathrm{F} \eta_{\mathrm{t}}}-e^{-\beta \mathrm{F} T} \eta_{\mathrm{t}}^{\mathrm{R} T}\right]
$$

donde $j_{0}$ es la densidad de corriente de intercambio y $\beta$ es el factor de simetría de la reacción catódica.

Si la reacción electroquímica posee una corriente de intercambio alta, se puede considerar que la concentración de la especie activa $c_{i}$ es la de equilibrio de acuerdo al potencial en la interfase, entonces se tiene:

$$
\mathrm{E}_{\mathrm{C}}=\mathrm{E}^{0}+{ }_{z_{\mathrm{i}} \mathrm{F}}^{\mathrm{R} T} \ln c_{\mathrm{i}}
$$

donde $\mathrm{E}_{\mathrm{c}}$ es el potencial en la interfase (ET/solución) para una concentración $c_{\mathrm{i}}$.

El apartamiento del potencial del ET con respecto al que corresponde al medio iónico de concentración $c_{0}\left(\eta_{\mathrm{c}}\right)$ puede expresarse: 


$$
\eta_{\mathrm{c}}=\left(\mathrm{E}^{0}+\frac{\mathrm{R} T}{z_{\mathrm{i}} \mathrm{F}} \ln c_{\mathrm{i}}\right)-\left(\mathrm{E}^{0}+\frac{\mathrm{R} T}{z_{\mathrm{i}} \mathrm{F}} \ln c_{0}\right)
$$

donde $c_{0}$, es la concentración de la especie electroactiva en el seno del medio iónico.

En este caso la relación entre la corriente y el sobrepotencial es:

$$
j=-j_{\mathrm{L}}\left\{\exp \left(\frac{n \mathrm{~F} \eta_{\mathrm{c}}}{\mathrm{R} T}\right)-1\right\}
$$

siendo $j_{\mathrm{L}}$, la densidad de corriente para la cual la concentración de la especie $\mathrm{i}$ en la superficie del electrodo es cero y $E_{c} \rightarrow-\infty$. Esta densidad de corriente recibe el nombre de densidad de corriente límite.

El sobrepotencial de cristalización $\left(\eta_{\text {crist }}\right)$ se puede escribir como $[4,5]$ :

$$
\eta_{\text {crist }}=\frac{\mathrm{R} T}{\mathrm{nF}} v_{\mathrm{ad}} \ln \underset{a_{\mathrm{ad}, \mathrm{eq}}}{a_{\mathrm{ad}}}
$$

donde $a_{\text {ad,eq }}$ es la actividad de los ad-iones adsorbidos en la superficie en condiciones de equilibrio y $v_{\mathrm{ad}}$ es el coeficiente estequiométrico del proceso superficial. En la sección 2.2 se analizarán otros aspectos del proceso de electro-cristalización.

\subsubsection{Transporte de materia}

La velocidad de transporte de materia o flujo de la especie i $\left(N_{\mathrm{i}}\right)$ en un volumen determinado de fluido constituido por una solución electrolítica es [6]:

$$
N_{\mathrm{i}}=-z_{\mathrm{i}} u_{\mathrm{i}} \mathrm{F} c_{\mathrm{i}} \nabla \phi-D_{\mathrm{i}} \nabla c_{\mathrm{i}}+c_{\mathrm{i}} V
$$

Los tres términos de la derecha de la ecuación (18) representan los tres mecanismos de transporte de materia: migración, difusión y convección, respectivamente. El flujo de la especie i, expresada en moles $\mathrm{cm}^{-2} \mathrm{~s}^{-1}$, es una magnitud vectorial. Indica el número de moles de la especie i que atraviesan un plano de $1 \mathrm{~cm}^{2}$, perpendicular a las líneas de flujo de $i$, en la unidad de tiempo. A este movimiento de la especie $\mathrm{i}$ contribuyen el movimiento del fluido a velocidad promedio $V$, la difusión determinada por un gradiente de concentración $\left(\nabla c_{i}\right)$, y la migración, si existe un campo eléctrico $(\nabla \phi)$ y la especie i está cargada $\left(z_{i}\right)$.

El término de migración se manifiesta en los sistemas que contienen especies cargadas en un campo eléctrico, aplicado entre los electrodos. La magnitud $u_{\mathrm{i}}$ es la movilidad iónica, definida como la velocidad promedio de la especie i en solución, cuando actúa una fuerza de $1 \mathrm{~N} / \mathrm{mol}$ y el producto $z_{\mathrm{i}} \mathrm{F}$ es la carga por mol de la especie i.

La transferencia de materia por difusión ocurre cuando se establece un gradiente de potencial químico entre dos puntos del fluido. Según la termodinámica del no equilibrio, el flujo de 
materia $N_{\mathrm{D}}$, debido a la difusión viene dado por:

$$
N_{\mathrm{D}, \mathrm{i}}=-\alpha \nabla \mu=-\alpha\left(\begin{array}{c}
\partial \mu \\
\partial \mathrm{c}_{\mathrm{i}}
\end{array}\right)_{\mathrm{T}, \mathrm{P}} \nabla c_{\mathrm{i}}
$$

$\alpha$ es una constante de proporcionalidad, $\mu$ es el potencial químico y $c_{\mathrm{i}}$ es la concentración de la especie que difunde. Siendo:

$$
D_{\mathrm{i}}=\alpha\left(\begin{array}{l}
\partial \mu \\
\partial c_{\mathrm{i}}
\end{array}\right)
$$

que se denomina coeficiente de difusión de la especie i.

La densidad de corriente en una solución electrolítica, que se origina en el movimiento de las especies cargadas a través de un plano perpendicular de $1 \mathrm{~cm}^{2}$ es:

$$
j=\mathrm{F} \sum_{\mathrm{i}} z_{\mathrm{i}} N_{\mathrm{i}}
$$

con $j$, la densidad de corriente en ampere por $\mathrm{cm}^{2}$.

El balance de materia para i está dado por la expresión:

$$
\frac{\partial c_{\mathrm{i}}}{\partial t}=-\nabla \cdot N_{\mathrm{i}}+R_{\mathrm{i}}
$$

La ecuación (2.22) establece que la velocidad de variación de $c_{\mathrm{i}}$ en un elemento de volumen diferencial es igual a la divergencia del flujo de materia en el elemento de volumen, más la producción de i por unidad de volumen $R_{\mathrm{i}}$, por reacciones químicas homogéneas en el seno de la solución.

La condición de electroneutralidad para la solución electrolítica es:

$$
\sum_{\mathrm{i}} z_{\mathrm{i}} c_{\mathrm{i}}=0
$$

y se cumple en toda la solución excepto en una delgada capa cargada cerca de la interfase $\mathrm{M} / \mathrm{M}^{\mathrm{z}}$.

\subsubsection{Electrolito binario}

Un electrolito binario está constituido por un único tipo de cationes y aniones, con carga $z+y z_{-}$, respectivamente. Sean $v_{+} y v_{-}$, el número de cationes y aniones, respectivamente, producidos por la disociación de una unidad constitutiva del electrolito. Entonces, por la condición de electroneutralidad, se pude definir una concentración del electrolito como:

$$
c=c_{+} / v_{+}=c_{-} / v_{-}
$$


Si se sustituye la ecuación (2.18) para el catión y el anión en la ecuación de balance de materia (2.22) y se supone $R_{\mathrm{i}}=0$, se tiene:

$$
\begin{aligned}
& \frac{\partial c}{\partial t}+V \nabla c=z_{+} u_{+} F \nabla \cdot(c \nabla \phi)+D_{+} \nabla^{2} c \\
& \frac{\partial c}{\partial t}+V \nabla c=z_{-} u_{-} F \nabla \cdot(c \nabla \phi)+D_{-} \nabla^{2} c
\end{aligned}
$$

Restando (2.26) de (2.25) resulta:

$$
\left(z_{+} u_{+}-z_{-} u_{-}\right) F \nabla(c \nabla \phi)+\left(D_{+}-D_{-}\right) \nabla^{2} c=0
$$

y reemplazando en (2.25) o (2.26) se obtiene:

$$
\begin{aligned}
& \partial c \\
& \partial t
\end{aligned}+V \cdot \nabla c=D \nabla^{2} c
$$

donde

$$
D=\begin{gathered}
z_{+} u_{+} D_{-}-z_{-} u_{-} D_{+} \\
z_{+} u_{+}-z_{-} u_{-}
\end{gathered}
$$

La ecuación (2.28) muestra que una sal binaria, como lo es una sal fundida y como puede considerarse en forma aproximada, el sulfato de plata en agua, se comporta como una única especie debido a la condición de electroneutralidad. El coeficiente de difusión representa una situación de compromiso entre el coeficiente de difusión del anión y del catión. Si los coeficientes del anión y del catión son distintos, las especies tenderán a separarse, creando en consecuencia una densidad de carga que impide tal separación. La densidad de carga así originada produce una diferencia de potencial que acelera a la especie más lenta y retarda a la especie más rápida.

Se puede concluir que la distribución de concentraciones en una solución de una única sal se puede describir por las mismas ecuaciones utilizadas para una especie neutra, aún cuando circula corriente.

\subsubsection{Electrolito soporte}

Substituyendo la ecuación de flujo para la especie i en el balance de materia para un fluido incomprensible se obtiene:

$$
\frac{\partial c_{\mathrm{i}}}{\partial t}+V \nabla c_{\mathrm{i}}=z_{\mathrm{i}} u_{\mathrm{i}} F \nabla \cdot\left(u_{\mathrm{i}} c_{\mathrm{i}} \nabla \phi\right)+\nabla\left(D_{\mathrm{i}} \nabla c_{\mathrm{i}}\right)+R_{\mathrm{i}}
$$


Si se agrega un electrolito en exceso, que no toma parte de la reacción electroquímica, y que aumenta la conductividad eléctrica de la solución, puede despreciarse la contribución de la migración de la especie i. Además, si $R_{\mathrm{i}}=0$, la ecuación (2.30) se simplifica:

$$
\frac{\partial c_{\mathrm{i}}}{\partial t}+V \nabla c_{\mathrm{i}}=D_{\mathrm{i}} \nabla^{2} c_{\mathrm{i}}
$$

En cinética electroquímica, cuando se estudian procesos de transferencia de materia, es usual incorporar electrolito soporte, con el fin de incrementar la conductividad eléctrica de la solución y por tanto, reducir el campo eléctrico. El transporte de materia de la especie reactiva ocurrirá, entonces principalmente por difusión y convección.

\subsection{Formación de metales por vía electroquímica}

La electrocristalización de metales comprende un proceso de electrodeposición del ion en la solución y su incorporación en la red del metal $[7,8]$.

Un ion en solución acuosa se encuentra solvatado. El electrón en un cierto nivel energético se transfiere del metal al ión solvatado por "efecto túnel". Esto ocurre cuando el ión solvatado se deforma hasta alcanzar la configuración energética apropiada. Producida la transferencia de carga (parcial o total) se produce un adión que difunde sobre la superficie, antes de ser totalmente neutralizado y perder gradualmente su solvatación. Así forma parte de la estructura cristalina del metal electrodepositado. El movimiento superficial de los "adiones" puede, en ciertas condiciones, llegar a ser la etapa determinante de la reacción electroquímica. Lorentz y Gerischer observaron este proceso en la electrocristalización metálica, estudiando transitorios galvanostáticos [7].

Existen varios modelos de electrocristalización, de los cuales los más significativos son: nucleación y crecimiento de monocapas sucesivas y crecimiento de terrazas originadas en "dislocaciones de tornillo". Estas dislocaciones se generan a partir de desniveles entre capas de átomos que forman una "cuña". La adición de nuevos átomos a lo largo del escalón formado por la cuña, produce el giro de la capa de átomos que se está formando, alrededor de un punto central, donde se inicia la dislocación ("cuña").

$\mathrm{Si}$ la superficie del cristal donde se produce la electrocristalización es perfectamente lisa, no puede formarse depósito al menos que se exceda un sobrepotencial crítico, necesario para la nucleación de la nueva fase en la superficie del cristal. Los núcleos pueden ser bidimensionales o tridimensionales. El crecimiento del cristal se completa a través de monocapas de átomos después de un proceso de nucleación en dos 
dimensiones. Si en cambio, el cristal inicial no es perfecto y contiene dislocaciones "de tornillo", el cristal puede crecer a un sobrepotencial más bajo que el necesario para la nucleación en dos dimensiones. Un cristal que posee dislocaciones "de tornillo", puede crecer en forma continua sin que se creen nuevos núcleos. El crecimiento de cristales imperfectos con dislocaciones se ve favorecido con respecto a cristales perfectos. Se han observado crecimientos tipo "espiral" en condiciones de alta pureza del medio electrolítico $[9,10]$.

\subsection{Electrodeposición de plata.}

\subsection{1 $\underline{\mathrm{La} \text { reacción } \mathrm{Ag}^{+} / \mathrm{Ag}^{0}}$}

El diagrama de Pourbaix [11], figura 1.3, para el sistema plata/solución acuosa muestra los potenciales reversibles calculados con la ecuación de Nerst en función del pH del medio para los distintos equilibrios posibles del sistema. Los potenciales están referidos al electrodo normal de hidrógeno $(\mathrm{ENH})[12]$. Las reacciones de equilibrio correspondientes a cada línea del diagrama se muestran en el apéndice A [13].

Las líneas identificadas por las letras a y b corresponden al equilibrio del agua con sus productos de reducción: hidrógeno (línea a), u oxidación: oxígeno (línea b), a la presión de 1 atm. La región encerrada por estas líneas es la región de estabilidad del agua. El diagrama determina las zonas de estabilidad, disolución activa y pasivación de la plata. 


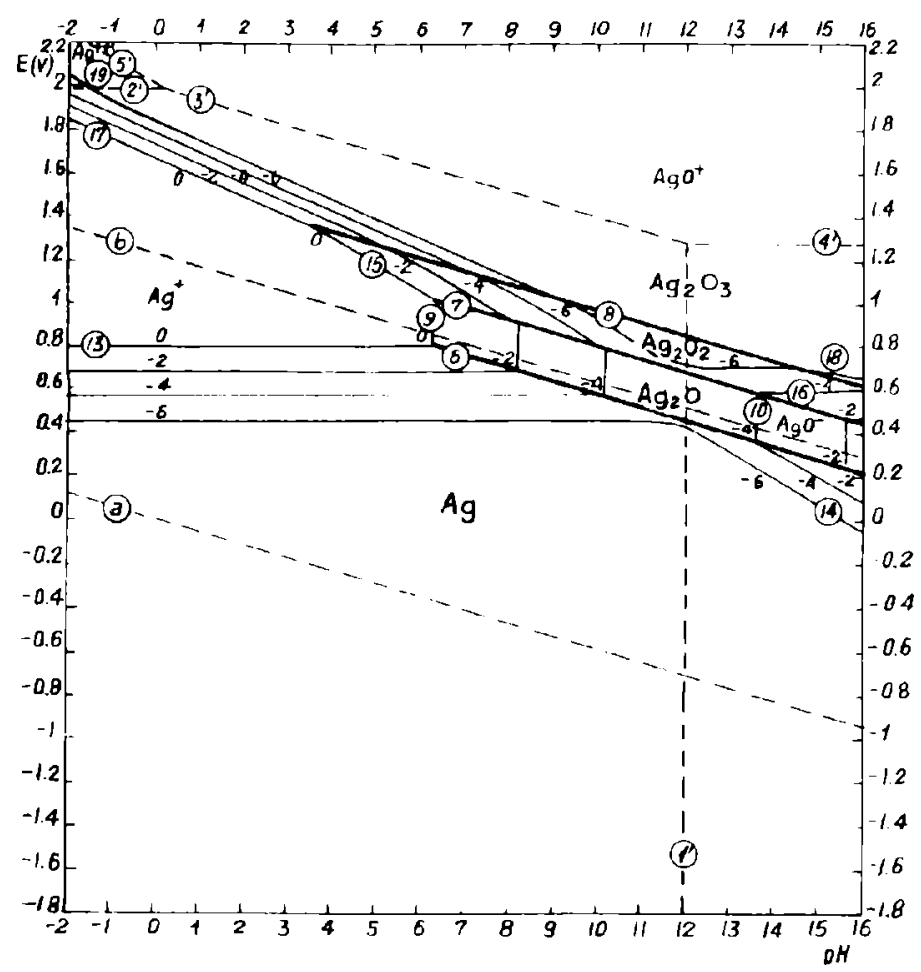

Figura 2.2. Diagrama de fase para el sistema plata/ agua. Extraído de Pourbaix [11].

\subsubsection{Características cinéticas para la transferencia de carga de la reacción $\mathrm{Ag}^{+} / \mathrm{Ag}^{0}$}

La cinética de electrodeposición de plata a partir de soluciones de iones $\mathrm{Ag}^{+}$en medios no complejantes (soluciones de perclorato de plata, nitrato de plata, sulfato de plata, etc.) $[14,15]$ es un proceso reversible, siendo la polarización debida a la transferencia de electrones despreciable. El sobrepotencial del proceso será casi completamente, el sobrepotencial de concentración. Entonces el potencial aplicado entre el electrodo de trabajo y el electrodo de referencia $\Delta \mathrm{E}$ viene dado por:

$$
\Delta \mathrm{E}=\Delta \mathrm{E}^{0}+\Delta \varphi_{\mathrm{ohm}}+\eta_{\mathrm{c}}
$$

Esto está de acuerdo con los altos valores de densidad de corriente de intercambio que se encuentran en literatura. Para una solución acuosa $1 \mathrm{M}$ de iones plata para la reacción de electroreducción de los iones $\mathrm{Ag}^{+}$sobre plata policristalina a $25^{\circ} \mathrm{C}, j_{0}=24 \pm 5$ $\mathrm{A} \mathrm{cm}^{-2}[16,17]$.

En el proceso de formación de monocristales con distinta estructura cristalina las densidades de corriente de intercambio son mucho menores que para la plata policristalina y la cinética del proceso está controlada por la transferencia de carga y el transporte de materia [13]. 


\subsection{Morfologia de depósitos (obietos)}

En la naturaleza existen objetos cuya forma es muy complicada y difícil de describir. El desarrollo de técnicas cuantitativas de caracterización juega un papel importante en el adelanto del conocimiento científico de estos objetos. Thomson [18] decía: "que si las gotas no son esferas perfectas, se debía a la existencia de otras fuerzas y resistencias distintas a las principales". Esto ocurre con las formas de los objetos de la naturaleza, siendo menester investigar cuales son las fuerzas que actúan.

Newton introdujo la idea de que las fuerzas actuantes sobre la Tierra debían hacer que adoptase una forma de esfera desformada, como se comprobó posteriormente. Sin embargo, hoy se acepta que su forma es aún más complicada, resultando necesaria la búsqueda de la fuerzas que han deformado el esferoide.

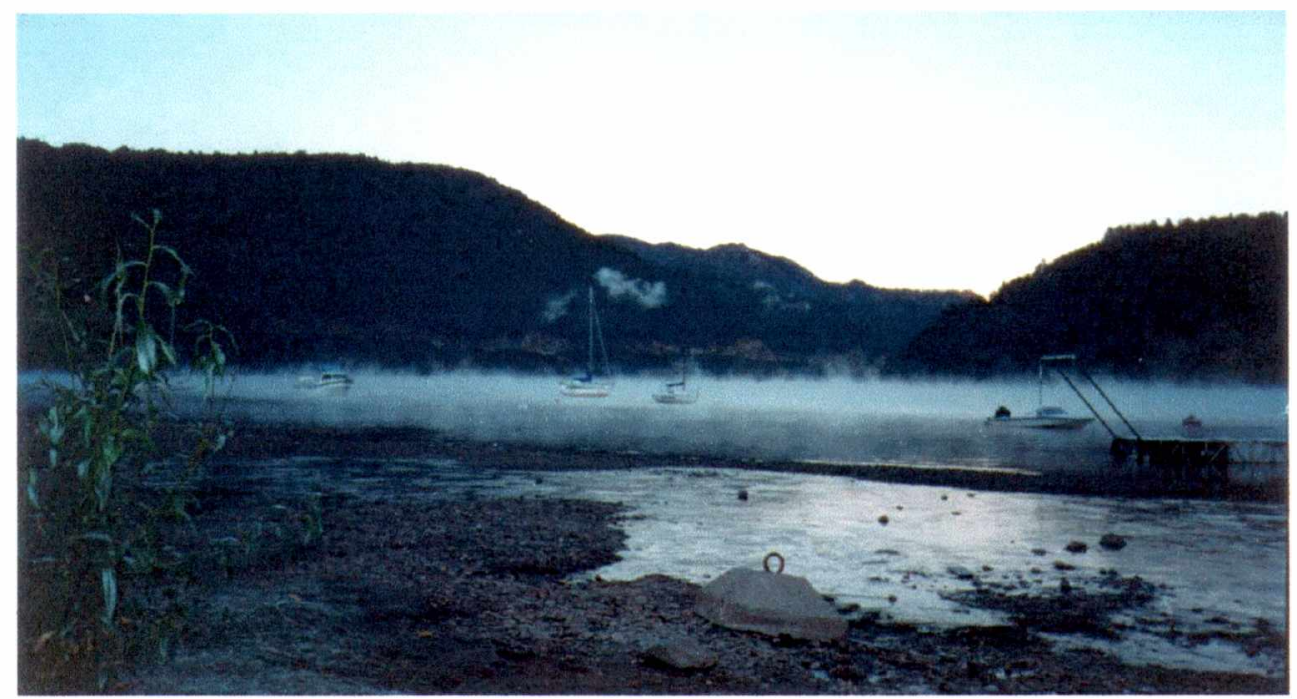

Figura 2.3. Foto que muestra la evaporación sobre las agua de un lago.

En condiciones cercanas al equilibrio es de esperar que la forma de los objetos, en primera aproximación, se puedan describir por la geometría euclideana. Son ejemplos, la forma simple de las películas de jabón, la superficies facetadas de cristales que crecen lentamente, o la superficie del agua no perturbada en un recipiente abierto. Es de notar, que existen pocos sistemas en la naturaleza que puedan ser explicadas como situaciones cercanas al equilibrio, como es el caso de los cambios energéticos que ocurren en el proceso de evaporación en equilibrio de una determinada cantidad de agua. Contrariamente la evaporación que tiene lugar en la superficie de un lago (figura 2.3), que es un proceso alejado del equilibrio, conduce a una interfase que requiere disponer de otras técnicas de medida e interpretación. 


\subsubsection{Clasificación morfológica}

En sistemas fuera del equilibrio es posible obtener una gran variedad de morfologías [19], entre ellas, las estructuras reminiscentes a los dedos de una mano, obtenidas al hacer fluir un líquido sobre otro más viscoso [20], la forma de la ruptura dieléctrica de un material [21], las formas obtenidas en el enfriamiento de metales y aleaciones y en la electrodeposición de metales [22,23]. En algunos casos, como sucede en este último, es posible clasificar las morfologías de los crecimientos (figura 2.4) en: a) crecimientos aciculares; b) morfología "tip-spliting" abierta, c) crecimientos dendríticos con punta estable (dendritas), similar a los cristales de hielo y d) estructuras densas $[24,25]$.

a)

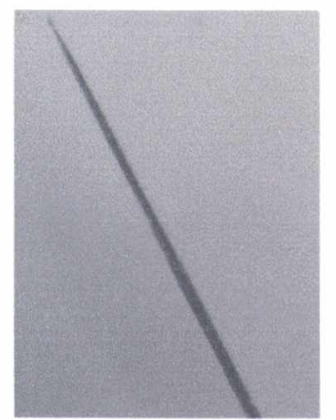

c)

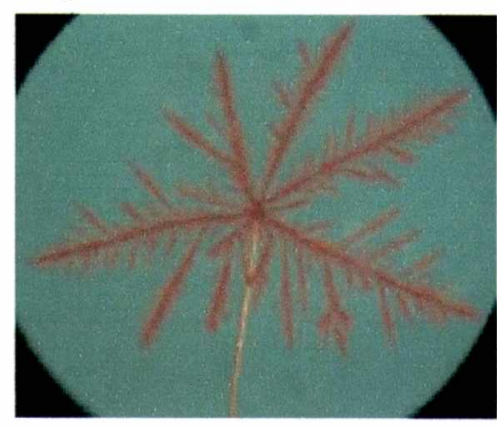

b)

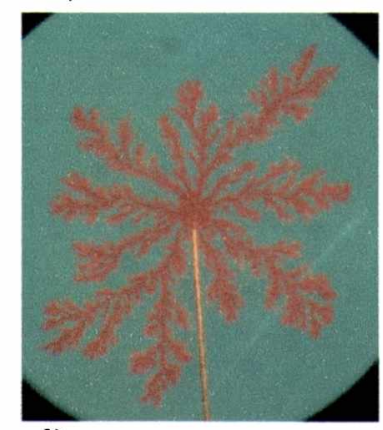

d)

Figura 2.4. Clasificación morfológica. a) Electrodepósitos aciculares, b) morfología “tip splitting", c) electrodepósito dendrítico y d) denso (radial).

Los crecimientos aciculares son semejantes a agujas. Su velocidad de crecimiento longitudinal es mucho mayor que la del crecimiento transversal. Poseen una punta tipo paraboloide estable y las caras laterales son de cristales facetados.

La morfología "tip-spliting" abierta está constituida por estructuras arborescentes 
con bifurcación de las puntas (tip splitting).

El crecimiento dendrítico, se caracteriza por estar constituido por ramas compuestas de un eje central adornado por ramas laterales [26] que crecen con un ángulo determinado con respecto al eje y cuya longitud aumenta a medida que aumenta la distancia desde la punta. La punta de las dendritas y los crecimientos aciculares conserva su forma durante el crecimiento.

La morfología densa (que como en el caso de la figura $2.4 \mathrm{~d}$, recibe el nombre de radial densa, por la geometría axial que posee) se aproxima a un objeto euclidiano, con una envolvente cuya forma se mantiene constante durante el crecimiento.

Estas morfologías, que pueden producirse en el laboratorio, se encuentran también en la naturaleza. En las últimas décadas ha resultado una herramienta importante, para el desarrollo de técnicas de caracterización de morfologías, la electrodeposición metálica en celdas denominadas quasi-bidimensionales de geometría axial (el electrodo de trabajo es concéntrico con el electrodo auxiliar) o rectangular (los electrodos se enfrentan paralelos entre sí) [27,28]. De esta manera es posible observar la evolución del electrodepósito por técnicas ópticas, como se describe en el capítulo 3 de este trabajo.

Un gran número de procesos de importancia tecnológica, como la deposición de átomos por medio de haces moleculares epitaxiales, utilizada en la industria de chips de computadoras y la manufactura de semiconductores [29], el proceso de erosión por bombardeo de átomos de oxígeno o argón [30], la formación de películas por bombardeo de átomos que la constituyen [31], sistemas biológicos como el crecimiento de colonias de bacterias, o la distribución de las bases purínas y pirimidinas en el ADN [32], producen morfologías que pueden estudiarse analizando la evolución de la interfase que forman. Cada campo tiene técnicas propias para atacar un determinado problema, pero encontrar herramientas con mayor generalidad descriptiva y poder de predicción resulta uno de los logros principales. A continuación se describen en forma sucinta algunas de las técnicas más utilizadas [18].

\subsubsection{Técnicas usadas en el estudio de las interfases}

\section{Escalado dinámico}

Muchas magnitudes obedecen relaciones que dependen de la escala de medida. Por ejemplo, el ancho $W$ de interfases relacionadas con muchas estructuras satisfacen $W(t) \sim t^{\beta}$. 
También el valor estacionario del ancho de la interfase aumenta con el tamaño del sistema de acuerdo a la ley de potencia $W(t) \sim L^{\alpha}$ ( $\alpha$ y $\beta$ son constantes). Estudiando estas relaciones de escalado se definen las clases de universalidad, que codifican la existencia de unos pocos elementos esenciales que determinan el valor de los exponentes. Así, sistemas diferentes, que en apariencia no presentan conexión alguna, se comportan de manera similar.

\section{Modelos discretos}

Se logra reproducir fenómenos naturales con algorítmos computacionales. La simulaciones presentan un lazo importante entre la teoría y los experimentos, y permiten separar las variables esenciales de las no esenciales, que determinan la morfología o la concreción de un proceso.

\section{Modelos continuos}

En estos modelos se trata de encontrar las ecuaciones que describan la evolución de la interfase o de la cinética de los procesos. De estas ecuaciones se deducen leyes de potencia cuyos exponentes pueden ser verificados con los obtenidos del escalado dinámico.

\subsubsection{Escalado dinámico}

Mediante el empleo de leyes de potencia es posible conocer el cambio de las magnitudes características de un determinado sistema con su longitud característica. Consecuentemente, si se estudia la rugosidad de una interfase, interesará conocer como se modifica un parámetro característico de la rugosidad de la interfase con el tiempo. El ancho de la interfase ( $W$ ), se suele utilizar como el parámetro de la rugosidad y se define por:

$$
W(L, t) \equiv \sum_{L}^{1}[h(\mathrm{i}, t)-h(t)]^{2}
$$

con

$$
h(t) \equiv{ }_{L}^{1} \sum_{i=1}^{L} h(\mathrm{i}, t)
$$


donde $h(\mathrm{i}, t)$ es la altura máxima al tiempo $t$ del depósito en el punto i sobre la línea $o$ substrato donde se genera el agregado y $L$ es una longitud característica del sistema (figura 2.3).

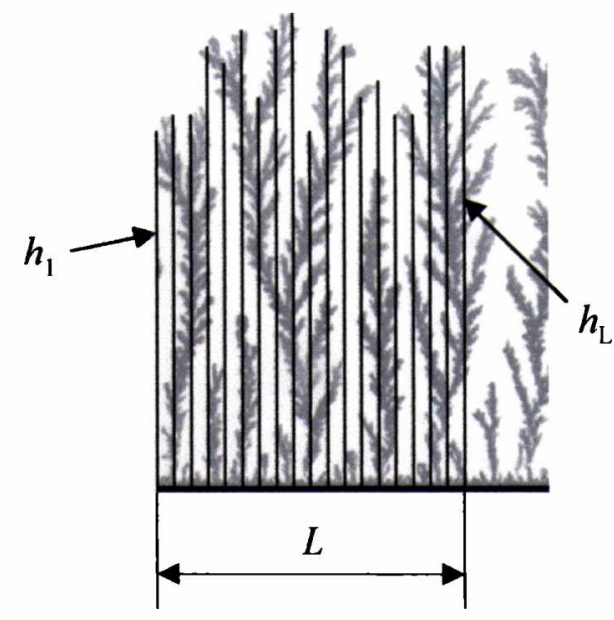

Figura 2.5. Medida de alturas sobre una longitud de substrato $L$, para determinar $W$.

En el análisis de la evolución de las interfases autoafines (ver 2.4.5.2) es común encontrar que, para tiempos menores que el tiempo de saturación $t_{\mathrm{x}}$, el ancho de la interfase y el tiempo, cumplen la relación:

$$
W(L, t) \propto t^{\beta}
$$

siempre que $t$ sea menor que $t_{\mathrm{x}}$ o tiempo de saturación (a partir del cual la rugosidad permanece constante); $\beta$ es el exponente de crecimiento que caracteriza la dependencia dinámica temporal del proceso de arrugosado.

El aumento del ancho de la interfase según la ley de potencia no continúa indefinidamente, sino que alcanza un valor constante (saturación) $W_{\text {sat }}$ a $t=t_{\mathrm{x}}$. Se encuentra que $W_{\text {sat }}$, a su vez, escala con el tamaño característico del sistema $L$ :

$$
W_{s a t} \propto L^{\alpha}
$$

siendo $\alpha$, el exponente de rugosidad. Este segundo exponente crítico caracteriza la rugosidad de la interfase en el régimen de saturación.

A su vez el tiempo de saturación, $t_{\mathrm{x}}$ cumple una ley de potencia con el tamaño característico del sistema,

$$
t_{x} \propto L^{Z}
$$

llamándose $Z$ el exponente dinámico del sistema.

Los exponentes de escalado $\beta, \alpha$ y $Z$ no son independientes entre sí, pues satisfacen la relación de escalado de Family-Vicsek [18]: 


$$
w(L, t) \propto L^{\alpha} f\left(\begin{array}{c}
t \\
L^{Z}
\end{array}\right)
$$

siendo $f$ la función de escalado. Esta adopta un valor constante para tiempos mayores al tiempo de saturación y sigue una ley de potencia como la (2.35), para tiempos menores que el tiempo de saturación.

Las interfases que responden a la relación (2.38), tienen sus exponentes críticos relacionados por medio de la ley de escalado:

$$
Z=\frac{\alpha}{\beta}
$$

\subsubsection{Modelos de crecimiento de las interfases}

Las ecuaciones continuas de crecimiento se obtienen de la resolución de ecuaciones diferenciales que describen la variación con el tiempo de la altura de la interfase $h(x, t)$ en un punto $x$, de un substrato de d-dimensiones. La ecuación continua es de la forma general:

$$
\frac{\partial h(x, t)}{\partial t}=\Phi(x, t)
$$

donde $\Phi(x, t)$ es el número de partículas por unidad de tiempo que llegan a la superficie al tiempo $t$ en la posición $x$. La altura se mide en número de partículas en la dirección perpendicular al substrato.

El flujo de partículas no es uniforme, ya que las partículas se depositan aleatoriamente. Este hecho se incorpora descomponiendo $\Phi(x, t)$ en un término $G(x, t, h)$ que representa el número promedio de partículas que llegan a la superficie, siendo constante para el proceso de deposición aleatoria, y un término que representa el ruido $\eta(x, t)$, debido a fluctuaciones en el proceso de deposición.

La resolución de la ecuación (2.40), cuando es posible, conduce a las mismas relaciones de escalado que el modelo discreto (algoritmo de deposición).

Uno de los modelos más simple, que permite relacionar el algoritmo discreto y la ecuación continua es el modelo de la deposición aleatoria [34]. Desde un sitio determinado se deja caer una partícula (reactivo) hasta que alcanza la parte más alta de una columna vertical (depósito) y se pega. En este caso no hay interacciones entre columnas, no se produce ramificación en una columna, es decir no existe correlación en la interfase. En este modelo discreto, únicamente está definido el exponente de crecimiento $\beta$ que toma el valor de $1 / 2$.

Otro modelo más complicado que la deposición aleatoria, es el que tiene en cuenta 
la relajación superficial de las partículas que llegan a la superficie [35]. La partícula entonces, puede difundir sobre la superficie una distancia finita, antes de depositarse finalmente, en la posición de menor altura. La ecuación continua que se puede deducir considerando principios de simetría [36], es la ecuación de Edwards-Wilkinson (EW) [37] donde el término general $G(\mathrm{x}, t, h)$ toma la forma $v \nabla^{2} h$, y es el responsable del alisado de la superficie. En este caso $v$ está asociado con la tensión interfacial. El modelo EW para el crecimiento en dos dimensiones conduce a los exponentes de escalado $\beta=1 / 4$ y $\alpha=1 / 2$. La ecuación EW es lineal en $h$ :

$$
\begin{gathered}
\partial h(x, t) \\
\partial t
\end{gathered}=v \nabla^{2} h+\eta(x, t)
$$

Otra ecuación de crecimiento más general, propuesta por Kardar, Parisi y Zhang (KPZ)[38], incorpora un término no lineal en la ecuación diferencial estocástica de crecimiento de la interfase y adopta la forma:

$$
\frac{\partial h(x, t)}{\partial t}=v \nabla^{2} h+{ }_{2}^{\lambda}(\nabla h)^{2}+\eta(x, t)
$$

La ecuación (2.42) presenta los exponentes críticos $\beta=1 / 3, \alpha=1 / 2$ y $Z=3 / 2$ para dos dimensiones. Es de notar que el modelo balístico (DB) tiene los mismo exponentes críticos que el modelo KPZ. En el modelo (DB), una partícula que parte de un lugar aleatorio por encima de la superficie, cae verticalmente y se "pega" al depósito cuando toca la primer columna en su parte superior o cualquier lado de una columna.

\section{Agregación limitada por difusión (DLA)}

A diferencia del modelo balístico, donde las partículas se desplazan en línea recta, en el modelo DLA, introducido por Witten y Sander [39], el crecimiento está gobernado por la llegada de partículas con un camino libre medio pequeño, a través de muchos pasos de un camino aleatorio antes de "agregarse" o depositarse. Puede utilizarse para generar agregados que se inician en un punto espacial determinado y la partículas se van depositando luego de realizar un camino aleatorio antes de tocar la superficie del depósito. El modelo DLA genera morfologías fractales (ver sección 2.4.4) con una dimensión fractal $D_{\mathrm{F}} \cong 1,7$ para el modelo bidimensional $(\mathrm{d}=2)$ y $D_{\mathrm{F}} \cong 2,5$ para el tridimensional $(\mathrm{d}=3)$.

La ecuación continua del modelo DLA es de la forma de la ecuación de difusión:

$$
\frac{\partial u}{\partial t}=D \nabla^{2} u
$$

siendo $u$ la densidad de probabilidad y $D$ la constante de difusión.

El modelo DLA describe muchos procesos, entre ellos la cristalización de 
substancias $[40,41,42]$, la electrodeposición de metales [25,28,43,44], morfologías en forma de "dedos de una mano" $[45,46,47,48]$, la ruptura dieléctrica, etc.

\subsubsection{Clases de universalidad}

Las ecuaciones de crecimiento pueden ser agrupadas dentro de determinadas clases de universalidad. La definición práctica de una clase de universalidad establece que dos sistemas pertenecen a la misma clase de universalidad si tienen los mismos exponentes de escalado. Esto a menudo significa que ambos sistemas se pueden describir por las mismas ecuaciones de crecimiento.

Así por ejemplo, la ecuación de KPZ y el modelo DB tienen iguales exponentes críticos, por lo que ambos pertenecen a la misma clase de universalidad. Ambos modelos permiten la existencia de crecimiento lateral y, por lo tanto, involucra correlación en la interfase.

Las ecuaciones de crecimiento constan de un término determinístico y otro de ruido. La parte determinística está gobernada por las simetrías de los procesos de relajación

y las leyes de conservación que actúan en los procesos en consideración [36]. Por otro lado el término de ruido, puede ser de tipo conservativo o no conservativo [18].

De esta manera es posible definir tres características principales que determinan las clases de universalidad: a) las leyes de conservación que gobiernan la parte determinística de la ecuación; b) si el sistema es lineal o no lineal, c) la naturaleza del ruido.

\subsubsection{Geometría fractal}

A partir de los trabajos de B. Mandelbrot [49], quedó demostrado que los conceptos de la geometría fractal se podían utilizar como herramienta útil para descubrir e interpretar una amplísima variedad de estructuras y fenómenos que se presentan en la naturaleza. En muchos casos la geometría fractal puede emplearse para dar una interpretación más intuitiva de las leyes del escalado.

Un fractal es un sistema desordenado cuyo desorden puede ser descripto en términos de una dimensión no entera [50,51]. El desorden aparece como una característica intrínseca del sistema y no como perturbación de un sistema de referencia ordenado. En otras palabras el desorden persiste cualquiera sea la escala. El punto crítico de la geometría fractal, es la existencia de desorden en todas las longitudes de escala, o la repetición de estructura dentro de la estructura. 
La geometría fractal puede ser la base para describir los objetos desde la escala molecular, como cadenas poliméricas, hasta objetos tan grandes como costas de los continentes o distribución de galaxias. También se aplica a las ciencias humanas, a la forma de centros urbanos, la distribución de estaciones de monitoreo del clima, la red de ferrocarriles, distribuciones neuronales, sistemas de vasos sanguíneos, etc.[52,53]. De igual manera la distribución temporal de acontecimientos puede pensarse mediante conceptos de fractalidad.

\subsubsection{Autosimilaridad y autoafinidad}

La autosimilaridad es una propiedad geométrica del sistema, e indica invarianza, bajo una transformación isotrópica. Si se considera un objeto $S$ formado por un conjunto de puntos $\mathrm{R}=\left(\mathrm{x}_{1}, \mathrm{x}_{2}, \mathrm{x}_{3}, \ldots\right)$, una transformación de similaridad con un factor $\mathrm{b}$, cambia las coordenadas de acuerdo $\mathrm{a} b \mathrm{~b}=\left(\mathrm{bx}_{1}, \mathrm{bx}_{2}, \mathrm{bx}_{3}, \ldots\right)$. El objeto $\mathrm{S}$ se llama autosimilar si permanece invariante al realizar esta transformación.

Por otro lado, los objetos autoafines son aquellos que conservan su estructura si se realiza una transformación anisotrópica (una dilatación de magnitud distinta en por lo menos una dirección particular). De esta manera la transformación $b R=\left(b_{1} x_{1}, b_{2} x_{2}, b_{3}\right.$ $\left.x_{3}, \ldots\right)$ para un objeto autoafin, significa que el sistema reescalado bR es idéntico a una parte del sistema original.

\subsubsection{Dimensión fractal}

Resulta conveniente, en primer lugar, definir las dimensiones utilizadas en matemática. La dimensión topológica $D_{\mathrm{t}}$ considera que un sistema tiene una dimensión igual al mínimo número de dimensiones necesario para describir espacialmente sus elementos. De esta manera los sistemas constituidos por puntos aislados tienen una dimensión topológica igual a cero (los puntos no ocupan espacio). Una línea, sea esta el borde de una costa o el contorno de una circunsferencia tiene una $D_{\mathrm{t}}$ igual a 1 ; una superficie tiene una $D_{\mathrm{t}}$ de 2 , corresponda esta a una esfera perfecta o a la superficie terrestre [51].

La dimensión de embebido, $D_{\mathrm{E}}$ es la dimensión euclidiana menor en la cual el objeto en estudio puede ser embebido. Finalmente, un objeto fractal tiene una dimensión menor que la $D_{\mathrm{E}}$ y mayor que la $D_{\mathrm{t}}$ y la llamamos dimensión fractal $D_{\mathrm{F}}$.

Para decidir acerca de la fractalidad de un objeto, se mide la dimensión de 
Hausdorff $\mu_{\mathrm{H}}$ [54]. Para ello se cubre un objeto arbitrario con $\mathrm{N}(l)$ cajas de tamaño $l$, de forma que:

$$
\mu_{\mathrm{H}}=\mathrm{N}(l) l^{D_{\mathrm{E}}}
$$

siendo $D_{\mathrm{E}}$ la dimensión de embebido. Se podría, de igual manera suponer, que para cualquier objeto vale:

$$
\mathrm{N}(l) \propto l^{-D_{\mathrm{E}}}
$$

puesto que el volumen de cualquier objeto euclidiano no cambia si se modifica la unidad de medida $l$. Para un objeto fractal, en cambio, se tendrá:

$$
\mathrm{N}(l) \propto l^{-D_{F}}
$$

y se tiene:

$$
D_{\mathrm{F}}=\lim _{l \rightarrow 0} \frac{\ln \mathrm{N}(l)}{\ln \left(\begin{array}{l}
1 \\
l
\end{array}\right)}
$$

Si se considera un objeto autosimilar se pueden ilustrar varios de los conceptos vistos. Podemos construir un fractal autosimilar partiendo de un triángulo equilátero, al que se le quita del centro un triángulo equilátero de área igual a 1/4 del total y que se forma por unión de los puntos medios de cada lado. Repitiendo este proceso en cada triángulo obtenemos el fractal de Sierpinski (figura 2.6). Es posible cubrir este objeto fractal a nivel $\mathrm{k}$ (el que se obtiene de realizar $\mathrm{k}$ procesos de quita de área de cada triángulo) con $\mathrm{N}(l)=3^{\mathrm{k}}$ triángulos de lado $l=(1 / 2)^{\mathrm{k}}$. La dimensión fractal de este sistema, según (2.47) es:

$$
D_{F}=\frac{\ln 3^{k}}{\ln (1 / 2)^{-k}}=\frac{\ln 3}{\ln 2}=1,585
$$

Se puede apreciar que la dimensión fractal obtenida no es entera y su valor se encuentra entre la dimensión de embebido $\left(D_{\mathrm{E}}=2\right)$ y la dimensión topológica $\left(D_{\mathrm{t}}=1\right)$. 


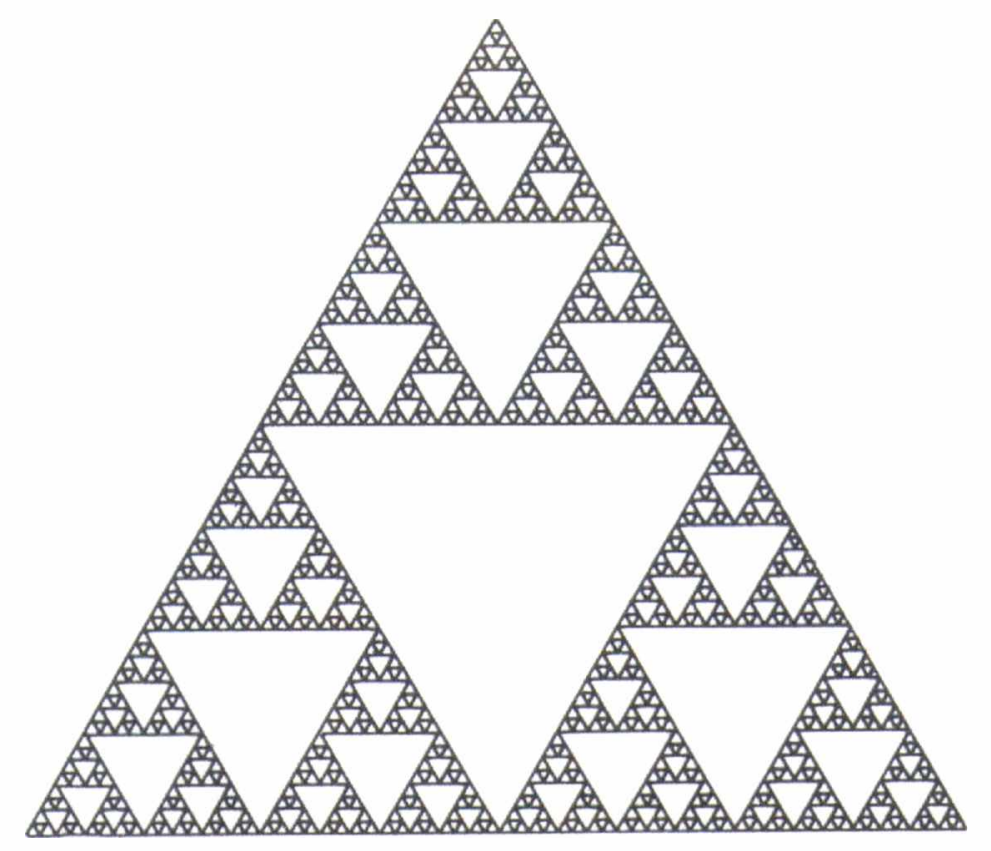

Figura 2.6. Carpeta bidimensional de Sierpinsky. La dimensión fractal es $\ln 3 / \ln 2$.

\subsubsection{Tipos de fractales}

En ciertas casos, es conveniente asignarle al sistema una dimensión fractal, de acuerdo a las leyes del escalado que se encuentren, esto es, de masa, de estructura porosa y de superficie. Así se pueden encontrar objetos en los que escala únicamente la superficie. Son fractales de superficie. Si, tanto la masa como la superficie escalan de igual manera, los sistemas se denominan fractales de masa y si la superficie como el espacio libre (poros), tienen la misma ley de escalado, entonces se llaman fractales de poro. Cuantitativamente para cada tipo de fractal las relaciones son:

$$
\begin{aligned}
& M_{\text {masa }}(R) \propto R^{D \text { masa }} \\
& M_{\text {superficie }}(R) \propto R^{D \text { superficie }} \\
& M_{\text {poro }}(R) \propto R^{D \text { poro }}
\end{aligned}
$$

siendo $\mathrm{M}$ el número de sitios cubiertos por elementos de masa, superficie o poros, y $\mathrm{R}$ el radio medio a partir de un sitio fijo [51].

\subsubsection{Métodos para determinar la dimensión fractal}

Método de contar cajas ("box counting")

Consiste en dividir el espacio en celdas de lado igual a $\varepsilon$ y contar las celdas 
interceptadas por la curva o superficie en estudio [55]. El número de celdas $\mathrm{N}(\varepsilon)$ necesarias para estimar la longitud $l$ o la superficie $S$ satisface expresiones del tipo:

$$
\mathrm{N}(\varepsilon) \propto \varepsilon^{-D_{\mathrm{F}}}
$$

Para el caso de una línea o superficie euclidiana, $D_{\mathrm{F}}{ }^{\prime}=1$ y $D_{\mathrm{F}}{ }^{\mathbf{S}}=2$, respectivamente. Cuando existen irregularidades en las curvas o superficies en toda longitud de escala, la ecuación (2.52) con $D_{\mathrm{F}}$ entero deja de cumplirse y tanto la curva como el área dejan de ser finitas.

El uso del método de "contar cajas o celdas interceptadas" para analizar sistemas a distintas longitudes de escala es de aplicación general. Tanto para partículas, curvas, superficies y volúmenes de sólidos. El número de estas celdas puede tomarse como el número de "pixeles", necesarios para representar el sistema con una resolución $\varepsilon$.

\section{Método de la relación masa-radio}

El método consiste en contar el número de sitios a una distancia $R$ desde un sitio dado (figura 2.7). Los sitios pueden ser pixeles obtenidos de contar celdas interceptadas, pasos de una caminata aleatoria, monómeros en una cadena polimérica, sitios de adsorción en una superficie, etc.

La ecuación que expresa la relación masa-radio es:

$$
M_{\text {sitios }}(R) \propto R^{D_{\mathrm{F}}}
$$

En los experimentos de electrodeposición realizados con celdas electroquímicas de geometría axial, $M_{\text {sitios }}$ se asocia a la carga que pasa por la celda, que es proporcional a la masa del electrodepósito, y $R$ se toma como el radio máximo que alcanza el electrodepósito. 


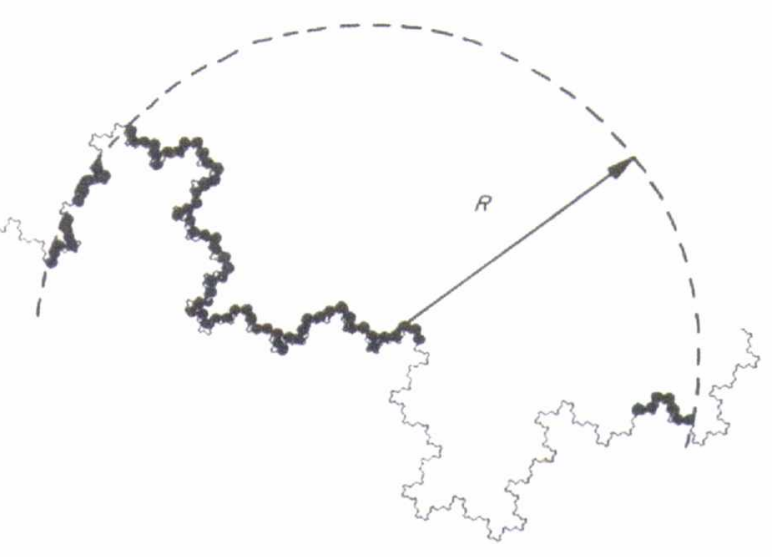

Figura 2.7. Esquema de $M_{\text {sitios }}$ en función del radio $R$

Método de la función de correlación de densidades

A partir de imágenes de depósitos se calcula la función de correlación de densidades definida como:

$$
C(r)=N^{-1} \sum_{r} \rho\left(r+r^{\prime}\right) \rho(r)
$$

donde $\rho$ (r) es la densidad del sitio (puede ser un pixel de una imagen digitalizada) que toma el valor 1 si se encuentra ocupado por el depósito ó 0 si está vacío ( $\mathrm{r}$ es el vector posición). Matsushita evaluó la función de correlación realizando una transformada de Fourier del perfil de densidades, obteniendo el espectro de potencia. Luego aplicó la transformada inversa y promedió sobre todas las direcciones. A partir de un gráfico log $C(r)$ versus $\log (r)$, de la pendiente se obtiene el exponente $A$, y la dimensión fractal de la relación $D_{\mathrm{F}}=2-\mathrm{A}[28]$.

\section{Método del ancho medio cuadrático de la intefase}

Se determina a cada tiempo el ancho medio cuadrático de la interfase del depósito, midiendo la altura de cada sitio ocupado a mayor distancia del substrato lineal inicial y se calcula:

$$
W=\frac{1}{\mathrm{~N}}\left(h_{\mathrm{i}}{ }^{2}-<h>^{2}\right)
$$

donde $h_{\mathrm{i}}$ es la distancia desde el substrato hasta el punto más alejado en dirección perpendicular al mismo, $\mathrm{i}=1,2,3, \ldots, \mathrm{N}$ y $<h>$ es la altura media.

Luego se determina $\mathrm{S}$, el número de partículas que constituyen el depósito por unidad de longitud (número de pixeles de una imagen del depósito) y se obtiene la dimensión fractal a partir de la relación: 


$$
\mathrm{S} \propto W^{D_{\mathbf{F}}\left(\mathbf{d}, \mathrm{d}_{\mathbf{b}}\right)}
$$

donde $d_{b}$ es la dimensión del substrato sobre el cual se produce el depósito, y d es la dimensión del espacio en el que crece el depósito. Para los electrodepósitos presentados en este trabajo, $\mathrm{d}_{\mathrm{b}}=1$ y d $=2$. $D_{\mathrm{F}}$ se obtiene considerando $D_{\mathrm{F}}\left(\mathrm{d}, \mathrm{d}_{\mathrm{b}}\right)=D_{\mathrm{F}}(\mathrm{d})-\mathrm{d}_{\mathrm{b}}[56]$.

\subsection{Formación de una fase en un medio desordenado}

Se describe, bajo este título, el avance del frente de crecimiento de un depósito a través de un medio estructurado desordenado. En este caso el medio domina la aleatoriedad del sistema en lugar de las fluctuaciones intrínsecas asociadas con el proceso de formación de la fase. Durante las décadas pasadas se ha dedicado un gran esfuerzo en el estudio de las interfases que avanzan en medios que contienen obstáculos fijos distribuidos desordenadamente, tanto desde el punto de vista de modelos de crecimiento, teorías analíticas y experimentos [18].

Son ejemplos de este proceso el avance de un fluido a través de un papel de filtro, la propagación de una mancha de café en un mantel de tela, la propagación de contaminantes en sedimentos [57], el avance de la interfase petróleo-agua en la extracción del petróleo [58], la propagación de colonias bacterianas en geles, etc. La velocidad de propagación de la interfase está afectada por las inhomogeneidades del medio que se constituyen en obstáculos para el crecimiento de la fase, diminuyendo localmente la velocidad de avance del frente en forma aleatoria $y$, consecuentemente, producen una disminución de la velocidad promedio de avance del frente.

Esta situación es equivalente a suponer que la rugosidad de la interface se ve incrementada por la presencia de obstáculos, que generan distintas velocidades de desplazamiento del frente. El arreglo de los obstáculos en el medio, se comporta como un ruido que perturba la interfase. El "ruido" no cambia en el tiempo, pues el arreglo desordenado de obstáculos es invariable, de ahí que reciba el nombre de "ruido congelado".

La interacción entre la interfase en movimiento y los obstáculos que presenta el medio se establece a través de las fuerzas de fricción. Puede ocurrir que la fuerza de fricción sea mayor que la fuerza que produce el movimiento de la interfase, fuerza impulsora $F$, en cuyo caso la interfase se hallará frenada ("pinned"). En cambio si la fuerza impulsora $F$ supera a la fuerza de fricción la interfase se moverá libremente (“depinned"). Son precisamente las transiciones "pinning-depinning" las que caracterizan el avance de una interfase en un medio estructurado desordenado. 
La figura 2.8 representa la velocidad de avance de la interfase en función de la fuerza impulsora. Se pueden distinguir tres regímenes. I) Interfase frenada, la fuerza de fricción es mayor que la fuerza impulsora. En este régimen pueden existir fluctuaciones en la posición de la interfase, como consecuencia de la agitación térmica. II) Interfase móvil con velocidad baja. En este régimen la fuerza impulsora supera a la fuerza de fricción y comienza a avanzar; aparecen entonces regiones frenadas y otras en movimiento. III) Interfase libre. En este régimen la fuerza impulsora es mucho mayor que la fuerza de fricción y la interfase se mueve libremente.

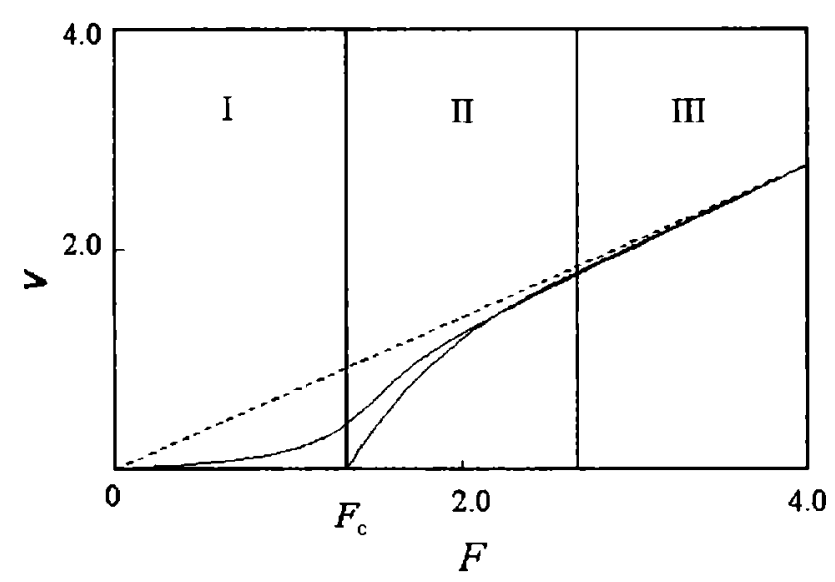

Figura 2.8. Transición pinning - depinning

Se han propuesto varios experimentos diseñados para el estudio del movimiento de interfases en medios desordenados. Entre ellos, el desplazamiento de un fluido por medio de otro inmiscible en un medio poroso formado por esferas de vidrio de distinto tamaños $[59,60,61]$. Otros experimentos, involucran la propagación en dos dimensiones del frente de un líquido que moja un papel y en tres dimensiones utilizando materiales de secado (absorbentes). En estos experimentos se determinó un factor de rugosidad mayor que el previsto por el modelo KPZ $[62,63]$. En la propagación del frente de avance que se forma al quemar un papel de características y tratamiento apropiado que evita la producción de llamas [64], se obtienen también exponentes de escalado más altos que los previstos por el modelo KPZ. El experimento es comparable al incendio de bosques. Experimentos similares sirven para estudiar modelos adecuados para describir el avance de estos incendios.

Las ecuaciones continuas utilizadas para describir el movimiento del frente de crecimiento en un medio desordenado, son del tipo mencionado en las secciones precedentes, esto es, la ecuación de Langevin del modelo EW y la ecuación KPZ [65]. Sin embargo, en estos casos, el término de ruido no depende del tiempo, pues los obstáculos que perturban el avance de la interfase se encuentran quietos, y dependen de la posición $h$ 
de la interfase. Estas ecuaciones continuas se resolvieron expresando el ruido como una función de potencia de la distancia [66], considerando correlaciones de largo alcance $[67,68]$ e incorporando la anisotropía del medio [69].

Con respecto a los modelo, el mayor número de ellos se basa en las ideas del depinning por percolación dirigida (DPD) [70]. Estos modelos fueron aplicados a varios sistemas $[62,63,71]$ y extendido a otros luego de algunas modificaciones $[72,73]$.

\subsection{Trabajos previos seleccionados en relación con la tesis}

Como se dijo en la sección 2.4 , en la electrodeposición de metales en celdas quasibidimensionales se obtiene, en forma controlada, una diversidad de morfologías. En la siguiente recopilación bibliográfica solo se consideran los trabajos que emplean celdas quasi-bidimensionales (2D) similares a las empleadas en el presente trabajo. Las celdas 2D hechas con placas de material transparente (vidrio, o acrílico), separadas por distancias menores a la décima de $\mathrm{mm}$, permiten observar la dinámica de crecimiento de los electrodepósitos. A partir de los trabajos de Brady y Ball [74] y Matsushita [28] se apreció la importancia de la electrodeposición de metales para generar estructuras fractales [49] similares a las que se encuentran en la naturaleza. Además la posibilidad de seguir la evolución de los crecimientos permite evaluar modelos de crecimiento teóricos.

Para electrodepósitos de zinc y cobre, obtenidos a partir de soluciones de sulfato de zinc y sulfato de cobre respectivamente, se determinaron dimensiones fractales en el rango de 1,4 a 1,8 , dependiendo del potencial aplicado [28,56,43,75-77]. En estos experimentos la concentración de la solución era baja y la fuerza impulsora relativamente pequeña, resultando morfologías en buen acuerdo con las predicciones del modelo DLA simple o con modificaciones, por ejemplo, incluyendo correlaciones a distancias grandes [41]. Sin embargo, se apreció rápidamente la influencia del potencial eléctrico, la convección y la descomposición del electrolito acuoso, particularmente cuando la fuerza impulsora y la velocidad de crecimiento del depósito son elevadas. El modelo DLA representa difusión en cualquier escala de tiempo y distancia. Por otro lado, cuando la velocidad de crecimiento de la interfase del depósito es mayor que la velocidad de penetración por difusión: $4 D$ ( $D$ : coeficiente de difusión y $t$ el tiempo) [78-80], aparecen otras longitudes características (i.e., radio del depósito). En estos trabajos se sugiere que el proceso deja de ser controlado por la difusión pura y el fenómeno de "advection" pasa a ser controlante. Las morfologías obtenidas en estos casos en general son densas (DR) según las publicaciones de distintos autores [81-84]. 
La presencia de transiciones morfológicas ocurre con frecuencia en la electrodeposición de metales en celdas quasi-bidimensionales de geometría rectangular o axial. Así, Sander encontró que estas transiciones tienen lugar en celdas axiales a una determinada relación de distancia cátodo-ánodo. Reciben el nombre de "transiciones de Hecker" $[85,86]$. Se propusieron distintas explicaciones para estas transiciones, basadas en cambios de composición química en las cercanías de la interfase, efectos del potencial aplicado, cambios de $\mathrm{pH}$, presencia de un frente de impurezas provenientes del ánodo [43, 87,88].

En el Capitulo 6 se realiza una amplia recopilación bibliográfica sobre convección natural en sistemas electroquímicos en los que se emplean celdas tridimensionales convencionales. En las celdas quasi-bidimensionales empleadas para generar estructuras fractales, el transporte de materia por convección, comenzó a estudiarse a partir de trabajos de Y. Kondo et. al, basados en medidas de interferométricas de los gradientes de concentración durante la electrodeposición de plata metálica [89]. Esta técnica de Schlieren se utilizó en la electrodeposición de $\mathrm{Cu}$ a partir de soluciones de sulfato de cobre sin soporte $[90,84]$ y depósitos de zinc obtenidos empleando soluciones de sulfato de zinc $[91,93]$. Es de notar que en estos experimentos, debido a las condiciones empleadas, es significativa la convección originada por la presencia de un fuerte campo eléctrico que afecta a las especies cargadas (electroconvección), más bien que la convección originada por fuerzas gravitatorias.

La electroconvección se produce cuando se aplican potenciales elevados y se emplean electrolitos binarios sin soporte. Constituye un tipo de inestabilidad electrodinámica, que fuera primeramente estudiada por Bruinsma y Alexander [94]. Hibbert y colaboradores [95] indicaron que la presencia de flujos electroconvectivos en las puntas de las dendritas o ramificaciones son responsables de la transición morfológica observada en los electrodepósitos. La electroconvección se asoció con varios mecanismos de crecimientos ramificados complejos y dendritas [96-99]. En otros trabajos, se empleó la electroconvección como un factor de selección morfológica para producir estructuras metálicas de mallas en la electro-reducción de sulfato de hierro (III) $[100,101]$.

La distribución de velocidades de los flujos hidrodinámicos afectan la morfología del electrodeopósito a través del espesor y la forma de la película de difusión o hidrodinámica. Cuando la convección libre contribuye en forma significativa al transporte de materia, se encuentran longitudes características en los electrodepósitos que van de los cientos de micrones al $\mathrm{mm}$. Este valor es intermedio entre las dimensiones de la celda y la estructura fina controlada por la difusión [78,87,102,103]. 
La estructura fina de los electrodepósitos se ha intentado explicar aplicando la teoría de estabilidad lineal [104-106], que se desarrolla en esta tesis en el capítulo 5.

La disminución del espesor de la celda electroquímica [107,91], la disposición de la celda en posición vertical con el cátodo en la parte superior, la operación en microgravedad [108] y la adición de aditivos que aumentan la viscosidad del medio minimizan los procesos de convección natural. Así, los experimentos que se realizan en el espacio, permiten examinar el efecto de la convección generada por fuerzas distintas a las gravitatorias.

Entre los aditivos incorporados a las soluciones electrolíticas se pueden mencionar aquellos que aumentan la viscosidad del medio minimizando la convección, como glicerina, polietilenglicol, etc. Además, es común el empleo de sustancias que a partir de cierta concentración crítica producen geles, como la carboximetil celulosa y la agarosa. El empleo de estos aditivos en celdas quasi-bidimensionales no es frecuente, Bennema y colaboradores emplearon agarosa en forma de soles y geles para disminuir la convección [109] y observaron distintas morfologías en electrodepósitos de cobre. Otra alternativa fue publicada por Hibbert y colaboradores, quienes emplearon papeles de filtro embebidos en el electrolito como medio para producir electrodepósitos de cobre [110]. Esto además de eliminar la convección permite preservar los electrodepósitos, cuya estructura puede estudiarse posteriormente por técnicas de microscopía electrónica. 


\section{CAPITULO 3}

Parte Experimental

\subsection{Técnicas electroquímicas}

La electrodeposición de plata se realiza en celdas quai-bidimensionales de geometría circular y rectangular. Este tipo de celdas resultan apropiadas para estudiar la morfología y la cinética de crecimiento de los electrodepósitos. Consiste en dos placas de un material transparente e inerte, que se encuentran separadas de 0,5 a 50 décimas de milímetro y entre las cuales se colocan los electrodos.

Los electrodepósitos se obtienen mediante la técnica potenciostática y en algunos casos galvanostática. En la modalidad potenciotática el potencial del electrodo de trabajo (ET), medido con respecto a un electrodo de referencia (ER), se mantiene a un valor constante y se mide la corriente que circula entre ET y el contra-electrodo (CE). En tanto que en la modalidad galvanostática, se mantiene constante la corriente que circula entre ET y el contraelectrodo (CE), y se mide como varía el potencial del ET con respecto a un electrodo de referencia (ENH, por ejemplo).

El instrumental básico para realizar la electrodeposición es el potenciostato. Que en la modalidad potenciostática, a través de un circuito de realimentación, hace que se modifique la corriente que pasa a través el ET y el CE para lograr mantener constante, en un valor seleccionado, el potencial aplicado al electrodo de trabajo con respecto al ER. Por el terminal conectado al electrodo de referencia no circula corriente debido a su alta impedancia de entrada. Además haciendo que el área del electrodo auxiliar sea mucho más grande que la del electrodo de trabajo, se logra que la polarización que regula el proceso sea la de los fenómenos electródicos que acontecen en el electrodo de trabajo. De esta manera, la corriente medida da cuenta de los procesos que ocurren en el electrodo de trabajo a potencial constante.

En la técnica potenciodinámica, el potencial seleccionado cambia linealmente a una velocidad constante con respecto al electrodo de referencia, obteniéndose una curva de corriente $(I)$ versus potencial (E) (curva de polarización).

En la figura 3.1 se muestra un escalón de potencial aplicado como estímulo de la interfase y su respuesta de corriente. 


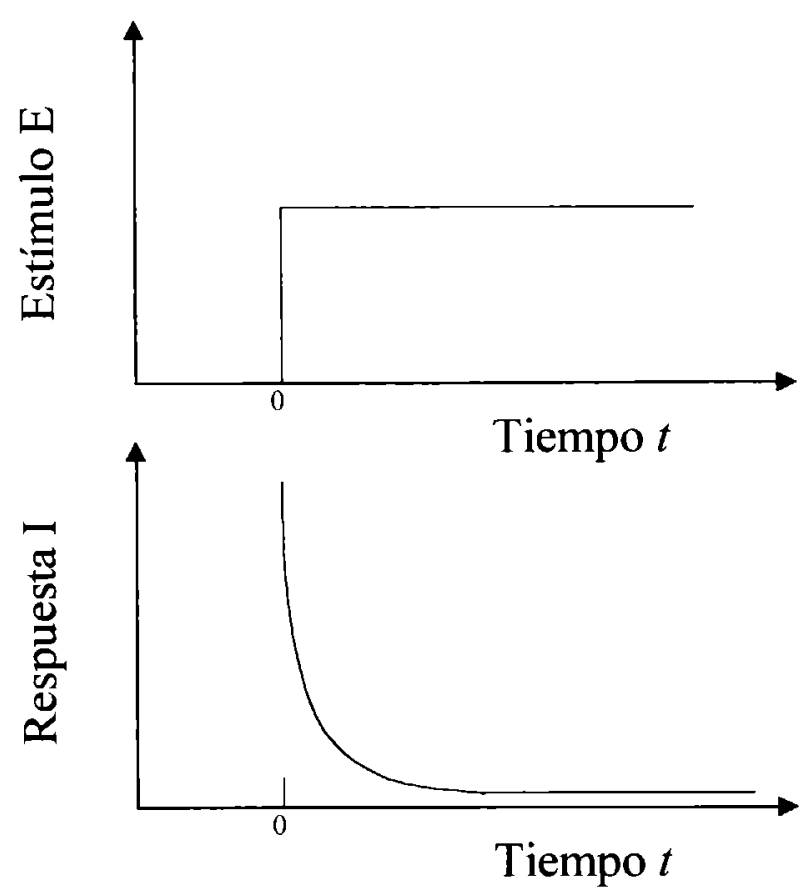

Figura 3.1. Escalón de potencial y respuesta de corriente del sistema perturbado.

De igual manera en la técnica galvanostática, el estímulo puede ser un escalón de corriente y la respuesta del sistema se sigue a través de la evolución del potencial (Fig. $3.2)$.

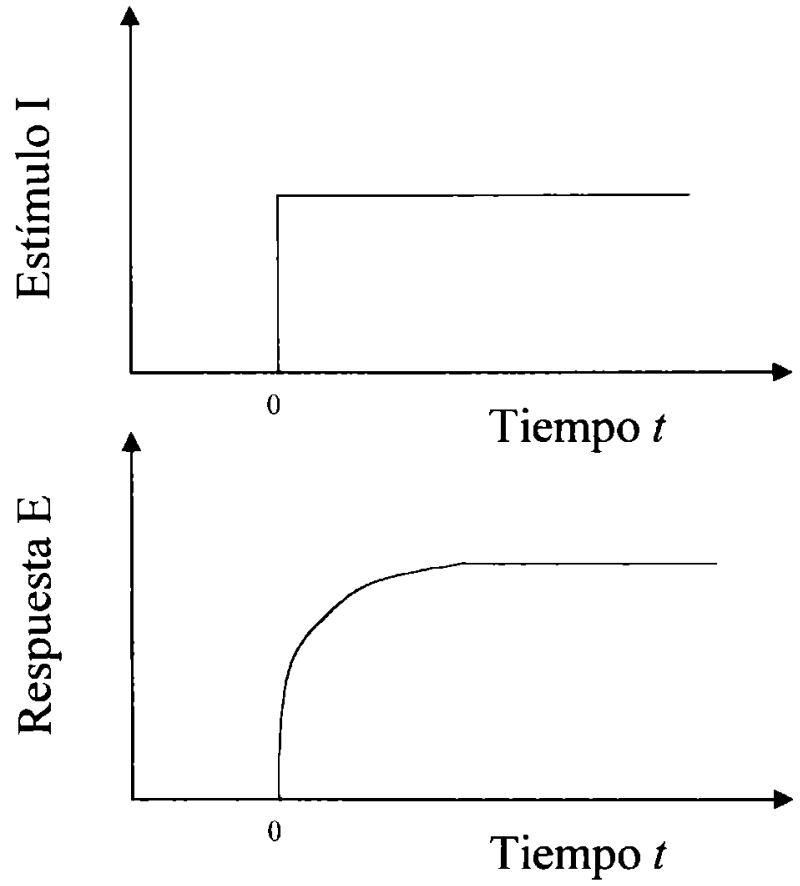

Figura 3.2. Escalón de corriente y respuesta de potencial del sistema perturbado.

En la técnica potenciodinámica, considerando que la interfase se estimula con una perturbación lineal o triangular, se tienen las posibles respuestas que se muestran en la figura 3.3. 


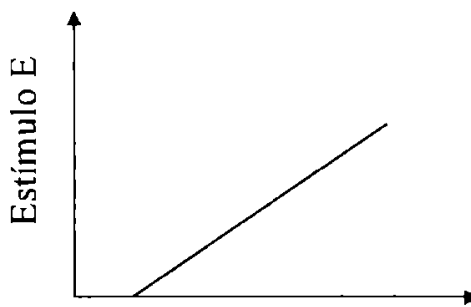

Tiempo $t$

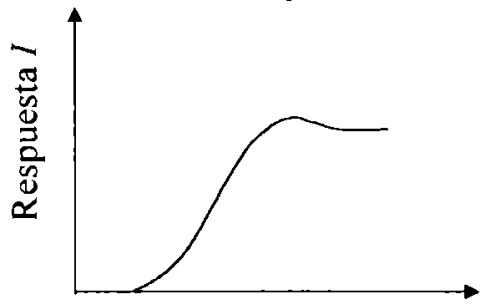

Potencial E

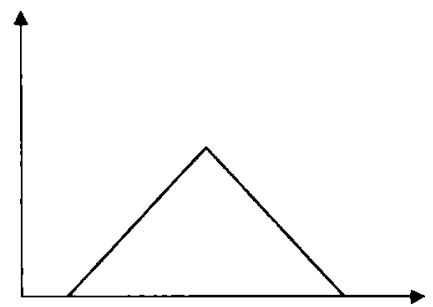

Tiempo $t$

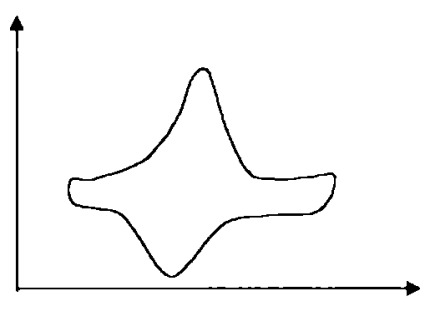

Potencial E

Figura 3.3. Perturbación lineal y triangular de potencial con sus respectivas respuestas de corriente.

En la celdas electroquímicas quasi-bidimensionales, la resistencia eléctrica puede alcanzar valores muy altos $(\approx 15000 \mathrm{ohm})$. Al aplicar una diferencia de potencial en la celda, se tuvo en cuenta la caída óhmica, que se produce entre el ER y el ET o entre el ET y el CE. Esto es, el potencial al que se encuentra el electrodo de trabajo es el aplicado, corregido por la caída óhmica debida a la circulación de corriente entre el electrodo de trabajo y el electrodo de referencia o contra-electrodo. En la figura 3.5 se muestra un símil de una celda electroquímica que permite comprender el efecto de la caída de potencial óhmico.

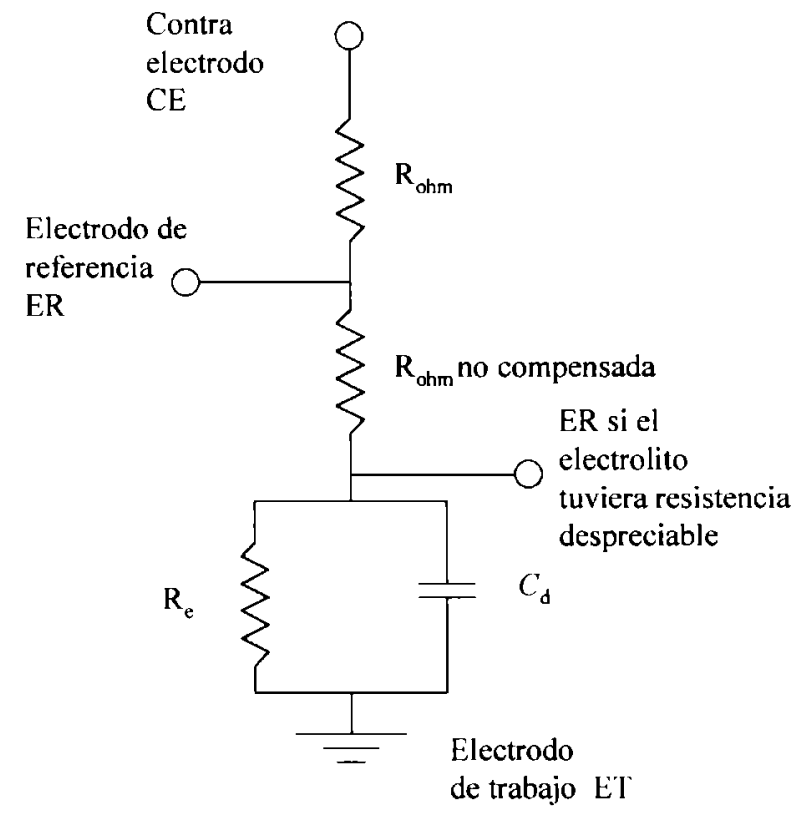

Figura 3.5. Símil de una celda electroquímica. 
La magnitud de esta resistencia puede ser medida o calculada a través de distintas expresiones, dependiendo de la geometría de la celda. Estas expresiones se obtienen por integración de la ecuación de Laplace del potencial eléctrico, con las condiciones de contorno apropiadas [111].

\subsubsection{Equipos y materiales empleados}

\subsubsection{Potenciostatos}

Para llevar a cabo las distintas rutinas electroquímicas se utilizan los potenciostatos bipotenciostato-galvanostato modelo Bipad 2 Tacussel, PAR modelo 362 de EE\&G Instruments (Princeton Applied Instrument) y LYP M6, provistos de un registrador Houston Omnigraphic 2000. También se usa un potenciotato Radiometer Voltalab 32 con interface digital.

En algunas experiencias para adquirir los datos sobre la evolución de la corriente durante el proceso de electrólisis, se utiliza el potenciostato bipotenciostato-galvanostato modelo Bipad 2 Tacussel y un programa desarrollado en el laboratorio, con una tarjeta adquisidora de alta velocidad que permite registrar y exportar los datos para ser tratados por programas de tratamiento de datos.

\subsubsection{Electrodos de referencia}
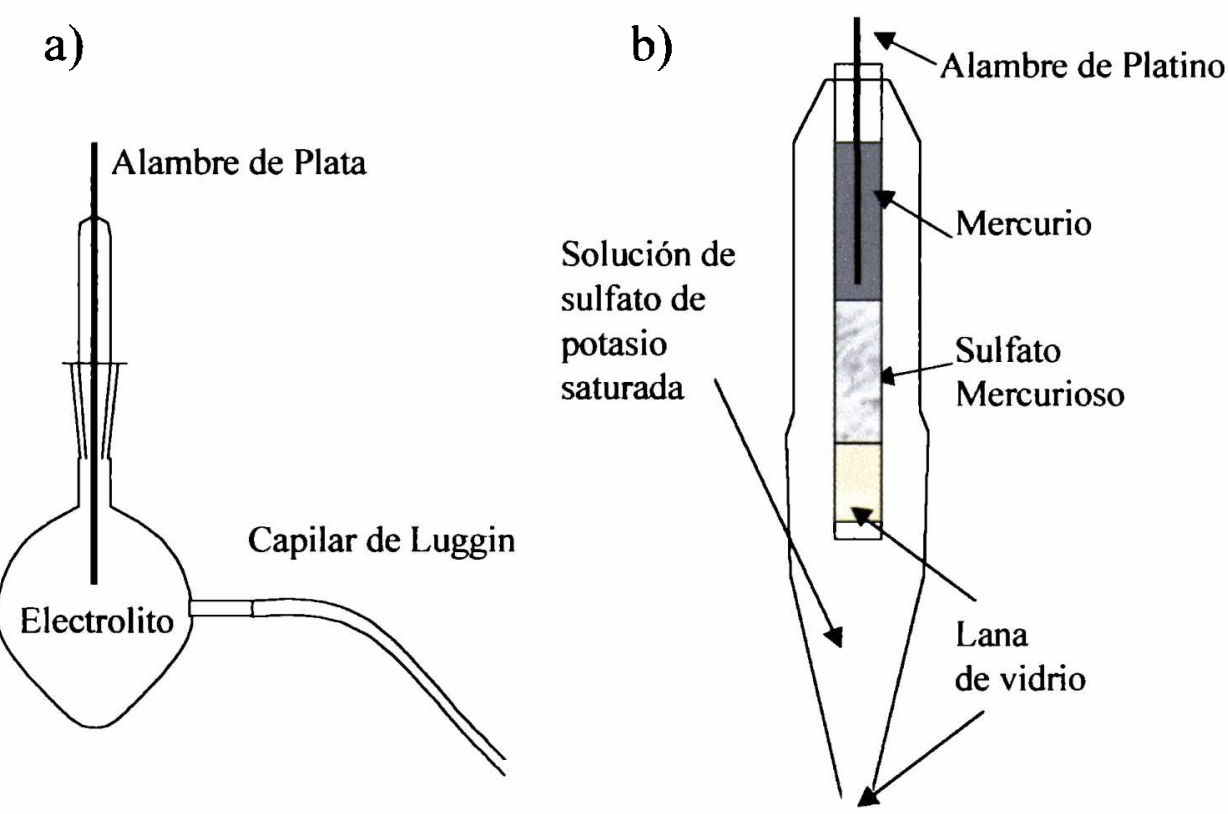

Figura 3.6. Esquemas de los electrodos de referencia típicos utilizados en las celdas quasi-bidimensionales. a) Se muestra el electrodo de plata sumergido en solución de sulfato de plata y el diseño para su conexión con la solución de la celda de electrodeposición. b) Electrodo de $\mathrm{Hg}^{\circ} / \mathrm{Hg}_{2} \mathrm{SO}_{4} / \mathrm{KCl}$ (sat.), para utilizarlo en la celda quasi-2D se lo coloca en un recipiente similar al mostrado en a). Los esquemas no están en escala. 
Se emplea como electrodo de referencia, o bien un alambre sumergido en una solución de iones $\mathrm{Ag}^{+}$o un electrodo de $\mathrm{Hg}^{\circ} / \mathrm{Hg}_{2} \mathrm{SO}_{4} / \mathrm{KCl}$ (sat.), $\mathrm{E}^{\circ}=0,658 \mathrm{~V}$. En la figura 3.6 se muestra un esquema de cada electrodo.

\subsubsection{Celdas de electrodeposición}

En la mayoría de los experimentos se emplearon celdas cuasi-bidimensionales de geometría A) cilindrica y B) rectangular en las que el crecimiento del electrodepósito se produce en el plano horizontal. Las celdas se construyen con dos placas paralelas y pulidas de Lucite $\circledast$ o de vidrio, que se mantienen separadas una distancia $l_{\mathrm{s}}$. En todos los casos se utilizan separadores de Teflon® para confinar la solución electrolítica.

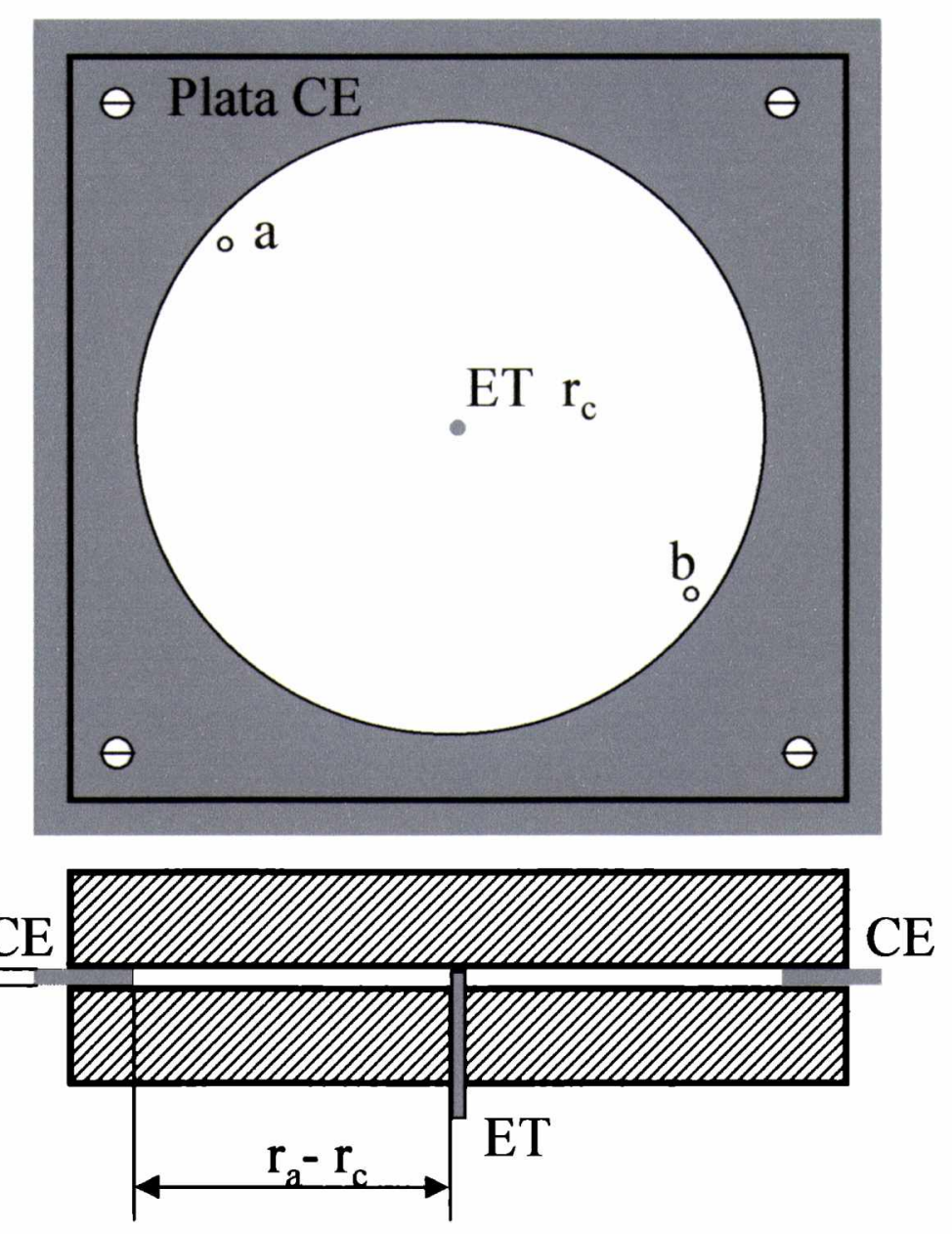

Figura 3.7. Celda circular. ET: electrodo de trabajo; CE: contra-electrodo; $r_{a}$ y $r_{c}$ radio del contraelectrodo y el electrodo de trabajo respectivamente, a y b orificios para introducir solución y conectar el capilar de Luggin. 
En la celda A) el electrodo de trabajo utilizado es un cilindro de plata o platino $(99,99 \%$ de pureza) de $0,05 \mathrm{~cm}$ de radio o de $0,1 \mathrm{~cm}$ de radio. El contra-electrodo es una lámina de plata $(99,9 \%$ pureza) de $0,025 \mathrm{~cm}$ de espesor, con un agujero de $5 \mathrm{~cm}$ de radio. Entre las placas de Lucite ${ }^{\circledR}$ o de vidrio y el contraelectrodo se colocan dos anillos armados con cinta de Teflon ${ }^{\circledR}$ para cerrar herméticamente la celda al presionar las placas con cuatro tornillos de sujeción ubicados en los vértices de las placas de Lucite®, de $12 \mathrm{~cm}$ de lado. La separación $l_{\mathrm{s}}$ va de $0,03 \mathrm{a} 0,06 \mathrm{~cm}$, dependiendo del espesor del anillo de Teflon® y la presión ejercida por los tornillos. La placa superior presenta dos orificios $(a, b)$ de $0,2 \mathrm{~cm}$ de diámetro, ubicados sobre una línea imaginaria de $9 \mathrm{~cm}$ que los une pasando por el centro donde se encuentra el electrodo de trabajo. Estos orificios son utilizados para cargar el electrolito e introducir el capilar de Luggin del electrodo de referencia, una vez armada la celda. (Ver figura 3.7).

En algunos casos el electrodo de trabajo se introduce por una perforación ubicada en la tapa superior y en otros, con el fin de observar los primeros estadios del crecimiento, por la tapa inferior.

En la celda B) se utiliza como electrodo de trabajo alambres de plata o de platino ( $99,99 \%$ de pureza) de $0,05 \mathrm{~cm}$ de diámetro ubicados según las configuraciones mostradas en las figuras 3.8 (a) y (b).

La celda consiste de dos placas de vidrio o Lucite ${ }^{\circledR}$ cuadradas, la superior posee dos orificios, uno para el llenado de la celda con el electrolito y otro para colocar el capilar de Luggin del electrodo de referencia. Entre las dos placas se confecciona un cuadrado de $4 \times 4 \mathrm{~cm}$ de cinta de Teflon ${ }^{\circledR}$ y, en algunos casos el electrodo de trabajo se incorpora por uno de los orificios de la tapa superior y se sostiene por medio de un tapón de Teflon® en el cual se inserta (celda BI), en tanto que en otros casos, dos alambres paralelos (el electrodo de trabajo de plata o de platino y el contraelectrodo de plata $99,99 \%$, ambos de $0,05 \mathrm{~cm}$ de diámetro) se ubican separados una distancia de $2,8 \mathrm{~cm}$ se insertándolos en el cuadrado de Teflon® (celda BII).

También se utiliza una celda de características similares a las de la celda BI, pero con mayor separación entre el electrodo de trabajo y el contra-electrodo $\left(l_{\mathrm{a}-\mathrm{c}}=7 \mathrm{~cm}\right)$. En este caso, el electrodo de trabajo consiste en un alambre de plata $99.99 \%$ de $0,05 \mathrm{~cm}$ de diámetro o una lámina de plata de $0,025 \mathrm{~cm}$ de espesor y con un área activa de $0,0175 \mathrm{~cm}^{2}$. 


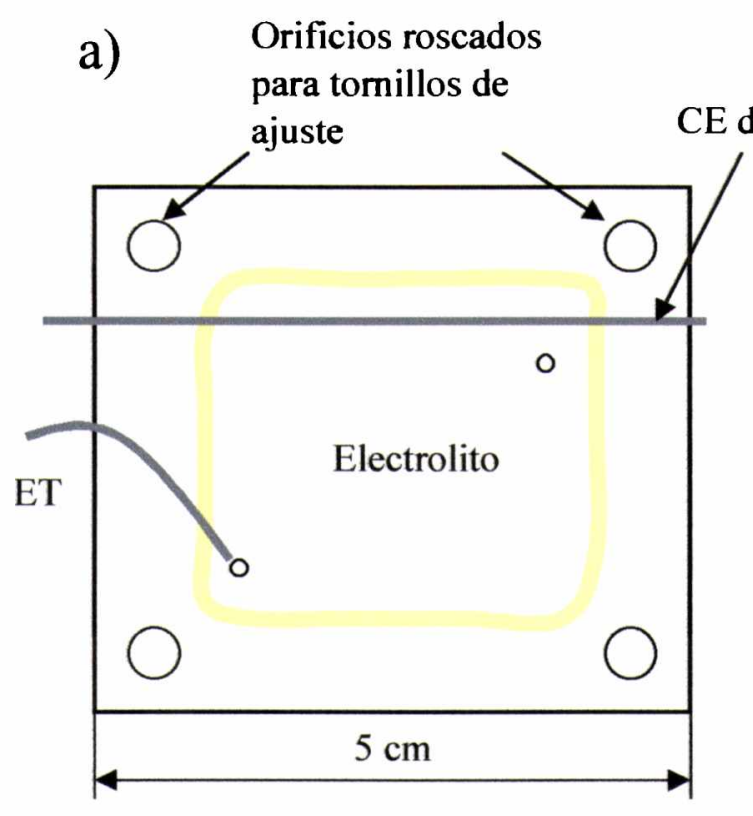

b)

c)

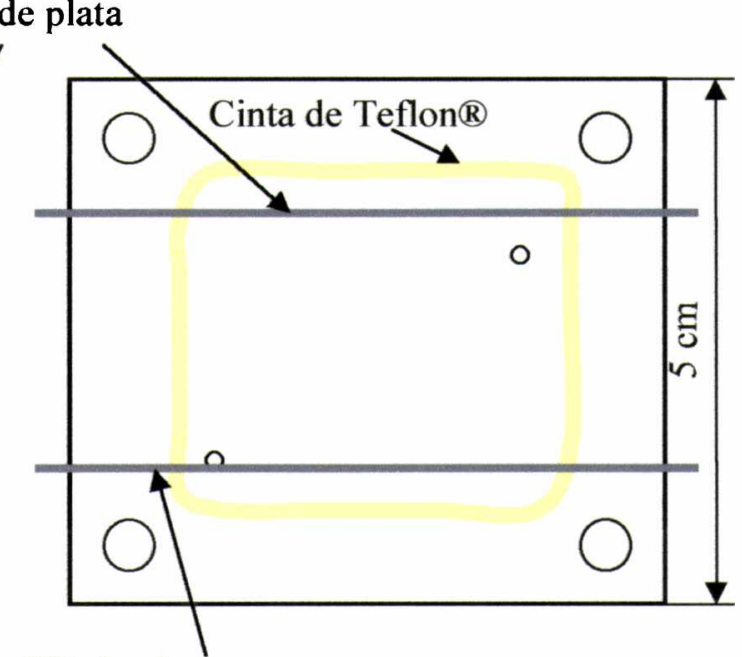

ET de plata o platino
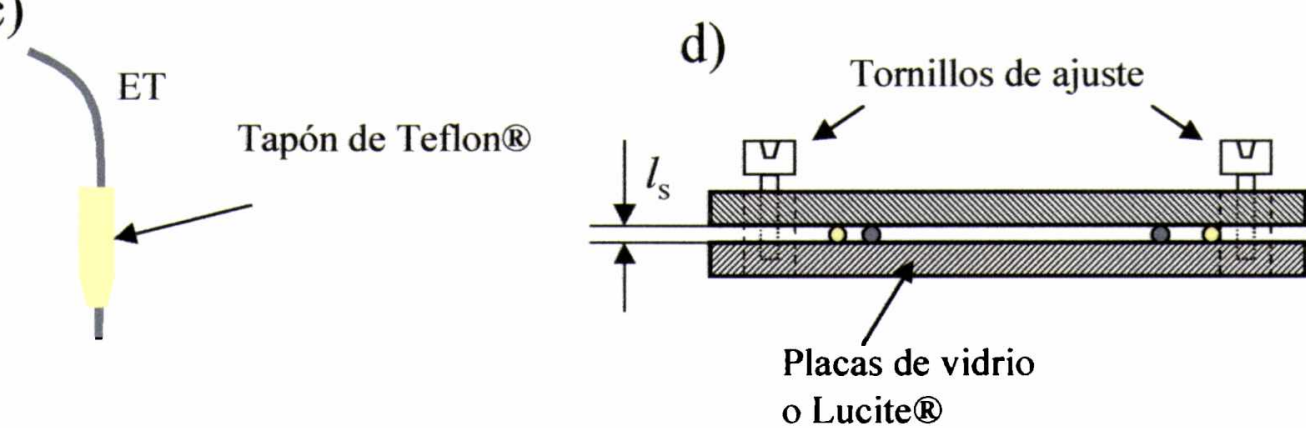

Figura 3.8. Celdas rectangulares: a) Bl y b) BII. En a) y b) se muestran dos configuraciones empleadas; c) Esquema del tapón de Teflon ${ }^{\circledR}$ donde se inserta el electrodo de trabajo (ET) para ser utilizado en la celda mostrada en a); d) vista transversal de la celda mostrada en $b$.

En estos dos diseño la separación final entre las placas, se mide con un tornillo micrométrico. El estudio del efecto de la separación de las tapas o altura de la celda presenta dificultades. En el caso de las celdas de geometría rectangular, los extremos de los electrodos pueden tener efectos pocos predecibles debido a la densidad de corriente local, o efecto de bordes, dependiente en gran medida, de la disposición geométrica resultante entre la cinta de Teflon® usada como sellador y el electrodo metálico. Estos problemas son resueltos con el diseño de celda propuesto a continuación. 


\subsubsection{Celdas empleadas en los experimentos con gradientes de temperatura}

Otra configuración utilizada para la celda de geometría rectangular B) consiste de dos placas paralelas, una inferior de $9 \times 9 \mathrm{~cm}$ y una superior de $3 \times 3 \mathrm{~cm}$ provista de una hendidura de $0,2 \mathrm{~cm}$ en el centro de uno de sus lados para ubicar un sensor térmico. La separación entre las placas es de $l_{\mathrm{s}}=0.025 \mathrm{~cm}$ (ver esquema en la figura 3.9) y está dada por el espesor de la lámina de plata usada como electrodo (celda BIII). Se utilizan como máscara, dos piezas de Teflon ${ }^{\circledR}$ de la misma altura que el electrodo, con el fin de asegurar una distribución apropiada de corriente y una mayor área del electrodo auxiliar. Los electrodos son dos láminas de plata de $2,5 \times 2,5$ y $0,025 \mathrm{~cm}$ de altura (Goodfellow 99,99 $\%)$. La separación entre el electrodo de trabajo y el contraelectrodo es de $2,3 \mathrm{~cm} \leq l_{\mathrm{a}-\mathrm{c}} \leq 5$ cm. En esta celda, se varía la separación entre los electrodos.

a)
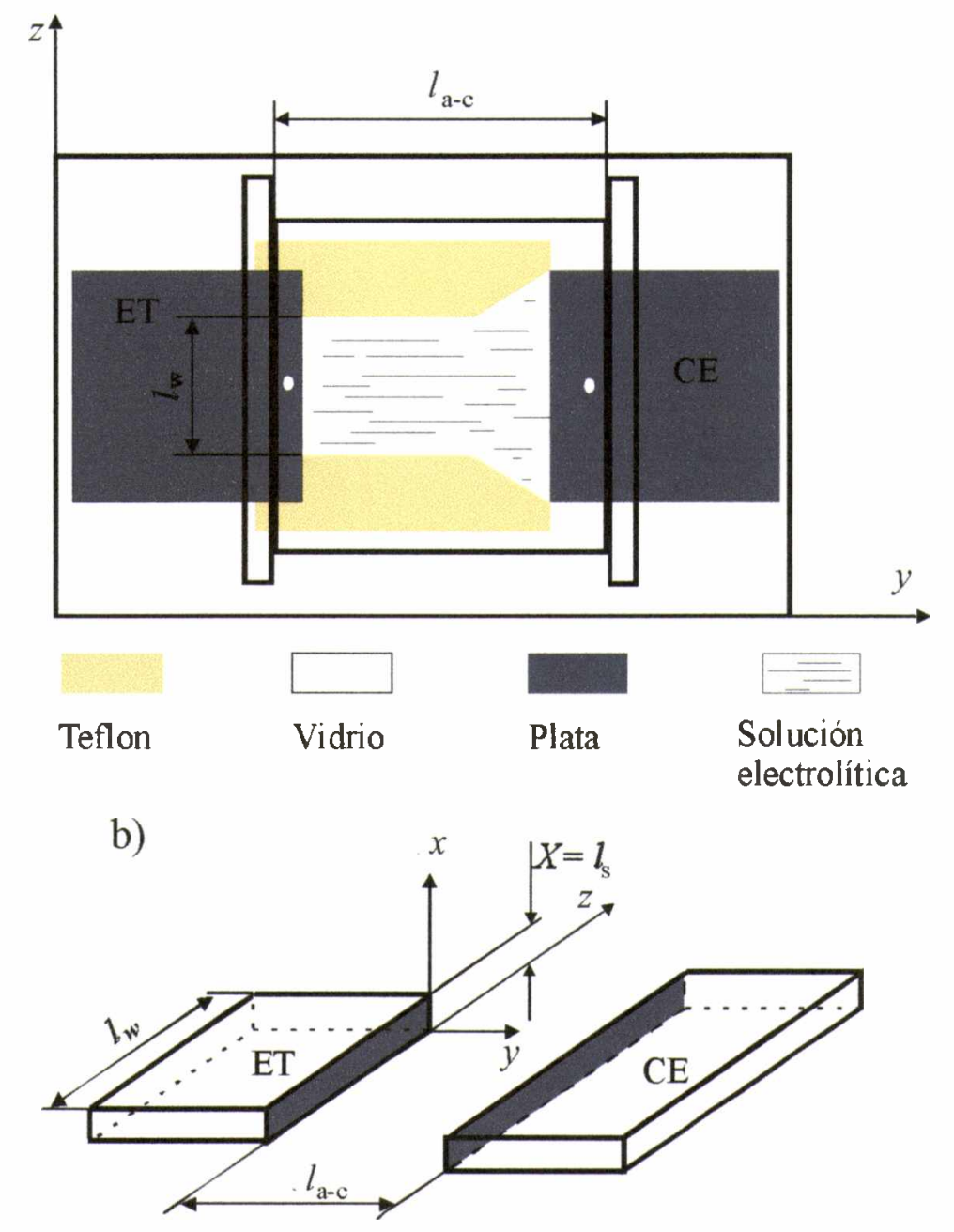

Figura 3.9. Celda BIII descripta en el texto. Se incluye en la figura superior el sistema de ejes de coordenadas que se utiliza en este trabajo. 
3.1.1.5 Celdas utilizadas para estudiar el efecto de un gradiente térmico y de la altura del electrodo

Las celdas se construyeron con Lucite ${ }^{\circledR}$ y poseen electrodos de plata metálica (99,9\% de pureza) de $1,5 \mathrm{~cm}$ de ancho $l_{\mathrm{w}}$ y de distintas alturas $\left(l_{\mathrm{s}} \equiv X=0,15 ; 0,3 \mathrm{y} 1 \mathrm{~cm}\right)$ (celda BIV). La separación entre electrodos $l_{\mathrm{a}-\mathrm{c}}$ es de $2,3 \mathrm{~cm}$, similar a la distancia entre el cátodo y el ánodo en las celdas 2D. Los electrodos aislados forman parte de una de las paredes de los compartimientos de $15 \mathrm{~cm}^{3}$ utilizados para termostatizar los electrodos por medio de la circulación de agua a temperatura controlada $\left( \pm 0,1{ }^{\circ} \mathrm{C}\right)$ por termostatos Lauda. En la figura 3.10 se muestra un esquema en planta a) y de un corte transversal b).

a)

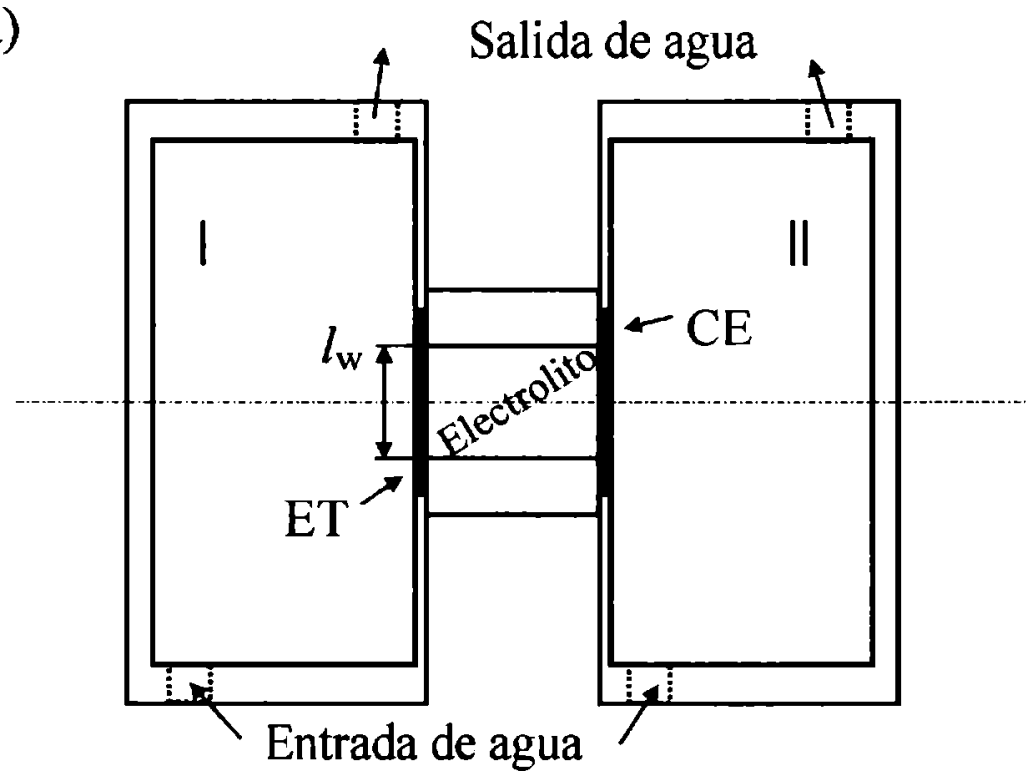

b)

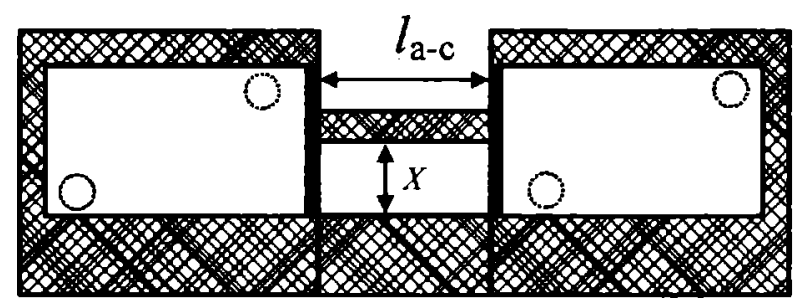

Figura 3.10. (a) Vista en planta y (b) corte transversal de la celda empleada para estudiar el efecto de la altura del electrodo y la incorporación de un gradiente térmico.

3.1.1.6 Celda empleada para realizar el estudio estadístico de la estructura interna de los electrodepósitos y el crecimiento en medios desordenados

La celda empleada en estos casos es de geometría rectangular (celda BV), construida con dos placas de vidrio de $5 \mathrm{~cm} \times 8 \mathrm{~cm}$ y $0,2 \mathrm{~cm}$ de espesor. Los electrodos son láminas de plata $99,9 \%$ de pureza y $0,025 \mathrm{~cm}$ de espesor, siendo el ET de $0,7 \times 10 \mathrm{~cm}$ y el CE de $1,5 \times 10 \mathrm{~cm}$. La distancia $l_{\mathrm{a}-\mathrm{c}}$ es de $2,3 \mathrm{~cm}$ y $l_{\mathrm{s}}$ resulta en $0,025 \mathrm{~cm}$. Las placas de 
vidrio se presionan con una prensa de acrílico o broches metálicos colocados de manera de lograr una presión homogénea en toda la superficie de las placas de vidrios (figura 3.11).

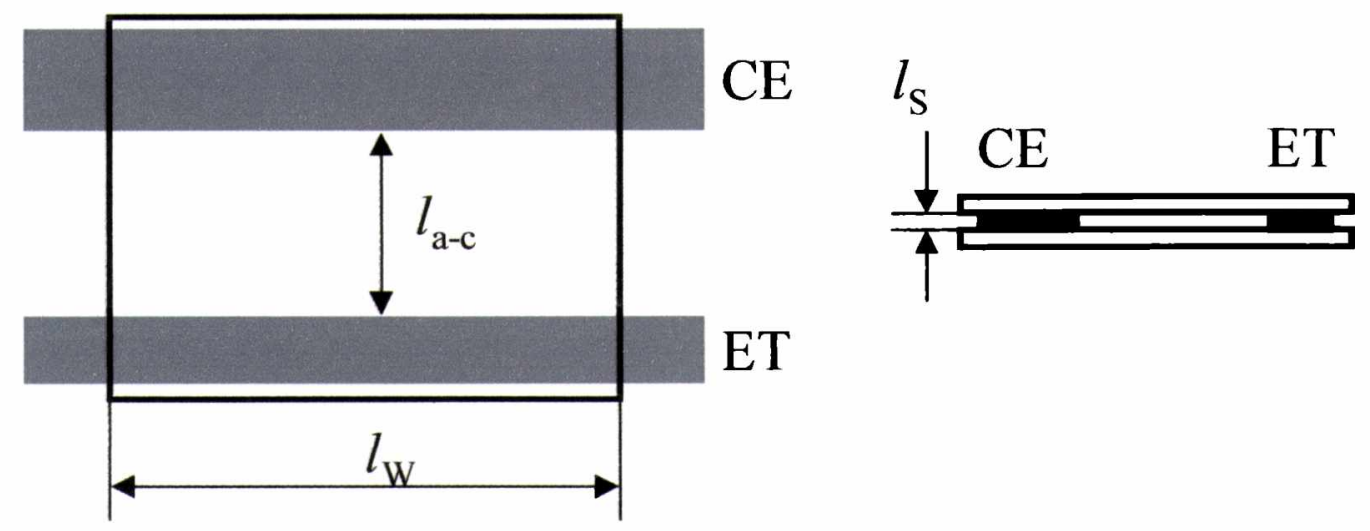

Figura 3.11. Celda rectangular BV (vista en planta y transversal).

\section{2 $\underline{\text { Soluciones empleadas }}$}

Para la preparación de las soluciones se emplea agua des-ionizada proveniente del Milli $Q \circledR$ y reactivos de calidad analítica:

sulfato de plata PA, Merck;

sulfato de sodio anhidro PA, Mallinckrodt;

ácido sulfúrico PA, Merck;

agarosa para electroforesis, Merck.

Para los experimentos complementarios de upd (deposición a subpotenciales), se utiliza:

perclorato de plomo PA, Mallinckrodt;

perclorato de sodio PA, Merck;

ácido perclórico PA, Merck.

\subsubsection{Soluciones empleadas en la electrodeposición de plata}

Soluciones acuosas de sulfato de plata con y sin electrolito soporte:

a) sulfato de plata $0,014 \mathrm{M}+$ sulfato de sodio $0,5 \mathrm{M}+$ ácido sulfúrico $0,01 \mathrm{M}$ (Solución $\mathrm{I}$ );

b) sulfato de plata $0,024 \mathrm{M}$ (Solución II);

c) sulfato de plata $0,024 \mathrm{M}+$ ácido sulfúrico $(0,5,1,1,5$ y $2 \mathrm{M})$;

Soles y geles de agarosa conteniendo sulfato de plata y electrolito soporte:

d) sulfato de plata $0,024 \mathrm{M}+\mathrm{y} \% \mathrm{p} / \mathrm{v}$ agarosa $(0,02 \leq \mathrm{y} \leq 0,5)$. (IA)

e) sulfato de plata $0,014 \mathrm{M}+$ sulfato de sodio $0,5 \mathrm{M}+$ ácido sulfúrico $0,01 \mathrm{M}+\mathrm{y} \% \mathrm{p} / \mathrm{v}$ agarosa $(0,02 \leq \mathrm{y} \leq 1.31)$. (IIA) 
f) sulfato de plata $\mathrm{x} M(0,008 \leq \mathrm{x} \leq 0,024)+$ sulfato de sodio $0,5 \mathrm{M}+$ ácido sulfúrico $0,01 \mathrm{M}+\mathrm{y} \mathrm{p} / \mathrm{v}$ agarosa $(0,5 \leq \mathrm{y} \leq 0,6 \% \mathrm{p} / \mathrm{v})$. (IIIA)

Los soles y geles de agarosa se preparan disolviendo en agua de milli-Q las sales mediante calentamiento y agitación. Cuando la solución comienza a hervir se agrega de a poco la cantidad de agarosa necesaria, manteniendo la ebullición hasta su disolución. El agregado del $\mathrm{H}_{2} \mathrm{SO}_{4}$ se realiza cuando se comienza a enfriar la solución y se completa el volumen para obtener la concentración requerida.

Otras soluciones necesarias para técnicas complementarias se consignan en las correspondientes secciones donde se describen estas técnicas.

\subsection{Sistema de seguimiento y observación del crecimiento del electrodepósito}

Para seguir la cinética del crecimiento de los depósitos se utilizó un sistema computarizado provisto de un software para el tratamiento de imágenes. Este sistema consta de una lupa estereoscópica Zeiss, modelo Stemi-C 2000, conectada a una cámara de video CCV Hitachi KP-C551, una P.C. Pentium, monitor de 1024 por 768 pixels y 256 colores y un frame grabber, Kontron Elektronik, versión 2.01 (1995) que incluye un paquete de software adecuado para el análisis de imágenes ejecutable en Windows 3.1. En la figura 3.10 se muestra un esquema de las partes del equipo utilizado para la adquisición y el análisis de imágenes. En algunos casos la señal proveniente de la cámara se dirigió a una video grabadora además de la PC para grabar en tiempo real todo el crecimiento. Es posible además adquirir y grabar las imágenes deseadas, en cada intervalo de tiempo y a través del uso del software se pueden realizar tratamientos para mejorar la definición y el contraste.

Con este sistema se logra observar en el monitor de la computadora todo el crecimiento a un aumento preseleccionado en el microscopio. En algunas experiencias la luz necesaria para obtener una buena imagen poveniente de la cámara, es provista por un dispositivo de "luz fría", Kl 1500 electronics, Schott. En los otros casos se usa la luz provista por el microscopio.

La medida de longitudes, ancho y largo, en los depósitos obtenidos se realiza con el software ya mencionado, haciendo una calibración con una imagen de tamaño conocido, para cada aumento (los aumentos que proporciona el microscopio Zeiss, van de 6,5 a 90x; además se dispone de un conector de $0,63 x$ que amplia el campo de la imagen). Se utiliza 
para la calibración la imagen de una regla con valores de longitud grabados en vidrio, provista por el fabricante del microscopio.

Para el seguimiento de los depósitos se debe asegurar, en primer lugar, que no se perturbe el crecimiento por medio de vibraciones o movimientos que afecten a la celda. De ahí que se dispuso la celda sobre una mesa antivibratoria que consiste en una estructura metálica de 1 × $0,5 \times 0,5 \mathrm{~m}$ llena de arena, sobre la cual se apoya una mesada de granito. La celda electroquímica se coloca sobre una mesa de madera separada de la mesada por trozos de goma con el fin de absorber vibraciones. Sobre el sistema antivibratorio y debajo de la mesa donde se dispone la celda se coloca, una mesa de coordenadas sobre la que se ubica el microscopio. De esta manera se puede desplazar el microscopio hacia la parte del electrodepósito de interés, sin necesidad de disminuir el aumento o mover la celda. (Ver esquema de la figura 3.12).

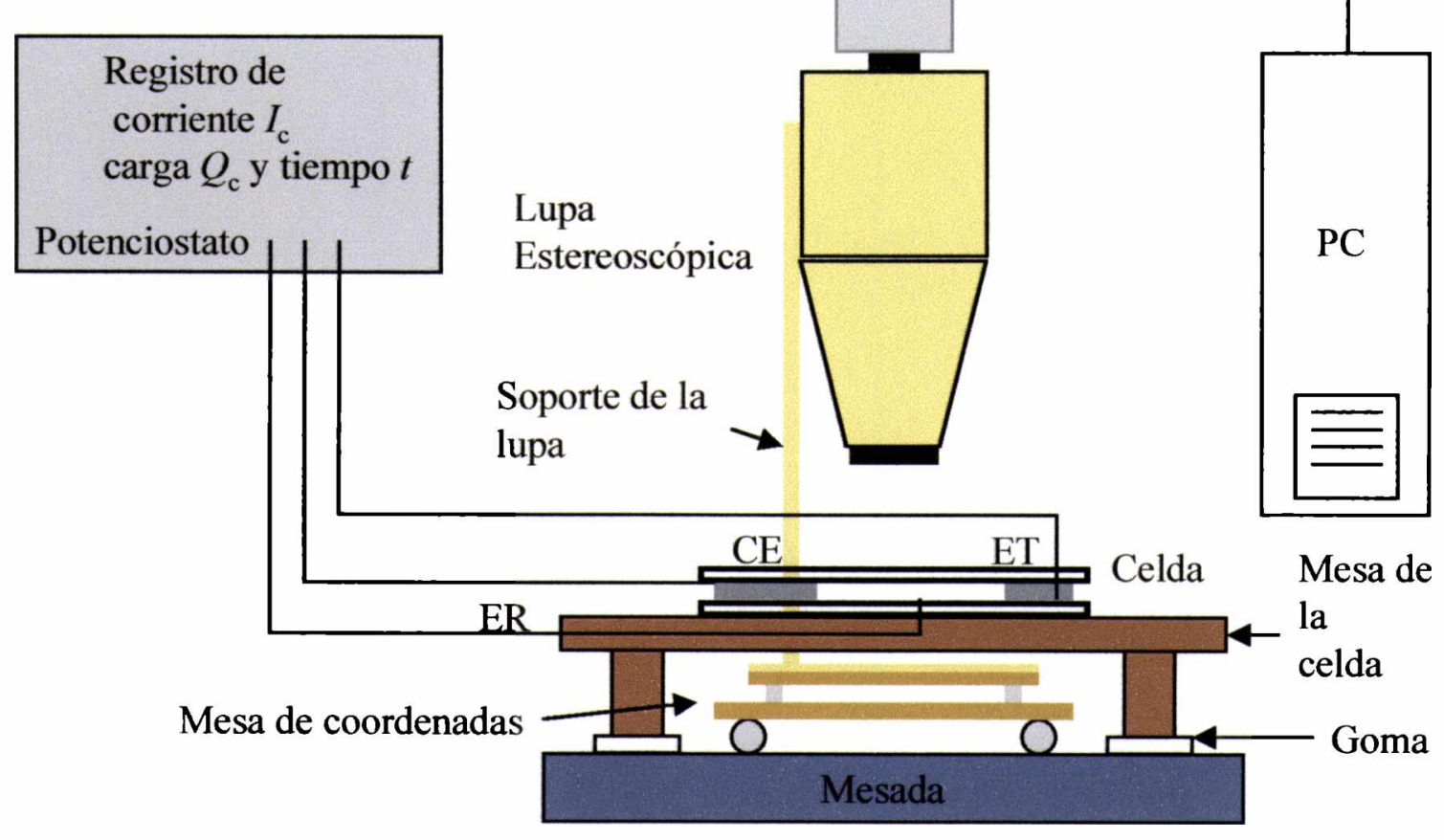

Figura 3.12. Esquema del sistema de adquisición de imágenes empleado. La lupa estereoscópica se coloca sobre la mesa de coordenadas permitiendo su movimiento en dos direcciones por medio de varillas roscadas (no se muestran en este esquema).

Algunos electrodepósitos se caracterizan por imágenes de microscopía electrónica de barrido (SEM) empleando un microscopio JEOL JSM-T100 disponible en el Museo de 
Ciencias Naturales de La Universidad Nacional de La Plata. Las muestras se adhieren a los porta-muestras mediante una pequeña cantidad de pintura de plata o por medio de cinta bifaz conductora de carbón.

3.4 Sistema de termostatización de los electrodos en celdas quasi-bidimensionales y tridimensionales

\subsubsection{Sensores de temperatura}

Se emplean diferentes sensores o transductores de temperatura:

* termómetro de mercurio a $0,1^{\circ} \mathrm{C}$ de $0-60^{\circ} \mathrm{C}$ certificado;

* termistores de precisión YSI 44001A (Yellow Spring Instruments) de 100 ohms de resistencia nominal. La curva de respuesta y algunas características de los termistores se encuentran en el apéndice B;

* sensores LM 35 de National y termocuplas de Fe/ constantán con vainas de vidrio.

En la figura 3.13 se muestran los sensores o transductores de temperatura empleados.

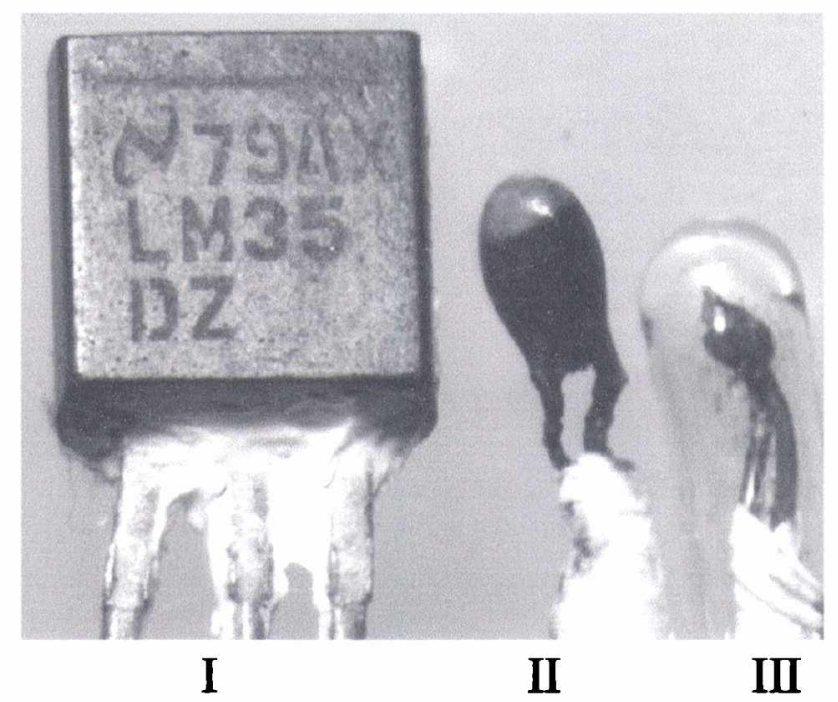

Figura 3.13. Transductores térmicos utilizados. I sensor LM 35; II termistor YSI; III termocupla de Fe-constantán con vaina de vidrio.

Los sensores LM 35 fueron calibrados utilizando un termostato Lauda cuya temperatura de baño se sensaba con un termómetro de mercurio certificado y con los termistores YSI. Para los termistores se encontró coincidencia entre las temperaturas leídas en el termómetro de mercurio certificado y la curva provista por el fabricante. Para los 
sensores LM 35 se construyeron las curvas de calibración que se muestran en la figura 3.14 .

Las termocuplas Fe-constantán contenidas en vainas de vidrio (figura 3.15), fueron calibradas de igual manera que los sensores LM 35. El uso de las termocuplas presenta la dificultad de requerir un baño de hielo a $0^{\circ} \mathrm{C}$, en donde se sumerge la junta fría de referencia, debido a que las temperaturas a medir son cercanas a la ambiente.

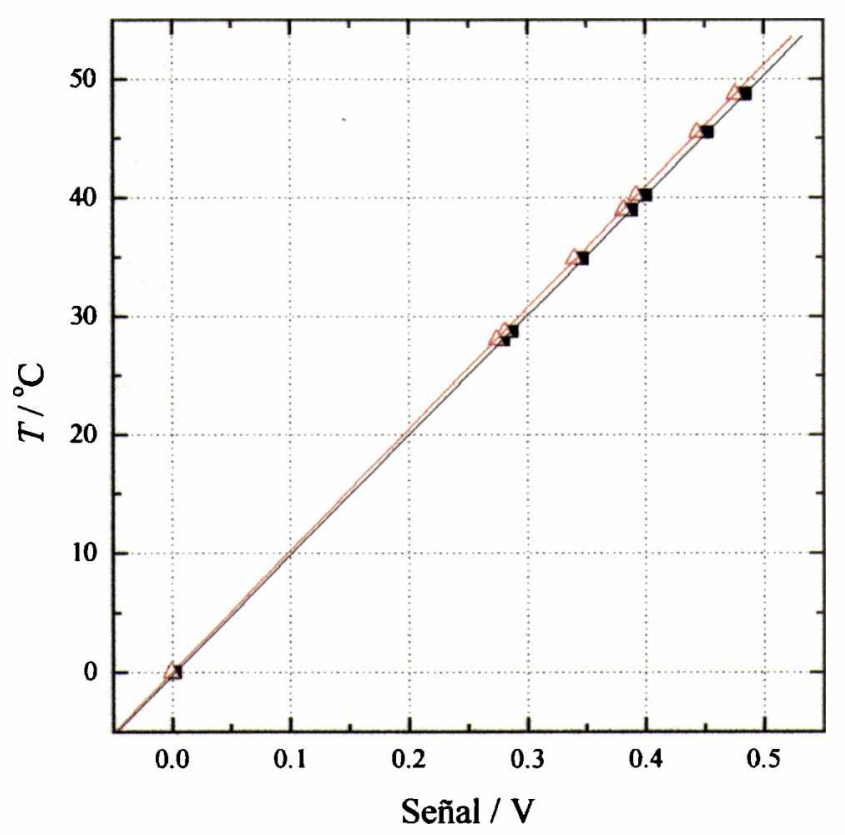

Figura 3.14. Curvas de calibración para los sensores National LM 35 empleados para sensar la temperatura en los bloques de cobre ubicados sobre los electrodos.

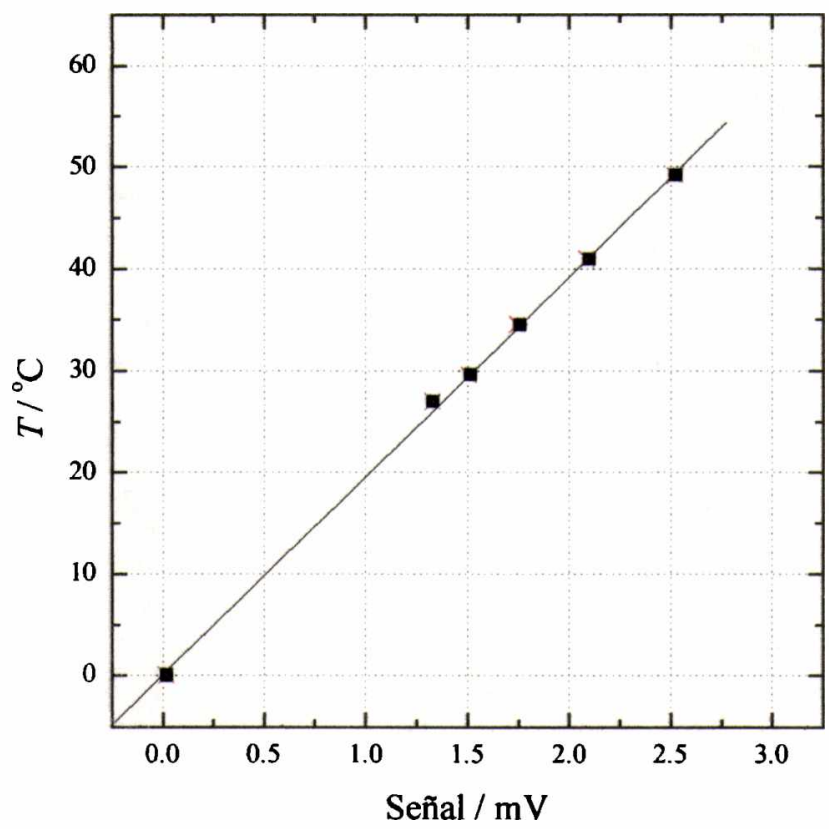

Figura 3.15. Curvas de calibración para las dos termocuplas Fe-constantán con vaina de vidrio, empleadas para medir la temperatura en la interfase electrodo/solución. 
En el apéndice $\mathrm{C}$ se muestra un esquema del circuito de conexión, algunas características y las curvas de respuesta de los sensores LM35 y las termocuplas.

\subsubsection{Sistema de calentamiento, medida y control de temperatura}

Para calentar en forma independiente cada electrodo, generalmente en la celda BIII, se emplean dos circuitos de seis resistencias en paralelo (cada una de $100 \mathrm{ohm}$ y 1/4 watt). Cada circuito se coloca sobre la cara superior de un bloque de cobre (área de la base $2,5 \mathrm{x}$ $2 \mathrm{~cm}$ y altura $1 \mathrm{~cm}$ ) y es alimentado con una fuente de corriente variable. Los bloques de cobre, que se colocan, uno sobre el electrodo de trabajo y el otro sobre el contraelectrodo,

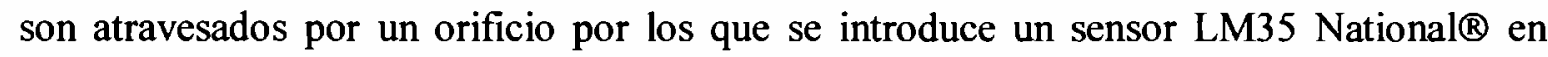
contacto con el electrodo de plata. Se utiliza grasa siliconada para fijar el circuito de resistencias y el sensor térmico. (ver figura $3.16 \mathrm{a} \mathrm{y} \mathrm{b)}$

a)

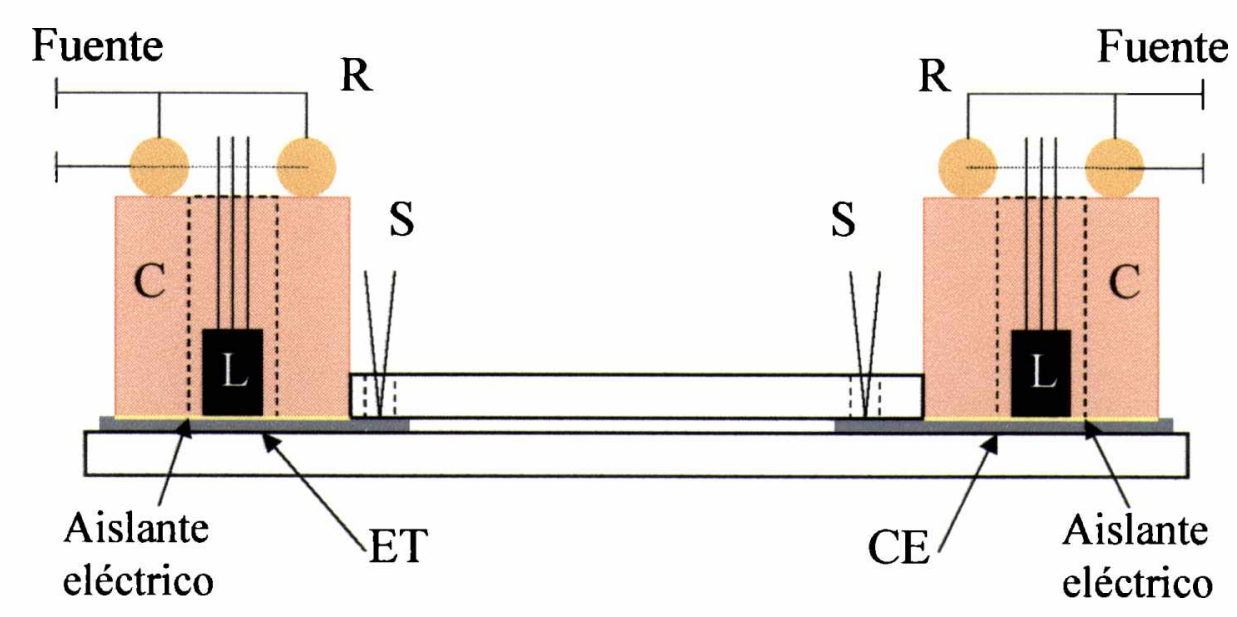

b)

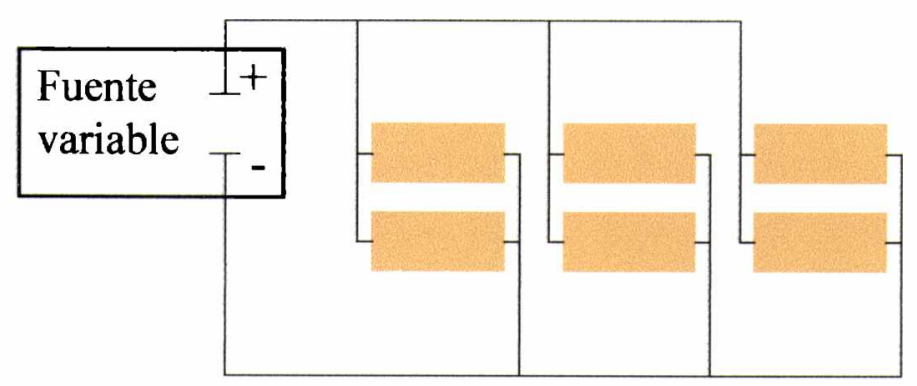

Figura 3.16. a) Esquema del arreglo experimental usado para calentar en forma independiente cada electrodo de la celda BIII y aplicar gradientes térmicos entre los electrodos; C: bloque de cobre; L: sensor de temperatura LM 35 de National; R: circuito de calentamiento; S: sensores de temperatura cercanos a la interfase metal/solución (Termocuplas de Fe/constantán o termistores YSI. b) Esquema del circuito de calentamiento constituido por 6 resistencias conectadas en paralelo a una fuente de tensión variable. 
La determinación de la temperatura de los electrodos cerca de la interfase metalsolución se realiza por medio de termistores YSI o por termocuplas Fe-constantán provistas de vainas de vidrios, ubicados en orificios sobre la superficie superior del ET y el $\mathrm{CE}$, cercanos a la interfase metal/solución, como se muestra en la figura 3.9 y 3.16. La señal de los sensores térmicos correspondientes a cada electrodo se mide con un multímetro Keithley modelo 173, y una llave selectora que permite conectar el sensor de interés (Figura 3.17 a).
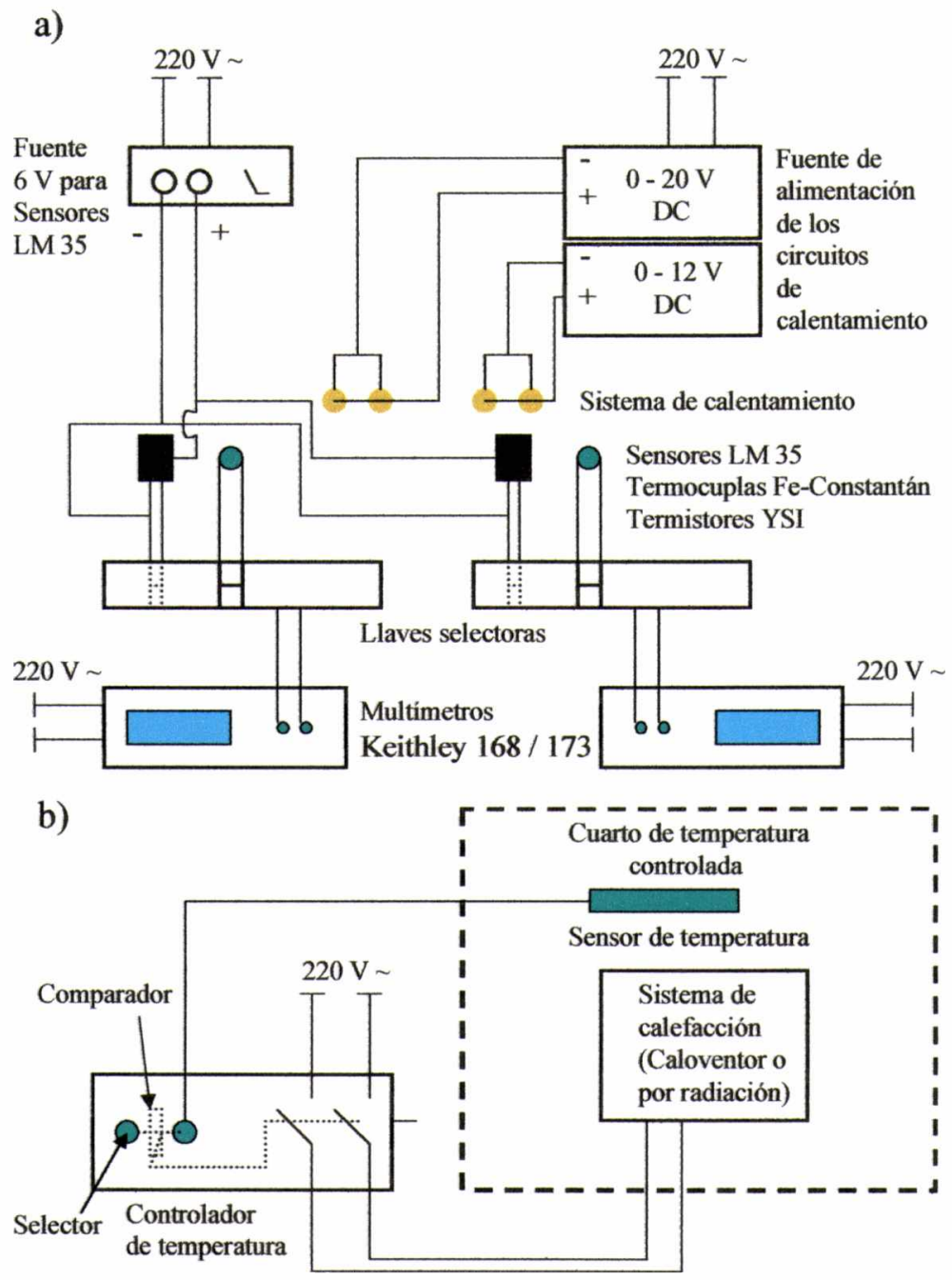

Figura 3.17. a) Diagrama de flujo del sistema utilizado para aplicar gradientes de temperatura. b) Esquema del sistema de control de temperaturas del cuarto termostatizado.

Para evitar fluctuaciones térmicas se coloca la celda junto con el microscopio, la cámara de video y el sistema antivibratorio dentro de un cuarto termostatizado de $8 \mathrm{~m}^{3}$ en el que se controla la temperatura en $\pm 0,25^{\circ} \mathrm{C}$, empleando un controlador de temperaturas que compara una temperatura establecida a priori (señal de voltage correspondiente) con la señal de un circuito sensor de temperatura LM 391. Si la señal del sensor es menor (mayor) 
que la señal establecida a priori, conecta (desconecta) el equipo calefactor, que puede ser un caloventor o lámparas infrarrojas (Figura 3.17 b).

En la figura 3.18 se muestran fotos del arreglo experimental completo, empleado para realizar la electrodeposición de plata con gradientes de temperatura.

a)

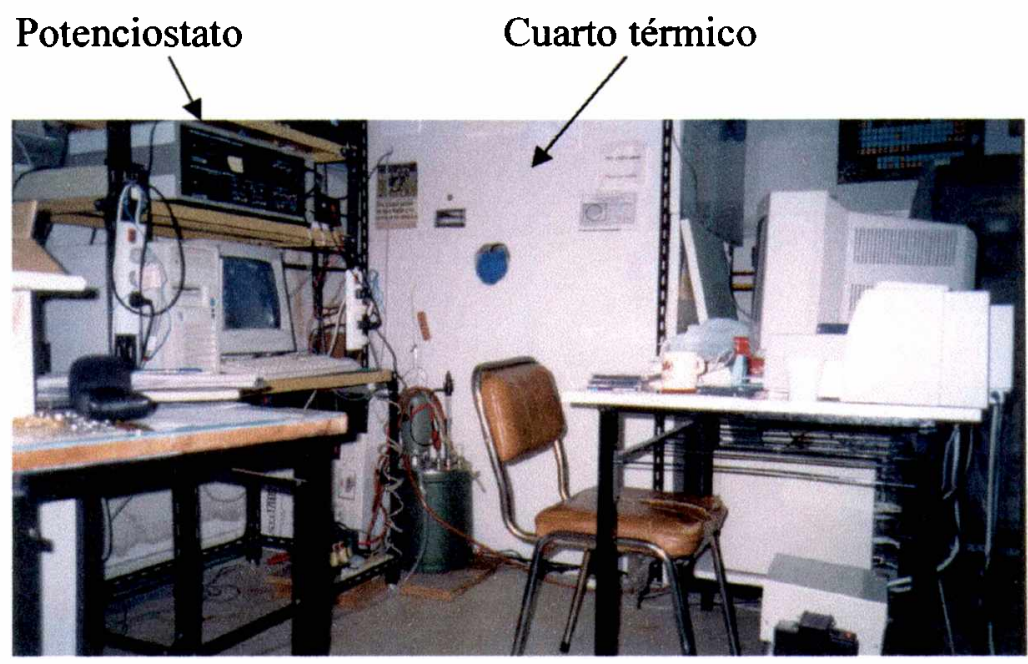

b)

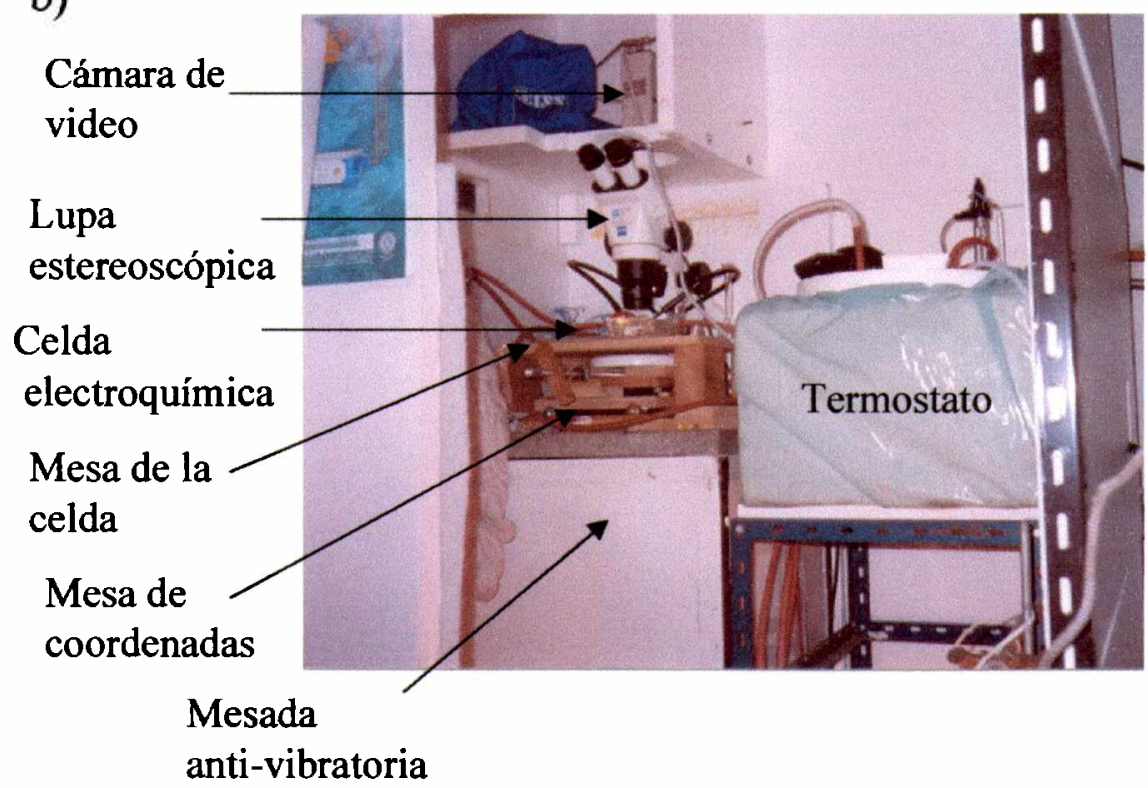

Figura 3.18. a) Cuarto de temperatura controlada visto desde afuera. Se puede ver además el potenciostato a la izquierda y el adquisidor de imágenes a la derecha. b) Interior del cuarto de temperatura controlada. Se observan distintos dispositivos para realizar los experimentos de electrodeposición.

En los experimentos, la temperatura deseada se alcanza haciendo pasar la corriente apropiada en cada circuito resistivo utilizado como calefactor, hasta que los sensores LM 35 indiquen una temperatura cercana a la deseada. Luego la corriente se ajusta cuidadosamente hasta que en los termistores se lea la temperatura elegida. 
Las temperaturas de trabajo utilizadas en la celda $\mathrm{BIII}$ son $27,30,35$ y $40^{\circ} \mathrm{C}$ para el electrodo de trabajo $T_{\mathrm{c}}$, y de $22^{\circ} \mathrm{C}<T_{\mathrm{a}}<50^{\circ} \mathrm{C}$ para el contrelectrodo.

Un perfil de temperaturas típico entre cátodo y ánodo, observado en la celda BIII, se muestra en la figura 3.19. Este se obtuvo empleando como placa superior de la celda un paralelepípero de Lucite $^{\circledR}$ de $3 \mathrm{~cm}$ de lado y $0,5 \mathrm{~cm}$ de espesor provisto de pequeños orificios pasantes separados 2 o $3 \mathrm{~mm}$, que permiten colocar una termocupla de Fe/constantán a distintas distancias de los electrodos. Los orificios están todos alineados a lo largo de un eje central que va desde un electrodo al otro.

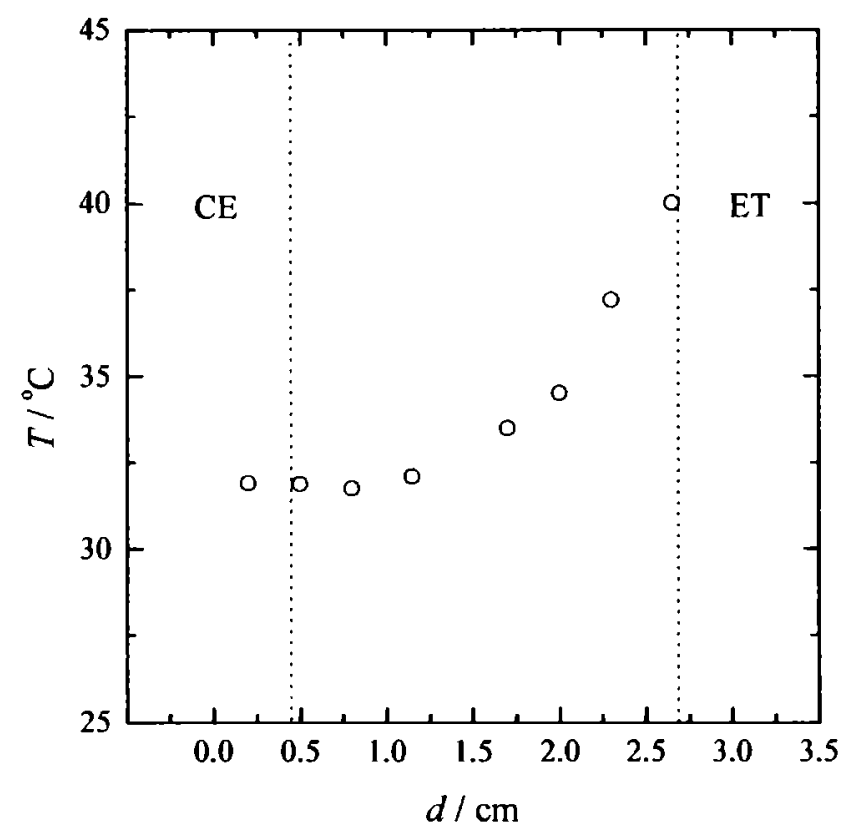

Figura 3.19. Perfil de temperaturas registrado con una termocupla de Fe/constantán en la celda BIII. $d$ es la distancia a la que se encuentra el sensor de temperatura, medida desde el contraelectrodo.

De la figura se puede ver que para ambos electrodos los perfiles son independientes y no se solapan por lo que se pueden tratar separadamente.

\subsection{Descripción del procedimiento experimental en la electrodeposición de plata}

En la mayoría de los experimentos se siguen los siguientes pasos:

1) Determinación de los parámetros cinéticos por técnicas electroquímicas convencionales estacionarias y no estacionarias. Se aplica un escalón de potencial o de corriente, o se realiza un barrido potenciodinámico. Se registran, durante el crecimiento del depósito, las curvas corriente/tiempo (o potencial/tiempo) y carga/tiempo. 
2) Seguimiento secuencial de las imágenes del electrodepósito mediante una cámara de video conectada a un "Frame grabber" incorporado en una PC. Adquisición de imágenes de las distintas etapas de crecimiento en forma simultánea con el registro de los transitorios de corriente o de potencial, según el experimento.

3) Procesamiento de imágenes por medio del "software" provisto por el "Frame grabber" y otros procesadores de imágenes. Determinación de la velocidad de crecimiento. Características geométricas a diferentes escalas, determinación de la estructura fractal y la cristalografia de los depósitos.

4) Variación del potencial aplicado y de la composición del electrolito.

\subsubsection{Influencia de la agarosa en la electrodeposición de plata en celdas quasi- bidimensionales}

En estos experimentos la electrodeposición de plata se realiza a $25^{\circ} \mathrm{C}$, a potencial cátodo-ánodo constante $\Delta \mathrm{E}_{\mathrm{c}-\mathrm{a}}=-0,30 \mathrm{~V}$, cuando se emplea la solución IA, y a $-0,518>\Delta \mathrm{E}_{\mathrm{c}-\mathrm{a}}>-1,2 \mathrm{~V}$ cuando se emplea la solución IIA y IIIA. Se utiliza un potenciostato PAR modelo 362 y un registrador Houston modelo Omnigraphic 2000 y en otros casos un potenciostato Voltalab 32 con interfase digital.

La evolución del depósito se sigue según la técnica descripta arriba (figura 3.12). En algunos casos se estudian ex situ los depósitos formados por microscopía de barrido electrónico SEM.

Algunos datos que dan cuenta de la estabilidad de las soluciones utilizadas y el efecto de la concentración de $\mathrm{H}_{2} \mathrm{SO}_{4}$ se analizan midiendo los tiempos de escurrimiento mediante viscosímetros Ostwald, y el potencial de reposo de las interfases Pt/solución y $\mathrm{Ag} /$ solución de agarosa.

3.6 Métodos ópticos empleados para estudiar perfiles de velocidad del fluido en las celdas quasi-bidimensionales

Se realizan experimentos simples para constatar la existencia de movimiento de liquido y tener idea de la magnitud de la velocidad del fluido con el fin de compararla con cálculos teóricos. Los experimentos consisten en incorporar, como trazadores, a las soluciones electrolíticas, partículas de latex de $\approx 1 \mu \mathrm{m}$ de diámetro o aceite de motor para formar una emulsión con partículas menores que $10 \mu \mathrm{m}$. La concentración de partículas se ajusta en aproximadamente $1 \%$. 
La electrodeposición de plata se lleva a cabo de la misma manera descripta en la sección 3.5. Para observar las partículas trazadoras y estimar su velocidad se emplea el sistema de adquisición de imágenes mostrado en la figura 3.12 y 3.18. La luz se dirige mediante una fibra óptica de manera de resaltar el contraste y poder distinguir las partículas en movimiento. La velocidad de las partículas se determina observando su desplazamiento en un determinado tiempo. Esto demanda disponer de imágenes a intervalos de tiempo suficientemente pequeños para evitar perder del campo de observación a las partículas. Estas observaciones se hacen con un aumento mínimo de $40 \mathrm{x}$, para poder distinguir las partículas de trazadores.

\subsection{Estudio de las propiedades electroquímicas de la interfase $\mathrm{Pt}$ / solución y $\mathrm{Ag} /$ solución} en presencia de agarosa

\subsubsection{Adsorción de agarosa sobre platino}

Con el fin de estudiar la adsorción de la agarosa sobre el platino, se utilizan dos celdas tridimensionales de tres electrodos. El electrodo de trabajo ET es de Platino (área: $0,20 \mathrm{~cm}^{2}$ ), el electrodo auxiliar CE también de Platino y electrodo de referencia ER es $\mathrm{Hg}^{\circ}$ / $\mathrm{Hg}_{2} \mathrm{SO}_{4} / \mathrm{KCl}$ (sat.) $\left(\mathrm{E}^{\circ}=0,658 \mathrm{~V}\right)$. Las soluciones empleadas son: agarosa $0,02 \%+$ $\mathrm{H}_{2} \mathrm{SO}_{4}$ 0,5 $\mathrm{M}$ y otra de $\mathrm{H}_{2} \mathrm{SO}_{4}$ 0,5 $\mathrm{M}$, preparadas con reactivos de calidad analítica. Ambas soluciones se saturan con nitrógeno por burbujeo durante 40 minutos. La calidad del agua se controla haciendo un voltamperograma sobre $\mathrm{Pt}$ de una solución $0,5 \mathrm{M}$ de ácido sulfúrico. Los experimentos se realizan a $25^{\circ} \mathrm{C}$.

En una celda se coloca la solución de agarosa $0,02 \%+\mathrm{H}_{2} \mathrm{SO}_{4} \quad 0,5 \mathrm{M}$ donde se introduce el electrodo de platino como electrodo de trabajo, usando la técnica de "cátodo vivo", esto es, teniendo conectado el ER y el CE al potenciontato (L.Y.P modelo M6) se somete el ET al potencial deseado antes de introducirlo en la celda y se desconesta después de retirarlo de la misma. Los potenciales de adsorción utilizados son: $-0,1 \mathrm{~V},+0,1 \mathrm{~V}$ y $+0,2 \mathrm{~V}$ versus $\mathrm{ENH}$, en tanto que los tiempos de adsorción son $1,5,15,25,45$ y 60 minutos. Después de cada adsorción, el electrodo ET se enjuaga con agua bi-destilada, se le aplica el potencial de base $(0,5 \mathrm{~V}$ versus $\mathrm{ENH})$, y luego se lo introduce dentro de la segunda celda que contiene solución de $\mathrm{H}_{2} \mathrm{SO}_{4} \quad 0,5 \mathrm{M}$. Se realiza entonces un voltamperograma sobre platino a partir del potencial de base, llevando el potencial a $0 \mathrm{~V}$, luego de 0 a $1,4 \mathrm{~V}$ y regresando a $0,5 \mathrm{~V}$. Se repiten 10 ciclos para cada determinación. 
Se utiliza el segundo ciclo para medir la carga puesta en juego a partir del área voltamperométrica en la zona de adsorción de hidrógeno. Se la compara con la de un voltamperograma obtenido usando el mismo ET de Pt (limpio) y que no se sometió a la adsorción de agarosa.

\subsubsection{Utilización de la celda de flujo}

También se realizan experiencias con una celda de flujo (figura 3.20). La celda se compone de dos recipientes esféricos A y B de $1700 \mathrm{ml}$ con los respectivos sistemas de burbujeo de nitrógeno, y una celda central cilíndrica de tres electrodos de $20 \mathrm{ml}$ de capacidad. Se utilizan las soluciones de agarosa $0,02 \%+\mathrm{H}_{2} \mathrm{SO}_{4}, 0,5 \mathrm{M}$ en el recipiente A y otra de $\mathrm{H}_{2} \mathrm{SO}_{4}$ 0,5 $\mathrm{M}$ en el recipiente $\mathrm{B}$, saturadas con nitrógeno por burbujeo durante $1 \mathrm{~h}$ 30 minutos. El electrodo de trabajo utilizado es de $\mathrm{Pt}^{\circ}$ 99,9\% y un área geométrica de 0,32 $\mathrm{cm}^{2}$; el electrodo de referencia utilizado es $\mathrm{Hg}^{\circ} / \mathrm{Hg}_{2} \mathrm{SO}_{4} / \mathrm{K}_{2} \mathrm{SO}_{4}$ saturado $\left(\mathrm{E}^{\circ}=0,658 \mathrm{~V}\right) . \mathrm{La}$ celda electroquímica posee en la parte superior, una entrada de líquido regulada por una llave doble de Teflon® que permite seleccionar el paso de alguna de las soluciones contenidas en los recipientes esféricos, y en la parte inferior una llave simple de Teflon® para desagotar la solución.

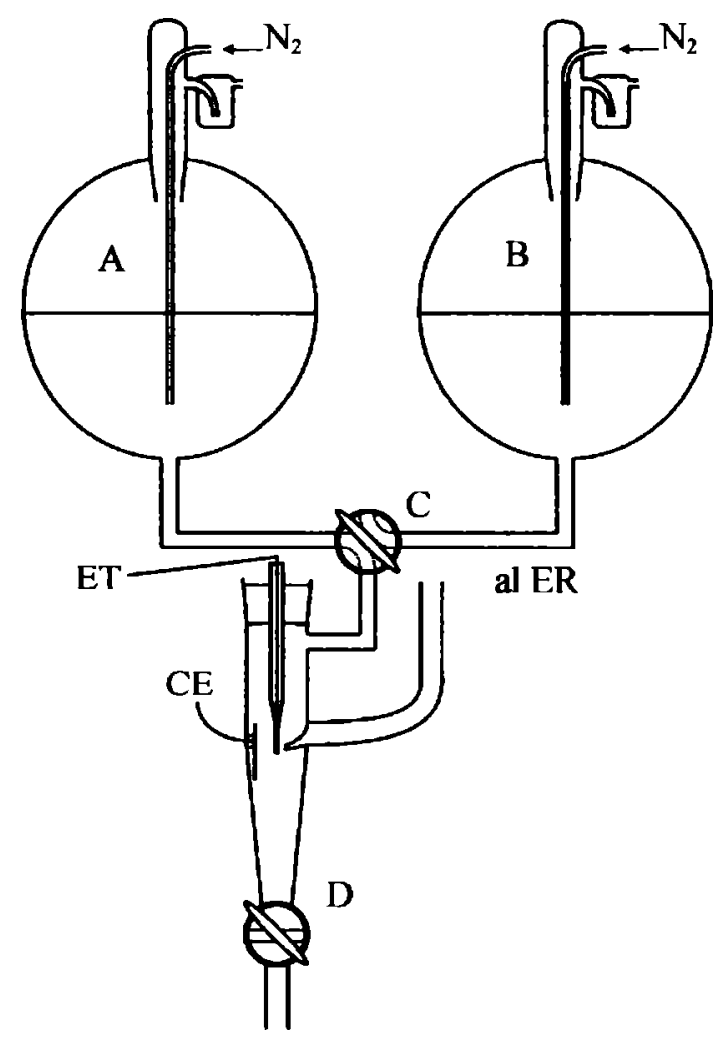

Figura 3.20. Celda de flujo 
En primer lugar se cargan los recipientes esféricos, el A con solución de agarosa $0,02 \%+\mathrm{H}_{2} \mathrm{SO}_{4} 0,5 \mathrm{M}$ y el B con $\mathrm{H}_{2} \mathrm{SO}_{4} 0,5 \mathrm{M}$, y la celda central con solución de $\mathrm{H}_{2} \mathrm{SO}_{4}$ 0,5 M saturada con nitrógeno. Se registra un voltamperograma de platino como blanco. Luego se aplica un escalón de potencial y se registra el transitorio de corriente. A los 60 segundos aproximadamente se abren sincronizadamente, sin dejar de registrar el transitorio, la llave que permite la entrada de la solución del compartimiento A que contiene agarosa y la llave de desagote, de manera que se conserve el nivel de líquido en la celda, y se reemplaze la solución de $\mathrm{H}_{2} \mathrm{SO}_{4}, 0,5 \mathrm{M}$ por la que contiene agarosa. Luego de aproximadamente 7,5 segundos se cierran ambas llaves y se continua registrando la corriente durante unos 7 minutos. Finalmente, se reemplaza la solución que contiene agarosa por la del compartimiento $\mathrm{B}\left(\mathrm{H}_{2} \mathrm{SO}_{4} \quad 0,5 \mathrm{M}\right)$ y se registra un voltamperograma de platino repitiendo tres ciclos. Los potenciales usados en los transitorios de corriente son: $0,658 \mathrm{~V}, 0,458 \mathrm{~V}, 0,247 \mathrm{~V}$ y $0,1 \mathrm{~V}$ respecto al ENH. Para cada potencial se realiza un blanco con la solución de $\mathrm{H}_{2} \mathrm{SO}_{4} \quad 0,5 \mathrm{M}$ sin agarosa siguiendo todos los pasos descriptos anteriormente.

\subsubsection{Adsorción de agarosa sobre plata}

El estudio de la adsorción de la agarosa sobre la plata se realiza en tres pasos: a) electrodeposición de plata sobre un electrodo de Pt, b) adsorción de agarosa sobre este electrodo, sumergiéndolo en una solución acuosa de agarosa, c) deposición electroquímica de plomo en condiciones de subpotencial (upd de plomo).

\section{a) Electrodeposición de plata}

Se utiliza un electrodo de platino con un área geométrica de $0,322 \mathrm{~cm}^{2}$, depositándole plata electrolíticamente a potencial constante, $-0,12 \mathrm{~V}$ respecto a un electrodo de $\mathrm{Ag}^{\circ} / \mathrm{Ag}^{+}$utilizado como referencia. El electrodo auxiliar es una lámina de plata de $1 \mathrm{~cm}^{2}$ de área. Se utiliza para la electrodeposición de plata la solución electrolítica $\mathrm{Ag}_{2} \mathrm{SO}_{4}$ 0,00005 $\mathrm{M}+\mathrm{HClO}_{4} 0,01 \mathrm{M}+\mathrm{NaClO}_{4}$ 0,5 $\mathrm{M}$ saturada con nitrógeno. Se realiza la electrodeposición hasta alcanzar una densidad de carga de $40 \mathrm{mC} / \mathrm{cm}^{2}$. 
b) Adsorción de agarosa

El electrodo de trabajo proveniente del paso a) se sumerge en una solución de agarosa $0,05 \% \mathrm{p} / \mathrm{v}$ saturada con nitrógeno contenida en una celda de cierre hermético y en estas condiciones se adsorbe agarosa a circuito abierto. Los tiempos de adsorción ensayados son: 40 minutos, 1, 2, 4 y 19 horas. Se realiza un blanco en el que se reemplaza la solución de agarosa por agua del Milli Q*.

Antes de cada electodeposición de plata, se pule el electrodo con alúmina de 1 micra y se lo desengrasa introduciéndolo en mezcla sulfonítrica durante 30 minutos. Finalmente se lo enjuaga con abundante agua del Milli $\mathrm{Q}^{*}$.

c) Upd de Plomo

El procedimiento consiste en realizar primero un upd de plomo sobre el electrodo proveniente del paso a), luego adsorber agarosa durante un tiempo determinado según el paso b) y realizar otro upd, comparando en ambos casos el 4to. ciclo del voltamperograma de "upd-anodic stripping".

En una celda de tres electrodos que contiene una solución de $\mathrm{Pb}\left(\mathrm{ClO}_{4}\right)_{2}, 0,01 \mathrm{M}+$ $\mathrm{HClO}_{4} 0,01 \mathrm{M}+\mathrm{NaClO}_{4}$ 0,5 $\mathrm{M}$ saturada con nitrógeno, el ET de platino sobre el que se deposita plata, proveniente de los pasos a) y b), y utilizando un $\mathrm{ER}$ de $\mathrm{Hg}^{\circ} / \mathrm{Hg}_{2} \mathrm{Cl}_{2} / \mathrm{KCl}$ (sat.), $\left(E^{\circ}=0,284 \mathrm{~V}\right)$ y un $\mathrm{CE}$ de $\mathrm{Pt}$, se realiza un barrido de potencial cíclico a $0,010 \mathrm{~V} / \mathrm{s}$ desde 0 hasta $-0,42 \mathrm{~V}$ respecto al $\mathrm{ENH}$. Se registran cinco ciclos voltamperométricos y se determinan las cargas anódicas y catódicas antes y después de realizar el paso b) (adsorción de agarosa).

El instrumental electrónico empleado para realizar estas experiencias es un potenciostato PAR modelo 173 y un registrador Houston modelo Omnigraphic 2000. 


\section{CAPITULO 4}

\section{Electrodepósitos ramificados de plata}

\subsection{Electrodeposición de plata en celdas quasi-bidimensionales}

En este capítulo se presentan distintos experimentos de electrodeposición realizados empleando celdas quasi-bidimensionales circulares y rectangulares. Se incluyen y describen, las curvas de polarización realizadas para cada condición de trabajo y los correspondientes transitorios potenciostáticos de corriente.

La descripción de la morfología de los electrodepósitos obtenidos se realiza en base a la clasificación morfológica dada en el capítulo 2. Esto es, se clasifican en: a) crecimientos aciculares; b) morfología "tip-splitting" (por bifurcación de la punta); c) crecimientos dendríticos; d) estructuras densas. En algunas ocasiones se hablará de electrodepósitos abiertos refiriéndose tanto a los dendríticos como a los de morfología "tipspliting", y en otras, de electrodepósitos mixtos para destacar la presencia de ambas estructuras.

4.1.1 Electrodeposición de plata utilizando la solución I en la celda circular quasibidimensional

Las curvas de polarización se realizan con el objeto de ubicar la región de potencial en la que se realizan las experiencias potenciostáticas, y saber cual es el paso controlante del proceso de electrodeposición en esa región de potencial.

En las figuras 4.1 y 4.2 se representan curvas de polarización catódicas realizadas a distintas velocidades de barrido de potencial, en la celda circular quasi-bidimensional A, empleando la solución de sulfato de plata $0,014 \mathrm{M}$, sulfato de sodio $0,5 \mathrm{M}$ y ácido sulfúrico 0,01 M (solución I). Se emplea una perturbación de potencial triangular y, en algunos gráficos, se incluye parcialmente la señal de corriente correspondiente al barrido de retorno hacia el potencial inicial, con el fin de estudiar la influencia del aumento de área activa del electrodo, en la curva de polarización.

La curva de polarización obtenida a $2 \mathrm{mV} / \mathrm{s}$ muestra una primera parte donde la funcionalidad $\mathrm{E}(I)$ se debe principalmente a la resistencia eléctrica de la solución. En el rango $-0,12 \geq \Delta \mathrm{E}_{\mathrm{c}-\mathrm{a}} \geq-0,25 \mathrm{~V}$ la velocidad de la reacción de electrodeposición de plata alcanza un valor límite. A $\Delta \mathrm{E}_{\mathrm{c}-\mathrm{a}}=-0,4 \mathrm{~V}$ la corriente aumenta hasta $\sim 1 \mathrm{~mA}, \mathrm{y}$ posteriormente aumenta en forma continua, siguiendo una relación aproximadamente 
lineal con el tiempo. Este aumento se puede asociar al aumento del área activa del electrodepósito. En el rango $0 \geq \Delta \mathrm{E} \geq-1,0 \mathrm{~V}$, no se observa la formación de burbujas de hidrógeno.

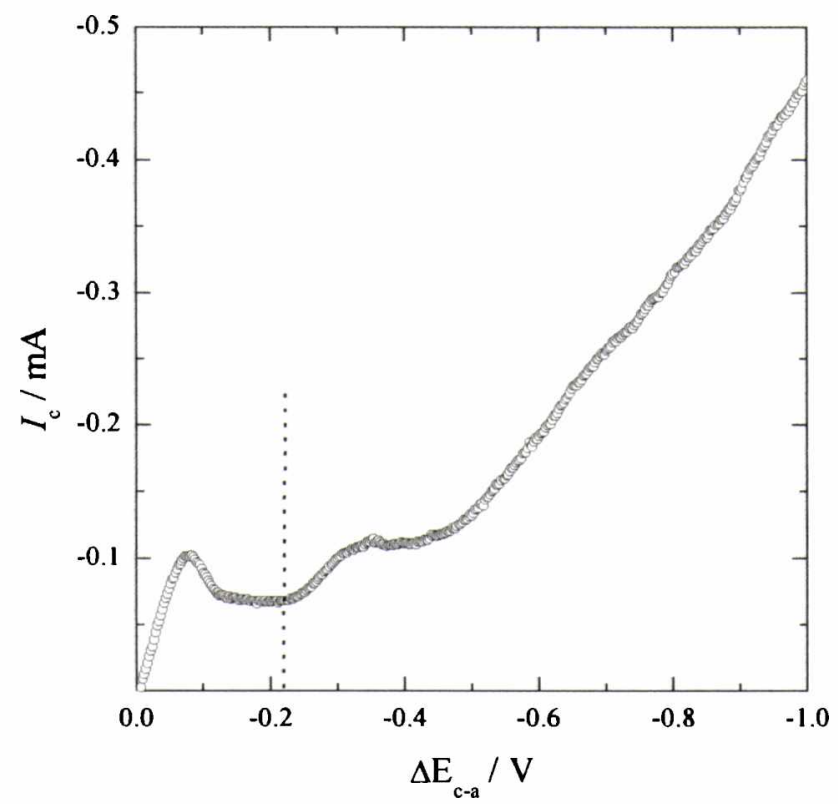

Figura 4.1. Curva de polarización obtenida empleando una velocidad de barrido de $2 \mathrm{mV} / \mathrm{s}$. Condiciones: Solución I; celda circular quasi-bidimensional. Temperatura ambiente.

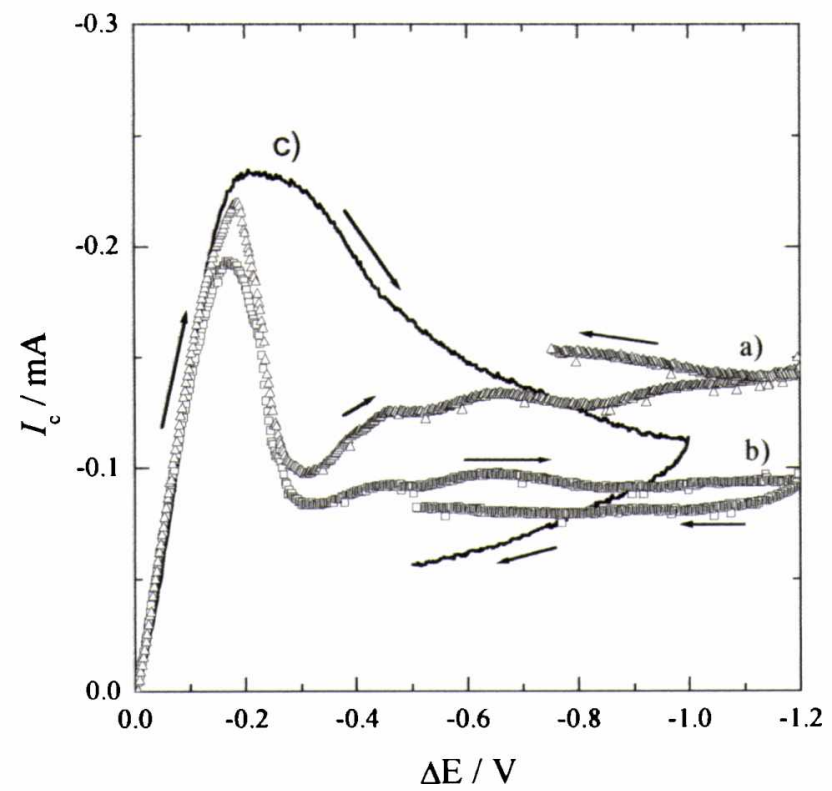

Figura 4.2. Curvas de polarización obtenidas empleando una velocidad de barrido de: a) $10 \mathrm{mV} / \mathrm{s}$; b) $20 \mathrm{mV} / \mathrm{s}$ y c) $100 \mathrm{mV} / \mathrm{s}$. Solución I; celda circular quasi-bidimensional. Temperatura ambiente. 
La figura 4.2 muestra curvas de polarización obtenidas a 10,20 y $100 \mathrm{mV} / \mathrm{s}$. Todas las curvas tienden a un mismo valor de corriente límite, $I_{\mathrm{c}}=-0,07 \mathrm{~mA}$, coincidente con el que se puede determinar de la curva de polarización obtenida a $2 \mathrm{mV} / \mathrm{s}$, en el rango $-0,22 \leq$ $\Delta \mathrm{E} \leq-0,10 \mathrm{~V}$. La corriente registrada durante el barrido decreciente de potencial (retorno hacia el potencial inicial) indica que a $10 \mathrm{mV} / \mathrm{s}$ el aumento de área del cátodo es significativo, pues la corriente en la etapa de retorno es mayor que la del barrido de potencial creciente. Para $20 \mathrm{mV} / \mathrm{s}$, la corriente durante el barrido decreciente es menor que durante el barrido creciente. En este caso, la aparición de oscilaciones de corriente sugiere la formación de área activa nueva con nuevas características morfológicas, que impide alcanzar la corriente límite "pseudo-estacionaria". A $100 \mathrm{mV} / \mathrm{s}$ no se observa aumento considerable del área activa del electrodo.

Se debe aclarar que las curvas de polarización mostradas no corresponden a condiciones estacionarias estrictas, ya que el potencial se varía linealmente en el tiempo, acompañado de un cambio de área catódica que no permite llegar a la constancia de la corriente.

Transitorios potenciostáticos de corriente y morfología de los electrodepósitos

En la figura 4.3 se muestran transitorios de corriente típicos para distintos potenciales aplicados. Para $\Delta \mathrm{E}_{\mathrm{c}-\mathrm{a}}=-0,518 \mathrm{~V}$ se puede observar una secuencia de imágenes del electrodepósito en forma simultánea con el correspondiente transitorio de corriente (figura 4.4).

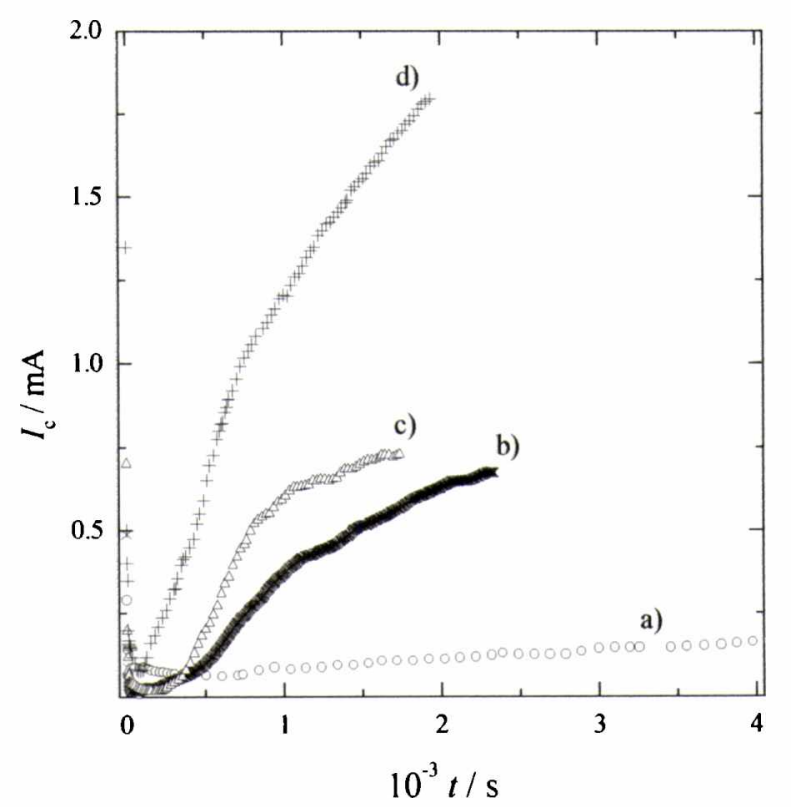

Figura 4.3. Transitorios potenciostáticos de corriente. Solución I; celda circular $A$; a) $\Delta E_{c-a}=-0,218 \mathrm{~V}$; b) $\Delta E_{c-a}=-0,318 \mathrm{~V}$; c) $\Delta E_{c-a}=-0,518 \mathrm{~V}$ y a) $\Delta E_{c-a}=-0,718 \mathrm{~V}$. Temperatura ambiente. 


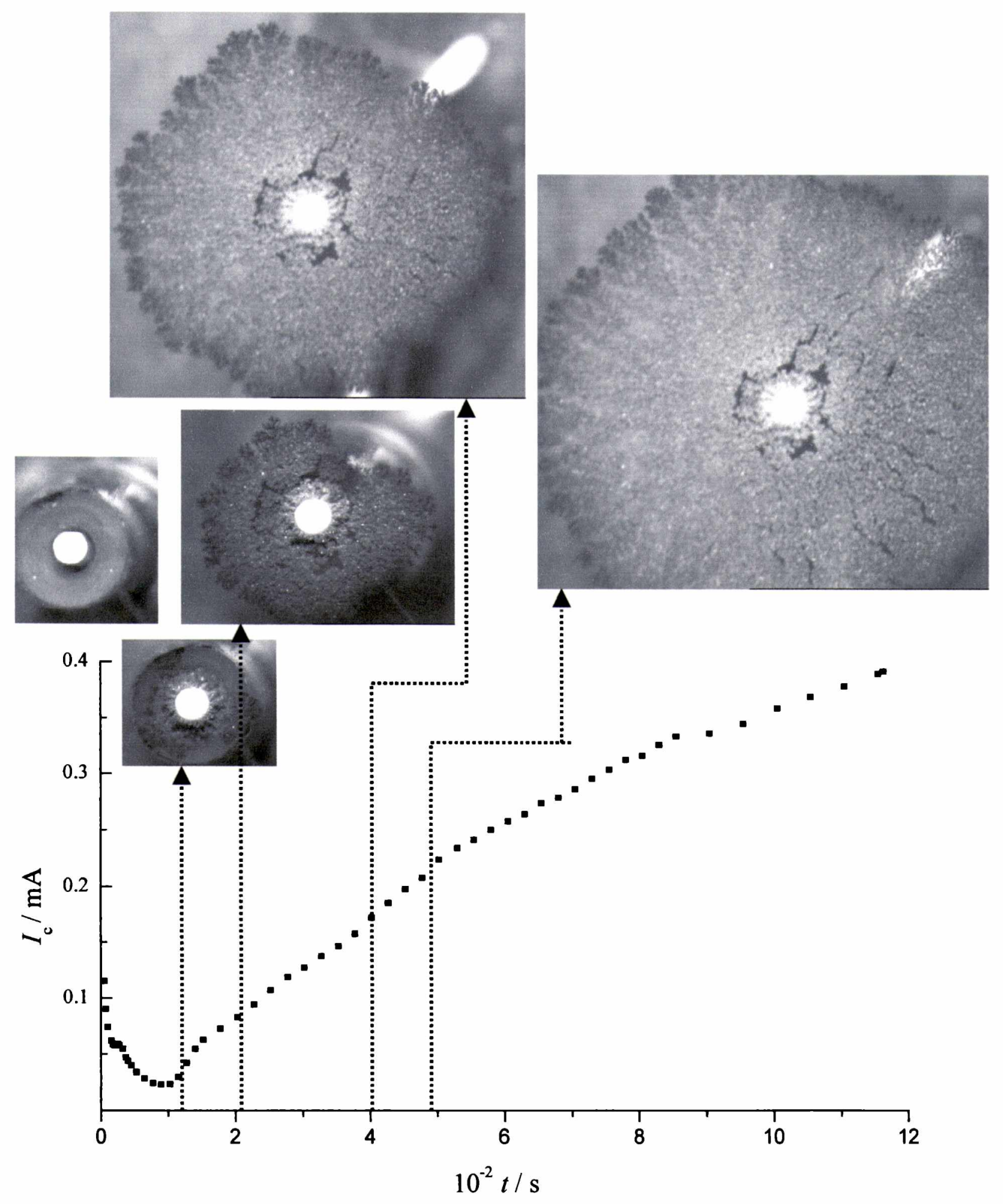

Figura 4.4. Transitorio de corriente y secuencia de imágenes del crecimiento. Condiciones: solución $\mathrm{I}, \Delta \mathrm{E}=-0,518 \mathrm{~V}$. En las imágenes el electrodo de trabajo tiene un diámetro de $0,5 \mathrm{~mm}$.

Los transitorios de corriente presentan una disminución de la corriente para $t<200 \mathrm{~s}$, que está asociada con la formación de la película de difusión. Durante este período el radio del electrodepósito es $r_{\mathrm{M}} \approx r_{\mathrm{c}}$ (radio del electrodo de trabajo), por lo que el efecto del aumento del área es despreciable. Luego la corriente alcanza un mínimo y, a 
tiempos mayores, aumenta abruptamente. Cuanto mayor es el potencial aplicado, menor el tiempo en el que se alcanza el valor mínimo y más pronunciado es el incremento de corriente. También se observa que la velocidad de aumento de corriente es mayor al comienzo de la electrodeposición y disminuye con el transcurso del tiempo.

De la figura 4.4 se puede correlacionar el incremento de corriente con el aumento del área activa del electrodo. A medida que transcurre la electrólisis, el electrodepósito avanza en dirección radial hacia el contraelectrodo aumentando el área activa del cátodo. La observación de las imágenes permite ver una diferencia de color entre el interior del electrodepósito y la pequeña región radial cercana a las puntas del electrodepósito, que sugiere que sólo en esta última región se establece la interfase electroquímicamente activa. Para $120<t<\sim 400 \mathrm{~s}$, el electrodepósito es asimétrico y para $t>400 \mathrm{~s}$ adopta forma cilíndrica y la densidad de masa permanece constante.

La descripción precedente explica cualitativamente los aspectos más notorios de los transitorios de corriente a todos los potenciales aplicados entre los electrodos.

En la tabla 4.1 se consignan los potenciales aplicados, la resistencia eléctrica de la celda, medida antes de comenzar la electrodeposición, las principales características morfológicas de los electrodepósitos y la velocidades medias de avance del frente de crecimiento $\left(V_{\mathrm{f}}\right)$.

Tabla 4.1. Condiciones y características morfológicas de los electrodepósitos obtenidos empleando la celda circular $\mathrm{A}-\mathrm{Ag}_{2} \mathrm{SO}_{4} \mathbf{0 , 0 1 4} \mathrm{M}+\mathrm{Na}_{2} \mathrm{SO}_{4} 0,5 \mathrm{M}+\mathrm{H}_{2} \mathrm{SO}_{4}$ 0,01 M.

\begin{tabular}{|c|c|c|c|}
\hline$\Delta \mathrm{E}_{\mathrm{c}-\mathrm{a}} / \mathrm{V}$ & $\mathrm{R}_{\mathrm{i}} / \Omega$ & $V_{\mathrm{f}} / \mu \mathrm{m} \mathrm{s}^{-1}$ & $\begin{array}{c}\text { Características } \\
\text { Morfológicas }\end{array}$ \\
\hline$-0,218$ & 398 & 0,9 & Ramificado con “tip-splitting" \\
\hline$-0,218$ & 440 & 2,0 & Idem, depósito ramificado asimétrico \\
\hline$-0,218$ & 422 & - & “ \\
\hline-0.218 & 422 & - & Dendrítico \\
\hline$-0,318$ & 205 & 3,1 & Dendrítico \\
\hline$-0,318$ & 206 & 2,9 & Dendrítico \\
\hline$-0,318$ & 227 & - & Dendrítico \\
\hline$-0,360$ & 375 & 7,0 & Denso \\
\hline$-0,380$ & 330 & - & Denso \\
\hline$-0,518$ & 383 & 7,9 & Denso \\
\hline$-0,518$ & 212 & 8,0 & Denso \\
\hline$-0,518$ & 205 & 8,5 & Denso \\
\hline$-0,660$ & 200 & - & Denso \\
\hline$-0,718$ & 373 & 9,0 & \\
\hline
\end{tabular}


En la figura 4.5 se ven las características morfológicas de los electrodepósitos obtenidos a diferentes $\Delta \mathrm{E}_{\mathrm{c}-\mathrm{a}}$. La figura $4.5 \mathrm{a}$ corresponde a un $\Delta \mathrm{E}_{\mathrm{c}-\mathrm{a}}$ entre electrodos de $-0,218 \mathrm{~V}$ y muestra un electrodepósito formado de ramas caracterizadas por predominio de "tip-splitting" o bifurcación de la punta. Para $\Delta \mathrm{E}_{\mathrm{c}-\mathrm{a}}=-0,318 \mathrm{~V}$, se obtiene un electrodepósito dendrítico, como se ve en la figura $4.2 \mathrm{~b}$, mientras que para $\Delta \mathrm{E}_{\mathrm{c}-\mathrm{a}}=-0,360 \mathrm{~V}$, la morfología aunque también es dendrítica, resulta más densa. Finalmente, para $\Delta \mathrm{E}_{\mathrm{c}-\mathrm{a}}=-0,518 \mathrm{~V}$, el electrodepósito tiene estructura densa (figura 4.2.d).

a)

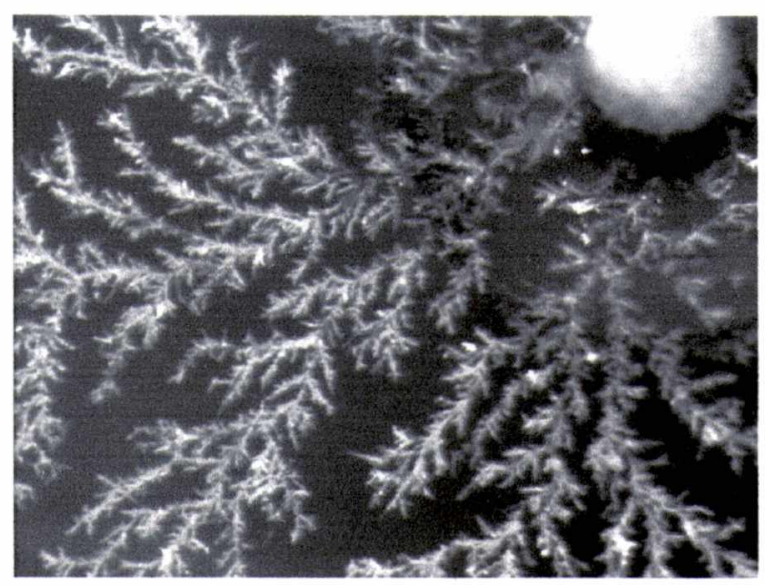

c)

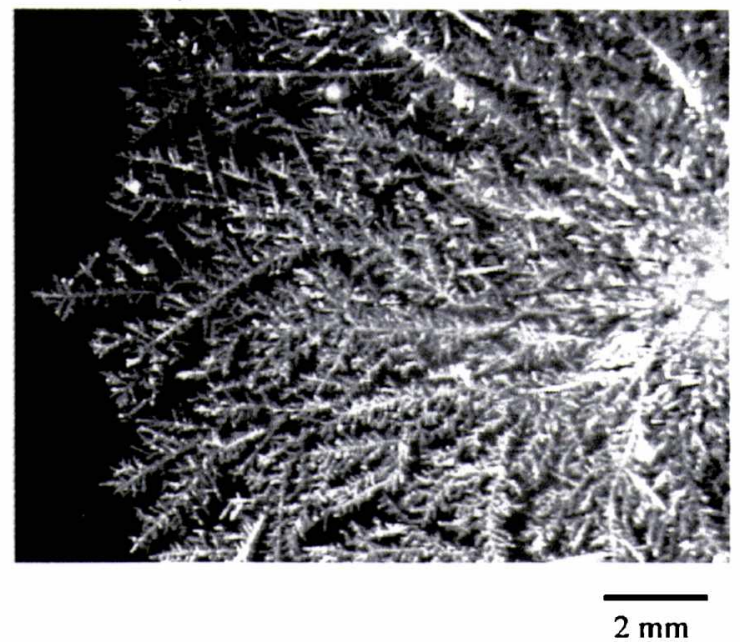

b)

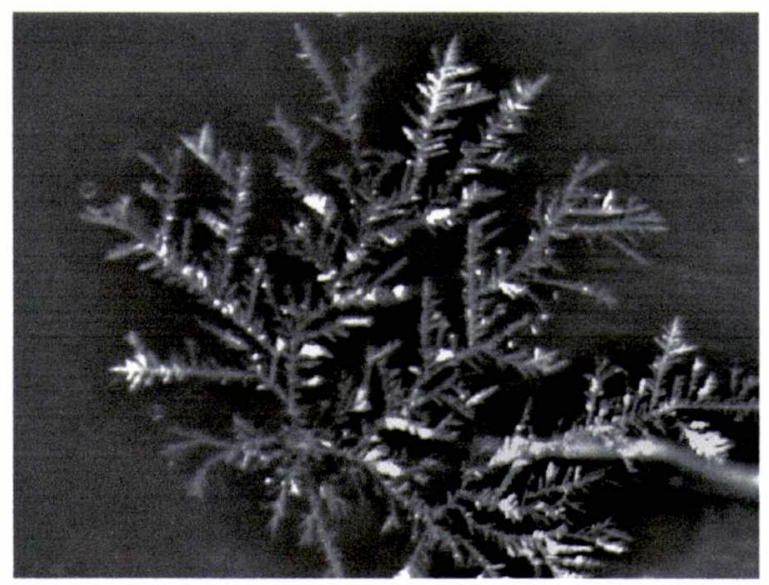

d)

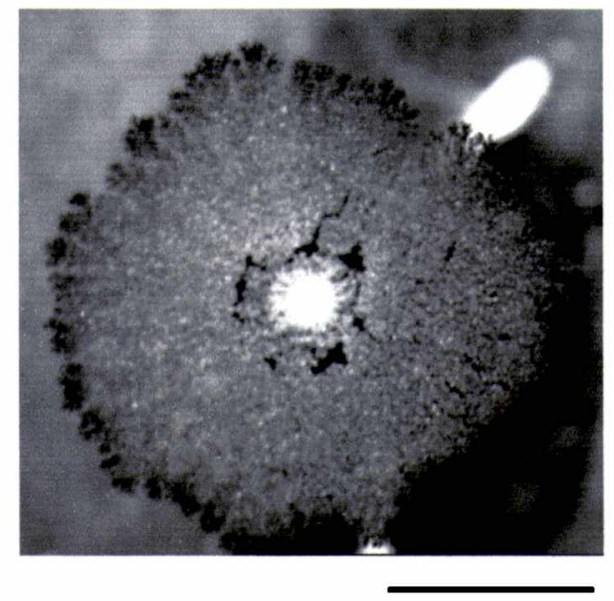

$2 \mathrm{~mm}$

Figura 4.5. Electrodepósitos obtenidos utilizando la celda circular A. Condiciones: solución I; a) $\left.\left.\Delta \mathrm{E}_{\mathrm{c}-\mathrm{a}}=-0,218 \mathrm{~V}, t=3240 \mathrm{~s} ; \mathrm{b}\right) \Delta \mathrm{E}_{\mathrm{c}-\mathrm{a}}=-0,318 \mathrm{~V}, t=1600 \mathrm{~s} ; \mathrm{c}\right) \Delta \mathrm{E}_{\mathrm{c}-\mathrm{a}}=-0,360 \mathrm{~V}, t=1750 \mathrm{~s} ;$ d) $\Delta \mathrm{E}_{\mathrm{c}-\mathrm{a}}=-0,518 \mathrm{~V}, t=400 \mathrm{~s}$. Temperatura ambiente. El diámetro del electrodo es de $0,05 \mathrm{~cm}$. 
4.1.2 Electrodeposición de plata utilizando la solución I en celda rectangular BIII quasibidimensional

Se describen experimentos obtenidos empleando la celda rectangular BIII con $l_{\mathrm{a} \bullet}=$ $4,3 \mathrm{~cm}$ y con la misma solución electrolítica utilizada en 4.1.1. En la figura 4.6 se muestra una curva de polarización obtenida a $100 \mathrm{mV} / \mathrm{s}$. También se incluye la curva de polarización corregida por la caída de potencial debido a la resistencia eléctrica de la solución.

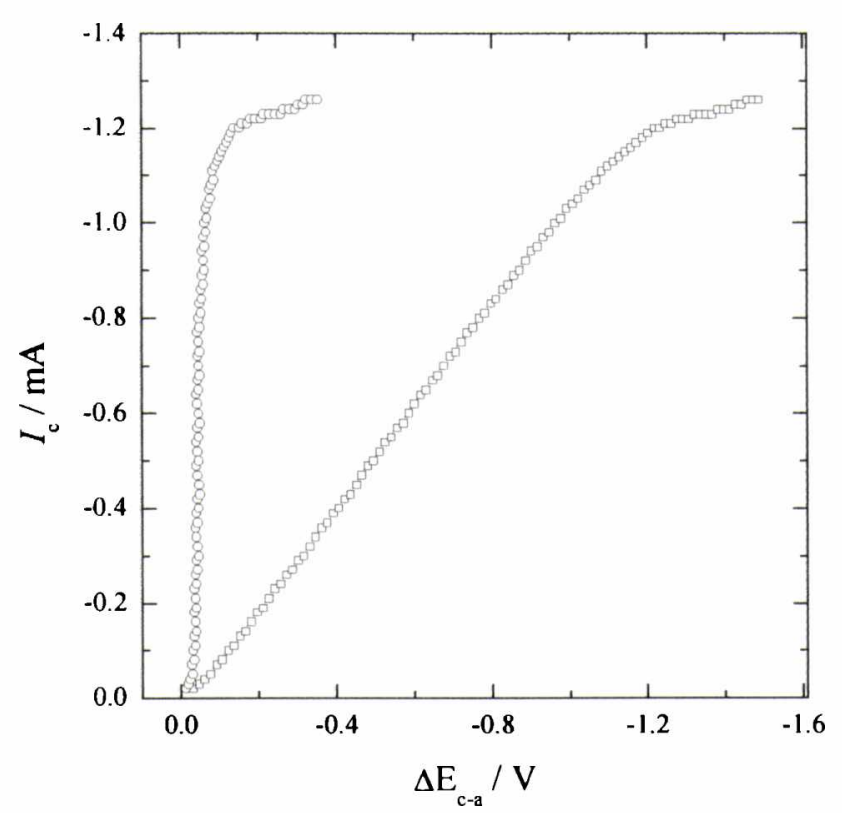

Figura 4.6. Curva de polarización. ( ) $I_{\mathrm{c}}$ versus $t \sin$ corregir por caída óhmica; (O) $I_{\mathrm{c}}$ versus $t$ después de corregir por caida óhmica. Condiciones: Solución I; velocidad de barrido $100 \mathrm{mV} / \mathrm{s}$. Temperatura ambiente.

La subida abrupta inicial y la rápida transición a una corriente límite muestra la alta reversibilidad del electrodo de plata/solución de $\mathrm{Ag}^{+}$, y el control por transporte de iones plata desde la solución al cátodo.

Transitorios potenciostáticos de corriente y morfología de los electrodepósitos

En la figura 4.7 se muestran transitorios de corrientes obtenidos a $\Delta \mathrm{E}_{\mathrm{c}-\mathrm{a}}=-0,4 \mathrm{~V}$ y $-0,45 \mathrm{~V}$. Para $t<100 \mathrm{~s}$, la corriente decrece aproximándose al comportamiento esperado para un proceso electroquímico simple controlado por difusión sobre un electrodo vertical plano. A $t>100 \mathrm{~s}$, la corriente permanece constante, aunque con oscilaciones de aproximadamente $0,25 \mathrm{~mA}$, debidas posiblemente, a la formación de nuevas ramas en el 
electrodepósito. En estos experimentos el área activa del electrodepósito en promedio se mantiene constante. Esto constituye una diferencia con la celda circular, donde a medida que el electrodepósito crece el perímetro de la interfase aumenta. En la figura 4.8 se muestra un transitorio de corriente típico a $\Delta \mathrm{E}_{\mathrm{c}-\mathrm{a}}=-0,52 \mathrm{~V}$, simultáneamente con las imágenes de los electrodepósitos obtenidos.

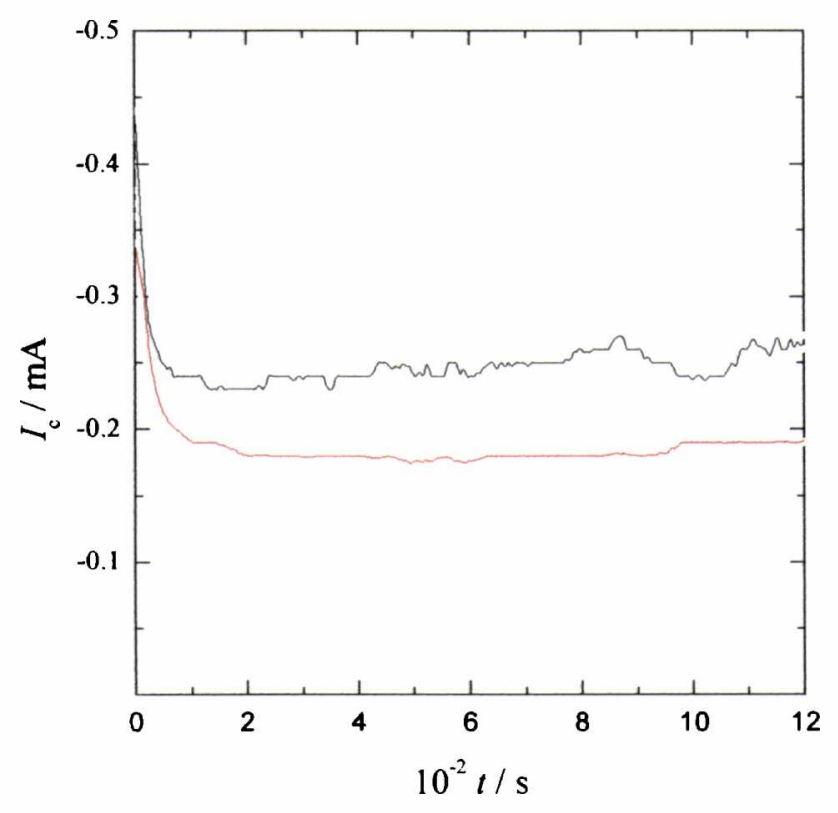

Figura 4.7. Transitorios de corriente obtenidos empleando la celda rectangular BIII $\left(l_{\mathrm{a}-\mathrm{c}}=4,3 \mathrm{~cm}\right.$ ), solución I $\Delta \mathrm{E}_{\mathrm{c}-\mathrm{a}}=-0,40 \mathrm{~V}$ (línea roja) y $\Delta \mathrm{E}_{\mathrm{c}-\mathrm{a}}=-0,45 \mathrm{~V}$ (línea negra). Temperatura ambiente.

En la tabla 4.2 se incluyen las condiciones de electrodeposición de plata.

Tabla 4.2 Condiciones y características morfológicas de los electrodepósitos obtenidos empleando Celda rectangular B III $\left(l_{\mathrm{a}-\mathrm{c}}=4,3 \mathrm{~cm}\right)-\mathrm{Ag}_{2} \mathrm{SO}_{4} 0,014 \mathrm{M}+\mathrm{Na}_{2} \mathrm{SO}_{4} 0,5 \mathrm{M}+\mathrm{H}_{2} \mathrm{SO}_{4} 0,01 \mathrm{M}$

\begin{tabular}{|c|c|c|c|}
\hline$\Delta \mathrm{E}_{\text {aplicado }} / \mathrm{V}$ & $\mathbf{R}_{\mathbf{i}} / \Omega$ & $\mathbf{v}_{\mathbf{f}} / \mathrm{m} \mathrm{s}$ & $\begin{array}{c}\text { Características } \\
\text { Morfológicas }\end{array}$ \\
\hline$-0,400$ & 970 & 1,2 & Ramificado (“tip-spitting”) \\
\hline$-0,450$ & 1030 & 2,1 & Ramificado (dendrítico) \\
\hline-0.520 & 1564 & 9,0 & Transición denso-ramificado \\
\hline-0.610 & 1527 & 15,0 & Transición denso-ramificado \\
\hline
\end{tabular}

En las figuras 4.9a y 4.3b, correspondientes a potenciales bajos, se observan morfologías ramificadas abiertas "tip-splitting" y crecimiento dendrítico respectivamente. Para $\Delta \mathrm{E}_{\mathrm{c}-\mathrm{a}}=-0,52$ y $-0,61 \mathrm{~V}$, el electrodepósito tiene estructura densa (figura 4.8 y $4.9 \mathrm{~d}$ ), y a partir de un cierto tiempo, que aumenta con el potencial 
aplicado, se presenta una transición del morfológica del electrodepósito de ramificado denso a ramificado abierto.

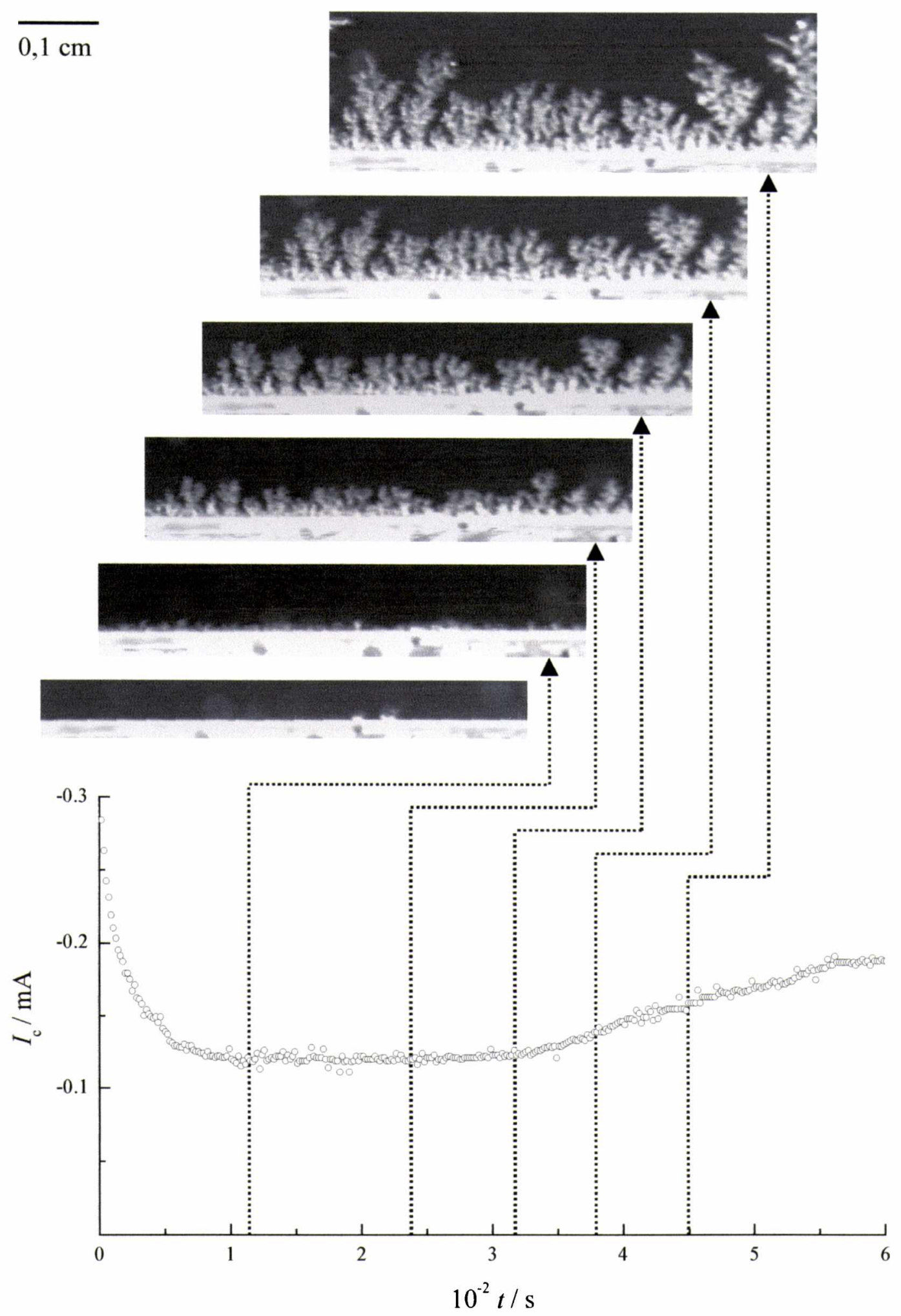

Figura 4.8. Secuencia de imágenes y transitorio de corriente 
a)

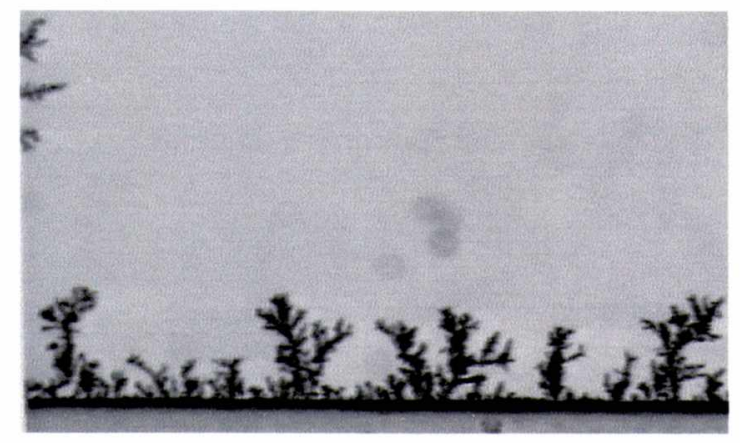

b)
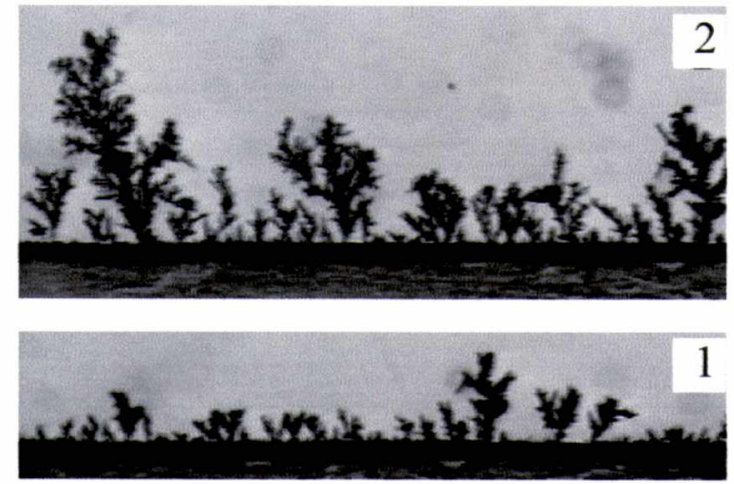

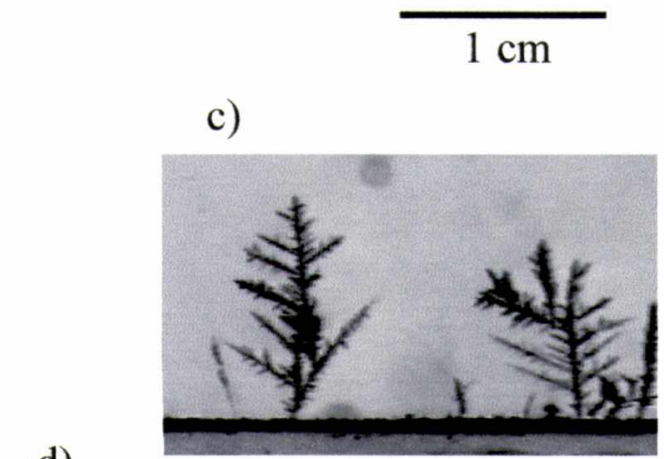

d)

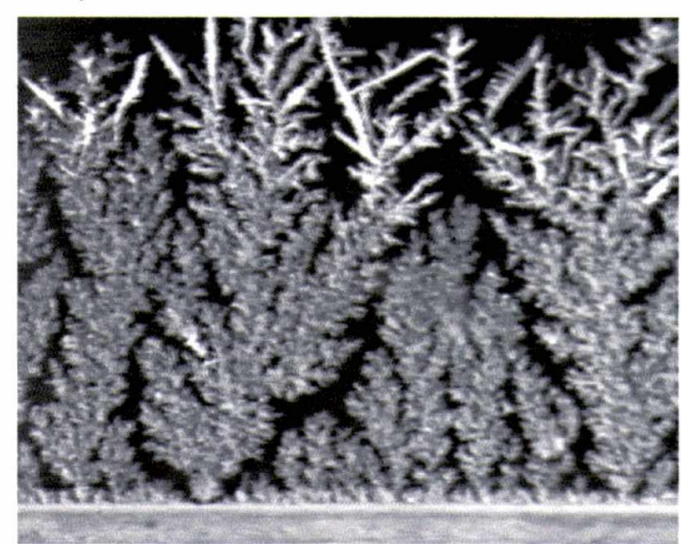

Figura 4.9. Electrodepósitos obtenidos utilizando la celda rectangular BIII con $l_{\mathrm{ac}}=4,3 \mathrm{~cm}$. Condiciones: solución I ; a) $\Delta \mathrm{E}_{\mathrm{c}-\mathrm{a}}=-0,40 \mathrm{~V}, t=1500 \mathrm{~s}$; b) $\Delta \mathrm{E}_{\mathrm{c}-\mathrm{a}}=-0,40 \mathrm{~V}$, 1) $t=600 \mathrm{~s}$, 2) $t=1500 \mathrm{~s}$; d) $\Delta \mathrm{E}_{\mathrm{c}-\mathrm{a}}=-0,45$ $\mathrm{V}$; d) $\Delta \mathrm{E}_{\mathrm{c}-\mathrm{a}}=-0,61 \mathrm{~V}, t=592 \mathrm{~s}$. Temperatura ambiente.

4.1.3 Electrodeposición de plata utilizando solución $\mathrm{II}+\mathrm{H}_{2} \underline{\mathrm{SO}}_{4} \underline{0.5 \mathrm{M} \text { en la celda }}$ rectangular BIII

A continuación se describen experimentos de electrodeposición empleando la celda rectangular BIII, $\left(l_{\mathrm{a}-\mathrm{c}}=2,3 \mathrm{~cm}\right)$ y solución de plata $0,024 \mathrm{M}$ (solución II) conteniendo ácido sulfúrico $0,5 \mathrm{M}$. Para este sistema la curva de polarización a $100 \mathrm{mV} / \mathrm{s}$ se muestra en la figura 4.10 .

El ácido sulfúrico posee mayor conductividad que el sulfato de sodio, por lo que la resistencia de la celda será menor. Además, al disminuir la distancia ánodo - cátodo ( $\left.l_{\mathrm{acc}}\right)$ de $4,3 \mathrm{~cm}$ a $2,3 \mathrm{~cm}$, disminuye la resistencia interna de la celda por efecto de la distancia. De esta manera se disminuyen los efectos resistivos en la curva de polarización.

La corriente límite se alcanza alrededor de $-0,45 \mathrm{~V}$ y a partir de $-0,70 \mathrm{~V}$ comienza a 
observarse incremento de área.

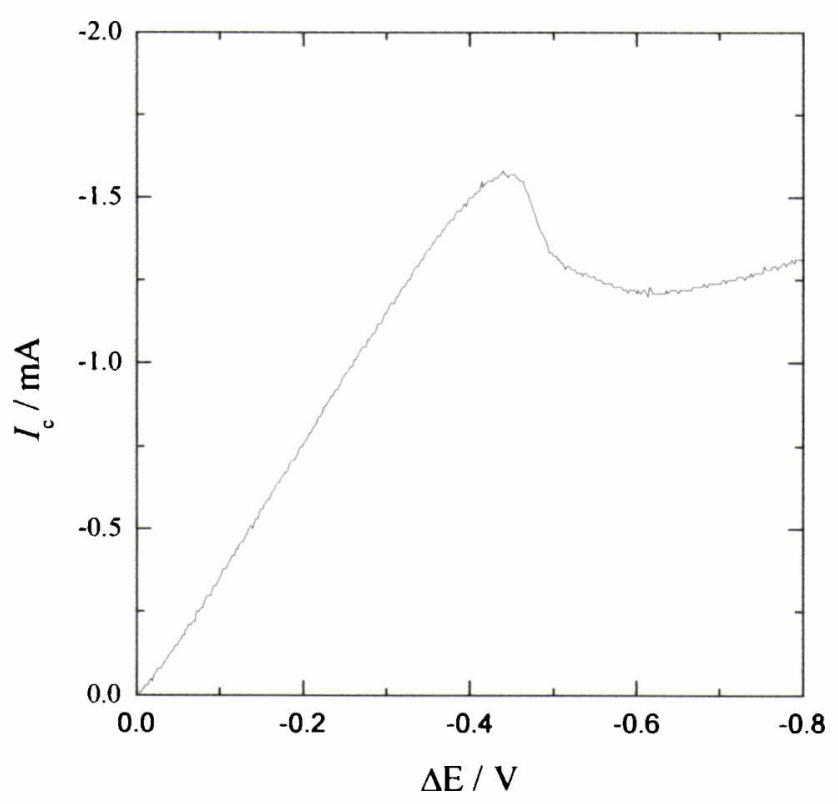

Figura 4.10. Curva de polarización obtenida a $100 \mathrm{mV} / \mathrm{s}$ empleando la celda rectangular BIIl con $l_{\mathrm{a}-\mathrm{c}}=2,3 \mathrm{~cm}$, y solución II + ácido sulfúrico $0,5 \mathrm{M}$. Temperatura ambiente.

Transitorios potenciostáticos de corriente y morfología de los electrodepósitos

En la figura 4.11 y 4.12 se muestran transitorios de corriente obtenidos a $\Delta \mathrm{E}_{\mathrm{c}-\mathrm{a}}=-0,23 \mathrm{~V}$ y $-0,65 \mathrm{~V}$, respectivamente, conjuntamente con una secuencia de imágenes que muestra la evolución del electrodepósito durante su crecimiento.

Para potenciales $\Delta \mathrm{E}_{\mathrm{c}-\mathrm{a}}=-0,20 \mathrm{~V}$ y $-0,23 \mathrm{~V}$ (figura 4.11) los transitorios presentan características similares a las de los experimentos realizados en celda rectangular (sección 4.1.2). La corriente disminuye rápidamente durante los primeros $50 \mathrm{~s}$, alcanza un mínimo entre los 50 y $100 \mathrm{~s}$, luego sube levemente y oscila alrededor de un valor medio de aproximadamente $-0,07 \mathrm{~mA}$ aproximadamente. Las imágenes muestran crecimientos dendríticos ("árboles"), que se origina en las protuberancias que aparecen a $t<300 \mathrm{~s}$. A $t\rangle$ $600 \mathrm{~s}$, se observan "árboles" que dejan de crecer porque son "apantallados" por sus vecinos que poseen mayor velocidad de avance. Este proceso conduce, en promedio, a un área activa constante en consonancia con la corriente medida.

Para $\Delta \mathrm{E}_{\mathrm{c}-\mathrm{a}}=-0,65 \mathrm{~V}$ (figura 4.12), la velocidad de crecimiento del electrodepósito es mucho mayor que en el caso anterior. Así, para $t \cong 30 \mathrm{~s}$, el electrodepósito, presenta un 
frente robusto que avanza hacia el contraelectrodo y a partir de los $100 \mathrm{~s}$ la corriente permanece constante.

$0,1 \mathrm{~cm}$

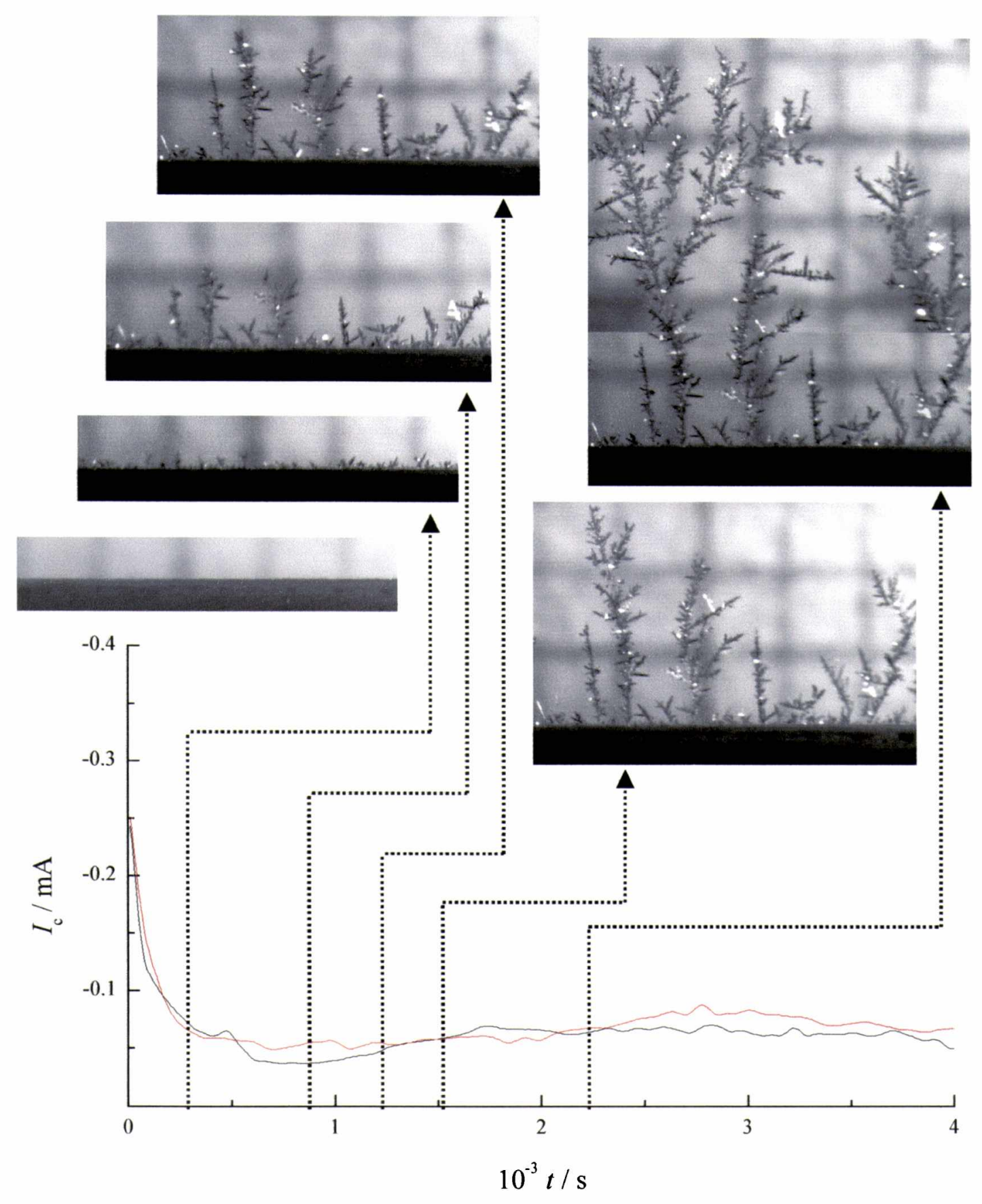

Figura 4.11. Transitorios de corriente y secuencia de imágenes de la evolución del electrodepósito. Condiciones: solución II + ácido sulfúrico $0,5 \mathrm{M}$. La curva roja corresponde a $\Delta \mathrm{E}_{\mathrm{c}-\mathrm{a}}=-0,23 \mathrm{~V}$ y la negra a $\Delta \mathrm{E}_{\mathrm{c}-\mathrm{a}}=-0,20 \mathrm{~V}$. Temperatura ambiente. 


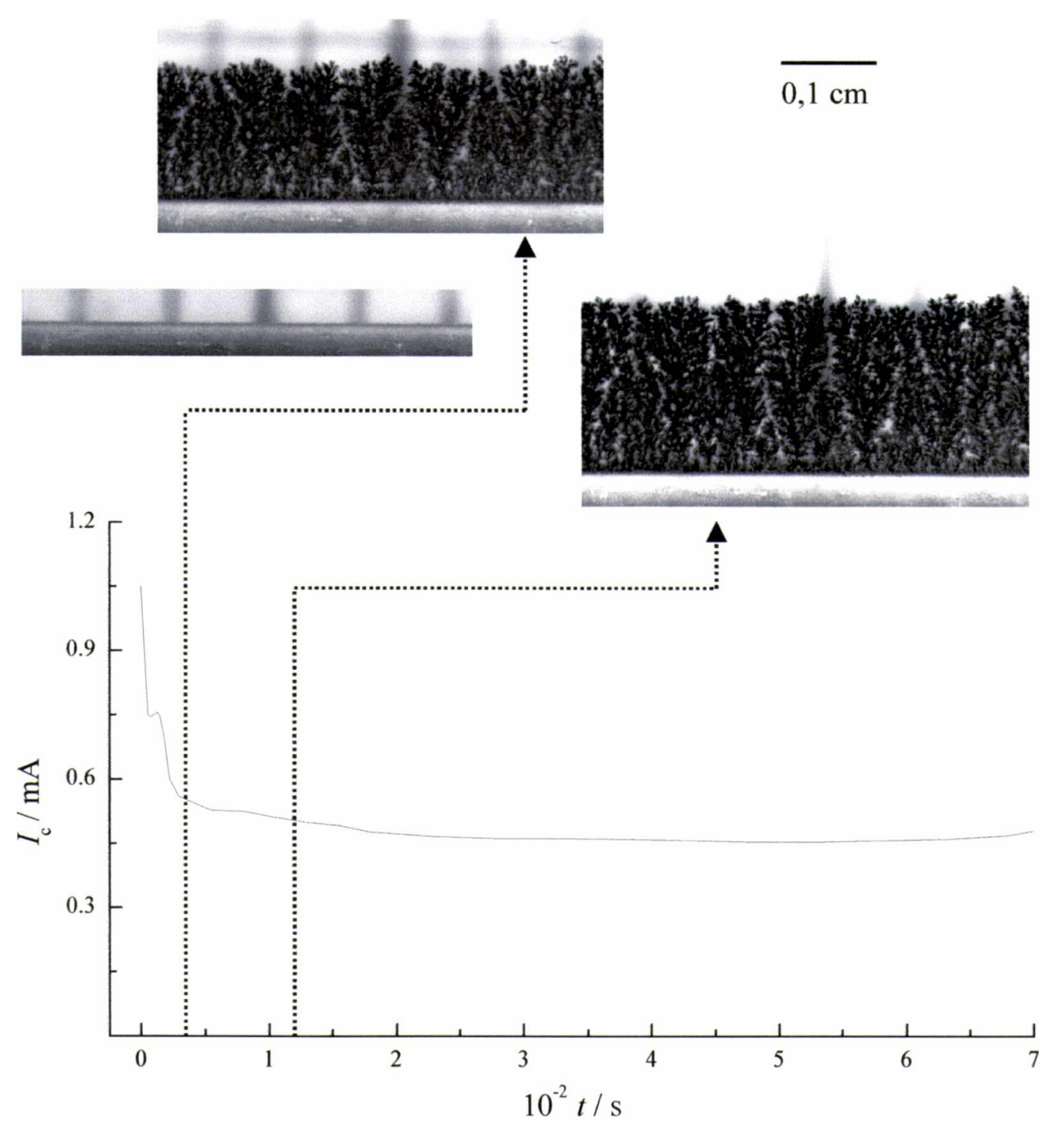

Figura 4.12. Transitorios de corriente y secuencia de imágenes de la evolución del electrodepósito. Condiciones: solución $\mathrm{II}+$ ácido sulfúrico $0,5 \mathrm{M}, \Delta \mathrm{E}_{\mathrm{c}-\mathrm{a}}=-0,65 \mathrm{~V}$. Temperatura ambiente.

Para potenciales intermedios entre $\sim-0,35 \geq \Delta \mathrm{E}_{\mathrm{c}-\mathrm{a}} \geq \sim-0,50 \mathrm{~V}$ los transitorios de corriente muestran a un cierto tiempo un incremento abrupto de la corriente. Esto ocurre a un tiempo que es mayor cuanto mayor es el potencial aplicado dentro del rango considerado. Luego del aumento abrupto de la corriente, esta oscila en forma no periódica, con amplitudes de hasta $50 \mathrm{~mA}$. Este comportamiento de los transitorios de corriente se correlaciona con los cambios morfológicos del electrodepósito. Estos experimentos serán considerados más extensamente en el Capítulo 7 con cierto detalle.

En la tabla 4.3 se consignan las condiciones de electrodeposición de los experimentos realizados. 
Tabla 4.3. Condiciones y características morfológicas de los electrodepósitos obtenidos.

Celda rectangular B III $\left(l_{\mathrm{a}-\mathrm{c}}=2,3 \mathrm{~cm}\right)-\mathrm{Ag}_{2} \mathrm{SO}_{4} 0,024 \mathrm{M}+\mathrm{H}_{2} \mathrm{SO}_{4} 0,5 \mathrm{M}$

\begin{tabular}{|c|c|c|c|}
\hline$\Delta \mathrm{E}_{\text {aplicado }} / \mathrm{V}$ & $\mathbf{R}_{\mathbf{i}} / \Omega$ & $v_{\mathbf{f}} / \mathrm{m} \mathrm{s}$ & $\begin{array}{c}\text { Características } \\
\text { Morfológicas }\end{array}$ \\
\hline$-0,150$ & 147 & - & Ramificado abierto (dendrítico) \\
\hline$-0,200$ & 193 & 0,5 & Ramificado abierto (dendrítico) \\
\hline$-0,235$ & 216 & 0,8 & Ramificado abierto (dendrítico) \\
\hline-0.291 & 212 & 20,0 & Mixto, dendritas y “tip-splitting”" \\
\hline$-0,400$ & 204 & 6,6 & Transición denso-abierto \\
\hline$-0,475$ & 266 & 13,6 & Transición denso-abierto \\
\hline$-0,575$ & 253 & 20,4 & Denso \\
\hline$-0,650$ & 255 & 24,3 & Denso \\
\hline
\end{tabular}

Se observa que al aumentar el $\Delta \mathrm{E}_{c-\mathrm{a}}$ la morfología pasa de una ramificada dendrítica (figura 4.13a), a una que exhibe transición morfológica, ramificado denso - ramificado abierto (figura $4.13 \mathrm{~b}$ ). Finalmente a los potenciales más altos, se obtiene únicamente un electrodepósito denso (figura 4.13c). Estas transiciones no están previstas en los diagrama de fases que se encuentran en la literatura $[23,24]$.

a)

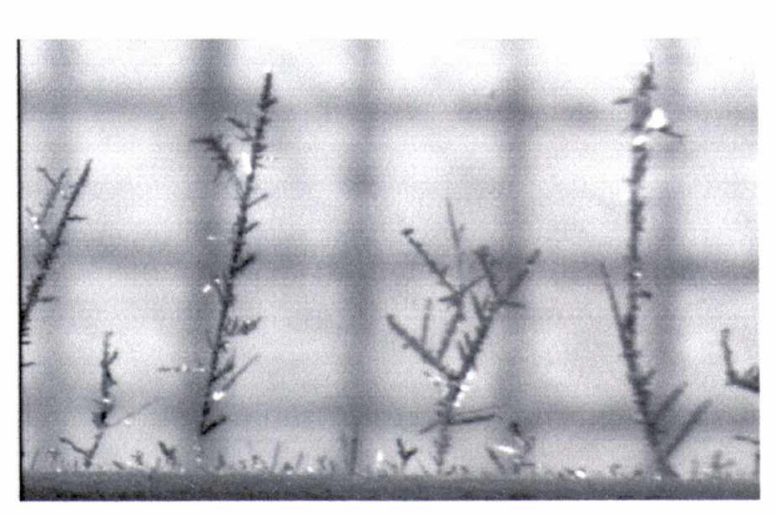

c)

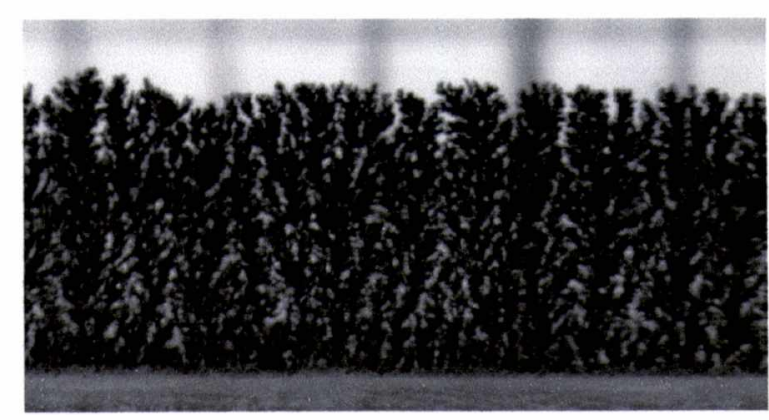

b)

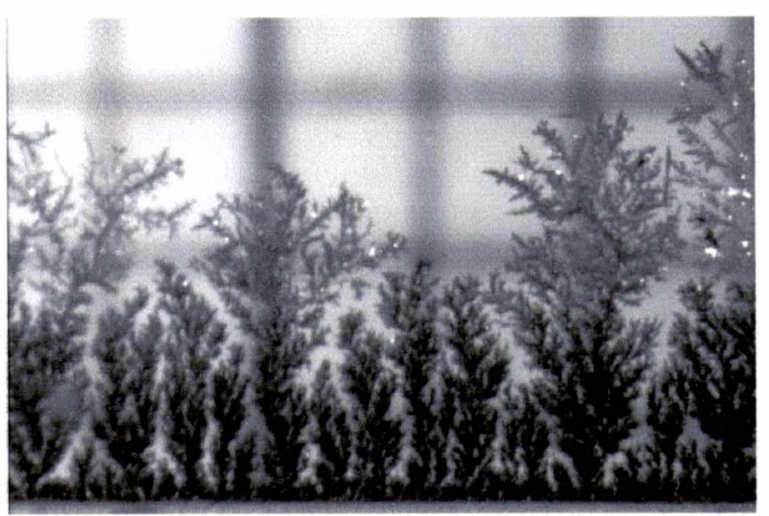

$1 \mathrm{~cm}$

Figura 4.13. Electrodepósitos obtenidos en la celda BIII. Condiciones: solución II + ácido sulfúrico $0,5 \mathrm{M}$; a) $\Delta \mathrm{E}_{\mathrm{c}-\mathrm{a}}=-0.20 \mathrm{~V}, t=4500 \mathrm{~s}$; b) $\Delta \mathrm{E}_{\mathrm{c}-\mathrm{a}}=-0.45 \mathrm{~V}, t=320 \mathrm{~s}$; c) $\Delta \mathrm{E}_{\mathrm{c}-\mathrm{a}}=-0.65 \mathrm{~V}, t=75 \mathrm{~s}$. Temperatura ambiente. 


\subsubsection{Electrodeposición de plata utilizando la solución II}

Se describen experimentos de electrodeposición en las celdas electroquímicas: circular A; rectangular BI y BII utilizando una solución de sulfato de plata $0,024 \mathrm{M}$ (solución II) sin electrolito soporte.

La curva de polarización obtenida a $0,3 \mathrm{~V} / \mathrm{s}$ en la celda circular A se muestra en la figura 4.14. La caída de potencial debido a la resistencia de la celda predomina en casi todo el rango de potenciales, pero considerando la corrección por la caída óhmica se obtiene la curva de polarización esperada para un sistema controlado por transferencia de materia.

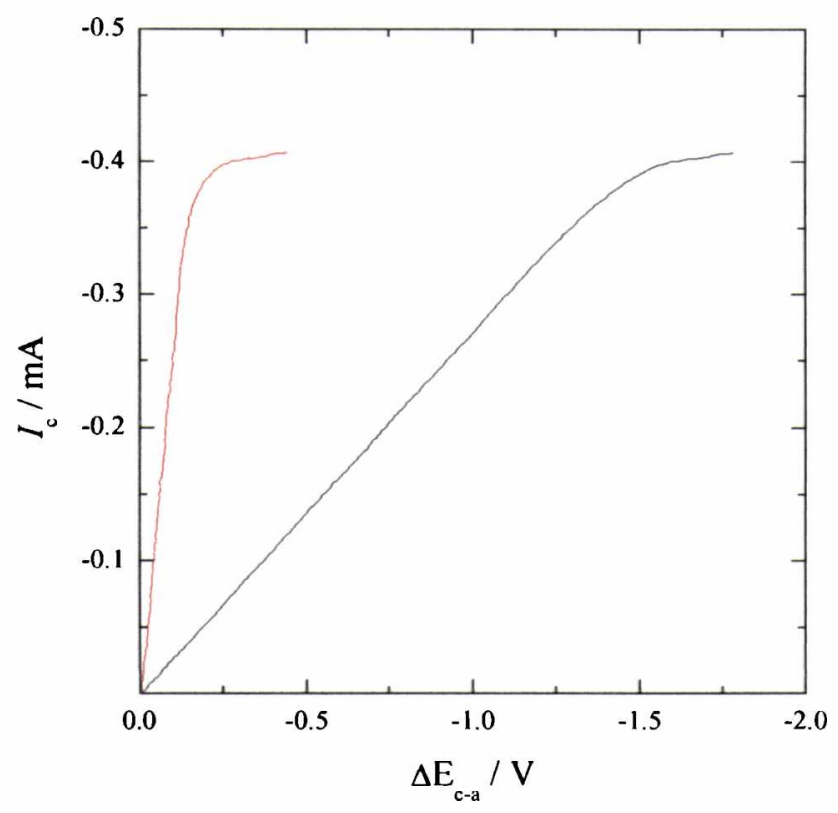

Figura 4.14. Curva de polarización obtenida en la celda circular A; solución II. Temperatura ambiente.

\section{Transitorios potenciostáticos de corriente y morfología de los electrodepósitos}

Los transitorios de corriente realizados a varios potenciales empleando la celda circular A y la solución II, se muestran en la figura 4.15. Estas curvas son similares a las mostradas en la sección anterior. Al comienzo se observa un descenso de $I_{\mathrm{c}}$ con $t$ y luego un aumento en la intensidad con el tiempo de electrólisis, principalmente provocado por el aumento del radio del electrodepósito. En varios transitorios, correspondientes a potenciales aplicados relacionados con crecimientos aciculares, a tiempos mayores que los $3500 \mathrm{~s}$ se observar regiones de corriente aproximadamente constante. La relación entre la evolución de la estructura del electrodepósito y la corriente se muestra en la figura 4.16. En los primeros $300 \mathrm{~s}$, la corriente disminuye rápidamente, alcanza un mínimo y 
posteriormente aumenta en forma casi lineal, con oscilaciones de hasta $20 \mu \mathrm{A}$. Esta respuesta se relaciona con el aumento del número de ramas o agujas a medida que el radio promedio del electrodepósito aumenta. Para $t>4000 \mathrm{~s}$ se alcanza un plateau de corriente, al tiempo que el crecimiento está dominado por una única aguja. La velocidad de crecimiento que es muy alta, ocurre a área activa constante. En el resto del electrodepósito la plata se deposita en forma compacta, sin incremento apreciable de área.

En la figura 4.15, el transitorio c) registrado a $-0,22 \mathrm{~V}$ muestra una corriente inicial alta ya que el área inicial del electrodo de trabajo es mayor que para los experimentos c) g). El radio del electrodo es de $1 \mathrm{~mm}$ para a) y b), y de $0,25 \mathrm{~mm}$ para el resto de los experimentos.

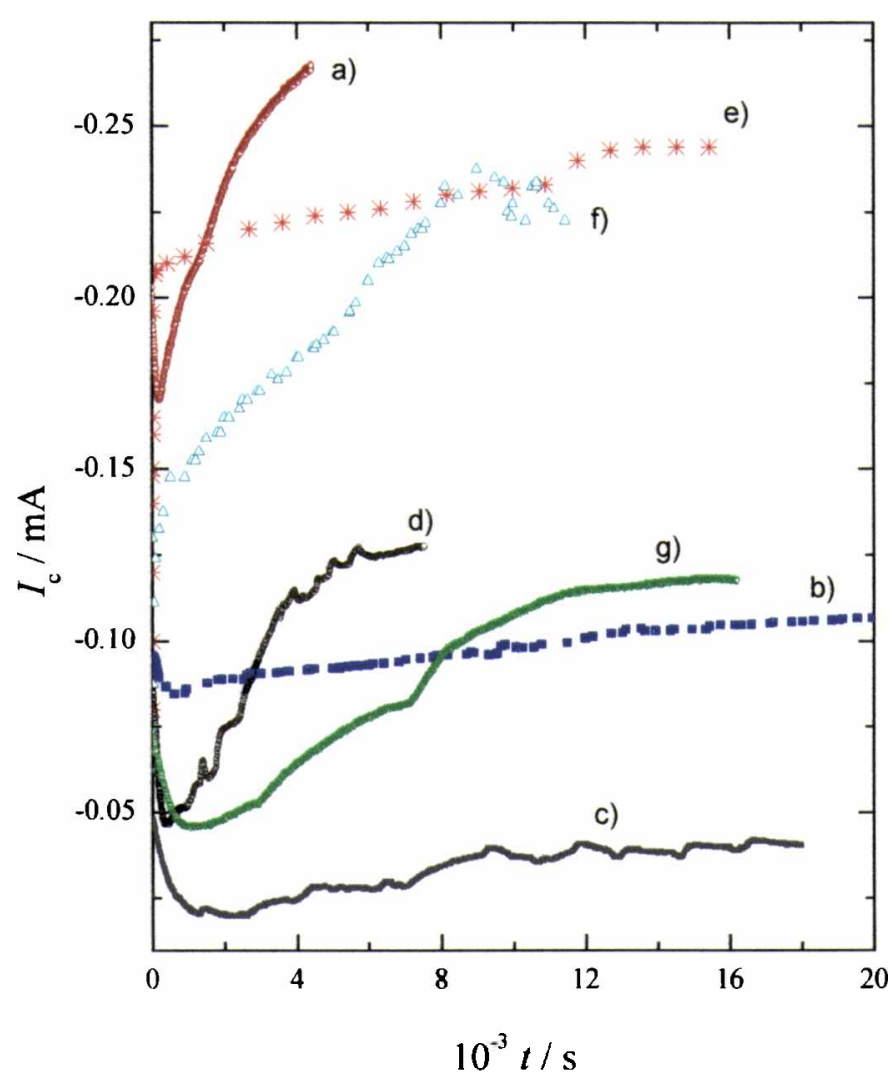

Figura 4.15. Transitorios de corriente realizados empleando la solución Il y la celda circular A, con el electrodo de trabajo de $2 \mathrm{~mm}$ de diámetro: a) $\Delta \mathrm{E}_{\mathrm{c}-\mathrm{a}}=-0,45 \mathrm{~V}$, b) $\Delta \mathrm{E}_{\mathrm{c}-\mathrm{a}}=-0,22 \mathrm{~V}$; con el electrodo de trabajo de $0,5 \mathrm{~mm}$ de diámetro: c) $\Delta \mathrm{E}_{\mathrm{c}-\mathrm{a}}=-0,25 \mathrm{~V}$; d) $\Delta \mathrm{E}_{\mathrm{c}-\mathrm{a}}=-0,39 \mathrm{~V}$, e) $\left.\left.\Delta E_{c-a}=-0,38 \mathrm{~V}, \mathrm{f}\right) \Delta \mathrm{E}_{\mathrm{c}-\mathrm{a}}=-0,38 \mathrm{~V}, \mathrm{~g}\right) \Delta \mathrm{E}_{\mathrm{c}-\mathrm{a}}=-0,30 \mathrm{~V}$. Temperatura ambiente. 


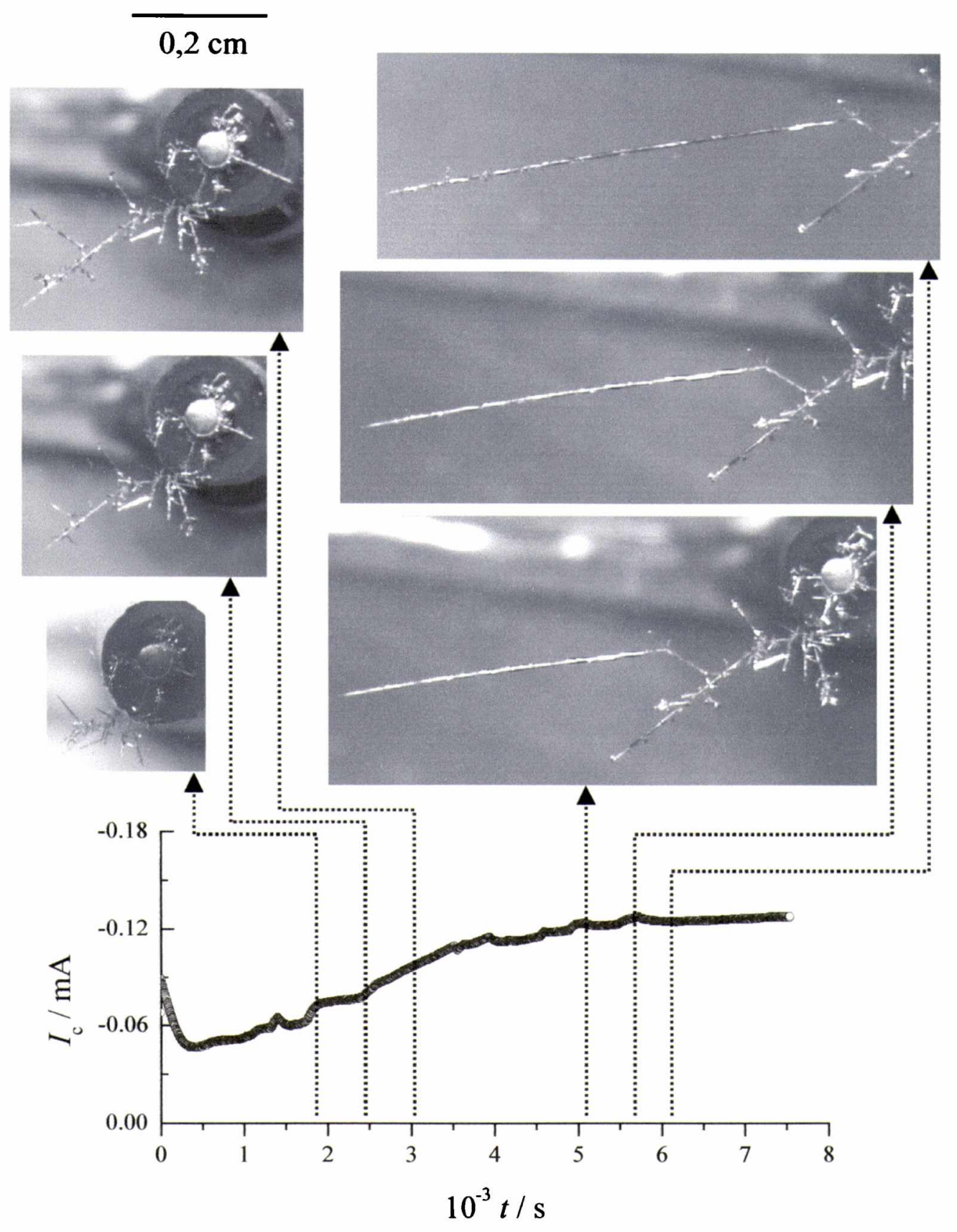

Figura 4.16. Secuencia de imágenes y transitorio de corriente. Condiciones: solución II a $\Delta E_{c-a}=-0,39 \mathrm{~V}$.

En la tabla 4.4 se compilan los potenciales aplicados en los experimentos de electrodeposición, la resistencia eléctrica medida entre los electrodos antes de iniciar la experiencia, las velocidades medias de avance y las características morfológicas más importantes de los electrodepósitos obtenidos. 
Tabla 4.4. Celda circular $\mathrm{A}-\mathrm{Ag}_{2} \mathrm{SO}_{4} 0,024 \mathrm{M}$

\begin{tabular}{|c|c|c|c|}
\hline$\Delta \mathrm{E}_{\mathrm{c}-\mathrm{a}} / \mathrm{V}$ & $\mathrm{R}_{\mathrm{i}} / \Omega$ & $<v>/ \mu \mathrm{m} \mathrm{s}^{-1}$ & $\begin{array}{l}\text { Caracteristicas } \\
\text { Morfológicas } \\
\end{array}$ \\
\hline$-0,220$ & 5200 & - & $\begin{array}{l}\text { Electrodepósito con ramas y } \\
\text { crecimientos aciculares }\end{array}$ \\
\hline$-0,220$ & 5550 & 0,01 & Electrodepósito con ramas anchas \\
\hline$-0,220$ & 4000 & 0,05 & Electrodepósito con ramas anchas \\
\hline$-0,220$ & 5000 & - & Electrodepósito con ramas anchas \\
\hline$-0,250$ & 5000 & 1,2 & $\begin{array}{l}\text { Ramificado abierto + crecimientos } \\
\text { aciculares }\end{array}$ \\
\hline-0.300 & 3401 & 0,6 & $\begin{array}{l}\text { Ramificado abierto + crecimientos } \\
\quad \text { aciculares } \\
\text { (predomina el crecimiento acicular) }\end{array}$ \\
\hline$-0,310$ & 5882 & - & $\begin{array}{l}\text { Electrodepósito con ramas y } \\
\text { crecimientos aciculares anchos }\end{array}$ \\
\hline$-0,275$ & 3200 & 1,0 & $\begin{array}{c}\text { Ramificado abierto }+ \text { crecimientos } \\
\text { aciculares (predomina el crecimiento } \\
\text { acicular) }\end{array}$ \\
\hline$-0,380$ & 2182 & 0,6 & $\begin{array}{l}\text { Ramificado abierto + crecimientos } \\
\text { aciculares (predomina el crecimiento } \\
\text { acicular) }\end{array}$ \\
\hline$-0,380$ & 2200 & 0,7 & $\begin{array}{c}\text { Ramificado abierto + crecimientos } \\
\text { aciculares (predomina el crecimiento } \\
\text { acicular) }\end{array}$ \\
\hline$-0,390$ & 4348 & 1,2 & $\begin{array}{l}\text { Ramificado abierto + crecimientos } \\
\text { aciculares (predomina el crecimiento } \\
\text { ramificado) }\end{array}$ \\
\hline$-0,450$ & 2060 & 1,22 & $\begin{array}{l}\text { Ramificado abierto + crecimientos } \\
\text { aciculares (predomina el crecimiento } \\
\text { ramificado) }\end{array}$ \\
\hline
\end{tabular}

A potenciales relativamente bajos, $\Delta \mathrm{E}_{\mathrm{c}-\mathrm{a}}=-0,22 \mathrm{~V}$, se produce un electrodepósito dominado por una morfología ramificada abierta constituida por ramas gruesa que crecen durante $20 \mathrm{hs}$ (figura $4.17 \mathrm{a}$ ). Cuando $\Delta \mathrm{E}_{\mathrm{c}-\mathrm{a}} \leq-0,38 \mathrm{~V}$ se obtienen, predominantemente, electrodepósitos ramificados mixtos complejos, con la presencia de crecimientos aciculares. Finalmente para $-0,275 \geq \Delta \mathrm{E}_{\mathrm{c}-\mathrm{a}} \geq-0,39 \mathrm{~V}$, predomina el crecimiento acicular.

Las figuras 4.17.b), c), d), e), f) y g) corresponden a electrodepósitos en los que la escala de tiempo y espacio son suficientemente grandes y predomina el crecimiento acicular (conocido muchas veces como "whiskers"). En estos experimentos se utiliza la solución II y $\Delta \mathrm{E}_{\mathrm{c}-\mathrm{a}}$ de $-0,38 \mathrm{~V},-0,39 \mathrm{~V},-0,30 \mathrm{~V},-0,45 \mathrm{~V},-0.275 \mathrm{~V}$ y $-0,31 \mathrm{~V}$, respectivamente. 
a)

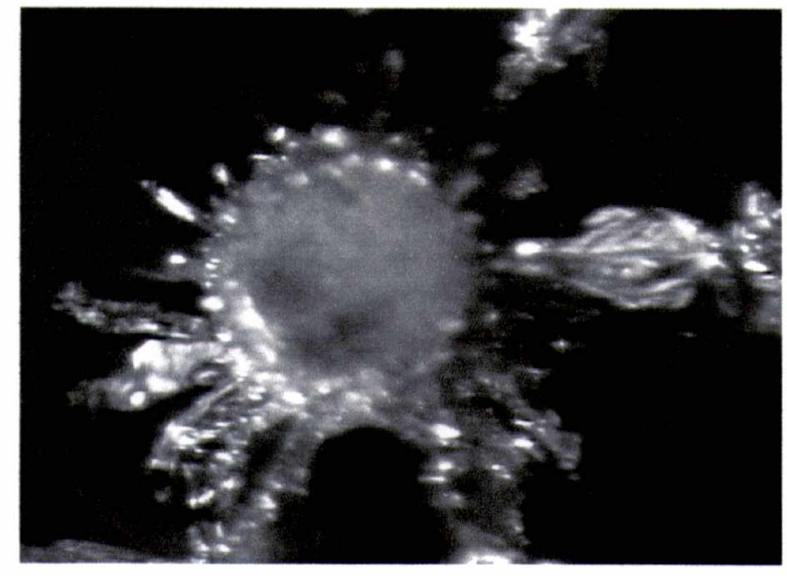

c)

b)

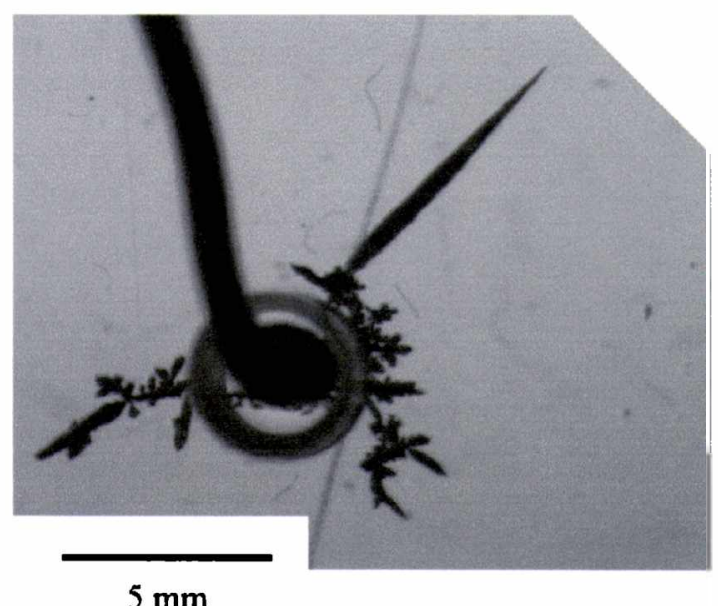

d)

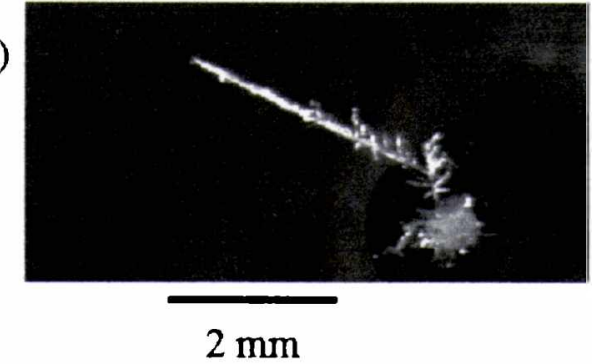

e)

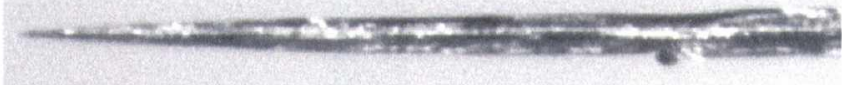

$1 \mathrm{~mm}$

f)

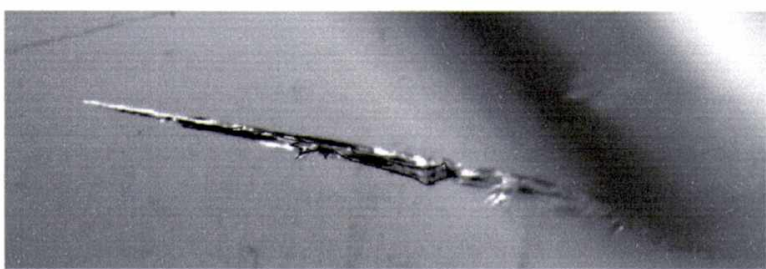

g)

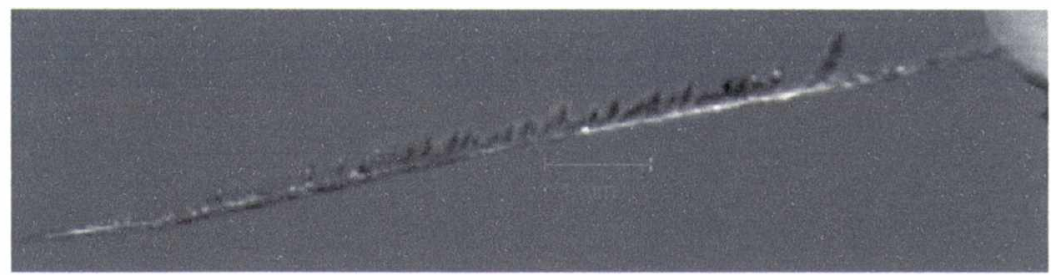

Figura 4.17. Electrodepósitos ramificados y aciculares obtenidos empleando la celda circular $A$, con la solución II sin electrolito soporte. a) $\Delta \mathrm{E}_{\mathrm{c}-\mathrm{a}}=-0,22 \mathrm{~V}$; b) $\Delta \mathrm{E}_{\mathrm{c}-\mathrm{a}}=-0,38 \mathrm{~V}$, c) $\Delta \mathrm{E}_{\mathrm{c}-\mathrm{a}}=$ $\left.\left.-0,39 \mathrm{~V}, \mathrm{~d}) \Delta \mathrm{E}_{\mathrm{c}-\mathrm{a}}=-0,30 \mathrm{~V}, \mathrm{e}\right) \Delta \mathrm{E}_{\mathrm{c}-\mathrm{a}}=-0,45 \mathrm{~V}, \mathrm{f}\right) \Delta \mathrm{E}_{\mathrm{c}-\mathrm{a}}=-0,275 \mathrm{Vy}$ g) $\Delta \mathrm{E}_{\mathrm{c}-\mathrm{a}}=-0,31 \mathrm{~V}$. 
En la figura 4.18 se muestran transitorios potenciostáticos de corriente para diferentes $\Delta \mathrm{E}_{\mathrm{c}-\mathrm{a}}$, obtenidos en la celda BI. empleando la solución II.

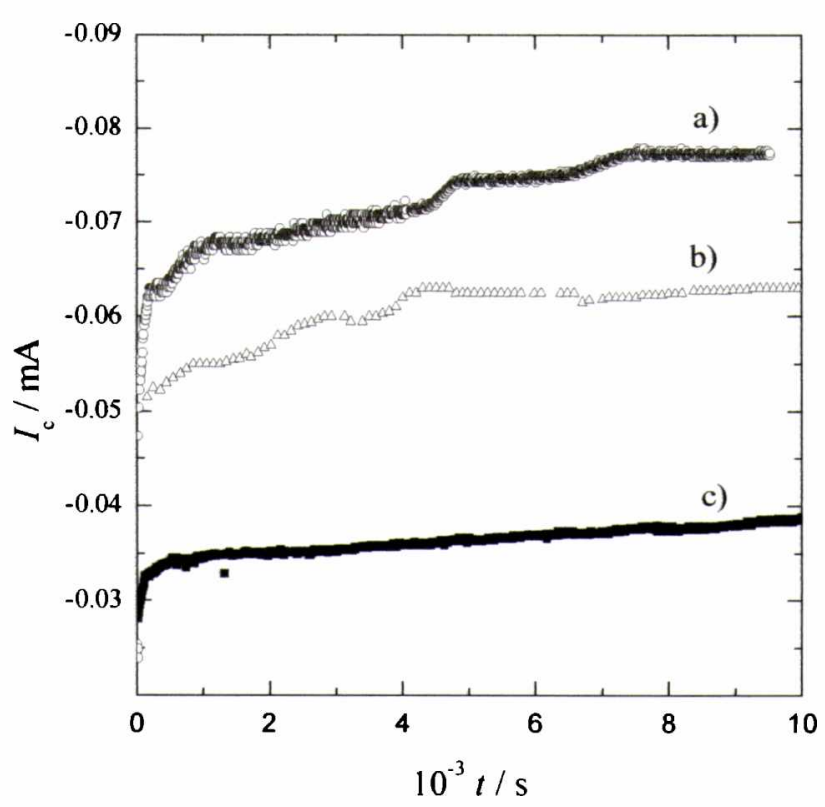

Figura 4.18. Transitorios de corriente obtenidos empleando solución Il y la celda rectangular $\mathrm{BI}$ con $l_{\mathrm{a}-\mathrm{c}}=7 \mathrm{~cm}$. a) $\Delta \mathrm{E}_{\mathrm{c}-\mathrm{a}}=-1 \mathrm{~V}$, a) $\Delta \mathrm{E}_{\mathrm{c}-\mathrm{a}}=-0,8 \mathrm{~V} \mathrm{y} \mathrm{c)} \Delta \mathrm{E}_{\mathrm{c}-\mathrm{a}}=-1,22 \mathrm{~V}$. Temperatura ambiente.

Luego de la caída inicial de corriente (no apreciable en la escala de tiempo de la figura) debido a la formación de la capa de difusión, la corriente sube, como consecuencia, principalmente, del incremento del área del electrodepósito. Esto se debe al propio diseño de la celda, cuyo electrodo de trabajo es de área menor al contraelectrodo pero está incorporado en un extremo de la celda, lo que hace posible el crecimiento radial del electrodepósito. Una vez que el frente de crecimiento ocupa el ancho de la celda, la corriente se comporta de igual manera que la descripta para los transitorios realizados con la celda BII.

En la tabla 4.5 y 4.6 se consignan las condiciones de electrodeposición.

Tabla 4.5. Celda rectangular $\mathrm{BI}\left(l_{\mathrm{a}-\mathrm{c}}=7 \mathrm{~cm}\right)-\mathrm{Ag}_{2} \mathrm{SO}_{4} 0,024 \mathrm{M}$

\begin{tabular}{|c|c|c|c|}
\hline$\Delta \mathrm{E}_{\mathrm{c}-\mathrm{a}} / \mathrm{V}$ & $<\mathrm{v} / \mu \mathrm{m} \mathrm{s}^{-1}$ & $\mathrm{R}_{\mathrm{i}} / \Omega$ & Características \\
\hline$-2,30$ & 2,3 & 5200 & Electrodepósito ramificado mixto \\
\hline-1.22 & 1,2 & 5000 & $\begin{array}{c}\text { Electrodepósito mixto con ramas y } \\
\text { crecimientos aciculares anchos }\end{array}$ \\
\hline$-1,00$ & 1,7 & 2000 & $\begin{array}{c}\text { Ramificado abierto + crecimientos } \\
\text { aciculares (predomina el crecimiento } \\
\text { ramificado) }\end{array}$ \\
\hline$-0,92$ & 0,6 & 5000 & $\begin{array}{c}\text { Ramificado abierto + crecimiento } \\
\text { acicular (predomina el crecimiento } \\
\text { ramificado) }\end{array}$ \\
\hline$-0,80$ & 0,5 & 5000 & $\begin{array}{c}\text { Ramificado abierto + crecimiento } \\
\text { acicular (predomina el crecimiento } \\
\text { acicular) }\end{array}$ \\
\hline
\end{tabular}


Tabla 4.6. Celda rectangular B I $\left(l_{\mathrm{a}-\mathrm{c}}=2 \mathrm{~cm}\right)-\mathrm{Ag}_{2} \mathrm{SO}_{4} 0,024 \mathrm{M}$

\begin{tabular}{|c|c|c|c|}
\hline$\Delta \mathrm{E}_{\mathrm{c- \textrm {a }}} / \mathrm{V}$ & $\left\langle v>/ \mu \mathrm{m} \mathrm{s}^{-1}\right.$ & $\mathrm{R}_{\mathrm{i}} / \Omega$ & Caracteristicas \\
\hline$-0,38$ & 0,04 & 2449 & $\begin{array}{c}\text { Ramificado abierto + crecimientos } \\
\text { aciculares }\end{array}$ \\
\hline-0.35 & 0,04 & 2409 & $\begin{array}{c}\text { Ramificado abierto + crecimientos } \\
\text { aciculares }\end{array}$ \\
\hline
\end{tabular}

Se observan electrodepósitos aciculares obtenidos en dos tipos de celda rectangular. En la celda rectangular $\mathrm{BI}$ con $l_{\mathrm{a}-\mathrm{c}}=7 \mathrm{~cm}$, a $\Delta \mathrm{E}_{\mathrm{c}-\mathrm{a}}=-1,0 \mathrm{~V}$ (figura 4.19.a) y a $\Delta \mathrm{E}_{\mathrm{c}-\mathrm{a}}=$ $-0,80 \mathrm{~V}$ (figura 4.19.b), y en la celda rectangular $\mathrm{BI}\left(l_{\mathrm{a}-\mathrm{c}}=2 \mathrm{~cm}\right.$ ), a $\Delta \mathrm{E}_{\mathrm{c}-\mathrm{a}}=-0,38 \mathrm{~V}$ (figura 4.19.c), para $\Delta \mathrm{E}_{\mathrm{c}-\mathrm{a}}>-0,35 \mathrm{~V}$, se obtienen cristales hexagonales bien definidos, en tanto que a $\Delta \mathrm{E}_{\mathrm{c}-\mathrm{a}}<-0,4 \mathrm{~V}$, la morfología dominante es la ramificada compleja.
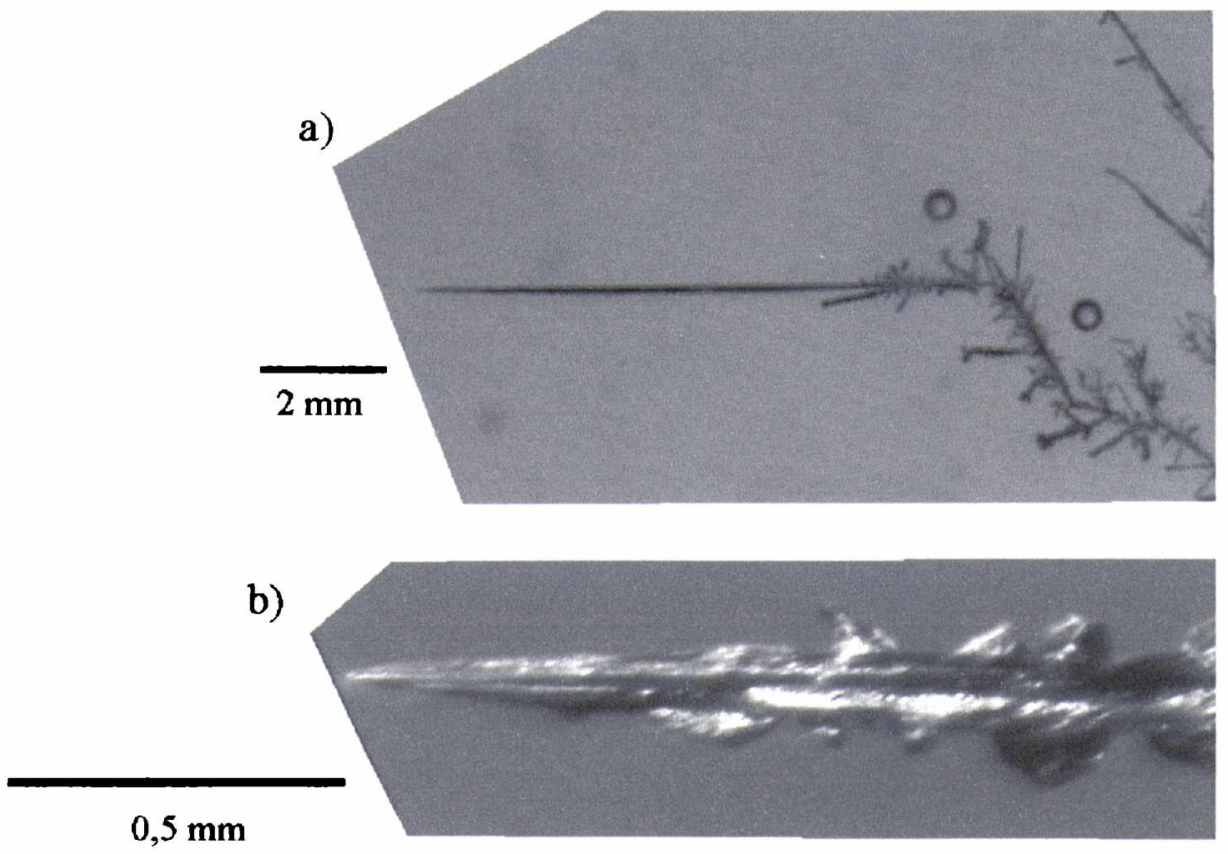

c)

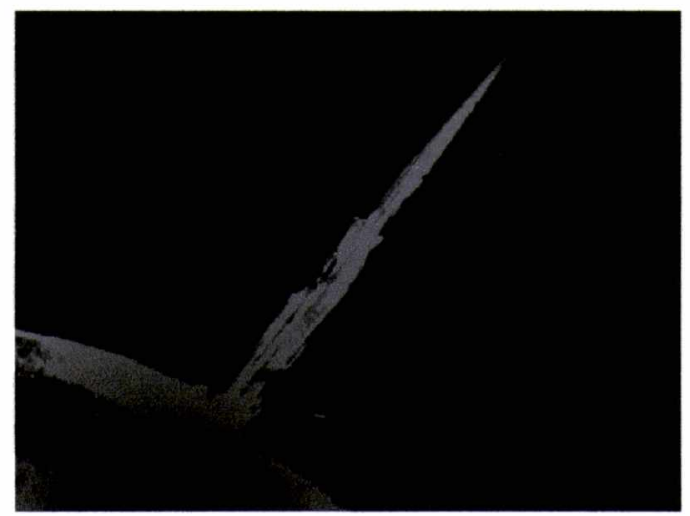

Figura 4.19. Electrodepósitos aciculares obtenidos empleando solución II. a) celda rectangular BI $\left(l_{\mathrm{a}-\mathrm{c}}=7 \mathrm{~cm}\right)$ y $\left.\Delta \mathrm{E}_{\mathrm{c}-\mathrm{a}}=-1 \mathrm{~V}, \mathrm{~b}\right)$ celda rectangular BI $\left(l_{\mathrm{a}-\mathrm{c}}=7 \mathrm{~cm}\right)$ y $\Delta \mathrm{E}_{\mathrm{c}-\mathrm{a}}=-0,80 \mathrm{~V}$; a) celda rectangular $\mathrm{BI}\left(l_{\mathrm{c}-\mathrm{a}}=2 \mathrm{~cm}\right)$ y $\Delta \mathrm{E}_{\mathrm{c}-\mathrm{a}}=-0,38 \mathrm{~V}$. 
El crecimiento acicular, resulta interesante tanto desde el punto de vista práctico, debido a las propiedades especiales de estos materiales, como desde el punto de vista teórico, pues permite investigar el mecanismo de cristalización asociado con la formación de electrodepósitos metálicos en particular y fases sólidas en general. Es posible estimar el área activa de captura y encontrar así las condiciones en las que el crecimiento es estable, inestable, o marginalmente estable, originando electrodepósitos ramificados (por ejemplo, dendritas).

\subsection{Experimentos galvanostáticos}

Se realizan experimentos a corriente constante (ver parte experimental), empleando la solución II sin soporte y la celda circular A. Se hace circular una corriente constante para obtener electrodepósitos gobernados por crecimiento acicular o ramificado abierto formado por ramas gruesas. Los transitorios galvanostáticos obtenidos para corrientes de $0,07 \mathrm{~mA}$ y $0,02 \mathrm{~mA}$ se muestran en la figura 4.20 .

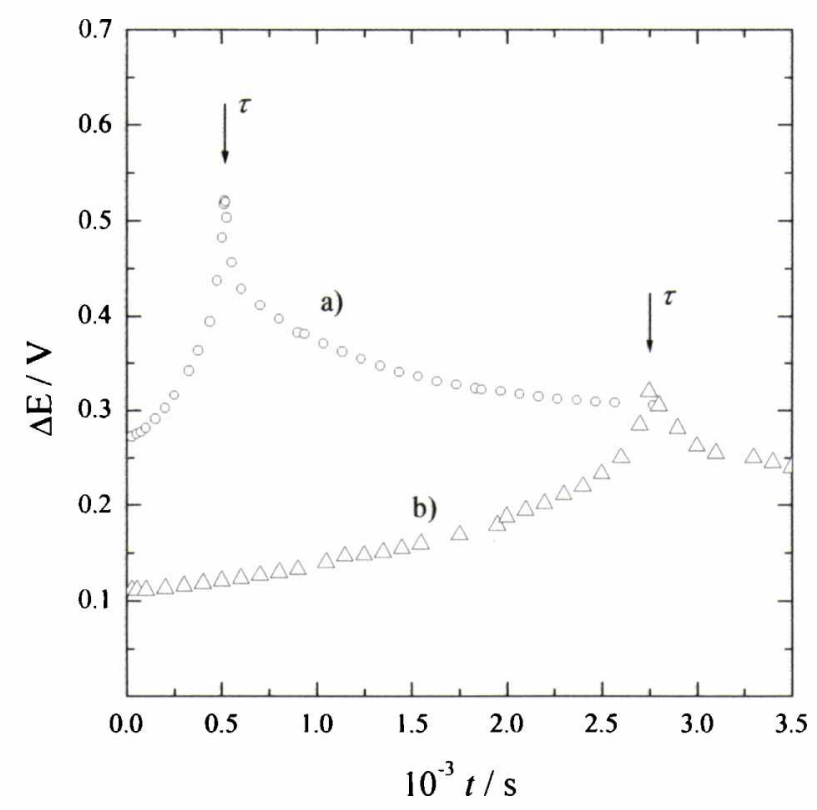

Figura 4.20. Experimentos galvanostáticos realizados empleando la solución II y la celda circular A. a) $I_{\mathrm{c}}=-0,07 \mathrm{~mA}$; b) $I_{\mathrm{c}}=-0,02 \mathrm{~mA}$.

En la figura 4.20 el valor máximo del potencial se logra al "tiempo de transición" $\tau$, en el que la concentración de $\mathrm{Ag}^{+}$en la interfase se hace cero. En esas condiciones vale [1]: 


$$
I_{\mathrm{c}} \tau^{1 / 2}={ }_{c^{0}}^{n \mathrm{FAD} D^{1 / 2} \pi^{1 / 2}}=85,5 n D^{1 / 2} \mathrm{~A}
$$

donde los símbolos tienen el significado usual. El tiempo $\tau$ se expresa en $\mathrm{s}, I_{\mathrm{c}}$ en $\mathrm{mA}$, A en $\mathrm{cm}^{2}, c^{0}$ en $\mathrm{mM}, D$ en $\mathrm{cm}^{2} \mathrm{~s}^{-1}$ y F se toma igual a 96500 Coulomb $\mathrm{mol}^{-1}$.

Los resultados de $I_{\mathfrak{c}} \tau / c^{0}$ obtenidos para la electrodeposición de plata a diferentes $I_{\mathrm{c}}$, empleando la solución II, se indican en la tabla 4.7.

Tabla 4.7. Valores de $\tau, I_{\mathrm{c}} \tau / c^{0}$ para distintos valores de corriente aplicados

\begin{tabular}{|c|c|c|}
\hline$I_{\mathrm{c}} / \mathrm{mA}$ & $\tau / \mathrm{s}$ & $I_{\mathrm{c}} \tau / c^{0} / \mathrm{mA} \mathrm{s}$ \\
\hline 0,007 & 20200 & 0,021 \\
\hline 0,014 & 10312 & 0,029 \\
\hline 0,020 & 2750 & 0,022 \\
\hline 0,070 & 515 & 0,033 \\
\hline
\end{tabular}

Por otro lado, calculando el miembro de la derecha de la ecuación (1) resulta, para $\mathrm{n}=1, D=1,39 \times 10^{-5} \mathrm{~cm}^{2} \mathrm{~s}^{-1}$ y A $=0,081 \mathrm{~cm}^{2}, I_{\mathrm{c}} \tau / c^{0}=0,026 \mathrm{~mA} \mathrm{~s} \mathrm{~s}^{1 / 2} \mathrm{mM}$. El promedio de los valores obtenidos en la tabla 4.7 resulta $0,026 \mathrm{~mA} \mathrm{~s}^{1 / 2} \mathrm{mM}$.

La constancia de la relación $I_{\mathfrak{c}} \tau / c^{0}$ está en acuerdo con un proceso controlado por transporte de materia por difusión. 


\subsection{Crecimientos aciculares}

En esta sección se describe la morfología de los electrodepósitos aciculares y se muestran resultados de la cinética de su crecimiento. Se emplea microscopía electrónica de barrido y el sistema de seguimiento del crecimiento descripto en la parte experimental (Capítulo 3).

Las condiciones más adecuadas para obtener los electrodepósitos aciculares son el empleo de una solución de sulfato de plata $0,024 \mathrm{M}$, sin electrolito soporte y en celdas quasi-bidimensionales de geometría circular.

Este tipo de crecimiento tiene importancia significativa en la industria electrónica debido a las propiedades fisicas y químicas de estos electrodepósitos. La obtención por vía electroquímica es un método sencillo y económico [112-117].

\subsubsection{Descripción macro y microscópica de los electrodepósitos aciculares}

Los electrodepósitos producidos en celdas 2-D son objetos tridimensionales con direcciones preferenciales de crecimiento. Presentan una morfología irregular con características diferentes a distintas escalas espaciales $(\mu \mathrm{m}, \mathrm{mm}, \mathrm{cm})$.

Los crecimientos aciculares, aparecen luego de transcurrido un cierto tiempo de electrólisis y tienden a dominar el crecimiento del electrodepósito (figuras 4.16. y 4.17). Si bien poseen una dirección de crecimiento preferencial, en algunos casos se ven ramas laterales o secundarias, que aparecen sobre las caras laterales, y crecen paralelas entre sí formando un ángulo constante de $60^{\circ}$ con el eje central del crecimiento acicular (figura $4.17 \mathrm{~g}$ ), en consonancia con la cristalografia de la plata metálica.

Muchos de los crecimientos aciculares obtenidos en este trabajo, muestran una actividad lateral constante, es decir formación de protuberancias, de pequeñas ramas y cristales cuyo tamaño puede medirse de las imágenes tomadas con aumentos mayores a $64 x$. La distribución de tamaños de las protuberancias y cristales que aparecen a una distancia de $\approx 100 \mu \mathrm{m}$ medida desde el ápice de la punta hacia la base del crecimiento acicular, se presenta en diagramas de barras (figura 4.21). La distribución de tamaños alcanza un máximo cuando el tamaño es de $\approx 60 \mu \mathrm{m}$. 


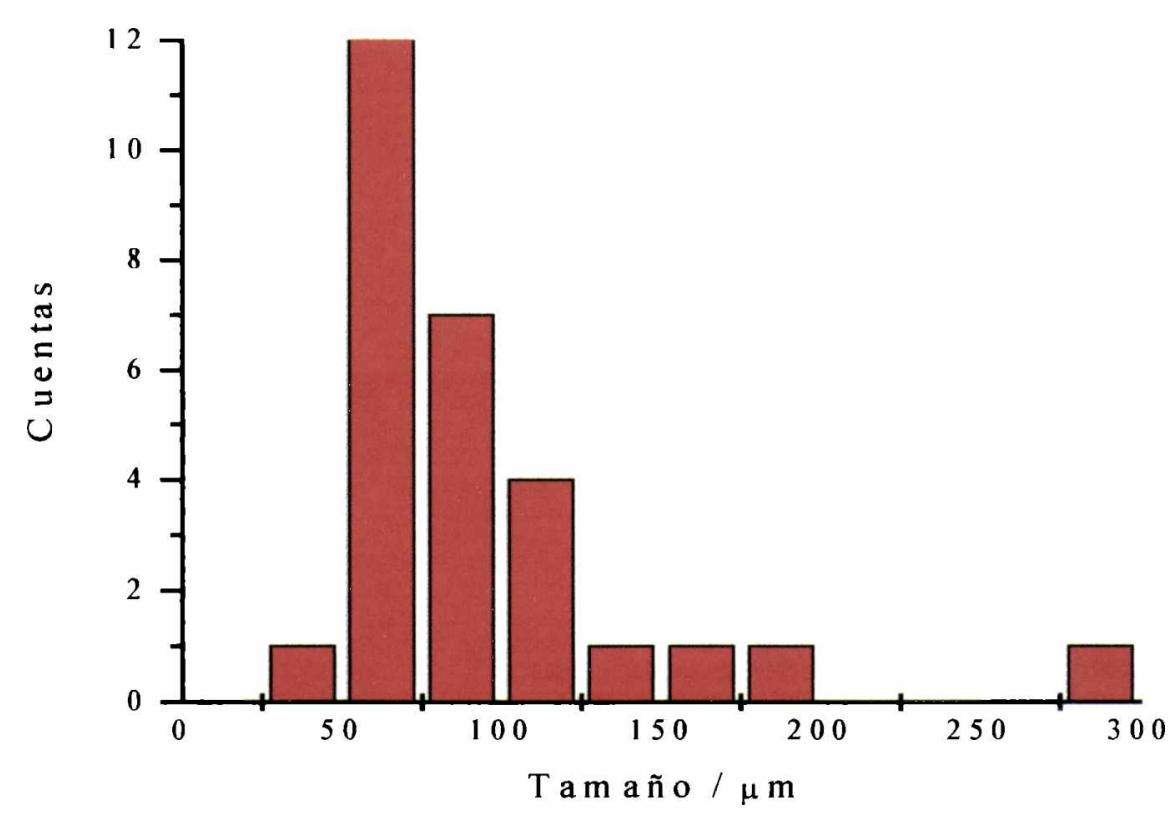

Figura 4.21. Distribución de tamaños de cristales en los sitios laterales del filamento mostrado en la figura $4.17 b$.

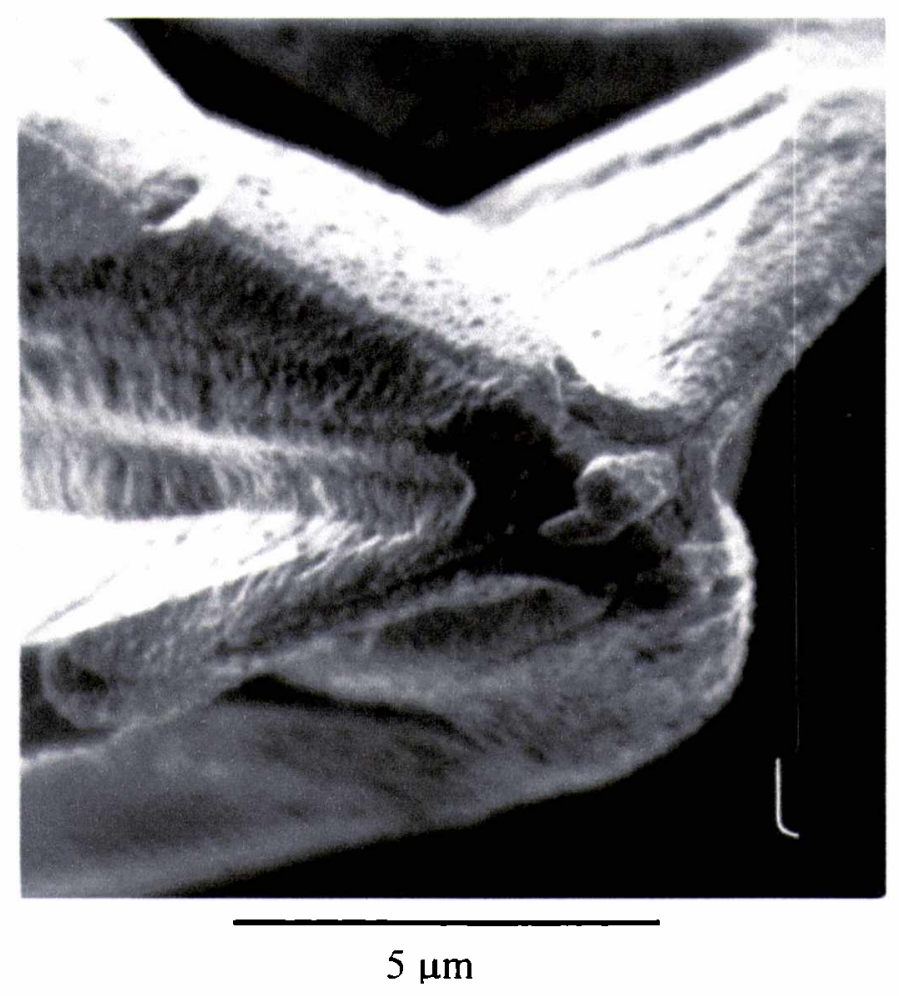

Figura 4.22. Imagen SEM. Vista transversal de la punta de una aguja. Se puede ver la forma de estrella. 
En la figura 4.22 se muestra una micrografía SEM de la punta de un whisker obtenido electroquímicamente. La sección transversal presenta forma de estrella y la punta es aproximadamente parabólica.

Los filamentos o agujas que se obtuvieron en este trabajo muestran una estructura similar a la informada por otros autores [118].

En la escala del $\mu \mathrm{m}$ es posible distinguir una forma parabólica en las puntas de las agujas. Según las imágenes SEM (figura 4.23 a y figura 4.23 b), el paraboloide se extiende a lo largo de unos $50 \mu \mathrm{m}$ y el ápice tiene un radio de aproximadamente 2-10 $\mu \mathrm{m}$. Debido a estas dimensiones, la tensión superficial debe jugar un papel importante en la formación electroquímica de los crecimientos aciculares.
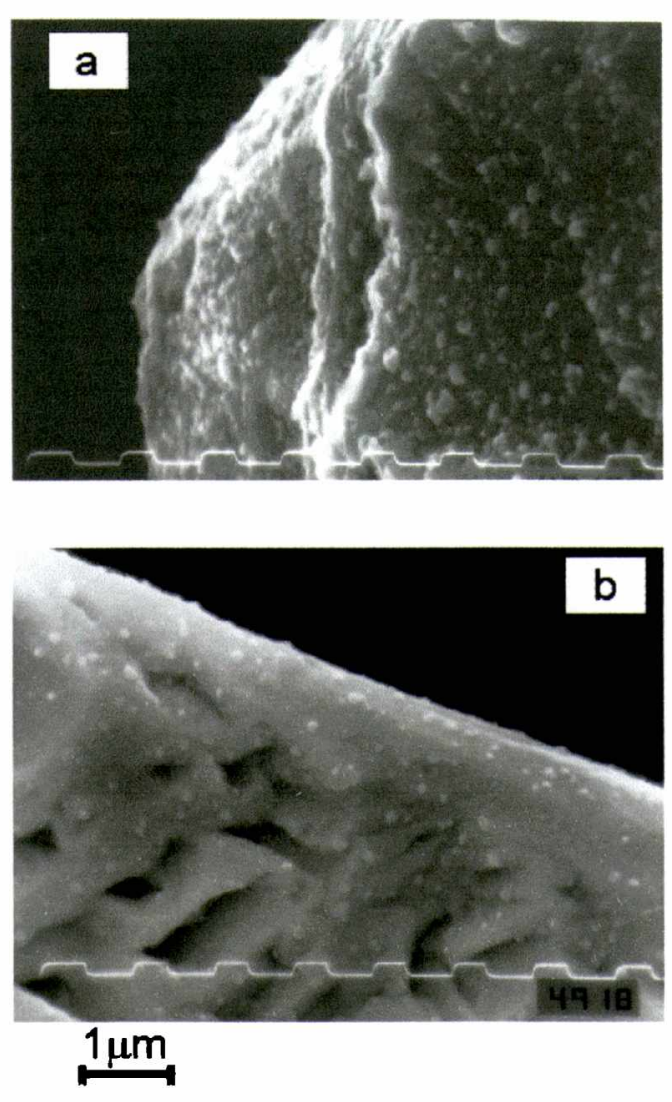

Figura 4.23. Imagen SEM de la punta de un Whisker. a ápice del filamento. b cara lateral del filamento.

La topografia de la punta consiste de terrazas escalonadas y cavidades con superficie del orden de $0,11 \pm 0,01 \mu \mathrm{m}^{2}$. Las terrazas y escalones están cubiertos por pequeños cristales de altura promedio $0,020 \pm 0,005 \mu \mathrm{m}$. La mayoría de estos cristales 
muestran una geometría piramidal según se ve en el perfil de la figura 4.23a. Los cristales en el ápice del paraboloide tienden a crecer en la dirección axial y no muestran procesos de formación de maclas ("twinning") ni bifurcación. La constancia de tamaño de estos cristales y su ubicación aleatoria, sugiere que aparecen y desaparecen continuamente en el proceso de avance del filamento hacia la solución. El tiempo de vida medio de estos cristales, calculado con una velocidad de avance de $1 \times 10^{-4} \mathrm{~cm} \mathrm{~s}^{-1}$, resulta ser de $0,01 \mathrm{~s}$. La distancia promedio instantánea entre cristales en el ápice del paraboloide es cercana a 0,4 $\mu \mathrm{m}$, magnitud bastante mayor que el tamaño de estos cristales. Una descripción similar es aplicable a la superficie lateral del paraboloide, pero con una densidad numérica de cristales mucho menor que en el ápice, y por lo tanto, una separación mayor entre cristales piramidales.

\subsubsection{Dinámica de crecimiento de los electrodepósitos aciculares}

En las figuras 4.24 y 4.25 se representan las longitudes axiales $L_{\mathrm{f}}$ (la dirección de máximo crecimiento para electrodepósitos aciculares) versus $t$ y las longitudes transversales (espesor o diámetro de la aguja) $L_{\mathrm{W}}$ versus $t$, respectivamente, obtenidos en celdas con distinta geometría. Las medidas de $L_{\mathrm{f}}$ y $L_{\mathrm{w}}$ se realizan en secuencias de imágenes como las mostradas en las figuras 4.26, 4.27 y 4.28. De la dependencia de $L_{\mathrm{f}} \mathrm{y}$ $L_{\mathrm{W}}$ con el tiempo, se determinan las respectivas velocidades locales $V_{\mathrm{f}}=d L_{\mathrm{f}} / d t$ y $V_{\mathrm{W}}=$ $d L_{\mathrm{W}} / d t$ (recta tangente a la curva).

Las diferencias entre las velocidades son apreciables. Se encuentran velocidades en la dirección de máximo crecimiento en el intervalo $0.03<v_{\mathrm{f}}<2 \mu \mathrm{m} \mathrm{s}^{-1}$ en tanto que para la velocidad de crecimiento transversal, $0.001<v_{\mathrm{W}}<0.028 \mu \mathrm{m} \mathrm{s}^{-1}$.

En la figura 4.25 se muestra además $(\nabla)$, como evoluciona $L_{\mathrm{W}}$ medido a una distancia de $0,02 \mathrm{~cm}$ de la punta o ápice del crecimiento acicular. Se ve que dentro del error de las medida, para $9 \times 10^{3}<t<11 \times 10^{3} \mathrm{~s}, v_{\mathrm{W}}$ permanece constante mientras la punta crece manteniendo su forma. Cuando, la velocidad de la punta disminuye, con el consecuente engrosamiento del ápice, $L_{\mathrm{W}}$ comienza a crecer en forma abrupta. La zona más activa, deja de ser el ápice de la punta y comienza a jugar un papel importante la electrodeposición en los sitios laterales de las agujas. Entonces mientras la aguja crece en condiciones quasi-estacionarias ("estables") consume gran parte de la corriente a través de una rápida electrodeposición de plata en el ápice del filamento y solo cuando la punta se desestabiliza, el crecimiento en los sitios laterales comienza a ser significativo. 


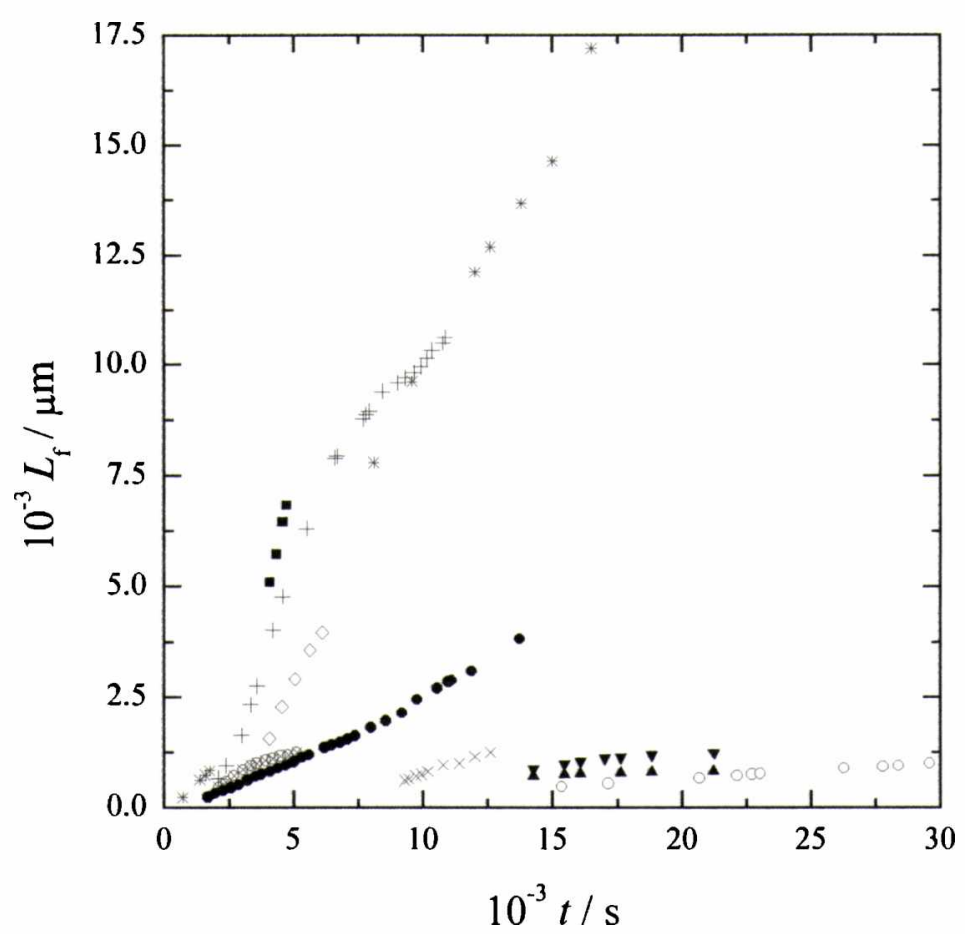

Figura 4.24. Longitudes axiales para los crecimientos aciculares obtenidos en distintas

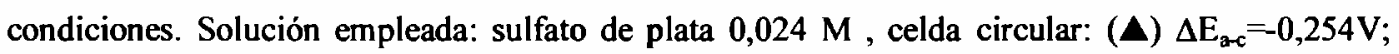

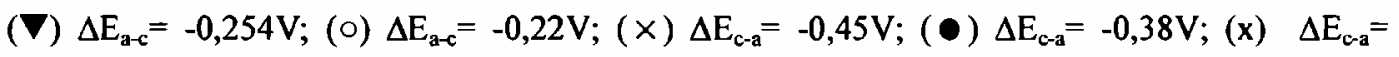
$-0,38 \mathrm{~V} ;(0) \Delta \mathrm{E}_{\mathrm{c}-\mathrm{a}}=-0,39 \mathrm{~V} ;(+) \Delta \mathrm{E}_{\mathrm{c}-\mathrm{a}}=-0,30 \mathrm{~V} ;\left(^{*}\right) \Delta \mathrm{E}_{\mathrm{c}-\mathrm{a}}=-0,275 \mathrm{~V}$. Celda rectangular $\mathrm{BI}$ $\left(l_{\mathrm{a}-\mathrm{c}}=7 \mathrm{~cm}\right)(\boldsymbol{\nabla}) \Delta \mathrm{E}_{\mathrm{c}-\mathrm{a}}=-1,0 \mathrm{~V}$, Temperatura ambiente.

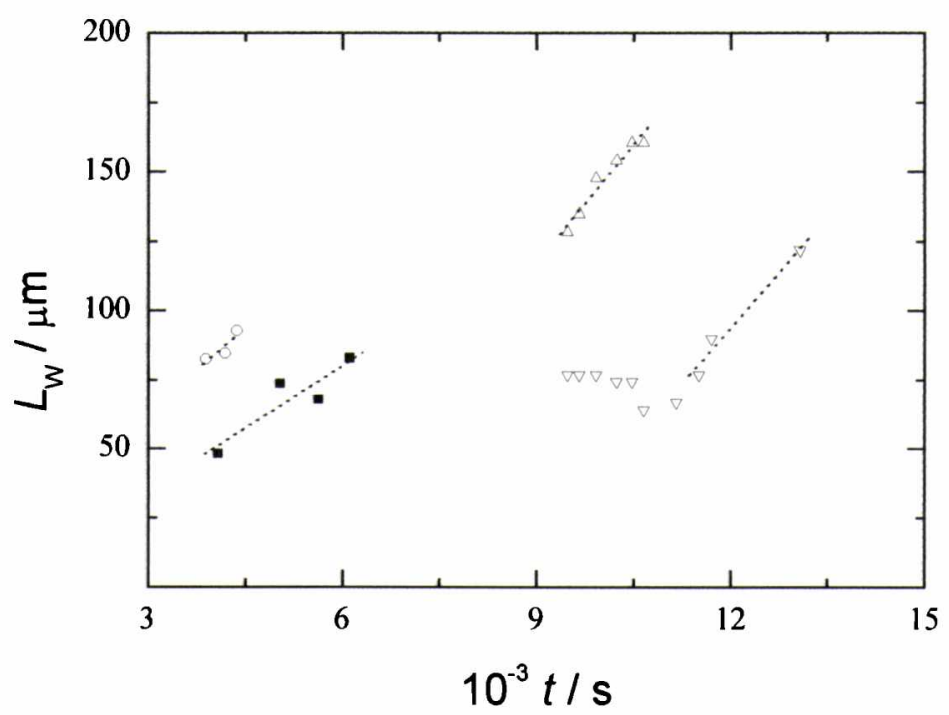

Figura 4.25. $L_{\mathrm{W}}$ en función del tiempo para varios filamentos. $(\nabla)$ Medida de $L_{\mathrm{W}}$ a $0,02 \mathrm{~cm}$ de la punta. 
a)

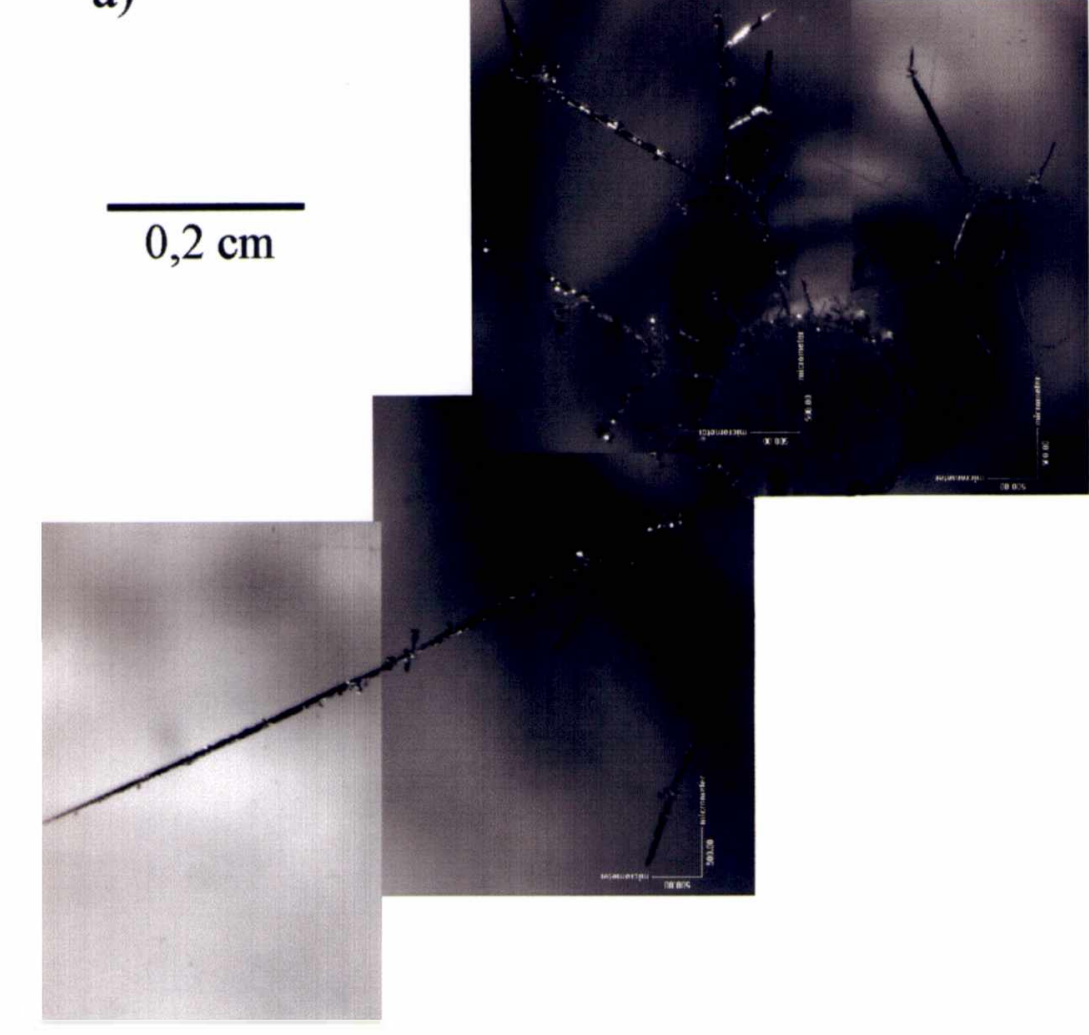

b)
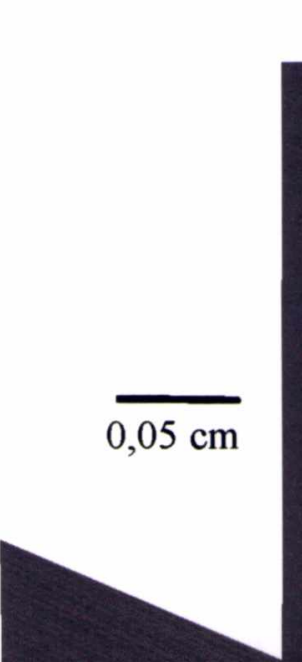

Figura 4.26. a)Electrodepósito ramificado complejo de donde nace el whisker y pasa a dominar el electrodepósito.

b) Secuencia de imágenes del crecimiento del filamento.

Condiciones: Solución II : $\Delta \mathrm{E}=-0,275 \mathrm{~V}$. 


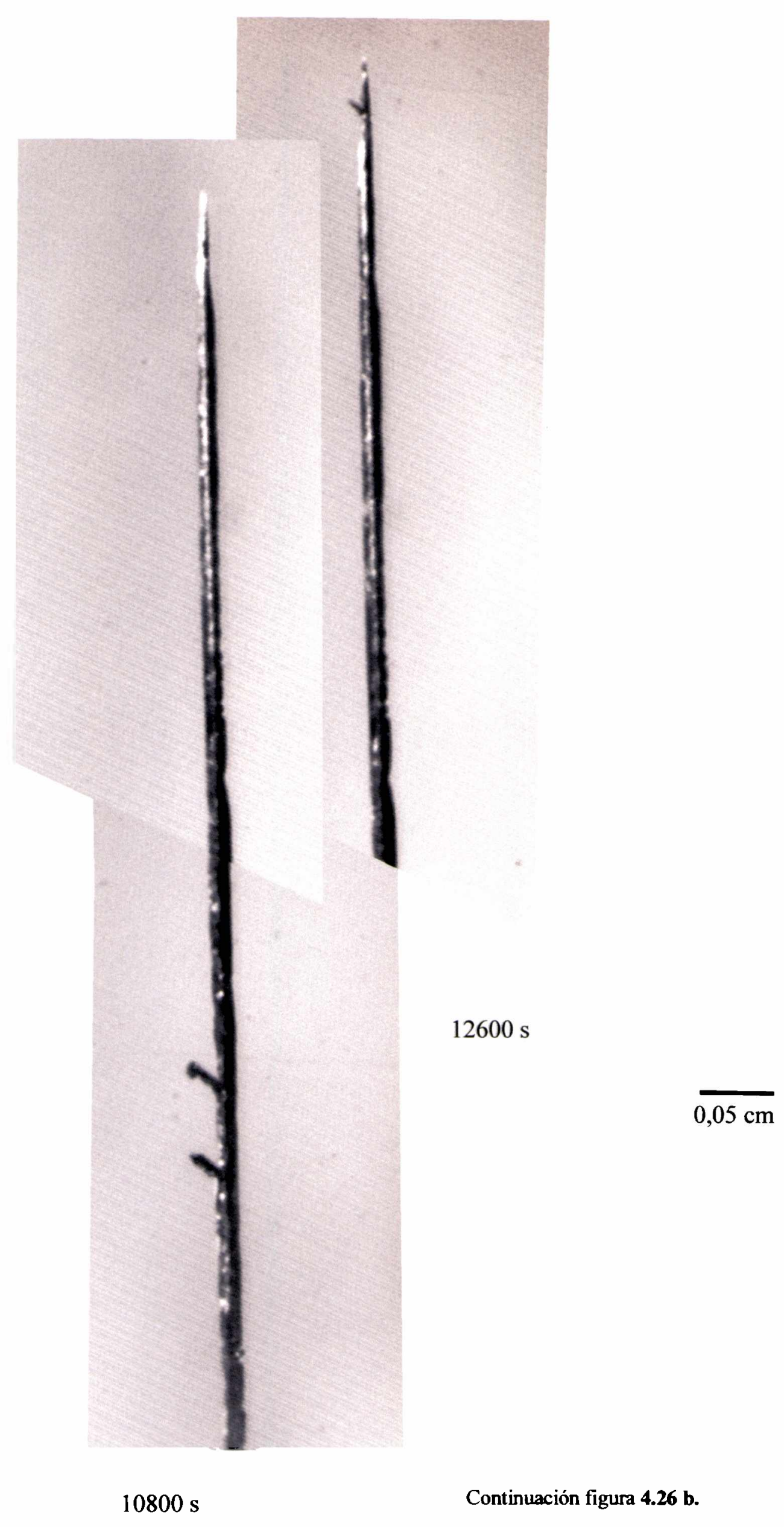




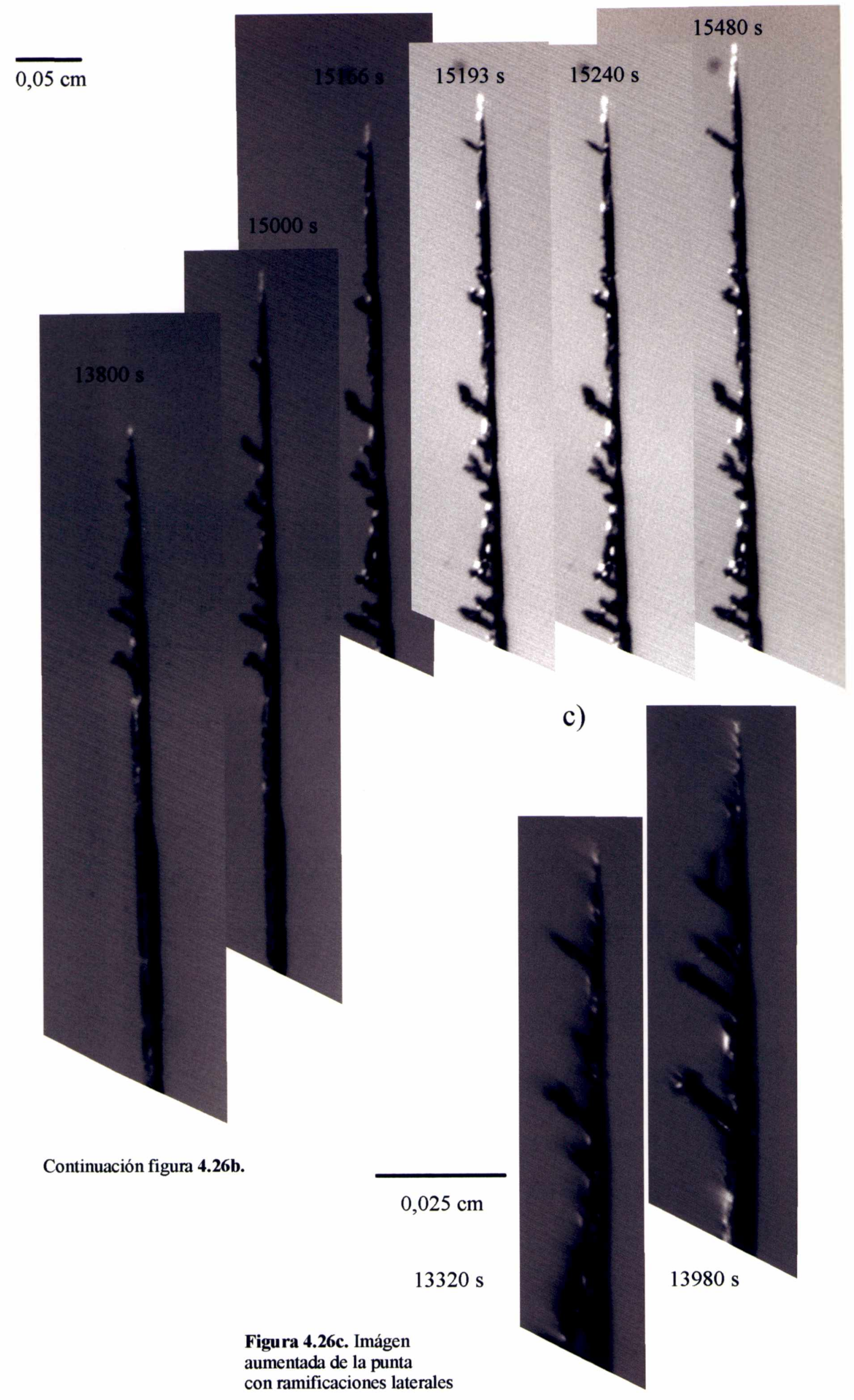




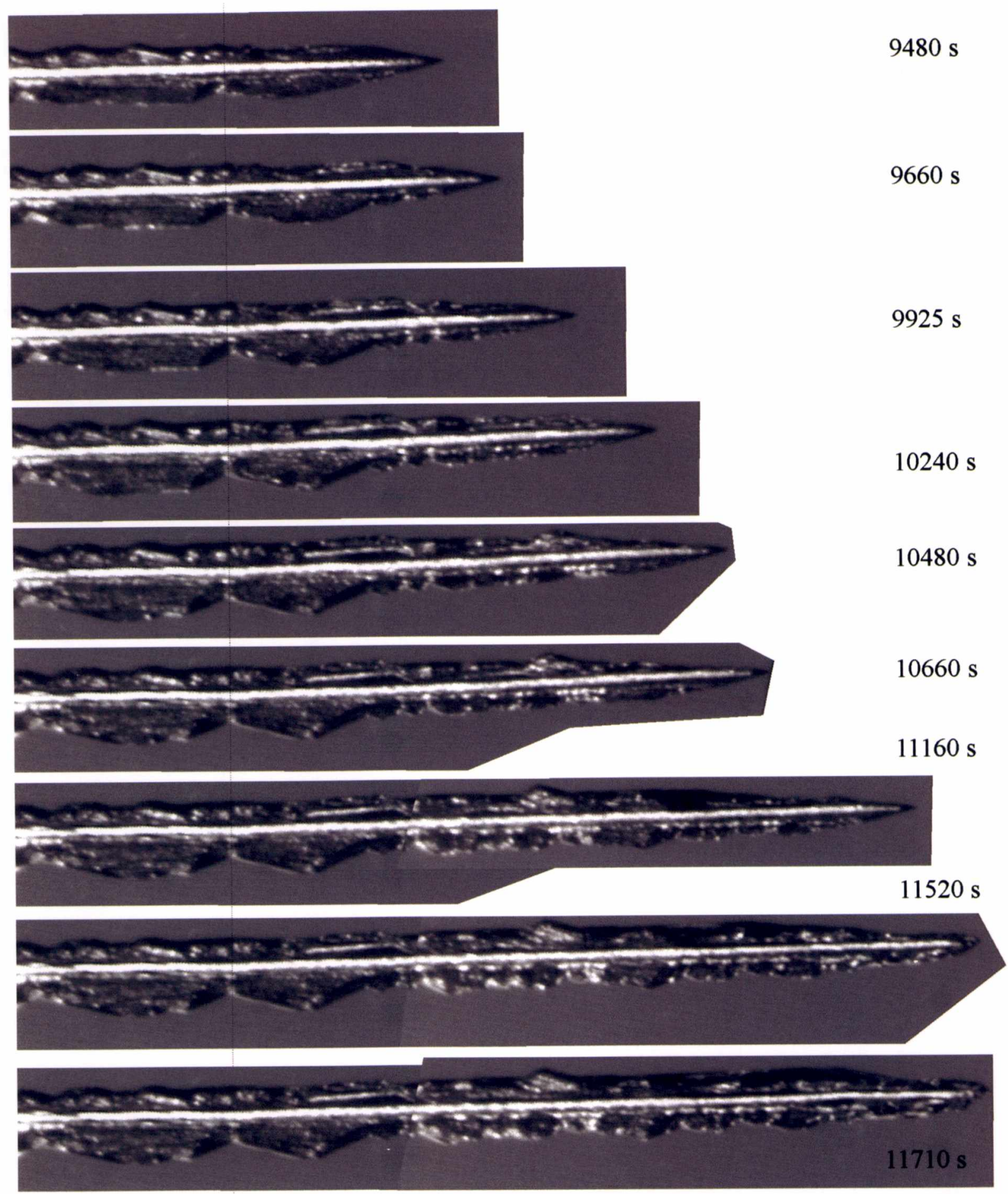

$0.050 \mathrm{~cm}$

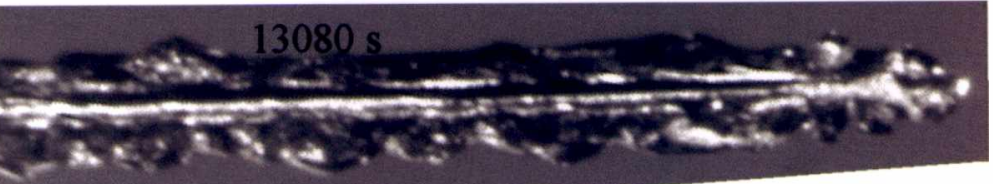

Figu ra 4.27. Secuencia de

imágenes del crecimiento

de un filamento.

Condiciones: Solución de

Solución II;

$\Delta \mathrm{E}=-0,30 \mathrm{~V}$

Temperatura ambiente.

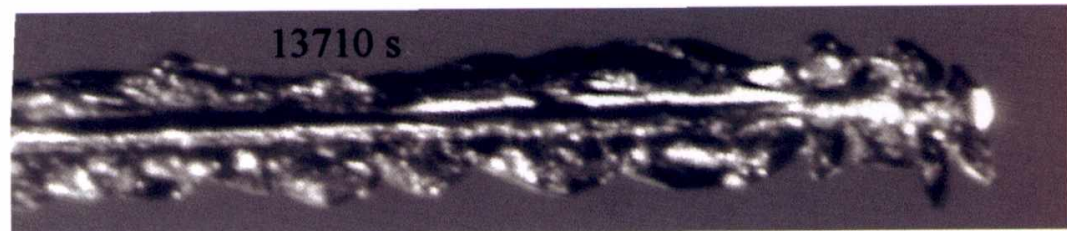




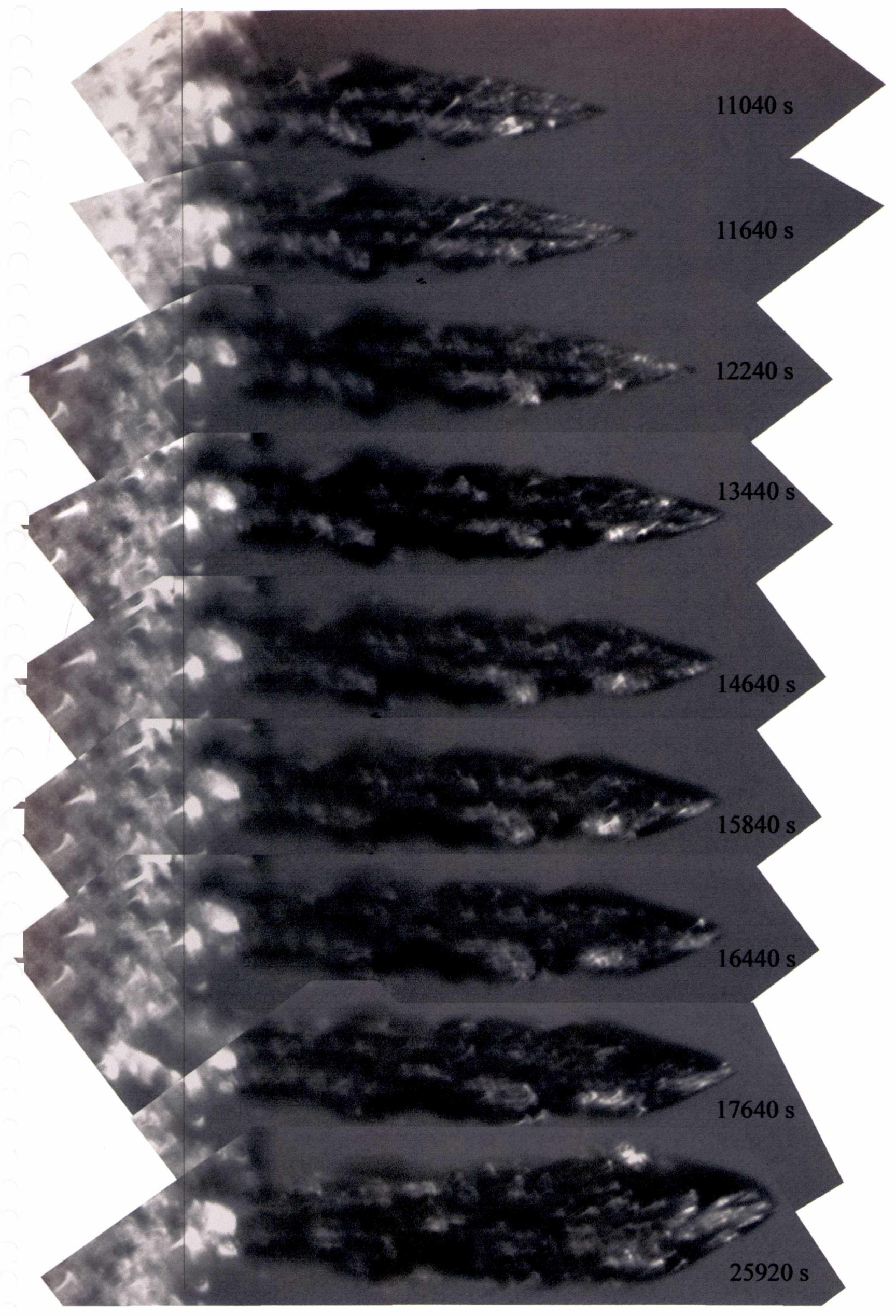

$\overline{0,01 \mathrm{~cm}}$

Figura 4.28. Secuencia de crecimiento de un filamento.

Condiciones : Solución II; $\Delta \mathrm{E}=-0.254 \mathrm{~V}$.Temperatura ambiente 


\subsection{Análisis e interpretación de resultados}

\subsubsection{Electrodeposición en celdas electroquímicas quasi-bidimensionales}

Los electrodepósitos de plata muestran una morfología irregular con características propias, tanto en la escala del mm-cm como en la del $\mu \mathrm{m}$.

La electrodeposición de plata sobre un electrodo de platino o de plata comienza con la nucleación y crecimiento de cristales de plata (no analizado en este trabajo) (figuras 4.3 y 4.9 de la sección 4.2). Cuando pasa a través de la celda una densidad de carga de aproximadamente $0,1 \mathrm{C} \mathrm{cm}^{-2}$, se observa la formación de ramas incipientes sobre la película inicial compacta de plata (figuras 4.29). Luego, dependiendo del $\Delta \mathrm{E}_{\mathrm{c}-\mathrm{a}}$, la concentración de la especie electroactiva $c_{\mathrm{i}}{ }^{0}$, la concentración y el tipo de electrolito soporte, se llega a producir un electrodepósito abierto ("tip splitting" o dendrítico), acicular, o denso.

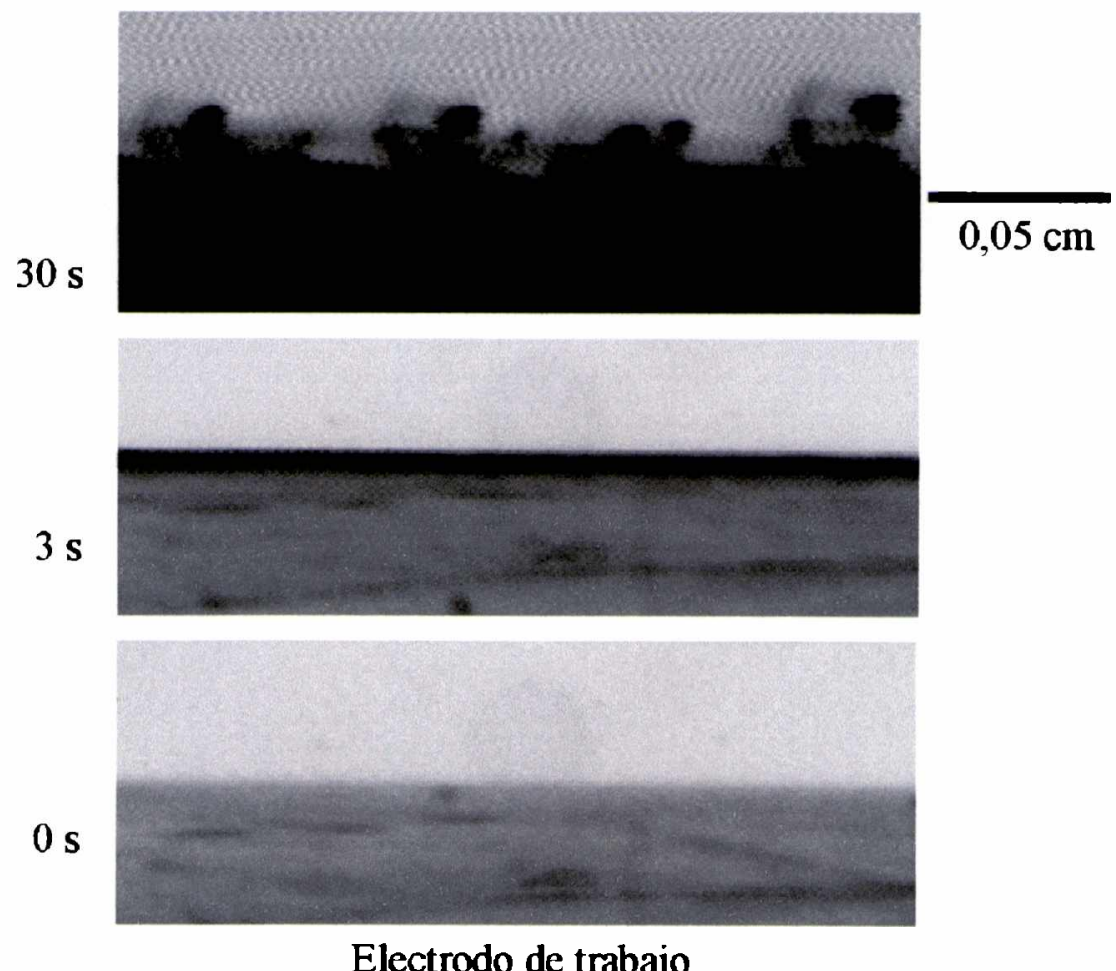

Figura 4.29. Imágenes de la formación de la capa compacta sobre la cual se forman las protuberancias que originan los “árboles” del electrodepósito.

En las experiencias realizadas a potenciales relativamente bajos, para cualquier $c_{0} \mathrm{y}$ en cualquier celda, a tiempos cortos se observan electrodepósitos compactos, mientras que 
a tiempos mayores y a desplazamientos mayores del frente de crecimiento, se producen inestabilidades que generan un electrodepósito ramificado.

En las secciones anteriores se mostraron ejemplos de las morfologías que se obtienen en las distintas condiciones de trabajo.

Las diferentes morfologías están en consonancia con el diagrama de fases propuesto por Sawada et. al., para experimentos realizados empleando celdas quasibidimensionales de geometría axial (figura 4.30a) y el diagrama de fases propuesto por Sagués et. al., para celdas de geometría rectangular (figura 4.30b). Estos diagramas fueron construidos en base a la electrodeposición de cinc, por tanto deben aplicarse con reserva para la clasificación de las distintas estructuras de los otros electrodepósitos metálicos. Sin embargo, aparecen aspectos comunes para los distintos sistemas electroquímicos y otros sistemas en los que se forman nuevas fases, por ejemplo en experimentos realizados con la celda de Hele-Shaw [20].

En la clasificación morfológica realizada en los dos diagramas de fases mostrados en la figura 4.30, se denomina depósito homogéneo, al que presenta un frente bien definido y paralelo al cátodo. El depósito homogéneo está formado por árboles que presentan crecimiento direccional, habiendo un predominio de bifurcación de las puntas. Dentro de esta clasificación se incluyen, los electrodepósitos densos y la morfología "tip-splitting". El depósito abierto está formado por ramas que crecen como "abanico". En tanto, se entiende por depósito mixto, al que está formado por ramas que tienen un "tronco" (bástago) principal del cual salen ramas laterales de longitud mucho menor a la del "tronco" principal y con bifurcación de las puntas. Las ramas no poseen una punta estable como en el crecimiento dendrítico descripto en el Capítulo 2.

Los electrodepósitos aciculares, están en la región superior derecha del diagrama de Sawada. Sin embargo, debido a su cinética de crecimiento, las agujas están muy emparentadas con las dendritas, pues ambos poseen una punta de forma quasi - paraboloide que se mantiene constante durante el crecimiento. 

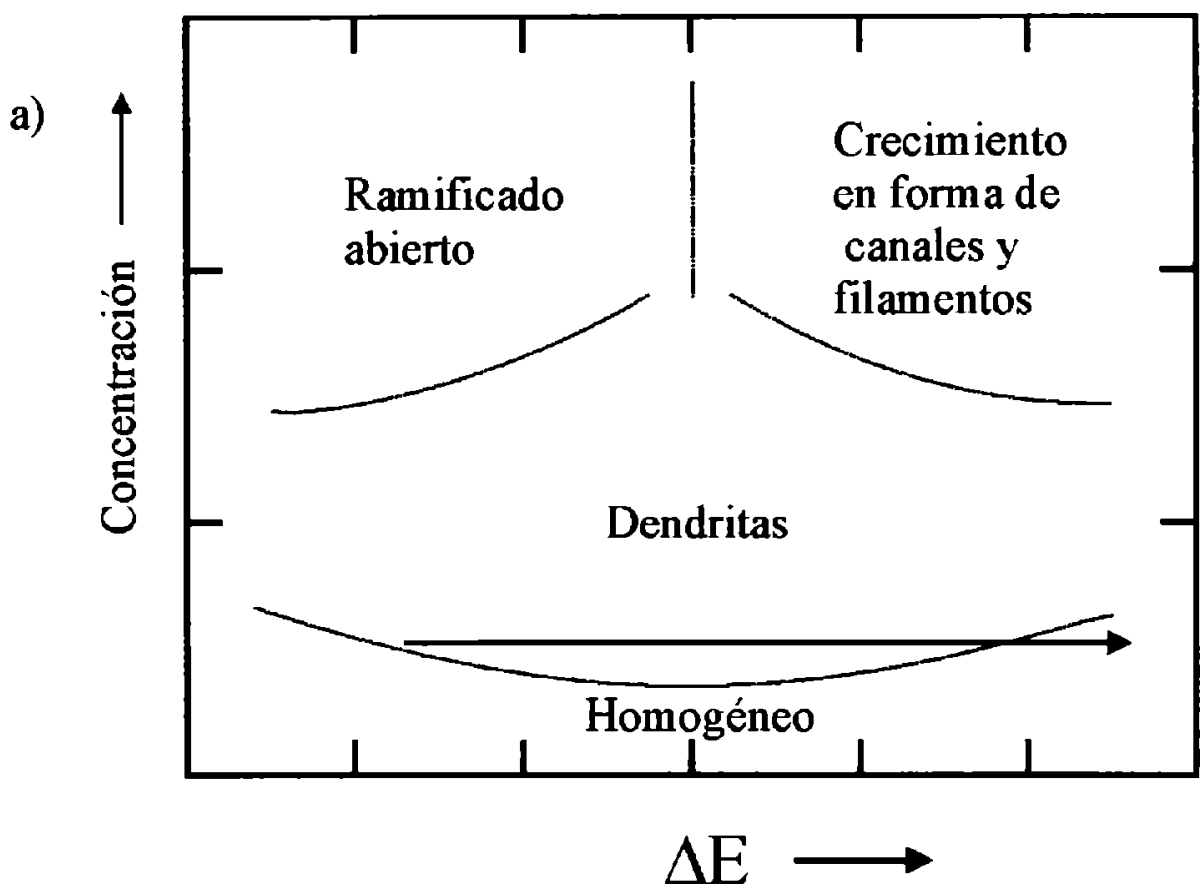

b)

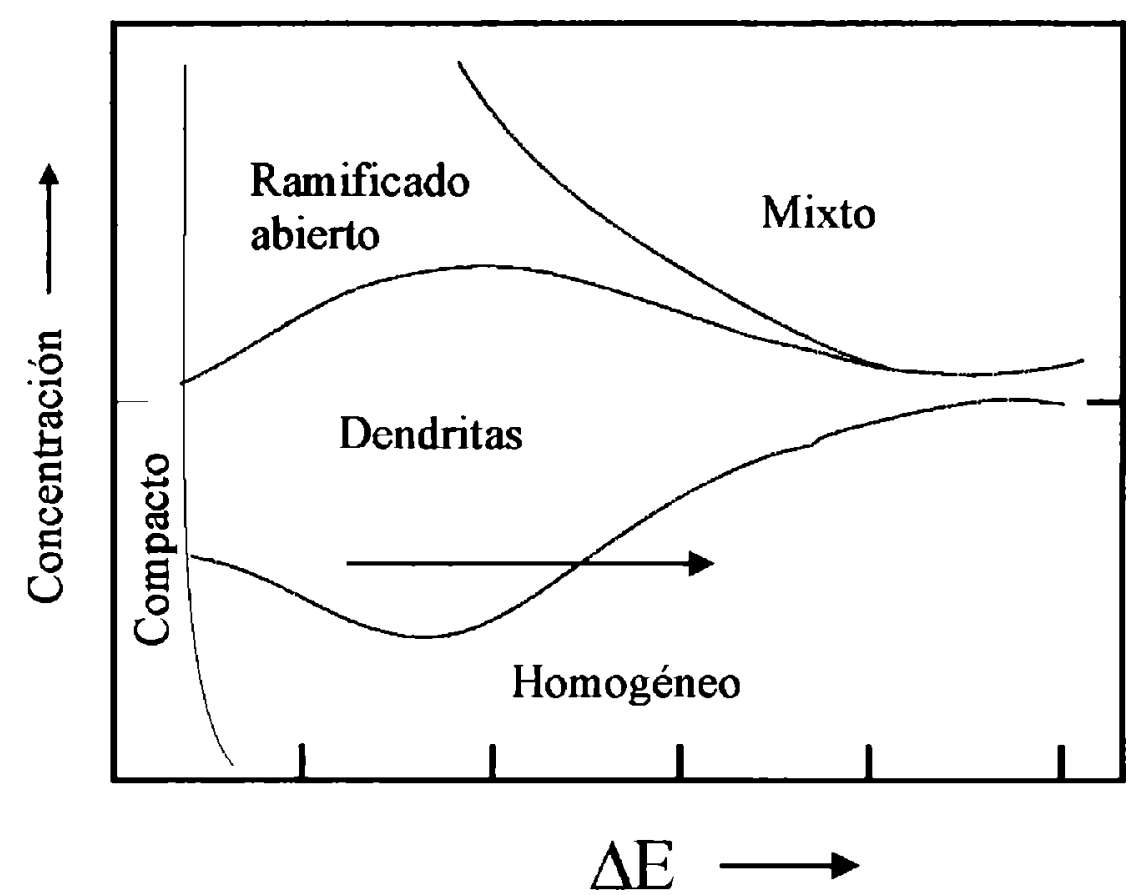

Figura 4.30. Diagramas morfológicos. a) Para celdas circulares según Sawada et. al. [24] y b) para celdas rectangulares según Sagués et. al. [23].

De los datos de la tabla 4.1, se concluye que para la celda circular y solución $I$, al aumentar catódicamente el potencial aplicado entre electrodos, se pasa de un electrodepósito homogéneo gobernado por la morfología "tip splitting" a un crecimiento dendritico, y finalmente, a una estructura densa [24]. Esto se muestra con una flecha en el diagrama correspondiente de la figura 4.30 a. 
De igual manera para la celda restangular BIII empleando solución II + ácido sulfúrico $0,5 \mathrm{M}$ (tabla 4.3), al aumentar catódicamente el potencial aplicado se pasa de una morfología dendrítica a una densa (homogénea), como lo representa el diagrama de Sagués, (fecha en la figura $4.30 \mathrm{~b}$ ).

\subsubsection{Celda circular y celda rectangular}

En la celda circular, el electrodepósito crece desde un electrodo quasi puntual concéntrico con un ánodo circular. El espacio disponible para el crecimiento radial aumenta con el radio del electrodepósito. Este comportamiento está en acuerdo con la forma de los transitorios presentados en 4.1 .

En las celdas rectangulares, con electrodos quasi lineales enfrentados, la corriente a partir de un cierto tiempo fluctúa en torno a un valor promedio constante. Esto se observa tanto para un frente de crecimiento bien definido y robusto o ramificado abierto. Generalmente, las ramas laterales crecen más lentamente en las celdas rectangulares que en las circulares, debido a que, la densidad de corriente es mucho mayor en las ramas que se encuentran en el frente que en las del interior del electrodepósito.

\subsubsection{Influencia de la migración, convección y difusión en la producción de} electrodepósitos ramificados y crecimientos aciculares

Siendo la transferencia de materia el proceso limitante, la difusión, la migración y la convección contribuyen entonces al transporte de los iones electroactivos. La difusión y la migración actúan conjuntamente en el interior de la película límite difusional que se establece alrededor del electrodepósito. La ecuación de flujo de una especie i, se mostró en el capítulo 2 (ecuación 2.18).

En ausencia de electrolito soporte, para una única especie que interviene en la reacción, se produce un elevado campo eléctrico en la película límite, entonces, la contribución de la migración, puede producir un aumento o una disminución en la corriente límite difusional [6]. El campo eléctrico se disminuye incorporando a la solución un electrolito soporte, que es electroquímicamente inactivo, y que lleva a cabo el proceso de conducción eléctrica. En estas condiciones la migración del ión reactivo puede llegar a ser despreciable frente a la difusión. 
Desafortunadamente la solución de la ecuación de flujo mostrada en el Capítulo 2, solo puede resolverse para geometrías simples [111]. Para geometrías complicadas como las que aparecen en la electrodeposición de plata, la contribución de los distintos mecanismos de transporte pueden estimarse por medio de un análisis adimensional [78]. Así, el número de Wagner $W_{\mathrm{t}}$ expresa el cociente entre la resistencia a la transferencia de carga $\left(\partial \eta_{t} / \partial j\right)$ y la resistencia eléctrica de la solución $\left(\partial \Delta \varphi_{\mathrm{ohm}} / \partial j\right)$,

$$
W_{\mathrm{t}}=\begin{gathered}
\partial \eta_{\mathrm{t}} \\
\partial j \\
\partial \Delta \varphi_{\mathrm{ohm}} \\
\partial j
\end{gathered}
$$

y es de esperar que sea poco significativo, debido a la rapidez del proceso de transferencia de carga para la electrodeposición de plata sobre plata policristalina [16,17]. Existe otro número adimensional, similar al número de Wagner, que fue definido por Prentice y Tobias :

$$
W_{\mathrm{C}}=\begin{gathered}
\partial \eta_{\mathrm{c}} \\
\begin{array}{c}
\partial \Delta \varphi_{\mathrm{ohm}} \\
\partial j
\end{array}
\end{gathered}=\operatorname{\mathrm {nF}Tj_{\mathrm {L}}(1-\begin{array} {c}
{j}\\
{j_{\mathrm {L}}}
\end{array} )}
$$

donde $\eta_{\mathrm{c}}$ es el sobrepotencial de concentración, $\Delta \varphi_{\text {ohm }}$ es el sobrepotencial óhmico, $\kappa$ la conductividad de la solución, $j_{\mathrm{L}}$ la densidad de corriente límite, $L$ una longitud característica y $\mathrm{nF}$ y $\mathrm{R}$ tienen los significados usuales. Valores grandes de $W_{\mathrm{C}}$ indican que el mecanismo gobernante es el transporte de materia, en consonancia con el número de Wagner pequeño.

Los experimentos en que resultan electrodepósitos ramificados (densos o dendríticos), se trabaja a corrientes cercanas a la corriente límite, tanto en ausencia de electrolito soporte como en presencia de soporte. Por tanto el valor de $W_{\mathrm{C}}$ resulta grande. Para los crecimientos aciculares (tabla 4.8), tomando como longitud característica el diámetro del ápice de la punta del crecimiento acicular, que es del orden del micrón, resulta un valor de $W_{\mathrm{C}}$ considerable, como se espera para un proceso controlado por transferencia de materia.

Es interesante analizar cuales son los mecanismos de transferencia de materia que se pueden tener en cuenta en la electroformación de plata en una celda quasi- 
bidimensional. Por ello se analiza que pasa con los números adimensionales que dependen del mecanismo preponderante.

Así, el número de Péclet $(P e)$ determina la contribución de la convección forzada en el sistema:

$$
P e=R e S c=\frac{\delta_{\mathrm{h}}}{\delta_{\mathrm{d}}}=L V / 2 D
$$

$\delta_{\mathrm{h}}$ y $\delta_{\mathrm{d}}$ son los espesores de la película hidrodinámica y de transferencia de materia, respectivamente, Re es el número de Reynolds, $L$ es una distancia característica y $v$ la velocidad de desplazamiento del frente de crecimiento.

El número de Rayleigh $(R a)$ indica la contribución de la convección natural y se define como el producto del número de Grashof $(G r)$ y del número de Schmidt $(S c)$,

$$
R a=G r S c=\begin{gathered}
g \alpha L^{3} \\
v D
\end{gathered}
$$

$g$ es la constante gravitatoria, $v$ la viscosidad cinemática de la solución y $\alpha$ el coeficiente de densificación definido como:

$$
\alpha=\begin{array}{ll}
c_{0} \partial \rho \\
\rho_{0} \partial c
\end{array}
$$

donde $\rho_{0}$ y $c_{0}$ son la densidad especifica y la concentración de reactivos en el seno de la solución respectivamente, en tanto que $\rho$ y $c$ son la densidad promedio y la concentración promedio de la solución en la película de difusión, respectivamente.

Los números de $P e$ y $R a$ para diferentes morfologías se pueden calcular con las ecuaciones (4.4) y (4.5) y conjuntamente con las magnitudes necesarias para calcularlos se muestran en la tabla 4.8 . 
Tabla 4.8. Valores de $L$, velocidad de avance del frente $<\vee, P e$ y $R a$ para electrodepósitos aciculares y ramificados abiertos.

\begin{tabular}{|c|c|c|c|c|}
\hline Morfologia & $L / \mathrm{cm}$ & $<\checkmark / \mathrm{cm} \mathrm{s}^{-1}$ & $P e$ & $R a$ \\
\hline Crecimiento acicular & 0,0004 & $2 \times 10^{-4}$ & $3 \times 10^{-3}$ & $2 \times 10^{-5}$ \\
\hline Crecimiento acicular & 0,0010 & $1 \times 10^{-4}$ & $4 \times 10^{-3}$ & $3 \times 10^{-4}$ \\
\hline Crecimiento acicular & $1 \times 10^{-8}$ & $2 \times 10^{-4}$ & $7 \times 10^{-8}$ & $2 \times 10^{-4}$ \\
\hline Ramificado & 0,025 & $8 \times 10^{-4}$ & 0,8 & 5,6 \\
\hline Ramificado & 0,025 & $27 \times 10^{-4}$ & 2,8 & 5,6 \\
\hline Ramificado & 0,005 & $1 \times 10^{-4}$ & $2 \times 10^{-2}$ & 1,1 \\
\hline
\end{tabular}

Para los crecimientos aciculares, la distancia característica se toma como el radio de la punta, $r_{\mathrm{t}}$, que fue determinado, a partir de micrografias SEM, y/o utilizando imágenes digitalizadas provenientes del sistema de adquisición. Los valores pequeños de $R a$ para el crecimiento acicular, indican que la convección natural no es un mecanismo determinante, y mucho menos la convección forzada.

Para los electrodepósitos ramificados se tomó como distancia característica, la altura de la celda $l_{\mathrm{s}}$. Los valores de $R a$ indican que la convección natural puede tener un cierto papel en la electrodeposición en celdas quasi - bidimensionales.

Los valores de $P e$ indican que tanto para los electrodepósitos aciculares como para los ramificados, la convección forzada en las celdas quasi-bidimensionales es de poca importancia.

Del análisis de la tabla se infiere que la transferencia de materia a la punta de la aguja se realiza por mecanismos de difusión y migración. Conjuntamente ambos mecanismos tienen como fuerza impulsora el gradiente de potencial electroquímico:

$$
\frac{\partial \bar{\mu}}{\partial y}=\frac{\partial \mu}{\partial y}+z_{i} \mathrm{~F} \frac{\partial \phi}{\partial y}
$$

donde $\mu$ es el potencial quimico, $(y)$ indica la dirección perpendicular a la superficie del electrodo y $\phi$ es el campo eléctrico. Cuando un proceso está controlado por transferencia de materia, el sobrepotencial que domina es el sobrepotencial de concentración [119] en el que intervienen en forma inseparable la difusión y la migración. En presencia de un electrolito soporte, basta considerar únicamente el proceso de difusión. Cuando se tiene en 
cuenta la migración, las ecuaciones resultantes difieren de las correspondientes a la

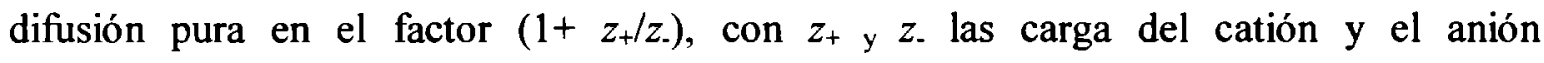
respectivamente como se vió en el capítulo 2 .

En la literatura reciente, se incorpora como contribución al mecanismo de transporte de materia el fenómeno de "advection", que tiene en cuenta el movimiento de la interface hacia el seno de la solución.

Es posible demostrar que la expresión matemática para el proceso de "advection", se puede obtener como caso límite de la resolución de la ecuación de Fick, con la condición de contorno de una interfase que se mueve a velocidad constante [120] (ver apéndice C). La densidad de corriente producida por el proceso de advection es proporcional a la velocidad de avance del frente y se escribe, $j^{\text {ad }}=\mathrm{F} \vee \delta / \mathrm{M}$ ( $\delta$ la densidad del metal, $\mathrm{M}$ el peso molecular del metal y $v$ la velocidad del avance del frente). 
4.4.3 Estudio de los transitorios de corriente en la electrodeposición de plata en celdas cuasi-bidimensionales controlada por transporte de materia

En esta sección se presentan resultados obtenidos a partir de transitorios potenciostáticos de corriente y se inferirá acerca de los fenómenos de transferencias de materia involucrados y la evolución del área activa del electrodo.

Como la reacción de electrodeposición de plata, es una reacción reversible $\left(j_{0} \approx 24\right.$ A $\left.\mathrm{cm}^{-2}[16,17]\right)$, si el potencial aplicado está suficientemente alejado del potencial reversible, la concentración del ion reactivo sobre la superficie tenderá a cero.

Si se supone un electrodo plano, la solución electrolítica en reposo y el potencial de trabajo suficientemente negativo, la resolución de la ecuación de difusión para la especie reactiva conduce a la expresión:

$$
j(t)=j_{\mathrm{c}}^{\mathrm{d}}(t)=-\frac{n \mathrm{FA} D_{\mathrm{i}}^{1 / 2} c_{\mathrm{i}}^{0}}{\pi^{1 / 2} t^{1 / 2}}
$$

con el mismo significado dado anteriormente para cada símbolo.

Por otro lado, para una celda de geometría cilíndrica se obtienen como expresiones límites para la densidad de corriente de difusión $j_{\mathrm{c}}{ }^{\mathrm{d}}[121]$ :

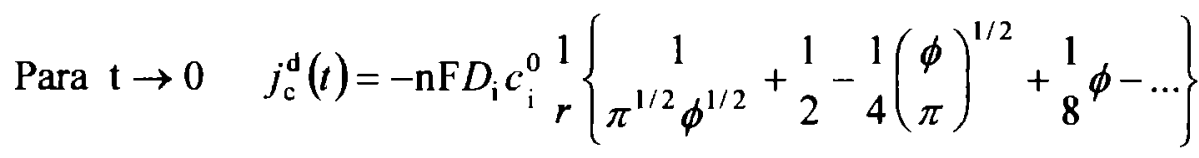

y para $\mathrm{t} \rightarrow \infty \quad j_{\mathrm{c}}^{\mathrm{d}}(t)=-n \mathrm{~F} D_{\mathrm{i}} c_{\mathrm{i}}^{0} \frac{2}{r}\left\{\begin{array}{c}1 \\ \ln (4 \phi)-2 \gamma-[\ln (4 \phi)-2 \gamma]^{2}\end{array}\right.$

donde $\gamma=0,5722$ es la constante de Euler-Mascheroni, y $\phi=D_{i} t / \mathrm{r}^{2}$ es una variable adimensional.

En las figuras 4.31 y 4.32 se representan las densidades de corriente de difusión en función del tiempo para celdas de geometría rectangular y cilíndrica respectivamente. Para la geometría cilíndrica solo se considera la expresión para tiempos cortos, pues es la que interesa en el presente trabajo debido a las características de la electrodeposición. 


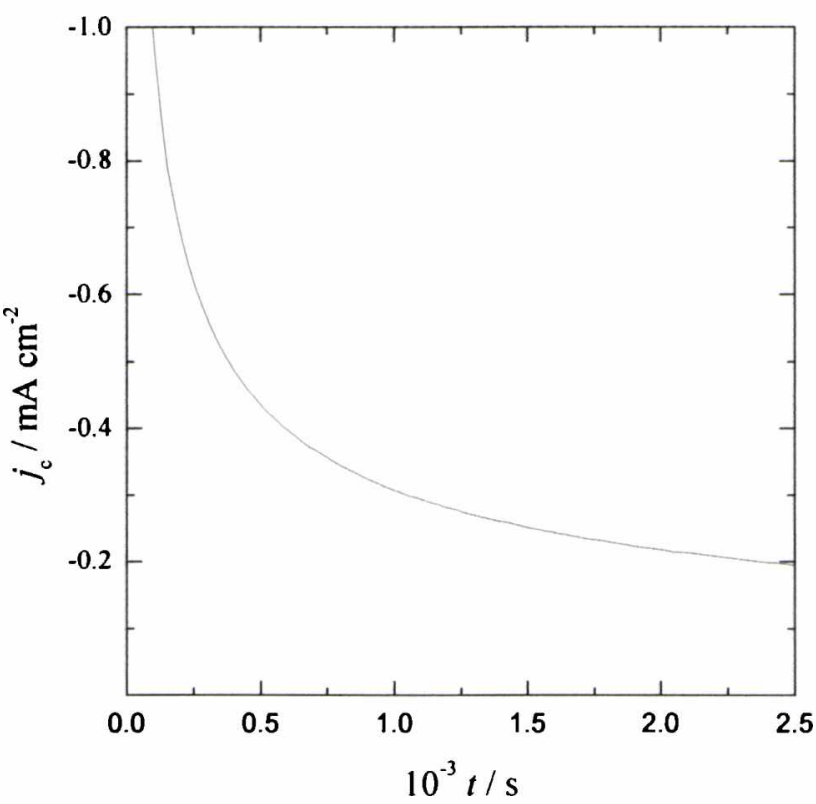

Figura 4.31. Difusión plana en condiciones no estacionarias. $D_{\mathrm{i}}=1,39 \times 10^{-5} \mathrm{~cm}^{2} \mathrm{~s} ; c_{\mathrm{i}}^{0}=4,8 \times 10^{-5} \mathrm{~mol} \mathrm{~cm}^{-3}$.

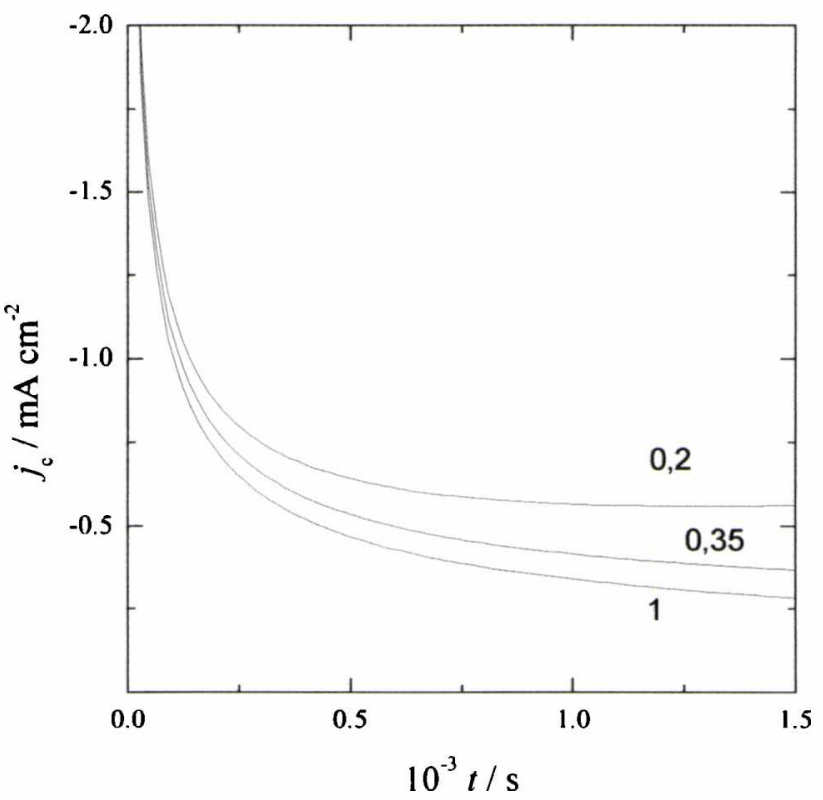

Figura 4.32. Difusión cilíndrica a tiempos cortos. Condiciones idem Fig. 4.31. Los números sobre las curvas corresponden a los radios del electrodo de trabajo en $\mathrm{cm}$. 


\subsubsection{Análisis de transitorios potenciostáticos de corriente}

Un transitorio de corriente, en el que la etapa determinante es el transporte de materia por difusión, viene descripto por las ecuaciones (4.8), (4.9) o (4.10) según sea la geometría del sistema. Experimentalmente, sin embargo, no se reproducen completamente las curvas teóricas, y esto puede deberse a que la convección pasa a ser importante.

Por otro lado, en la electrodeposición se produce un depósito ramificado que conduce a un área activa mayor que el área inicial del electrodo y que resulta dificil de conocer.

Un modo alternativo de analizar los transitorios de corriente gobernados por transferencia de materia, que se propone en este trabajo, consiste en representar el cociente entre la carga puesta en juego y la corriente $Q_{\mathrm{c}} / I_{\mathrm{c}}$, en función del tiempo de electrodeposición y compararlos con las representaciones que surgen de las ecuaciones teóricas. Así cuando el área de la fase metálica que se forma es constante o varía de acuerdo a una función conocida del tiempo, se puede prescindir del conocimiento del área real y se pueden analizar los transitorios en término de las distintas contribuciones de los mecanismos de transporte de materia. Por el contrario, si el área evoluciona en forma desconocida durante la electrodeposición y se conoce el mecanismo de transporte predominante, es posible mediante el uso de los gráficos de $Q d I_{\mathrm{c}}$ asociar los resultados experimentales a variaciones de área. Así, en algunos casos, puede ser posible estimar el área activa del electrodepósito.

En general, el cociente de la carga puesta en juego y la corriente, se puede expresar como:

$$
\underset{I_{\mathrm{c}}}{Q_{\mathrm{c}}}=\underset{j_{\mathrm{c}}(t) S(t)}{\int j_{\mathrm{c}}(t) S(t) d t}=f(t)=\mathrm{K} t
$$

donde $S(t)$, función del tiempo, es el área activa del electrodo metálico, y el resto de los símbolos conserva el significado dado anteriormente; $j_{\mathrm{c}}(t)$ depende del mecanismo cinético que domina el proceso. Resultando en los casos más simples, y a la vez más útiles, $f(t)=$ $\mathrm{K} t$, siendo $\mathrm{K}$ una constante de proporcionalidad. Esta constante puede ser evaluada a partir de la resolución de la ecuación (11) para distintas funciones $j_{\mathrm{c}}(t)$ y $S(t)$. Su valor luego se compara con aquellos obtenidos experimentalmente.

Las relaciones de $Q_{\mathcal{d}} I_{\mathfrak{c}}$ también dependen de la geometría de la celda electroquímica que se utiliza para la electrodeposición. Para cada situación, las relaciones 
$Q d I_{\mathrm{c}}$, considerando difusión pura, convección natural estacionaria, "advection" (ver al final de la sección 4.4.2) y distintas funciones del área activa con el tiempo $t$, dan los valores de $\mathrm{K}$ que se consignan en la Tabla 4.9 .

Respecto a la difusión pura en coordenadas cilíndricas, para tiempos suficientemente cortos, la expresión de $Q_{d} I_{\mathrm{c}}$ se hace igual a la correspondiente en coordenadas cartesianas.

Tabla 4.9. Mecanismos de transportes y geometría

\begin{tabular}{|c|c|l|l|}
\hline $\begin{array}{c}\text { Mecanismo de } \\
\text { transporte }\end{array}$ & Geometría & Función del área & \\
\hline Difusión pura & Plana & $\mathrm{S}=\mathrm{S}(t)=$ constante & 2 \\
\hline Difusión pura & Plana & $\mathrm{S}=\mathrm{S}(t)=\mathrm{m} t$ & $2 / 3$ \\
\hline $\begin{array}{c}\text { Difusión pura } \\
\text { Cilíndrica }\end{array}$ & $\mathrm{S}=\mathrm{S}(t)=$ constante & $\left(2 r t^{1 / 2}(\pi D)^{-1 / 2}+0,5 t\right)$ \\
& $r=$ constante & $\left(r(\pi D t)^{-1 / 2}+0,5\right)$ \\
\hline $\begin{array}{c}\text { Advection" } \\
\text { natural }\end{array}$ & Plana & $\mathrm{S}=\mathrm{S}(t)=$ constante & 1 \\
\hline $\begin{array}{c}\text { "Advection" } \\
\text { cilíndrica }\end{array}$ & Plana & $\mathrm{S}=\mathrm{S}(t)=\mathrm{m} t$ & $(\mathrm{para} 1 \geq r \geq 0,01 \mathrm{~cm})$ \\
\hline $\begin{array}{c}\text { Convección } \\
\text { natural }\end{array}$ & $\begin{array}{c}\text { Plana o } \\
\text { cilíndrica }\end{array}$ & $\mathrm{S}=\mathrm{S}(t)=$ constante & 1 \\
\hline
\end{tabular}




\subsubsection{Aplicación a los datos experimentales}

Los procesos de transporte dependen de la longitud que caracteriza al sistema y que para los distintos tipos de morfología pueden resumirse así:

a) Estructuras densas: constituidas por crecimientos que presentan una interfase rugosa robusta, formada por puntas con tip-splitting y resultan en un electrodepósito que puede considerarse como un cilindro (si la celda electroquímica es de geometría axial) o un paralelepípedo (para el caso de la celda rectangular) que avanza hacia la solución. La longitud característica es la altura de la celda o la distancia recorrida por el electrodepósito.

b) Estructuras ramificadas abiertas, constituidas por dendritas, depósitos aciculares y "árboles" con morfología tip-splitting. En la celda axial al aumentar el radio del electrodepósito, el número de puntas activas también aumenta, resultando en un aumento del área total de puntas del electrodepósito con el tiempo de electrodeposición. La longitud característica es generalmente el radio de la punta de la dendrita o del crecimiento acicular.

En las celdas rectangulares cuando avanza un frente de crecimiento homogéneo, el aumento del área es poco significativo. En la Tabla 4.9 se considera la variación temporal del área según una dependencia lineal con $t$, esto debido a que en una celda quasibidimensional de geometría axial, si se considera el electrodepósito como un cilindro de altura constante $X=l_{\mathrm{s}}$ que crece desde el cátodo hacia el ánodo con velocidad constante, el perímetro, y por ende el área, crece linealmente con el tiempo.

Los procesos de convección, sea esta natural o forzada, consisten en el movimiento macroscópico del electrolito como consecuencia de los gradientes de densidad en un campo gravitatorio o por movimiento externo del fluido, respectivamente. Como se viera en el análisis de números adimensionales realizado en la sección anterior, esos fenómenos convectivos, se pueden considerar despreciables para electrodepósitos con longitud característica menor que las decenas de micrones, siendo el transporte molecular el proceso dominante, es decir la difusión pura.

Los transitorios de corriente experimentales representados como $Q_{d} I_{c}$ reflejan notorias diferencias cuando corresponden a las morfologías descriptas por a) estructura densa y b) estructuras abiertas, como se muestra en la figura 4.33. 


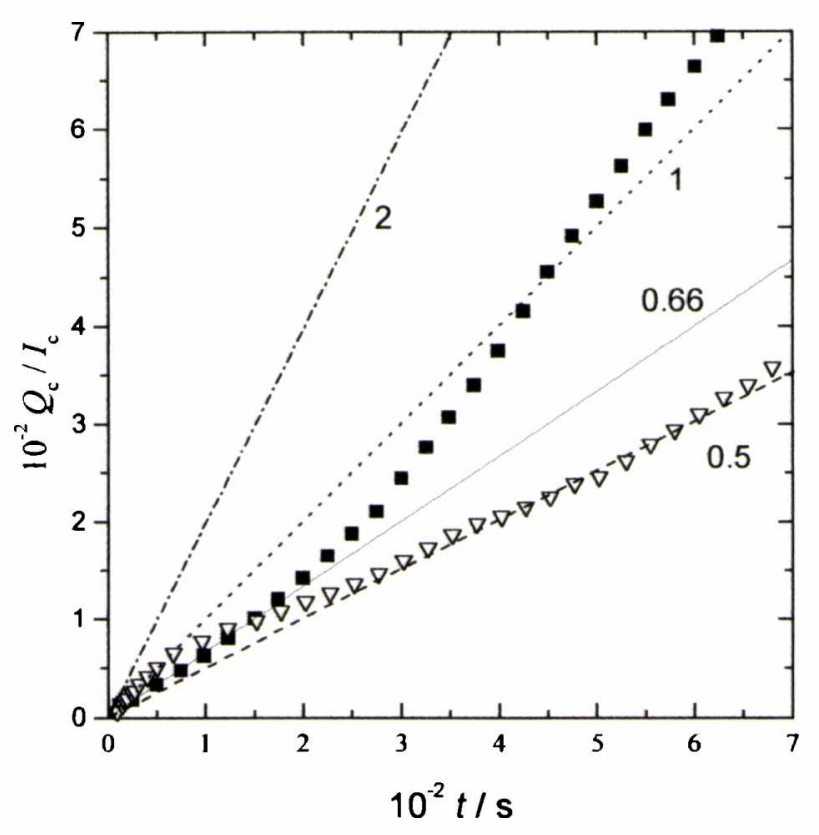

Figura 4.33. Transitorios de corriente representados como $Q d I_{\mathrm{c}}$ versus $t$. Celda de geometría cilíndrica. Los números sobres las curvas corresponden a las pendientes o valores de $\mathrm{K}$ de la tabla 4.9. (ロ) Electrodepósito constituido por dendritas y agujas obtenido empleando solución de sulfato de plata $0,024 \mathrm{M}$ a $\Delta \mathrm{E}_{\mathrm{c}-\mathrm{a}}=-0,38 \mathrm{~V} ;(\nabla)$ Electrodepósito "denso" formando un cilindro que avanza durante la electrodeposición, realizada empleando solución de sulfato de plata $0,014 \mathrm{M}+$ sulfato de sodio $0,5 \mathrm{M}+$ ácido sulfürico $0,01 \mathrm{M}$ (solución I), a $\Delta \mathrm{E}_{\mathrm{c}-\mathrm{a}}=-0,518 \mathrm{~V}$. Temperatura ambiente.

El transitorio correspondiente al electrodepósito denso, que en una celda de cilíndrica puede ser descripto como un cilindro que crece, presenta una primera región lineal, para $t<100 \mathrm{~s}$ con pendiente cercana a 1.2 y para $t>300 \mathrm{~s}$ una relación lineal con pendiente 1/2. Según la Tabla 4.9 los cocientes $Q_{d} / I_{\mathrm{c}}$ calculados, que responden a estas pendientes, son los asociados a los procesos de difusión pura cilíndrica con área constante $(t<100 \mathrm{~s})$ y convección libre o "advection" con aumento lineal del área activa, respectivamente. Por otro lado, el transitorio de corriente para un electrodepósito ramificado formado por crecimientos aciculares, muestra una primera región lineal con pendiente cercana a $2 / 3$ y otra región, a tiempos mayores, con pendiente $\cong 2$. Según las relaciones que se muestran en la Tabla 4.9 , se puede inferir que a tiempos cortos domina la difusión pura con un aumento lineal del área activa, en tanto que a tiempos más grandes, cuando solo un filamento con área constante domina el electrodepósito, si bien no se está seguro del control imperante, los resultados sugieren que la difusión pura con área constante es el proceso que se refleja en el transitorio de corriente. 


\subsection{Transitorios de corriente para la celda circular con la solución I}

En la figura 4.34 y 4.35 se representan los transitorio de corriente como $Q_{d} I_{\mathrm{c}}$ versus $t$ para $\Delta \mathrm{E}_{\mathrm{c}-\mathrm{a}}=-0,218 \mathrm{~V}$ y $-0,718 \mathrm{~V}$, respectivamente. Para el primer potencial el electrodepósito obtenido es el de la figura $4.5 \mathrm{~b}$ y para el segundo el de la figura $4.5 \mathrm{~d}$. En el primer caso para $t<700 \mathrm{~s}$, la relación $Q_{\mathrm{d}} / I_{\mathrm{c}}$ versus $t$ se aproxima a una función lineal de pendiente $\approx 2$, y para $t>1000 \mathrm{~s}$ tiende a una función lineal con pendiente 0,62 . Para el segundo potencial solo para $t<100 \mathrm{~s}$, la relación $Q_{\mathrm{c}} / I_{\mathrm{c}}$ versus $t$ se aproxima a una función lineal de pendiente $\approx 2$. Luego par $t>200 \mathrm{~s}$ se aproxima a una a 0,5 . La pendiente $\approx 2$ es consistente con un proceso de difusión cilíndrica a área constante que se transforma a convección con aumento lineal de área según la pendiente se acerca a 0,5.

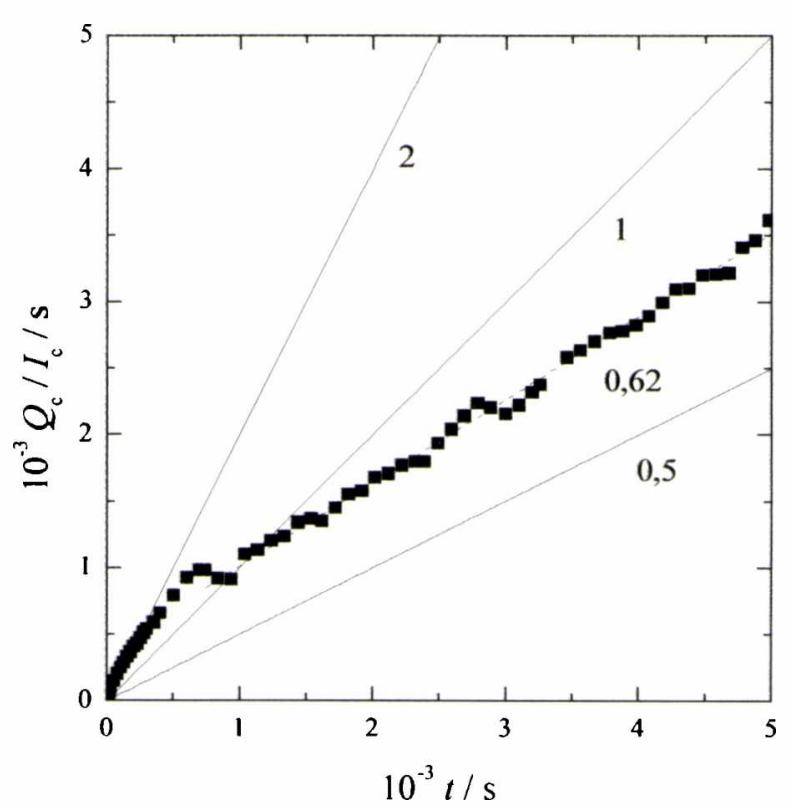

Figura 4.34. Transitorios de corriente representados como $Q_{d} / I_{\mathrm{c}}$ versus $t$ para experimentos realizados empleando la solución $\mathrm{I}, \mathrm{a} \Delta \mathrm{E}_{\mathrm{c}-\mathrm{a}}=-0,218 \mathrm{~V}$. Celda circular $\mathrm{A}$. 


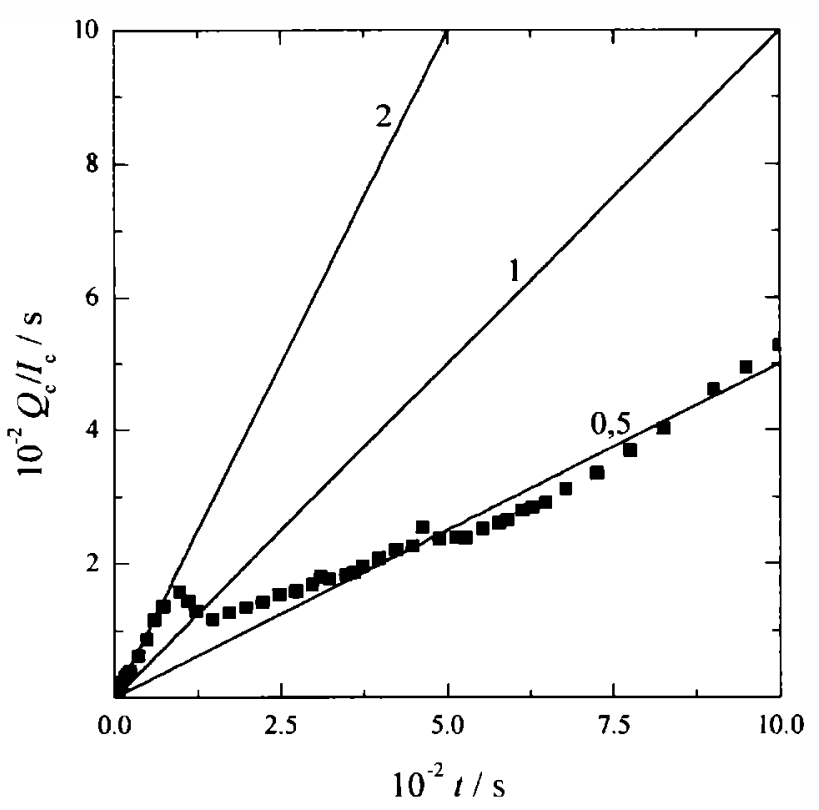

Figura 4.35. Transitorios de corriente representados como $Q_{\mathrm{c}} / I_{\mathrm{c}}$ versus $t$ para experimentos realizados empleando la solución $\mathrm{I}$, a $\Delta \mathrm{E}_{\mathrm{c}-\mathrm{a}}=0,718 \mathrm{~V}$. Celda circular $\mathrm{A}$.

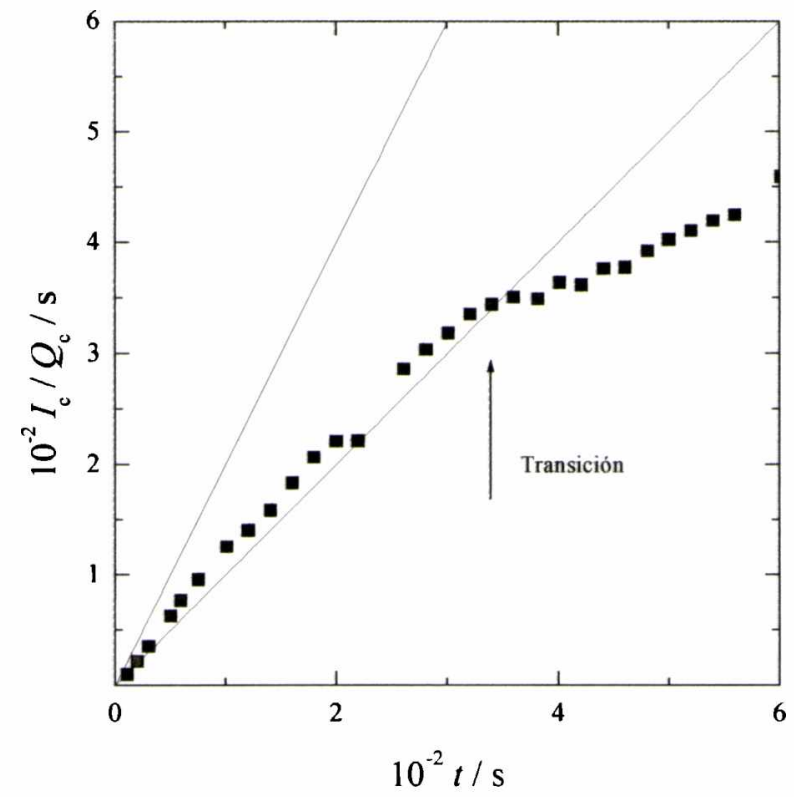

Figura 4.36. Transitorios de corriente representados como $Q_{\mathrm{c}} / I_{\mathrm{c}}$ versus $t$ para experimentos realizados empleando la solución $\mathrm{I}, \mathrm{a} \Delta \mathrm{E}_{\mathrm{c-a}-\mathrm{a}^{-}}=0,512 \mathrm{~V}$, con la celda rectangular BIII. 


\subsection{Transitorios de corriente para la celda rectangular con la solución I}

Un análisis similar para el transitorio de corriente obtenido a $\Delta \mathrm{E}_{\mathrm{c}-\mathrm{a}}=-0,52 \mathrm{~V}$, donde se obtiene un electrodepósitos denso (figura 4.9d), se muestra en la figura 4.36.

La relación $Q d I_{\mathrm{c}}$ versus $t$ se aproxima a una relación lineal con pendiente 1 . Según la tabla 4.9, se podría asociar a la existencia de convección natural. Este análisis es válido en ausencia de transición morfológica, que ocurre a $\mathrm{t} \approx 400 \mathrm{~s}$.

\subsection{Transitorios de corriente para la celda rectangular con solución II + ácido} sulfúrico $0.5 \mathrm{M}$

En este caso los transitorios obtenidos en la celda rectangular BII a $\Delta \mathrm{E}_{\mathrm{c}-\mathrm{a}}=-0,235 \mathrm{~V}$ y $\Delta \mathrm{E}_{\mathrm{c}-\mathrm{a}}=-0,65 \mathrm{~V}$, representados como $Q_{d} I_{\mathrm{c}}$ versus $t$, se muestran en las figuras 4.37 y 4.38 y corresponden a los electrodepósitos mostrados en las figuras 4.11 y 4.12 , respectivamente.

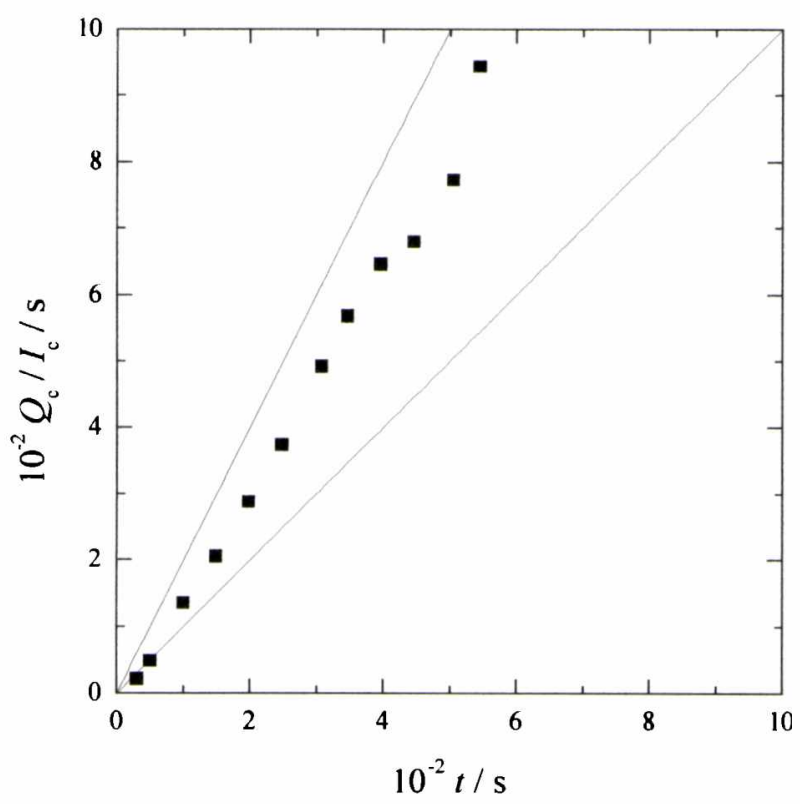

Figura 4.37. Transitorio de corriente representado como $Q_{\mathrm{c}} / I_{\mathrm{c}}$ para un electrodepósito formado por dendritas. 


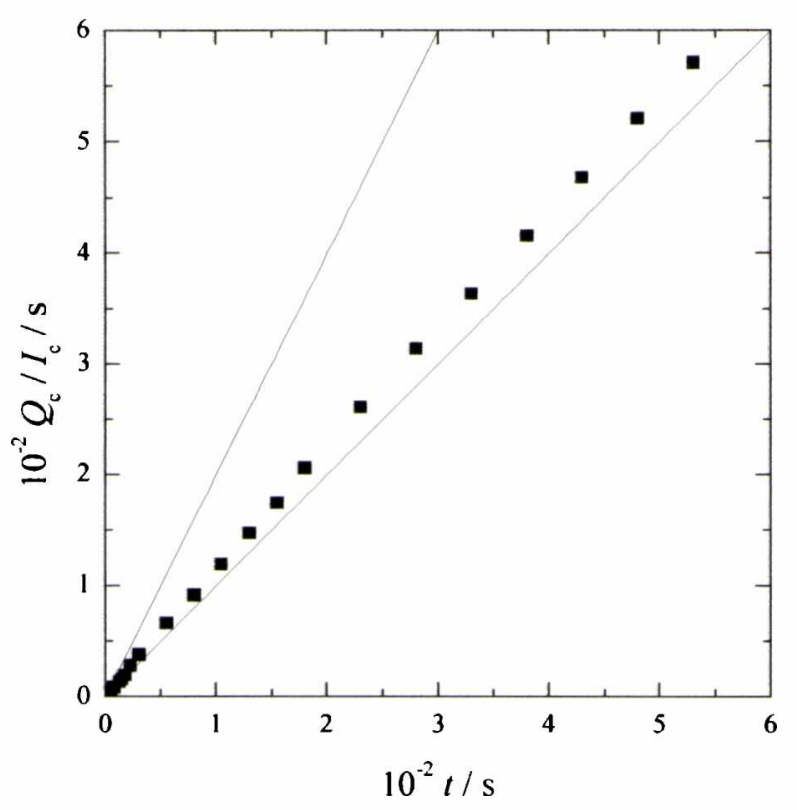

Figura 4.38. Transitorio de corriente representado como $Q_{\mathfrak{c}} / I_{\mathrm{c}}$ para un electrodepósito con estructura densa.

El análisis de los transitorios de corriente, realizado en esta sección está en acuerdo con las conclusiones derivadas de los números adimensionales (sección 4.4.2). Si bien las conclusiones que puedan extraerse del análisis de las representaciones $Q_{\mathrm{d}} I_{\mathrm{c}}$ debe tomarse con cierto cuidado, en especial cuando el frente de crecimiento del electrodepósito es irregular, permite inferir la participación de fenómenos convectivos en celdas quasibidimensionales.

Se incluyó en las tablas el término "advection", que conduce prácticamente a iguales resultados que la convección natural. El proceso de "advection" tiene involucrada la velocidad de avance del frente y se puede obtener como caso límite para $t$ suficientemente grande, de la solución de la ecuación de difusión con la condición de contorno que involucra una frontera móvil con la velocidad del frente del electrodepósito (similar al problema de Stefan de una sola fase)[120-122]. Es conveniente hacer notar que la convección forzada, incluye la velocidad en la ecuación de transferencia de cantidad de movimiento y no como condición de contorno.

En los experimentos realizados en este trabajo, generalmente aquellos con estructura densa crecen con una velocidad de avance del frente mayor que aquellos con estructura ramificada abierta.

En el desarrollo del presente trabajo se utilizarán constantemente las representaciones $Q_{\mathrm{c}} / I_{\mathrm{c}}$ versus $t$ y podrá apreciarse la utilidad que poseen para el estudio de los mecanismos de transporte de materia. 


\subsubsection{Corriente en la punta de los crecimientos aciculares}

Los crecimientos aciculares pueden considerarse como microelectrodos, siendo el área de captura una fracción de la superficie del paraboloide asociada a la punta de la aguja. El crecimiento abrupto de los sitios laterales se favorece cuando se bloquea el ápice de la punta (área de "captura").

La densidad de corriente en la aguja $\left(j_{f}\right)$ se puede determinar relacionando la ley de Faraday con la velocidad de desplazamiento axial $\partial L_{\mathrm{f}} / \partial t$ :

$$
-j_{\mathrm{f}}=\begin{array}{rr}
d L_{\mathrm{f}} & \mathrm{nF} \\
d t & \Omega
\end{array}
$$

donde $\Omega$ es el volumen molar de la plata metálica. El signo menos indica un proceso catódico.

Por otro lado, la densidad de corriente en un sistema electroquímico con geometría esférica, para un electrolito binario, resulta:

$$
-j_{\mathrm{d}}=\left(1+\begin{array}{c}
z_{+} \\
z_{-}
\end{array}\right) \mathrm{F}\left[D^{1 / 2} c_{\mathrm{i}}^{0} \pi^{-1 / 2} t^{-1 / 2}+D c_{\mathrm{i}}^{0} r^{-1}\right]
$$

con el significado de los símbolos ya conocido.

Igualando las ecuaciones (4.12) y la (4.13) [123], es posible calcular el radio $r$ de una hemiesfera de superficie equivalente al área de captura del crecimiento acicular. El radio obtenido puede ser tomado como la longitud característica del proceso de crecimiento $\left(r_{t}\right.$ : radio del ápice de la aguja).

$$
\begin{array}{rr}
d L_{\mathrm{f}} & \mathrm{nF} \\
d t & \Omega
\end{array}=\left(1+\frac{z_{+}}{z_{-}}\right) \mathrm{F}\left[D^{1 / 2} c_{\mathrm{i}}^{0} \pi^{-1 / 2} t^{-1 / 2}+D c_{\mathrm{i}}^{0} r_{\mathrm{t}}^{-1}\right]
$$

En la ecuación 4.14 se considera $r \equiv r_{\mathrm{t}}$ y $D \cong 1,55 \times 10^{-5} \mathrm{~cm}^{2} \mathrm{~s}^{-1}, \mathrm{~F}=96.500 \mathrm{C} \mathrm{mol}^{-1}$, $\Omega=10,273 \mathrm{~cm}^{3} \mathrm{~mol}^{-1}$ y $c_{\mathrm{i}}{ }^{0}=4,8 \times 10^{-5} \mathrm{~mol} \mathrm{~cm}^{-3}$. Las magnitudes de $d L_{\mathrm{f}} / d t=V_{\mathrm{f}}$ se obtienen de las representaciones de $L_{\mathrm{f}}$ en función del $l$ (figura 4.24). 
En la tabla 4.10 se reúnen valores de $v_{\mathrm{f}}$, de $j_{\mathrm{f}}$ calculados con la ley de Faraday (4.12) y los radios de la hemiesfera efectiva de captura $r_{t}(4.14)$.

El tiempo $(t)$ en la tabla 4.10 es el tiempo de electrólisis. La velocidad $v_{\mathrm{f}}$ es la velocidad promedio del crecimiento acicular en este lapso de tiempo. Los resultados de las estimaciones de las áreas de capturas para los distintos crecimientos aciculares, permite ver que ésas son muchos más chicas que el área del paraboloide con el que puede describirse la punta del crecimiento acicular. Esto muestra que la distribución de corriente en la aguja no es uniforme, siendo mucho mayor la densidad de corriente en el ápice del crecimiento acicular.

Tabla 4.10. Valores de $v_{\mathrm{f}}, j_{\mathrm{d}}$ y $r_{\mathrm{f}}$ obtenidos a distintos tiempos para crecimientos aciculares.

\begin{tabular}{|c|c|c|c|}
\hline Tiempo de electrólisis /s & $\begin{array}{c}\text { Velocidad de avance } \\
\text { del frente. } \\
10^{4} \mathbf{v}_{\mathrm{f}} / \mathrm{cm} \mathrm{s}^{-1}\end{array}$ & $\begin{array}{c}j_{\mathrm{d}} / \mathrm{A} \mathrm{cm}^{-2} \\
(\mu \mathrm{m})\end{array}$ \\
\hline 2000 & 1,1 & $-1,1$ & 1,2 \\
\hline 9000 & 0,4 & $-0,38$ & 3,4 \\
\hline 1060 & 1,0 & $-1,3$ & 1,4 \\
\hline 724 & 6,3 & $-0,59$ & 2,2 \\
\hline 16500 & 2,0 & $-1,9$ & 0,7 \\
\hline 20700 & 0,047 & $-0,044$ & 29 \\
\hline 3950 & 2,0 & $-1,9$ & 0,7 \\
\hline 9000 & 0,7 & $-0,66$ & 2 \\
\hline 17650 & 0,013 & $-0,012$ & 100 \\
\hline 14275 & 0,035 & $-0,033$ & 39 \\
\hline 14275 & 0,13 & $-0,12$ & 10 \\
\hline
\end{tabular}

El gráfico de $I_{\mathrm{d}}=I_{\mathrm{c}}$ versus $r_{\mathrm{esfera}}$ (figura 4.39), muestra que las densidades de corriente esperadas para los radios de los crecimientos aciculares que se muestran en la tabla 4.10, no se diferencian apreciablemente de la del estado estacionario $(t>10000 \mathrm{~s})$. 


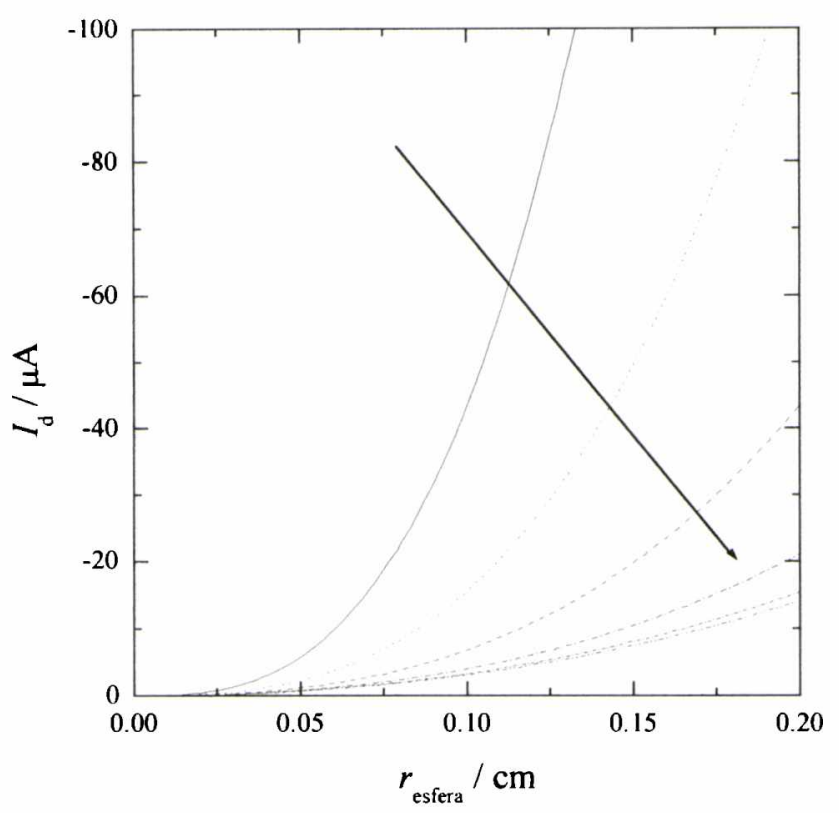

Figura 4.39. Corriente versus radio de la esfera. Las curvas de izquierda a derecha corresponden a los tiempos de $1 \mathrm{~s}, 10 \mathrm{~s}, 100 \mathrm{~s}, 1 \times 10^{3} \mathrm{~s}, 5 \times 10^{3} \mathrm{~s}$ y $1 \times 10^{4} \mathrm{~s}$ respectivamente. La flecha indica la dirección creciente del tiempo.

Si bien existe un tiempo a partir de la cual el electrodepósito es dominado por el crecimiento acicular, la corriente que se registra no corresponde exclusivamente al crecimiento de la aguja. La plata metálica continúa depositándose en forma compacta en el resto del electrodepósito. Esto se deduce estimando la corriente en base al volumen del crecimiento acicular calculado a partir de la secuencia de imágenes del crecimiento de la aguja. Este volumen permite estimar la masa del crecimiento acicular y la carga involucrada.

El volumen a cada tiempo (instantáneo) se determina considerando que la aguja posee una columna central de forma cilíndrica y una punta cónica, siendo el largo total, la longitud máxima medida en la dirección axial. El producto del volumen y $\mathrm{F} \rho / \mathrm{M}$, con $\rho$ la densidad de la plata metálica y $\mathrm{M}$ el peso molecular $\left(\mathrm{M}=107,87 \mathrm{~g} \mathrm{~mol}^{-1} ; \rho=10,5 \mathrm{~g} \mathrm{~cm}^{-3}\right)$ corresponde al valor de la carga involucrada $Q_{\text {f }}$. Finalmente, calculando la pendiente de la recta tangente a cada punto de la representación de $Q_{\mathrm{f}}$ versus $t$ se tiene la corriente asociada al crecimiento acicular.

En la tabla $4.11 \mathrm{a}, 4.11 \mathrm{~b}$ y $4.11 \mathrm{c}$, se presentan valores de la carga total $Q_{\mathrm{c}}$, la carga de la aguja $Q_{\mathrm{f}}$, la velocidad axial $v_{\mathrm{f}}$, la corriente asociada al crecimiento acicular $I_{\mathrm{f}}$ y la corriente total $I_{\mathrm{c}}$ (corriente catódica), para distintos tiempos y tres crecimientos aciculares analizados. Se ve que la corriente correspondiente a la aguja es varias veces menor que la 
corriente total. A medida que transcurre el tiempo de crecimiento, la relación entre la corriente o carga total y la corriente o carga de la aguja se hace menor. Esto está de acuerdo con los cambios en la morfología del electrodepósito. A tiempos largos, el electrodepósito está dominado por el crecimiento acicular. En algunos casos, después de un cierto tiempo de crecimiento acicular, se produce un nuevo cambio morfológico que conduce a la formación de un depósito ramificado complejo. Este cambio morfológico está asociado a la naturaleza aleatoria de estos procesos. Por otro lado, como se discutirá en el Capítulo 5, la punta de la aguja crece en condiciones marginalmente estables. Cuando una perturbación localizada en la punta es de amplitud y frecuencia suficientemente grande se favorece la bifurcación de la punta y el electrodepósito pasa a ser ramificado complejo. Hay otras perturbaciones que no llegan a desestabilizar la punta, y producen ramificaciones laterales que consumen una parte de la carga total. En las figuras 4.40 y 4.41 , se representan las cargas totales y la de los crecimientos aciculares en función del tiempo, para las situaciones descriptas arriba.

Tabla 4.11a. Sulfato de plata $0,024 \mathrm{M} ; \Delta \mathrm{E}_{\mathrm{c}-\mathrm{a}}=-0,30 \mathrm{~V}$. Celda circular A.

$\begin{array}{cccccc}t / \mathrm{s} & Q_{\text {c rotas }} / \mathrm{C} & Q_{\mathrm{f}} / \mathrm{C} & V_{\mathrm{f}} / \mu^{-1} & 10^{+5} I_{\mathrm{f}} / \mathrm{A} & 10^{+5} I_{\text {c tolas }} / \mathrm{A} \\ 8100 & -0,362 & -0,207 & - & -4,01 & -4,89 \\ 9600 & -0,450 & -0,255 & 1,30 & -3,00 & -5,28 \\ 12000 & -0,601 & -0,321 & 1,10 & -2,45 & -5,79 \\ 12600 & -0,641 & -0,337 & 1,00 & -2,45 & -5,90 \\ 13800 & -0,723 & -0,363 & 0,97 & -2,16 & -6,08 \\ 15000 & -0,807 & -0,389 & 0,93 & -3,30 & -6,22 \\ 6500 & -0,916 & -0,457 & 1,60 & -4,42 & -6,49 \\ 19800 & -1,165 & -0,650 & 2,10 & -6,95 & -7,00\end{array}$

Tabla 4.11b. Sulfato de plata $0,024 \mathrm{M} ; \Delta \mathrm{E}_{\mathrm{c}-\mathrm{a}}=-0,39 \mathrm{~V}$. Celda circular A.

$\begin{array}{cccccc}t / \mathrm{s} & Q_{\mathrm{c} \text { loctat }} / \mathrm{C} & Q_{\mathrm{f}} / \mathrm{C} & V_{\mathrm{f}} / \mu \mathrm{s}^{-1} & 10^{+5} I_{\mathrm{f}} / \mathrm{A} & 10^{+4} I_{\mathrm{c} \text { cosd }} / \mathrm{A} \\ 4080 & -3,15 & -0,020 & 1,6 & -2,06 & -1,12 \\ 4560 & -3,70 & -0,030 & 1,4 & -1,81 & -1,16 \\ 5060 & -4,27 & -0,038 & 1,2 & -1,55 & -1,23 \\ 5640 & -5,00 & -0,046 & 0,94 & -1,25 & -1,26 \\ 6120 & -5,61 & -0,051 & 0,70 & -1,00 & -1,24\end{array}$


Tabla 4.11c. Sulfato de plata $0,024 \mathrm{M} ; \Delta \mathrm{E}_{\omega=}=-0,38 \mathrm{~V}$. Celda circular $\mathrm{A}$

$\begin{array}{cccccc}t / \mathrm{s} & Q_{\mathrm{ctotal}} / \mathrm{C} & Q_{\mathrm{f}} / \mathrm{C} & V_{\mathrm{f}} / \mu \mathrm{s}^{-1} & 10^{+5} I_{\mathrm{f}} / \mathrm{A} & 10^{+4} I_{\mathrm{c} \text { cots }} / \mathrm{A} \\ 2280 & -0,471 & -0,010 & 0,32 & -1,20 & -2,18 \\ 2580 & -0,546 & -0,013 & 0,32 & -1,20 & -2,19 \\ 2880 & -0,596 & -0,019 & 0,32 & -1,20 & -2,20 \\ 3220 & -0,675 & -0,026 & 0,30 & -1,20 & -2,21 \\ 3540 & -0,745 & -0,030 & 0,30 & -1,68 & -2,22 \\ 3780 & -0,808 & -0,029 & 0,30 & -1,68 & -2,22 \\ 4100 & -0,871 & -0,035 & 0,29 & -3,06 & -2,23 \\ 4400 & -0,946 & -0,038 & 0,30 & -3,06 & -2,23 \\ 4700 & -1,021 & -0,055 & 0,32 & -4,30 & -2,24 \\ 5600 & -1,194 & -0,118 & 0,32 & -5,24 & -2,25 \\ 6200 & -1,350 & -0,159 & 0,33 & -6,25 & -2,26 \\ 6500 & -1,425 & -0,161 & 0,33 & -6,65 & -2,27 \\ 6800 & -1,487 & -0,173 & 0,33 & -6,65 & -2,27 \\ 7100 & -1,550 & -0,196 & 0,33 & -6,65 & -2,28 \\ 7400 & -1,620 & -0,225 & 0,33 & -6,65 & -2,29 \\ 8000 & -1,767 & -0,273 & 0,33 & -6,65 & -2,30 \\ 8600 & -1,904 & -0,302 & 0,33 & -8,70 & -2,30 \\ 9205 & -2,033 & -0,400 & 0,34 & -11,70 & -2,32 \\ 9800 & -2,181 & -0,494 & 0,34 & -11,70 & -2,32 \\ 10570 & -2,369 & -0,571 & 0,34 & -17,00 & -2,33 \\ 11009 & -2,456 & -0,635 & 0,35 & -17,00 & -2,34\end{array}$

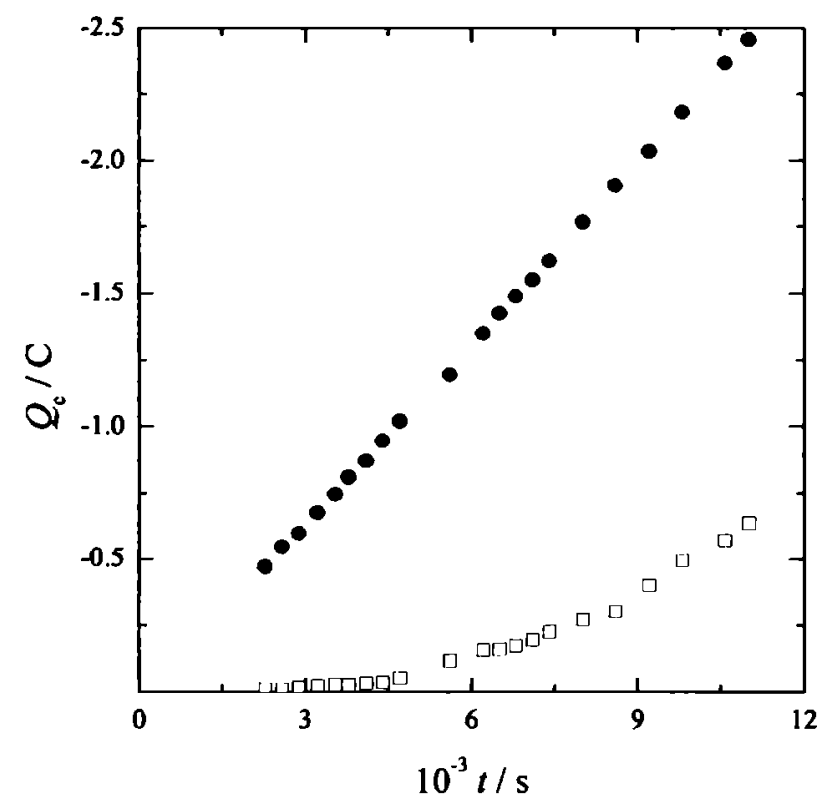

Figara 4.40. (•) Carga total pasada por la celda y ( $\square$ ) carga asociada al crecimiento acicular para un experimento de electrodeposición empleando la solución II a $\Delta E=-0,38 \mathrm{~V}$ en la celda circular

A. 


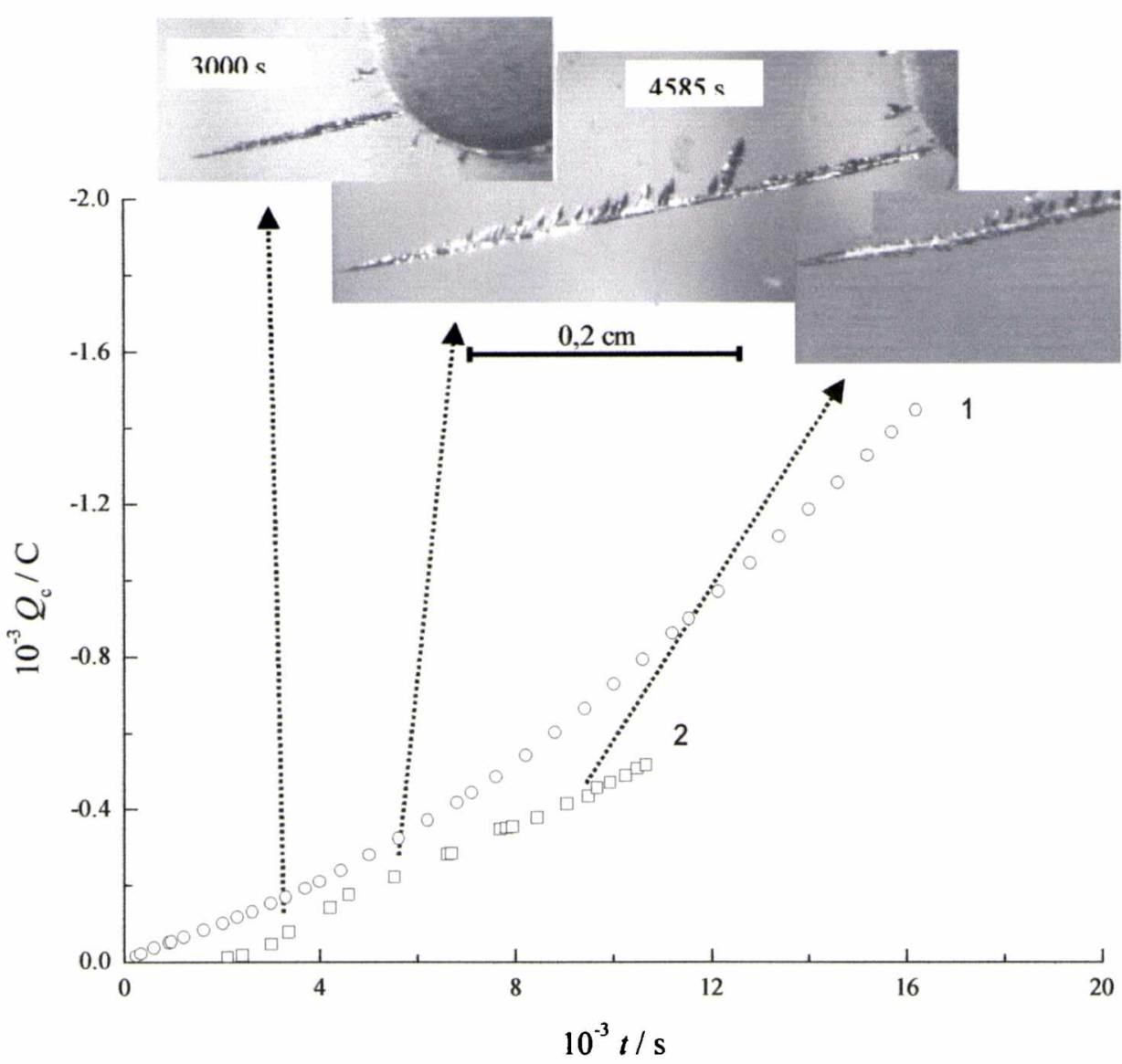

Figura 4.41. (O) Carga total pasada por la celda y ( $\square$ ) carga asociada al crecimiento acicular para un experimento de electrodeposición empleando la solución II a $\Delta \mathrm{E}=-0,38 \mathrm{~V}$ en la celda circular A. Se muestra una secuencia de imágenes y las flechas indican las regiones donde los valores de las pendientes $d Q_{\mathrm{f}} / d t$ se correlacionan con cambios morfológicos.

En la figura 4.41 se observan tres regiones caracterizadas por sus valores de $d Q_{\mathrm{F}} / d t$ (o corriente asociada al crecimiento acicular) y los cambios morfológicos que ocurren en estas regiones. En la primer región, el valor $d e d Q_{\mathrm{F}} / d t$, (calculada a partir del volumen de la aguja) es significativamente mayor que $d Q_{d} / d t$ (de la carga medida en el experimento), asociada a la carga total, por tanto el crecimiento de la aguja domina la cinética de crecimiento del electrodepósito. En la segunda región la pendiente $d Q_{\mathrm{F}} / d t$ disminuye, por la aparición de ramas laterales que consume parte de la carga evolucionada. En la forma que se estima la carga, no se tuvo en cuenta el volumen de las ramas laterales. En la tercera región, nuevamente la morfología del electrodepósito es dominada por el crecimiento acicular.

La estimación de la corriente asociada al crecimiento acicular es cualitativamente ilustrativa. El error de esta estimación es aproximadamente $20 \%$. 


\section{Capítulo 5}

Teoría de estabilidad de Mullins - Sekerka

\subsection{Inestabilidades de Mullins - Sekerka}

Los trabajos de Mullins-Sekerka $[124,125]$ sobre la estabilidad de la morfología de partículas que crecen bajo control difusional constituyen una base para explicar las morfologías observadas en distintos sistemas materiales, cubriendo desde la escala atómica a dimensiones galácticas.

Mullins y Sekerka estudiaron la estabilidad de la forma de partículas de una nueva fase en crecimiento, por ejemplo durante un proceso de precipitación, introduciendo una perturbación en la interfase inicial y determinando si la perturbación se amplificaba o decaía en el tiempo. En el crecimiento de una partícula esférica la perturbación produce una desviación de la esfericidad que se expresa mediante una expansión en términos de esféricos armónicos. Se calcula la dependencia temporal de los coeficientes de la expansión y se determina si el sistema es inestable o estable, según muestre o no crecimiento de algún componente de la expansión en armónicos.

La expresión para la velocidad de crecimiento de la amplitud de la perturbación, se compone de un término positivo proporcional al gradiente de concentración, y un término negativo, proporcional a la tensión superficial $\gamma$, que hace que la amplitud de la perturbación se incremente o disminuya respectivamente. El efecto puramente difusivo se obtiene cuando $\quad \gamma \rightarrow 0$, de forma que la concentración superficial resulte uniforme. Las líneas de concentración constante se juntan en las protuberancias y se separan en las depresiones, aumentando la amplitud de las perturbaciones. Por el contrario, el efecto puramente capilar, se obtiene cuando el término positivo es despreciable. En este caso, hay un flujo de material desde las protuberancias hacia las depresiones, reduciendo la amplitud de la perturbación.

La expresión para el radio crítico $R_{\mathrm{c}}$, a partir del cual puede producirse el crecimiento de la partícula se obtiene considerando el segundo armónico:

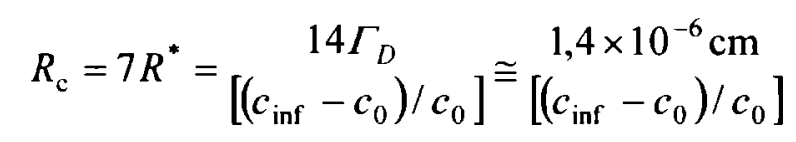

con $R^{*}=2 \Gamma_{D}\left[\left(c_{\mathrm{inf}}-c_{0}\right) / c_{0}\right]$, el radio crítico de nucleación. Para $R>R^{*}$, la partícula crece y para $R<R^{*}$ desaparece; $\Gamma_{D}=(\gamma \Omega) /(\mathrm{R} T)$ es la constante de capilaridad, $\Omega$ el incremento de volumen del depósito por mol de soluto agregado, $c_{0}$ y $c_{\text {inf }}$ son las concentraciones de 
equilibrio en una interfase plana y una esférica, respectivamente; $\mathrm{R}$ es la constante de los gases y $T$ es la temperatura absoluta.

Con la ecuación (5.1) se calcula $R_{\mathrm{c}}$. En la figura 5.1 se representa $R_{\mathrm{c}}$ versus ( $c_{\text {inf }}$ $\left.c_{0}\right) / c_{0}$. En este gráfico se definen las regiones de inestabilidad y de estabilidad de las partículas. Aquellas con radio $R>R_{\mathrm{c}}$ son inestables y por lo tanto no conservan su forma. Por el contrario para $R<R_{\mathrm{c}}$, el crecimiento es estable. En este caso la amplitud de la perturbación es despreciable y no perturba la forma de la partícula en su crecimiento.

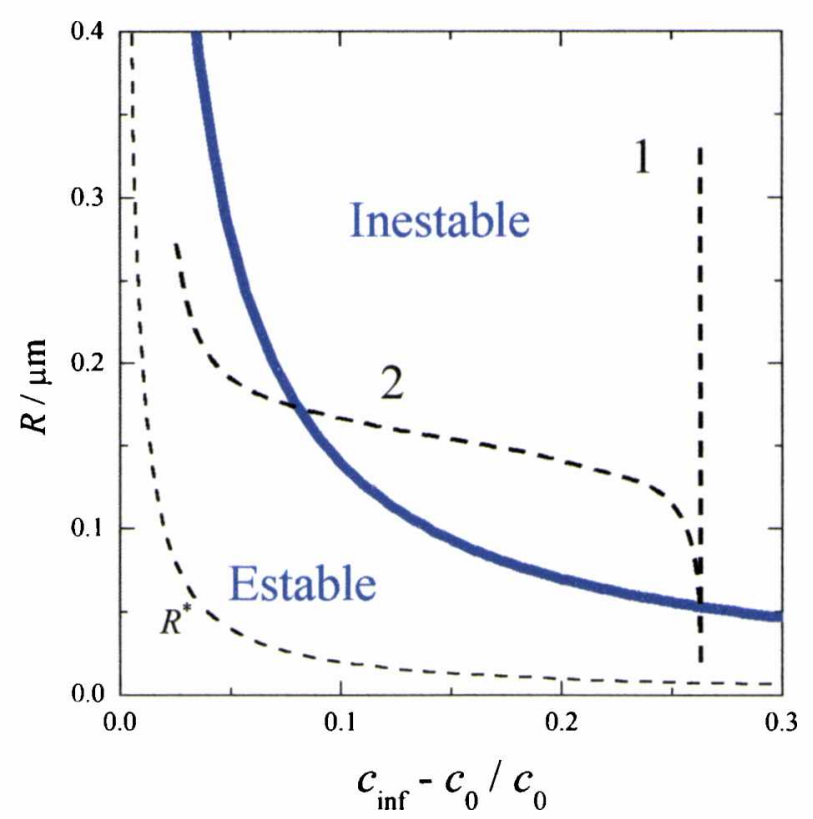

Figura 5.1. La línea sólida delimita la estabilidad de una esfera en función de su radio y la supersaturación. La línea de trazos indica el radio de nucleación crítico $R^{*}$. 1 y 2 indican trayectorias posibles de crecimiento de una esfera.

\subsubsection{La teoría de estabilidad en la electrodeposición de metales}

Para tratar el problema de la estabilidad de electrodepósitos metálicos se desarrollaron distintas teorías basadas en los trabajos pioneros de Mullins-Sekerka. En general, para la electrodeposición en estado estacionario y sobre una superficie regular, se resuelve la ecuación de difusión (ley de Fick), luego se impone una perturbación en la forma de la superficie y se estudia la velocidad de crecimiento de la amplitud de la perturbación a través de las ecuaciones que gobiernan la distribución de corriente.

Mc. Geough y Rasmusen [126] en el análisis perturbativo del proceso de electroforado usaron la solución de Wagner de la distribución primaria de corriente [111] 
en un perfil sinusoidal asociado a los componentes de una serie de Fourier, considerando solamente el sobrepotencial óhmico.

Posteriormente Aogaki y colaboradores consideraron una superficie plana que avanza y que al cambiar su forma se perturba el campo de concentración [127-130]. La perturbación adquiere la forma de una serie de Fourier en dos dimensiones con un término exponencial dependiente del tiempo. La velocidad de avance de la interface al igual que el campo de concentración se expresa por un término estacionario y otro que contiene la perturbación. Esto hace que la condición de contorno para la concentración a distancias muy grandes del electrodo aún resulte perturbada. Sin embargo, según Chao-Peng Chen y colaboradores [131] la velocidad de avance de la interface se incluye en la ecuación de difusión debido al movimiento de la interfase generada por la electrodeposición y por lo tanto no es necesario que se introduzca una perturbación en la velocidad.

Una perturbación de la superficie expresada en término del desarrollo de Fourier resulta:

$$
\psi=\xi e^{i w_{\mathrm{x}}+p t}
$$

donde $\xi$ es una constante, $w_{\mathrm{x}}$ es el vector longitud de onda con componentes en $x, y, z ; p$ es el factor de amplificación o constante de tiempo de crecimiento. La constante de tiempo, se obtiene resolviendo la ecuación de distribución de corriente sujeta a las condiciones de contorno impuestas a la superficie que avanza. Estas condiciones incluyen solamente la capilaridad. No se tiene en cuenta el sobrepotencial de activación. Para períodos espaciales menores que $\cong 0,1 \mu \mathrm{m}$, la interface es estable. La velocidad de crecimiento de la amplitud de la perturbación según Aogaki et. al. es:

$$
\begin{gathered}
\partial \ln \psi \\
\partial t
\end{gathered}=p=2 D \kappa w \Omega \begin{gathered}
\mathrm{R} T j_{\mathrm{L}}-\begin{array}{c}
2 \Omega \gamma w^{2} c_{s} \\
n \mathrm{~F} \\
D(n \mathrm{~F})^{2} c_{s}+\kappa \mathrm{R} T
\end{array}
\end{gathered}
$$

F la constante de Faraday, $\Omega$ el volumen molar, $\kappa$ la conductibilidad de la solución, $D$ y $c_{\mathrm{s}}$ el coeficiente de difusión y la concentración de la especie activa en la interface respectivamente, $j_{\mathrm{L}}$ es la densidad de corriente límite, $2 w^{2}=w_{\mathrm{x}}{ }^{2}+w_{\mathrm{z}}{ }^{2}$ es el doble de la frecuencia espacial media en las coordenadas $x$ y $z$. Para una superficie de forma sinusoidal el potencial de capilaridad $\phi_{\mathrm{s}}$ tiene la forma:

$$
\phi_{s}={ }_{n F}^{2 \Omega} \gamma w^{2} A \operatorname{sen}\left(w_{x} x\right) \operatorname{sen}\left(w_{z} z\right)
$$


Aogaki et. al. [127,132], aplicaron su teoría a la electrodeposición de la plata. La topografia de la superficie del depósito se representa por una serie de Fourier, y se analiza la estabilidad de cada término. Para la superficie original se supone una distribución Gaussiana de las alturas de las protuberancias ubicadas aleatoriamente en la superficie.

Aogaki et. al., incluyeron posteriormente el efecto de la difusión superficial de adatomos para tener en cuenta que en los depósitos reales no aparecen períodos espaciales tan pequeños como los encontrados en la teoría. La teoría sin embargo no considera el sobrepotencial de activación, el cambio de la tensión interfacial $(\gamma)$ debido a la adsorción de impurezas, y los límites en el tamaño de las perturbaciones gobernadas por la densidad de nucleación.

Landau [133] estudió un sistema bajo control difusional y activado y resolvió la ecuación de distribución de corriente para una superficie sinusoidal utilizando perturbaciones lineales. En esta teoría se concluye que para una densidad de corriente dada existe un sobrepotencial crítico a partir del cual el electrodepósito se hace rugoso. También explica la posible actividad de los inhibidores por el aumento de la energía superficial. La ecuación de Landau indica que el aumento de la energía superficial extiende la región de estabilidad a zonas de frecuencias espaciales o longitudes de onda $(w)$ menores.

Barkey et. al. $[134,135]$, realizaron un análisis de estabilidad lineal para el proceso de electroformado, partiendo de la ecuación de Laplace para el campo eléctrico y de concentración. En este análisis se considera que dentro de la película límite, el transporte de iones procede únicamente por difusión y que en la superficie (considerada sinusoidal) tanto el gradiente de concentración como el de potencial definen el valor de la densidad de corriente (j):

$$
n \mathrm{~F} D \frac{\partial c}{\partial y}=\kappa \frac{\partial \phi}{\partial y}=j
$$

A diferencia de -P. Chen y de Aogaki, en el análisis de Barkey et. al., se supone que el avance del electrodepósito es despreciable y se trata solamente el caso de protuberancias mucho menores que el espesor de la película límite (figura 5.2). Tanto -P. Chen como Barkey representan la superficie con una función sinusoidal y se considera la caída de potencial por efectos óhmicos, el sobrepotencial de concentración, de transferencia de carga y de capilaridad. Barkey desprecia la migración como mecanismo de transporte, mientras que $-\mathrm{P}$. Chen trata tanto una solución con un electrolíto binario o con exceso de electrolito soporte. En las situaciones consideradas por -P. Chen, la separación entre protuberancias o longitud de onda $\lambda$ (inverso del período espacial), es mucho menor o mucho mayor que el espesor de la película límite $\delta$ (figura 5.2). 
En el caso en que $\lambda<<\delta$ la película límite no es perturbada por los armónicos que describen la superficie; lo contrario ocurre si $\lambda \gg>\delta$. Según Chao-Peng Chen, esto se tiene en cuenta introduciendo el factor de amortiguación $\zeta$ en la ecuación de la película límite: $y=\delta+\zeta \psi\left(\right.$ donde $\psi$ representa la superficie con perturbación sinusoidal), y $\zeta=\mathrm{e}^{-\delta / \lambda}$. El factor de amortiguación es la causa principal de las diferencias que existen entre los tratamientos de -P. Chen y Barkey, generando distintos tipos de comportamientos para el periodo espacial. Sin embargo, las predicciones de ambos describen rasonablemente bien los resultados experimentales.
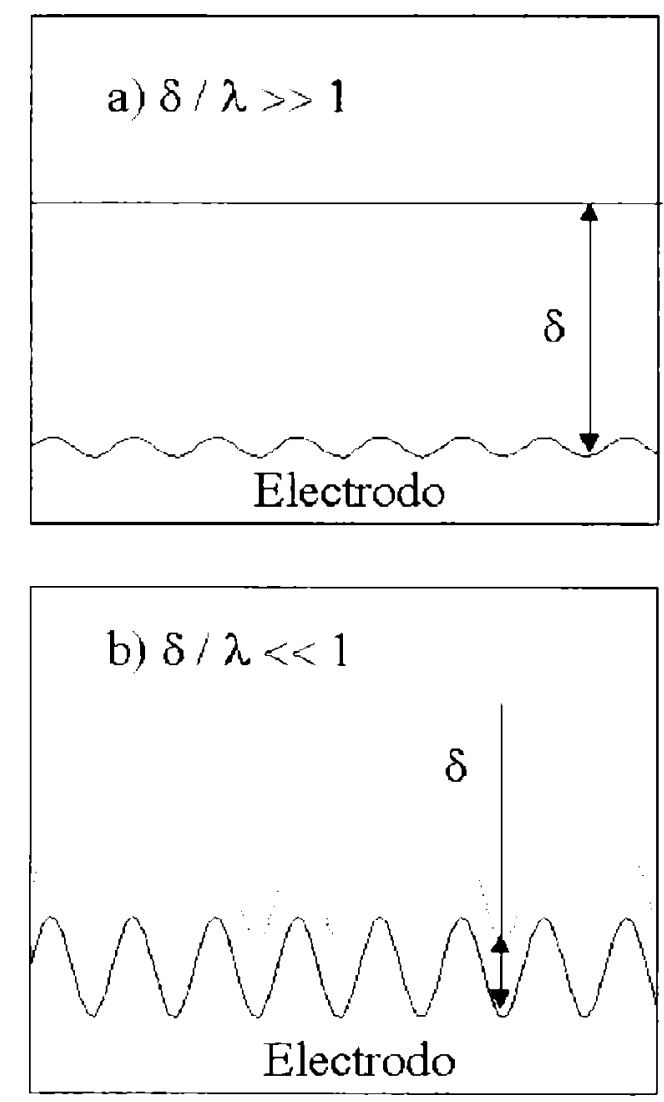

Figura 5.2. Situaciones consideradas en el desarrollo de -Peng Chen y colaboradores. Tomado de [131].

\subsubsection{Teoría de la estabilidad y crecimiento dendrítico}

La teoría de estabilidad lineal [136] fue aplicada al problema de la dendrita desde 1969 por Hoffmann [137]. En 1973 Oldfield [138] realizó estudios numéricos que 
permitieron proponer un criterio de estabilidad para el crecimiento dendrítico. Sin embargo, recién tuvo aceptación en la comunidad científica después de los trabajos de Langer, Muller y Krumbhaar [139-144]. La teoría de estabilidad lineal podía dar cuenta de los aspectos morfológicos estacionarios, la forma constante con que avanza la punta de la dendrita, y de aquellos que dependen del tiempo, como el crecimiento de las ramas laterales. La teoría original trata la solidificación de una sustancia pura fundida y luego se la extendió para estudiar aleaciones [145]. Al igual que las indicadas en las secciones anteriores, la teoría se basa las ideas previas de Mullins - Sekerka [124].

Langer resuelve la ecuación de difusión en coordenadas cartesianas, en un sistema de referencia que se mueve con velocidad $v$ en la dirección $y$,

$$
\nabla^{2} u+\frac{2 \partial u}{l \partial y}=0
$$

con la longitud de difusión $l=2 \mathrm{D} / \mathrm{V}$ (siendo $v$ la velocidad de avance de la interfase en la dirección $y$ ); la variable $u$ puede ser la temperatura si se trata de sustancias puras y transferencia de calor, o la concentración si se trata de aleaciones donde la difusión de una especie química controla el proceso de solidificación.

Para una perturbación pequeña:

$$
\xi(y, t)=\xi \exp (i k y+p t)
$$

con $p$, la velocidad de crecimiento de la amplitud de la perturbación o el factor de amplificación (1/s). Se puede demostrar la siguiente relación de dispersión para $p$ :

$$
p \cong k v\left[1-1 / 2(1+b) d_{0} l k^{2}\right]
$$

siendo

$$
\begin{aligned}
& b=\begin{array}{l}
D^{\prime} \\
D
\end{array} \\
& d_{0}=\frac{\gamma}{\left(c-c_{0}\right)^{2}\left(\begin{array}{ll}
\partial \mu & \\
& \partial c
\end{array}\right)}
\end{aligned}
$$

$k$ es el vector longitud de onda en dos dimensiones, $D$ y $D^{\prime}$ son los coeficientes de difusión en las fases líquida y sólida, respectivamente y $\mu$ es el potencial químico.

La solución de la ecuación de difusión que contiene la perturbación de la interface genera una nueva longitud característica del sistema, cuyo valor es la longitud de onda de la perturbación $\lambda_{s}$ que anula la velocidad de crecimiento de la amplitud de la perturbación. En este caso, a $\lambda_{s}$, se lo denomina punto de estabilidad neutro y queda expresado por: 


$$
\lambda_{s}=\frac{2 \pi}{k_{s}}=2 \pi \varepsilon\left(l d_{0}\right)^{1 / 2}
$$

con

$$
\varepsilon=[(1+\beta) / 2]^{1 / 2}
$$

La expresión (5.8) consiste de un término positivo que determina la inestabilidad de la interfase y otro negativo que la estabiliza. El primer término contiene la velocidad de avance de la interfase, y el segundo la tensión superficial. Si bien la relación (5.8), vale para una geometría plana, ella muestra la esencia del desarrollo, que es similar al utilizado en los análisis realizados en la secciones anteriores.

Para el crecimiento dendrítico, la elección del sistema de coordenadas, complica la manipulación matemática. Sin embargo, vale destacar algunos aspectos del procedimiento empleado. Se procede, en primer lugar, a resolver las ecuaciones (5.6) y (5.7) para un crecimiento acicular (dendrita sin crecimiento de ramificaciones laterales) que avanza conservando la forma de la punta. Las coordenadas parabólicas $\zeta, \eta, \theta$, que se consideran solidarias a la punta que se desplaza son

$$
\zeta=(r-y) / \rho \quad \eta=(r+y) / \rho
$$

r es la distancia radial desde el origen y $\rho_{\text {l }}$ es el radio de la punta; el ángulo $\theta$ mide las rotaciones en torno al eje $z$.

Se resuelve entonces la ecuación de Laplace despreciando los efectos de capilaridad [146], resultando:

$$
\begin{aligned}
& u_{s}=\left\{\begin{array}{l}
0, \quad \eta \leq 1 \\
-\Delta+\underset{E_{1}(P e)}{\Delta} E_{1}(P e \eta), \eta>1
\end{array}\right. \\
& E_{1, y}=\int_{y}^{\infty} y^{e^{-y^{\prime}}} d y^{\prime} \Delta=P e e^{P e} E_{1}(P e)
\end{aligned}
$$

$P e$ representa el número de Péclet, $P e=\rho_{\mathrm{t}} v / 2 D=\rho_{\mathrm{t}} / l$, siendo $l$ la longitud de difusión. Además $\Delta$, el sobreenfriamiento o gradiente de concentración, es:

$$
\Delta=P e e^{P e} E_{1}(P e)
$$

que al fijar $\Delta$ queda determinado el valor de $P e$ que contiene el producto de $v$ y $\rho_{\text {t }}$.

En este punto, la mayoría de los estudios introducen la tensión superficial para poder predecir independientemente $v$ y $\rho_{1}$. La forma más simple de considerar los efectos de capilaridad, siguiendo el modelo de crecimiento estacionario de la punta de la dendrita, se realiza suponiendo, según de Chalmers y Fisher [147], que: 


$$
v \cong \frac{D}{\rho_{\mathrm{t}}}\left(\Delta-\frac{2 d_{0}}{\rho_{\mathrm{t}}}\right)
$$

Temkin [148] y Sekerka et.al. [149] propusieron otras modificaciones a la ecuación de Ivantsov que no son analizadas en el contexto de este trabajo.

La teoría estacionaria de crecimiento acicular (despreciando la actividad de las ramas laterales), fue probada por Glicksman et.al. [150], utilizando dendritas obtenidas por solidificación de succinonitrilo en solución de acetona. Se logró así medir en forma independiente el radio de curvatura de la punta $\rho_{\mathrm{t}}$ y la velocidad de crecimiento $v$, aún en condiciones de microgravedad (IDGE), durante el viaje espacial del transbordador espacial Columbia [151].

Gliksman, demostró que la hipótesis de velocidad máxima, que surge al introducir los efectos de tensión superficial, con la cual se solucionaba el problema de la degeneración de la solución de Ivantsov, no se cumple para la solidificación del succinonitrilo en acetona. Por tanto, aunque consideró plausible la teoría del crecimiento dendrítico en estado estacionario se concluyó que no constituye un mecanismo de selección natural.

Siguiendo el desarrollo de Langer [142], resolviendo la ecuación (5.6), se busca una descripción matemática del crecimiento de las ramas laterales. En primera aproximación la concentración continúa expresada por la ecuación (5.14). La perturbación de la interface se escribe como:

$$
\eta_{s}(\zeta, \theta, t)-1=F_{m}(\zeta, \tau) \exp (i m \theta)
$$

$m=$ nro. entero y $\tau=2 \mathrm{vt} / \rho_{\mathrm{t}} . F_{\mathrm{m}}(\zeta, \tau)$ se puede escribir como el producto de dos factores, uno que depende de $\tau$ y otro de $\zeta, F_{\mathrm{m}}(\zeta, \tau)=\mathrm{e}^{\chi \tau} F_{\mathrm{m}, \chi}(\zeta)$, con $\chi$ autovalor del sistema.

El resultado final de este desarrollo es el siguiente. El caso límite $P e \rightarrow 0$, es adecuado para los experimentos de solidificación más corrientes, como los de succinonitrilo en acetona [142,150]. En estas circunstancias, la longitud de difusión deja de ser una longitud característica y la estabilidad del sistema queda circunscripta a dos parámetros,

$$
\begin{aligned}
& \sigma=\begin{array}{l}
2 d_{0} D \\
\rho_{\mathrm{t}}^{2} \mathrm{~V}
\end{array}=\left(\begin{array}{c}
\lambda_{s} \\
2 \pi \rho
\end{array}\right)^{2} \\
& \sigma^{\prime}=\beta \sigma
\end{aligned}
$$

donde cada parámetro corresponde a una fase y $\lambda_{\mathrm{s}}=2 \pi\left(d_{0} l\right)^{1 / 2}$. Resultan entonces dos longitudes características del sistema, $\rho_{\mathrm{t}} \mathrm{y} \lambda_{\mathrm{s}}$, el radio de curvatura de la punta y la 
longitud de estabilidad (longitud de onda), respectivamente. Solamente su cociente se puede conocer. Se establece el criterio de estabilidad de la forma:

$$
\sigma=\frac{2 d_{0} D}{\rho_{1}^{2} \mathrm{~V}}=\frac{1}{\rho^{\prime}}=\sigma^{*}
$$

$\sigma^{*}$ es una constante que puede depender de $\beta$, pero es independiente de $\rho_{\mathrm{t}} \mathrm{y}$ de $v$. Langer et.al. calcularon el valor $\sigma^{*}=0,025$. Para esta situación la punta es estable, y existen ramificaciones laterales a cierta distancia de la misma. El modo más activo es aquel que cumple $\operatorname{Re} \Omega=0$ (parte real del autovalor). Esta condición define un régimen marginalmente estable en la que el término estabilizador que contiene la tensión superficial, se compensa con el término desestabilizador, proporcional al gradiente de concentración. Langer sostiene que esta selección puede ser un proceso natural.

En el presente trabajo, se demuestra que el crecimiento electroquímico acicular se produce bajo un régimen marginalmente estable. Para tal fin se combinan la teoría de Langer con los desarrollos de estabilidad realizados en el campo de la electroquímica. El término desestabilizante estará representado por el sobrepotencial de concentración y el estabilizador, nuevamente por la tensión superficial metal/solución. 
5.2 Relación entre el radio de la punta de los electrodepósito aciculares y la velocidad de avance

En esta sección se analizan los datos de la cinética de formación de las agujas con el fin de establecer las relaciones entre el diámetro de la punta del crecimiento acicular o ápice del paraboloide y la velocidad de avance. Las teorías más simples proponen una relación entre la velocidad de avance $v$ y el radio de la punta del crecimiento acicular $\rho_{\mathrm{t}}$ del tipo $v \times \rho_{\mathrm{t}}=$ cte. Sin embargo, los resultados experimentales, correspondientes a agujas y dendritas obtenidas tanto por vía electroquímica como a partir de una sustancia fundida, muestran que la relación $v \times \rho_{\mathrm{t}}=$ cte no es válida [151]. Actualmente, los experimentos más precisos muestran que el radio de la punta y la velocidad de avance cumplen con la relación:

$$
v \times \rho_{\mathrm{t}}^{2}=\mathrm{cte}
$$

como predice la teoría de la estabilidad.

De las secuencias de imágenes del crecimiento acicular (Capítulo 4, figura 4.26 4.28), se puede observar que el sistema satisface cualitativamente las predicciones de la relación de selección (ecuación 5.19). El radio del ápice del crecimiento acicular, es menor cuanto mayor es su velocidad, y similarmente a los experimentos de Glicksman et. al.[151], el surgimiento de ramas laterales hace que la aguja se comporte como si tuviera un ápice de mayor tamaño. Las representaciones de las longitudes de avance axiales en función del tiempo muestran que la velocidad de avance axial (figura 4.24) disminuye con perturbaciones de amplitud suficientemente grande que originan ramificación, al propagarse desde la punta de la aguja. Esto se ve en, la figura $4.26 \mathrm{c}$, donde se presentan imágenes aumentadas de una ramificación en los sitios laterales de crecimiento de la aguja, cuyos valores de $L_{\mathrm{f}}$ se representan con $\left(^{*}\right)$ en la figura 4.24. El área de la punta, que se mantiene sin cambios durante el crecimiento, es mayor que el área de captura. Por lo que, algún proceso de estabilización debe estar involucrado.

El hecho de que la tensión superficial juegue un papel importante en el crecimiento electroquímico de agujas, explicaría porqué estas tienen un diámetro menor que los obtenidos por solidificación desde la sustancia fundida o desde una solución saturada de ácido piválico o succinotrilo en acetona. Esto hace que las medidas de los valores de $\rho_{\mathrm{t}}$ tengan un error mayor. En la figura 5.3, se comparan dendritas obtenidas electroquímicamente con las obtenidas de la solidificación de succinonitrilo a partir de solución acetónica saturada y por solidificación de agua (figura 5.3b). Se ve que las dendritas y los crecimientos aciculares de este trabajo tienen un diámetro en el ápice de 
aproximadamente 10 veces menor. Esto sugiere que la longitud capilar $d_{0}$ deba ser mayor para los experimentos electroquímicos que para los experimentos de solidificación.

a)

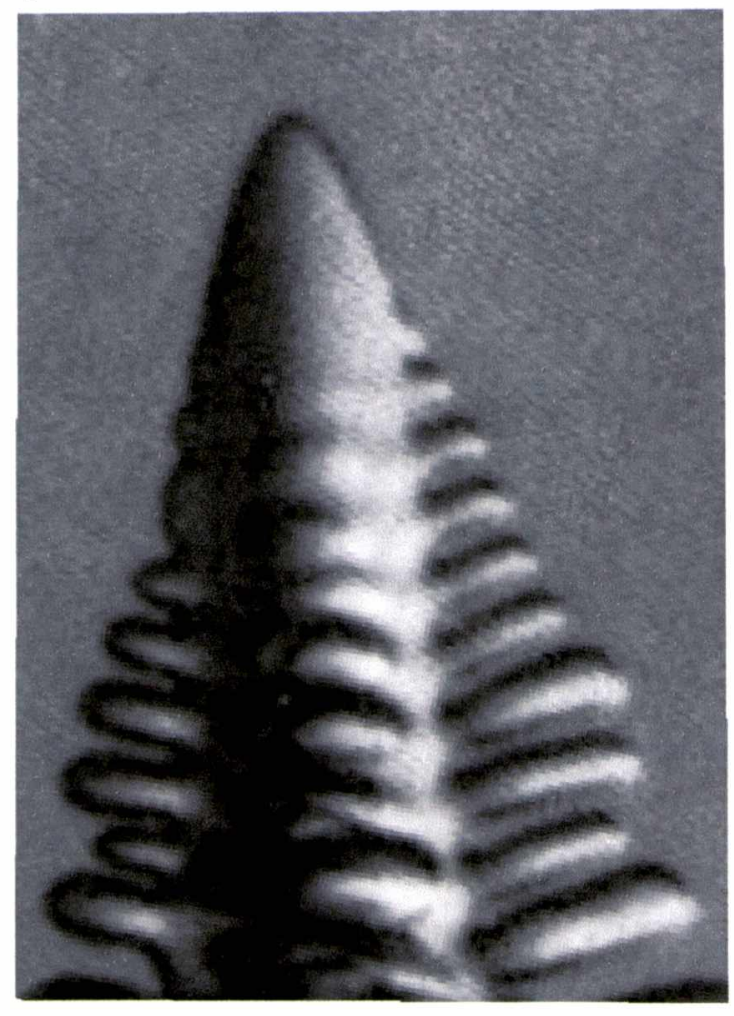

c)

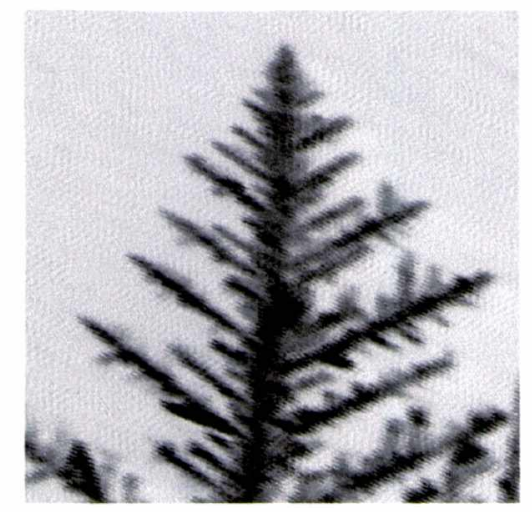

b)

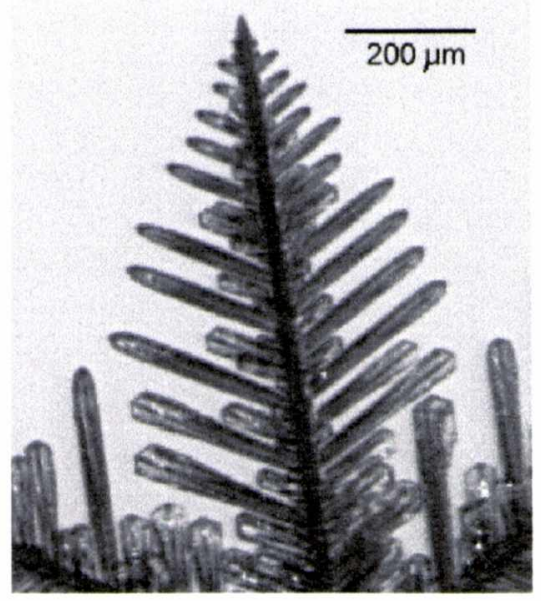

d)

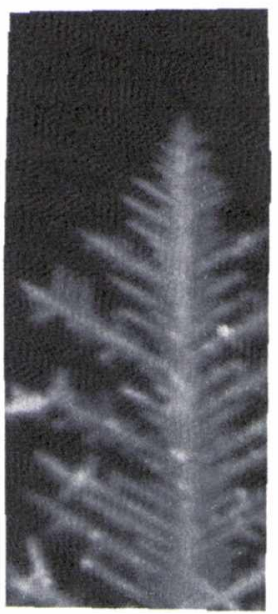

Figura 5.3. Comparación de varias dendritas. a) Dendrita obtenida por cristalización de succinonitrilo disuelto en acetona [150]; b) dendrita de hielo [152] ; c) y d) dendritas obtenidas electroquímicamente en este trabajo. La escala mostrada en b) es válida para todas las imágenes.

En la sección 5.1 se presentó la teoria de estabilidad según Langer et. al. y se introdujo la hipótesis de la estabilidad marginal con el parámetro de selección $\sigma^{*}=0,025$ (ecuación 5.19). En los experimentos electroquímicos descriptos en este trabajo, resulta $\sigma^{*}$ 
$=0,11$, tomando $d_{0} \approx 1 \times 10^{-7} \mathrm{~cm}[19], \mathrm{D}=1 \times 10^{-5} \mathrm{~cm}^{2} \mathrm{~s}^{-1}, \rho_{\mathrm{t}}$ (radio de la punta) $=3 \times 10^{-4}$ $\mathrm{cm} \mathrm{y} v=2 \times 10^{-4} \mathrm{~cm} \mathrm{~s}^{-1}$. Ese valor de $\sigma^{*}$ es cercano al de otros trabajos experimentales y teóricos [153,154] para el ácido piválico, en los que se admite una fuerte anisotropia en la tensión superficial. El valor alto de $\sigma^{*}=0,11$ está en acuerdo con la mayor influencia de la capilaridad en los experimentos electroquímicos.
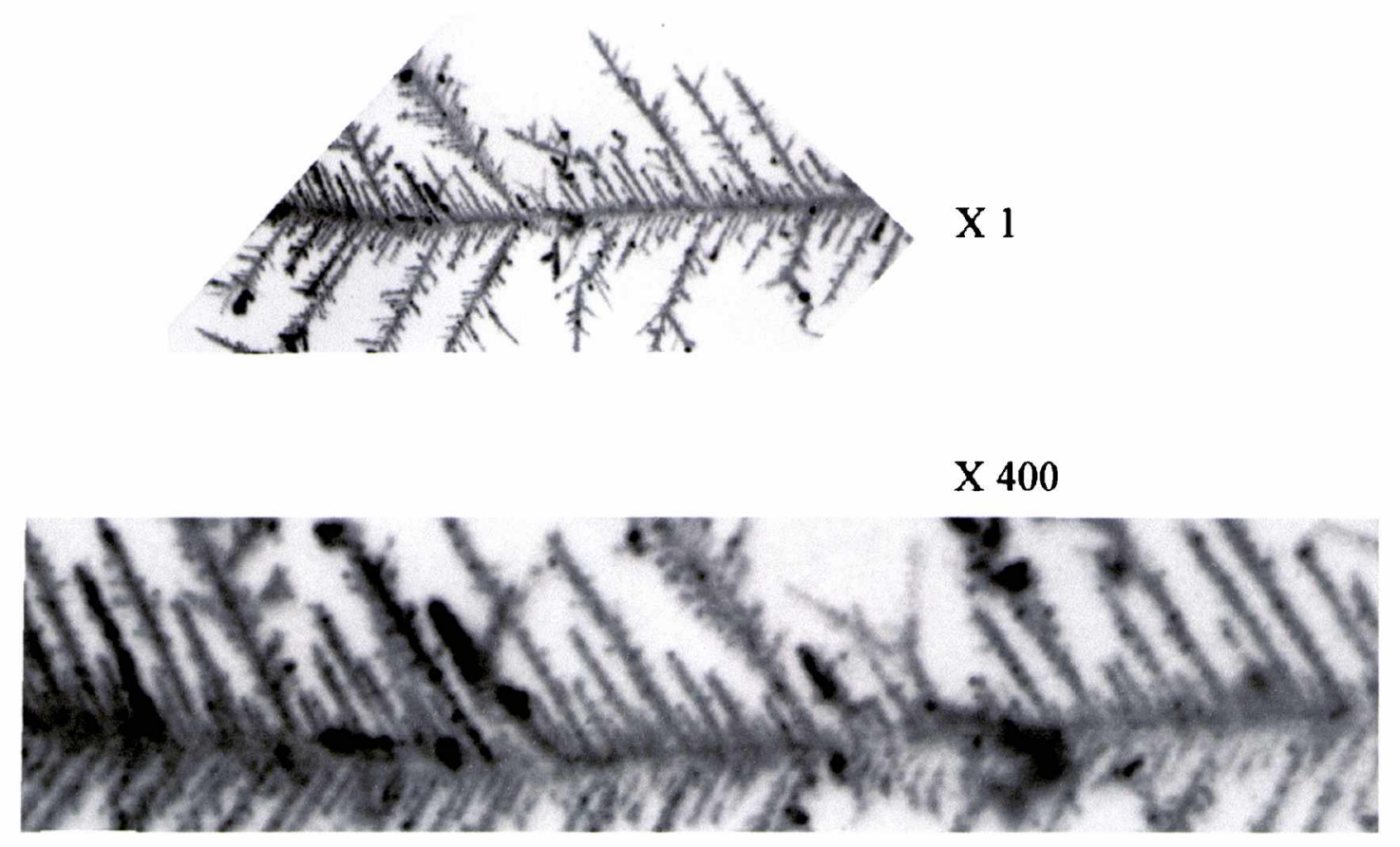

Figura 5.4. Periodicidad de las ramas laterales de una dendrita obterida empleando la solución I a $\Delta \mathrm{E}_{\mathrm{c}-\mathrm{a}}=-0,40 \mathrm{~V}$, en la celda rectangular BIII. Ver tabla 4.2 .

Al igual que en los experimentos de Gliskman [150], las dendritas de plata presentan un ápice en forma de paraboloide. Si bien la forma de la punta o ápice de la dendrita se mantiene invariante durante el crecimiento, existe una actividad contante en las ramas laterales, que emergen a una distancia de varios radios detrás de la punta. Inicialmente las ramas laterales se presentan como ondulaciones que tienen una longitud de onda cercana al propio diámetro de la punta que avanza. A distancias mayores de la punta, las ondulaciones se convierten en ramas bien definidas cuya separación es mucho mayor que cerca del ápice [144].

En la figura 5.4 se puede ver de una imagen ampliada, una periodicidad de los sitios de crecimiento laterales iniciales que debe estar asociada a una longitud de onda en la perturbación del campo difusional. Así, se puede medir una longitud de separación entre las ramas laterales de $13 \mu \mathrm{m}$, magnitud similar al diámetro del ápice de la punta. 


\subsection{Análisis de estabilidad lineal}

En esta sección se lleva a cabo un análisis de estabilidad lineal, basado en la teoría de Mullins-Sekerka. El procedimiento utilizado en este trabajo, incluye la teoría desarrollada por Barkey et. al. para procesos de electrodeposición y se introduce la hipótesis propuesta por Langer et. al., para obtener la condición de crecimiento marginalmente estable para el frente de crecimiento.

La interfase puede reaccionar ante una perturbación local de pequeña amplitud en la interfase, tal como un cambio local en la interfase, de manera de producir una respuesta que la estabilice o desestabilice.

La teoría de estabilidad formulada por Barkey, Muller y Tobias tiene en cuenta el sobrepotencial óhmico, el de transferencia de carga y el de concentración. Esta teoría relaciona las variables de fácil control en los experimentos electroquímicos, como $j_{\mathrm{c}}$ y $j_{\mathrm{c} . \mathrm{L}}$, la densidad de corriente durante la electrodeposición y la densidad de corriente límite, respectivamente, con la longitud de onda de la perturbación. Para el caso de los experimentos de este trabajo, la teoría se simplifica y contiene básicamente dos términos: uno desestabilizante que contiene la densidad de corriente medida en la electrodeposición, y otro término estabilizante que contine la tensión superficial como factor de relajación en el proceso de electrodeposición. Con la incorporación de la hipótesis de estabilidad marginal, el término estabilizador se iguala al término desestabilizador y la ecuación de Barkey et. al. resulta,

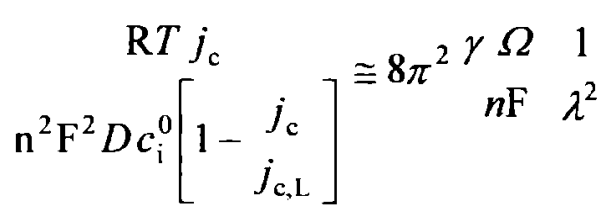

donde $\lambda$ es la longitud de onda de la perturbación, $\Omega$ y $\gamma$ son el volumen molar y la tensión superficial, respectivamente, $c^{0}$. Los otros simbolos tienen el significado conocido. 
Una curva de polarización para la electrodeposición de plata empleando solución de sulfato de plata 0,024 M se muestra en la figura 5.5. Las curvas de polarización se obtienen a $0,1 \mathrm{~V} / \mathrm{s}$ con el fin de disminuir la influencia de la rugosidad superficial del electrodepósito en la respuesta de la corriente. En la figura 5.5 se representa además la curva de polarización corregida por las pérdidas óhmicas. Se indica con una flecha el valor de $\Delta \mathrm{E}_{\mathrm{c}-\mathrm{a}}=-0,38 \mathrm{~V}\left(\Delta \mathrm{E}_{\text {efectivo }}=-0,04 \mathrm{~V}\right)$ utilizado en los experimentos. A este potencial le corresponde un valor de $j_{\mathrm{c}} / j_{\mathrm{c}, \mathrm{L}}=0,28$ y en estas condiciones (capitulo 4 ), se obtiene predominantemente crecimiento acicular.

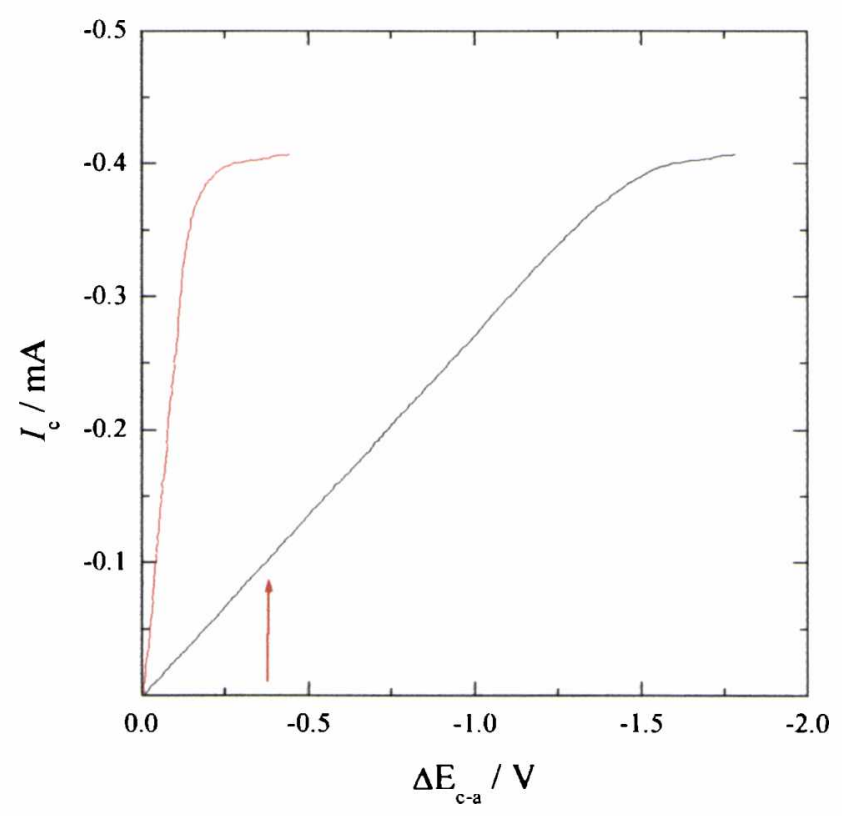

Figura 5.5. Curva de polarización

La ecuación (5.21) representada como $j_{\mathrm{c}}$ en función de $\lambda$ genera una familia de curvas para cada valor particular del cociente $j_{\mathrm{c}} / j_{\mathrm{c}, \mathrm{L}}$. La condición de estabilidad definida para un cierto valor de $j_{\mathrm{c}} / j_{\mathrm{c}, \mathrm{L}}$ divide el plano $j_{\mathrm{c}}-\lambda$ en una región de estabilidad que se encuentra por debajo y una región inestable que se encuentra por encima de la condición de estabilidad marginal para el crecimiento de la interfase. En este trabajo se aplica la ecuación (5.21) a los estadios iniciales del crecimiento de los electrodepósitos de plata (figura 5.6) y a las puntas de los crecimientos aciculares (figura 4.23 y figura 5.7). Se emplea la celda circular A y la celda rectangular BII, siendo el electrodo de trabajo un alambre de plata de $0,025 \mathrm{~cm}$ de diámetro, con el fin de mejorar la visión del perfil de las protuberancias. 
Para los estadios iniciales del proceso de electrodeposición de plata, $j_{\mathrm{c}}$ se obtiene de la corriente estacionaria medida en los transitorios de corriente y refiriéndola al área inicial del electrodo. La longitud de onda de la perturbación $\lambda$ se tomó como la distancia promedio entre las protuberancias. En los primeros estadios de crecimiento, las protuberancias aparecen sobre la capa compacta de plata electrodepositada y resulta $\langle\lambda\rangle=$ $0,28 \pm 5 \mu \mathrm{m}$.

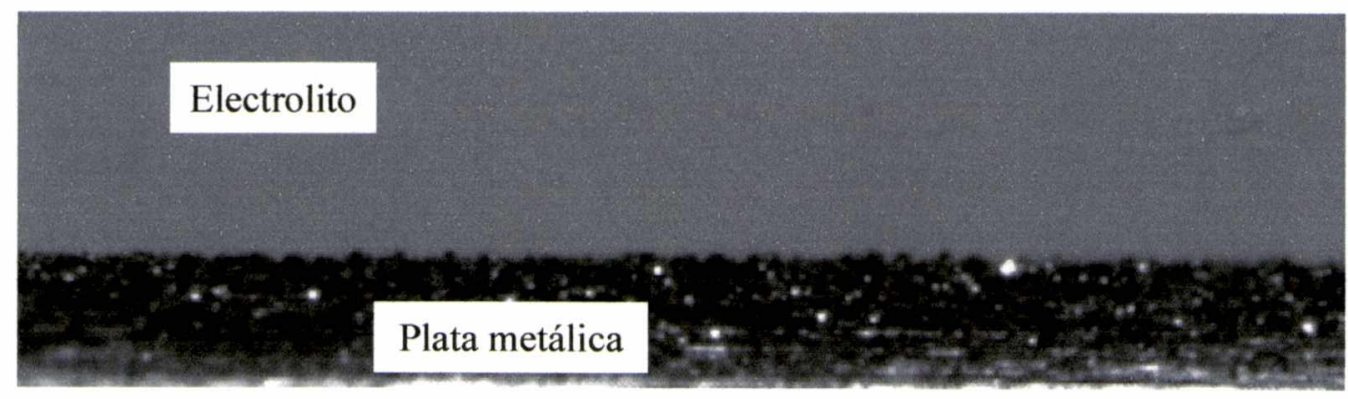

$0,01 \mathrm{~cm}$

Figura 5.6. Estadios iniciales donde se mide la distancia entre protuberancias

En el gráfico de la figura 5.8 (ángulo superior derecho) se incluyen los valores de $j_{\mathrm{c}}$ y $\lambda$ correspondientes a distintos experimentos. En el gráfico también se incluye la representación de la ecuación (5.21) para el valor de $j_{\mathrm{c}} / j_{\mathrm{c}, \mathrm{L}}=0,28$, relación que surge de la curva de polarización. En todos los casos los datos fueron promediado sobre al menos tres experimentos independientes. Como se esperaba, los resultados que surgen se ubican en la zona inestable del gráfico. 
a)

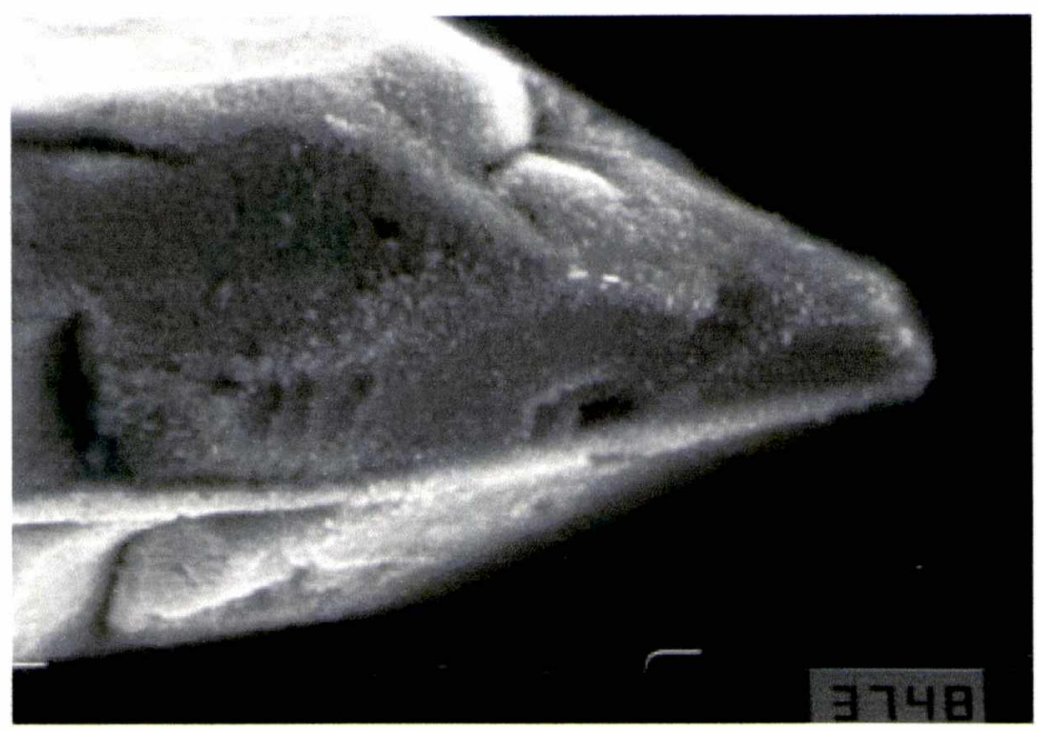

$10 \mu \mathrm{m}$

b)

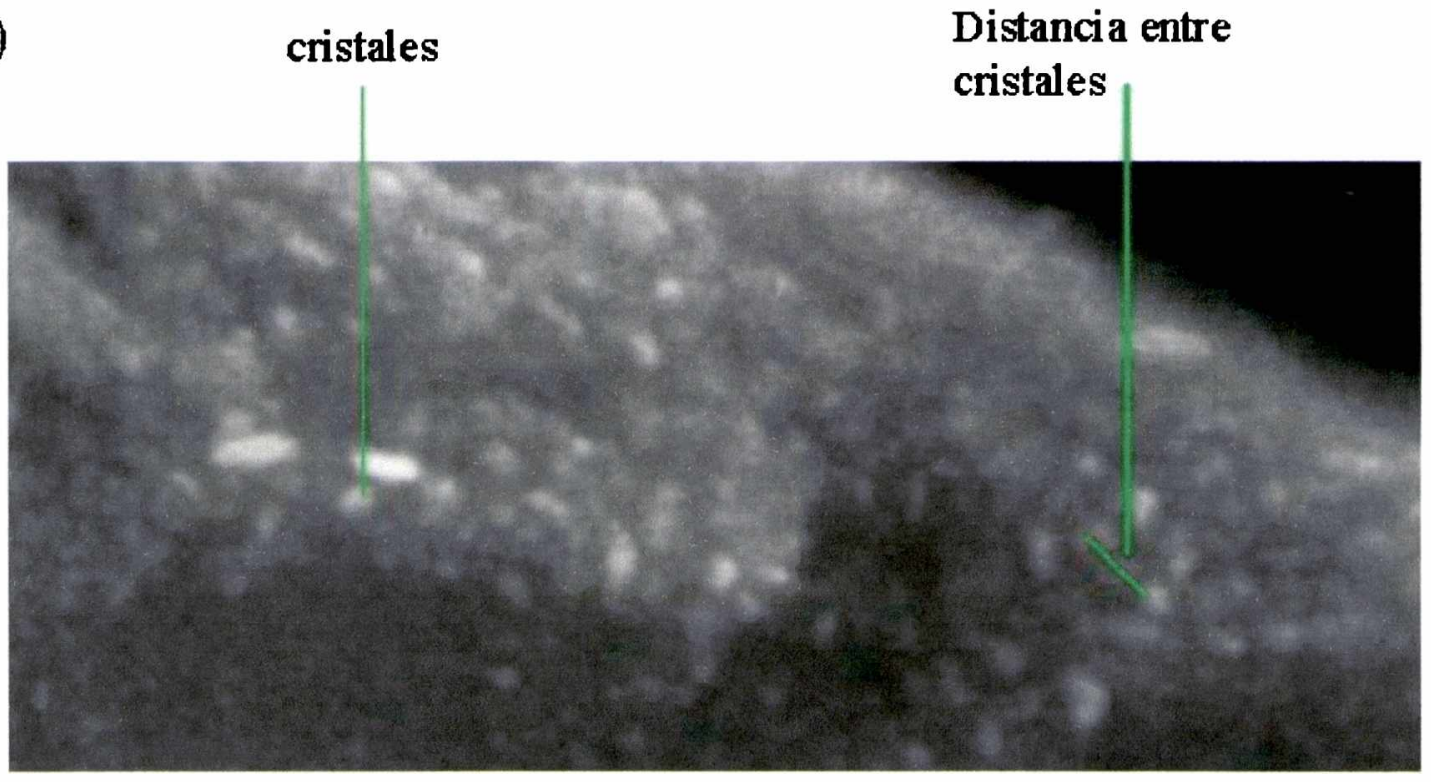

Figura 5.7. Punta de un crecimiento acicular obtenido empleando sulfato de plata $0,024 \mathrm{M}$ (solución II) en la celda circular $A$, a potencial de $\Delta \mathrm{E}_{\mathrm{c}-\mathrm{a}}=-0,38 \mathrm{~V}$. b) se muestra una región de la punta con un aumento de $4 \mathrm{x}$ respecto al aumento de a); se indica un cristal y la distancia medida entre cristales.

Para los crecimientos aciculares la densidad de corriente se estima con la relación $j_{\mathrm{f}}=v_{\mathrm{f}} \mathrm{F} \rho / \mathrm{M}$, donde $v_{\mathrm{f}}$ es la velocidad de avance del crecimiento acicular, calculada de la secuencia de imágenes y $\rho$ la densidad de la plata metálica $\left(10,5 \mathrm{~g} \mathrm{~cm}^{-3}\right)$. El valor promedio de la longitud de onda de la perturbación se tomó como la distancia de separación entre cristales que se encuentran en la punta del crecimiento acicular (figura 5.7). En el capítulo 4, se describió la morfología de los crecimientos aciculares empleando micrografias de SEM (figura 4.24). La distancia promedio entre cristales resulta $\langle\lambda\rangle=$ 
$0,37 \pm 0,04 \mu \mathrm{m}$. A diferencia de los obtenidos de los estadios iniciales, estos datos caen razonablemente bien sobre la curva de crecimiento marginalmente estable (figura 5.8).

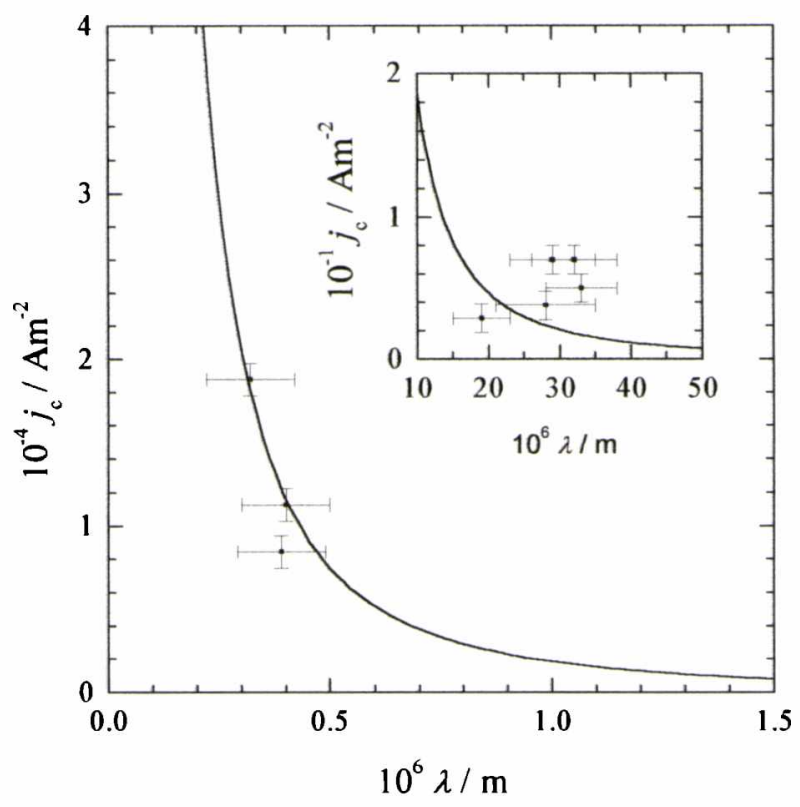

Figura 5.8. Diagrama de estabilidad. El gráfico ubicado en el ángulo superior derecho corresponde a los resultados obtenido de los primeros estadios de crecimiento.

De acuerdo a la cinética de crecimiento de las agujas, a sus características morfológicas y a la distribución de corriente imperante, descriptas en secciones anteriores, resulta plausible el mecanismo de crecimiento que se describe a continuación. Para ello se tiene en cuenta que:

-La aguja avanza a velocidad constante, y el frente puede ser descripto por un paraboloide de revolución, que mantiene constante su forma. Esto es cierto solo en ausencia de ramificaciones laterales, de lo contrario la velocidad de crecimiento en dirección del eje central disminuye y el radio del ápice se hace más grande.

-La corriente en la punta del crecimiento acicular, es inhomogénea, siendo la densidad de corriente mucho mayor en el ápice que en el resto de la punta descripta por el paraboloide de revolución.

Según estas observaciones es plausible asociar a la cinética de formación de un crecimiento acicular un proceso de rápida descarga en el ápice, seguido de una difusión 
rápida de adiones plata que se distribuyen en toda la superficie de la punta para mantener constante la forma.

Este proceso de difusión superficial rápida o anómala ha sido encontrado en clusters de oro formados por 140 átomos adsorbidos sobre grafito [155]. En este caso se sugirió que este tipo de difusión respondía a leyes de potencias correspondientes a los "vuelos de Levy". Se designa así a las trayectorias que alcanzan una distancia grande comparada con la difusión normal. De manera similar se encontraron procesos de difusión anómala con "clusters" de iridio formados por 19 o 7 átomos, sobre iridio (111) [156]. 


\section{CAPITULO 6}

\section{Convección natural en celdas quasi-bidimensionales}

\subsection{Convección natural en sistemas electroquímicos}

Karaglanoff, observó que existe movimiento del líquido en las regiones cercanas al electrodo [157]. Las fuerzas que producen el movimiento de la solución, denominadas fuerzas de Arquímides, se generan como consecuencia de gradientes de densidad que se establecen en las cercanías del electrodo. Esta diferencia de densidad entre el seno de la solución y la región cercana al electrodo, en general puede ser causada tanto por gradientes de concentración o de temperatura en la solución, generándose convección libre o natural. $\mathrm{Si}$ ambos fenómenos se encuentran acoplados, se habla de convección natural no isotérmica $[158,159]$.

En los sistemas electroquímicos, las fuerzas de Arquímides, se originan por los procesos electródicos. Las soluciones empleadas en los procesos electroquímicos contienen varios tipos de iones y el gradiente de concentración de cada uno afecta a las fuerzas de Arquímides.

Pueden ser asociadas a las fuerzas de Arquímides, dos fenómenos: la convección libre y la inestabilidad convectiva. Se habla de convección libre cuando el producto vectorial entre el gradiente de densidad $\nabla \rho$ y el vector de aceleración gravitacional cumple con $\nabla \rho \times \mathrm{g} \neq 0$. En cambio, cuando el gradiente de densidad es paralelo a $\mathrm{g}$, existe equilibrio mecánico hasta un cierto valor crítico de $\nabla \rho$, a partir del cual comienzan a aparecer estructuras disipativas como las celdas de Bénard [160]. Un tratamiento extenso de estos dos temas puede encontrarse en el trabajo de recopilación de Grigin y Davidov [161].

La convección natural juega un papel importante en muchos procesos electroquímicos, por ejemplo, la electrodeposición en los procesos de purificación y la disolución anódica utilizada en el electropulido de metales.

Grigin y Davidov, definen la densidad de fuerzas de Arquímides como:

$$
f_{\mathrm{g}}=g \nabla \rho
$$

El pasaje de corriente a través de una celda electroquímica, produce cambios en la densidad de la solución debido a las variaciones de concentración de las especies iónicas o al calentamiento local de la solución. 
Considerando equilibrio termodinámico, la densidad del líquido depende de la presión, la temperatura y la concentración de las especies disueltas (i). Utilizando la aproximación de Boussineq, en la cual la solución se considera incompresible, se tiene:

$$
\rho=\frac{\partial \rho}{\partial \mathrm{T}}\left(\mathrm{T}-\mathrm{T}_{0}\right)+\sum_{\mathrm{i}}^{\partial \rho} \partial c_{\mathrm{i}}\left(c_{\mathrm{i}}-c_{\mathrm{i}}^{0}\right)
$$

La suma se extiende a todos los iones en solución.

Para conocer la densidad de fuerzas de Arquimides, es necesario conocer la distribución de concentración de todos los componentes en la solución mientras pasa corriente por la celda electroquímica. Utilizando un desarrollo en serie se resuelve el conjunto de ecuaciones y se determina $\bar{f}_{\mathrm{g}}[162]$.

La convección natural se describe por las ecuaciones hidrodinámicas ( Navier Stokes) y las ecuaciones de trasferencia de masa (Ley de Fick). En el caso de convección natural no isotérmica, se consideran además las ecuaciones de transferencia de calor (Ley de Fourier).

\subsection{Electrodos planos verticales}

\subsubsection{Aproximación de la película límite y solución de Levich}

En la interfase sólido-fluido, la zona del fluido donde se producen cambios grandes en la velocidad se encuentra en las vecindades de la interfase. En esta zona son importantes las fuerzas viscosas o esfuerzos de corte, definidos por $\tau=\mu(\partial V / \partial x)$ (con $x$ la coordenada en dirección perpendicular a la velocidad $V$, aún para valores pequeños de la viscosidad $\mu$, puesto que el gradiente de velocidad $\partial V / \partial x$ es máximo.

A distancias grandes el esfuerzo de corte es cada vez más pequeño en razón de que el gradiente de velocidad disminuye, haciéndose su influencia despreciable. Por otra parte, a medida que la viscosidad del fluido decrece, el espesor de la zona mencionada disminuye.

Esta descripción física, permite dividir el fluido en dos regiones, con lo cual se facilita su estudio. Una de ellas es una capa de pequeño espesor inmediata a la superficie sólida, que se denomina capa límite hidrodinámica, $\delta_{\mathrm{h}}$, en la cual la fricción tiene un efecto considerable, y otra, donde la influencia de la fricción es prácticamente nula y es aplicable la aproximación del fluido ideal (sin fricción).

La generación de un gradiente de concentración debido a la reacción de electrodo determina una película difusional. La magnitud relativa de las películas límites 
hidrodinámica y difusional para convección libre, ha sido motivo de una amplia consideración. Wagner [163] postuló que la longitud de propagación de la no uniformidad del momento es mayor que la correspondiente distancia donde ocurre la variación de concentración. Por otra parte Levich [164], consideró que siendo el gradiente de concentración el causante del movimiento del fluido, toda la variación de la velocidad y de la concentración ocurrían dentro del mismo espesor. Esta última aproximación es la que se utiliza en las ecuaciones que se emplearán para describir la convección natural en el proceso de electrodeposición estudiado en este trabajo.

La aproximación de la capa límite al problema de la convección natural [161], permite obtener ecuaciones simplificadas al introducir el parámetro $\delta=\delta_{\mathrm{h}} / X$, con $X$ siendo la altura del electrodo, y despreciando los términos con órdenes superiores de $\delta$. Las ecuaciones que resultan, muestran que la concentración de la especie electroactiva y la de los iones indiferentes están acopladas a través de la condición de electroneutralidad y el transporte convectivo de los iones, con la velocidad del líquido que depende de la variación de concentración de todos los componentes de la solución. Una considerable simplificación se obtiene si el sistema satisface:

$$
\begin{gathered}
\partial \rho, y\rangle \\
\partial c_{\text {reactivo }} \partial \rho \\
\partial c_{\text {soporte }}
\end{gathered}
$$

que indica que el cambio de densidad producido por la variación de la concentración de la especie reactiva es mucho mayor que el cambio de densidad producido por la variación de concentración de la especie indiferente o soporte.

Cuando se inicia el pasaje de corriente por la celda electroquímica, la convección natural no se establece en forma instantánea. La convección natural en estado no estacionario fue estudiada por varios autores [165-169]. Después de un cierto tiempo de iniciado el pasaje de corriente $\delta_{\mathrm{d}}$ y $\Delta c_{\mathrm{i}}$ se estabilizan, probablemente debido a la agitación producida por la convección natural.

Para un sistema electroquímico con exceso de electrolito soporte, en estado estacionario, y con las aproximación (6.3), el sistema de ecuaciones acopladas que se debe resolver es el siguiente:

$$
\begin{gathered}
V_{x} \partial V_{x}+v_{\mathrm{y}} \frac{\partial V_{y}}{\partial y}=\begin{array}{c}
\partial^{2} V_{\mathrm{x}} \\
\partial y^{2}
\end{array} \frac{\rho_{0}-\rho}{\rho_{0}} \mathrm{~g} \\
\partial V_{x}+\partial V_{\mathrm{y}}=0 \\
\partial x+\partial y
\end{gathered}
$$




$$
V_{x} \frac{\partial c_{\mathrm{i}}}{\partial x}+V_{y} \partial c_{\mathrm{i}}=\begin{aligned}
& D_{i} \partial^{2} c_{\mathrm{i}} \\
& v
\end{aligned}
$$

Las condiciones de contorno son:

$$
\begin{gathered}
V_{x_{y=0}}=0, \quad V_{y_{y=0}}=0, \quad V_{x} y \rightarrow \infty \\
c_{i_{y=0}}=0, \quad c_{i_{y \rightarrow \infty}}=0
\end{gathered}
$$

La densidad de la solución puede expresarse como función lineal de la concentración

$$
\rho_{0} \approx \rho^{S}+\frac{\partial \rho}{\partial c_{\mathrm{i}}} c_{\mathrm{i}}^{0}
$$

donde $\rho^{S}$ es la densidad del fluido en la superficie.

Para simplificar las ecuaciones diferenciales se introducen variables adimensionales. Se definen las variables $\varphi, \eta$ y la función de flujo $\psi$.

$$
\begin{gathered}
\varphi=c_{\mathrm{i}}^{0}-c_{\mathrm{i}} \\
c_{\mathrm{i}}^{0} \\
\eta=\left(\begin{array}{l}
g \cdot \alpha \\
4 v^{2}
\end{array}\right)^{1 / 4} x^{1 / 4} \\
\psi=4 v\left(\begin{array}{l}
g \cdot \alpha \\
4 v^{2}
\end{array}\right)^{1 / 4} x^{3 / 4} f(\eta)
\end{gathered}
$$

$v$ es la viscosidad cinemática y $\alpha$ el coeficiente de densificación definido según:

$$
\alpha=c_{\mathrm{i}}^{0}\left(\begin{array}{c}
\partial \rho \\
\rho_{0} \\
\partial c_{\mathrm{i}}
\end{array}\right)_{c_{\mathrm{i}}=c_{\mathrm{i}}^{0}}
$$

Así las ecuaciones (6.4) y (6.5) se reducen a ecuaciones diferenciales ordinarias.

La función de flujo está relacionada con $V_{\mathrm{x}}, V_{\mathrm{y}} \mathrm{y}$ con la función desconocida $f(\eta)$,

$$
\begin{gathered}
V_{\mathrm{x}}=4 v\left(\begin{array}{l}
g \cdot \alpha \\
4 v^{2}
\end{array}\right)^{1 / 2} x^{1 / 2} d f \\
V_{\mathrm{y}}=v\left(\begin{array}{l}
g \cdot \alpha \\
4 v^{2}
\end{array}\right)^{1 / 4} x^{-1 / 4}\left(\begin{array}{c}
d f \\
d \eta
\end{array}-3 f\right)
\end{gathered}
$$

El procedimiento de resolución se encuentra resuelto extensamente en [163,164]. Aquí solo se da el resultado final, que expresa la concentración de la especie reactiva $c_{i}$ :

$$
c_{\mathrm{i}}=0,7 c_{\mathrm{i}}^{0}\left({ }^{v_{D_{\mathrm{i}}}}\right)^{1 / 4}\left(\begin{array}{ll}
g \alpha & \\
& 4 v^{2}
\end{array}\right)^{1 / 4}\left(\begin{array}{ll}
y & \\
& X^{1 / 4}
\end{array}\right)
$$


y la densidad de corriente en un punto de la superficie del electrodo es:

$$
j=0,7 \mathrm{z}_{\mathrm{i}} \mathrm{F} D_{\mathrm{i}} c_{\mathrm{i}}^{0}\left({ }^{v}{ }_{D_{\mathrm{i}}}\right)^{1 / 4}\left({ }^{g \alpha} 4 v^{2}\right)^{1 / 4} X^{-1 / 4}
$$

\subsection{Convección natural no isotérmica}

Los procesos de transferencia de materia están generalmente acompañados por transferencia de calor [170]. Las fuerzas de Arquímides, afectadas por el calentamiento no uniforme de la solución, pueden representarse en forma aproximada por la suma de los cambios de densidad producidos por las variaciones de concentración de las especies disueltas debido a la reacción electroquímica, y por los cambios de densidad producidos por los gradientes térmicos en el sistema. La fuerza de Arquímides por unidad de área transversal puede expresarse como:

$$
f_{\mathrm{g}}=g \sum_{i}^{\partial \rho} \partial c_{\mathrm{i}}\left(c_{\mathrm{i}}-c_{\mathrm{i}}^{0}\right)+g \frac{\partial \rho}{\partial T}\left(T-T_{0}\right)
$$

donde $c_{\mathrm{i}}^{0}$ y $T_{0}$ representan las concentración de las especies disueltas y la temperatura del seno de la solución, respectivamente.

En la convección natural no isotérmica, la temperatura además de las fuerzas de Arquímides afecta también las leyes de conservación de las especies disueltas. La presencia de gradientes térmicos puede producir, en ciertos casos, la difusión de las especies disueltas. Este fenómeno se conoce como efecto Soret [171,172]. El efecto contrario, la producción de flujo térmico debido a la presencia de gradientes de concentración, se conoce como efecto Dufour [171]. Para las temperaturas empleadas en la mayoría de las soluciones acuosas estos dos efectos pueden despreciarse [158].

Las primeras soluciones numéricas de las ecuaciones que describen la transferencia simultánea de materia y de calor en convección natural, utilizando electrodos planos verticales, se obtuvo en la aplicación de la pulverización de gotas y el funcionamiento de reactores catalíticos [173].

En los procesos electroquímicos, el calentamiento no uniforme surge del efecto Joule [174], esto es, disipación de calor por pasaje de corriente en un medio resistivo. El efecto Joule puede ser beneficioso en algunas circunstancias, como medio de calentamiento en los procesos que involucran sales fundidas, o perjudiciales, en los equipos de almacenamiento y conversión de energía. A diferencia de otras variables electroquímicas, como el potencial aplicado y la corriente, la temperatura como fuerza 
impulsora fue considerada en la mayoría de los casos en forma independiente en los problemas de transferencia de calor por convección. En estos casos se utilizaron perturbaciones térmicas simples o periódicas [174-179].

Marchiano y Arvia $[158,180]$ consideraron el problema de la convección natural no isotérmica teóricamente en la aproximación del modelo de la película límite, y experimentalmente con un sistema de electrodos planos verticales termostatizados. Las ecuaciones que plantean el problema incluyen la transferencia de momento, materia y calor. Utilizando un procedimiento similar al mostrado en la sección 7.2.1, resolvieron el sistema de ecuaciones para encontrar la expresión de la función de distribución de concentraciones y así el flujo y la corriente en la superficie del electrodo. Un esbozo del procedimiento empleado para la resolución se muestra en el apéndice D.

La ecuación que resulta para la densidad de corriente límite promedio $\left\langle j_{\mathrm{L}}>\right.$ es:

$$
j_{\mathrm{L}}=0,90 z_{\mathrm{i}} \mathrm{F} D_{\mathrm{i}} c_{\mathrm{i}}^{0}\left(\begin{array}{l}
\alpha^{3 / 4} \pm \beta^{3 / 4} \\
S c^{1 / 4} \pm \operatorname{Pr}^{1 / 4}
\end{array}\right)^{1 / 3} S c^{1 / 3}\left(\begin{array}{c}
g \\
4 v^{2}
\end{array}\right)^{1 / 4} X^{-1 / 4}
$$

donde $\alpha$ y $\beta$ son los coeficientes de densificación:

$$
\begin{gathered}
\alpha=\begin{array}{l}
c_{i}^{0} \partial \rho \\
\rho_{0} \partial c
\end{array} \\
\beta=\begin{array}{ll}
\Delta T^{\prime} & \partial \rho \\
\rho_{0} & \partial T
\end{array}
\end{gathered}
$$

$\operatorname{Pr}$ es el número de Prandlt cuya expresión es $\operatorname{Pr}=v \rho_{0} C_{\mathrm{p}} / \kappa$, con $C_{\mathrm{p}}$ la capacidad calorífica a presión constante, $\rho_{0}$ y $\kappa$ la densidad y la conductividad térmica de la solución, respectivamente, $S c=v / D$ es el número de Schmidt, $\Delta T^{\prime}=T_{0}-T_{\mathrm{c}}, T_{0}$ la temperatura promedio entre el cátodo y el ánodo y $T_{\mathrm{c}}$ la temperatura del electrodo de trabajo. El resto de los símbolos tienen el significado conocido.

La ecuación (6.25) puede expresarse en forma de una correlación adimensional:

$$
\begin{gathered}
S h=(0,9)\left(S c G r^{*}\right)^{1 / 4} \\
G r^{*}=\left[\alpha^{3 / 4} \pm \beta^{3 / 4}\left(\begin{array}{c}
S c \\
P r
\end{array}\right)^{1 / 4}\right]^{4 / 3}\left(\begin{array}{c}
g \\
4 v^{2}
\end{array}\right) X^{3}
\end{gathered}
$$




$$
S h=\begin{gathered}
j_{\mathrm{L}} X \\
n F c_{\mathrm{i}}^{0} D_{\mathrm{i}}
\end{gathered}
$$

La validez de la ecuación (6.28) fue comprobada utilizando datos electroquímicos para la electrodeposición de cobre bajo control de difusión y convección usando solución acuosa de $\mathrm{CuSO}_{4}+\mathrm{H}_{2} \mathrm{SO}_{4}$ y diferencias de temperatura positivas y negativas $\Delta T$ entre el cátodo y el ánodo [180].

La teoría predice que para cierto gradiente de temperatura crítico, los efectos convectivos originados por los gradientes de densidad que se producen por los cambios locales en la concentración de las especies debido a la reacción electroquímica en la interface, se contrarestan con los gradientes de densidad producidos por el $\Delta T$ entre los electrodos $\mathrm{y}$, por ende, en la interfase electrodo/solución. Recientemente, la teoría fue confirmada por experimentos de impedancia faradaica [181] utilizando funciones de transferencias termoelectroquímicas $[182,183]$. 


\subsection{Resultados del estudio de la convección natural en celdas quasi-bidimensionales}

En las próximas secciones de este capítulo se muestra la influencia de la incorporación de un campo de temperaturas y de la variación de la altura del electrodo de trabajo (i.e. la altura de la celda en el presente caso) en la densidad de corriente límite para la electrodeposición de la plata, utilizando las celdas BIII y BIV. En el capítulo 4, se demostró que la convección natural es un proceso de transporte importante en la electrodeposición de plata en celdas quasi-bidimensionales. Además se observa que después de un cierto tiempo se producen transiciones morfológicas en los electrodepósitos que sugieren cambios en el flujo de la especie electroactiva. Los diagrama morfológicos presentados en el capítulo 4 muestran varias morfologías que dependen de la concentración de las especies electrolíticas $c_{\mathrm{i}}$ y del potencial aplicado $\Delta \mathrm{E}_{\mathrm{c}-\mathrm{a}}$ en celdas de geometría circular y rectangular. Es necesario indagar acerca de la magnitud de los distintos mecanismos de transporte para complementar la información que pueden aportar los diagramas morfológicos.

Como se discutió en las secciones precedentes, los cambios de densidad se pueden originar por variaciones en la concentración de las especies electrolíticas en las inmediaciones de los electrodos o debida a gradientes de temperatura, sean estos consecuencia del efecto Joule o de un campo térmico externo. Por otro lado, en la literatura se pueden encontrar resultados experimentales, obtenidos por distintas técnicas, que apoyan la presencia de fenómenos convectivos en celdas cuasi-bidimensionales $[78,87,92,93]$. Cave mencionar que en muchos de esos trabajos, debido a que los potenciales aplicados son mayores que $5 \mathrm{~V}$, el efecto Joule y los fenómenos de electroconvección pueden ser procesos importantes, y pueden enmascarar la convección libre.

A continuación, en 6.4.1. se aplica la correlación general deducida para la difusiónconvectiva estacionaria a los datos de electrodeposición de plata obtenidos en celdas cuasibidimensionales y tridimensionales, tanto en condiciones isotérmicas como no isotérmicas. Se determinan las propiedades fisicoquímicas de las soluciones electrolíticas, se analizan los transitorios de corriente, y se estudia la influencia de la rugosidad de la interfase en relación a los errores que puede causar en la determinación de la densidad de corriente límite. En 6.4.2 se analizan las posibles causas de error en las determinaciones como consecuencia de las características intrínsecas del proceso de electrodeposición en las condiciones del presente trabajo. En 6.4.3 se comparan resultados de otros autores frente a la correlación usada en este trabajo. 
6.4.1 Verificación de la ecuación general de difusión convectiva en condiciones isotérmicas y no-isotérmicas en celdas cuasi-bidimensionales y celdas tridimensionales

Para verificar la ecuación (6.25), es necesario, por un lado, medir la densidad de corriente límite y, por el otro, evaluarla reemplazando las magnitudes de las propiedades y constantes involucradas.

Se comienza con el cálculo de la densidad de corriente límite media $<j_{\mathrm{L}}>$ por medio de (6.25). Se deben tener en cuenta algunas aproximaciones en el cálculo de las propiedades del sistema. Así, las propiedades fisicoquímicas del seno de la solución se refieren a la temperatura media $T_{0}=\left[T_{\mathrm{c}}+T_{\mathrm{a}}\right] / 2$, mientras que las de la solución en la superficie del electrodo de trabajo se refieren a la temperatura del cátodo $\left(T_{\mathrm{c}}\right)$.

Para calcular el grupo adimensional $S c G r^{*}(6.28)$ las propiedades del seno de la solución se consideran independientes de la concentración. Esto resulta real cuando se trabaja en presencia de una alta concentración de electrolito soporte. La densidad de las soluciones se determinaron por medidas picnométricas cubriendo el rango de temperatura usado en los experimentos y el rango de concentración resultante de los cambios de concentración producidos por la reacción de electrodeposición, en el electrodo de trabajo.

Tabla 6.1. Valores de $\kappa, C_{p}, \rho, v, \alpha, \operatorname{Pr}$ y $S c$ a diferentes $T_{0}$ para Soluciones acuosas de sulfato de plata $0,024 \mathrm{M}+$ ácido sulfúrico $0,5 \mathrm{M}$.

\begin{tabular}{cccccccc}
\hline$T_{0} /{ }^{\circ} \mathrm{C}$ & $\kappa / \mathrm{J} \mathrm{s} \mathrm{cm}^{-1}{ }^{\circ} \mathrm{C}^{-1}$ & $C_{\mathrm{p}} / \mathrm{J} \mathrm{g}^{-10} \mathrm{C}^{-1}$ & $\rho / \mathrm{gcm}^{-3}$ & $10^{2} v / \mathrm{cm}^{2} \mathrm{~s}^{-1}$ & $10^{3} \alpha$ & $P r$ & $S c$ \\
\hline 22.5 & 0,00578 & 4,1824 & 1,0207 & 0,9500 & 3,32 & 7,0 & 841 \\
25 & 0,00582 & 4,1813 & 1,0202 & 0,8860 & 3,33 & 6,4 & 724 \\
27.5 & 0,00586 & 4,1803 & 1,0198 & 0,8335 & 3,53 & 6,1 & 641 \\
30 & 0,00590 & 4,1795 & 1,0192 & 0,7856 & 3,53 & 5,7 & 565 \\
32.5 & 0,00594 & 4,1795 & 1,0187 & 0,7650 & 3,63 & 5,5 & 517 \\
35 & 0,00598 & 4,1795 & 1,0183 & 0,7095 & 3,83 & 5,1 & 452 \\
37.5 & 0,00602 & 4,1795 & 1,0178 & 0,6779 & 3,93 & 4,8 & 408 \\
40 & 0,00606 & 4,1800 & 1,0173 & 0,6448 & 3,93 & 4,5 & 368 \\
45 & 0,00614 & 4,1813 & 1,0163 & 0,5904 & 4,13 & 4,1 & 304 \\
50 & 0,00622 & 4,1825 & 1,0153 & 0,5417 & 4,33 & 3,7 & 256 \\
\hline
\end{tabular}

Según las ecuaciones (6.26) y (6.27), los valores de $\alpha$ y $\beta$ se evalúan tomando $\partial \rho / \partial c_{\mathrm{i}}=1,886 \times 10^{-4} \mathrm{~g} \mathrm{~mol}^{-1}$ y $\partial \rho / \partial \mathrm{T}=1,950 \times 10^{-4} \mathrm{~g} \mathrm{~cm}^{-3}{ }^{\circ} \mathrm{C}^{-1}$, obtenidos de las pendientes de los gráficos de $\rho$ en función de la concentración de sulfato de plata y de $\rho$ en función de la temperatura, respectivamente. Los valores de los coeficientes de difusión del ión reactivo $D_{\mathrm{i}}$, la conductividad térmica $\kappa$, la capacidad calorífica a presión constante $C_{\mathrm{p}}$, y la viscosidad cinemática $v$, se tomaron de la literatura [183]. Estos valores, junto con los de $\rho$, $\alpha, \operatorname{Pr}$ y $S c$ para distintas temperaturas, se consignan en la Tabla 6.1. 
La medida de la corriente de los transitorios potenciostáticos, debe realizarse a un tiempo en el cual el área inicial (la única conocida) pueda usarse para calcular la densidad de corriente. Como la cinética de crecimiento está gobernada por la transferencia de materia, la corriente medida en las curvas de relajación correspondientes al potencial de corriente límite es $\left\langle I_{\mathrm{L}}>\right.$.

Para los experimentos con $X \geq 0,3 \mathrm{~cm}$, los transitorios de corriente (figura 6.1a) muestran un decrecimiento de $I_{\mathrm{c}}$ en el rango $20 \leq t \leq 0 \mathrm{~s}$ que se aproxima a $I_{\mathrm{c}} \propto t^{-1 / 2}$ solo en los primeros $5 \mathrm{~s}$ iniciales. Luego $I_{\mathrm{c}}$ alcanza un valor mínimo y, a partir de allí, aumenta nuevamente hasta un valor máximo cuando se establece la convección natural. El tiempo al cual aparece el valor máximo de $I_{\mathrm{c}}$ decrece o crece con $\Delta T^{\prime}=T_{0}-T_{\mathrm{c}}$, dependiendo si $\Delta T^{\prime}$ es negativo o positivo, respectivamente. Esto está en acuerdo con la teoría de la ecuación (6.25). Finalmente, $I_{\mathrm{c}}$ alcanza un valor estacionario para $t>300 \mathrm{~s}$. La misma descripción vale para los transitorios realizados empleando celdas con $X=0,025 \mathrm{~cm}$ (figura $6.1 \mathrm{~b}$ ), aunque en estos casos, como se ve del gráfico $I_{\mathrm{c}}$ versus $t$, después de la caída inicial, la corriente se hace ruidosa. En el rango $150 \leq t \leq 300 \mathrm{~s} I_{\mathrm{c}}$ permanece constante y luego aumenta debido a las transiciones morfológicas (analizadas en el próximo capítulo) que aumentan el área activa. 

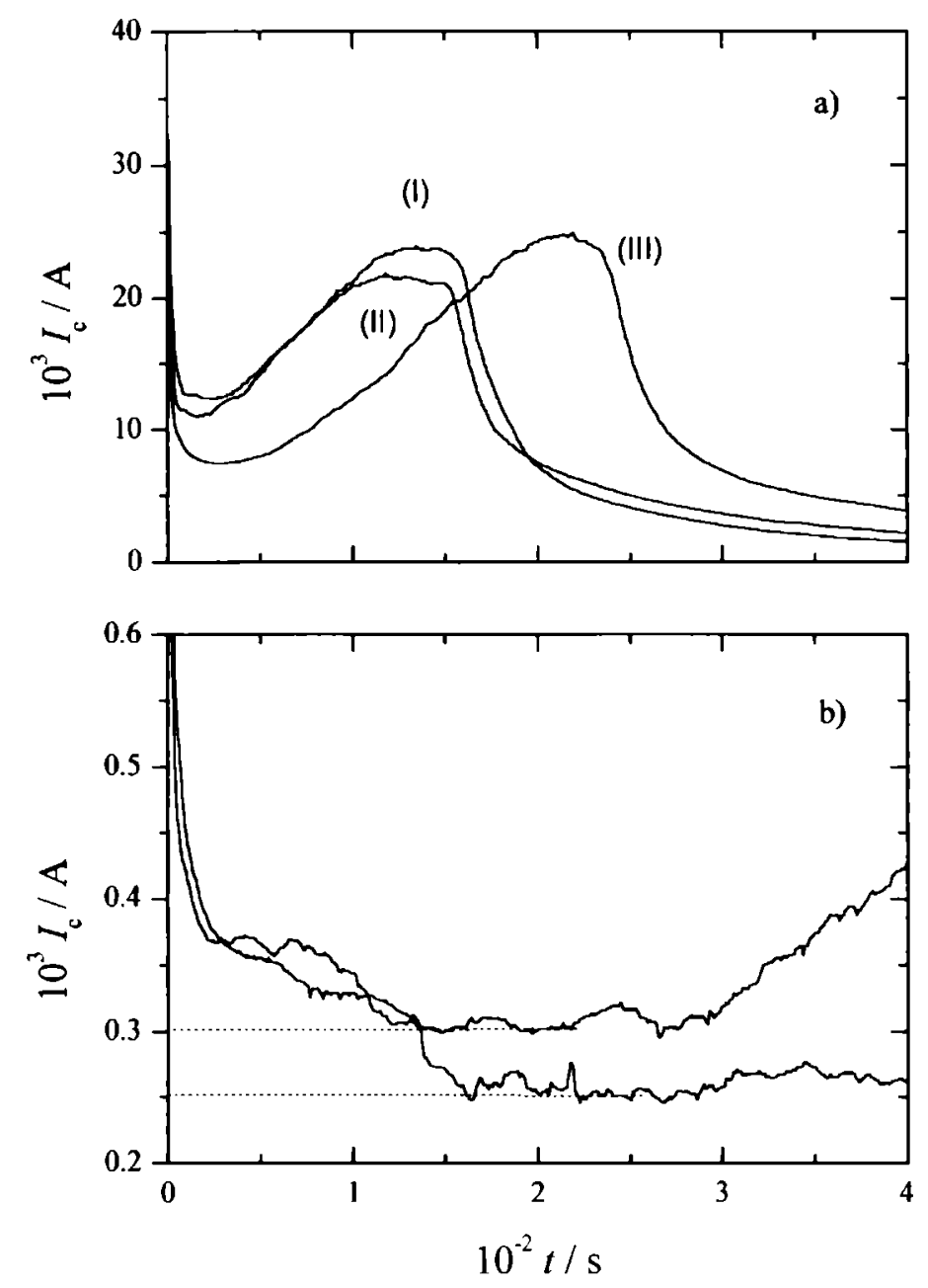

Figura 6.1. Transitorios potenciostáticos de corriente para la electrodeposición de plata empleando solución II + ácido sulfúrico $0.5 \mathrm{M}$. a) celda rectangular tridimensional BIV a $\Delta \mathrm{E}_{\mathrm{c}-\mathrm{a}}=-0.40 \mathrm{~V}$; (I) $T_{\mathrm{a}}=T_{\mathrm{c}}=27^{\circ} \mathrm{C}$; (II) $T_{\mathrm{a}}=22.5^{\circ} \mathrm{C}$ and $T_{\mathrm{c}}=27^{\circ} \mathrm{C}$; (III) $T_{\mathrm{a}}=35^{\circ} \mathrm{C}$ and $T_{\mathrm{c}}=27^{\circ} \mathrm{C}$. b) celda rectangular 2-D BIII, a $\Delta \mathrm{E}_{\mathrm{c}-\mathrm{a}}=-0,45 \mathrm{~V}$. Las líneas horizontales de trazo indican las zonas donde se toman los valores de la corriente.

Para la difusión pura el gráfico de $Q_{\mathrm{d}} I_{\mathrm{c}}$ en función del tiempo, es una recta de pendiente 2 , mientras que para la convección natural, el gráfico es una recta de pendiente 1 (ver capítulo 4, Tabla 4.9). Los gráficos $Q_{\mathrm{d}} I_{\mathrm{c}}$ experimentales muestran que para la electrodeposición de plata en condiciones isotérmicas, para tiempos en el rango $\approx 0 \leq t \leq$ $600 \mathrm{~s}$, los datos se aproximan dentro del error experimental a la curva de convección estacionaria de pendiente 1 . La representación de $Q_{\mathrm{d}} / I_{\mathrm{c}}$ en función del tiempo para los datos de los transitorios de corriente potenciostáticos, en principio debería ser independiente del área del electrodo de trabajo. Sin embargo, las desviaciones al comportamiento teórico se deben a la variación del área activa con el tiempo. 


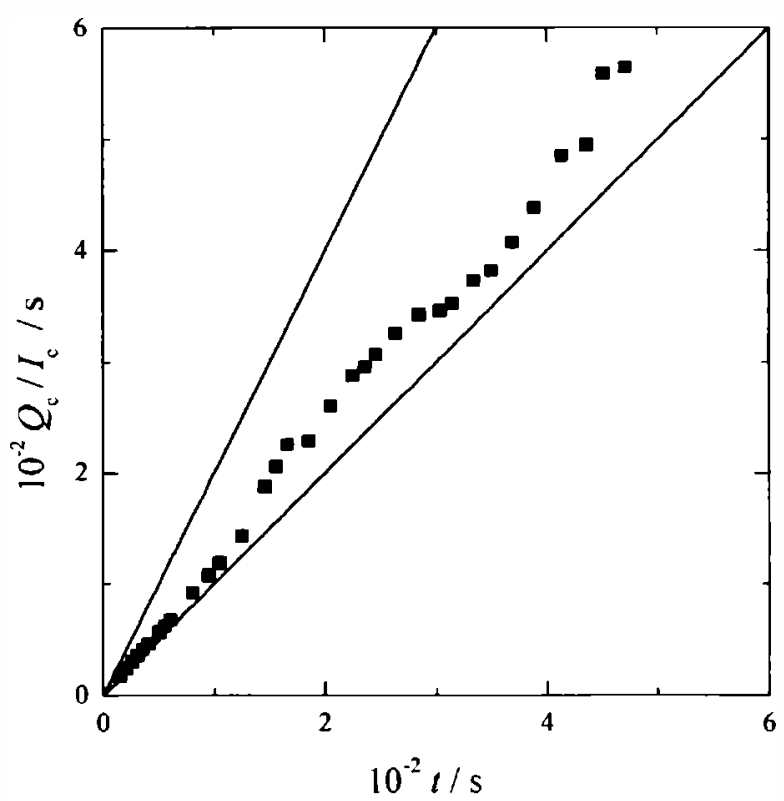

Figura 6.2. Representación de $Q_{\mathrm{c}} / I_{\mathrm{c}}$ versus $t$ correspondiente a un transitorio potenciostático de corriente para la electrodeposición de plata con $T_{\mathrm{a}}=T_{\mathrm{c}}=30{ }^{\circ} \mathrm{C}$. Las condiciones de electrodeposición se indican en la figura 6.1b. La línea continua superior corresponde a la difusión pura y la inferior a la convección natural.

Las representaciones $Q_{d} I_{\mathrm{c}}$ para los experimentos no isotérmicos se muestran en la figura 6.3 y 6.4

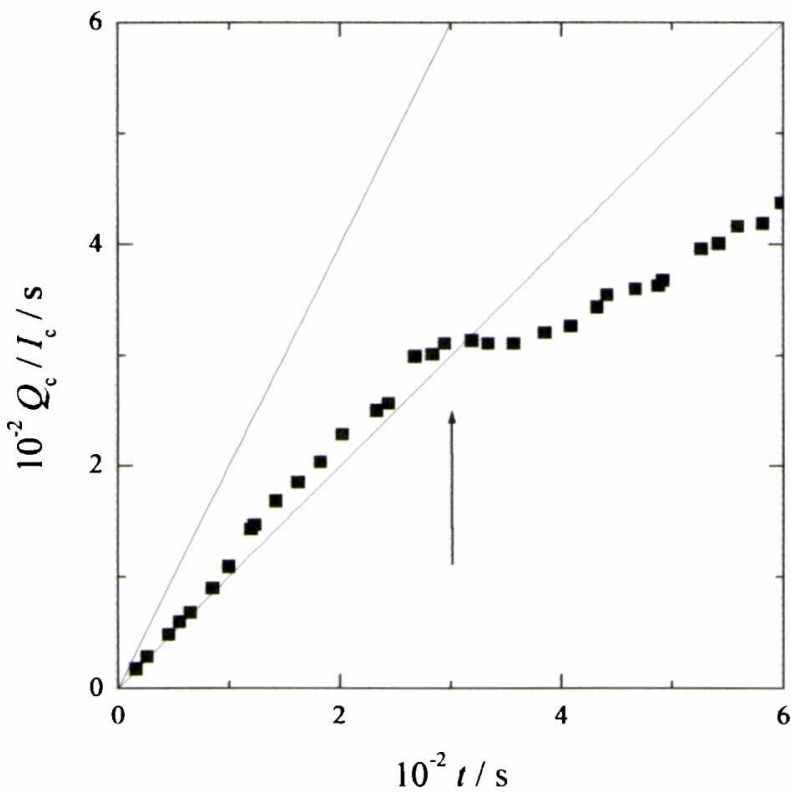

Figura 6.3. Representación de $Q_{\mathrm{d}} I_{\mathrm{c}}$ versus $t$ correspondiente a un transitorio potenciostático de corriente para la electrodeposición de plata con $T_{\mathrm{a}}=40$ y $T_{\mathrm{c}}=30^{\circ} \mathrm{C}$. Las condiciones de electrodeposición se indican en la figura 6.1b. La línea continua superior corresponde a la difusión pura y la inferior a la convección natural. La flecha vertical indica transición en el crecimiento. 


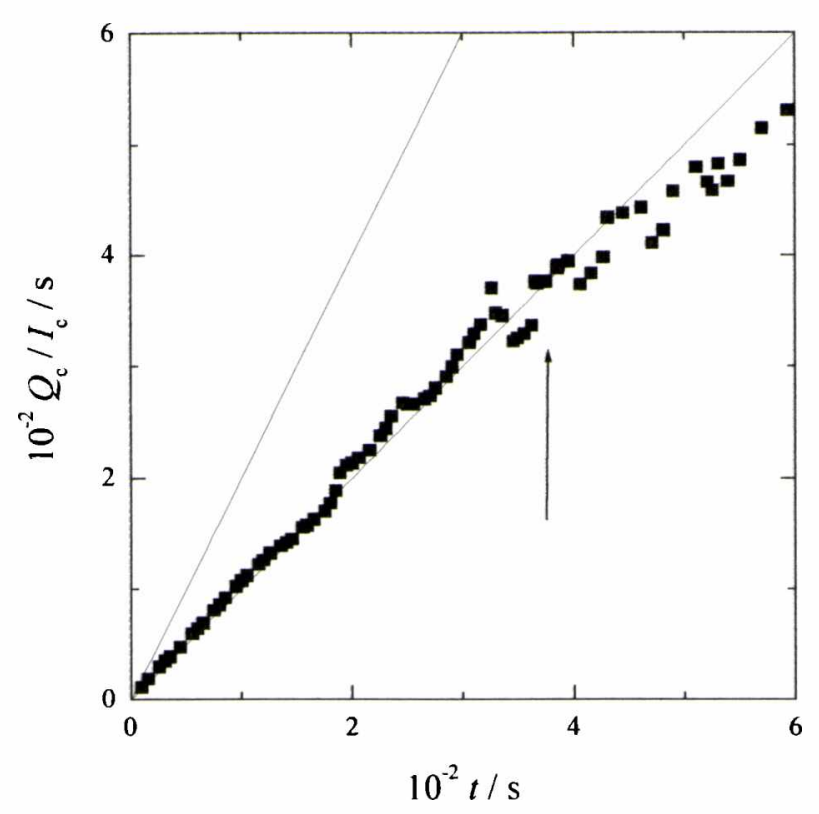

Figura 6.4. Representación de $Q d I_{\mathrm{c}}$ versus $t$ correspondiente a un transitorio potenciostático de corriente para la electrodeposición de plata con $T_{\mathrm{a}}=40$ y $T_{\mathrm{c}}=30^{\circ} \mathrm{C}$. Las condiciones de electrodeposición se indican en la figura 6.1b. La línea continua superior corresponde a la difusión pura y la inferior a la convección natural. La línea vertical indica transición en el crecimiento.

Para los experimentos no isotérmicos (figura 6.3 y 6.4), para $t$ pequeños y antes de producirse transición morfológica, las representaciones de $Q_{d} I_{\mathrm{c}}$ muestran al igual que los resultados isotérmicos, una dependencia lineal con el tiempo, con una pendiente que se aproxima a 1. Los datos no isotérmicos muestran menor dispersión que los datos isotérmico, siempre y cuando no se produzcan transiciones morfológicas en el electrodepósito (ver capítulo 4 y 7). Las transiciones se indica con las flechas verticales, indicando el tiempo a partir del cual la variación de área hace incierta la determinación de $<I_{\mathrm{L}}>$.

Las secuencias de imágenes obtenidas en la electrodeposición de plata, dan información acerca de la evolución de la rugosidad $\left(W_{y}\right)$ del frente, definida por la expresión (2.33). 


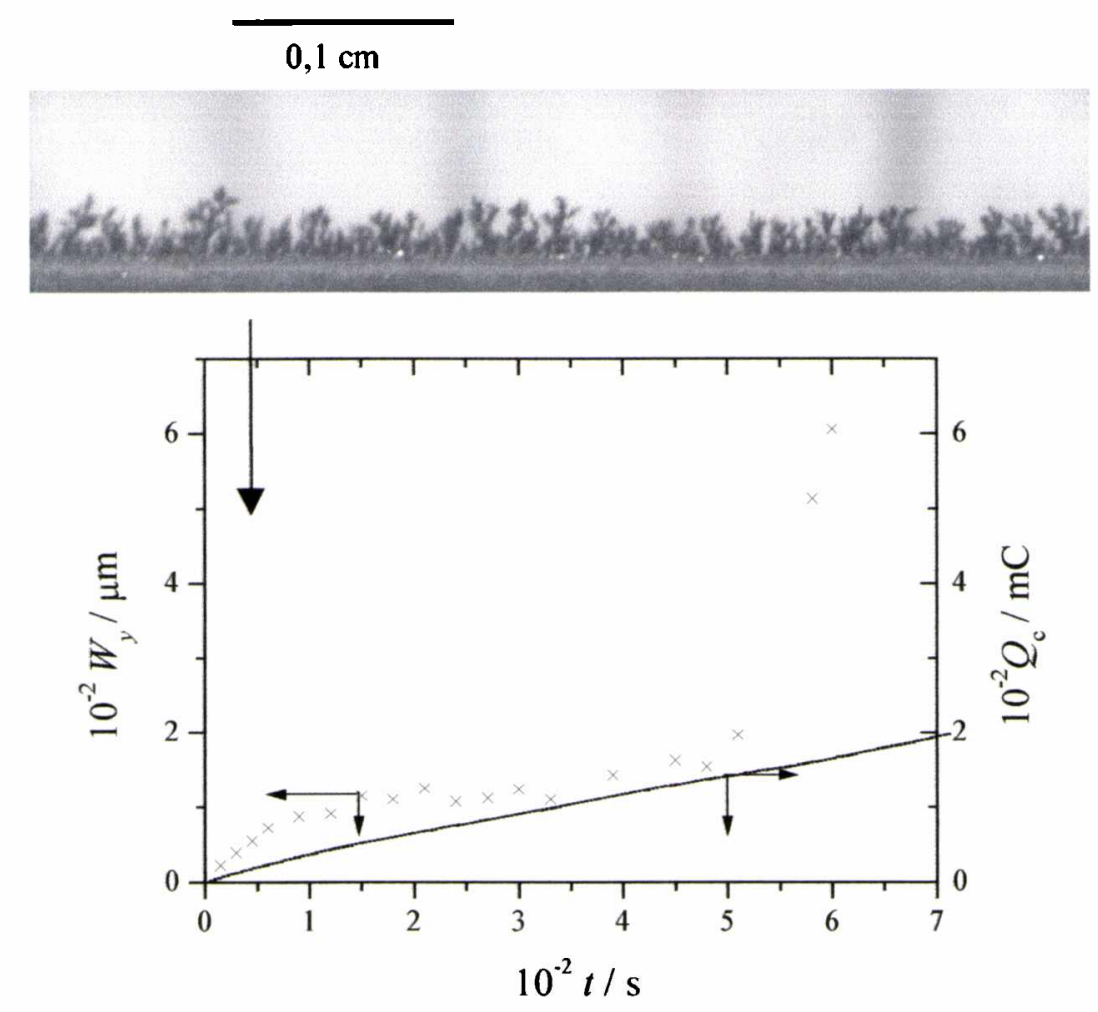

Figura 6.5. Gráfico típico de $W_{y}$ y $Q_{\mathrm{c}}$ versus $t$. Crecimiento de los electrodepósitos obtenidos bajo las condiciones especificadas en la Fig. 6.1b. En el intervalo $70 \leq t \leq 350 \mathrm{~s}$ la rugosidad permanece constante. Se incluye en la parte superior una imágen del electrodepósito a $t=25 \mathrm{~s}$ en la que se midió la rugosidad.

De acuerdo con el gráfico de $W_{y}$ en función del tiempo (figura 6.5) el valor de $W_{y}$ aumenta con $t$, pero en el rango $70 \leq t \leq 300 \mathrm{~s} W_{y}$ permanece constante y siempre menor que el espesor de la película límite. Los valores de los espesores de la película hidrodinámica se compilan más adelante en la tabla 6.3. Por lo tanto, se concluye que en el rango $70 \leq t \leq 300 \mathrm{~s}$, la influencia de la rugosidad en el valor de $I_{\mathrm{L}}$ es pequeña, lo cual hace posible calcular la densidad de corriente como $j_{\mathrm{c}, \mathrm{L}}=I_{\mathrm{c}, \mathrm{L}} / \mathrm{A}$, donde A es el área inicial del cátodo.

Los valores de $S h$ calculados a partir de la corriente límite para distintas condiciones experimentales se consignan en la tabla 6.2. 
Tabla 6.2. Valores de la densidad de corriente límite y los $S h$ experimentales para distintas $X, \Delta T^{\prime}$ y $T_{\mathrm{c}}$.

\begin{tabular}{|c|c|c|c|c|}
\hline$T_{\mathrm{c}} /{ }^{\circ} \mathrm{C}$ & $\Delta T^{\prime} /{ }^{\circ} \mathrm{C}$ & $X / \mathrm{cm}$ & $10^{4} I_{\mathrm{L}} / \mathrm{A}$ & $S h$ \\
\hline 30.0 & $-6,8$ & 0,025 & 2,7 & 3,0 \\
\hline 30.0 & $-6,0$ & 0,025 & 2,5 & 2,8 \\
\hline 30.0 & $-2,5$ & 0,025 & 2,7 & 3,0 \\
\hline 30.0 & 0,0 & 0,025 & 3,1 & 3,4 \\
\hline 30.0 & 2,5 & 0,025 & 2,1 & 2,3 \\
\hline 30.0 & 5,1 & 0,025 & 2,2 & 2,4 \\
\hline 30.0 & 7,5 & 0,025 & 2,9 & 3,2 \\
\hline 30.0 & 8,2 & 0,025 & 3,2 & 3,6 \\
\hline 30.0 & 9,4 & 0,025 & 3,0 & 3,4 \\
\hline 30.0 & 11,6 & 0,025 & 2,7 & 3,0 \\
\hline 30.0 & 15,0 & 0,025 & 3,4 & 3,7 \\
\hline 35.0 & 0 & 0,025 & 2,7 & 2,7 \\
\hline 35.0 & $-2,5$ & 0,025 & 2,1 & 2,1 \\
\hline 35.0 & 2,5 & 0,025 & 2,8 & 2,8 \\
\hline 40.0 & 0,0 & 0,025 & 39 & 3,4 \\
\hline 40.0 & $-2,5$ & 0,025 & 34 & 3,0 \\
\hline 30.0 & 3,3 & 0,15 & 10,8 & 5.6 \\
\hline 30.0 & 6,5 & 0,15 & 185 & 9,6 \\
\hline 30.0 & 8,5 & 0,15 & 15,0 & 7,8 \\
\hline 30.0 & 0,0 & 0,30 & 28,9 & 15,0 \\
\hline 30.0 & 6,5 & 0,30 & 35,8 & 18,5 \\
\hline 30.0 & 8,5 & 0,30 & 34,8 & 18,0 \\
\hline 45.5 & 9,3 & 1,00 & 95,0 & 52,6 \\
\hline 47.0 & 8,5 & 1,00 & 73,0 & 37,8 \\
\hline 43.0 & 6,5 & 1,00 & 73,0 & 37,8 \\
\hline 45.5 & 7,8 & 1,00 & 93,5 & 48,4 \\
\hline 45.0 & 2.5 & 1.00 & 97.5 & 40,1 \\
\hline 40.0 & 0,0 & 1,00 & 96,5 & 39,7 \\
\hline 40.0 & $-1,8$ & 1,00 & 100,0 & 41,1 \\
\hline 27.0 & $-2,3$ & 1,00 & 97,0 & 53,7 \\
\hline 0.0 & $-2,5$ & 1,00 & 103,0 & 57,0 \\
\hline 30.0 & $-4,0$ & 1,00 & 120,0 & 62,2 \\
\hline 40.0 & $-5,0$ & 1,00 & 112,5 & 46,3 \\
\hline
\end{tabular}

En la figura 6.6 se grafican como $\log S h$ vs. $\log \left(S c G r^{*}\right)$ a) y $S h$ vs. $S c G r^{*}$ b), los resultados de las mediciones con las celdas BIII y BIV para distintos sistemas electroquímicos. En los gráfico se incluye también datos correspondientes a la electrodeposición de cobre $[159,180]$ obtenidos usando celdas de geometría similar pero tridimensionales $\left(X=1 \mathrm{~cm}, l_{w}=1 \mathrm{~cm}\right.$ y $\left.l_{\mathrm{a}-\mathrm{c}}=4 \mathrm{~cm}\right)$. La línea punteada corresponde a la ecuación (6.28). 

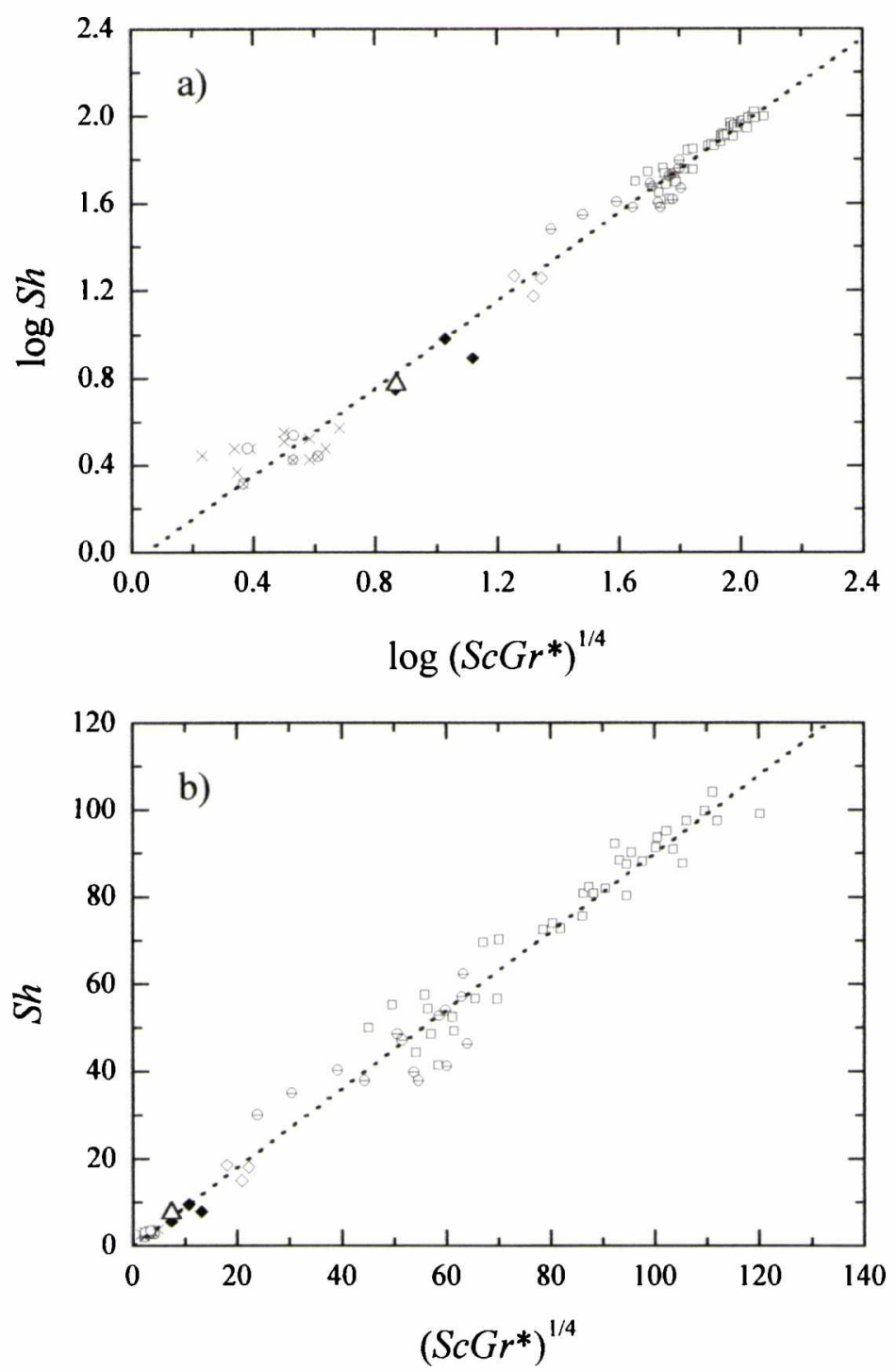

Figura 6.6. Gráficos de: a) $\log S h$ versus $\log \left(S c G r^{*}\right)^{1 / 4}$ y b) $S h$ versus $\left(S c G r^{*}\right)^{1 / 4}$. Los datos corresponden a distintas reacciones electroquímicas, dimensiones de celda y gradientes de temperatura. Electrodeposición de plata empleando solución II + ácido sulfúrico $0.5 \mathrm{M}:(\mathrm{x}) X=0,025 \mathrm{~cm}, \Delta \mathrm{E}_{\mathrm{c}-\mathrm{a}}=$ $-0,45 \mathrm{~V} ;(\mathrm{O}) X=0,025 \mathrm{~cm}, \Delta \mathrm{E}_{\mathrm{c}-\mathrm{a}}=-0,475 \mathrm{~V} ;(\bullet) X=0,15 \mathrm{~cm}, \Delta \mathrm{E}_{\mathrm{c}-\mathrm{a}}=-0,40 \mathrm{~V} ;(0) X=0,3 \mathrm{~cm}, \Delta \mathrm{E}_{\mathrm{c}-\mathrm{a}}=$ $-0,40 \mathrm{~V} ; \mathrm{y}(\Theta) X=1,0 \mathrm{~cm}, \Delta \mathrm{E}_{\mathrm{c}-\mathrm{a}}=-0,40 \mathrm{~V}$. Electrodeposición de palta empleando solución II + ácido sulfúrico 1,0 M: $(\otimes) X=0,025 \mathrm{~cm}, \Delta \mathrm{E}_{\mathrm{c}-\mathrm{a}}=-0,45 \mathrm{~V}$. Electro-reducción del ión Ferricianuro sobre níquel, empleando solución de ferri/ferrocianuro de potasio $0,05 \mathrm{M}+$ hidróxido de sodio $2 \mathrm{M}:(\Delta) X=0,10 \mathrm{~cm}$, $\Delta \mathrm{E}_{\mathrm{c}-\mathrm{a}}=-0,40 \mathrm{~V}$; Electrodeposición de cobre empleando solución de sulfato de cobre $0,005 \mathrm{M}+$ ácido sulfúrico 1,5 M (datos extraídos de [159]): ( $\square) X=1,0 \mathrm{~cm}$. La línea punteada corresponde a la ecuación (6.28). El gráfico de $S h$ versus $\left(S c G r^{*}\right)^{1 / 4}$ (b) permite una apreciación más clara de la magnitud del error de las determinaciones. 
El acuerdo entre los datos experimentales y la ecuación teórica es razonablemente bueno y se extiende a dos órdenes de magnitud en $\left(S c G r^{*}\right)^{1 / 4}$, cubriendo los rangos $-10 \leq \Delta T^{\prime} \leq 15^{\circ} \mathrm{C}$ y $1 \geq X \geq 0,025 \mathrm{~cm}$.

El error de las determinaciones, referido a la pendiente teórica (ecuación 7.24) en el gráfico log-log, es $\pm 0,01$ y el error probable es $\pm 0,04$.

\subsubsection{Posibles interferencias en el proceso de difusión convectiva}

\subsubsection{El efecto Stefan}

En todas las condiciones, tanto para condiciones isotérmicas como no isotérmicas, la formación del electrodepósito sólido implica el avance del frente que crece en la solución. Este fenómeno, se conoce como efecto Stefan y puede resultar importante en los experimentos aquí presentados [122]. Se intenta saber entonces, en qué medida este efecto contribuye a la transferencia de materia en la interfase. Para ello, se mide la velocidad de desplazamiento del frente en la dirección perpendicular al electrodo para distintos valores de $x$ (altura del electrodo). Simultáneamente se determina la velocidad de desplazamiento de partículas inertes de latex agregadas en la solución.

La velocidad local del frente de crecimiento (v) en el rango $0 \leq x \leq X=1 \mathrm{~cm}$ se determina utilizando la celda electroquímica con $X=1 \mathrm{~cm}$, y la velocidad del fluido $\left(V_{y}\right)$ en la dirección $y$ se evalúa por medio del desplazamiento de las partículas de látex suspendidas después de un tiempo de $50 \mathrm{~s}$ de iniciado el experimento. La velocidad del fluido medida es $V_{y}=140 \mu \mathrm{m} \mathrm{s}^{-1}$ (figura 6.7) y la velocidad del frente del electrodepósito resulta, $v \cong 32 \mu \mathrm{m} \mathrm{s}^{-1}$ para $x \rightarrow 0 \mathrm{~cm} ; v \cong 21 \mu \mathrm{m} \mathrm{s}^{-1}$ para $x \cong 0,5 \mathrm{~cm} \mathrm{y} v \cong 7,2 \mu \mathrm{m} \mathrm{s}^{-1}$ para $x \rightarrow 1 \mathrm{~cm}$. Estos resultados indican que para $X=1 \mathrm{~cm}$, la influencia del avance del frente en la transferencia de materia depende en forma inversa con la altura del cátodo.

Sin embargo es conveniente notar que la ecuación deducida en la sección 6.3 es válida para un sistema en el que un frente plano se mueve con velocidad constante. En los experimentos de electrodeposición descriptos en este trabajo, en los primeros estadios del crecimiento, el frente del electrodepósito es poco definido. Recién, luego de un cierto tiempo se forma un frente más o menos homogéneo que se desplaza a velocidad constante, y cuya área, en ausencia de transiciones morfológicas, permanece sin cambios. 

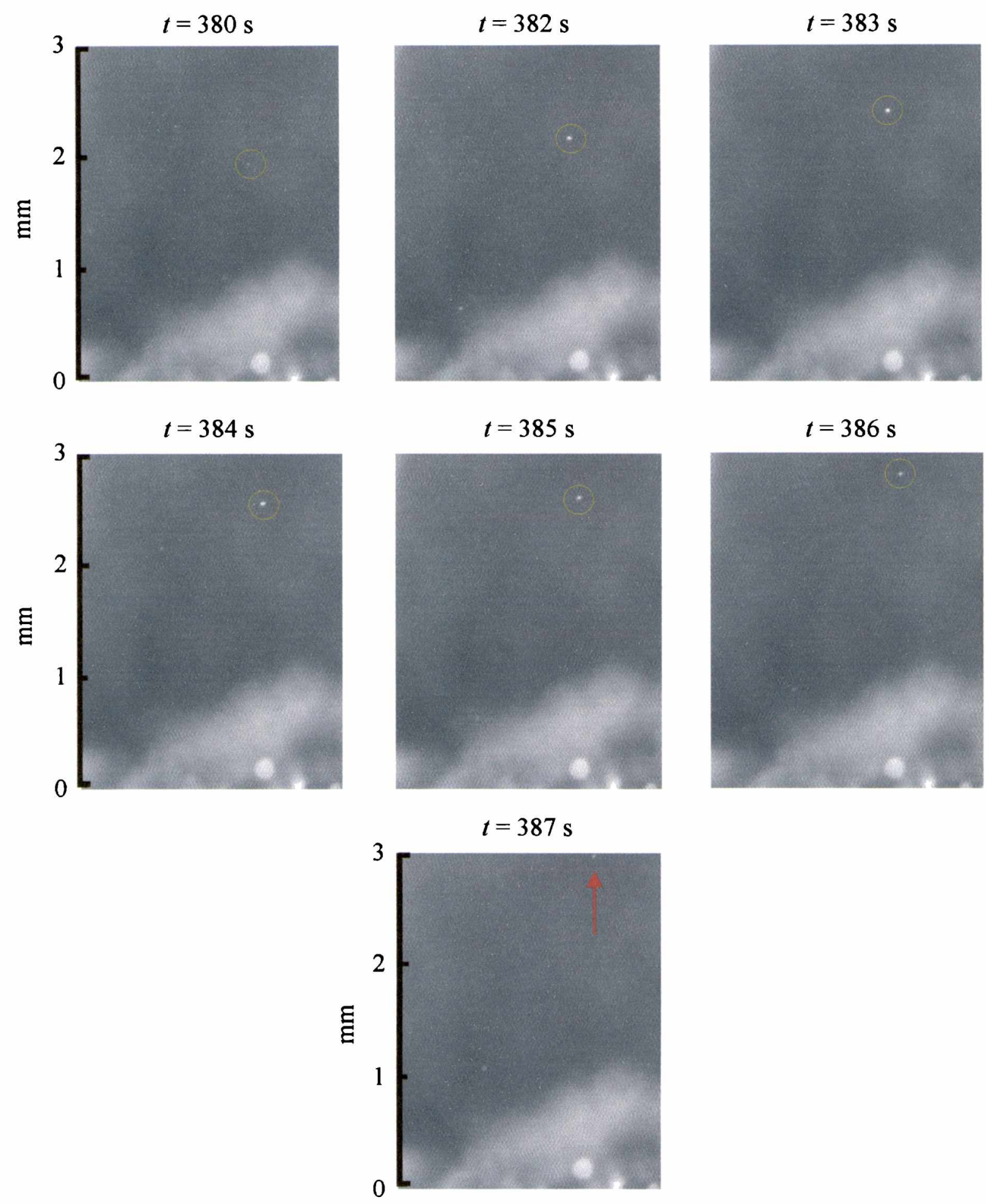

Figura 6.7. Secuencia de imágenes utilizadas para medir la velocidad del electrolito durante la electrodeposición de plata. Se utiliza la celda rectangular BIII con $X=1 \mathrm{~cm}$. Condiciones: solución $\mathrm{II}+$ ácido sulfúrico $0,5 \mathrm{M}, \Delta \mathrm{E}_{\mathrm{c}-\mathrm{a}}=-0,45 \mathrm{~V}$. Temperatura ambiente. 


\subsubsection{Distancia cátodo-ánodo}

Otra variable de importancia crítica, particularmente para las experiencias no isotérmicas, es la distancia mínima ánodo-cátodo $\left(l_{\mathrm{a}-\mathrm{c}}\right)$ que debe ser mayor que el doble del espesor de la película límite, para evitar el solapamiento de las películas límite catódica y anódica.

En este caso, puesto que en la convección no isotérmica el espesor de la película límite $\delta_{\mathrm{T}}$ está principalmente determinado por los cambios de densidad producidos por la diferencia de temperatura en distintas regiones del fluido, el gradiente de temperatura es determinante.

El espesor de la película límite se obtiene considerando la ecuación de distribución de temperaturas $[128,159]$ (ver apéndice D). Cuando la distancia desde el electrodo hacia la solución $(y)$, alcanza el valor del espesor de la película límite, la variable adimensional $\tau=$ $\left(T-T_{0}\right) / T_{0}$, se anula y la variable adimensional $\lambda$ en la ecuación de distribución (6.31), toma el valor de $\Lambda_{0}$.

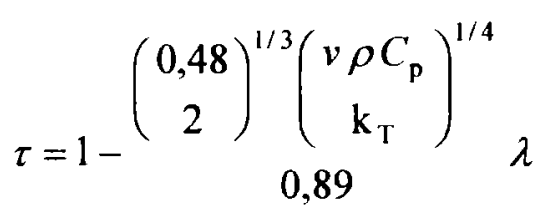

$$
\begin{aligned}
& \Lambda_{0}=0,89\left(\begin{array}{c}
0,48 \\
2
\end{array}\right)^{-1 / 3}\left(\begin{array}{c}
v \rho C_{\mathrm{p}} \\
\mathrm{k}_{\mathrm{T}}
\end{array}\right)^{-1 / 4}
\end{aligned}
$$

donde el significado de los símbolos se indicó en 6.2. El valor de $\delta_{\mathrm{T}}$ se estima para las condiciones de trabajo que hacen máximo el valor de $\Lambda_{0}$, de manera que resulte el valor mayor esperado del espesor de la película límite asociada con los fenómenos de transporte.

Luego con la definición de la variable adimensional (6.32) se calcula $y=\delta_{\text {T }}$ reemplazando en $\lambda$ el valor $\Lambda_{0}$ calculado de (6.31a)

$$
\lambda=\left(\begin{array}{c}
g \beta \\
4 v^{2} X
\end{array}\right)^{1 / 4} y
$$

Para los dos tipos de celda empleados, la película hidrodinámica, la térmica y la difusional se inician en el mismo punto, i.e., $x=0$ (ver esquemas de celda BIII y BIV en la parte experimental). Se calcularon los valores de $\delta_{\mathrm{T}}$ para distintas alturas de electrodo $(X)$, tomando $\Lambda_{0}=0,810$ y $v=9,500 \times 10^{-3} \mathrm{~cm}^{2} \mathrm{~s}^{-1}$, que se muestran en la Tabla 6.3. La dependencia de $\delta_{\mathrm{T}}$ con $X$ viene dada por la función $\delta_{\mathrm{T}}=0,168 X^{1 / 4}$. Por consiguiente, es 
posible concluir que las dimensiones de las dos celdas son apropiadas para los experimentos programados.

Tabla 6.3. Valores de $\delta_{\mathrm{T}}$ para distintas $X$.

\begin{tabular}{|c|c|}
\hline$X / \mathrm{cm}$ & $\delta_{\mathrm{T}} / \mathrm{cm}$ \\
\hline 0,010 & 0,053 \\
\hline 0,025 & 0,067 \\
\hline 0,150 & 0,104 \\
\hline 0,300 & 0,124 \\
\hline 0,500 & 0,141 \\
\hline 1,00 & 0,168 \\
\hline 5,00 & 0,251 \\
\hline
\end{tabular}

\subsection{Datos complementarios e interpretación de resultados}

\subsubsection{Correlación general}

Los datos experimentales confirman la validez de la ecuación (6.28) para electrodos verticales, usando tres tipos de reacciones electroquímicas, dos reacciones de electrodeposición que están asociadas con la formación de superficies rugosas y una reacción electroquímica en solución que tiene lugar en un electrodo liso inerte. La validez de la ecuación (6.28) se extiende dos ordenes de magnitud en $\left(S c G r^{*}\right)^{1 / 4}$, con alturas de electrodo que van desde los $0,025 \mathrm{~cm}$ a $1 \mathrm{~cm}$. Cuando el $\Delta T=0$, la ecuación (6.28) se convierte en la correlación isotérmica de transferencia de masa con presencia de convección natural, que se encuentra en la literatura.

Además se encuentra que los valores de la densidad de corriente límite $\left(j_{\mathrm{L}}\right)$ que se obtienen en la electrodeposición de plata sobre electrodos de plata, graficados en función de $\Delta T^{\prime}\left(\Delta T^{\prime}=T_{0}-T_{\mathrm{c}}, T_{0}=1 / 2\left[T_{\mathrm{c}}+T_{\mathrm{a}}\right]\right.$ ) (figura 6.10), muestran que $j_{\mathrm{L}} \rightarrow 0$ cuando el valor de $\Delta T^{\prime} \rightarrow\left(\Delta T^{\prime}\right)_{\text {crit }} \cong 3,5^{\circ} \mathrm{C}$, i.e., el sistema electroquímico a este valor de $\Delta T$, se acerca a la difusión pura. Este comportamiento predicho por la ecuación (6.25), involucra la oposición de las fuerzas de empuje originadas por cambios de densidad debido a variaciones locales de la concentración y a variaciones locales de temperatura. De otra manera, tanto para $\Delta T^{\prime}>\left(\Delta T^{\prime}\right)_{\text {crit }}$ o $\Delta T^{\prime}<\left(\Delta T^{\prime}\right)_{\text {crit }}$ en el sistema existen fuerzas de 
empuje en oposición o en cooperación. De esta manera para la electrodeposición de plata y cobre, las fuerzas existentes cooperan y refuerzan la convección para $T_{\mathrm{a}}<T_{\mathrm{c}}$.

Es de notar la fluctuación que presentan los valores de Sh experimentales en torno a la representación de la correlación general (6.25). Estas se deben en principio a la existencia de condiciones no estacionarias (renovación constante de área activa) y al movimiento del frente en la dirección $y$.

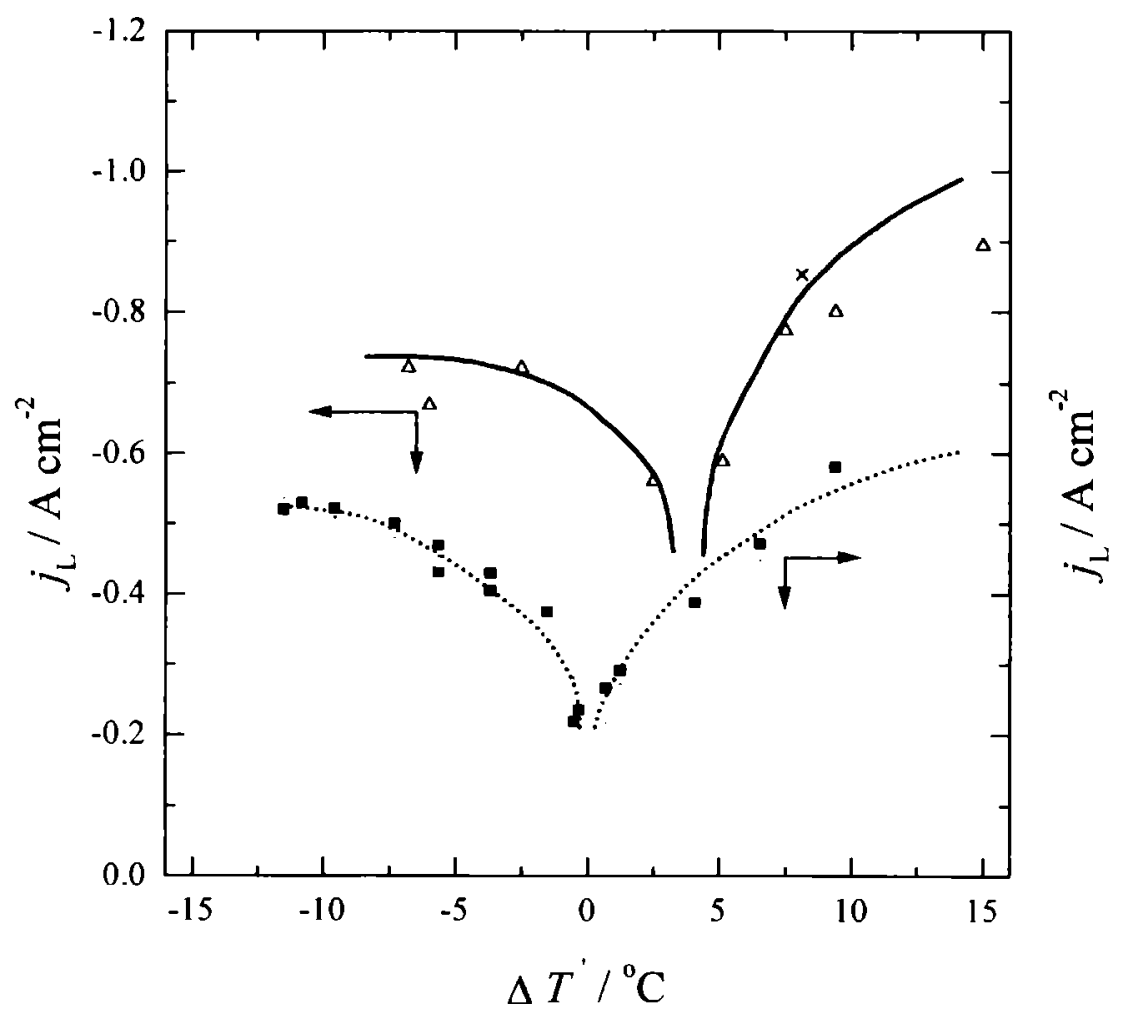

Figura 6.9 Dependencia de $j_{L}$ con $\Delta T^{\prime}$. $(\Delta ; \mathrm{x})$ Datos de la electrodeposición de plata sobre plata empleando solución II + ácido sulfúrico $0,5 \mathrm{M}(\Delta)$ y ácido sulfúrico $1,0 \mathrm{M}$ (x). (घ) Electrodeposición de cobre empleando solución de sulfato de cobre $0,005 \mathrm{M}+$ ácido sulfúrico 1,5 M, datos de la referencia [195]. Las líneas sólidas corresponden a la ecuación (6.25) para cada sistema. 
En la figura 6.10 se muestra esquemáticamente el movimiento del electrolito en las cercanías del cátodo durante la electroreducción de los iones plata bajo control por transferencia de materia, en presencia de una diferencia de temperatura entre el cátodo y el seno de la solución.

\section{Efectos de la aplicación de gradientes de} temperatura
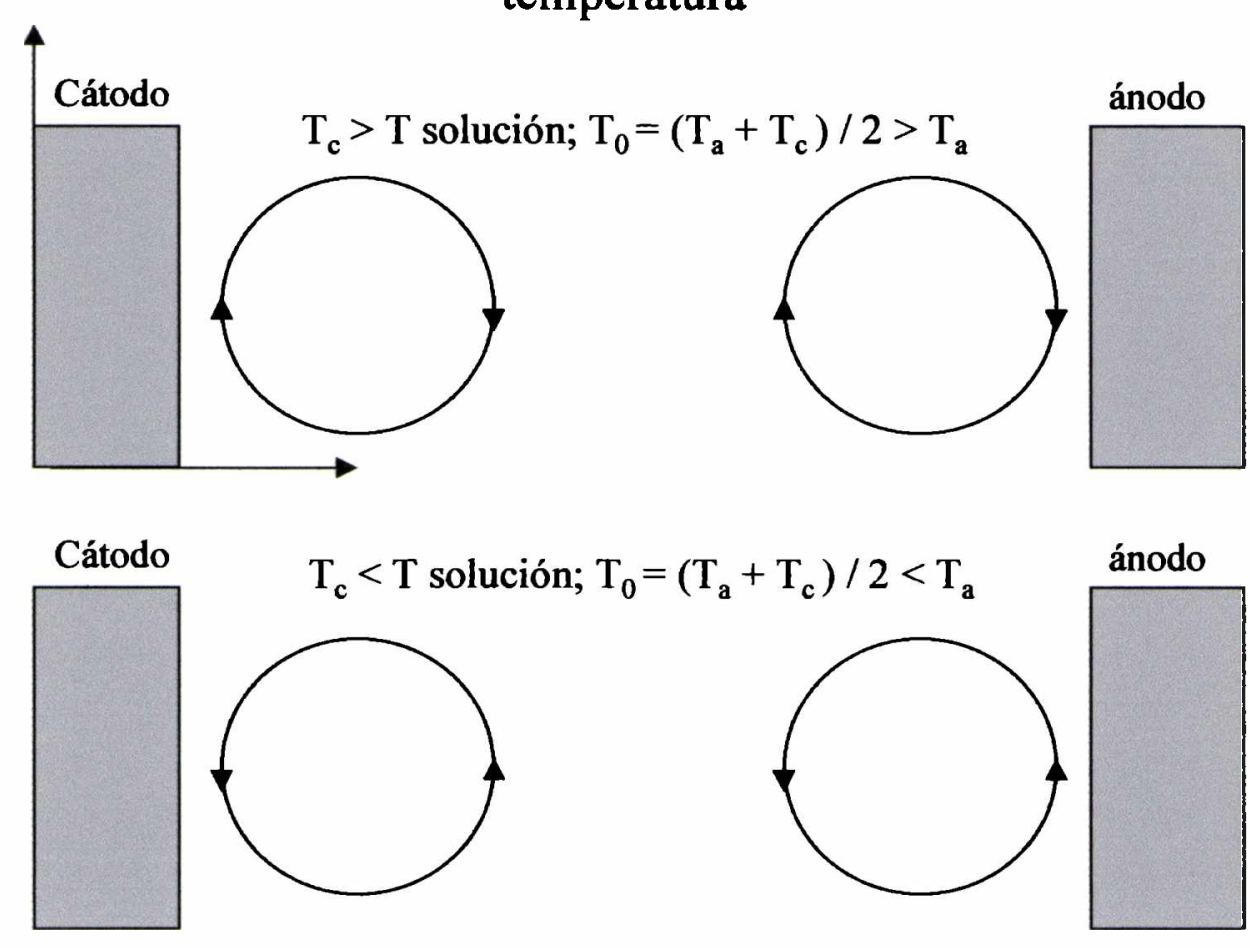

Efectos de la reacción de electrodeposición bajo control difusional

Cátodo

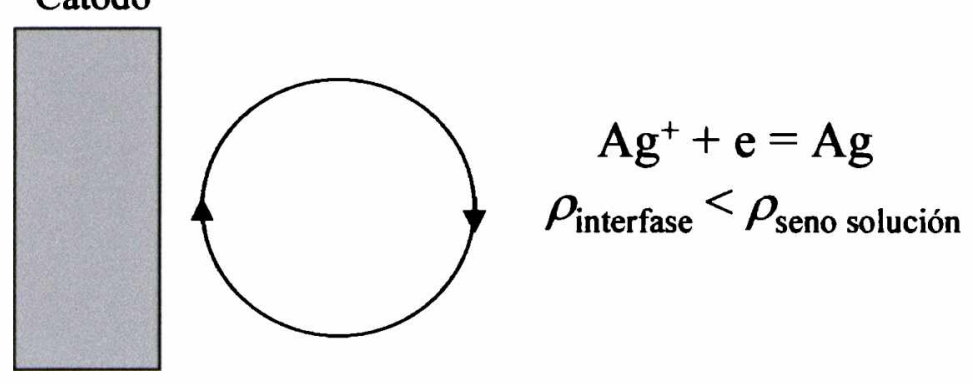

Figura 6.10. Esquema del proceso de convección libre que tiene lugar en las cercanías del cátodo en presencia de un campo térmico y un proceso electroquímico controlado por difusión.

\subsubsection{Comparación de la correlación general propuesta con datos de otros autores}

En esta sección se prueba la generalidad de la correlación utilizada en el presente trabajo. Se emplean datos de la bibliografia para distintos sistemas experimentales. En la 
referencia [185] se utiliza la reacción de electrodeposición de cobre y se aplican distintos gradientes de temperatura. Los autores de este trabajo definen un número de $\operatorname{Grashof}_{\left(\mathrm{Gr}_{\mathrm{m}}\right)}$ expresado en término de las variables $\alpha$ y $\beta$,

$$
G r_{\mathrm{m}}=\left(\begin{array}{ll}
g X \\
v
\end{array}\right)\left(\alpha+\beta\left(S_{\mathrm{Pr}}\right)^{2}\right)
$$

El número de Grashof definido por (6.34) resulta ser aproximadamente 8 veces más grande que el número de Grashof definido por la ecuación (6.29). Esta conclusión sale de reemplazar las magnitudes de las constantes y variables que aparecen en (6.34). Se toma $X=1 \mathrm{~cm}, \Delta T:=15^{\circ} \mathrm{C}, c^{0}{ }_{\mathrm{i}}=0,05 \mathrm{M}, v=0,0176 \mathrm{~cm}^{2} \mathrm{~s}^{-1}, T_{0}=5^{\circ} \mathrm{C}, \alpha=7,18 \times 10^{-3}$, $\beta=6,49 \times 10^{-3}, S c=5590$ y $P r=9,1$. Por lo tanto, para un valor constante del $S h$, si se supone que esta diferencia en el Grashof se conserva en todo el rango de valores analizado y se corrigen los valores de $G r_{m}$ en la abscisa del gráfico de la referencia [185] se obtiene buen acuerdo con la ecuación (6.28) (figura 6.11).

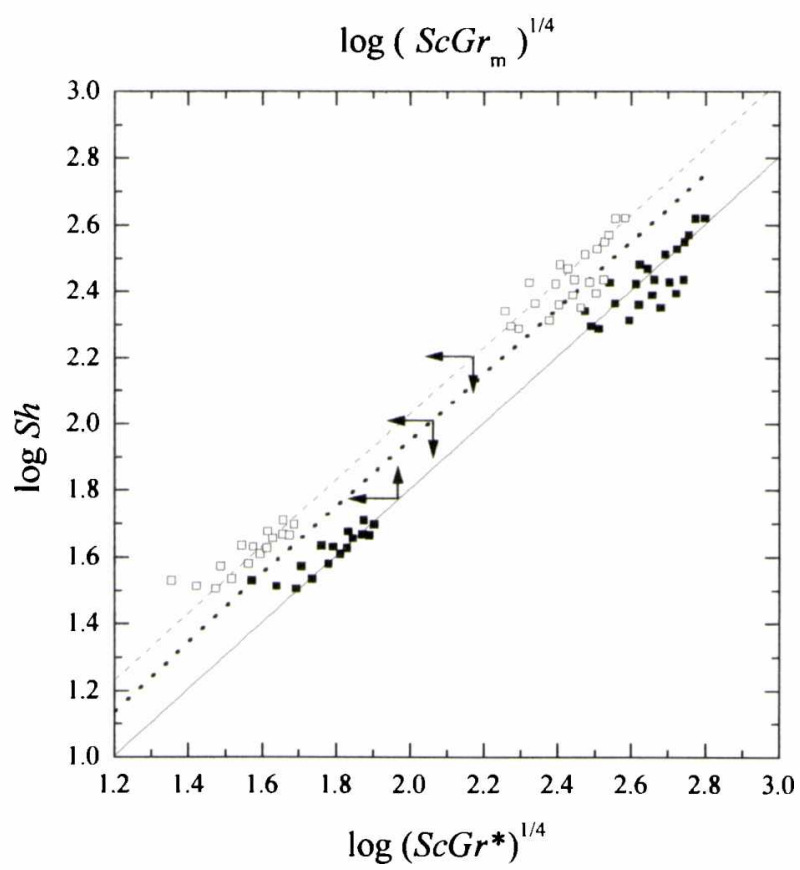

Figura 6.11. Gráficos de $\log S h$ versus $\log \left(S c G r_{\text {tn }}\right)^{1 / 4}(\square)$ y $\log S h$ versus $\log (S c G r)^{1 / 4}(\square)$. Datos extraídos de la referencia [185]. La línea sólida inferior corresponde a la correlación propuesta en [185] $\left(S h=(0,63 \pm 0,05)\left(S c G r_{m}\right)^{0,243 \pm 0,037}\right)$; la línea de trazos corresponde a la ecuación (6.28) con los datos de [185].

En la referencia [186], se aplica como reacción de ensayo la reacción redox ferri/ ferrocianuro de potasio en hidróxido de sodio acuoso como electrolito soporte, y la celda que consta de un anillo concéntrico entre dos electrodos cilíndricos de níquel con control de la temperatura de cada electrodo. Procediendo de igual manera que para establecer la 
validez de la ecuación (6.28) se utilizaron los datos de [186] para construir el gráfico log $S h$ versus $\log (S c G r)$ (figura 6.12). Este gráfico muestra que para cada serie de datos experimentales obtenidas por los autores, el valor de $S h$ para $\Delta T \rightarrow 0$ tiende a permanecer constante, pero para $\Delta T>\left|0,5^{\circ} \mathrm{C}\right|$, los datos se aproximan a la ecuación (6.28) en forma aceptable. Es decir, la mayor parte de los datos involucran una contribución térmica a la convección natural relativamente grande, y se ajustan rasonablemente con la ecuación (6.28).

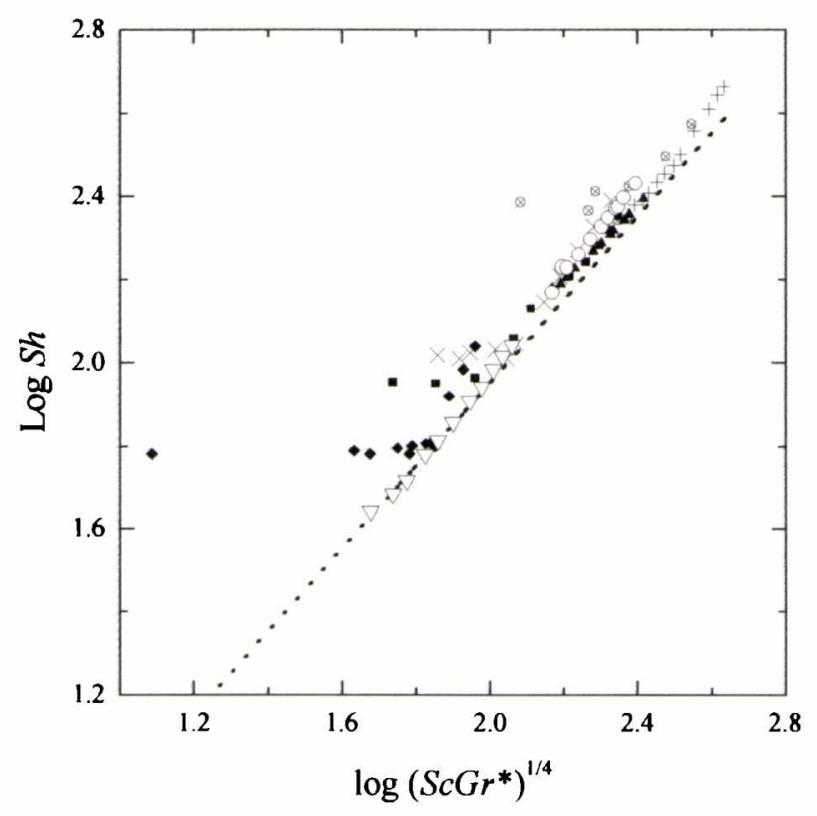

Figura 6.12. Gráfico de $\log S h$ versus $\log (S c G r)^{1 / 4}$ construido empleando los resultados de la referencia [186] para la reacción ferri/ferrocianuro sobre electrodos de níquel, utilizando solución equimolar de ferro/ferricyanide de potasio $\mathrm{x}$ + hidróxido de sodio $0,5 \mathrm{M}$. (ם) $\mathrm{x}=0,01, X=5$ $\mathrm{cm} ;(\nabla) \mathrm{x}=0,01, X=2 \mathrm{~cm} ;(\times) \mathrm{x}=0,03, X=5 \mathrm{~cm} ;(\diamond) \mathrm{x}=0,06, X=2 \mathrm{~cm} ;(\Delta) \mathrm{x}=0,06, X=5$ $\mathrm{cm} ;(\mathrm{O}) \mathrm{x}=0,06, X=5 \mathrm{~cm} ;(\otimes) \mathrm{x}=0,06, X=10 \mathrm{~cm} ;(+) \mathrm{x}=0,06, X=10 \mathrm{~cm}$. La línea de trazos corresponde a la ecuación (72). Las desviaciones tienen lugar cuando el gradiente de temperatura es inferior a $0.5^{\circ} \mathrm{C}$. 


\section{CAPITULO 7}

\section{Efecto de gradientes térmicos en la electrodeposición de plata bajo convección natural}

En este capítulo se describen los resultados obtenidos en la electrodeposición de plata a potencial constante, utilizando soluciones de sulfato de plata $0,024 \mathrm{M}$ (solución II) y ácido sulfúrico de distinta concentración, en la celda BIII, con la aplicación de gradientes de temperatura. Se hace particular énfasis en la morfología de los electrodepósitos y en las transiciones morfológicas y su relación con los mecanismos de transporte de materia. De lo analizado en los capítulos 4 y 6 se concluye que la convección natural juega un papel importante en la cinética de crecimiento de estos depósitos. La incorporación de un campo térmico genera fuerzas de empuje que se suman o se restan a las que produce la variación de concentración, modificando la contribución de la convección en la cinética de electrodeposición. En el capítulo anterior se demostró la validez de la ecuación de difusión convectiva para procesos de electrodeposición en situaciones no isotérmicas en celdas quasi-bidimensionales.

\subsection{Transiciones morfológicas}

En ciertas condiciones de electrodeposición y para determinado tiempo de electrólisis se producen transiciones morfológicas en los depósitos de plata del tipo densoabierto (ver capítulo 4). Variando la concentración de ácido sulfúrico empleado como electrolito soporte y el potencial aplicado se consigue controlar el tiempo de electrólisis asociado con la aparición de transiciones morfológicas. La concentración de ácido sulfúrico se varía en el rango $0,5 \leq c_{\text {soporte }} \leq 2 \mathrm{M}$, y el potencial aplicado entre electrodos se varía en el rango $-0,15 \geq \Delta \mathrm{E}_{\mathrm{c}-\mathrm{a}} \geq-0,65 \mathrm{~V}$.

Las características más sobresalientes resultantes de las transiciones morfológicas son:

I) Cambio en la velocidad de aparición de ramas laterales; II) aumento de la velocidad de desplazamiento del frente del depósito global; III) disminución en la densidad aparente del depósito; IV) cambio morfológico de la meso - estructura; V) incremento en la pendiente $d I_{\mathrm{c}} / d t$. 
En la figura 7.1 se muestra una secuencia de crecimiento del electrodepósito de plata en la que se produce la transición morfológica tipo denso-abierto, empleando solución II + ácido sulfúrico $2 \mathrm{M}, \mathrm{a} \Delta \mathrm{E}_{\mathrm{c}-\mathrm{a}}=-0,40 \mathrm{~V}, \mathrm{y} 25^{\circ} \mathrm{C}$.

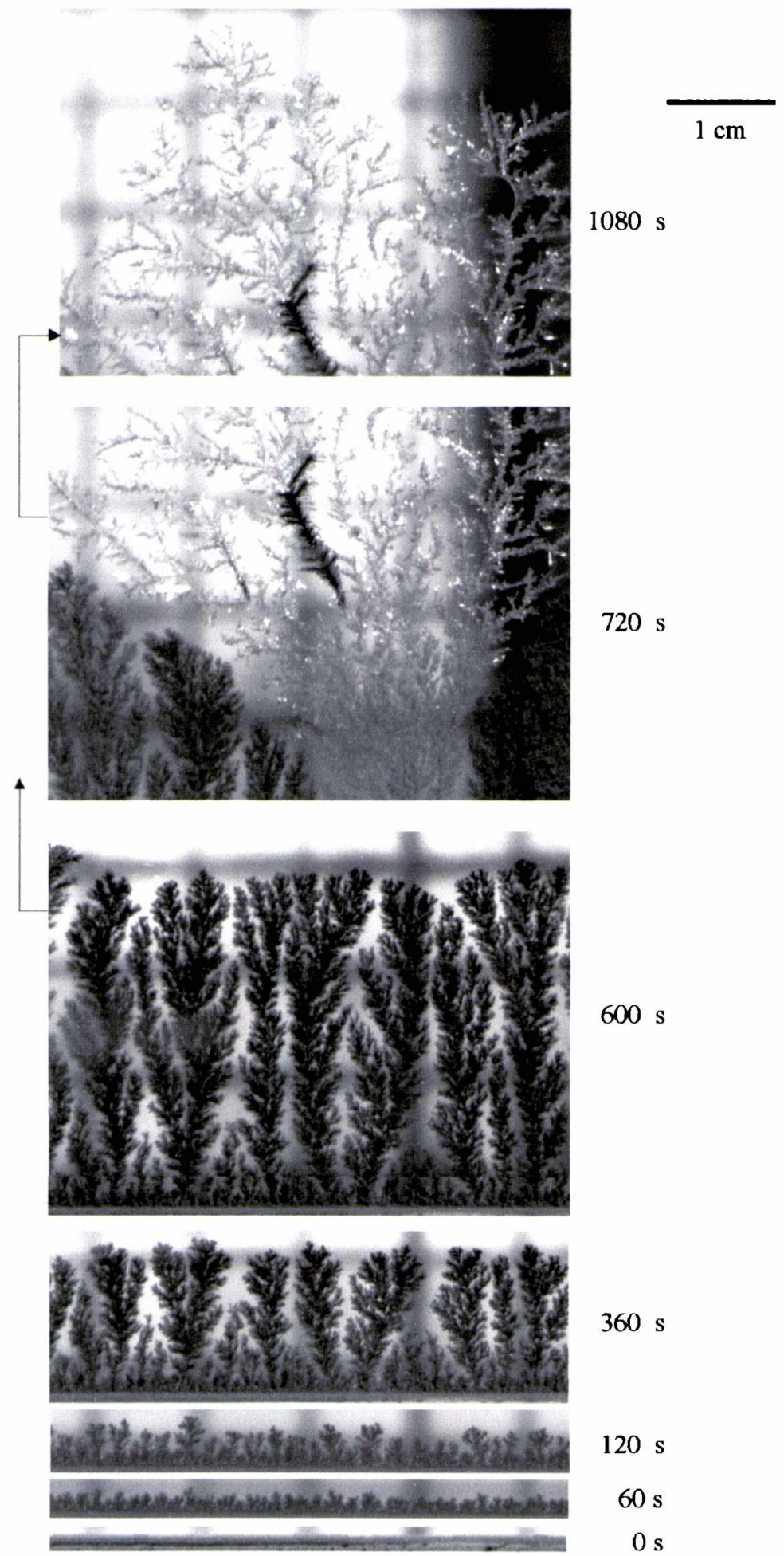

Figura 7.1. Secuencia de crecimiento del electrodepósito. Condiciones: Solución II + ácido sulfúrico $2 \mathrm{M}, \Delta \mathrm{E}_{\mathrm{c}-\mathrm{a}}=-0,40 \mathrm{~V}$, celda rectangular BIII. 
En la figura 7.2 se representa el transitorio de corriente y la longitud media $\left\langle h_{y}\right\rangle$ de avance del frente del electrodepósito en función del tiempo para el experimento de la figura 7.1.

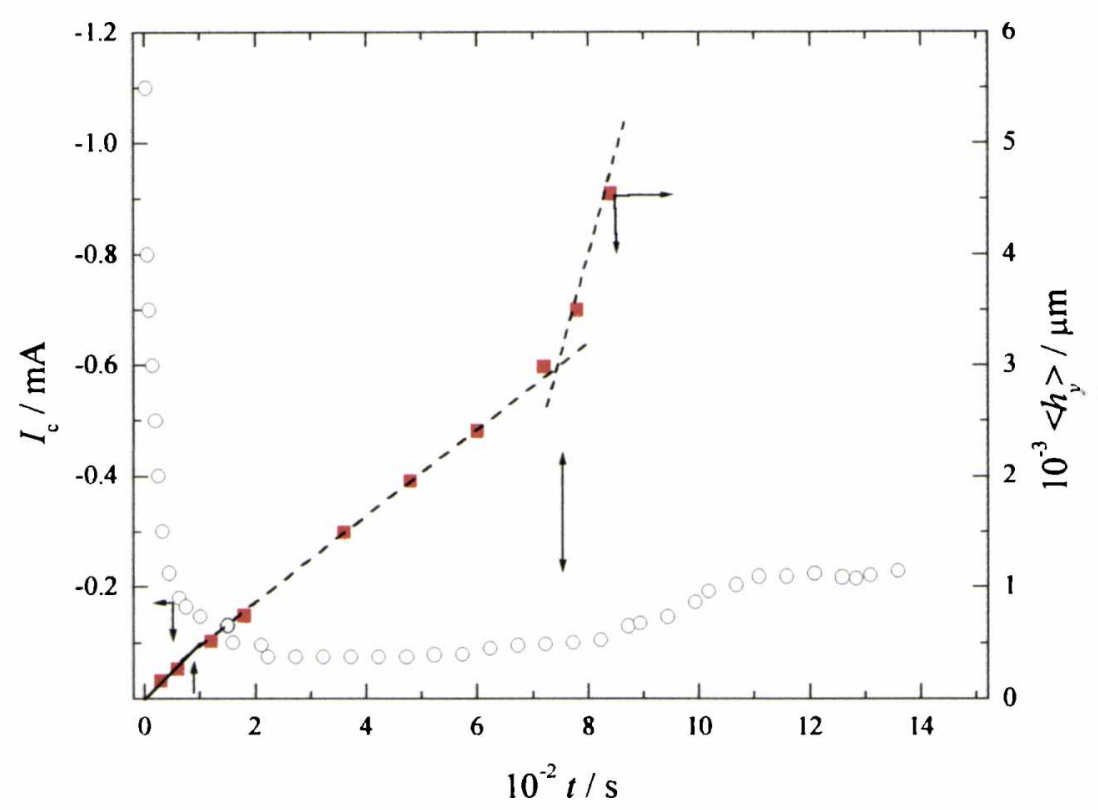

Figura 7.2. Representación del transitorio de corriente potenciostático y del desplazamiento promedio del frente de crecimiento para la secuencia de la figura 7.1. La flecha a $\sim 100 \mathrm{~s}$ indica transición VII (ver texto).

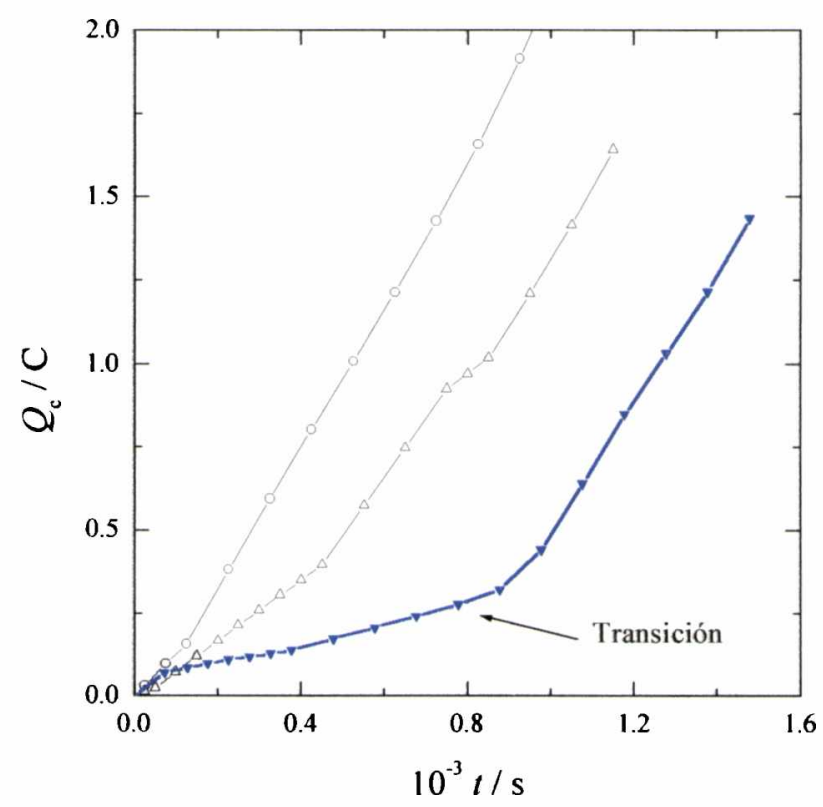

Figura 7.3. Cargas en función del tiempo; en triángulos llenos azules las correspondientes al experimento de la figura 7.1. Se agregan resultados de otros experimentos realizados empleando solución II + ácido sulfúrico $0,5 \mathrm{M},(0) \Delta \mathrm{E}_{\mathrm{c-a}}=-0,65 \mathrm{~V} ;(\Delta) \Delta \mathrm{E}_{\mathrm{c}-\mathrm{a}}=-0,575 \mathrm{~V}$, en la celda BIII. En estos experimentos no se observa transición morfológica. 
En la figura 7.4 se representa $\left\langle h_{y}\right\rangle$ en función del tiempo, para experimentos, realizados con solución II y ácido sulfúrico de concentración $0,5 \leq c_{\mathrm{H}_{2} \mathrm{SO}_{4}} \leq 2 \mathrm{M}$ a distintos potenciales. Las velocidades de avance del frente varian entre 4 y $25 \mu \mathrm{m} \mathrm{s}^{-1}$. Se aprecian quiebres pronunciados en las representaciones de los experimentos que involucran transiciones morfológicas.

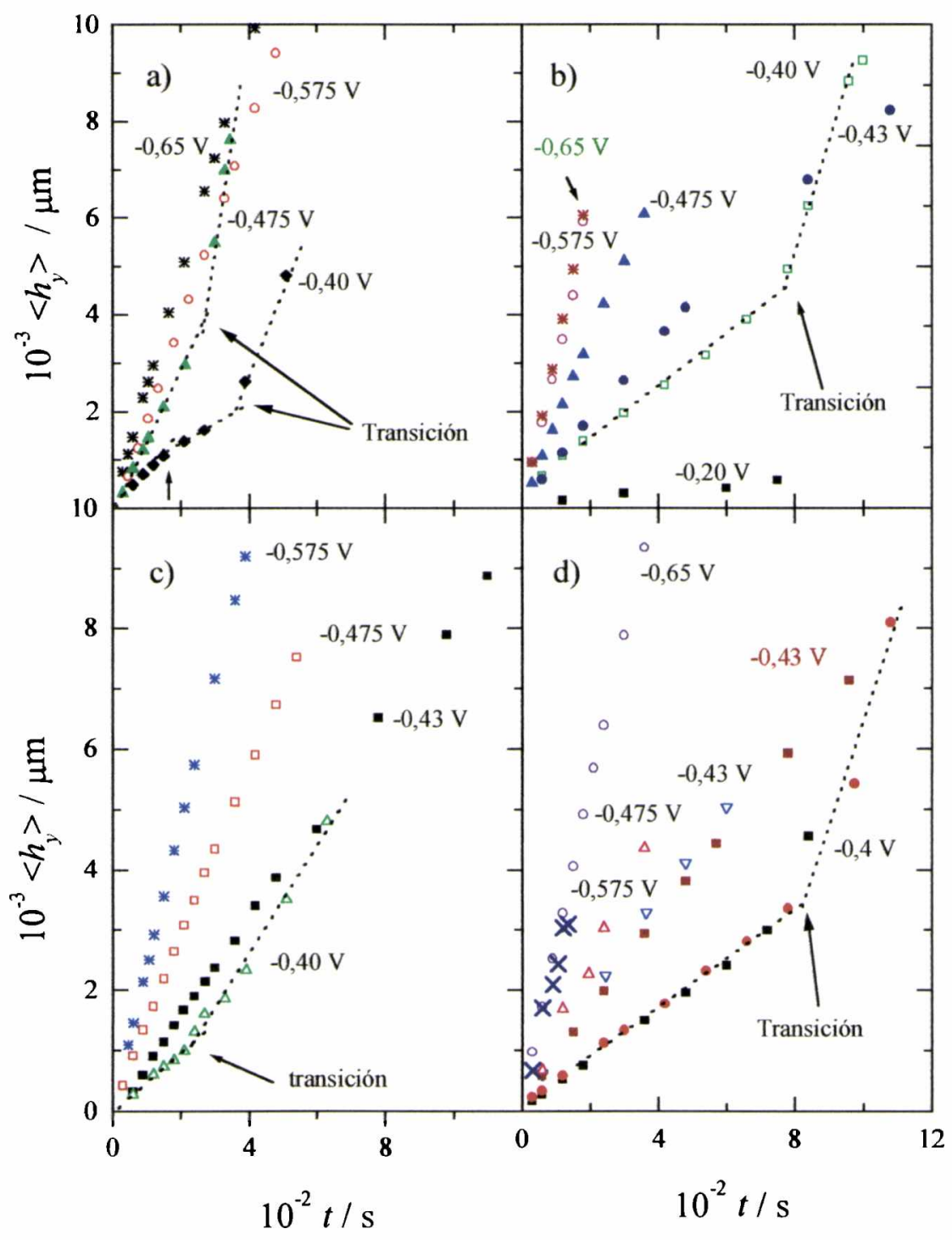

Figura 7.4. Representaciones de $\left\langle h_{y}\right\rangle$ versus $t$ para experimentos de electrodeposición realizados empleando solución II + ácido sulfúrico de concentración $c_{\mathrm{H}_{2} \mathrm{SO}_{4}}$, a) $c_{\mathrm{H}_{2} \mathrm{SO}_{4}}=0,5 \mathrm{M}$; b) $\left.c_{\mathrm{H}_{2} \mathrm{SO}_{4}}=1,0 \mathrm{M} ; \mathrm{c}\right) c_{\mathrm{H}_{2} \mathrm{SO}_{4}}=1,5 \mathrm{M} \mathrm{y} \mathrm{d)} c_{\mathrm{H}_{2} \mathrm{SO}_{4}}=2,0 \mathrm{M}$

Las figuras 7.1-7.3, muestran que la transición de la morfología densa a abierta aparece conjuntamente con cambios marcados en las representaciones de $I_{\mathrm{c}},\left\langle h_{y}\right\rangle$ y $Q_{\mathrm{c}}$ en función del tiempo $t$. Los puntos de corte o cruzamiento de las porciones lineales 
("crossovers") determinan los parámetros $\left\langle h_{y}\right\rangle_{\mathrm{II}, \mathrm{III}}, Q_{\mathrm{c}}$ II,III y $t_{\mathrm{IIIIII}}$ que caracterizan una transición morfológica. Las representaciones de $\left\langle h_{y}>\right.$ y $Q_{\mathrm{c}}$ en función del tiempo $t$, en los experimentos a potenciales menores que $-0,575 \mathrm{~V}$, muestran también líneas rectas que se interceptan a $t<100 \mathrm{~s}$. Estos cruzamientos están relacionados con formación de una morfología densa a partir de protuberancias y de pequeñas ramas aisladas (flecha a $t<100 \mathrm{~s}$ en la figura 7.2 y 7.4a). De la misma manera, estos cruzamientos definen los parámetros de la transición $\left\langle h_{y}\right\rangle_{1, \mathrm{II}}, Q_{\mathrm{cl}, \mathrm{II}}$ y $t_{\mathrm{I}, \mathrm{II}}$ (estudiada en la sección 7.3). Consiguientemente se definen las regiones de crecimiento I, II y III con morfologías típicas.

\subsubsection{Efecto de la concentración de electrolito soporte, el potencial aplicado y el gradiente térmico}

En la figura 7.5, se representan las regiones caracterizadas por una morfología dada que está determinada por el potencial aplicado y la concentración de electrolito soporte $\left(0,5 \leq c_{\text {soporte }} \leq 2 \mathrm{M}\right)$, utilizado en la electrodeposición potenciostática de plata en la celda rectangular BIII $\left(l_{\mathrm{s}}=0,025 \mathrm{~cm}\right.$, separación entre cátodo y ánodo, $l_{\mathrm{ac}}=2,3 \mathrm{~cm}$, área del ET $=0,0375 \mathrm{~cm}^{2}$ ). Se distinguen tres regiones $\mathrm{A}, \mathrm{B}$ y C asociadas a electrodepósitos que en la escala de tiempo de los experimentos de electrodeposición realizados en este trabajo, presentan morfología abierta, densa y transición densa-abierta, respectivamente.

Para los experimentos con menor concentración de electrolito soporte y $-0,6 \approx \leq$ $\Delta \mathrm{E}_{\mathrm{c}-\mathrm{a}} \leq \approx-0,3 \mathrm{~V}$ la aplicación de gradientes de temperatura (figura 7.5), aumenta la extensión de la región $\mathrm{C}$.

La figura 7.6a-c muestra crecimientos con tres tipos de morfologias. La figura 7.6a y $7.6 \mathrm{~b}$ corresponde a una secuencia a $\Delta \mathrm{T}=0$. Para $t=30 \mathrm{~s}$, se observa un depósito abierto formado por protuberancias y pequeños árboles que se transforma en un electrodepósito con morfología densa como lo muestra la figura 7.6b $(t=300 \mathrm{~s})$. En la figura 7.6c se distingue la transición denso-abierto $(t=300 \mathrm{~s})$, para un electrodepósito obtenido en condiciones similares a las de la figura 7.6a-b y con gradiente de temperatura $\left(\Delta T=T_{\mathrm{c}}-T_{\mathrm{a}}\right)$ de $-10^{\circ} \mathrm{C}$. En estas condiciones de trabajo, empleando en ambas, solución II + ácido sulfúrico $0,5 \mathrm{M}$ a un potencial aplicado de $-575 \mathrm{mV}$ el gradiente de temperatura asiste la transición morfológica denso-abierto. Un efecto similar se observa para la electrodeposición a $\Delta \mathrm{E}_{\mathrm{c}-\mathrm{a}}=-0,65 \mathrm{~V}$ y $\Delta T=20^{\circ} \mathrm{C}$. 


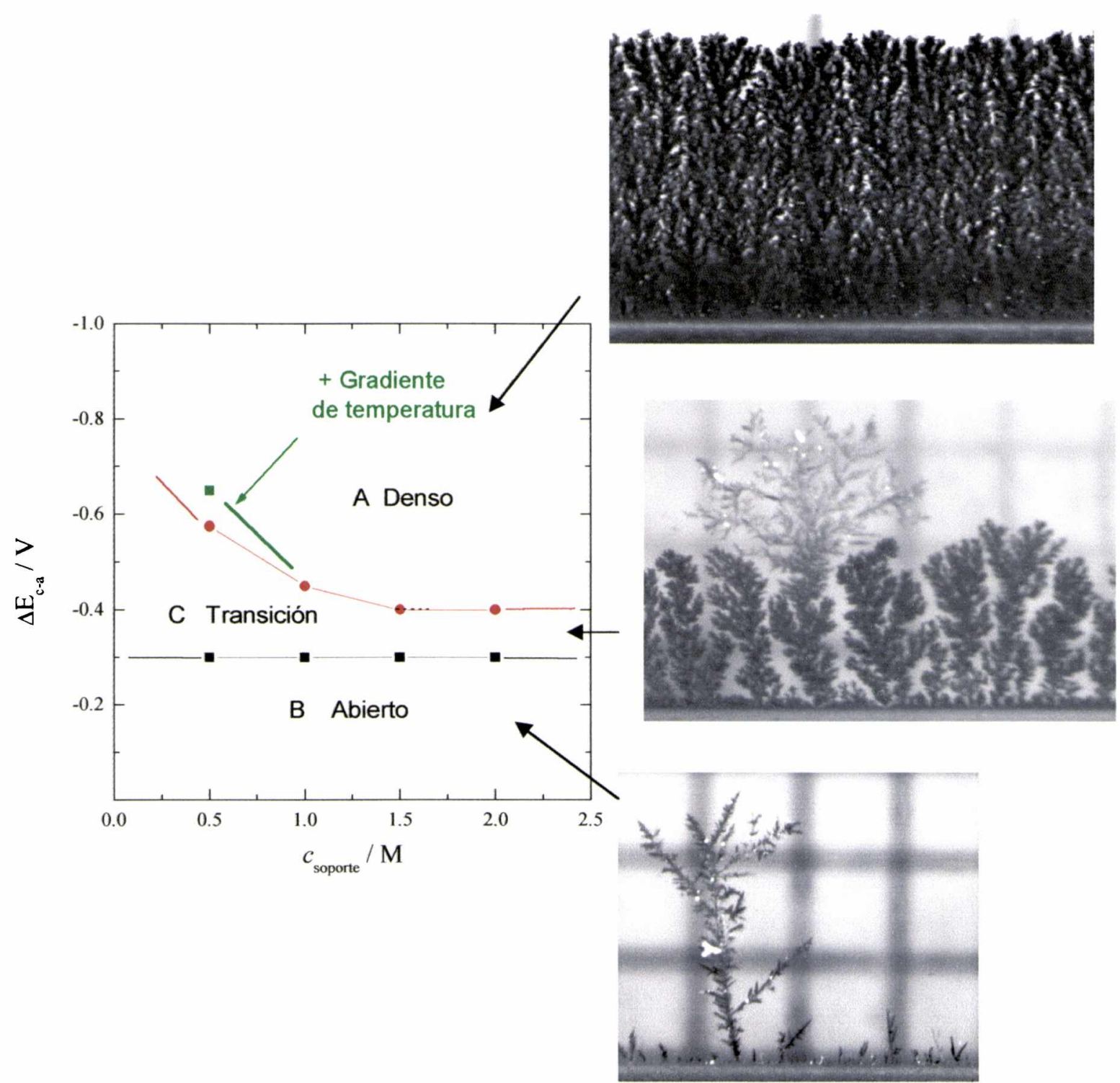

Figura 7.5. Diagrama morfológico $\left(\Delta \mathrm{E}_{\mathrm{c}-\mathrm{a}}-c_{\text {soportc }}\right)$ en el que se definen los dominios $\mathrm{A}$ (denso), $\mathrm{B}$ (abierto) y C (denso-abierto) para la electrodeposición de plata empleando la celda rectangular BIII y solución II con distintas concentraciones de ácido sulfúrico. Se incluyen imágenes de las estructuras de los electrodepósitos en cada región del diagrama morfológico.

El diagrama morfológico que se muestra en la figura 7.5 se ha construido en base a 90 experimentos de electrodeposición de plata en distintas condiciones experimentales, isotérmicas y no isotérmicas. 
c)

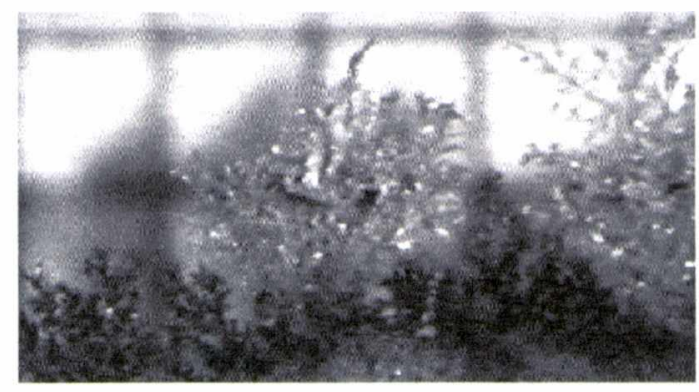

b)

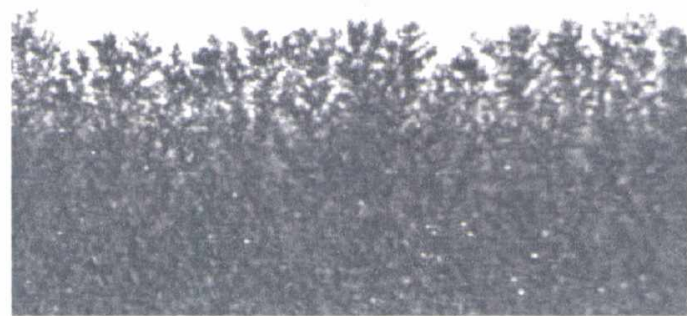

a)

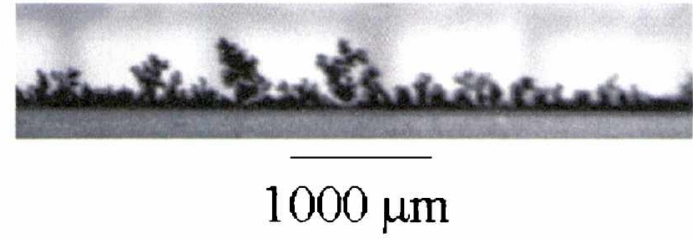

Figura 7.6. Electrodepósitos de plata obtenidos empleando solución II + ácido sulfúrico $0,5 \mathrm{M}$ a $-0.575 \mathrm{~V}$. a) depósito abierto inicial, $t=30 \mathrm{~s}$; b) denso, $t=300 \mathrm{~s}, \Delta \mathrm{T}=0{ }^{\circ} \mathrm{C}$ y c) depósito abierto, $t=300 \mathrm{~s}, \Delta \mathrm{T}=-10^{\circ} \mathrm{C}$.

La influencia del gradiente de temperaturas en los electrodepósitos de plata será analizado en las secciones siguientes, por medio de los experimentos de electrodeposición realizados empleando sulfato de plata $0,024 \mathrm{M}+$ ácido sulfúrico $0,5 \mathrm{M}$ y a $\Delta \mathrm{E}_{\mathrm{c}-\mathrm{a}}=-0,45 \mathrm{~V}$, esto es en las condiciones experimentales más favorables para estudiar este efecto. 
7.2 Descripción de la evolución de los electrodepósitos que presentan transición morfológica

En esta sección se analizan las relaciones entre la convección libre isotérmicas y no isotérmicas y las transiciones morfológicas en la electrodeposición de plata.

Para potenciales más negativos que $-0,3 \mathrm{~V}$, los electrodepósitos de plata, a $t<100 \mathrm{~s}$, se produce la transición I/II, en la que las protuberancias que se desarrollan sobre la capa compacta de plata adoptan estructuras arborescentes y comienza la competencia entre árboles vecinos, para generar una morfología más densa. Luego, en las experiencias en las que son favorables las transiciones morfológicas II/III, a $t>300 \mathrm{~s}$, se comienza a formar un electrodepósito abierto a partir de algunas de las puntas del depósito denso (Figura 7.1).

Como se deduce del gráfico de las figuras $7.7-7.8$, las transiciones aparecen a tiempos más cortos y distancias $<h>$ menores para experimentos no isotérmicos que isotérmicos. Sin embargo, las características de las transiciones morfológicas son independientes del signo y de la magnitud del gradiente térmico $\Delta T$ aplicado, dentro del ámbito cubierto por este trabajo.

Algunas fotografias típicas de los electrodepósitos (figura 7.9 a-d), muestran la morfología densa entre $t_{\mathrm{II}}$ y $t_{\mathrm{III}}$ y la morfología abierta para $t>t_{\mathrm{III}}$. La morfología densa se caracteriza por la bifurcación de las ramas de plata que forman el electrodepósito (tipsplitting) y la distribución aleatoria de islas y canales en el electrodepósito. La morfología abierta, consiste de ramas con un eje central en la dirección de crecimiento y ramificaciones laterales (dendrítico). Estas ramas laterales, por lo general forman un ángulo de $60^{\circ}$ con el eje principal que es compatible con la red cristalogáfica (111) del metal. El depósito abierto presenta pequeños cristales cuyas caras reflejan luz. 


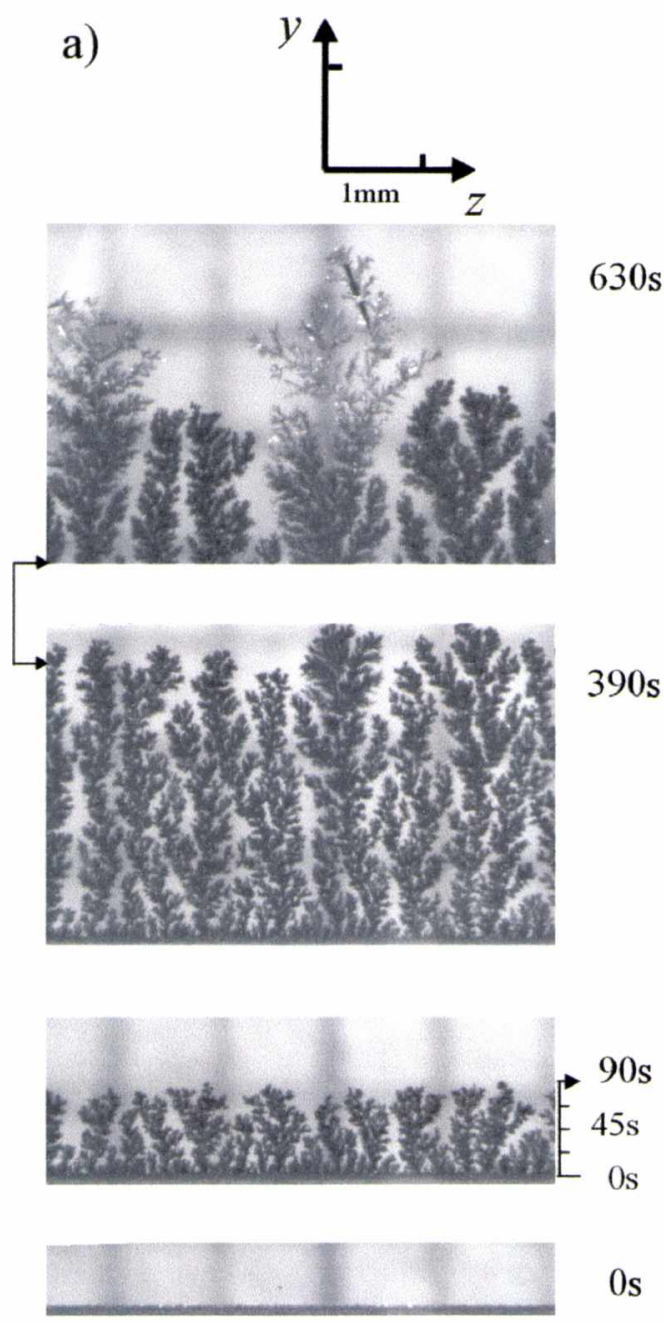

b)

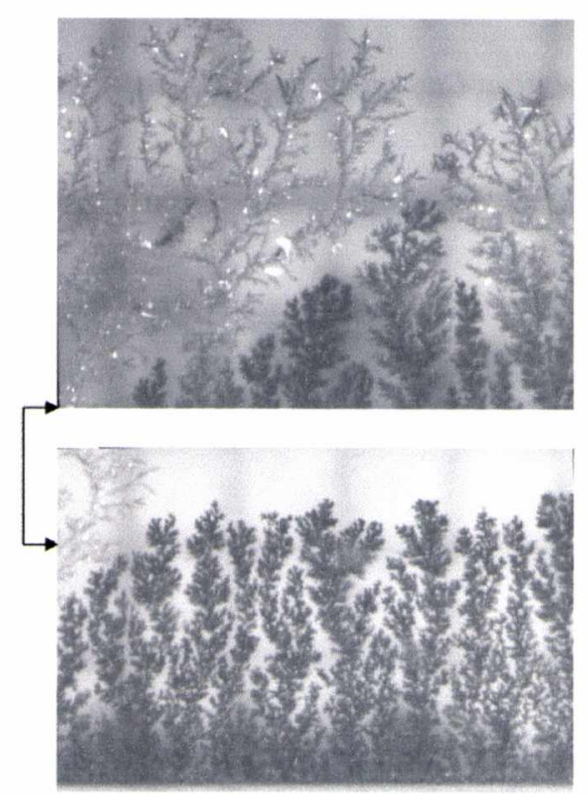

$455 \mathrm{~s}$

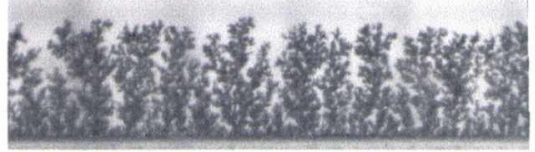

$90 \mathrm{~s}$

Os

Figura 7.7. Secuencia de imágenes de crecimientos de plata empleando las mismas condiciones establecidas en la Fig. 7.3b. a) $T_{\mathrm{c}}=T_{\mathrm{a}}=30^{\circ} \mathrm{C}$; b) $T_{\mathrm{c}}=30^{\circ} \mathrm{C}$ y $T_{\mathrm{a}}=40^{\circ} \mathrm{C}$. Como la velocidad de crecimiento es directamente proporcional a $t$, una escala de tiempo se agregó sobre la imagen correspondiente a $90 \mathrm{~s}$. Para las imágenes a $t=630 \mathrm{~s}$ y $455 \mathrm{~s}$, el valor inicial de $y$ corresponde al valor de $y$ de la imagen precedente indicado por las flechas. 


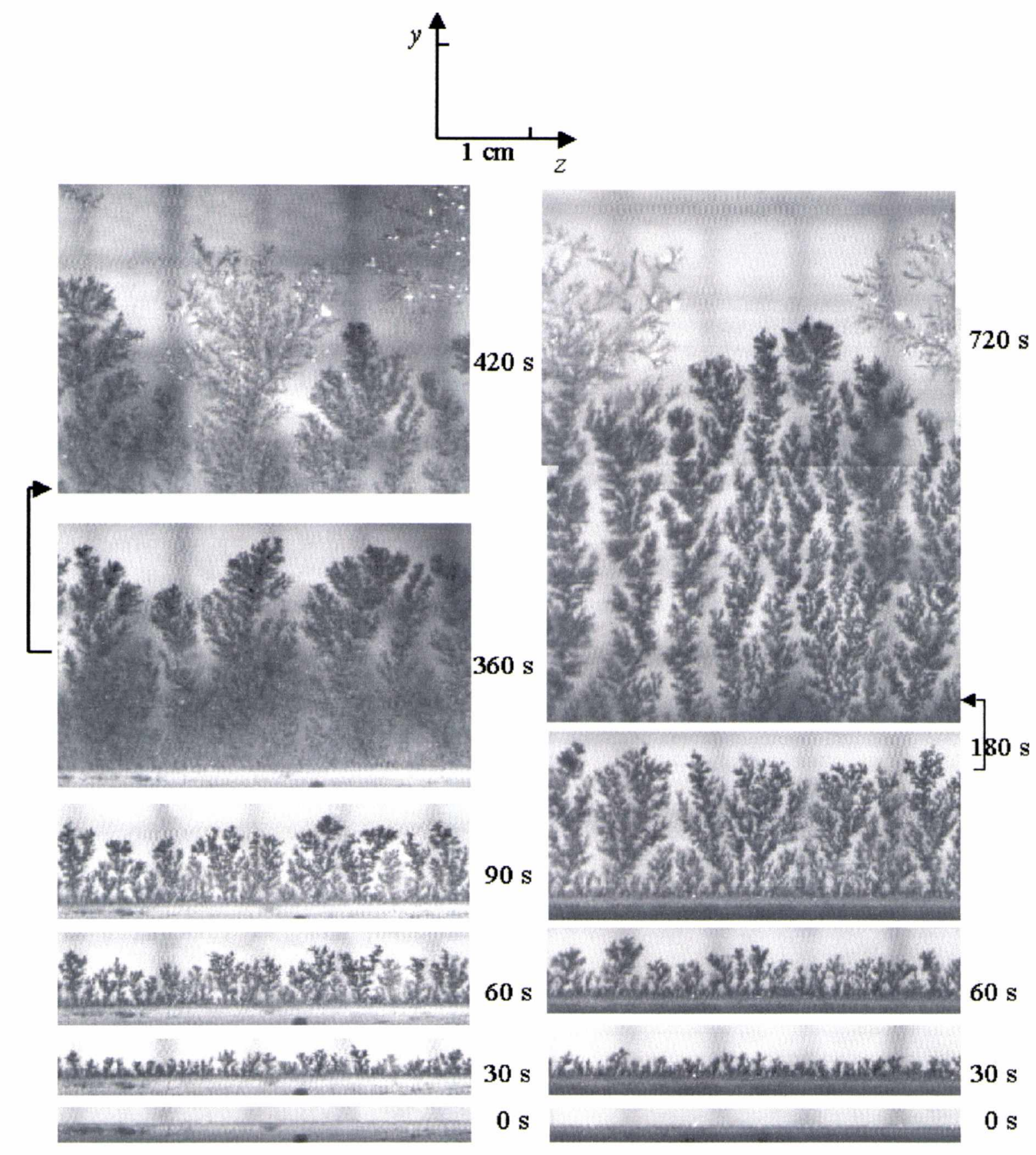

Figura 7.8. Secuencia de imágenes de crecimientos de plata empleando las mismas condiciones establecidas en la Fig. $7.3 \mathrm{~b}$. a) $T_{\mathrm{c}}=40^{\circ} \mathrm{C}$ y $T_{\mathrm{a}}=30^{\circ} \mathrm{C}$; b) $T_{\mathrm{c}}=T_{\mathrm{a}}=40^{\circ} \mathrm{C}$. Para las imágenes a $t=$ $420 \mathrm{~s}$ y $720 \mathrm{~s}$ el valor inicial de $y$ corresponde al valor de $y$ de la imagen precedente indicado por las flechas. 
a)

b)

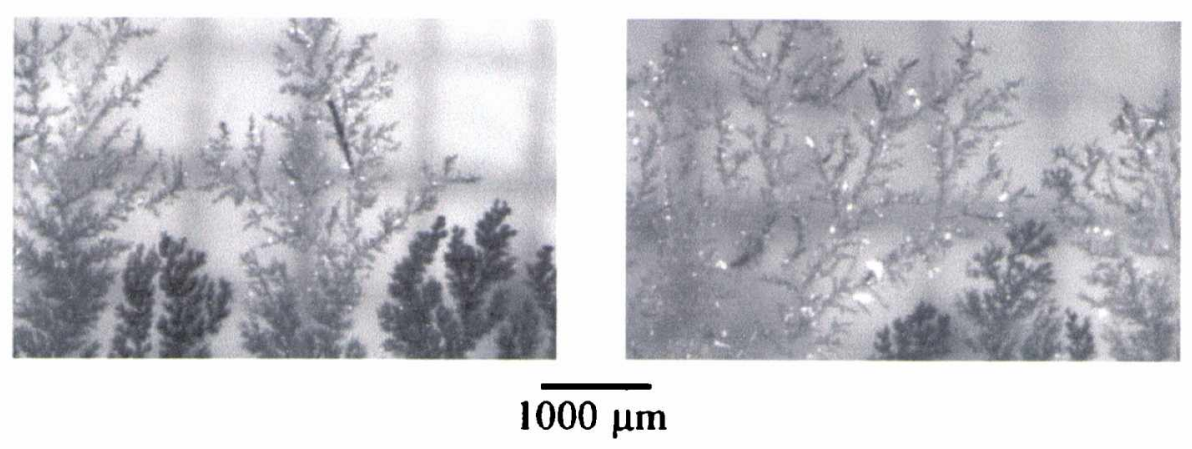

c)

d)
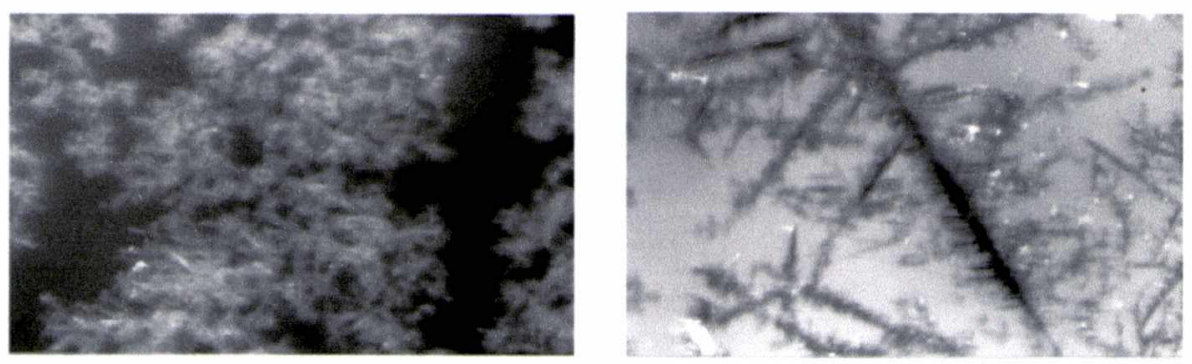

$600 \mu \mathrm{m}$

Figura 7.9. Fotos aumentadas a) y b) de la transición IL/III. Se puede observar distinto brillo para la morfología densa y la abierta. En c) se muestran detalles del depósito denso. El depósito abierto es principalmente dendrítico, caracterizado por la presencia de un eje central de crecimiento y ramas secundarias formando un ángulo de $60^{\circ}$ con el eje central.

La velocidad del frente de crecimiento en las direcciones $y$ (perpendicular al electrodo) y $z$ (paralela al electrodo) son $v_{y}=\Delta\left\langle h_{y}\right\rangle / \Delta t$ y $\quad v_{z}=\Delta\left\langle h_{z}\right\rangle / \Delta t$, respectivamente, con $\left\langle h_{z}\right\rangle=\sum_{\mathrm{n}} h_{z, \mathrm{M}, \mathrm{n}} / N_{\mathrm{g}}$, siendo $h_{z, \mathrm{M}, \mathrm{n}}$ el ancho máximo de la rama o columna n en la dirección $z$ y $N_{\mathrm{g}}$ en número de columnas o ramas.

La definición del ancho de la interfase es:

$$
W_{y}=\left(1 / N\left\{\sum_{\mathrm{n}}\left[h_{y}\left(z_{\mathrm{i}}\right)-\left\langle h_{y}\right]^{2}\right\}^{1 / 2}\right.\right.
$$

donde $\mathrm{n}=1,2,3, \ldots, N$ son los números de puntos en la dirección $z,\left\langle h_{y}\right\rangle=h_{\mathrm{y}, \mathrm{M}, \mathrm{n}} / N_{\mathrm{g}}$, con $h_{y, \mathrm{M}, \mathrm{n}}$ la altura máxima de la enésima columna o rama en la dirección $y$.

Las velocidades $v_{y}$ y $v_{z}$, junto con el ancho de la interfase, son parámetros de importancia en la caracterización de los electrodepósitos. 
El número de árboles muertos aumenta con el tiempo, aunque cuando se producen transiciones morfológicas (figura 7.10-7.13), el número de árboles muertos para $t>300 \mathrm{~s}$ aumenta muchos más rápidamente que para $t<300 \mathrm{~s}$ (figura 7.10).
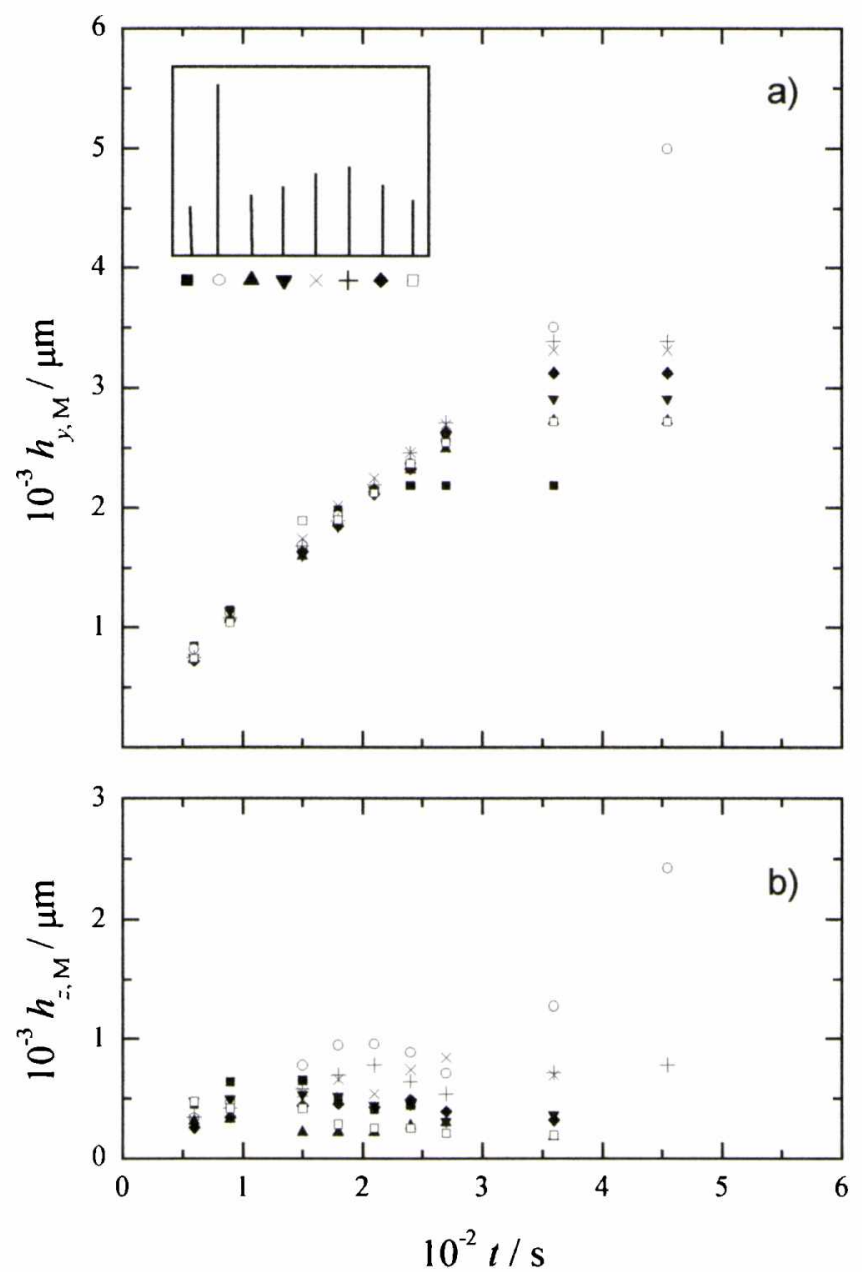

Figura 7.10. a) Representación de $h_{y, \mathrm{M}}$ en función del tiempo para cada árbol o columna ( $\mathrm{n}=1,2$ $, \ldots, N$ ) considerados separadamente. El "inset" es un esquema de la identificación de cada árbol al tiempo $t ; T_{\mathrm{c}}=40$ y $T_{\mathrm{a}}=30^{\circ} \mathrm{C}$. Se observa que al transcurrir el tiempo solo algunas ramas siguen creciendo; b) $h_{z, \mathrm{M}}$ en función de $t$ para las mismas ramas que en a). 

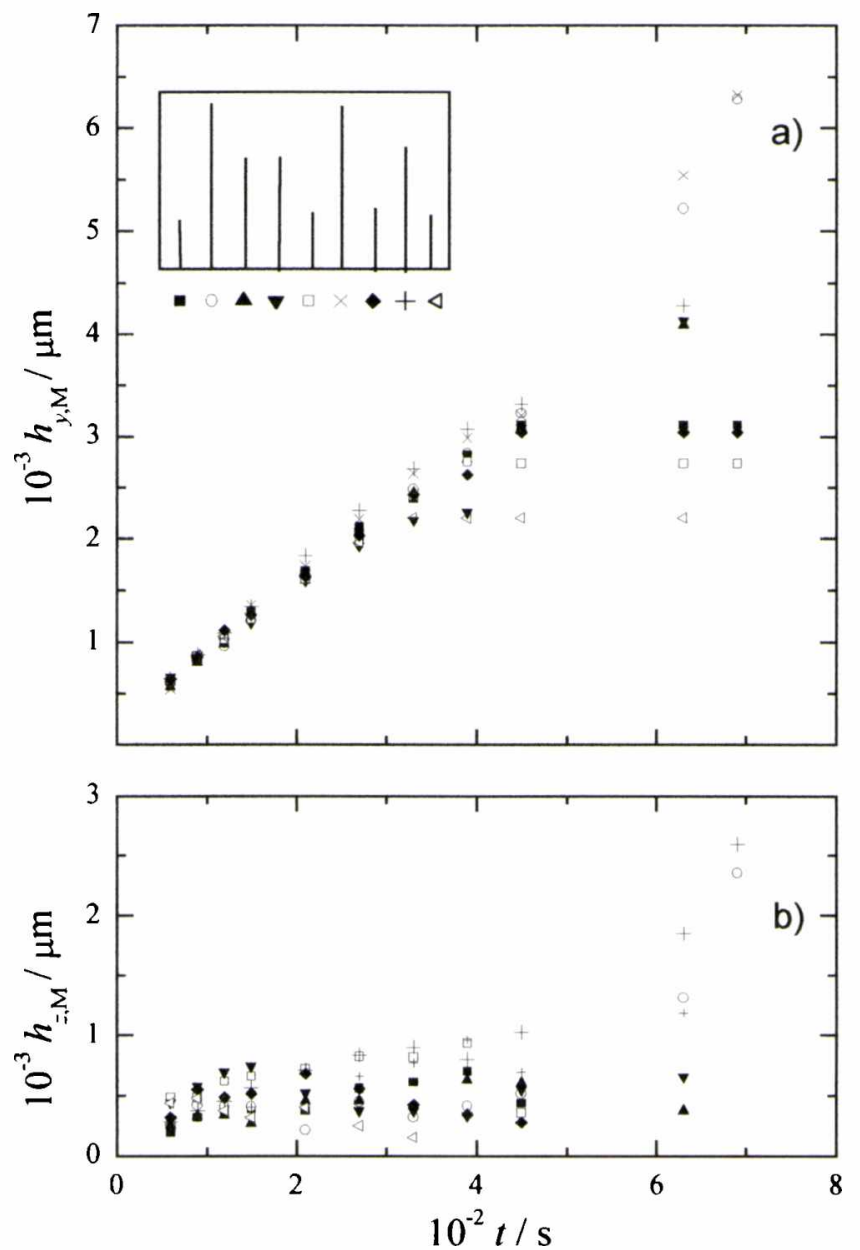

Figura 7.11. a) Representación de $h_{y, \mathrm{M}}$ en función del tiempo para cada árbol o columna ( $\mathrm{n}=$ $1,2, \ldots, N)$ considerados separadamente. El "inset" es un esquema de la identificación de cada árbol al tiempo $t ; T_{\mathrm{c}}=30$ y $T_{\mathrm{a}}=40^{\circ} \mathrm{C}$. Se observa que al transcurrir el tiempo solo algunas ramas continúan creciendo; b) $h_{z, \mathrm{M}}$ en función de $t$ para las mismas ramas que en a). 

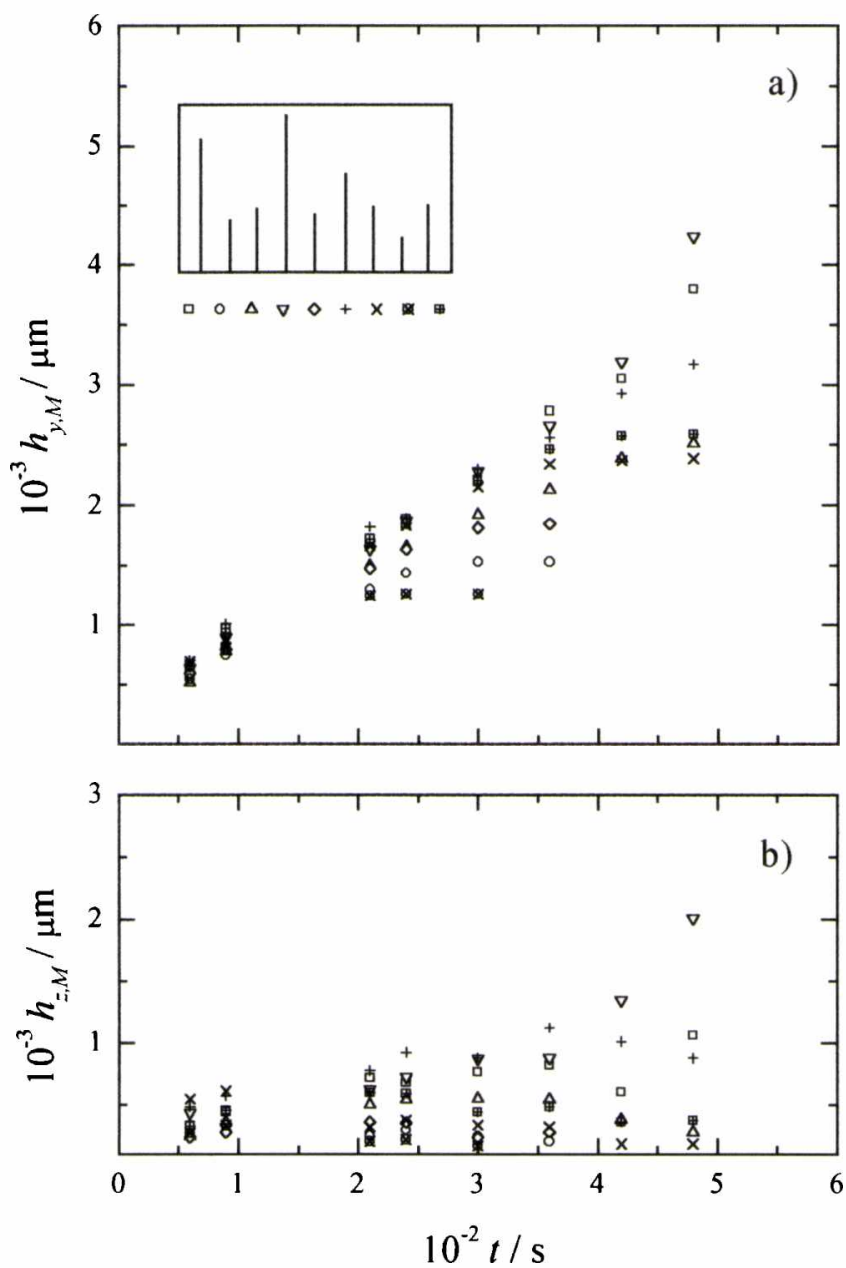

Figura 7.12. a) Representación de $h_{y, \mathrm{M}}$ en función del tiempo para cada árbol o columna ( $\mathrm{n}=1,2$, $\ldots, N)$ considerados separadamente. El "inset" es un esquema de la identificación de cada árbol al tiempo $t ; T_{\mathrm{c}}=40$ y $T_{\mathrm{a}}=30^{\circ} \mathrm{C}$. Se observa que al transcurrir el tiempo solo algunas ramas siguen creciendo; b) $h_{z, M}$ en función de $t$ para las mismas ramas que en a). 

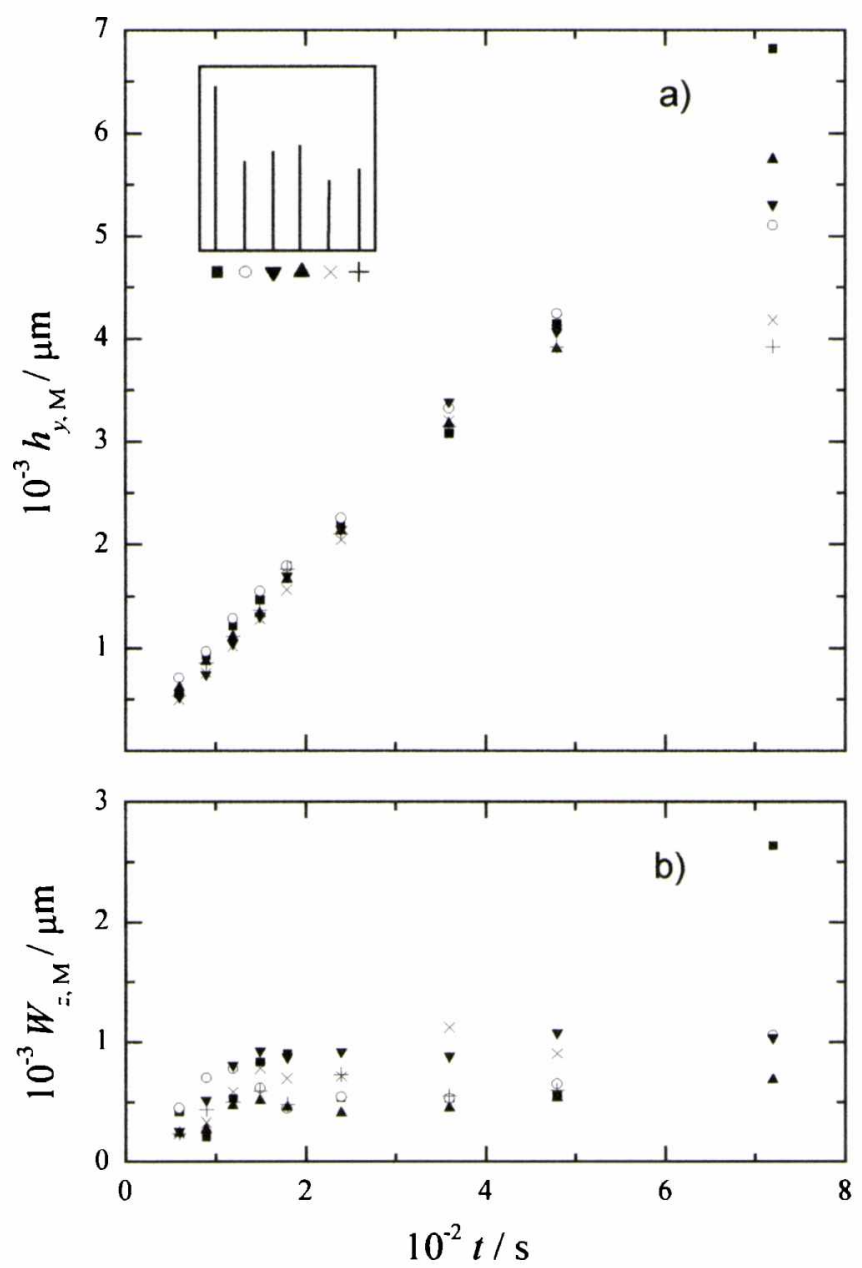

Figura 7.13. a) Representación de $h_{y, \mathrm{M}}$ en función del tiempo para cada árbol o columna ( $\mathrm{n}=1,2$, ..., $N$ ) considerados separadamente. El "inset" es un esquema de la identificación de cada árbol al tiempo $t ; T_{\mathrm{c}}=40$ y $T_{\mathrm{a}}=40^{\circ} \mathrm{C}$. b) $h_{z, \mathrm{M}}$ en función de $t$ para las mismas ramas que en a). 


\subsection{Parámetros relacionados con las transiciones morfológicas}

Para el análisis de las transiciones morfológicas se toman cuatro experimentos. En todos, el potencial aplicado entre cátodo y ánodo es de $-0,45 \mathrm{~V}$ y la solución empleada es la II con $0,5 \mathrm{M}$ en ácido sulfúrico. Se consideran dos experimentos isotérmicos con $T_{\mathrm{a}}=T_{\mathrm{c}}=30^{\circ} \mathrm{C}$ y $T_{\mathrm{a}}=T_{\mathrm{c}}=40^{\circ} \mathrm{C}$ respectivamente, y dos no isotérmicos con $T_{\mathrm{a}}=30$, $T_{\mathrm{c}}=40^{\circ} \mathrm{C}$ y con $T_{\mathrm{a}}=40, T_{\mathrm{c}}=30^{\circ} \mathrm{C}$, respectivamente. Todos estos experimentos, muestran los cruzamientos ("cross-over") correspondientes a las transiciones (I/II) y (II//II), que aparecen cuando se excede la carga crítica $Q_{\mathrm{c}, \mathrm{IIII}}$ para $t=t_{\mathrm{I} / \mathrm{II}}$ y $Q_{\mathrm{c}, \mathrm{IIIII}}$ para $t=t_{\mathrm{II} / \mathrm{III}}$. Para los experimentos realizados en condiciones no isotérmicas, las transiciones I/II y II/III se producen más rápidamente que para los experimentos iso-térmicos. (Figura 7.14).

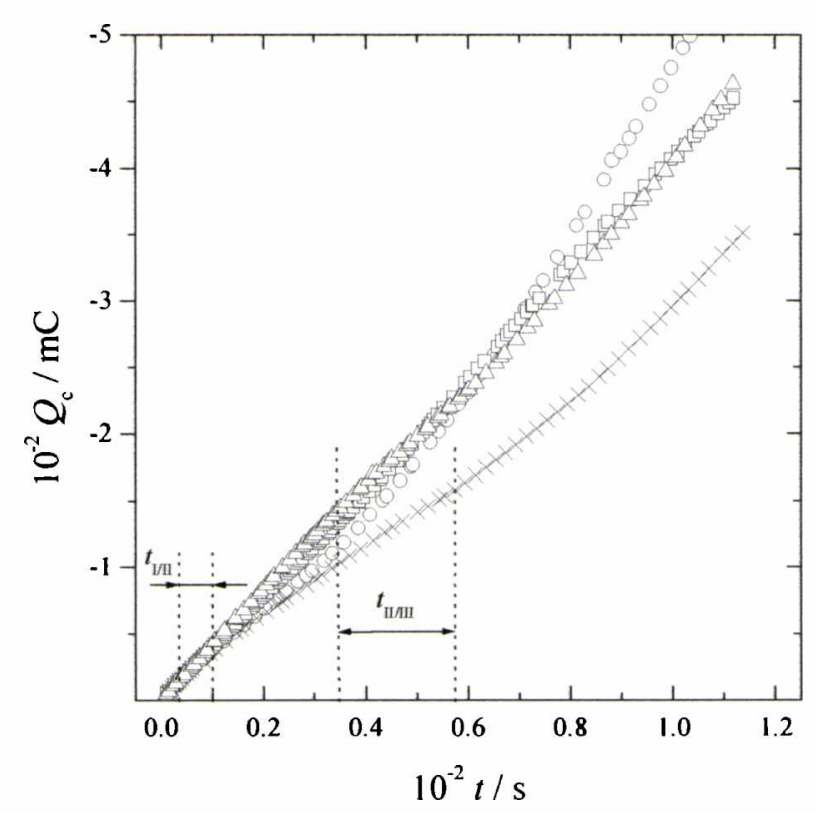

Figura 7.14. Representación de $Q_{\mathrm{c}}$ en función de $t$. (x) $T_{\mathrm{a}}=T_{\mathrm{c}}=30^{\circ} \mathrm{C} ;(\mathrm{O}) T_{\mathrm{a}}=40^{\circ} \mathrm{C} \mathrm{y}$ $T_{\mathrm{c}}=30^{\circ} \mathrm{C} ;(\square) T_{\mathrm{a}}=30^{\circ} \mathrm{C}$ y $T_{\mathrm{c}}=40^{\circ} \mathrm{C} ;(\Delta) T_{\mathrm{a}}=T_{\mathrm{c}}=40^{\circ} \mathrm{C}$ Condiciones: Solución II + ácido sulfúrico $0,5 \mathrm{M}, \Delta E_{\mathrm{c}-\mathrm{a}}=-0,450 \mathrm{~V}$. Las líneas de trazos indican la región donde se observan $t_{\mathrm{y} / 1} \mathrm{y}$ $t_{1 / 111}$.

Las densidades aparentes de los electrodepósitos se calculan considerando que el electrodepósito ocupa el volumen encerrado por un paralelepípedo cuyas dimensiones están dadas por la altura de la celda $l_{\mathrm{s}}=0,025 \mathrm{~cm}$, la longitud activa del electrodo de trabajo $l_{\mathrm{w}}=1,5 \mathrm{~cm} \mathrm{y}\left\langle h_{y}\right\rangle$. La masa se calcula de la carga medida al tiempo $t$, cuando el electrodepósito alcanzó una longitud media $\left\langle h_{y}\right\rangle$. Las representaciones de $Q_{\mathrm{c}}$ en función de $\left\langle h_{y}>\right.$ (figura 7.15), en acuerdo con la secuencia de imágenes de las figuras 7.7 y 7.8, 
muestran que la densidad aparente $(\rho)$ del depósito para las regiones I, II y III varía en el orden $\rho_{\mathrm{II}}>\rho_{\mathrm{I}}>\rho_{\mathrm{III}}$.

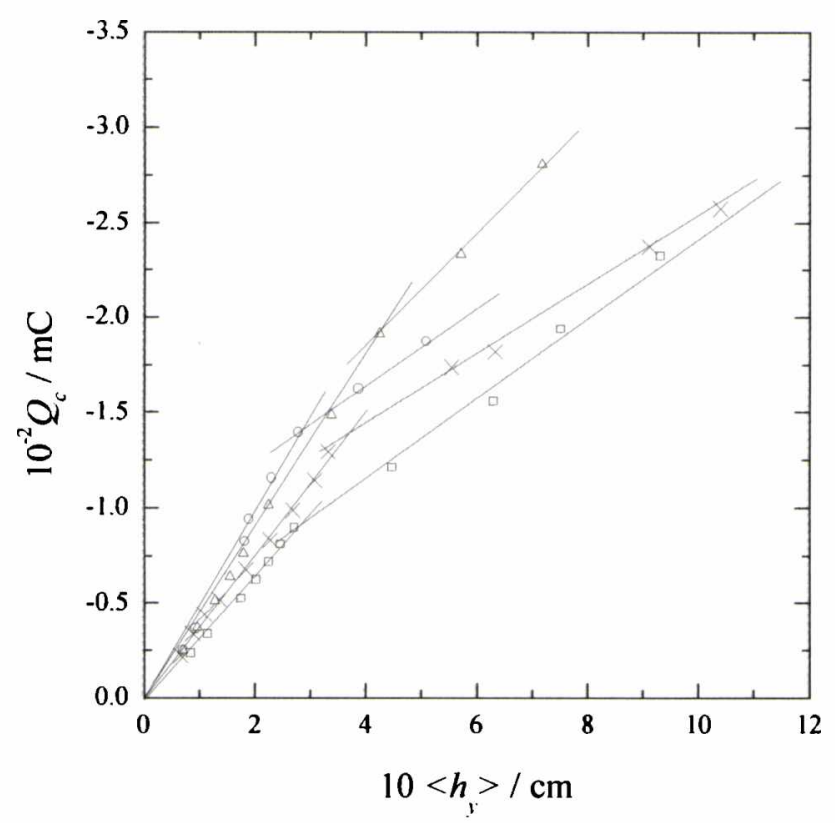

Figura 7.15. Representación de $Q_{c}$ en función de $\left\langle h_{y}\right\rangle$ correspondientes a los experimentos isotérmicos y no isotérmicos de la Fig. $7.14,(\mathrm{x}) T_{\mathrm{a}}=T_{\mathrm{c}}=30^{\circ} \mathrm{C} ;(\mathrm{O}) T_{\mathrm{a}}=40^{\circ} \mathrm{C}$ y $T_{\mathrm{c}}=30^{\circ} \mathrm{C}$; (口) $T_{\mathrm{a}}=30^{\circ} \mathrm{C}$ y $T_{\mathrm{c}}=40^{\circ} \mathrm{C} ;(\Delta) T_{\mathrm{a}}=T_{\mathrm{c}}=40^{\circ} \mathrm{C}$. En la escala del gráfico solo se puede observar el cruzamiento relacionado a la transición II/III. Cuando se aplica un gradiente térmico los cruzamientos se observan a menores tiempos.

La evolución de $\left\langle h_{y}>\right.$ (Figura 7.16 y 7.17) exhibe dos cruzamientos caracterizados por los valores $\left\langle h_{y}>_{\mathrm{I} / \mathrm{II}}\right.$ y $t_{\mathrm{I} / \mathrm{II}}, \mathrm{y}\left\langle h_{y}\right\rangle_{\mathrm{II} / \mathrm{III}}$ y $t_{\mathrm{II} / \mathrm{III}}$, respectivamente. Estos parámetros definen las regiones de crecimiento I, II y III, tanto para los experimentos isotérmicos como para los no-isotérmicos. Se obtienen distintos valores de $\left\langle v_{y}\right\rangle$ para las regiones I, II y III (Tabla 1). Los valores de $Q_{\mathrm{c}, \mathrm{II} / \mathrm{II}}, \rho_{\mathrm{II}}, \rho_{\mathrm{III}}$ se compilan en la tabla 2. 
Tabla 7.1. Valores de $\left\langle h_{y}\right\rangle_{\text {III }},\left\langle h_{y}\right\rangle_{\text {IVIII }}, t_{\text {III }}, t_{\text {IIIII }},\left\langle V_{y}\right\rangle_{I},\left\langle V_{y}\right\rangle_{\text {II }},\left\langle V_{y}\right\rangle_{\text {III }}$, para las transiciones I/II y II/III, y las regiones I, II y III. Condiciones: sulfato de plata $0,024 \mathrm{M}+$ ácido sulfúrico $0,5 \mathrm{M}$; $\Delta E_{\mathrm{c}-\mathrm{a}}=-0,450 \mathrm{~V}$.

\begin{tabular}{|l|l|l|l|l|l|l|l|l|l|}
\hline $\begin{array}{l}T_{\mathrm{c}} \\
{ }^{\circ} \mathrm{C}\end{array}$ & $\begin{array}{c}T_{\mathrm{a}} \\
{ }^{\circ} \mathrm{C}\end{array}$ & $\begin{array}{c}\Delta T \\
{ }^{\circ} \mathrm{C}\end{array}$ & $\begin{array}{c}\left\langle h_{Y}\right\rangle_{\text {VII }} \\
\mu \mathrm{m}\end{array}$ & $\begin{array}{c}t_{\text {VII }} \\
\mathrm{s}\end{array}$ & $\begin{array}{c}\left\langle h_{y}\right\rangle_{\text {IIIIII }} \\
\mu \mathrm{m}\end{array}$ & $\begin{array}{c}t_{\mathrm{II} / I I} \\
\mathrm{~s}\end{array}$ & $\begin{array}{c}\left\langle V_{y}\right\rangle_{\mathrm{I}} \\
\mu \mathrm{m} \mathrm{s}^{-1}\end{array}$ & $\begin{array}{c}\left\langle V_{y}\right\rangle_{\mathrm{II}} \\
\mu \mathrm{m} \mathrm{s}^{-1}\end{array}$ & $\begin{array}{c}\left\langle V_{y}\right\rangle_{\text {III }} \\
\mu \mathrm{m} \mathrm{s}^{-1}\end{array}$ \\
\hline 30 & 30 & 0 & $800 \pm 20$ & 100 & $4000 \pm 20$ & 600 & 9,0 & 6,4 & 19,2 \\
\hline 30 & 40 & -10 & $1000 \pm 20$ & 80 & $2700 \pm 20$ & 275 & 11,0 & 9,2 & 18,8 \\
\hline 40 & 30 & +10 & $500 \pm 20$ & 65 & $2800 \pm 20$ & 380 & 8,3 & 5,5 & 13,0 \\
\hline
\end{tabular}

Tabla 7.2. Valores de $Q_{\text {c.IVIII }}, \rho_{\text {II }}, \rho_{\text {III }}, D_{\mathrm{FII}}, D_{\mathrm{FIII}}$ obtenidos de los electrodepósitos en las regiones II y III. Condiciones: sulfato de plata $0,024 \mathrm{M}+$ ácido sulfúrico $0,5 \mathrm{M} ; \Delta E_{\mathrm{c}-\mathrm{a}}=-0,450 \mathrm{~V}$.

\begin{tabular}{|c|c|c|c|c|c|c|}
\hline$T_{\mathrm{c}} /{ }^{\circ} \mathrm{C}$ & $T_{\mathrm{a}} /{ }^{\circ} \mathrm{C}$ & $Q_{\mathrm{c}, \mathrm{II} / \mathrm{III}} / \mathrm{mC}$ & $\begin{array}{c}\rho_{\mathrm{Il}} / \\
\mathrm{g} \mathrm{cm}^{-3}\end{array}$ & $\begin{array}{c}\rho_{\mathrm{III}} / \\
\mathrm{g} \mathrm{cm}^{-3}\end{array}$ & $D_{\mathrm{FII}}$ & $D_{\text {FIII }}$ \\
\hline 30 & 30 & 135 & 0,0113 & 0,0053 & $2,0 \pm 0,1$ & $1,7 \pm 0,04$ \\
\hline 40 & 40 & 190 & 0,0126 & 0,0093 & $2,0 \pm 0,1$ & $1,7 \pm 0,04$ \\
\hline 30 & 40 & 85 & 0,0099 & 0,0069 & $2,0 \pm 0,1$ & $1,7 \pm 0,04$ \\
\hline 40 & 30 & 137 & 0,0143 & 0,0063 & $2,0 \pm 0,1$ & $1,7 \pm 0,04$ \\
\hline
\end{tabular}

Para las distintas regiones de crecimiento, el comportamiento de $\left\langle h_{y}\right\rangle$ en función del tiempo (figuras 7.16 y 7.17) tiene la forma $\left\langle h_{y}\right\rangle \propto t^{\mathrm{p}}$, variando p. En los rangos $0 \leq t \leq t_{\mathrm{I} / \mathrm{II}}$ y $0 \leq\left\langle h_{y}>\leq 10^{3} \mu \mathrm{m}, \mathrm{p} \cong 1,4 ;\right.$ para $t_{\mathrm{I} / \mathrm{II}} \leq t \leq t_{\mathrm{II} / I I}$ y $10^{3} \leq\left\langle h_{y}>\leq 4 \times 10^{3} \mu \mathrm{m}, \mathrm{p} \cong 1 ;\right.$ para $t>t_{\text {II/III }}$ y $\left\langle h_{y}>>4 \times 10^{3} \mu \mathrm{m}, \mathrm{p} \cong 1,4\right.$.

Los valores de $\left\langle V_{\mathrm{y}}\right\rangle$ decrecen al pasar de la región I a la II y aumentan al pasar de la II a la III. Además para los experimentos isotérmicos $\left(\Delta T=0{ }^{\circ} \mathrm{C}\right),\left\langle V_{y}\right\rangle_{\text {III }}$ es mayor que para los no isotérmicos, aunque en este caso, para $\Delta T=+10^{\circ} \mathrm{C}$ es menor que para $\Delta T=-10^{\circ} \mathrm{C}$. 


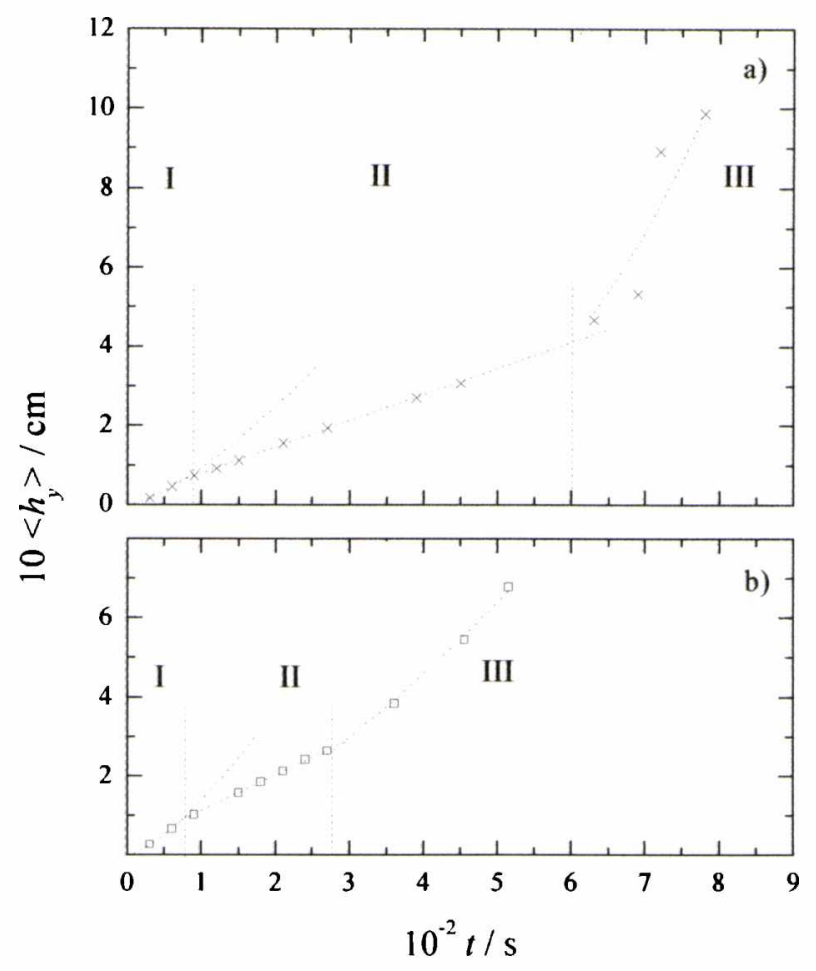

Figura 7.16. Representación de $\left\langle h_{y}\right\rangle$ en función de $t$; a) $T_{\mathrm{a}}=T_{\mathrm{c}}=30^{\circ} \mathrm{C}$; b) $T_{\mathrm{a}}=40^{\circ} \mathrm{C} \mathrm{y}$ $T_{\mathrm{c}}=30^{\circ} \mathrm{C}$. Iguales condiciones que las de la figura 7.14. Se indican las regiones $\mathrm{I}$, II y III y las transiciones $\mathrm{I} / \mathrm{II}$ y II/III.

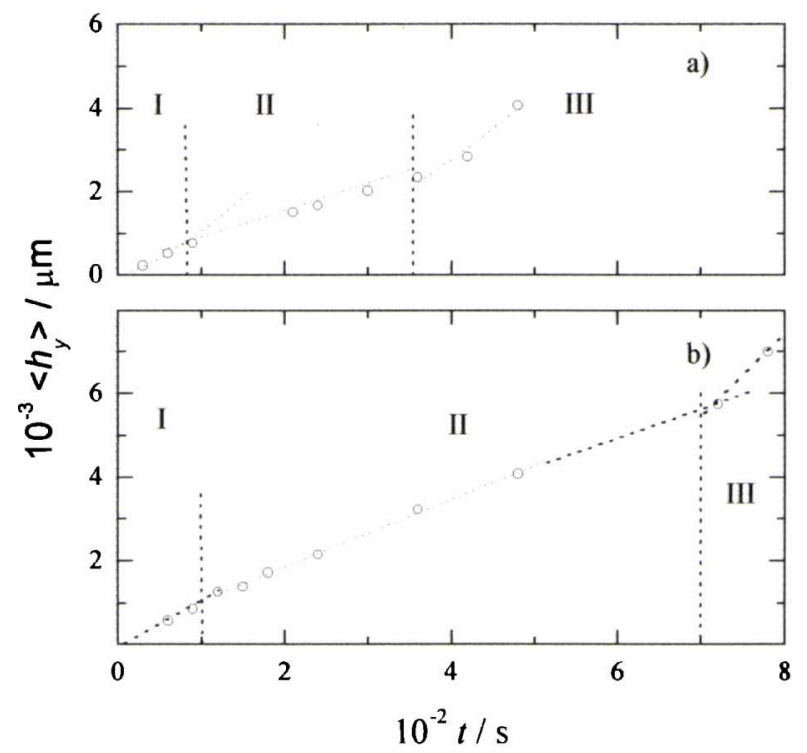

Figura 7.17. Representación de $\left\langle h_{y}\right\rangle$ en función de $t$; a) $T_{\mathrm{a}}=30^{\circ} \mathrm{C}$ y $T_{\mathrm{c}}=40^{\circ} \mathrm{C}$; b) $T_{\mathrm{a}}=T_{\mathrm{c}}=$ $40^{\circ} \mathrm{C}$. Iguales condiciones que las de la figura 7.14. Se indican las regiones I, II y III y las transiciones I/II y II/III. 
La dimensión fractal de los electrodepósitos correspondientes a la región II y III, se determinan mediante el método de conteo de cajas ocupadas que se describió en el capítulo 2.

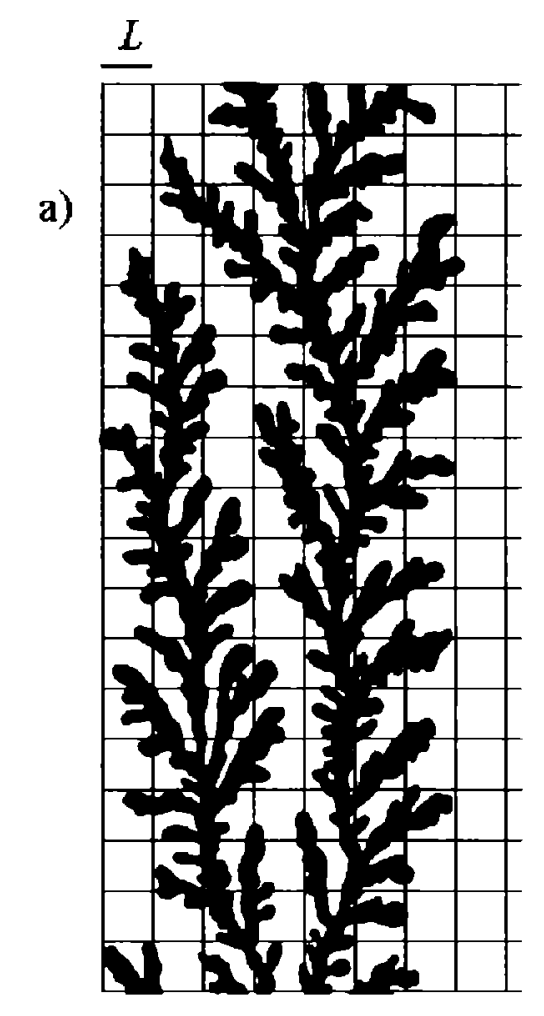

b)

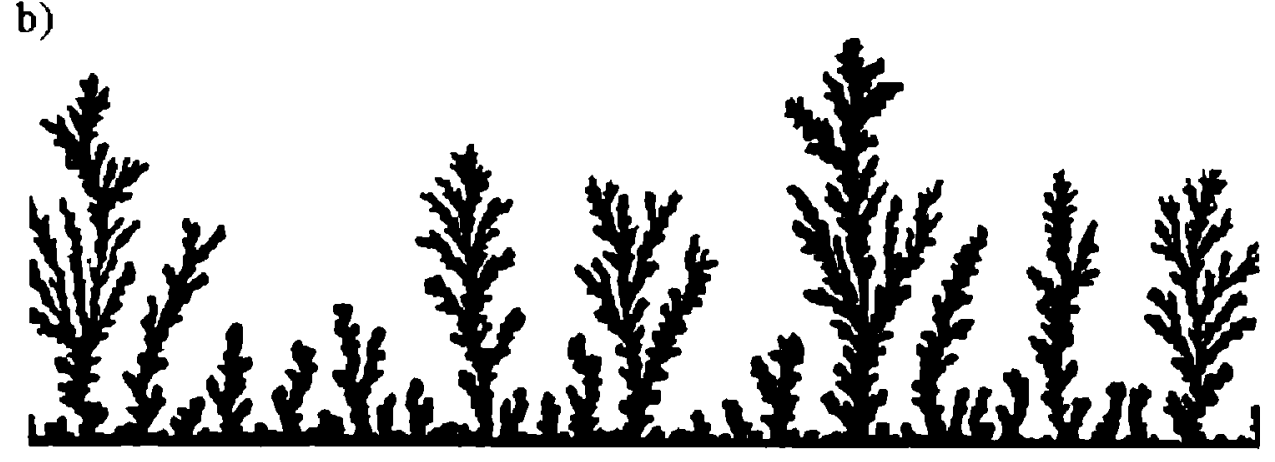

Figura 7.18. a) Morfología "tip-splitting" obtenida por desplazamiento de un líquido por otro menos viscoso [50] ; b) Electrodepósito con morfología "tip-splitting"de cinc [28].

La validez del método empleado para determinar la dimensión fractal, se verifica aplicándolo a imágenes de la morfología generada por el desplazamiento de un líquido más viscoso por uno menos viscoso (figura 7.18a)[50] y del electrodepósito de cinc publicadas por Matsushita (figura 7.18) [28] de dimensión fractal conocida. Se construye una red con 
cuadrados de tamaño $L$, y se determina el número de cajas ocupadas por el electrodepósito. No se incluye ninguna escala en las imágenes pues no es relevante para el cálculo de $D_{\mathrm{F}}$.

La pendiente de la representación de log $\mathrm{N}$ (número de cajas ocupadas) en función del $\log L$ (lado de la caja), da el valor de $D_{\mathrm{F}}$. Los datos experimentales de las experiencias de electrodeposición isotérmicas y no isotérmicas se muestran en la figura 7.19.

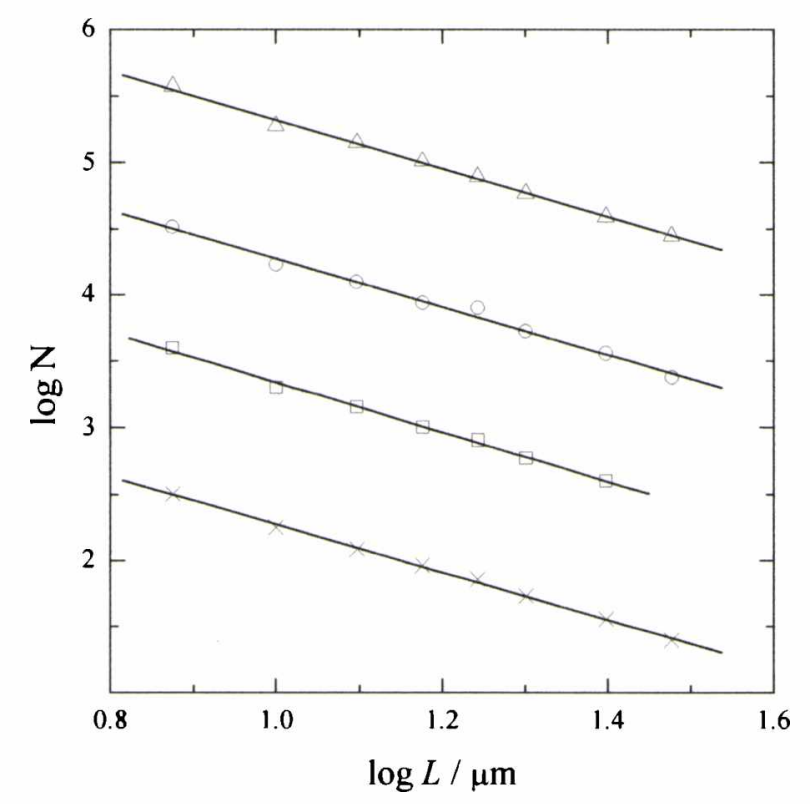

Figura 7.19. Representaciones de $\log \mathrm{N}$ versus $\log L$ para $\operatorname{los}$ experimentos realizados en las condiciones de la figura 7.14. (x) $T_{\mathrm{a}}=T_{\mathrm{c}}=30^{\circ} \mathrm{C} ;(\mathrm{O}) T_{\mathrm{a}}=40^{\circ} \mathrm{C}$ y $T_{\mathrm{c}}=30^{\circ} \mathrm{C}$; ( $\left.\square\right) T_{\mathrm{a}}=30^{\circ} \mathrm{C} \mathrm{y}$ $T_{\mathrm{c}}=40^{\circ} \mathrm{C} ;(\Delta) T_{\mathrm{a}}=T_{\mathrm{c}}=40^{\circ} \mathrm{C}$.

En todos los casos, el valor de la pendiente es $-b=D_{\mathrm{F}}$ (II) $=1,8$ a $1,9 \approx 2$, para los electrodepósitos correspondientes a la región II, valor consistente con una morfología densa. Después de la transición morfológica II/III, región III, resulta $D_{\mathrm{F}}(\mathrm{III})=1,6 \pm 0,15$.

Los valores de $Q_{\mathrm{c}, \mathrm{II} / \mathrm{III}}, \rho_{\mathrm{II}}, \rho_{\mathrm{III}}$ y las dimensiones fractales $D_{\mathrm{F}}(\mathrm{II})$ y $D_{\mathrm{F}}(\mathrm{III})$ se agrupan en la tabla 7.2.

Los valores mayores de $\rho_{\mathrm{Il}}, \rho_{\mathrm{III}}$ y $Q_{\mathrm{c}, \mathrm{II} / \mathrm{III}}$ se obtienen para $T_{\mathrm{a}}=T_{\mathrm{c}}=40^{\circ} \mathrm{C}$. Por otro lado, para $T_{\mathrm{c}}$ constante, los experimentos no isotérmicos muestran los menores valores de $Q_{\mathrm{c}, \mathrm{II} / \mathrm{III}},\left\langle h_{y}>_{\mathrm{II} / \mathrm{III}}\right.$ y $t_{\mathrm{III} / \mathrm{III}}$.

Los experimentos de electrodeposición empleando solución II + ácido sulfúrico $0,5 \mathrm{M}$, y la celda BIII con electrodos de plata de altura $X=0,005 \mathrm{~cm}$, a potenciales correspondientes a la corriente límite originan electrodepósitos de morfología "tip- 
splitting" (figura 7.20) en lugar de densos, como se obtienen con electrodos de $X=0,025$ $\mathrm{cm}$.

En este caso la dimensión fractal se aproxima a la de la morfología "tip-splitting" que resulta de la simulación del modelo de crecimiento DLA, i.e., $D_{\mathrm{F}}=1,6$ (figura 7.18). La representación de $\log \mathrm{N}$ versus $\log L$ para el electrodepósito de la figura 7.20 , da $D_{\mathrm{F}}=$ 1,66 $\pm 0,05$ (figura 7.21), consistente con procesos de agregación en presencia de un campo difusivo, sin participación efectiva de convección.

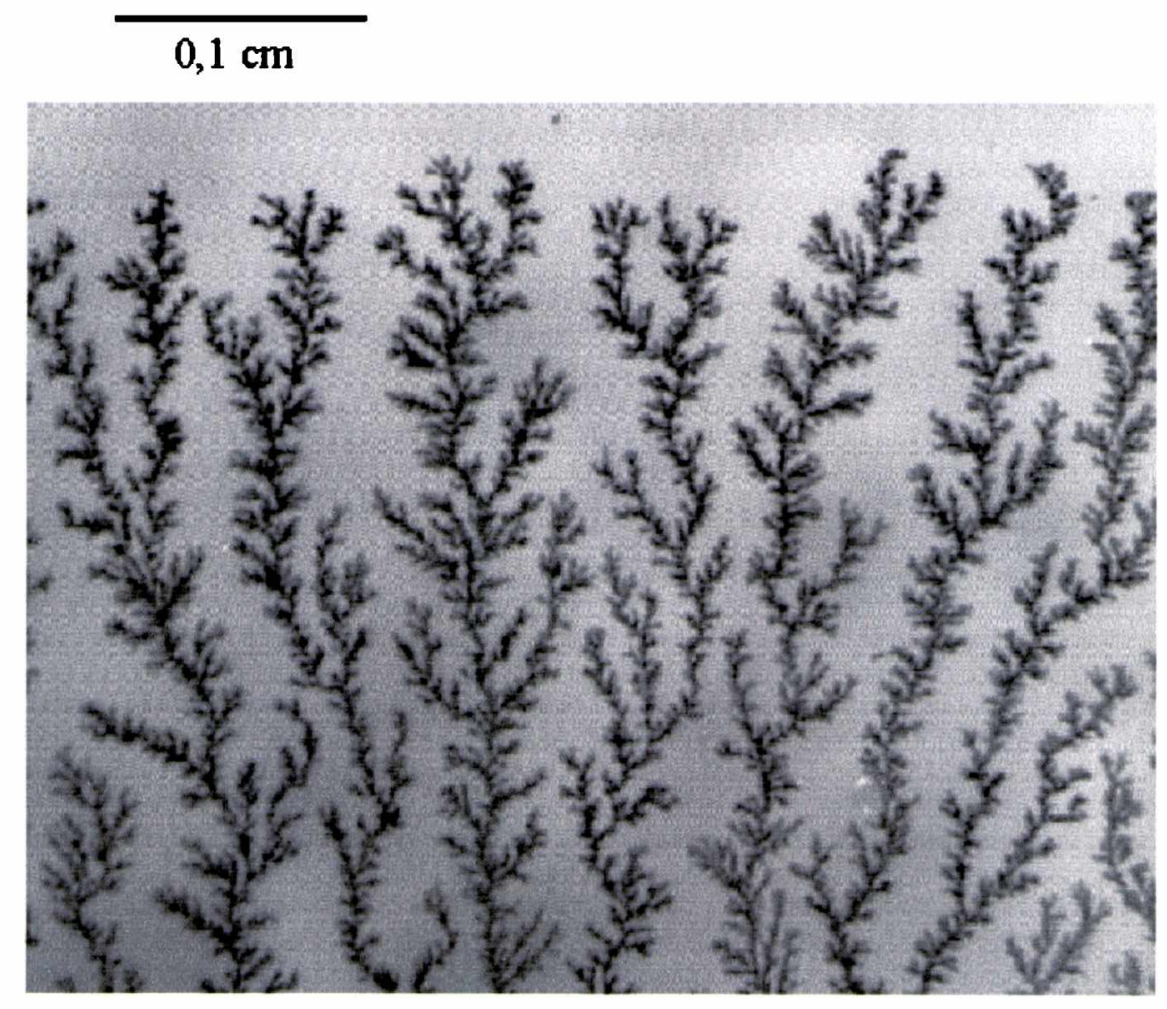

Figura 7.20. Electrodepósito obtenido en la celda BIII con electrodos de plata de $0,005 \mathrm{~cm}$ de espesor (ver texto). 


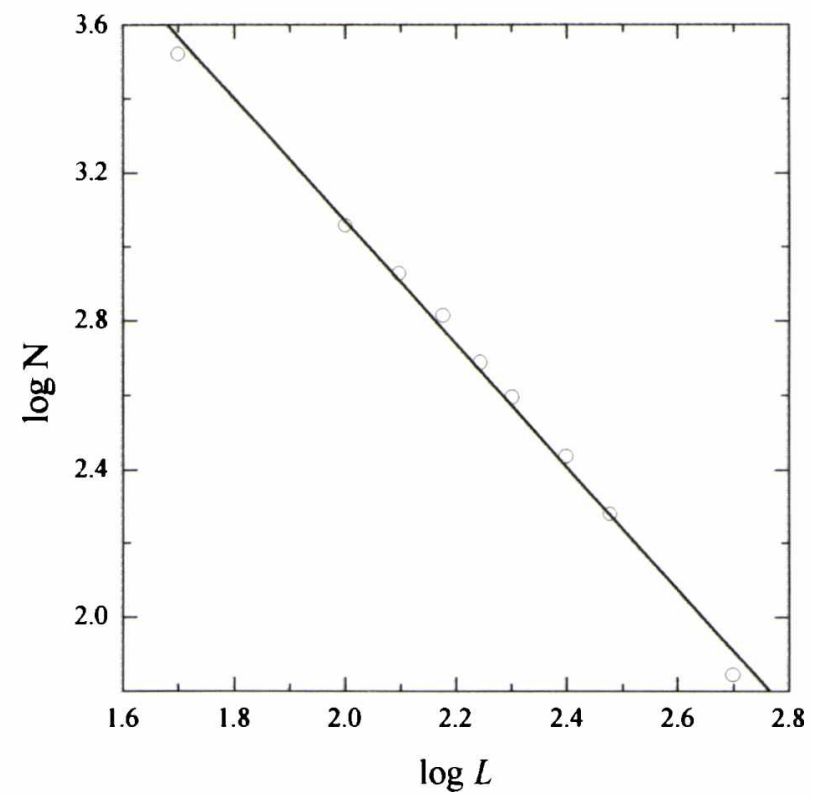

Figura 7.21. Representación de $\log \mathrm{N}$ en función de $\log L$, para el electrodepósito de la figura 7.20. 


\subsection{Datos complementarios e interpretación de resultados}

Resulta interesante estudiar un transitorio de potencial a una corriente constante, similar a la alcanzada en los transitorios potenciostáticos a $-0,45 \mathrm{~V}$, i.e, $-3 \times 10^{-4} \mathrm{~A}$, empleando la solución II + ácido sulfúrico $0,5 \mathrm{M}$, en la celda BIII.

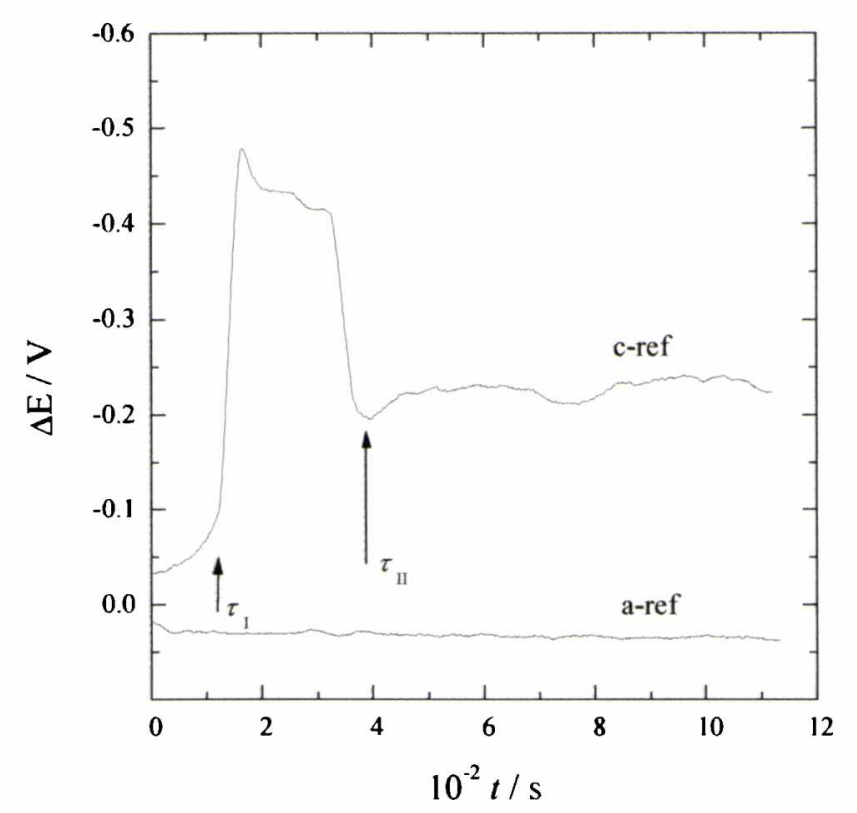

Figura 7.22. Transitorio galvanostático de potencial realizado a $I_{\mathrm{c}}=-3 \times 10^{-4} \mathrm{~A}$; solución II + ácido sulfúrico $0,5 \mathrm{M} ; 25^{\circ} \mathrm{C}$; c-ref. y a-ref. se refiere al cátodo-electrodo de referencia y ánodo-electrodo de referencia, respectivamente. Los valores de $\tau_{1}$ y $\tau_{2}$ se indican con las flechas correspondientes; $l_{\mathrm{a}-\mathrm{c}}=2,3 \mathrm{~cm}$.

Los transitorios de corriente descriptos en el capítulo anterior y el valor de $\tau_{\mathrm{I}}=115 \mathrm{~s}$ que sale de la figura 7.22, indican que la contribución de la convección natural a partir de $t=\tau_{\mathrm{I}}$ es considerable. En efecto, la ecuación de Sand (difusión pura):

$$
-I_{\mathrm{L}}\left(\tau_{\mathrm{l}}\right)^{1 / 2}=\left[\pi^{1 / 2} \mathrm{~A} n F D_{\mathrm{i}}^{1 / 2} c_{0}\right] / 2
$$

tomando $I_{\mathrm{L}}=-3 \times 10^{-4} \mathrm{~A}, n=1, c_{0}=4,8 \times 10^{-5} \mathrm{~mol} \mathrm{~cm}{ }^{-3}, D_{\mathrm{i}}=1,4 \times 10^{-5} \mathrm{~cm}^{2} \mathrm{~s}^{-1} \mathrm{~A} 25$ ${ }^{\circ} \mathrm{C}$ y A (área inicial) $=0,0375 \mathrm{~cm}^{2}$, predice un valor de $\tau_{1}$ que es un orden de magnitud menor que $\tau_{\mathrm{I}}=115 \mathrm{~s}$, medido experimentalmente. Para $\tau_{\mathrm{I}}=115 \mathrm{~s}$ la carga de plata depositada es $q_{\mathrm{c}, 1}=4,7 \times 10^{2} \mathrm{mC} \mathrm{cm}^{-2}$ y para $\tau_{2}$ (figura 7.22 ), $q_{\mathrm{c}, 2}=3,1 \times 10^{3} \mathrm{mC} \mathrm{cm}^{-2}$, es decir, son cargas suficientes para generar convección libre. Además, la rugosidad del depósito no afecta significativamente la densidad de corriente que se evalúa con el área inicial del electrodo de trabajo. 
El transitorio de potencial (c-ref) de la figura 7.22 se obtiene a $I_{\mathrm{c}}=-3 \times 10^{-4} \mathrm{~A}$, midiendo la diferencia de potencial entre el cátodo y un electrodo $\mathrm{Ag} / \mathrm{Ag}^{+}$como referencia, colocado a $1 \mathrm{~cm}$ del cátodo. El transitorio (a-ref) se obtiene aplicando la misma corriente $\quad\left(I_{\mathrm{c}}=-3 \times 10^{-4}\right.$ A) y midiendo la diferencia de potencial entre el ánodo y el electrodo de referencia. Estas experiencias muestran que los cambios observados en los transitorios de potencial, y por lo tanto también en los de corriente, responden a procesos que tienen lugar únicamente en el cátodo. Otros experimentos realizados en una celda similar a la BIII, con valores de $l_{\mathrm{acc}}$ mayores $\left(l_{\mathrm{acc}}=5 \mathrm{~cm}\right)$, corroboran esta conclusión. Así, se puede deducir que las transiciones en el modo de crecimiento del electrodepósito son, dentro del error de medida, independientes de la distancia $l_{\mathrm{a}-\mathrm{c}}$.

Se concluye entonces que la convección natural o en general el movimiento macroscópico del electrolito, es de importancia en los cambios morfológicos del electrodepósito, durante el proceso electroquímico, en consonancia con las conclusiones de las experiencias con superposición de un campo térmico. Ya que los gradientes de temperaturas también producen cambios en los parámetros que caracterizan las transiciones morfológicas I/II y II/III.

\subsubsection{Perfiles de velocidad del fluido}

En el capítulo anterior se probó la validez de la ecuación de difusión convectiva para la convección libre isotérmica y no isotérmica en la electrodeposición de plata en celdas quasi-bidimensionales. Esto permite analizar el movimiento del electrolito con las ecuaciones de la teoría y vincular los perfiles de velocidad del fluido con la morfología del sistema. Este análisis es aplicable, al menos cualitativamente, a todos los experimentos realizados empleando la solución $\mathrm{II}+$ ácido sulfúrico $0,5 \mathrm{M}$ a $\Delta \mathrm{E}_{\mathrm{c}-\mathrm{a}}=$ $0,45 \mathrm{~V}$.

Para $t \cong t_{1 / 11}$, la disminución de iones plata producida en el cátodo resulta suficiente para producir un cambio apreciable en la composición de la solución en el frente de crecimiento. Esto da lugar a la aparición de gradientes de densidad locales en el frente. Por lo tanto, en convección natural, las componentes de la velocidad del fluido, vertical o paralela a la superficie del electrodo $\left(V_{x}\right)$ y horizontal o perpendicular a la superficie del electrodo $\left(V_{y}\right)$ contribuyen a que el espesor de la película límite de transporte de materia sea más delgada, hasta alcanzar las condiciones de la transición I/II. Así, el número de árboles decrece y el ancho de cada árbol en el frente de 
crecimiento aumenta. Esto produce un depósito denso con densidad constante, y $D_{\mathrm{F}} \rightarrow 2$.

\subsubsection{Electrodeposición en condiciones isotérmicas}

Para la convección libre isotérmica, los perfiles estacionarios de las componentes de velocidad del fluido $\left(V_{x}, V_{y}\right)$, calculados para dos temperaturas distintas $\left(25^{\circ} \mathrm{C} \mathrm{y} 40^{\circ} \mathrm{C}\right)$ y $X=0,025 \mathrm{~cm}$ se muestran en la figura 7.23.

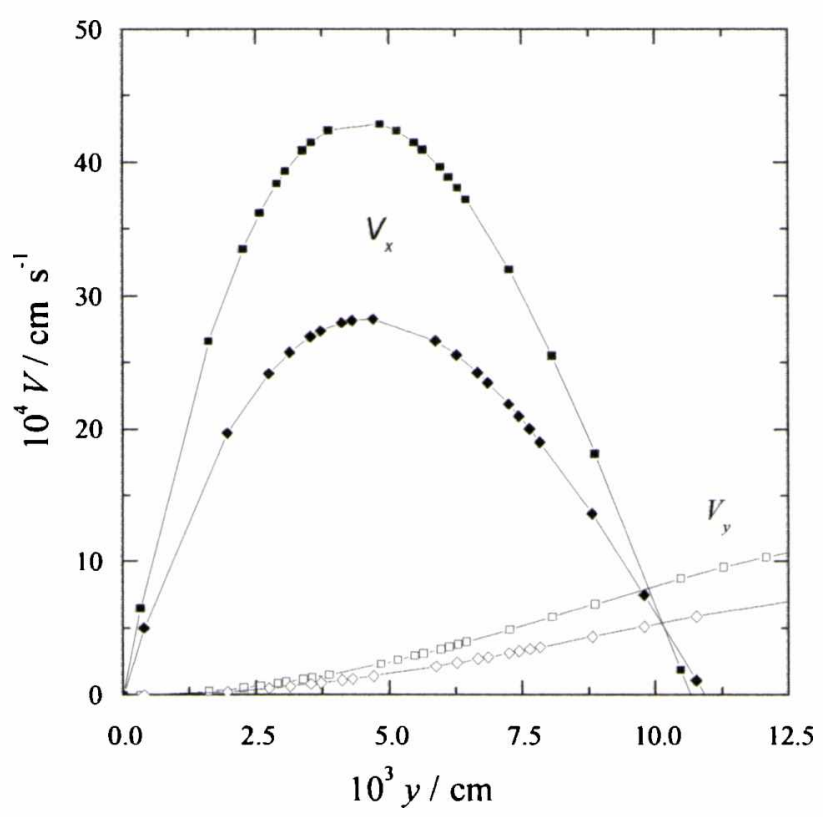

Figura 7.23. Perfiles de las componentes de velocidad del fluido $V_{x}$ y $V_{y}$ calculadas para convección natural isotérmica de acuerdo a las expresiones que se muestran en el apéndice $\mathrm{D}$.

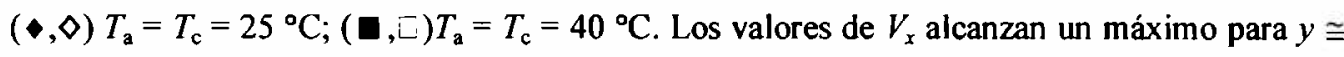
$5 \times 10^{-3} \mathrm{~cm}$, y exceden el valor de $V_{y}$ para $y \leq 10^{-2} \mathrm{~cm}$. Para $T_{\mathrm{a}}=T_{\mathrm{c}}=40^{\circ} \mathrm{C}$, se obtienen valores más grandes de $V_{x}$ y $V_{y}$.

Se observa el valor máximo para $V_{x}$ en $y=3,5 \times 10^{-3} \mathrm{~cm}$, y un aumento continuo en $V_{y}$. Sin embargo, en el rango $0 \leq y \leq 1,1 \times 10^{-3} \mathrm{~cm}$ siempre se cumple que $V_{x}>V_{y}$. En el valor máximo de $V_{x}$, resulta $V_{x} / V_{y} \cong 27$. Se puede concluir entonces, que para $h_{y, 1 / 11} \leq h_{y} \leq h_{y, 11 / I I}$, el proceso de electrodeposición está fuertemente afectado por $V_{x}$. Entonces, $h_{y, 1 / 1}$ puede considerarse como la longitud característica relacionada con el comienzo de la convección natural. Por otro lado, $V_{x}$ gobierna la trayectoria y flujo de los iones que llegan a la superficie del cátodo, para generar un depósito denso. 
La transición II/III resulta en un aumento del área efectiva, la disminución en la densidad aparente del electodepósito, y la tendencia a un desplazamiento radial de ciertos árboles en el frente del depósito. Esto debe disminuir la convección natural y los perfiles de velocidad establecidos para un frente quasi-plano dejan de ser válidos. En la región III, la selección de la morfología está fuertemente influenciada por la tensión interfacial, como se viera en el Capítulo 5, para los electrodepósitos dendríticos o aciculares. Se podría postular entonces que en ciertas regiones del frente del electrodepósito, debido a la modificación que ejerce la conveción natural sobre el flujo de iones plata, se produce un balance entre la transferencia de materia (factor desestabilizante) y la tensión superficial (factor estabilizante), que favorece la generación de morfología dendrítica.

\subsubsection{Influencia del gradiente térmico}

En los experimentos no isotérmicos, antes de comenzar la electrólisis se fija un campo térmico estacionario entre el cátodo y el ánodo, que genera un gradiente de densidad en la solución. En comparación con el caso en que $\Delta T=0$, para el mismo valor de $T_{0}$, los perfiles de velocidad estacionarios cambian con la magnitud y el signo de $\Delta T$. Para $y$ constante y $\Delta T$ positivo (Figura 7.24a), los valores de $V_{x}$ y $V_{y}$ son más grandes que para $\Delta T$ negativo (Figura 7.24b), aunque en los dos casos el máximo valor de $V_{x}$ aparece para el mismo valor de $y$. Para ambos, el cociente $V_{x} / V_{y} \cong 10$. En forma similar la extensión del perfil $V_{x}$ para $\Delta T \neq 0$ es mayor que para $\Delta T=0$. Puesto que el cambio de densidad producido por la reacción electroquímica se suma al producido por el cambio de temperatura, el efecto neto es el cambio en los valores de los parámetros asociados a las transiciones morfológicas, que se consignan en la Tabla 2.

Las características de los distintos modos de crecimiento asociados a las regiones I, II y III son independientemente de cual sea el signo y la magnitud del gradiente de temperatura aplicado entre los electrodos. La diferencia radica en el valor de los parámetros asociados a las transiciones y en las velocidades del fluido debido al acoplamiento de los gradientes. En condiciones no isotérmicas, en igualdad de las demás condiciones, las transiciones ocurren a menores tiempos. 


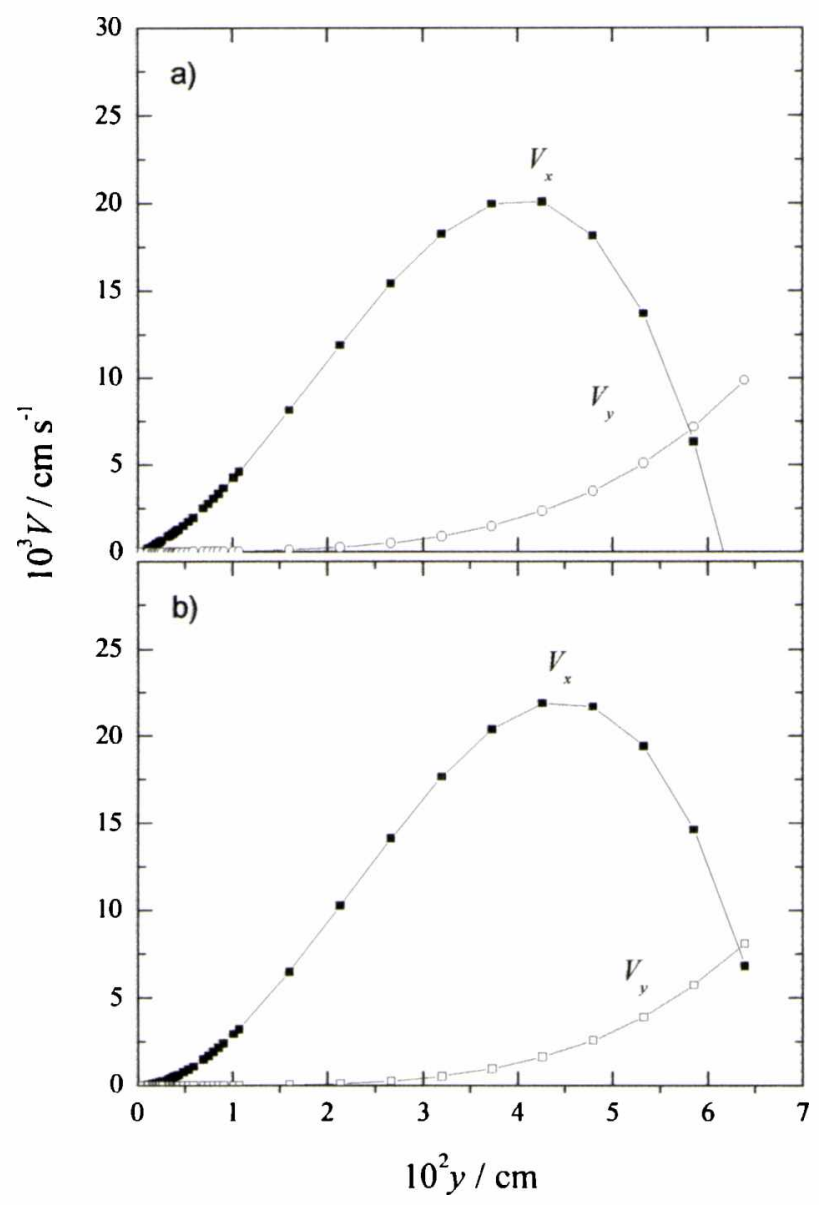

Figura 7.24. Perfiles de las componentes de velocidad del fluido $V_{x}$ y $V_{y}$ calculadas para convección natural no isotérmica de acuerdo a las expresiones que se muestran en el apéndice D. a) $T_{\mathrm{c}}=30$ y $T_{\mathrm{a}}=40{ }^{\circ} \mathrm{C}$; b) $T_{\mathrm{c}}=40$ y $T_{\mathrm{a}}=30^{\circ} \mathrm{C}$. Los perfiles de $V_{x}$ son asimétricos, las magnitudes de $V_{x}$ y $V_{y}$ son más grandes y el cociente $V_{x} / V_{y}$ más pequeño que para el caso isotérmico mostrado en Fig. 7.23. 


\section{CAPITULO 8}

\section{Simulaciones y caracterización de los electrodepósitos}

\subsection{Simulaciones}

La importancia de las componentes de velocidad del fluido en la selección de la morfología de los electrodepósitos, fue explotada en trabajos teóricos de Hibbert et. al. [187], en los que se modifica el modelo DLA, para tener en cuenta no solo la difusión pura, sino la migración y convección en diferentes direcciones.

Se emplea un modelo de DLA modificado con el fin de incorporar al campo eléctrico y de concentraciones, el campo gravitacional. Esto es necesario, pues el proceso de difusión pura no es capaz de dar cuenta de las distintas morfologías que se obtienen en la electrodeposición en celdas quasi-bidimensionales [23,24,28]. Además los perfiles de concentración determinados por algunos autores, durante la electrodeposición [77,91] no responden a las ecuaciones de difusión.

El modelo que se utiliza en este capítulo para realizar las simulaciones es el de Hibbert y Huang y el programa se escribió en Borland Pascal. Aquí se lo adaptó utilizando $\mathrm{C}++$ turbo, y se corrió en una computadora personal. En el apéndice $\mathrm{E}$ se describe el programa completo. El crecimiento se realiza en dos dimensiones $\mathrm{y}$, a diferencia de las secciones anteriores, la dirección $x$ es ahora paralela al electrodo y horizontal (lo que en la sección anterior era la dirección $z$ ).

Los resultados obtenidos ponen de manifiesto en forma cualitativa, el papel decisivo de las componentes de velocidad del movimiento del fluido en la morfología de los electrodepósitos.

\subsubsection{Características del modelo}

Se considera la electrodeposición en una celda rectangular bidimensional de geometría rectangular de ancho $l_{\mathrm{w}}$ y longitud $l_{\mathrm{c}-\mathrm{a}}$ con dos electrodos paralelos. El cátodo se ubica en $y=0$ y el ánodo en $y=l_{\mathrm{c}-\mathrm{a}}$. Se supone que el electrodepósito crece en estado estacionario gobernado por difusión, migración y convección en un campo eléctrico invariante en la dirección $y$. El campo en la dirección paralela al electrodo $(x)$ se lo considera igual a cero. La concentración satisface la ecuación diferencial

$$
D_{\mathrm{i}} \frac{\partial^{2} c}{\partial x^{2}}+D_{\mathrm{i}} \frac{\partial^{2} c}{\partial y}-V_{x} \frac{\partial c}{\partial x}-V_{y} \frac{\partial c}{\partial y}-\mu E \frac{\partial c}{\partial y}=0
$$


donde $D_{\mathrm{i}}$ es el coeficiente de difusión del ión plata, $V_{\mathrm{x}}$ y $V_{\mathrm{y}}$ son las componentes de velocidad en la dirección $x$ e $y$, respectivamente, $\mu$ es la movilidad del ión, y el campo eléctrico $E=-U / l_{\mathrm{c}-\mathrm{a}}$, donde $U$ es la diferencia de potencial aplicada entre los electrodos. Los primeros dos términos están asociados a la difusión en las direcciones $x$ e $y$, el tercero y cuarto corresponden a los procesos convectivos en las direcciones $x$ e $y$, el último término representa la migración en la dirección $y$.

Para simplificar la resolución de la ecuación diferencial (8.1), se la expresa en forma adimensional, definiendo la concentración adimensional $C=c / c_{0}$, las componentes de velocidad convectiva adimensional $v_{x}=V_{x} L / D_{\mathrm{i}}$ y $v_{y}=V_{y} L / D_{\mathrm{i}}$ (donde $L$ es una longitud característica), la distancia adimensional $X=x / L$ y el campo eléctrico adimensional $M=\mu E L / D_{\mathrm{i}}$, y multiplicando los términos por $L / D_{\mathrm{i}} c_{0}$. Así, la ecuación (8.1) resulta:

$$
\frac{\partial^{2} C}{\partial X^{2}}+\frac{\partial^{2} C}{\partial Y^{2}-v_{x}} \partial C-v_{y} \partial C-M \frac{\partial C}{\partial Y}=0
$$

\subsubsection{Ecuaciones para un campo difusional}

Cuando solo se considera la difusión, la ecuación (8.2) se reduce a:

$$
\begin{aligned}
& \partial^{2} C+\partial^{2} C=0 \\
& \partial X^{2}+\partial Y^{2}=0
\end{aligned}
$$

y la forma discreta de la ecuación se obtiene definiendo los siguientes operadores diferenciales:

$$
\begin{gathered}
\partial C=\left(C_{X, Y}-C_{X-1, Y}\right) / \Delta \\
\partial X=\left(C_{X, Y}-C_{X, Y-1}\right) / \Delta \\
\partial Y \\
\partial^{2} C=\left(C_{X+1, Y}+C_{X-1, Y}-2 C_{X, Y}\right) / \Delta^{2} \\
\partial X^{2} \\
\partial^{2} C=\left(C_{X, Y+1}+C_{X, Y-1}-2 C_{X, Y}\right) / \Delta^{2} \\
\partial Y^{2}
\end{gathered}
$$

$\Delta$ es el paso en las expresiones discretas, que es el mismo en la dirección $x$ e $y$.

Substituyendo (8.6) y (8.7) en (8.3) se obtiene la expresión de $C_{X, Y}$

$$
C_{X, Y}=C_{X+1, Y}+C_{X-1, Y}+C_{X, Y+1}+C_{X, Y-1}
$$

que es el resultado del modelo de agregación limitado por difusión (DLA). La contribución a la concentración en el punto $(X, Y)$ proveniente desde las cuatro direcciones consideradas 
en la programación, viene dada por el producto de la concentración en el punto $(X+\mathrm{i}, Y+\mathrm{i})$, $(\mathrm{i}=1,0,-1)$ y la probabilidad $\mathrm{p}(X+\mathrm{k}, Y+\mathrm{k})(\mathrm{k}=-1,1)$ de que una partícula se mueva en la dirección $X$ o $Y$ desde el punto $(X+\mathrm{k}, Y+\mathrm{k})$ hasta el punto $(X, Y)$. En el modelo DLA, la probabilidad de movimiento de una partícula es la misma en las cuatro direcciones (similar a una caminata aleatoria) y vale $1 / 4$ para cada dirección. La concentración adimensional puede expresarse:

$C_{X, Y}=\mathrm{p}(X+1, Y) C_{X+1, Y}+\mathrm{p}(X-1, Y) C_{X-1, Y}+\mathrm{p}(X, Y+1) C_{X, Y+1}+\mathrm{p}(X, Y-1) C_{X, Y-1}$

\subsubsection{Efecto de la incorporación de la convección y la migración en un campo eléctrico}

Para tener en cuenta la convección y la migración en un campo eléctrico en dos dimensiones se substituyen las expresiones (8.4) - (8.7) en (8.2) obteniéndose:

$$
\begin{aligned}
& C_{X, Y}=\underset{4+\left(v_{X}+v_{Y}+M\right) \Delta}{C_{X+1, Y}}+\begin{array}{c}
\left(1+v_{X} \Delta\right) C_{X-1, Y} \\
4+\left(v_{X}+v_{Y}+M\right) \Delta
\end{array}+ \\
& C_{X, Y+1}+\left(1+v_{Y} \Delta+M \Delta\right) C_{X, Y-1} \\
& 4+\left(v_{X}+v_{Y}+M\right) \Delta+{ }^{+} 4+\left(v_{X}+v_{Y}+M\right) \Delta
\end{aligned}
$$

En este caso las probabilidades tienen la forma:

$$
\begin{gathered}
\mathrm{p}(X+1, Y)=\begin{array}{c}
1 \\
4+\left(v_{X}+v_{Y}+M\right) \Delta
\end{array} \\
\mathrm{p}(X-1, Y)=\begin{array}{c}
1+v_{X} \Delta \\
4+\left(v_{X}+v_{Y}+M\right) \Delta
\end{array} \\
\mathrm{p}(X, Y+1)=\begin{array}{c}
1 \\
4+\left(v_{X}+v_{Y}+M\right) \Delta \\
1+\left(v_{Y}+M\right) \Delta \\
4+\left(v_{X}+v_{Y}+M\right) \Delta
\end{array}
\end{gathered}
$$

Puesto que las probabilidades son positivas se toman los valores absolutos de los parámetros en las expresiones anteriores. 
El programa adaptado a $\mathrm{C}+$ Turbo, utilizado aqui, permite variar en forma independiente las componentes de velocidad adimensional $v_{X}, v_{Y}$ y el valor del campo adimensional $M$, que tiene en cuenta la contribución de la migración.

Se calculan a continuación $v_{X}, v_{Y}$ y $M$ para las condiciones de electrodeposición empleadas en este trabajo.

Para calcular $M$, se toma, $\Delta \mathrm{E}_{\mathrm{a}-\mathrm{c}} \equiv \mathrm{U}=0,45 \mathrm{~V}$ y $l_{\mathrm{a}-\mathrm{c}}=2,3 \mathrm{~cm}, L=0,025 \mathrm{~cm}$ (espesor de la celda) y $D_{\mathrm{i}}=1,39 \times 10^{-5} \mathrm{~cm}^{2} \mathrm{~s}^{-1}$; la movilidad iónica del catión plata $\left(\mu_{\mathrm{Ag}+}\right)$ calculada a partir de la conductividad molar, $61,92 \mathrm{~S} \mathrm{~cm}^{2} \mathrm{~mol}^{-1}$, con la expresión:

$$
\lambda=z_{\mathrm{i}} \mid F \mu_{\mathrm{i}}
$$

resulta $\mu_{\mathrm{Ag}^{+}}=6,4 \times 10^{-4} \mathrm{~cm} \mathrm{~V}^{-1} \mathrm{~s}^{-1}$. Entonces, $M=E \mu_{\mathrm{i}} L / D \cong 0,3$. En las simulaciones se toma $M=1$.

Los valores de las componentes de la velocidad van variando de acuerdo a la distancia entre el frente de crecimiento y el contraelectrodo, de acuerdo a la solución de la ecuación de difusión convectiva para las componente de las velocidades (figuras $7.23 \mathrm{y}$ 7.24). Las componentes de velocidad $v_{x}$ y $v_{y}$, se varían en el rango $\approx 1 \leq v \leq \approx 20$, de manera que las componentes $V_{x}$ y $V_{y}$, tomen valores similares a los obtenidos de la ecuación de difusión convectiva (Capítulo 6, ecuación 6.25), para la celda quasibidimensional.

En la figura 8.1 y 8.2 se muestran algunos resultados de las simulaciones de crecimiento del depósito. En estas simulaciones se mantiene constante el valor de $E=1$ y se varía la relación $V_{x} / V_{y}$. Esta relación puede asociarse con el ángulo de incidencia del vector velocidad del fluido, sobre la superficie del electrodo. Los electrodepósitos se componen de 5000 partículas que se dejan caer una a una desde una distancia de 20 posiciones por encima de la altura máxima alcanzada por el electrodepósito.

Manteniendo constante $E$, al aumentar $V_{y}$ o al disminuir la relación $V_{x} / V_{y}$ se obtiene un electrodepósito con mayor densidad. Esto está en acuerdo, con algunos aspectos de la evolución de los electrodepósitos descriptos en secciones anteriores. Se aprecia que los primeros árboles o protuberancias forman un electrodepósito relativamente abierto respecto al formado a escalas mayores de longitud, o equivalentemente a mayores escala de tiempo, donde aumenta la velocidad de crecimiento lateral y la competencia entre árboles. A tiempos más largos la componente $V_{\mathrm{y}}$ es más apreciable que a tiempos menores.

Sería necesario realizar un estudio dinámico del crecimiento simulado, pero en este punto debe decirse que la electrodeposición de plata, empleando soluciones de sulfato de 
plata a potenciales de corriente límite, y las celdas quasi-bidimensionales con altura de electrodo mayor que $0,025 \mathrm{~cm}$, puede describirse satisfactoriamente por el modelo de $\mathrm{KPZ}$ (como se verá en la sección siguiente), y mejor que con el modelo DLA. Por tal razón, las simulaciones aquí presentadas son cualitativas y solo muestran el efecto de la variación de la relación entre las componentes de velocidad del fluido.
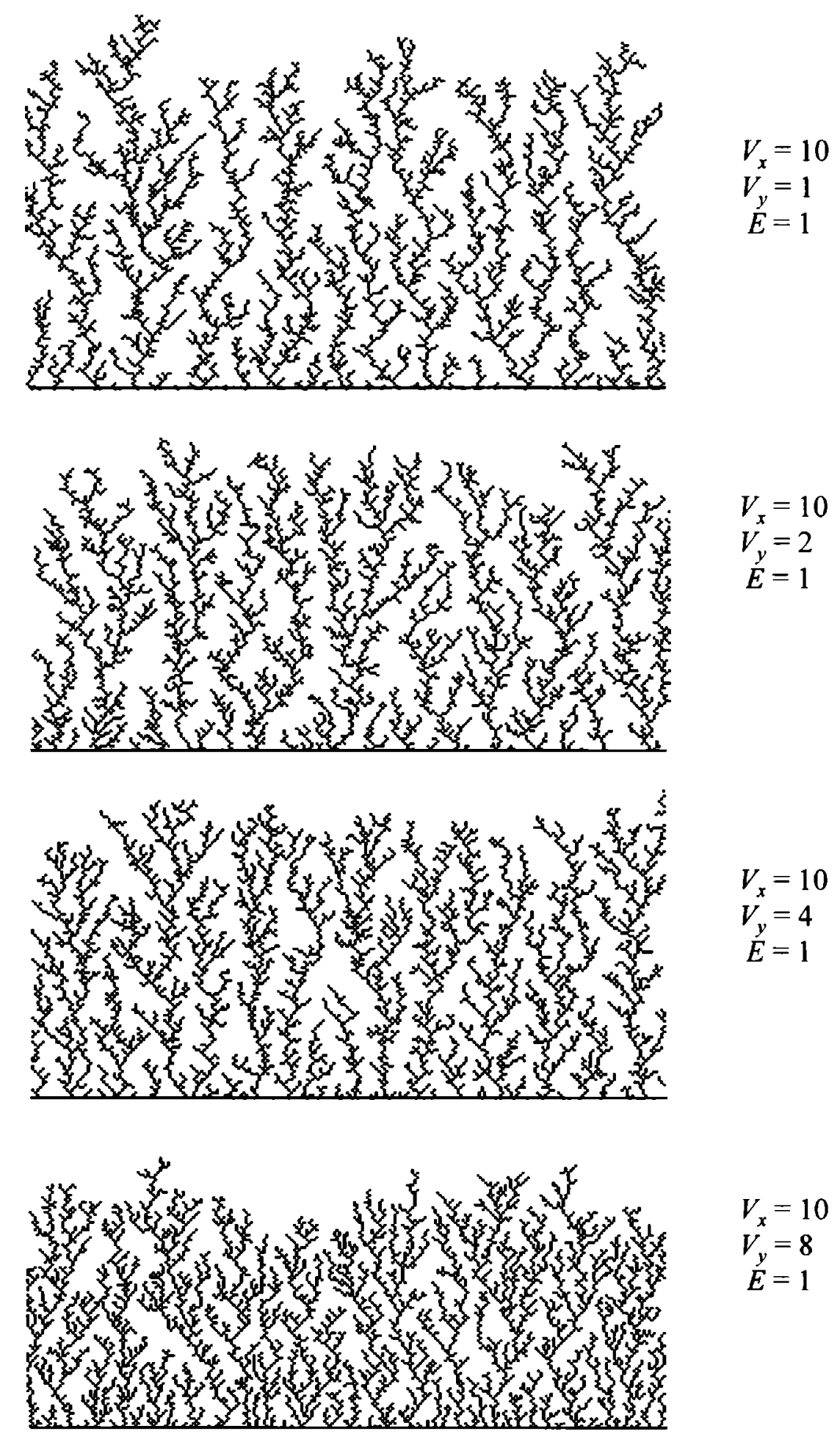

Figura 8.1. Simulaciones DLA 


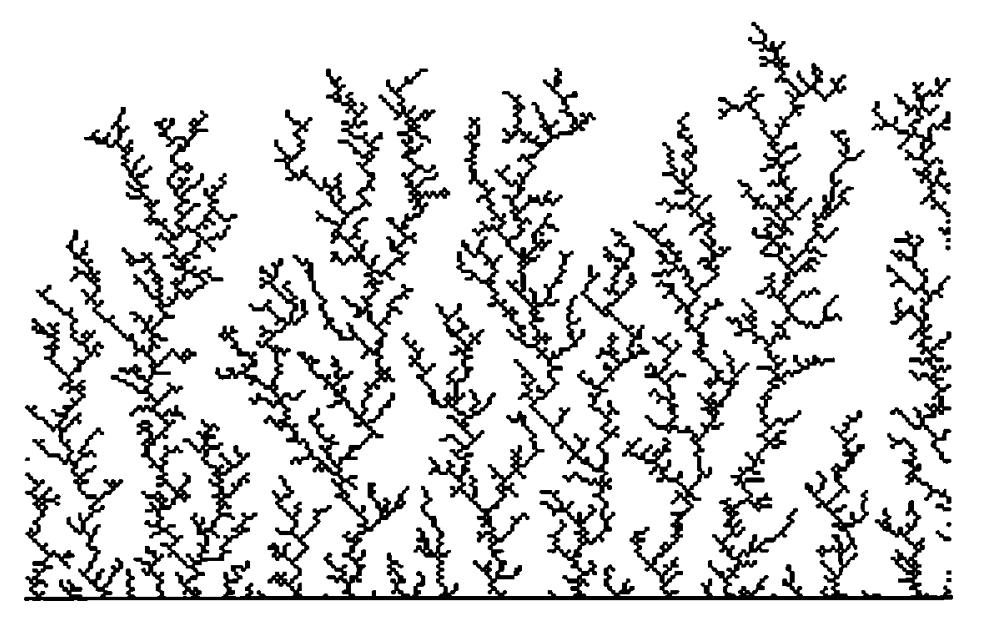

$$
\begin{aligned}
V_{x} & =10 \\
V_{y} & =2 \\
E & =1
\end{aligned}
$$

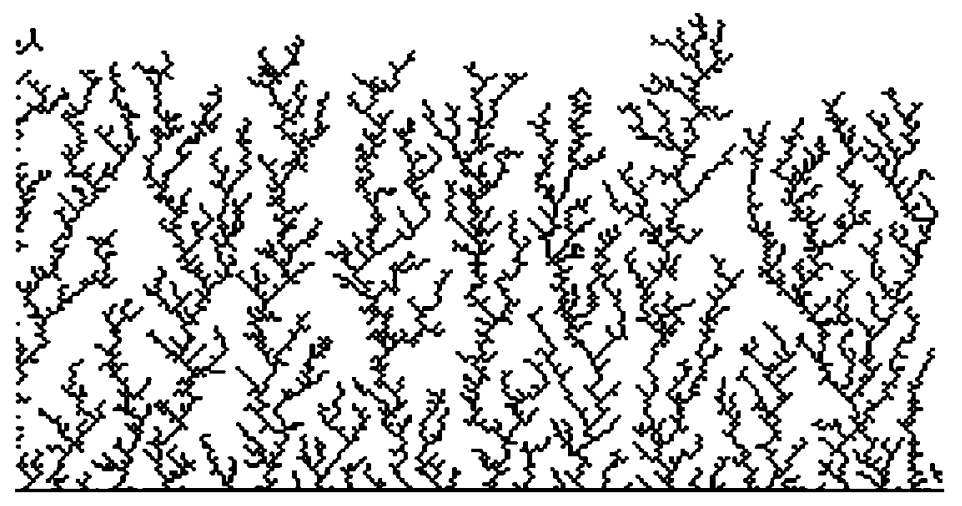

$$
\begin{aligned}
V_{x} & =20 \\
V_{y} & =5 \\
E & =1
\end{aligned}
$$

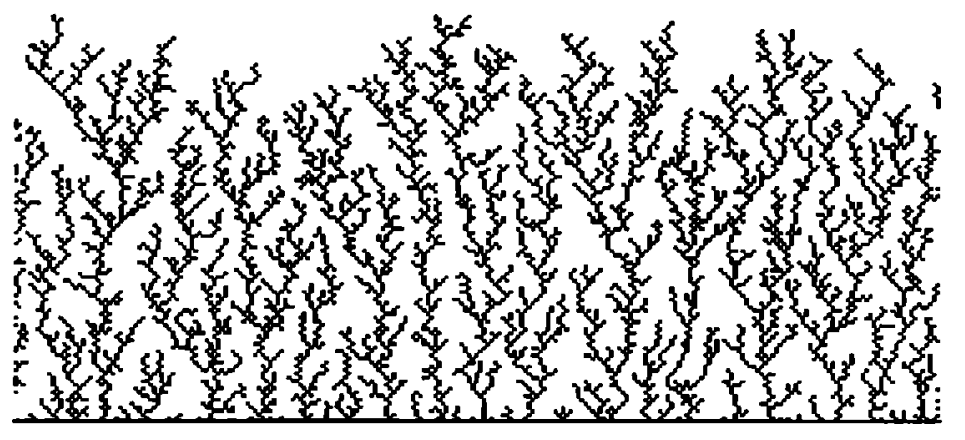

$\begin{aligned} V_{x} & =20 \\ V_{y} & =10 \\ E & =1\end{aligned}$

Figura 8.2. Simulaciones DLA 


\subsection{Caracterización de los electrodepósitos}

En las próximas secciones se utilizan dos técnicas de caracterización de los electrodepósitos.

En primer lugar se aplica a los experimentos de electrodeposición mostrados en 7.4 (celda BIII cuasi-2D, en condiciones isotérmicas y no isotérmicas), la teoría de escalado dinámico presentada en el capítulo 2 . Se interpretan los resultados de 7.4 en base al modelo de crecimiento que surge de los exponentes obtenidos mediante el escalado dinámico. Lo que requiere asociar al modelo $\mathrm{KPZ}$, fenómenos físicos involucrados en la cinética de formación y morfología de los electrodepósitos.

En segundo lugar, se emplea el análisis estadístico de la estructura interna, a electrodepósitos con estructura densa, similares a los obtenidos en 7.4. En la región II de crecimiento (mostrada en el capítulo 7), durante la evolución del electrodepósito existe una continua competencia entre árboles: aquellos que crecen más rápidamente "apantallan" a sus vecinos. Este proceso, continuaría hasta que unos pocos árboles dominen el crecimiento. El estudio de la estructura interna del electrodepósito, se puede abordar considerándolo formado por árboles o "clusters" individuales constituidos por partículas conectadas. La estructura de cada árbol, la distribución de tamaño y su ubicación en el depósito global son consecuencia del mecanismo de crecimiento. La distribución estadística de los árboles determina la estructura interna. Esta contiene información sobre la dinámica de crecimiento y refleja, en principio, la forma por el cual la "información" de cada árbol se transmite lateralmente (espacial y temporalmente) conduciendo al depósito global. El análisis estadístico de la estructura interna de los depósitos resulta especialmente útil para los casos en que no se dispone de la evolución del depósito y solo de la estructura final alcanzada. La cantidad de parámetros que provee el análisis es suficiente para establecer la universalidad a la que puede asociarse el proceso, sin necesidad de conocer la secuencia de estados de crecimiento del electrodepósito. Es necesario notar que la utilización de este método para caracterizar los electrodepósitos, requiere disponer de un número grande de datos para reducir la dispersión en los parámetros involucrados. Esto, desde el punto de vista práctico constituye una desventaja respecto al método tradicional de escalado dinámico.

Tanto los resultados del escalado dinámico como el análisis de la estructura interna de los electrodepósitos indican que la ecuación de KPZ puede describir la evolución del electrodepósito en las condiciones de este trabajo [188]. 


\subsubsection{Escalado dinámico}

Para aplicar la teoría de escalado dinámico se necesita disponer de un procedimiento que permita, de acuerdo a las posibilidades que provee el experimento, calcular los exponentes de las leyes de potencia del escalado dinámico (Capítulo 2).

El exponente de crecimiento $\beta$ se obtiene de la pendiente de la dependencia del ancho de la interfase $W_{y}$ con el tiempo de electrodeposición para tiempos menores que el tiempo de saturación $t_{\mathrm{x}}$. Para tiempos mayores que el tiempo de saturación, el ancho de la interfase permanece constante.

El exponente de rugosidad $\alpha$ se obtiene de la pendiente de la representación del ancho de la interfase con el tamaño del sistema $L$, para $t<t_{\mathrm{x}}$. En la práctica, esto significa realizar experimentos de electrodeposición variando el ancho del electrodo, $l_{\mathrm{w}}$, lo que constituye una tarea sumamente tediosa. Además, para electrodos muy pequeños aparecen efectos de bordes que afectan a la cinética de crecimiento y la morfología de los electrodepósitos.

En este trabajo, como en la mayoría de las interfases obtenidas experimentalmente, para determinar $\alpha$, se mide en lugar del ancho total del sistema (ecuación 2.33), el ancho local, esto es, el ancho de una porción del sistema [18]. Para la interfase del electrodepósito en la que el exponente de rugosidad es independiente del tiempo, se selecciona una porción de la interfase (en este trabajo una región rectangular de la imagen de un electrodepósito), que se extiende a lo largo de una longitud $l$ sobre el electrodo, y se mide su ancho $W_{y}$. Esto se repite para distintas porciones y los valores de $W_{y}$ obtenidos se promedian. Luego se representa $W_{y}$ versus $l$ para obtener $\alpha$.

Las representaciones $W_{y}$ versus $t$ (figura 8.3) exhiben tres regiones I, II, III que corresponden a funciones $W_{y} \propto t^{\beta}$, con valores característicos del exponente $\beta$. 


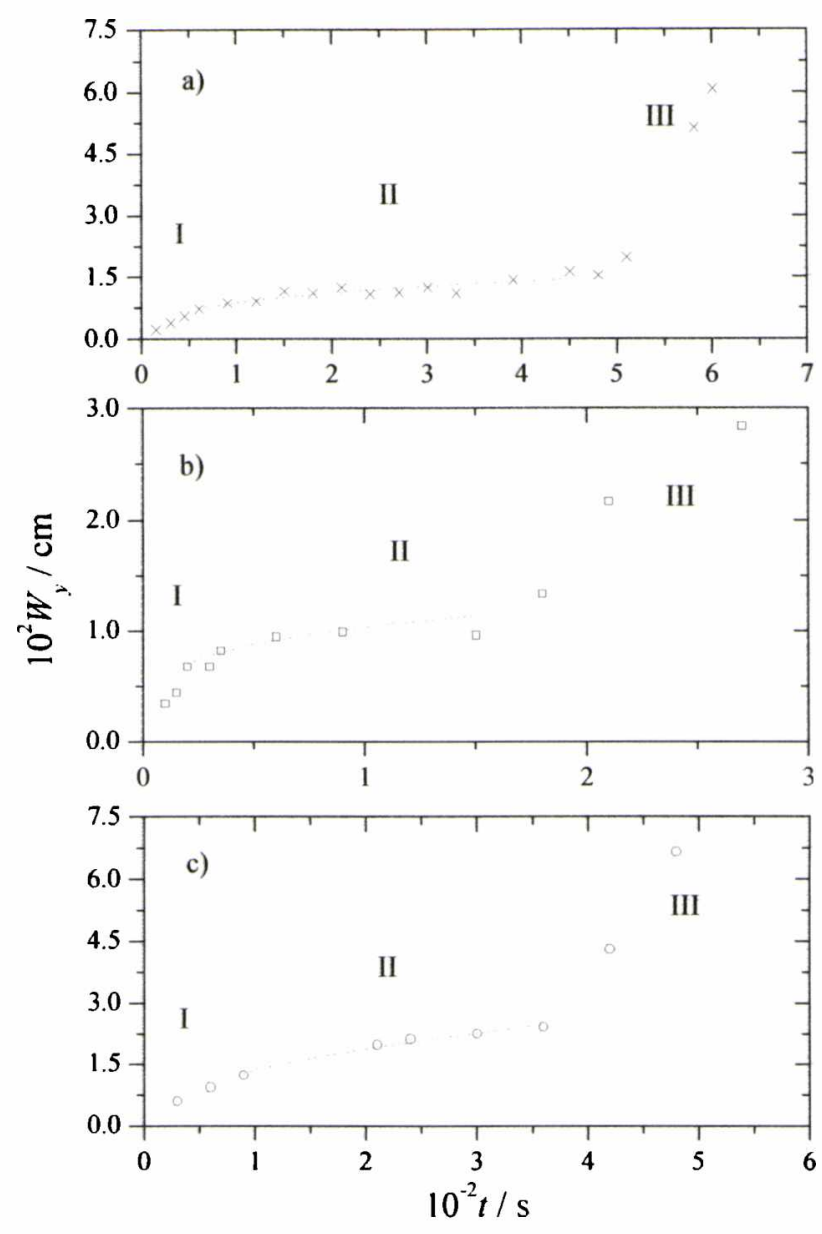

Figura 8.3. Gráficos de $W_{y}$ en función de $t$. a) $T_{\mathrm{a}}=T_{\mathrm{c}}=30^{\circ} \mathrm{C}$; b) $T_{\mathrm{a}}=40^{\circ} \mathrm{C}$ y $T_{\mathrm{c}}=30^{\circ} \mathrm{C}$; c) $T_{\mathrm{a}}=$ $30{ }^{\circ} \mathrm{C}$ y $T_{\mathrm{c}}=40^{\circ} \mathrm{C}$. Se indican las regiones I, II y III y las curvas de trazo discontinuo corresponden a la función $W_{y} \propto \ell^{1 / 3}$ para la región II.

Para la región $\mathrm{I}$, se tiene $\beta \rightarrow 1$ para $\approx 0 \leq t \leq \approx 50 \mathrm{~s}, 0 \leq W_{y} \leq \approx 80 \mu \mathrm{m}$ y $\Delta T=0{ }^{\circ} \mathrm{C} ; \approx 0 \leq t \leq \approx 30 \mathrm{~s}, 0 \leq W_{y} \leq \approx 75 \mu \mathrm{m}$ y $\Delta T=-10{ }^{\circ} \mathrm{C} ; \approx 0 \leq t \leq \approx 50 \mathrm{~s}$, $0 \leq W_{y} \leq \approx 80 \mu \mathrm{m}$ y $\Delta T=+10^{\circ} \mathrm{C}$. Para la región Il se obtiene $\beta \rightarrow 1 / 3$ para $\approx 50 \leq t \leq$ $\approx 500 \mathrm{~s}, 80 \leq W_{y} \leq \approx 150 \mu \mathrm{m}$ y $\Delta T=0{ }^{\circ} \mathrm{C} ; \approx 30 \leq t \leq \approx 150 \mathrm{~s}, \approx 75 \leq W_{y} \leq \approx 100 \mu \mathrm{m} \mathrm{y}$ $\Delta T=-10^{\circ} \mathrm{C} ; \approx 50 \leq t \leq \approx 350 \mathrm{~s}, \approx 80 \leq W_{y} \leq \approx 240 \mu \mathrm{m}$ y $\Delta T=+10^{\circ} \mathrm{C}$. Finalmente, para la región III $\beta \rightarrow 1$.

En las representaciones $W_{y}$ versus $l$ (figura 8.4), se aproximan funciones $W_{y} \propto l^{\alpha}$. Para la región I, $\alpha \rightarrow 1,0$ para $l \leq \approx 300 \mu \mathrm{m}, W_{y} \leq \approx 75 \mu \mathrm{m}$ y $\Delta T=0{ }^{\circ} \mathrm{C} ; l \leq \approx 250 \mu \mathrm{m}$, $W_{y} \leq \approx 70 \mu \mathrm{m}$ y $\Delta T=-10^{\circ} \mathrm{C}$ y $l \leq \approx 1170 \mu \mathrm{m}, W_{y} \leq \approx 215 \mu \mathrm{m}$ y $\Delta T=10^{\circ} \mathrm{C}$. Para la región II $\alpha \rightarrow 0,5$ para $\approx 300 \leq l \leq \approx 1500 \mu \mathrm{m}, \approx 75 \leq W_{y} \leq \approx 120 \mu \mathrm{m}$ y $\Delta T=0{ }^{\circ} \mathrm{C}$; $\approx 250 \leq l \leq \approx 1200 \mu \mathrm{m}, \approx 70 \leq W_{y} \leq \approx 125 \mu \mathrm{m}$ y $\Delta T=-10^{\circ} \mathrm{C}$ y $\approx 1170 \leq l \leq \approx 1750 \mu \mathrm{m}$, $\approx 215 \leq W_{y} \leq \approx 265 \mu \mathrm{m}$ y $\Delta T=+10^{\circ} \mathrm{C}$. Para la región III $\alpha \approx 0$. Los valores de $l_{\mathrm{I} / \mathrm{II}}$ y $l_{\mathrm{II} / \mathrm{III}}$ 
obtenidos de las representaciones $W_{y}$ versus $l$ son comparables al espesor de la película límite de transferencia de materia [164].
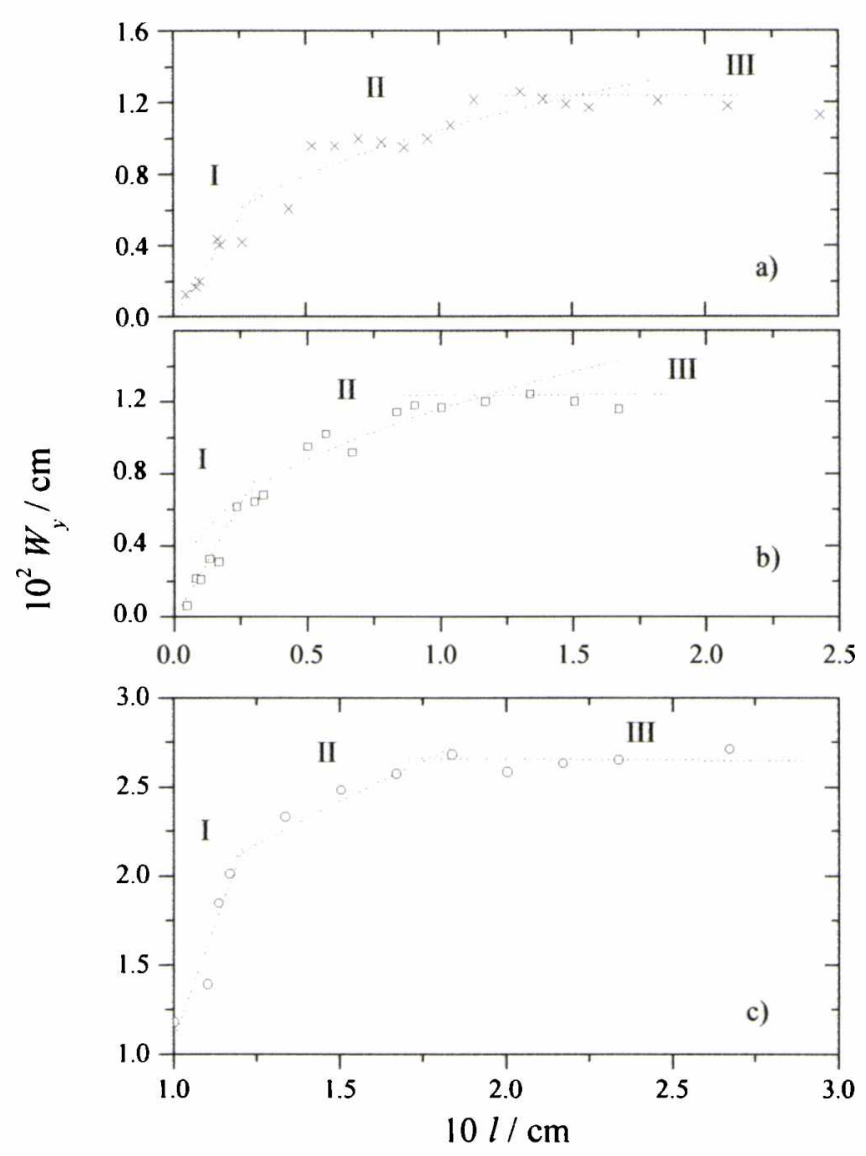

Figura 8. 4. Gráficos de $W_{y}$ en función de $l$ a) $T_{\mathrm{a}}=T_{\mathrm{c}}=30^{\circ} \mathrm{C}$; b) $T_{\mathrm{a}}=40^{\circ} \mathrm{C}$ y $T_{\mathrm{c}}=30^{\circ} \mathrm{C}$; c) $T_{\mathrm{a}}=$ $30{ }^{\circ} \mathrm{C}$ y $T_{\mathrm{c}}=40^{\circ} \mathrm{C}$. Se indican las regiones I, II y III. Las curvas de trazo discontinuo corresponden a la función $W_{y} \propto l^{\prime}$ para la región I, $W_{y} \propto l^{1 / 2}$ para la región II y finalmente saturación.

Los exponentes $\alpha$ y $\beta$ de la región II tienen valores próximos a los que predice la ecuación de Kardar-Parisi-Zhang, para la evolución unidireccional $(\mathrm{d}=1)$ de la interfase, con $\alpha=1 / 3, \beta=1 / 2$ y $Z=3 / 2$. Valores de $\beta$ próximos al $/ 4$ se relacionarían con un mecanismo de difusión superficial de átomos para la relajación de la interfase [18], aunque, en la escala de tamaño de los experimentos, solo es posible asociar longitudes características de procesos de transporte en la meso-escala.

En la electrodeposición de plata a partir de solución II + ácido sulfúrico $0,5 \mathrm{M}$, la incorporación de gradientes térmicos, positivos o negativos, manteniendo la temperatura del electrodo de trabajo constante, hace que el régimen de crecimiento correspondiente a la región II se alcance a menores tiempos. De igual forma, los datos experimentales se ajustan 
a la ecuación de KPZ a tiempos más cortos. Por lo tanto, este comportamiento se puede asociar, con el aumento de la velocidad de llegada de los iones reactivos.

Es conveniente, en este punto, hacer notar la analogía existente entre la ecuación de KPZ que describe la rugosidad de una interfase y la ecuación de Burgers que incluye un término de ruido (aleatorio) empleada en hidrodinámica para describir el proceso de mezclado caótico de fluidos

$$
\frac{\partial V}{\partial t}+\lambda(\mathrm{V} . \nabla) \mathrm{V}=v \nabla^{2} V-\nabla \eta(\mathrm{x}, t)
$$

donde $V=V(\mathrm{x}, t)$ es la velocidad del fluido, $\mathrm{x}$ es el vector posición, $v$ la viscosidad cinemática, $\lambda$ una constante y $\nabla \eta(\mathrm{x}, t)$ es el término de ruido. La ecuación de Burgers considera un fluido libre de vorticidad, $\nabla \times V=0$.

Si se hace el cambio de variable

$$
V \approx-\nabla h
$$

la ecuación (8.16) se convierte en la de KPZ. El término no linear incluye las derivadas espaciales de las componentes de velocidad del fluido. 


\subsection{Análisis de la estructura interna de los electrodepósitos de plata de la región II (denso)}

El análisis de la distribución de tamaño de los árboles que forman un electrodepósito metálico se aplicó [56] a electrodepósitos de cinc, obtenidos en una celda lineal quasi-bidimensional. La teoría de las leyes de escala para este análisis estadístico de la estructura interna de los depósitos $[189,190]$ fue aplicada recientemente a modelos de deposición aleatoria (perteneciente a la clase de universalidad de Edward-Wilkinson) y deposición balística (perteneciente a la clase de universalidad de Kardar-Parisi-Zhang) [191]. Este análisis se aplica a las secuencias de imágenes que muestran la evolución de los electrodepósitos de plata descriptos en esta tesis.

En esta sección se utilizará el término "agregado" como denominación general de electrodepósito y "cluster" para los "árboles" que forman el electrodepósito.

Durante la formación de un electrodepósito denso, los árboles compiten constantemente entre sí. En la sección 7.3, se mostró la evolución de la altura y el ancho de los árboles que forman el electrodepósito y se observó que en el transcurso del tiempo solo algunos árboles que "sobrevivían" dominaban el crecimiento del electrodepósito. La estructura de cada árbol y de todo el electrodepósito está determinada por el mecanismo de formación de la fase metálica. Así, para el modelo DLA, debido a las propiedades autosimilares (ver Capítulo 2) de los agregados, tanto la estructura de cada árbol individual, como la del agregado completo son iguales. Sin embargo, en la mayoría de los agregados, la estructura de un árbol difiere de la estructura del sistema. Así, éste puede ser compacto y los árboles individualmente considerados, autoafines.

Para "clusters" autoafines (en el presente trabajo los árboles del electrodepósito), tanto la altura media cuadrática $h_{\mathrm{s}}$, como el ancho medio cuadrático $w_{\mathrm{S}}$, aumentan algebraicamente con el tamaño $s$ de los "clusters":

$$
\begin{aligned}
& w_{\mathrm{s}} \propto s^{v_{\perp}} \\
& h_{\mathrm{s}} \propto s^{v_{/ /}}
\end{aligned}
$$

donde $v_{\perp}$ y $v_{/ /}$son exponentes, que en general, toman valores distintos. Para "clusters" autosimilares, $v_{\perp}$ y $v_{/ /}$son iguales.

Si se considera un electrodepósito formado por $N_{\mathrm{T}}$ partículas iguales, que crece en un espacio de dimensión $d$ a partir de un substrato de dimensión $d_{\mathrm{s}}$ y con un tamaño $L$ (para los experimentos aquí analizados $d=2$ y $d_{\mathrm{s}}=1$ ), el número de partículas por unidad de longitud de substrato es: 


$$
N=N_{\mathrm{T}} / L
$$

Si el electrodepósito (o agregado formado por "clusters") se considera como un objeto autosimilar con una dimensión fractal $D_{\mathrm{F}}$, su altura media cuadrática $H$, medida a partir del electrodo, sigue una ley de escalado del tipo:

$$
H \propto N^{v_{\mathrm{e}}}
$$

para $H \ll L$. De igual manera, se espera que la densidad del electrodepósito siga una ley de potencia con la altura:

$$
\rho(h) \propto h^{a}
$$

Así, $N$ se puede expresar como $N \propto \int_{0}^{H} \rho(h) d h \propto H^{1-a}$, por lo que de la comparación con (8.21) surge:

$$
v_{\mathrm{e}}^{-1}=1-a
$$

Para longitudes de escala $\gg H$, la estructura es uniforme en la dirección lateral paralela al electrodo, $d_{\mathrm{s}}$. Entonces se puede escribir:

$$
D=v_{\mathrm{e}}^{-1}+d_{\mathrm{s}}
$$

Se debe notar que la relación (8.24) se dedujo utilizando las propiedades autosimilares del electrodepósito (agregado) completo. Pero se puede aplicar aún cuando el agregado esté formado por "clusters" autoafines.

Por otro lado, si se cuenta el número de "clusters" $N_{\mathrm{s}}(N)$ conteniendo $s$ partículas (árboles de tamaño $s$ ) en todo el electrodepósito (agregado) se puede escribir:

$$
N_{\mathrm{T}}=\sum_{s} s N_{s}(N)
$$

La función de distribución de tamaño de los "clusters" (la probabilidad por unidad de longitud de encontrar árboles de tamaño $s$ ) en el agregado completo se define:

$$
n_{s}(N)=\begin{gathered}
N_{s}(N) \\
L^{d_{s}}
\end{gathered}
$$

Substituyendo (8.20) y (8.26) en (8.25) se deduce: 


$$
N=\sum_{s} s n_{s}(N)
$$

Dentro de los límites prácticos, la competencia en el crecimiento entre árboles que forman el depósito se extiende a toda escala (tiempo y espacio) y por lo tanto, es rasonable suponer que se cumpla la ley de potencia:

$$
n_{s}=s^{-\tau}
$$

donde $n_{\mathrm{s}}$ es el número de árboles de tamaño $s$ y $\tau$ es el exponente de escalado.

Se puede considerar entonces, para $n_{\mathrm{s}}$ la siguiente relación de escalado:

$$
n_{s}(N) \propto s^{-\tau} f\left(\begin{array}{ll}
s^{\sigma} & \\
& N
\end{array}\right)
$$

donde $f(x)$ es una función de escalado, que tiende asintóticamente $\mathrm{a} \approx 1$, para $x<<1$ y a $\approx 0$ para $x \gg 1$, siendo la ecuación (8.29) válida para valores grandes de $N$ y $s$.

Substituyendo (8.29) en (8.27) y reemplazando la suma por la integral, luego de manipular algebraicamente, se obtiene la relación de escalado [192]:

$$
\sigma=2-\tau
$$

Por otro lado, la altura media cuadrática $H$ del electrodepósito, viene dado por:

$$
H^{2}={ }_{N_{\mathrm{T}}}^{1} \sum_{i} h_{i}^{2}=\underset{N L^{d_{s}}}{1} \sum_{s}\left[\sum_{i \in s} h_{i}^{2}\right] N_{s}(N)
$$

donde $h_{\mathrm{i}}$ es la distancia de la partícula $i$ medida a partir del substrato. La altura media cuadrática de cada árbol es:

$$
h_{i}^{2}={ }_{s}^{1} \sum_{i \in s} h_{i}^{2}
$$

con lo que la ecuación (8.31) se puede escribir:

$$
H^{2}={ }_{N_{\mathrm{T}}}^{1} \sum_{i} s h_{s}^{2} n_{s}(N)
$$

donde se usó la definición de la función de distribución $n_{\mathrm{s}}$. Substituyendo la expresión (8.19), la (8.23) y la (8.29) en la (8.33) y convirtiendo la suma en integral, se obtiene la relación de escalado [191]: 


$$
2 v_{e}=-1+\left(2+2 v_{1 /}-\tau\right) / \sigma
$$

luego de usar (8.26) y (8.30) se tiene la relación:

$$
\tau=2-v_{/ /}\left(D-d_{\mathrm{s}}\right)
$$

La ecuación (8.35) relaciona el exponente $\tau$, asociado a la distribución de tamaño de los árboles, con $v_{\| l}$, exponente de la ley de escalado dado por (8.19). Resulta interesante notar que en la expresión (8.35), no aparece $v_{\perp}$, debido a que aquellos árboles que crecen más rápido, impiden el crecimiento de los más pequeños. La invarianza de escala en la distribución de tamaño que resultan del proceso de competencia entre árboles, está gobernada por la altura de los árboles [192].

Para la formación de electrodepósitos de plata densos, $D=2$ y $d_{\mathrm{s}}=1$, pues el crecimiento se puede considerar bidimensional. Se tiene entonces,

$$
\tau-2+v_{/ /}=0
$$

La ecuación (7.36) muestra la consistencia del método, ya que nos relaciona dos exponentes que se pueden determinar experimentalmente en forma independiente.

Por otro lado, el volumen ocupado por cada árbol que constituye el electrodepósito escala con el número de partículas que forman el árbol según la ley:

$$
v_{\mathrm{s}} \propto h_{s} w_{s}^{d-1} \propto s^{v / /+v_{\perp}}
$$

Es útil, entonces, definir la relación

$$
v_{\mathrm{S}} \propto s^{\pi}
$$

$\operatorname{con} \pi=v_{/ /}+d v_{\perp}$.

Para árboles compactos $\pi=1$, mientras que para árboles no compactos $\pi>1$.

Si ahora se identifica $v_{/ /}$con el ancho de la interfase $w_{\mathrm{s}}$, y a $h_{\mathrm{s}}$ con el tiempo, se obtiene el exponente dinámico $Z$ :

$$
Z=v_{/ /} / v_{\perp}
$$

De esta forma se pueden relacionan las características auto-afines $(Z)$ de los agregados, que se obtienen del escalado dinámico, y los parámetros que surgen del análisis de la estructura interna. 
Recientemente se realizaron simulaciones para el modelo de crecimiento de la deposición balística BD [191] (comentado en el capítulo 2) y se realizó un estudio de la estadística de la estructura interna del agregado. Se estudiaron agregados obtenidos en espacios de hasta 6 dimensiones. En la tabla 8.1, se muestran los resultados hasta 4 dimensiones, obtenidos para el modelo BD por Horowitz et. al. [191].

Tabla 8.1. Valores de $v_{1}, v_{/ /}, \pi, \tau$ y $Z$ para dimensiones geométricas $2 \leq \mathrm{D} \leq 4$ calculados empleando el análisis de la estructura interna del agregado obtenido por medio del modelo de deposición balístico. (RG) y (NS) indican el empleo del método de grupo de renormalización y simulaciones numéricas para calcular $\tau$.

\begin{tabular}{|c|c|c|c|c|c|c|c|}
\hline $\mathrm{D}$ & $v_{\perp}$ & $v_{/}$ & $\pi$ & $\tau$ & $\tau(\mathrm{RG})$ & $\tau(\mathrm{NS})$ & $Z$ \\
\hline $1+1$ & $0,40(1)$ & $0,60(1)$ & $1,00(2)$ & $1,40(1)$ & 1,40 & 1,40 & $3 / 2$ \\
\hline $2+1$ & $0,29(1)$ & $0,45(1)$ & $1,03(2)$ & $1,57(1)$ & 1,54 & 1,55 & - \\
\hline $3+1$ & $0,23(2)$ & $0,38(1)$ & $1,07(6)$ & $1,65(1)$ & 1,63 & 1,64 & - \\
\hline
\end{tabular}

* Los números encerrados por paréntesis indican el error en la última cifra decimal.

Para el método balístico, los exponentes de escalado dinámico, $\alpha, \beta$, y $Z$ [18], se pueden calcular analíticamente, observándose que posee idénticos exponentes que la ecuación de Kardar-Parisi-Zhang (KPZ), es decir pertenece a la misma clase de universalidad. Esto está en acuerdo con los resultados de las simulaciones presentados en la tabla 8.1. Así, para 2 dimensiones, se tiene un valor de $Z$ de $3 / 2$, idéntico al que sale por la técnica del escalado dinámico.

\subsubsection{Resultados experimentales}

En esta sección se emplea el método del análisis estadístico de la estructura interna, para caracterizar los electrodepósitos de plata al final del proceso de electrodeposición. Se estudia la estadística de los árboles cuyo crecimiento se ve impedido por el apantallamiento de los vecinos que crecen más rápido (“árboles muertos”) que aparecen durante el crecimiento. Se evalúa el número de árboles por unidad de longitud de electrodo $n_{\mathrm{s}}$, el ancho medio cuadrático $w_{\mathrm{S}}$ y la altura media cuadrática $h_{\mathrm{s}}$ de cada árbol muerto en función del número de partículas (tamaño) $s$ que constituyen el árbol considerado.

Se fijan las condiciones de electrodeposición para obtener la morfología densa como dominante (región II). Se emplea una celda lineal (BV), solución II + ácido sulfúrico $0,5 \mathrm{M}$ y potenciales $\Delta \mathrm{E}_{\mathrm{c}-\mathrm{a}}=-0,80 \mathrm{y}-1,20 \mathrm{~V}$. En estas condiciones no se observa la 
transición densa-abierta y crecen electrodepósitos densos cuya extensión alcanza $1,5 \mathrm{~cm}$ aproximadamente desde la posición inicial del electrodo de trabajo. El número de árboles que se producen es adecuado para el tratamiento estadístico. Se realizan 20 experimentos para cada potencial aplicado de manera de obtener una muestra de cerca de 2000 árboles y relaciones de escala que cubren más de 2 órdenes de magnitud.

Para identificar cada árbol se requiere el sistema de adquisición de imágenes descripto en la parte experimental (Capítulo 3) con un aumento adecuado. Esto restringe el campo óptico y hace necesario, desplazar la lupa estereoscópica por medio de la mesa de coordenadas con el fin de observar todo el electrodepósito. Las imágenes de los electrodepósitos digitalizadas mediante el software del "Frame grabber" se compaginan y editan con Corel Draw 9.0 y binarizan con una resolución de 31,25 $\mu \mathrm{m}$ por pixel. Finalmente, mediante un programa escrito en Fortran 77, se leen las imágenes compaginadas de los electrodepósitos globales y se distinguen los árboles muertos formados por partículas conectadas entre sí. El mismo programa mide $s, w_{\mathrm{s}}$ y $h_{\mathrm{s}}$ de cada árbol. En las figuras 8.5 - 8.7 se muestran imágenes de una fracción de electrodepósitos obtenidos en la celda $\mathrm{BV}$ a $-0,8 \mathrm{~V}$ y $-1,2 \mathrm{~V}$, respectivamente. La figura 8.5 corresponde a una imagen original. En las figuras 8.7 y 8.8 se incluyen las imágenes binarizadas (blanco y negro) como también las imágenes reconstruidas de los árboles "muertos" seleccionados que aparecen en el electrodepósito.

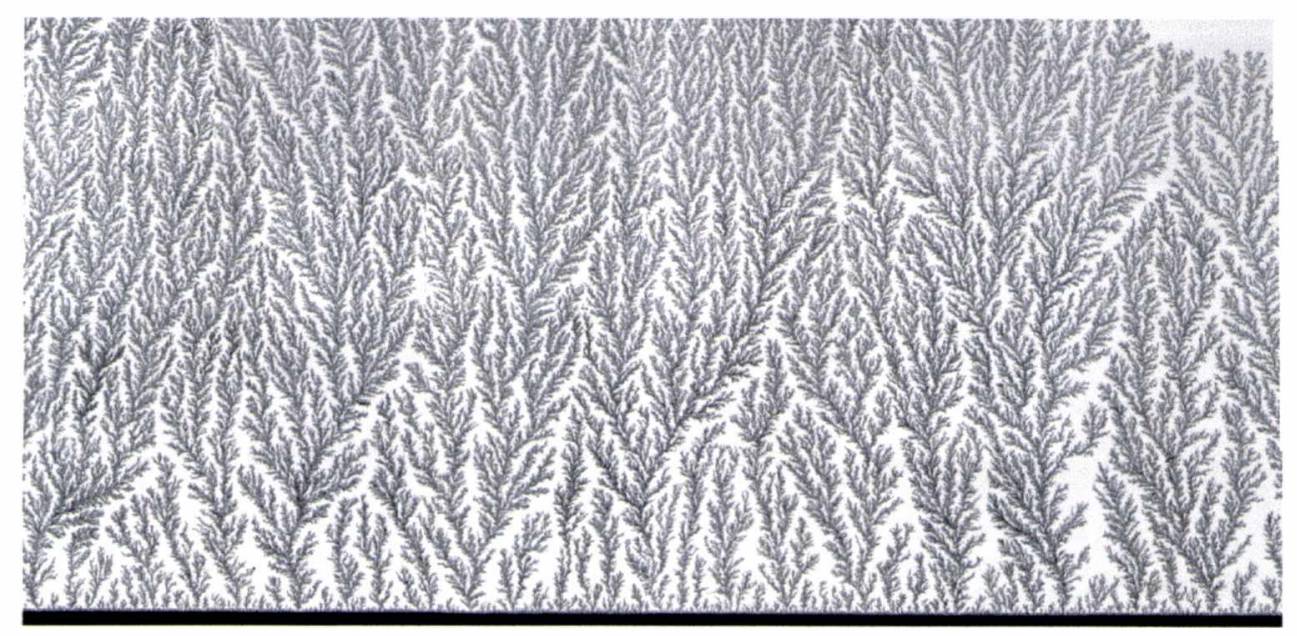

Figura 8.5. Imagen parcial original de un electrodepósito de plata obtenido a $\Delta \mathrm{E}_{\mathrm{c}-\mathrm{a}}=-0,80 \mathrm{~V}$, empleando la celda BV y la solución II + 0,5 M en ácido sulfúrico. El lado del cuadrado negro en la figura superior corresponde a $1250 \mu \mathrm{m}$. 

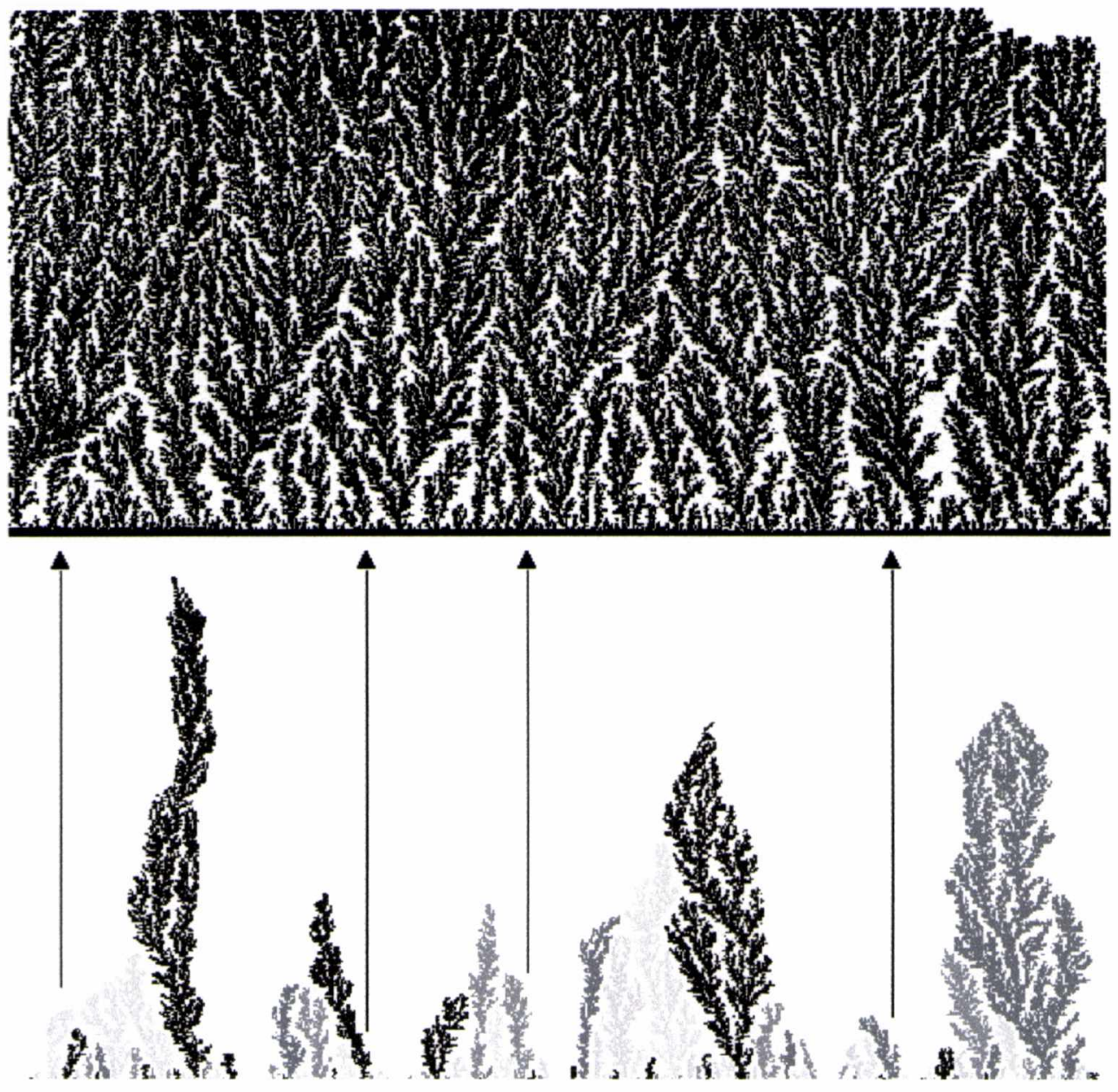

Figura 8.6. En la parte superior se muestra una imagen parcial binarizada (blanco y negro) del electrodepósito obtenido a $\Delta \mathrm{E}_{\mathrm{c}-\mathrm{a}}=-0,80 \mathrm{~V}$. En la parte inferior se muestran los árboles muertos seleccionados para el análisis estadístico de la estructura interna, la flechas indican algunas de las ramas seleccionadas del electrodepósito y permiten visualizar la ubicación de las ramas muertas en el electrodepósito completo. El lado del cuadrado negro en la figura superior corresponde a $1250 \mu \mathrm{m}$. 

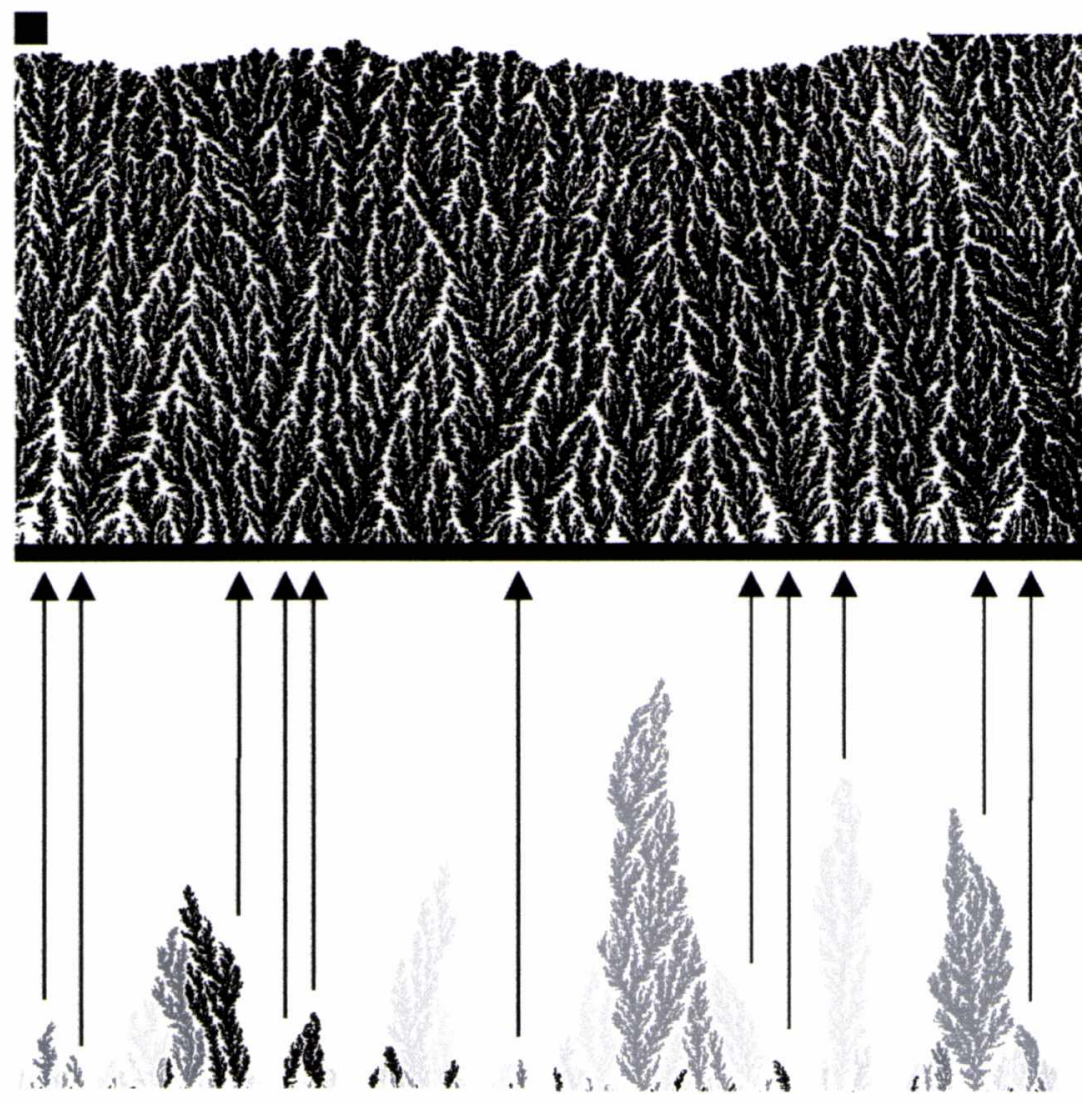

Figura 8.7. En la parte superior se muestra una imagen parcial binarizada (blanco y negro) del electrodepósito obtenido a $\Delta \mathrm{E}_{\mathrm{c}-\mathrm{a}}=-1,20 \mathrm{mV}$. En la parte inferior se muestran los árboles muertos seleccionados para el análisis estadístico de la estructura interna, la flechas indican algunas de las ramas seleccionadas del electrodepósito y permiten visualizar la ubicación de las ramas muertas en el electrodepósito completo. El lado del cuadrado negro en la figura superior corresponde a $1250 \mu \mathrm{m}$. 
Los comportamientos de $h_{\mathrm{s}} \mathrm{y} w_{\mathrm{s}}$ como función del número de partículas que forman el árbol s, para $\Delta \mathrm{E}_{\mathrm{c}-\mathrm{a}}=-0,80 \mathrm{y}-1,20 \mathrm{~V}$, se muestran en las figuras 8.8 y 8.9 como gráficos en escala logarítmica, de manera que la pendiente en la zonas lineales da el exponente de las leyes de potencia correspondientes. Para ambos potenciales aplicados para la electrodeposición se obtiene relaciones lineales que se extienden dos órdenes de magnitud con la misma pendiente. Del gráfico $\log h_{\mathrm{s}}$ versus $\log s$ para $\Delta \mathrm{E}_{\mathrm{c}-\mathrm{a}}=-0,80 \mathrm{~V}$ se obtiene $v_{/ /}=0,63 \pm 0,03$ y para $\Delta \mathrm{E}_{\mathrm{c}-\mathrm{a}}=-1,20 \mathrm{~V}, v_{/ /}=0,62 \pm 0,03$. La pendiente de la relación lineal $\log w_{\mathrm{s}}$ versus $\log s$, para $\Delta \mathrm{E}_{\mathrm{c}-\mathrm{a}}=-0,80 \mathrm{~V}$ da $v_{\perp}=0,46 \pm 0,06$ y para $\Delta \mathrm{E}_{\mathrm{c}-\mathrm{a}}=-1,20 \mathrm{~V}$, $v_{\perp}=0,46 \pm 0,06$.

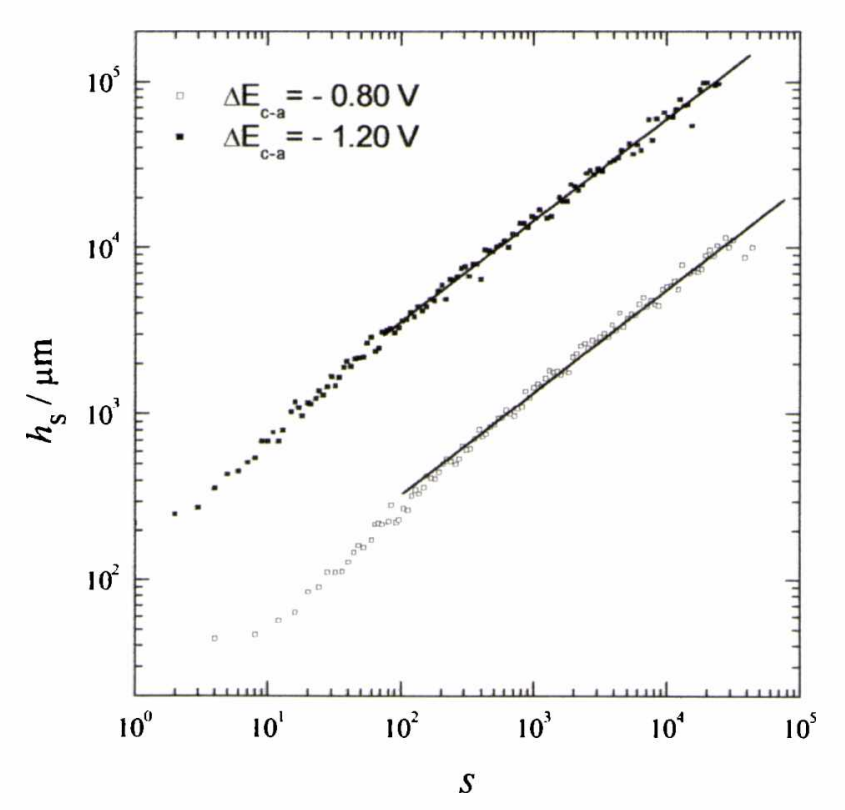

Figura 8.8. Representación $\log h_{\mathrm{s}}$ (altura media cuadrática de cada árbol) versus $\log s$ (número de particulas que forman el árbol). $h_{\mathrm{s}}$ se expresa en $\mu \mathrm{m}$ y $s$ en número de pixel que ocupa cada árbol. Los resultados obtenidos a $\Delta \mathrm{E}_{\mathrm{c}-\mathrm{a}}=-1,20 \mathrm{~V}$ están desplazados para mayor claridad en el gráfico.

En la figura 8.10 , se representa en escala logarítmica el número de "árboles muertos" en función del número de partículas (pixeles). Para ambos potenciales se obtienen nuevamente relaciones de escala similares que se extiende más de dos órdenes de magnitud De ellas resulta $\tau=1,37 \pm 0,04$. 


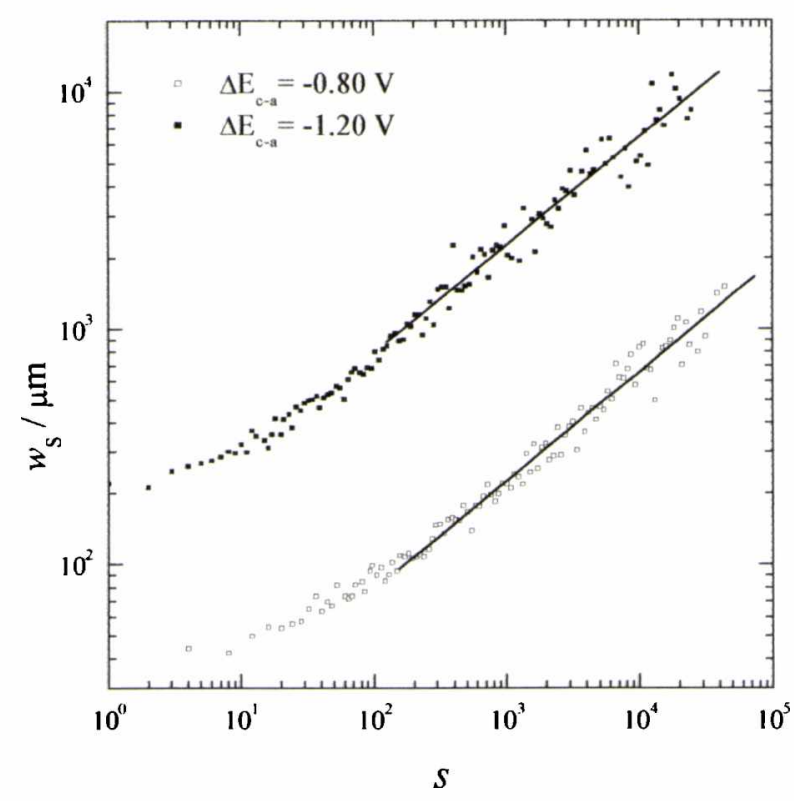

Figura 8.9. Representación $\log w_{\mathrm{s}}$ (ancho medio cuadrático de cada árbol) versus $\log s$ (número de particulas que forman el árbol). $w_{\mathrm{s}}$ se expresa en $\mu \mathrm{m}$ y $s$ en número de pixel que ocupa cada árbol. Los resultados obtenidos a $\Delta \mathrm{E}_{\mathrm{c}-\mathrm{a}}=-1,20 \mathrm{~V}$ están desplazados para mayor claridad en el gráfico.

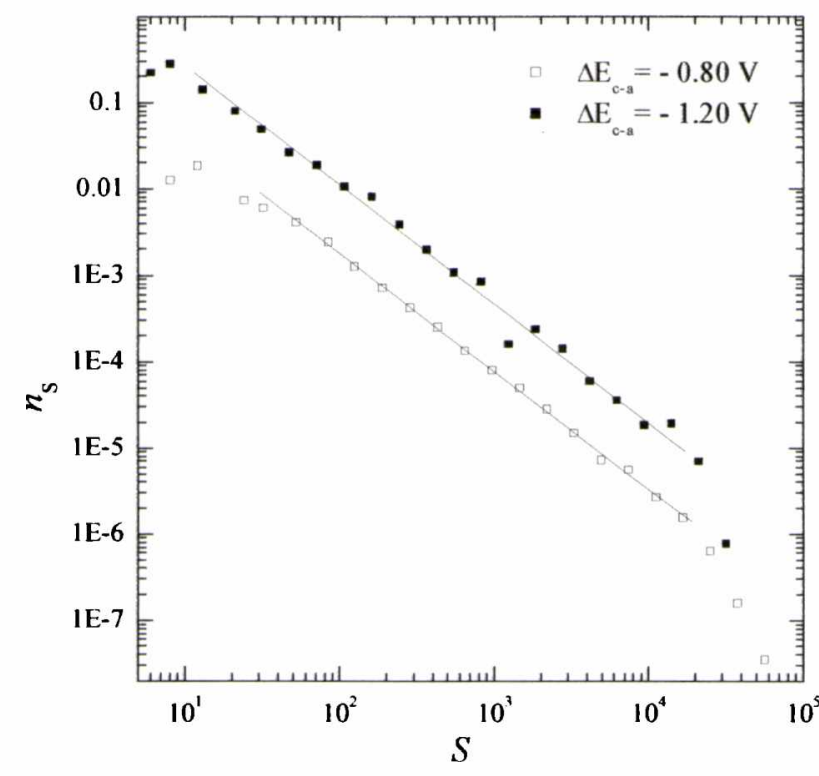

Figura 8.10. Representación $\log n_{\mathrm{s}}$ versus $\log s$ para $\Delta \mathrm{E}_{\mathrm{c}-\mathrm{a}}=-0,80 \mathrm{~V}$ y $\Delta \mathrm{E}_{\mathrm{c}-\mathrm{a}}=-1,20 \mathrm{~V}$. Los resultados obtenidos a $\Delta \mathrm{E}_{\mathrm{c}-\mathrm{a}}=-1,20 \mathrm{~V}$ se desplazaron para proporcionar claridad en el gráfico.

Finalmente en la tabla 8.2 se resumen los resultados experimentales obtenidos y se los compara con los obtenidos en [191] para el modelo de deposición balístico. 
Tabla 8.2. Valores de $v_{/ /}, v_{\perp}, \pi, \tau$ y $Z$ experimentales (primera y segunda fila) y para el modelo KPZ o DP. Además se incluye en la columna 5 el valor que toma la ecuación (8.36).

\begin{tabular}{|c|c|c|c|c|c|c|}
\hline Condiciones & $v_{/ /}$ & $v_{\perp}$ & $\tau$ & $\tau+v_{/ /}-2$ & $\pi$ & $Z$ \\
\hline$\Delta \mathrm{E}_{\mathrm{c}-\mathrm{a}}=-0.80 \mathrm{~V}$ & $0,63(3)$ & $0,46(6)$ & $1,37(4)$ & $0,00(5)$ & $1,09(7)$ & $1,4(2)$ \\
\hline$\Delta \mathrm{E}_{\mathrm{c}-\mathrm{a}}=-1.20 \mathrm{~V}$ & $0,62(3)$ & $0,46(6)$ & $1,37(4)$ & $0,01(5)$ & $1,08(7)$ & $1,4(2)$ \\
\hline Modelo KPZ & 0,60 & 0,40 & 1,40 & 0 & 1 & $3 / 2$ \\
\hline
\end{tabular}

Matsushita et. al. determinaron el valor $\tau=1,54$, para electrodepósitos de cinc obtenidos en celdas quasi-bidimensionales [56]. La dimensión fractal de estos electrodepósitos resultó consistente con la de agregados producidos por el modelo DLA y consistente con el exponente de escalado $\tau$. En este trabajo, el exponente $\tau=1,37 \pm 0,04$ para la electrodeposición de plata está lejos del correspondiente al modelo DLA.

La ecuación de KPZ describe satisfactoriamente la electroformación de plata en las condiciones aquí presentadas, ya que los exponentes que se obtienen del análisis de la estructura interna del electrodepósito se aproximan a los que se obtienen para el modelo DB. Este último pertenece a la misma clase de universalidad que la ecuación de KPZ. 


\section{CAPITULO 9}

\section{Efecto del agregado de aditivos}

\subsection{Electrodeposición de plata empleando soluciones de sulfato de plata en presencia y} ausencia de electrolito soporte, conteniendo distintas concentraciones de agarosa

En los dos capítulos siguientes se estudia el efecto del agregado de agarosa en la electrodeposición de plata en celdas quasi-bidimensionales.

La agarosa es un polisacárido que se extrae de algas marinas. La molécula polimérica está formada por unidades de 3,6-anhidro- $\alpha$-galactosa unidas por medio de enlaces (1-4) y (1-3) (figura 9.1). Las uniones a través del carbono 4 dan origen a una cadena recta, mientras que las unidas por medio del carbono 3, generan una hélice con un hueco en el centro [193-195]. Los estudios de difracción de rayos X permiten postular una estructura de doble hélice, que persiste aún después de hidratarse. La formación de un gel involucra la asociación de cadenas a través de la doble hélice para desarrollar un red tridimensional.

Así como la contribución de la migración a la transferencia de materia puede hacerse prácticamente nula por el agregado de un exceso de electrolito soporte, la convección natural puede eliminarse por agregado de sustancias orgánicas capaces de formar geles, evitando el movimiento macroscópico del electrolito. Entre las sustancias más usadas para este fin, se encuentran la agarosa y la carboximetil celulosa. En bajas concentraciones estas sustancias forman soles y cuando se alcanza una determinada concentración crítica se forman geles.

Los soles de agarosa con concentración $\approx 0,04 \% \mathrm{p} / \mathrm{v}$ se utilizaron para estudiar el efecto de la viscosidad en la cinética de los procesos controlados por transferencia de materia o cinética intermedia. Los soles de agarosa se comportan como un fluido noNewtoniano y pasan a tener el comportamiento de los plásticos de Bingham cuando superan la concentración crítica y forman geles [196]. Similar uso se le da a sustancias como la glicerina que, a diferencia de la agarosa, forma soluciones que se comportan como fluidos Newtonianos.

Se realizaron trabajos sobre el efecto del transporte de materia en la cinética de electrodeposición de la plata [197-199] donde se utilizan soles y geles de agarosa para la electrodeposición empleando celdas convencionales y en algunos casos electrodo de disco 
rotante. En estos trabajos se puede apreciar claramente la influencia de los fenómenos de transporte en la cinética de electrodeposición de plata. Naturalmente, las sustancias orgánicas empleadas no deben modificar la velocidad de transferencia de electrones, ni adsorberse significativamente sobre la superficie.

En la electrodeposición de plata en celdas quasi-bidimensionales, empleando soles y geles de agarosa, además de verse afectadas las propidades de transporte de materia con respecto a las soluciones acuosas libres de agarosa, los soles y geles contienen aglomerados que actúan como obstáculos al avance del frente del electrodepósito. Los obstáculos se ubican aleatoriamente en el medio que contiene el reactivo. Esto, si bien resulta una complicación adicional para encontrar las condiciones para obtener estructuras determinadas, constituye un sistema experimental novedoso para el estudio del movimiento de interfases en medios estructuralmente desordenados, que actualmente merecen mucha atención desde el punto de vista teórico.

En este capítulo se estudia la química de las soluciones que contienen agarosa y los posibles efectos sobre la reacción heterogénea de electrodeposición de plata. Para ello se requiere conocer, cómo la agarosa afecta las propiedades del sistema electroquímico y cómo interactúa con la interface metálica. Por otro lado, es necesario determinar, si la composición y estructura de los soles y geles de agarosa cambian con el tiempo y, si lo hacen, en que medida se pueden controlar estos cambios.

En las próximas secciones se presenta un estudio sistemático de las caracteristicas de adsorción de la molécula de agarosa sobre platino y plata, y la estabilidad de las soluciones electrolíticas con agarosa, empleadas en la electrodeposición de plata. Se emplean las siguientes técnicas electroquímicas y no electroquímicas:

I) Medida del potencial de reposo de la interfase $\mathrm{Pt} /$ solución y $\mathrm{Ag}$ /solución, empleando diversas soluciones electrolíticas conteniendo agarosa y utilizadas en los experimentos de electrodeposición. Si existe descomposición de la solución, posiblemente catalizada por la interface metálica, la composición de la solución y de la región interfacial se verá modificada, produciéndose cambios en el potencial de reposo.

II) Deposición a sub-potencial (upd) y electrodisolución anódica de plomo sobre substratos de plata, empleando soluciones de perclorato de plomo. Mediante esta técnica se estudia la adsorción de la agarosa o de productos de su descomposición sobre la superficie de plata. 
III) Voltamperometría sobre Pt, empleando celdas convencionales y celda de flujo. Se trata de determinar el grado de descomposición de la agarosa en soluciones electrolíticas de distinta acidez. Mediante la celda de flujo se investiga la posible electroadsorción de agarosa o de productos de su descomposición.

IV) Espectroscopía infrarroja (IR), para caracterizar los posibles cambios en la molécula de agarosa bajo distintas condiciones experimentales.

V) Viscosimetria de las soluciones electrolíticas empleadas, utilizando un viscosímetro de Ostwald. Se miden tiempos de escurrimiento que dependen principalmente del peso molecular de la sustancia orgánica disuelta y de la interacción entre las moléculas. La descomposición de las soluciones producirá variación en los tiempos de escurrimiento.

a

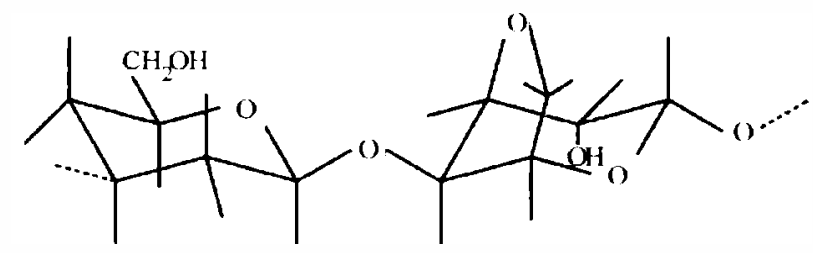

$\mathrm{b}$

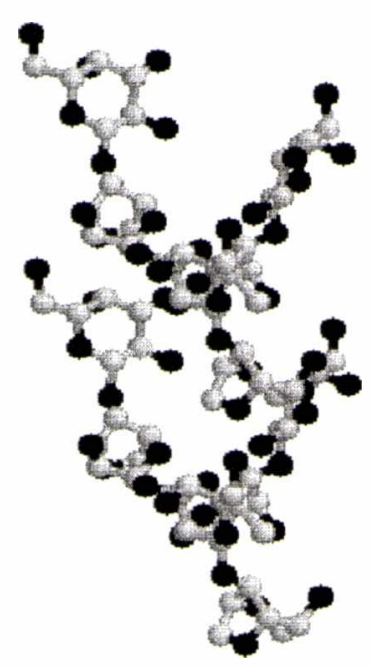

Figura 9.1. a) Unidades de 3,6-anhidro- $\alpha$-galactosa unidas por medio de enlaces (1-4) y (1-3). b) Modelo espacial de la molécula de agarosa donde se puede ver la doble hélice. Las bolas blancas corresponden a átomos de carbono y las bolas negras corresponden a los de oxígeno.

\subsection{Medidas de potencial de reposo.}

La evolución del potencial de reposo ( $\mathrm{E}_{\text {rep }}$ ) de la interfase Pt/solución y $\mathrm{Ag} /$ solución 
se relaciona con la estabilidad de las soluciones que contienen agarosa y con la posible adsorción de la agarosa y productos de su descomposición sobre la superficie metálica.

Para un electrodo de plata, sumergido en solución acuosa de sulfato de plata $0,014 \mathrm{M}+$ sulfato de sodio $0,5 \mathrm{M}+$ ácido sulfúrico $0,01 \mathrm{M}$ (solución $\mathrm{I}$ ) $+0,05 \% \mathrm{p} / \mathrm{v}$ de agarosa, el potencial de reposo vale $E_{\text {rep }}=0,669 \pm 0,025 \mathrm{~V}$ en la escala del electrodo normal de hidrógeno $(\mathrm{ENH})$. Este valor, cercano al potencial reversible de electrodo para el sistema $\mathrm{Ag}^{+} / \mathrm{Ag}^{0}\left(\mathrm{E}_{\text {rev }}\right.$ vs $\mathrm{ENH}=0,675 \mathrm{~V}$, a $25^{\circ} \mathrm{C}$ y concentración de $\left.\mathrm{Ag}^{+}=0,048 \mathrm{M}\right)$, permanece constante durante más de dos semanas.

Para un electrodo de platino sumergido en ácido sulfúrico $0,5 \mathrm{M}+0,1 \% \mathrm{p} / \mathrm{v}$ de agarosa, el potencial de reposo cambia desde $\mathrm{E}_{\text {rep }}=0,904 \mathrm{~V}$ al valor mínimo $\mathrm{E}_{\text {rep }}=0,694$ $\mathrm{V}$ durante los primeros cinco días. Tres días después aumenta hasta alcanzar el valor $\mathrm{E}_{\text {rep }}=0,769 \mathrm{~V}$ (figura 9.2).

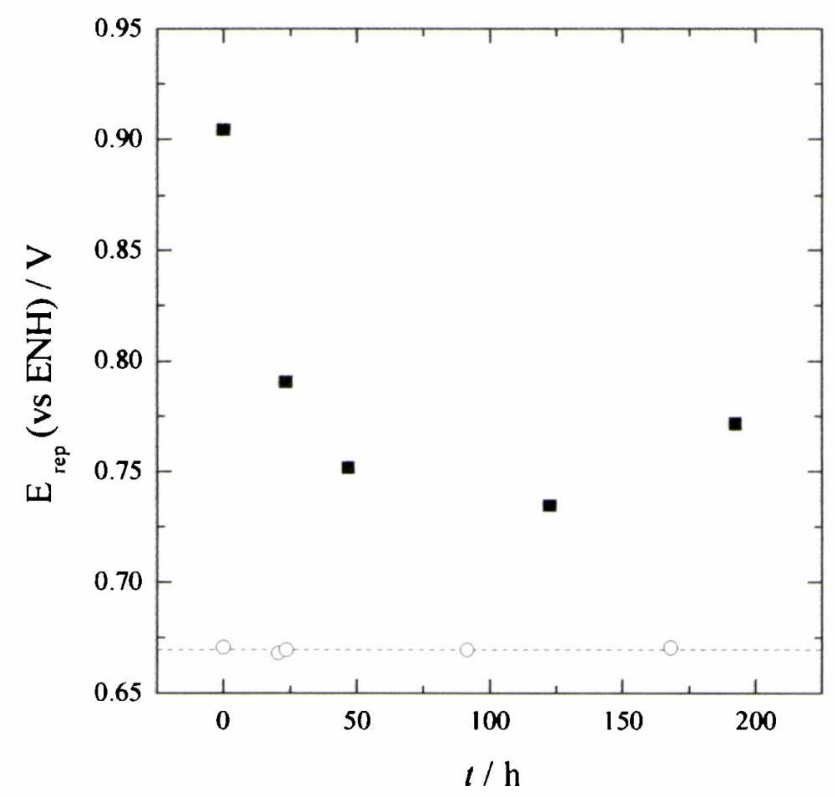

Figura 9.2. Comportamiento del potencial de reposo en función del tiempo: (o) electrodo plata / solución I, conteniendo $0,05 \% \mathrm{p} / \mathrm{v}$ de agarosa; ( $($ ) electrodo de platino/solución de ácido sulfúrico $0,5 \mathrm{M}$ conteniendo $0,1 \% \mathrm{p} / \mathrm{v}$ de agarosa. Se utiliza como electrodo de referencia un electrodo de mercurio /sulfato mercurioso /sulfato de potasio saturado $\left(E^{\circ}=0,657 \mathrm{~V}\right.$ versus $\left.E N H\right)$.

\subsection{Deposición a subpotencial v electrodisolución anódica de plomo (upd/anodic stripping)} sobre plata

Para ciertos metales se produce la electrodeposición de $\mathrm{Me}^{+}$sobre un substrato metálico distinto de $\mathrm{Me}$, a potenciales más positivos que el previsto por la ecuación de Nerst para la electrodeposición de $\mathrm{Me}^{+}$sobre Me. Este proceso recibe el nombre de deposición a subpotenciales [1] y depende de la naturaleza del substrato (B) y de la 
adsorción de $\mathrm{Me}^{+}$. Durante la electrodeposición a subpotenciales se forma una monocapa metálica que cubre al substrato. La evaluación de la carga de esta monocapa es útil para determinar el área del substrato y su rugosidad.

Estos experimentos se realizan a fin de conocer la superficie activa del electrodo en soles de agarosa, y el grado de recubrimiento por moléculas de agarosa o de productos de su descomposición. Los voltamperogramas de "upd/anodic stripping", presentan cambios en la distribución de carga entre los picos de corriente y distorsiones de estos, debido a cambios en la distribución de energía de los sitios superficiales que interactúan con la molécula de agarosa agregada.
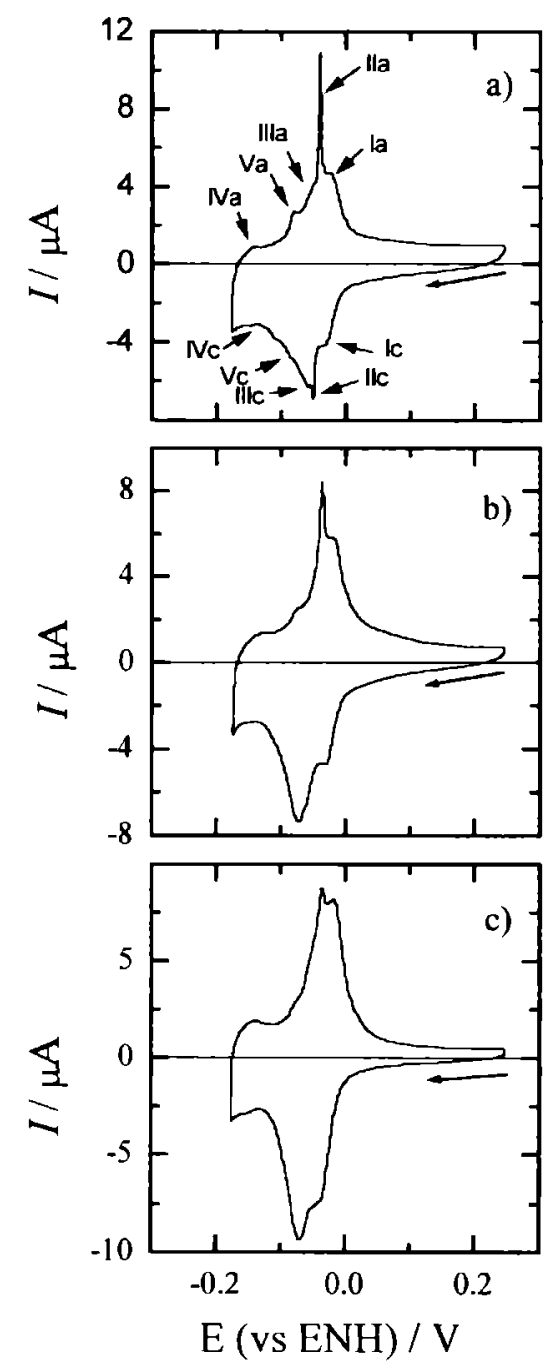

Figura 9.3. a) Volatamperogramas "upd /anodic stripping" de plomo, sobre un electrodo de platino plateado y solución de perclorato de plomo $0,01 \mathrm{M}+$ perclorato de sodio $0,5 \mathrm{M}+$ ácido perclórico 0,01 M (blanco). b) Similar al descripto en a), luego de sumergir a circuito abierto el electrodo de platino plateado en solución acuosa de agarosa $0,02 \% \mathrm{p} / \mathrm{v}$ durante $t_{\mathrm{ad}}=40 \mathrm{~min}$. c) Similar al descripto en b) para $t_{\mathrm{ad}}=60 \mathrm{~min}$. Las flechas sobre los voltamperogramas indican el origen y la dirección del barrido de potencial. 
En este trabajo los experimentos de upd se realizan empleando un electrodo de plata obtenido electrodepositando plata sobre un alambre de platino pulido (electrodo $\mathrm{Pt} / \mathrm{Ag}$ ), empleando sulfato de plata $5 \times 10^{-5} \mathrm{M}+$ perclorato de sodio $0,5 \mathrm{M}+$ ácido perclórico 0,01 M. La densidad de carga es $0,04 \mathrm{C} \mathrm{cm}^{-2}$.

Los voltamperogramas "upd/anodic stipping" de plomo se realizan según el procedimiento descripto en los trabajos anteriores [200-205]. Se varía el potencial inicial a $0,01 \mathrm{~V} / \mathrm{s}$, partiendo de $0,45 \mathrm{~V}$ hasta $-0,155 \mathrm{~V}$ (versus $\mathrm{ENH}$ ) y volviendo al potencial inicial. El voltamperograma realizado, sin adsorción previa de agarosa (blanco) mostrado en la figura 9.3a, exhibe una multiplicidad de picos catódicos y anódicos semejante a la que se describe en la literatura para plata policristalina. El pico anódico IIa es agudo y muestra una marcada asimetría con el pico catódico. Este último involucra la energía necesaria para iniciar la formación de la nueva fase. Los picos Ic y Ia corresponden a procesos de adsorción/desorción localizada en defectos (escalones, etc), donde la energía de adsorción es más alta que en una superficie lisa. Los picos $\mathrm{V}$ están relacionado con procesos de reorganización de la superficie de plata. Los picos III se asocian a contribuciones de las caras $\mathrm{Ag}$ (111) y los picos IV a la contribución de caras $\mathrm{Ag}$ (110), como consecuencia de la deposición de una segunda capa de plomo sobre la capa adsorbida primeramente $[200,204]$.

El electrodo de platino plateado $(\mathrm{Pt} / \mathrm{Ag})$ se sumerge y se mantiene a circuito abierto en solución acuosa de agarosa $0,02 \% \mathrm{p} / \mathrm{v}$ durante distintos tiempos $\left(t_{\mathrm{ad}}\right)$. Para cada ensayo, se prepara el electrodo de la manera descripta en el Capítulo 3. luego, se lo transfiere a otra celda que contiene perclorato de plomo $0,01 \mathrm{M}+$ perclorato de sodio $0,5 \mathrm{M}+$ ácido perclórico 0,01 M y se registran los voltamperogramas que se muestran en la figura $9.3 \mathrm{~b}$ y 9.3c. Para $t_{\text {ad }}<60$ minutos, en comparación con el blanco se observan pequeños cambios en la características voltamperométricas. Para tiempos $t_{\mathrm{ad}}>60$ minutos, la estructura fina de picos desaparece. Sin embargo, la densidad de carga catódica y anódia permanecen constante, $q_{\mathrm{a}} \cong q_{\mathrm{c}} \cong 0,47 \pm 0,02 \mathrm{mC} \mathrm{cm}^{-2}$.

Estos resultados indican que para $t_{\mathrm{ad}}<60$ minutos, el bloqueo de la superficie, si existe, debe ser menor que el $5 \%$. El error de la medida impide distinguir claramente la adsorción de agarosa sobre la superficie de plata.

\subsection{Interacción agarosa - platino}

\subsubsection{Voltamperometría sobre platino}

La finalidad de estos experimentos es estudiar la adsorción de la agarosa y posibles 
productos de su descomposición en fase homogénea. En este caso se realiza el voltamperograma de platino en ácido sulfúrico $0,5 \mathrm{M}$ entre 0 y $1,4 \mathrm{~V}$ (versus $\mathrm{ENH}$ ), a 0,02 $\mathrm{V} / \mathrm{s}$. El electrodo se sumerge en solución de agarosa $0,02 \%+0,5 \mathrm{M}$ de ácido sulfúrico, a potencial contante $\left(E_{a d}\right)$ en el rango $0,0<E_{a d}<0,2 \mathrm{~V}$ durante tiempos entre 0 y $3600 \mathrm{~s}$. Para cada potencial se eligen distintos valores de $\boldsymbol{t}_{\mathrm{ad}}$. Inmediatamente después de obtenido el voltamperograma, el electrodo se enjuaga con agua bidestilada y, manteniendo $\mathrm{E}_{\mathrm{ad}}=0,390 \mathrm{~V}$, se lo sumerge en ácido sulfúrico $0,5 \mathrm{M}$ para correr un nuevo voltamperograma desde $0,390 \mathrm{~V}$ a $0 \mathrm{~V}$, y luego de $0 \mathrm{~V}$ hasta el límite anódico de $1,4 \mathrm{~V}, \mathrm{y}$ finalmente, volviendo a $0,390 \mathrm{~V}$. Las figuras 9.4 y 9.5 . muestran varios voltamperogramas para distintos $t_{\mathrm{ad}}$.

La voltamperometría muestra en los picos de electroadsorción de hidrógeno entre $0 \mathrm{~V}$ y $0,3 \mathrm{~V}$, una disminución de la altura, una distorsión progresiva y un aumento de la relación carga catódica/ carga anódica con $t_{\text {ad }}$. En el rango $0,75 \mathrm{~V}$ a $1,40 \mathrm{~V}$, donde se forman sobre el platino especies que contienen oxígeno, se observa una disminución del pico II a $0,90 \mathrm{~V}$ (figura 9.4) y la aparición del pico III a 1,05 V. Este se corre a potenciales menores y su área aumenta con $t_{\mathrm{ad}}$. Simultáneamente, se produce una disminución en la carga de electroreducción de las especies oxigenadas superficiales (pico IV a $0685 \mathrm{~V}$ ).

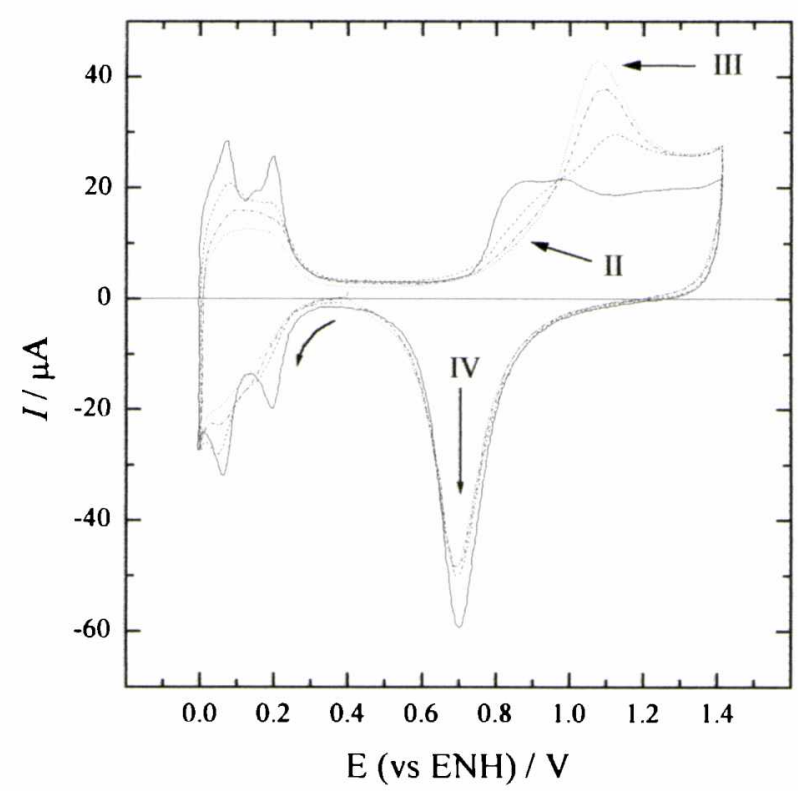

Figura 9.4. Voltamperogramas obtenidos sobre platino policristalino a $0,05 \mathrm{~V} \mathrm{~s}^{-1}$ después de sumergir el electrodo a $E_{a d}=0,20 \mathrm{~V}$ versus $E N H$ a distintos $t_{\text {ad }}$, en solución acuosa de agarosa $0,02 \% \mathrm{w} / \mathrm{v}+$ ácido sulfúrico $0,5 \mathrm{M}$ recientemente preparada.; Línea de trazos: $t_{\mathrm{ad}}=5 \mathrm{~min}$; línea de puntos y trazos: $t_{\mathrm{ad}}=20 \mathrm{~min}$; línea punteada: $t_{\mathrm{ad}}=1 \mathrm{~h}$. La línea continua corresponde al blanco. Area geométrica del electrodo de trabajo: $0,159 \mathrm{~cm}^{2} .25^{\circ} \mathrm{C}$. La flecha curva indica el origen y dirección de barrido de potencial. 


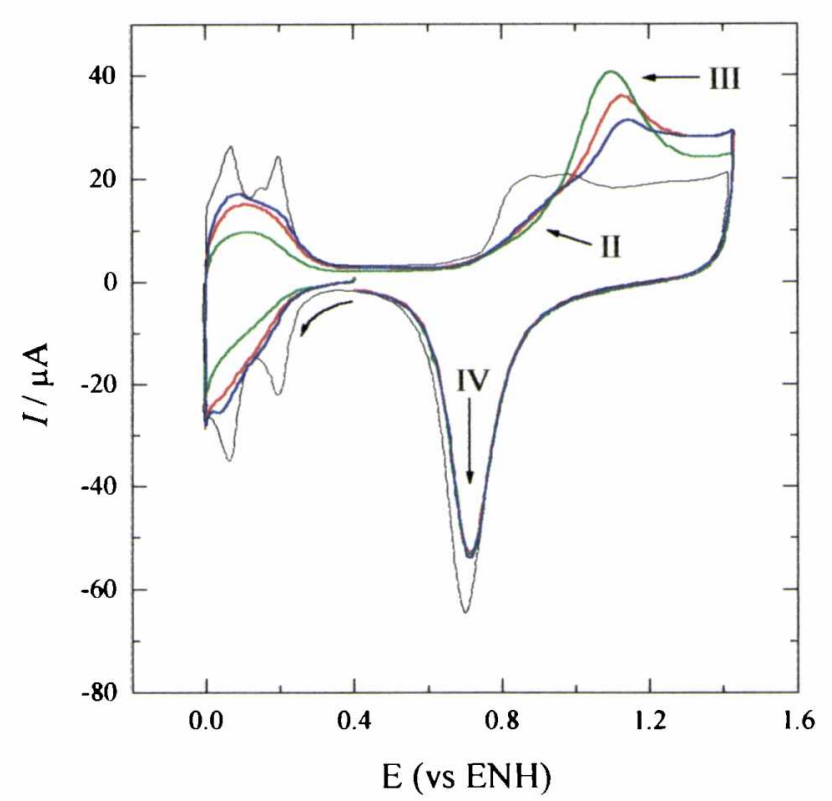

Figura 9.5. Voltamperogramas obtenidos sobre platino policristalino a $0,05 \mathrm{~V} \mathrm{~s}^{-1}$ después de sumergir el electrodo a $E_{a d}=0,10 \mathrm{~V}$ vesus $E N H$ a distintos $t_{\text {ad }}$, en solución acuosa de agarosa $0,02 \% \mathrm{w} / \mathrm{v}+$ ácido sulfúrico $0,5 \mathrm{M}$ recientemente preparada. Línea azul: $t_{\mathbf{a d}}=5 \mathrm{~min}$; línea roja: $t_{\mathrm{ad}}=20 \mathrm{~min}$; línea verde: $t_{\mathrm{ad}}=1 \mathrm{~h}$. La línea negra corresponde al blanco. Area geométrica del electrodo de trabajo: $0,159 \mathrm{~cm}^{2} .25^{\circ} \mathrm{C}$. La flecha curva indica el origen y dirección de barrido de potencial.

Esto muestra que los residuos de agarosa impiden la formación de especies conteniendo oxígeno sobre el platino y óxidos de platino. Se descarta la posibilidad de que el pico III, corresponda a especies azufradas provenientes de las impurezas de la agarosa utilizada, pues el análisis EDAX no mostró azufre, en un electrodo de platino sumergido, a circuito abierto, durante $4 \mathrm{hs}$, en la misma solución de agarosa utilizada para los ensayos de adsorción. Es entonces plausible asociar al pico III con la electrooxidación de residuos de agarosa que interaccionan con el platino.

La carga del pico III puede resultar de la electrooxidación de absorbatos proveniente de la agarosa, adsorbidos en el barrido de potencial desde $0,50 \mathrm{~V}$ a $0 \mathrm{~V}$, y a la electrooxidación competitiva del agua sobre la superficie libre del platino, desde un potencial mayor que $0,7 \mathrm{~V}$. Entonces, la carga, de electrooxidación de productos derivados de la agarosa puede estimarse para cada $t_{\mathrm{ad}}$, restando a la carga total de electrooxidación, la carga de electroreducción de la capa superficial de compuestos que contienen oxígeno. El pico IV proporciona la carga de electroreducción. 


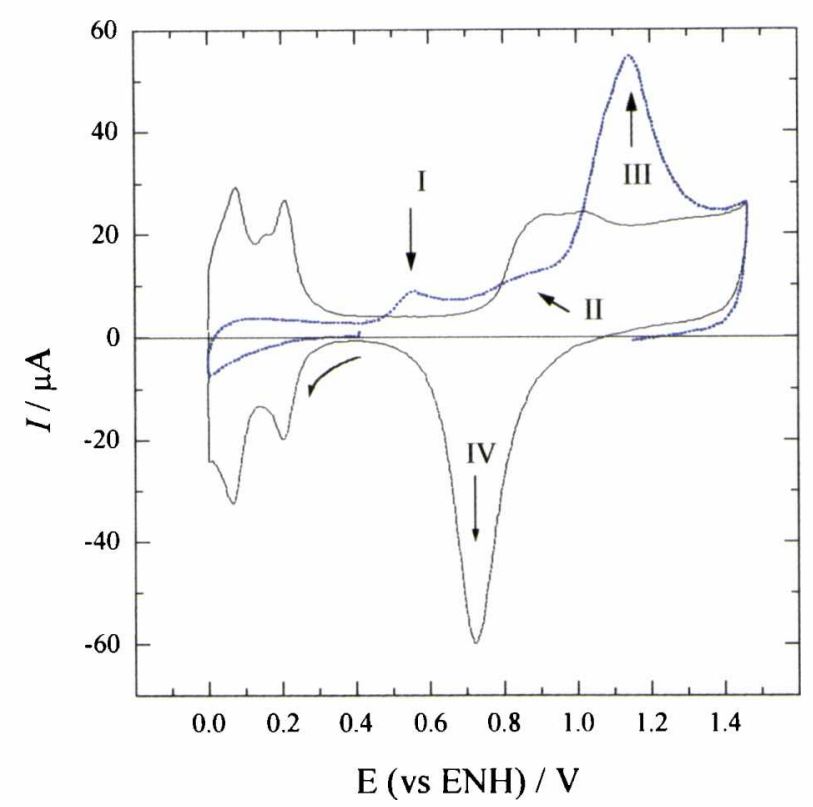

Figura 9.6. Voltamperogramas obtenidos utilizando platino policristalino a $0,05 \mathrm{~V} \mathrm{~s}^{-1}$ luego de sumergir el electrodo a $\mathrm{E}_{\mathrm{ad}}=0,44 \mathrm{~V}$, durante $t_{\mathrm{ad}}=1 \mathrm{~h}$, en solución acuosa de agarosa $0,02 \% \mathrm{p} / \mathrm{v}+$ ácido sulfúrico 0,5 $\mathrm{M}$ después de 15 días. La línea continua corresponde al voltamperograma de Pt en ácido sulfúrico 0,5 $\mathrm{M}$ en ausencia de agarosa adsorbida (blanco). Area geométrica del electrodo de trabajo: $0,159 \mathrm{~cm}^{2} .25^{\circ} \mathrm{C}$.

Si la soluciones que contienen agarosa y ácido sulfúrico empleadas para analizar la adsorción, se guardan durante una semana, se observa una disminución notable de la carga de electroadsorción de hidrógeno, con una desaparición completa de los picos correspondientes. Además aparece un nuevo pico a $0,55 \mathrm{~V}$ (pico I) y el pico III a $1,175 \mathrm{~V}$ se exalta (figura 9.6).

La adsorción de agarosa sobre platino a partir de soluciones acuosas sulfúricas de agarosa, se expresa por el grado de recubrimiento superficial porcentual $\theta=\left(q_{\mathrm{H}}^{0}-q_{\mathrm{H}}\right) 100 /$ $q_{\mathrm{H}}^{0}$, donde $q_{\mathrm{H}}^{0}$ y $q_{\mathrm{H}}$ son las densidades de cargas de electrooxidación de los adatomos de hidrógeno en el voltamperograma de platino sin adsorbato y en el realizado después de la adsorción de agarosa, respectivamente. En la figura 9.7 se ilustra el significado de $q_{\mathrm{H}}^{0}$ у $q_{\mathrm{H}}$ para determinar $\theta$. Las concentraciones de agarosa ensayadas abarcan el rango $0,01 \leq c_{\text {aga }} \leq$ $0,08 \% \mathrm{p} / \mathrm{v}$.

En el rango de $\mathrm{E}_{\text {ad }} \mathrm{y}$ de $c_{\text {aga }}$ mencionados arriba, para $t_{\mathrm{ad}}=10$ minutos, resulta $\theta \cong$ $25 \%$ en todos los casos (figura 9.8). Solo se muestran dos condiciones con el fin de simplificar el gráfico. En la tabla 9.1 se reúnen los valores de $\theta$ obtenidos en distintas experiencias. 


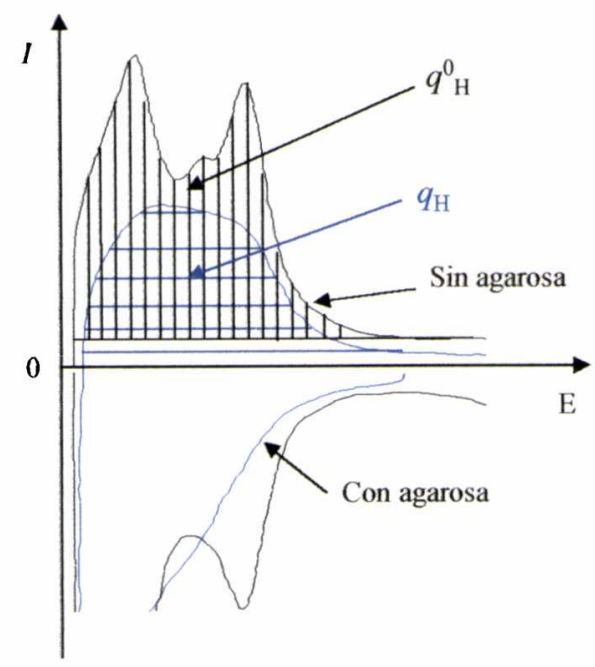

Figura 9.7. Esquema de la determinaciones realizadas para determinar el grado de recubrimiento.

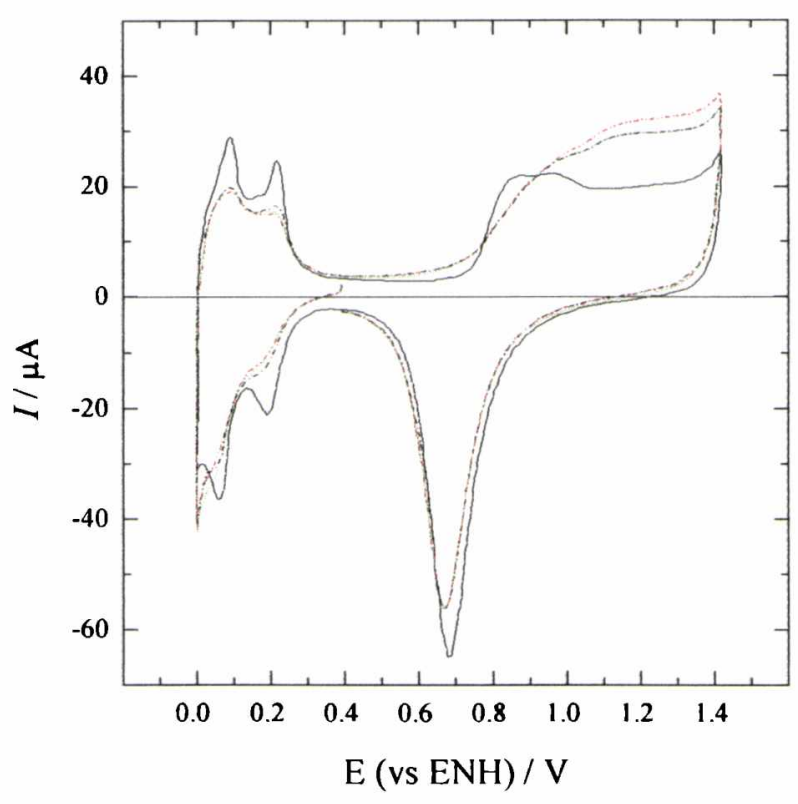

Figura 9.8. Voltamperogramas realizados a $0,05 \mathrm{~V} \mathrm{~s}^{-1}$ empleando ácido sulfúrico $0,5 \mathrm{M}$ usando un electrodo de platino que fue sumergido previamente en solución acuosa recientemente preparada de agarosa $0,02 \% \mathrm{p} / \mathrm{v}+0,5 \mathrm{M}$ ácido sulfúrico, $t_{\mathrm{ad}}=600 \mathrm{~s}$, a diferentes $E_{\mathrm{ad}} . E_{\mathrm{ad}}=0 \mathrm{~V}$ (línea de puntos y trazos negra); $E_{\mathrm{ad}}=0.2 \mathrm{~V}$ (línea verde); $E_{\mathrm{ad}}=0.1 \mathrm{~V}$ (línea roja). El voltamperograma dibujado con línea continua corresponde al blanco en solución acuosa de ácido sulfúrico $0,5 \mathrm{M} .25^{\circ} \mathrm{C}$.

Tabla 9.1. Grado de recubrimiento para distintas $c_{\text {aga }}$ y $\mathrm{E}_{\mathrm{ad}}$ para $t_{\mathrm{ad}}=10 \mathrm{~min}$.

\begin{tabular}{|c|c|c|}
\hline$\% \mathrm{p} / \mathrm{v}$ de agarosa & $\mathrm{E}_{\mathrm{ad}}$ versus ENH & Grado de recubrimiento $\boldsymbol{\theta}$ \\
\hline 0,04 & 0,2 & 23 \\
\hline 0,04 & 0,1 & 25 \\
\hline 0,04 & 0,0 & 25 \\
\hline 0,08 & 0,1 & 26 \\
\hline 0,08 & 0,3 & 25 \\
\hline 0,08 & 0,5 & 25 \\
\hline
\end{tabular}


Para el rango $0,0 \leq E_{\text {ads }} \leq 0,2 \mathrm{~V}$ se estudió el efecto del $t_{\mathrm{ad}}$, empleando soluciones $0,5 \mathrm{M}$ en ácido sulfúrico y $0,02 \% \mathrm{p} / \mathrm{v}$ de agarosa recientemente preparadas. Dentro del error de las medidas no es posible distinguir una diferencia notable de la adsorción de agarosa a distintos $E_{\mathrm{ad}}$. Para aquel rango de $E_{\mathrm{ad}}$ y $5 \leq t_{\mathrm{ads}} \leq 4500 \mathrm{~s}$, se cumple la relación lineal entre $\theta$ y el $\log t_{\text {ads }}$ (figura 9.9):

$$
\theta=(-62 \pm 7)+(32 \pm 2) \log t_{\mathrm{ads}}
$$

donde $\theta$ es el grado de recubrimiento y $t_{\mathrm{ad}}$ está expresado en segundos. Este comportamiento es el que se espera para un proceso de adsorción tipo Elovich. Según la ecuación (9.1) $\theta$ no depende del potencial de adsorción.
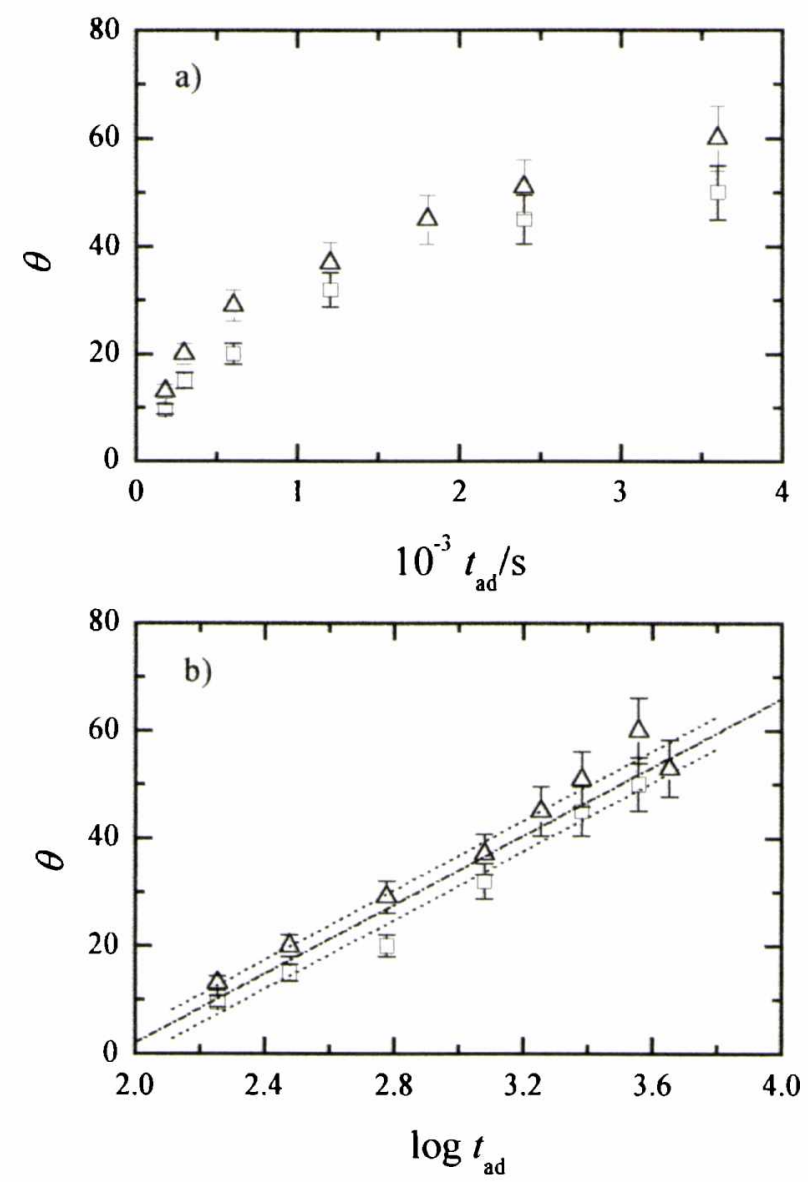

Figura 9.9. Representaciones de a) $\theta$ versus $t_{\mathrm{ad}}$ y b) $\theta$ versus $\log t_{\mathrm{ad}}$. Datos provenientes de voltamperogramas realizados en solución acuosa de ácido sulfúrico $0,5 \mathrm{M}$, en rango de $0-1.4 \mathrm{~V}$ comenzando de $0,39 \mathrm{~V}$, a $0,05 \mathrm{~V} \mathrm{~s}^{-1}$. Se emplean electrodos de platino previamente sumergidos en solución acuosa recientemente preparada de agarosa $0,02 \% \mathrm{p} / \mathrm{v}+$ ácido sulfúrico $0,5 \mathrm{M}$, para distintos $t_{\mathrm{ad}}$ y $\mathrm{E}_{\mathrm{ad}} ;(\square) \mathrm{E}_{\mathrm{ad}}=0,2 \mathrm{~V},(\Delta) \mathrm{E}_{\mathrm{ad}}=0 \mathrm{~V}$. La relación lineal en b) corresponde a una ecuación de adsorción de Elovich (línea de puntos y trazos). $25^{\circ} \mathrm{C}$. 
9.4 Experimentos voltamperométricos realizados empleando la celda de fluio

Los experimentos realizados en la celda de flujo (ver Experimental) permiten distinguir entre el proceso de adsorción y el de electroadsorción y detectar algún proceso, que halla tenido lugar sobre el electrodo por efecto de la agarosa presente en la solución.
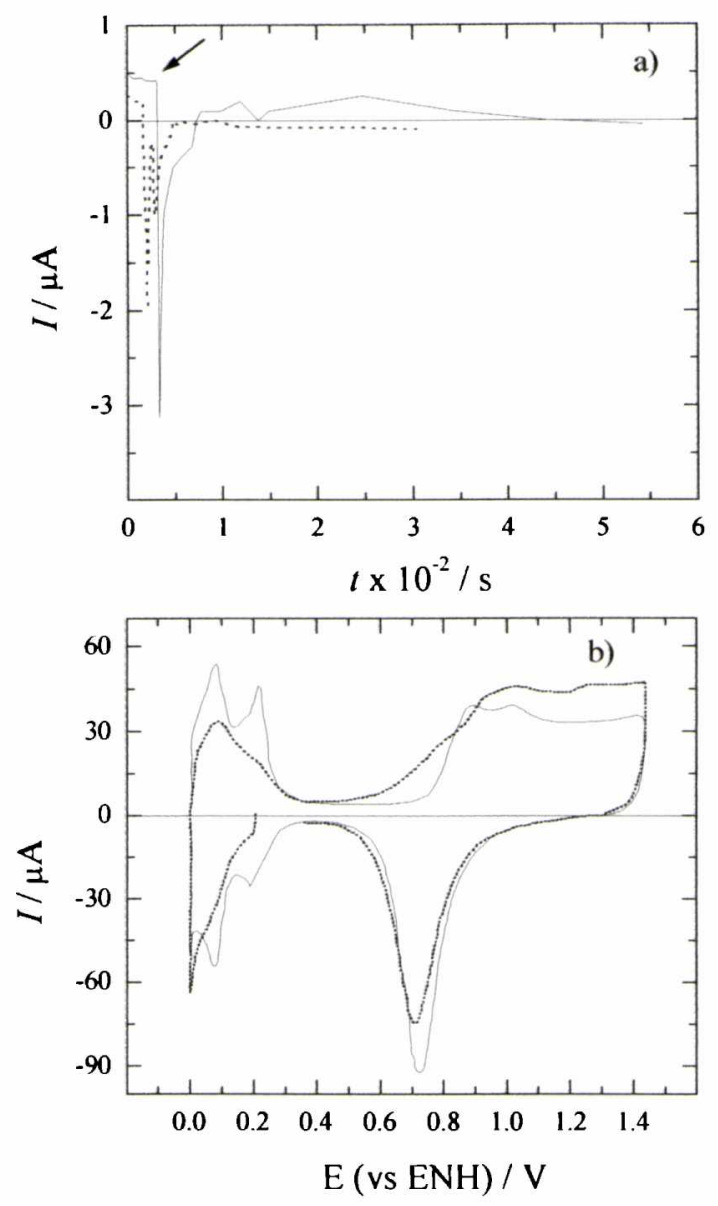

Figura 9.10. a) Transitorios a $\mathrm{E}_{\mathrm{ad}}=0,2 \mathrm{~V}$. (línea sólida) Blanco; (línea punteada) solución acuosa de agarosa $0,02 \% \mathrm{p} / \mathrm{v}+0,5 \mathrm{M}$ ácido sulfúrico. La flecha indica la entrada de solución de agarosa.

b) Voltagramas realizados sobre un electrodo de platino en ácido sulfúrico $0,5 \mathrm{M}$; (línea punteada ) después de sumergir el electrodo en solución acuosa de agarosa $0,02 \% \mathrm{p} / \mathrm{v}+$ ácido sulfúrico $0,5 \mathrm{M}$ durante $t_{\mathrm{ad}}=660 \mathrm{~s}$ y mantener el potencial $\mathrm{E}_{\mathrm{ad}}=0,2 \mathrm{~V}$; (línea sólida) voltamperograma similar al blanco, después de "ciclado de potencial" a $0,05 \mathrm{~V} \mathrm{~s}^{-1}$ durante $40 \mathrm{~min}$.

Los experimentos se inician realizando un voltamperograma de $\mathrm{Pt}$ en ácido sulfúrico $0,5 \mathrm{M}$ con la celda de flujo. Luego se polariza el electrodo a potencial constante ( $\left.E_{a d}\right)$. Seguidamente para el experimento blanco, se abren las llaves del compartimiento que contiene solución de ácido sulfúrico $0,5 \mathrm{M}$ y simultáneamente la de evacuación de la celda, durante aproximadamente $7 \mathrm{~s}$ y se registra el transitorio de corriente durante aproximadamente 5 minutos. Al final del transitorio, se vuelve a reemplazar la solución en 
la celda (abriendo la llave del compartimiento que contiene ácido sulfúrico 0,5 M) y se registra otro voltamperograma. Para el estudio de la adsorción se realiza lo descripto arriba, pero el transitorio de corriente se registra reemplazando la solución de ácido sulfúrico $0,5 \mathrm{M}$ por solución $0,02 \% \mathrm{p} / \mathrm{v}$ de agarosa en sulfúrico $0,5 \mathrm{M}$, abriendo la llave del compartimiento que contiene tal solución de agarosa simultáneamente con la llave de desagote de la celda. Finalmente, se vuelve a lavar con solución sulfúrica sin agarosa y se ensaya un voltamperograma observando cuantos ciclos se necesitan para recobrar el voltamperograma inicial. Esto indica la magnitud de la energía de interacción adsorbatoplatino. En la figura 9.10 se muestran resultados de estos experimentos.

Para todos los valores de $\mathrm{E}_{\mathrm{ads}}$ se registraron corrientes anódicas algo ruidosas. La densidad de carga puesta en juego resulta ser menor que $0,09 \mathrm{mC} \mathrm{cm}$, lo que indica electroadsorción de un número pequeño de moléculas orgánicas en la superfície del electrodo. Se concluye que la interacción entre el platino y la agarosa en las condiciones de trabajo aquí ensayadas, se debe analizar sobre la base de un proceso de adsorción, más que de electroadsorción.

\subsection{Espectros infrarrojos}

Las figuras 9.1 la y b muestran espectros infrarojos de una muestra sólida (pastilla), preparada comprimiendo una mezcla homogeneizada de agarosa y bromuro de potasio 1 parte en 7.

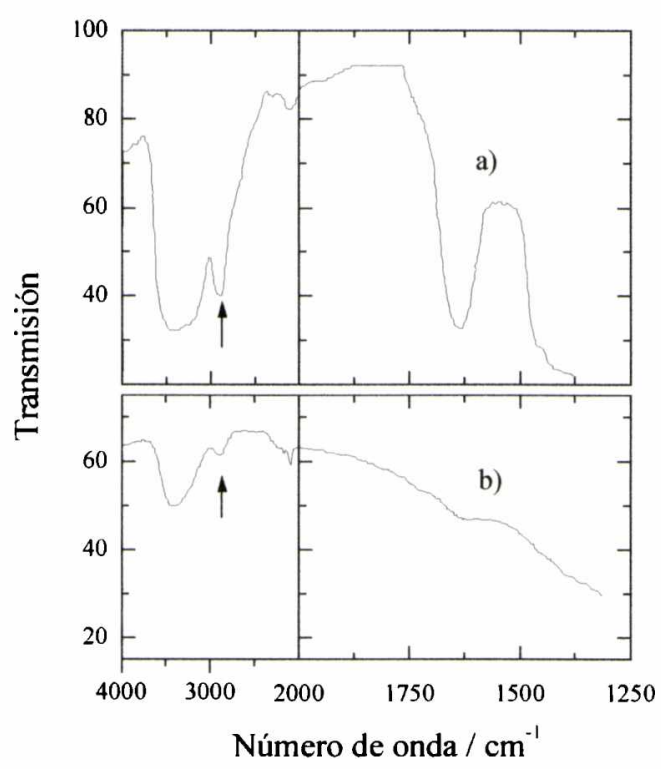

Figura 9.11. Espectro infrarojo en bromuro de potasio. (a) Agarosa pura; (b) Gel de agarosa secado después de transcurrir dos semanas de su preparación en solución acuosa de sulfato de sodio. Las flechas indican cambios en las bandas de absorción del grupo O-H. 
En la región 3700-2500 $\mathrm{cm}^{-1}$, se observan dos picos anchos, en la región 200-2500 $\mathrm{cm}^{-1}$, dos picos pequeños y un pico agudo a $1620 \mathrm{~cm}^{-1}$ (figura 9.11 ). Este último se encuentra en la región de adsorción del enlace $\mathrm{O}-\mathrm{H}[206,207]$.

Un espectro similar, de agarosa gelificada, separada de una solución que contiene sulfato de plata $0,014 \mathrm{M}+$ sulfato de sodio $0,5 \mathrm{M}$ + ácido sulfúrico $0,01 \mathrm{M}$ y agarosa $0,1 \%$ se muestra en la figura $9.1 \mathrm{lb}$. Este espectro muestra una disminución en la intensidad de las bandas en la región $3700-2500 \mathrm{~cm}^{-1}$. Esto demuestra que solo se produce un cambio de la estructura del gel poco influenciada por la presencia del electrolito soporte.

\subsection{Propiedades fisicoquímicas de las soluciones. Medidas del tiempo de escurrimiento}

Las propiedades fisicoquímicas de polímeros en solución están relacionadas con su peso molecular promedio, el tamaño molecular y la forma.

El coeficiente de viscosidad $(\eta)$ de la solución aumenta al incorporar un polímero. La variación de $\eta$ depende del peso molecular del polímero, de la temperatura, de la naturaleza del solvente y de la interacción solvente-polímero [208].

Se determina la viscosidad con un viscosímetro de Ostwald, midiéndose el tiempo que tarda un volumen $\mathrm{V}$ de fluido en atravesar un capilar cilíndrico ubicado verticalmente. Este tiempo, denominado tiempo de escurrimiento $\left(t_{\mathrm{f}}\right)$, se relaciona con la viscosidad del fluido por:

$$
t_{\mathrm{f}}=\begin{gathered}
\eta \\
\mathrm{A} \rho
\end{gathered}
$$

donde A es la constante del viscosímetro, $\rho$ la densidad del fluido y $\eta$ es la viscosidad dinámica. El cociente $\eta / \rho$ se denomina viscosidad cinemática.

En este trabajo se comparan los valores de $t_{\mathrm{f}}$ de soluciones recientemente preparadas de sulfato de plata $0,024 \mathrm{M}+$ sulfato de sodio $0,5 \mathrm{M}+$ ácido sulfúrico $0,01 \mathrm{M}$ (solución I) conteniendo agarosa, con los $t_{\mathrm{f}}$ de aquellas guardadas durante distintos tiempos (envejecimiento). Se intenta observar cambios de $t_{\mathrm{f}}$ posiblemente vinculados a la alteración química del sistema.

Cada valor de $t_{\mathrm{f}}$ es el promedio de cinco determinaciones, que se realizan empleando soluciones acuosas de agarosa que se guardan por distintos períodos de tiempo, de hasta 4 semanas. En cada serie de medidas, el valor de $t_{\mathrm{f}}$ aumenta desde la primera a la última determinación, debido a la adhesión gradual de aglomerados de agarosa al vidrio. Por ello se toma la primer medida de la serie como la medida más representativa. 
Para la solución I, con $c_{\mathrm{aga}}=0,05 \% \mathrm{w} / \mathrm{v}, t_{\mathrm{f}}$ decrece con el envejecimiento, alcanza un mínimo a las dos semanas y luego crece gradualmente (figura 9.12). En cualquier caso los cambios de $t_{\mathrm{f}}$, aunque relativamente pequeños indican la aparición de nuevas interacciones, como se deduce de los espectros IR correspondientes. Se observa que luego de transcurridas 2,5 horas después de la preparación de la solución, la disminución de la viscosidad alcanza solo el $0,1 \%$, y recién luego de 18 horas alcanza el $1 \%$. Esto indica la estabilidad relativamente grande del sistema dentro de la duración de los experimentos de electrodeposición de plata en presencia de agarosa.

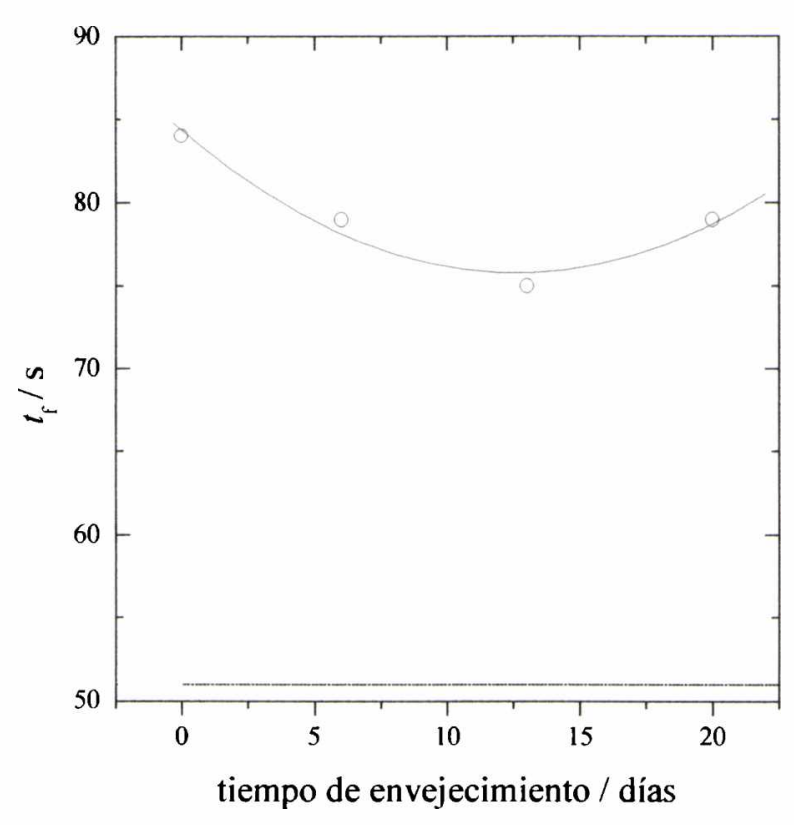

Figura 9.12. Representación del tiempo de escurrimiento en función del tiempo de envejecimiento para una solución acuosa de agarosa $0,05 \% \mathrm{p} / \mathrm{v}+$ sulfato de plata $0,014 \mathrm{M}+$ sulfato de sodio $\quad 0,5$ $\mathrm{M}+$ ácido sulfúrico $0,01 \mathrm{M}$ saturada con nitrógeno. $25^{\circ} \mathrm{C}$. La línea de trazo corresponde al agua.

\subsection{Interpretación de resultados}

La influencia de la agarosa en las características voltamperométricas de la interface metal/solución depende principalmente de la naturaleza de los constituyentes de la interface y del tiempo transcurrido desde la preparación de la solución.

Es fundamental en las características voltamperométricas, la naturaleza del electrodo de trabajo (plata o platino). Con plata, los cambios más significativos se manifiestan en la modificación de la multiplicidad de los picos relacionados con el upd de plomo (figura 9.3). Así, el voltamperograma de upd de plomo del blanco presenta los pares de picos anódicos y catódicos Ia-Ic, IIa-IIc y IIIa bien definidos, similares a los 
encontrados en literatura [200-205], mientras que en presencia de agarosa (adsorción a partir de solución acuosa $0,02 \%$ en agarosa), los picos agudos se redondean, independientemente del tiempo de adsorción $\left(t_{\mathrm{ad}}<1 \mathrm{~h}\right)$. El cociente entre las cargas anódicas y catódicas, permanece cercano a 1 como en el blanco. Se sabe que la movilidad de los átomos de plata sobre la superficie, se induce por la presencia de una fracción de monocapa de átomos de plomo [200-204], y según los resultados arriba presentados, la agarosa en la interface metal/solución afecta la difusión superficial de los átomos metálicos sobre la superficie.

Los resultados voltamperométricos, en los que se emplean electrodos de platino previamente sumergidos en soluciones recientemente preparadas de agarosa en medio ácido, indican que la adsorción de agarosa o sus derivados no depende del potencial aplicado al electrodo de trabajo durante la adsorción ( $E_{a d s}$ ), dentro del rango 0 a $0,5 \mathrm{~V}$ (versus ENH). Como se concluye del análisis de las cargas de la electroadsorción de adátomos de hidrógeno en ácido sulfúrico $0,5 \mathrm{M}$ con agarosa, a diferentes potenciales (figura 9.8).

Por otro lado, cuando el electrodo de platino se sumerge previamente en soluciones envejecidas de agarosa en medio ácido, los voltamperogramas de platino son similares a los obtenidos para soluciones de galactosa, constituyente del polímero de agarosa. Por lo tanto, los datos voltamperométricos sobre platino deben relacionarse con la electroquímica de glúcidos sencillos en solución ácida (figura 9.6).

El estudio de la descomposición electrocatalítica de sustancias orgánicas sobre platino, ayuda a la identificación de las sustancias orgánicas que se producen a partir de la agarosa, y sirve para conocer la cinética de descomposición de estas sustancias en medio ácido.

La electro-oxidación voltamperométrica de los adsorbatos, sobre platino provenientes de las soluciones de agarosa, se caracterizan por tres picos anódicos a $0,55 \mathrm{~V}$ (pico I), 0,85 V (pico II) y $1,175 \mathrm{~V}$ (pico III) (figura 9.6). Los picos II y III, a 0,9V y $1,175 \mathrm{~V}$, respectivamente, se encuentran en el rango de potencial donde la adsorción de especies que contienen $-\mathrm{OH}$ compiten con la adsorción de iones sulfato. El pico I, aparece a $0,55 \mathrm{~V}$, donde se espera encontrar los picos de electrooxidación de especies orgánicas simples [209-214]. Por lo tanto, los picos I y II, pueden relacionarse con la electrooxidación de compuestos orgánicos débil y fuertemente adsorbidos sobre el platino. El pico I está probablemente relacionado con la electrooxidación de residuos de "dióxido 
de carbono reducido", como se demostró para varios sacáridos sobre platino [209-214].

En forma similar a los materiales celulósicos, la agarosa sufre también reacción de hidrólisis cuando la concentración de ácido sulfúrico es suficientemente alta. Entre los posibles productos de hidrólisis, podemos encontrar polisacáridos de menor peso molecular y compuestos con mayor porcentaje de carbono. La cinética de descomposición de la agarosa se describe con una ecuación de velocidad de primer orden [215]:

$$
N=N_{o} \exp (-k t)
$$

donde $N$ es el número de cadenas de la molécula adsorbida, $N_{\mathrm{o}}$ es el valor de $N$ para $t=0$, que es proporcional a la concentración de reactivo (polisacárido). Para varios polisacáridos similares a la agarosa, el valor de la constante específica de velocidad resulta $k=7.2 \times 10^{-5}$ $\mathrm{s}^{-1}$ [215], esto es, el tiempo de vida medio $\left(t_{1 / 2}\right)$ es $1,4 \times 10^{4} \mathrm{~s}$.

Los datos cinéticos de la descomposición de agarosa en solución de ácido sulfúrico $0.5 \mathrm{M}$ se pueden estimar a partir de la carga $\left(q_{\mathrm{a}}\right)_{\mathrm{ad}}$ del pico III, que corresponde a la máxima carga de oxidación de los productos de descomposición fuertemente ligados a la superficie y de la carga de electrooxidación de los adátomos de hidrógenos residuales $\left(q_{\mathrm{a}}\right)_{\mathrm{H}}$, que se detectan en soluciones ácidas conteniendo agarosa. En la figura 9.13 se esquematiza un voltamperograma y se muestran las cargas empleadas para determinar $\left(q_{\mathrm{a}}\right)_{\mathrm{ad}}$. Considerando que el cociente $\left(q_{\mathrm{a}}\right)_{\mathrm{ad}} /\left(q_{\mathrm{a}}\right)_{\mathrm{H}}=\Gamma$ es proporcional a $\mathrm{N}$, el número de cadenas en la molécula adsorbida, al graficar $\Gamma$ versus $t_{\text {ad }}$ (Fig. 9.14) se obtiene una relación lineal de cuya pendiente del gráfico se obtiene $k=4.3 \times 10^{-3} \min ^{-1} \mathrm{y}$ $t_{1 / 2}=2.3 \times 10^{2} \min =1,5 \times 10^{4} \mathrm{~s}$. Estos valores coinciden razonablemente bien, con los datos correspondientes a otros polisacáridos $[215,216]$.

El comportamiento voltamperométrico de la agarosa o productos de su descomposición coincide con el mostrado en trabajos previos sobre la electrooxidación de polisacáridos [214,216]. Para compuestos que poseen un grupo hemiacetálico, tal como la xilosa y la arabinosa, se pueden distinguir dos etapas principales de reacción. La primera, electroadsorción de moléculas con la electrooxidación del átomo de hidrógeno del $\mathrm{C} 1$, que es el más lábil. La segunda etapa consiste en la electrooxidación de los residuos fuertemente unidos al electrodo. Así, el mecanismo propuesto para la molécula de glucosa también es aplicable al comportamiento electroquímico de la agarosa en la interface $\mathrm{Pt}$ /solución ácida. Para la hidrólisis ácida de la agarosa o residuos de su descomposición, se obtiene un valor de la constante específica de velocidad semejante al de otros polisacáridos, por lo que se puede decir que en la reacción global se encuentran 
involucrados grupos glicosídicos que se comportan de igual manera.

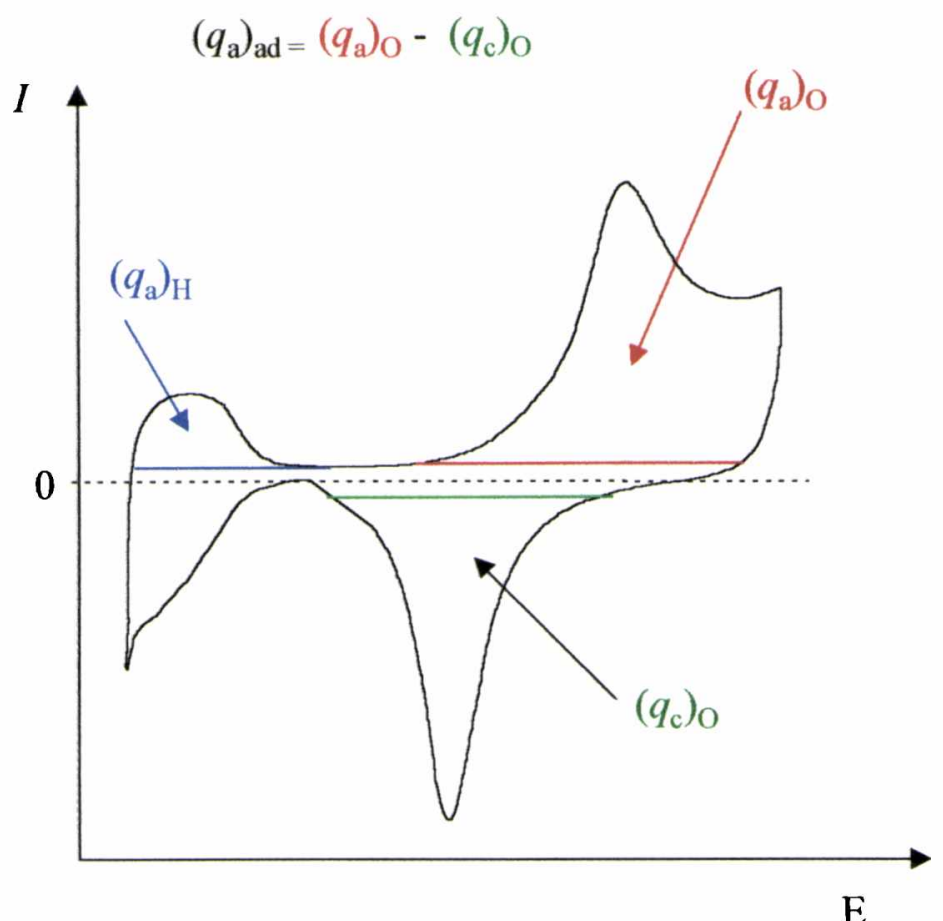

E

Figura 9.13. Determinación de $\left(q_{\mathrm{a}}\right)_{\mathrm{ad}}$. Se muestran las magnitudes necesarias para calcular $\Gamma=\left(q_{\mathrm{a}}\right)_{\mathrm{ad}} /\left(q_{\mathrm{a}}\right)_{\mathrm{H}}$. Las cargas se determinan como el área encerrada por los picos del voltamperograma y la línea horizontal trazada en la base de cada pico.

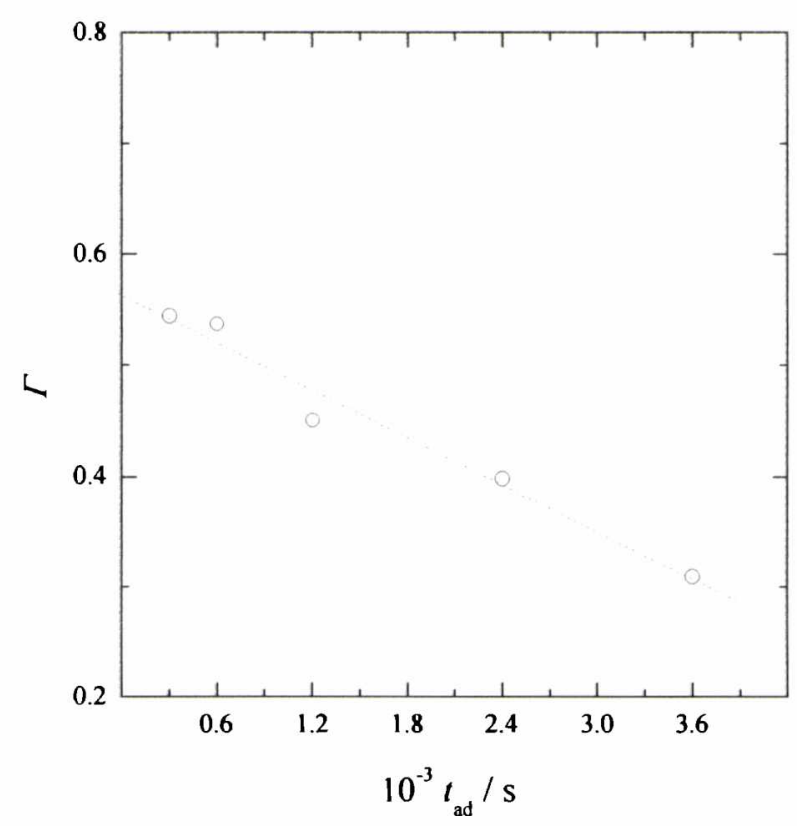

Figura 9.14. Representación del $\log \Gamma$ versus $t_{\text {ad }}$. Se muestra la velocidad de descomposición de la agarosa. Los datos se obtienen de los voltamperogramas de electroreducción de los residuos de agarosa sobre la superficie de platino, empleando solución acuosa de agarosa $0,02 \% \mathrm{p} / \mathrm{v}+$ ácido sulfúrico $0,5 \mathrm{M} .25^{\circ} \mathrm{C}$. 
Lo dicho en las secciones precedentes permite concluir que, las soluciones de agarosa fuertemente ácidas ( $c_{\text {ácido sulfúrico }}=0,5 \mathrm{M}$ ), no son estables. La agarosa se descompone en moléculas orgánicas más simples, que se adsorben en la interface metal/solución, afectando la cinética de la electrodeposición de plata.

Las soluciones de agarosa conteniendo sulfato de plata $0,024 \mathrm{M}$, sulfato de sodio 0,5 $\mathrm{M}$ y ácido sulfúrico $0,01 \mathrm{M}$, son estables por lo menos durante dos semanas. La formación de geles en soluciones con alta concetración de sulfato de sodio, implica cambios de la estructura del gel sin cambios químicos, como se concluye de las medidas de potencial de reposo y de los resultados de espectrometría IR.

La adsorción de agarosa sobre plata a partir de soluciones acuosas de agarosa sin ácido sulfúrico no supera el $5 \%$ de recubrimiento de la superficie metálica. El estudio del upd de plomo, solo muestra que la agarosa puede afectar la movilidad de los adátomos de plata.

La información precedente es importante para interpretar las morfologías de los electrodepósitos de plata empleando soluciones conteniendo agarosa. 


\section{CAPITULO 10}

\section{Electrodeposición en medios estructurados desordenados}

En el capítulo anterior se evaluó la magnitud de la adsorción de la agarosa y su posible influencia en la reacción de electrodeposición de plata. También se consideró la descomposición de soluciones de distinta composición. En este capítulo se estudia la electrodeposición de plata en geles de agarosa. Principalmente se analiza el efecto de la estructura desordenada que presentan los geles en las propiedades de transporte y en la dinámica de crecimiento de los electrodepósitos. Se presenta un nuevo modelo para explicar el comportamiento de estos sistemas.

Se describirán las transiciones tipo "pinning-depinning" y se ensayará un análisis de escalado dinámico, haciendo énfasis en las relaciones que surgen con la estructura de los geles.

Se muestran resultados obtenidos con las celdas quasi-2D de geometría circular y rectangular, estas última resultan apropiadas para el escalado dinámico. Para cada celda se presentan resultados de transitorios de corriente, característica morfológicas y datos cinéticos.

\subsection{Estructura de geles de agarosa}

Cuando la concentración de agarosa supera el $0,12 \% \mathrm{p} / \mathrm{v}$ se obtienen geles que se comportan reológicamente como plásticos de Bingham. Es necesario conocer la estructura de estos geles y su relación con la morfología y la cinética de formación de los electrodepósitos y los posibles mecanismos involucrados.

En los experimentos de observación de los geles se usa la lupa estereoscópica descripta en la sección experimental (Capitulo 3), iluminando el gel colocado en la celda quasi-2D con luz incidente a pequeños ángulos. Para dirigir la luz se utilizan fibras ópticas de luz blanca y, en algunos casos, luz roja de un láser de $4 \mathrm{mV}$. Para algunas muestras de geles se toman micrografias de microscopía láser confocal de barrido (CLMS) empleando el microscopio disponible en la Universidad Nacional de Buenos Aires.

Se emplean geles de agarosa preparados mediante dos procedimientos: geles "in situ" y geles "ex situ"(Capítulo 3). En un caso, la solución conteniendo agarosa que se encuentra a una temperatura por encima de la temperatura de gelificación, se vierte en la celda y se deja enfriar (preparación in-situ). Mientras que en el otro, se coloca la solución ya gelificada dentro de las celdas quasi-2D, presionándolo entre las placas de vidrio o 
Lucite ${ }^{\circledR}$ (preparación ex-situ). Ambos geles, "in situ" y "ex situ" contienen sulfato de plata $x \mathrm{M}(0,008<x<0,024 \mathrm{M})$, sulfato de sodio $0,5 \mathrm{M}$ y ácido sulfúrico $0,01 \mathrm{M}$. Esta composición, permite disponer de un sistema electroquímico suficientemente estable para la electroformación de plata (Capítulo 9).

En los geles de agarosa que contiene sulfato de plata, sulfato de sodio y ácido sulfúrico (ver parte experimental), tanto in-situ como ex-situ, existen distintas estructuras que se ponen de manifiesto a diversas escalas de observación. En la fracción de milímetro se distinguen aglomerados y canales ocupados por soles que contienen pequeñas partículas de agarosa. En tanto que en la escala de las décimas de micrones, existe una estructura de poros en los aglomerados de agarosa [217].

Según estudios previos [217] se estimó, mediante medidas electroforéticas, el radio promedio de los poros en los geles de agarosa utilizados en electroforésis. Se encontró que el radio de los poros es función de la concentración de agarosa utilizada para preparar el gel y cumple con la relación:

$$
P_{\mathrm{E}}=118 \times c_{\mathrm{aga}}^{-0,74}
$$

donde $P_{\mathrm{E}}$ es el radio promedio de los poros (en $\left.\mathrm{nm}\right)$ y $c_{\mathrm{aga}}$ la concentración de agarosa $(\% \mathrm{p} / \mathrm{v})$. Empleando esta expresión, con $c_{\mathrm{aga}} \cong 0,6 \% \mathrm{p} / \mathrm{v}$ (concentración empleada en la mayoría de los geles usados en la electrodeposición) se obtiene $P_{\mathrm{E}}=0,14 \mu \mathrm{m}$.

En la Fig. 10.1a y $10.1 \mathrm{~b}$ se muestran imágenes obtenidas con la lupa estereoscópica de los geles de agarosa preparados "ex situ" e "in situ", respectivamente. Ambos geles, están constituidos por aglomerados de agarosa de distinto tamaño, distribuidos en forma desordenada. En el gel "in situ" el tamaño de los aglomerados puede alcanzar un área de $5 \times 10^{4} \mu \mathrm{m}^{2}$. Se observan canales entre los aglomerados de tamaño variable, con diámetros de hasta $1000 \mu \mathrm{m}$ y longitudes del orden del milímetro. En los geles "ex situ" se observa que la distribución de tamaños de aglomerados, excluyendo los más grandes, es mayor que en los geles preparados "in situ". Además el tamaño de los canales en los geles "ex situ" es aproximadamente $1 / 4$ del tamaño de los canales correspondientes al "in situ". Esto se debe, en principio, a la manipulación que sufre el gel al incorporarlo y presionarlo entre las tapas de la celda.

Esta descripción de los geles está de acuerdo con los resultados de microscopía electrónica (SEM) de geles usados en electroforesis [218-220]. 
a)

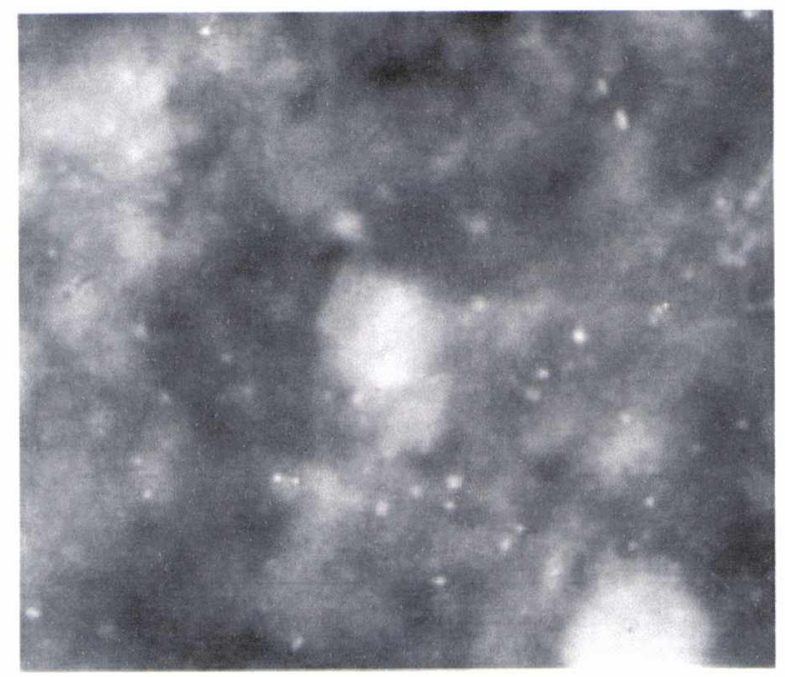

b)

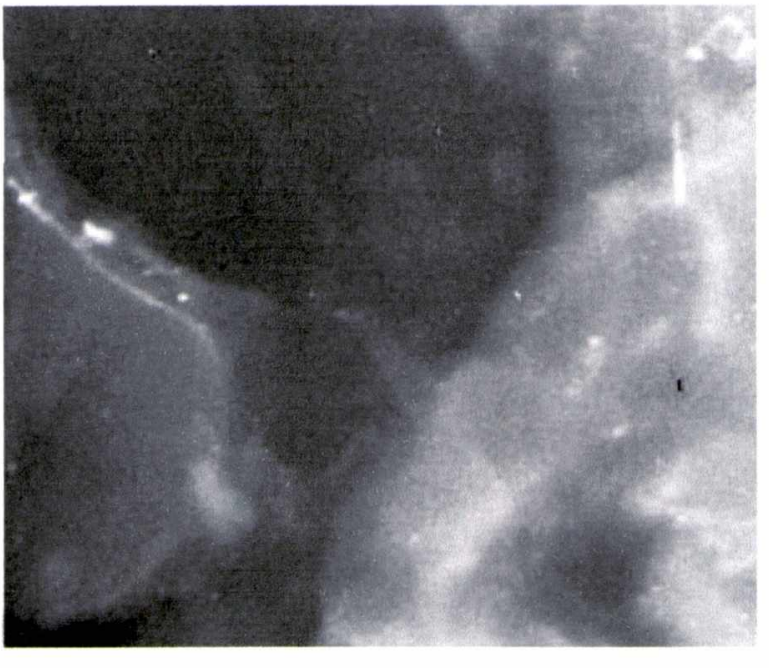

$500 \mu \mathrm{m}$

Figura 10.1. Fotografias de geles de agarosa tomada con la lupa estereoscópica. a) Gel "ex-situ" y b) gel "in situ".

En la figura 10.2, se muestra una micrografia obtenida por microscopía láser confocal de barrido (CLMS) de un gel "in situ" que muestra pequeñas partículas de agarosa $\mathrm{de} \approx 0,1 \mu \mathrm{m}$ de diámetro.

Se puede decir que en los geles se encuentran dos estructuras límites, la primera constituida por pequeñas partículas coloidales dotadas de movimiento, y la segunda que aparece como una estructura de aglomerados "percolados" de gran tamaño, que permanecen prácticamente inmóviles. 


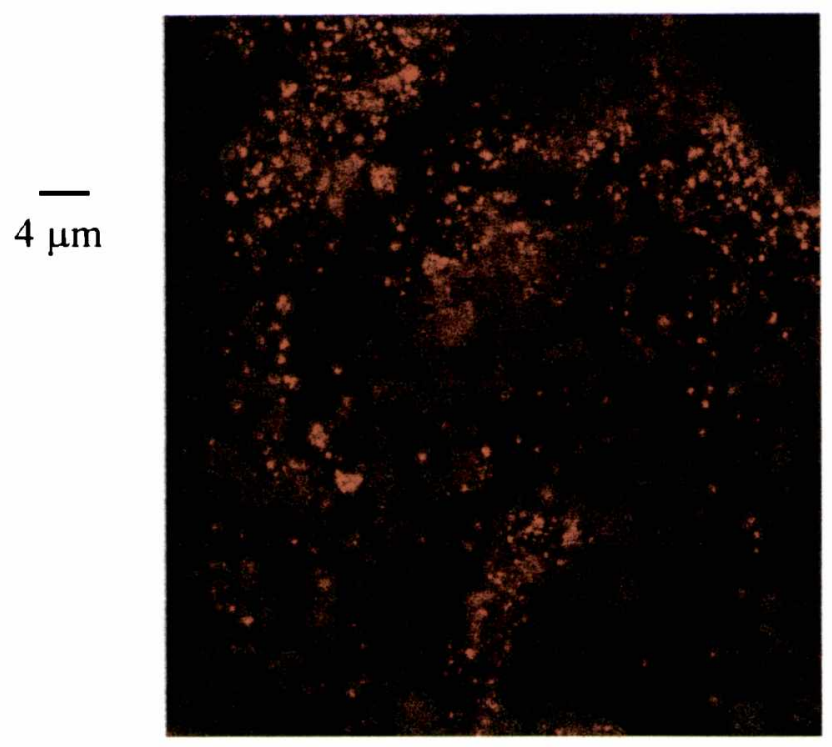

Figura 10.2. Imagen CLMS a $1000 \mathrm{x}$ para una muestra de un gel de agarosa compuesto por sulfato de plata $0,024 \mathrm{M}$, sulfato de sodio $0,5 \mathrm{M}$, ácido sulfúrico $0,01 \mathrm{M}$ y agarosa $0,6 \% \mathrm{p} / \mathrm{v}$, preparado "ex situ". Se ven partículas de agarosa menores que $0,1 \mu \mathrm{m}$.

A partir de imágenes $(1000 \mathrm{x})$ del gel obtenidas por microscopia láser confocal de barrido (CLMS) (figura 10.2) e imágenes (90x) similares a las mostradas el la figura 10.1, se realiza un análisis estadístico del tamaño de los aglomerados. Los datos se representan como una función de distribución de tamaños en la que la frecuencia de aparición de aglomerados de área $A$ mayor que un área minima $a$ es función de $a$ (figura 10.3). De acuerdo a la función de distribución empírica de Korcak [49], $(\mathrm{P}(\mathrm{A}>\mathrm{a}))$ la probabilidad de que un aglomerado de área $A$ supere un valor de área mínimo igual a $a$, es una función hiperbólica:

$$
\mathrm{P}(A>a)=\mathrm{C} \mathrm{x}^{-\mathrm{B}}
$$

C y B son constantes. Con los datos de este trabajo, la función de Korcak se cumple razonablemente bien para $\mathrm{C}=2,5 \mathrm{y} \mathrm{B}=1,3$, y se deduce que el exponente de la función empírica de Korcak está relacionado con la dimensión fractal del sistema de acuerdo con: $2 \cdot \mathrm{B}=D_{\mathrm{F}}$. Del gráfico de la figura 10.3 , resulta $D_{\mathrm{F}} \cong 2,5$, como se espera para un proceso de percolación cuya cinética está gobernada por la formación de enlaces químicos [51]. La dimensión fractal resulta coherente con la anisotropía del desplazamiento del frente de crecimiento del electrodepósito que imponen los aglomerados. Estos actúan como obstáculos para el crecimiento de la fase sólida.

Resumiendo, los obstáculos que proporciona el gel determinan la velocidad promedio de desplazamiento del frente del electrodepósito, a distintas escala de tiempo y a dos longitudes de escala: una dominada por las partículas de agarosa de tamaño 10-0,1 $\mu \mathrm{m}$, y otra asociada a los aglomerados y canales cuyos diámetros están dentro de la fracción de 
milímetro. En las próximas secciones se estudiará el efecto que produce la presencia de estos obstáculos en la electrodeposición, y su relación con la variación de las propiedades de transporte de la especie electroactiva.

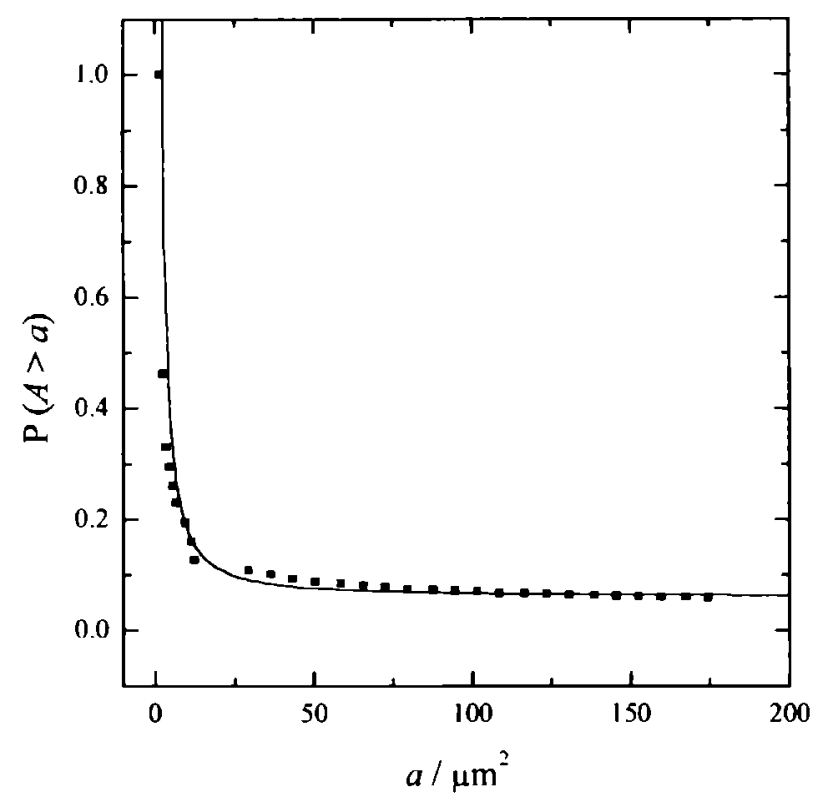

Figura 10.3. Representación de la probabilidad de hallar aglomerados de área $A$ mayor que un cierto límite $a$, en función de $a$. La línea continua es la función de distribución empírica de Korcak.

10.2 Efecto de la agarosa en la electrodeposición de plata en celdas circulares quasi-2D empleando solución II

\subsubsection{Transitorios de corriente}

La figura 10.4 muestra transitorios de corriente para la electrodeposición de plata en la celda quasi-2D de geometría circular, a $\Delta \mathrm{E}_{\text {efectivo }}=-0,18 \mathrm{~V}$, empleando soluciones de sulfato de plata $0.024 \mathrm{M}$ (solución II) $+x \% \mathrm{p} / \mathrm{v}$ de agarosa $(0<x<0.5)$ preparación "in situ", en ausencia de electrolito soporte.

En ausencia de agarosa, para $0<t<1700 \mathrm{~s}$, la corriente $I_{\mathrm{c}}$ disminuye y presenta un hombro a $t \cong 300 \mathrm{~s}$. A $t \cong 1700 \mathrm{~s} I_{\mathrm{c}}$ alcanza un mínimo, y para $t>1700 \mathrm{~s}$ vuelve a aumentar. Los transitorios potenciostáticos obtenidos en presencia de soles y geles son similares a los obtenidos en ausencia de agarosa, excepto que el mínimo de corriente disminuye al aumentar $c_{\text {aga }}$, quizá debido a la disminución del coeficiente de difusión del ión $\mathrm{Ag}^{+}$en presencia de agarosa. 


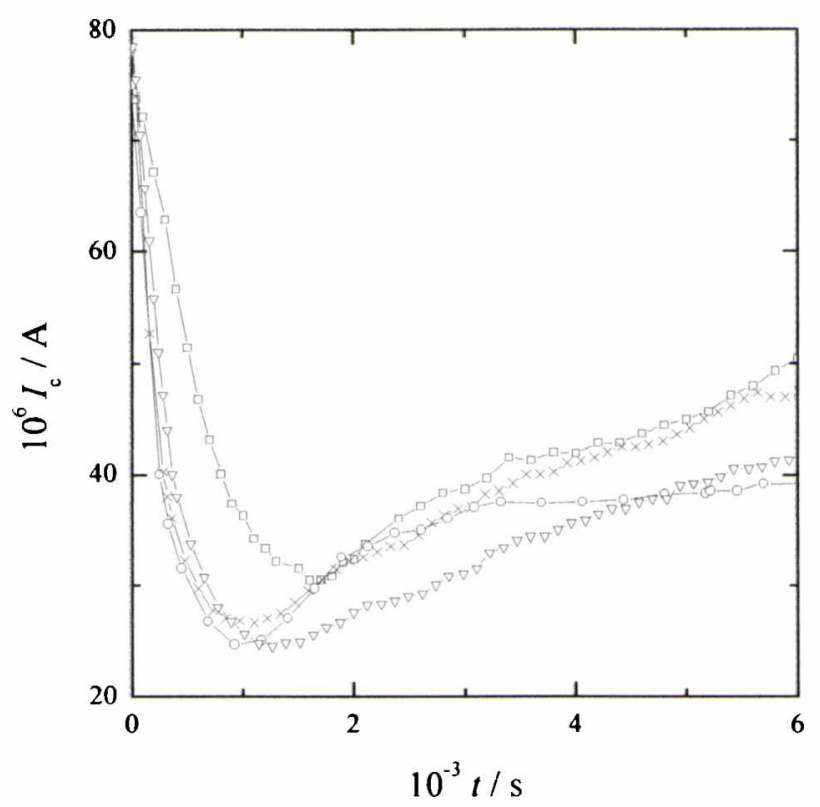

Figura 10.4. Transitorios de corriente potenciostáticos obtenidos en la celda circular, a $\Delta \mathrm{E}_{\text {effectivo }}=-0,18 \mathrm{~V}$. Condiciones: sulfato de plata $0,024 \mathrm{M}+$ agarosa ( ) $0 \% ;(\mathrm{x}) 0,2 \% \mathrm{p} / \mathrm{v} ;(\mathrm{o})$ $0,35 \% \mathrm{p} / \mathrm{v} ;(\nabla) 0,5 \% \mathrm{p} / \mathrm{v} .25^{\circ} \mathrm{C}$.

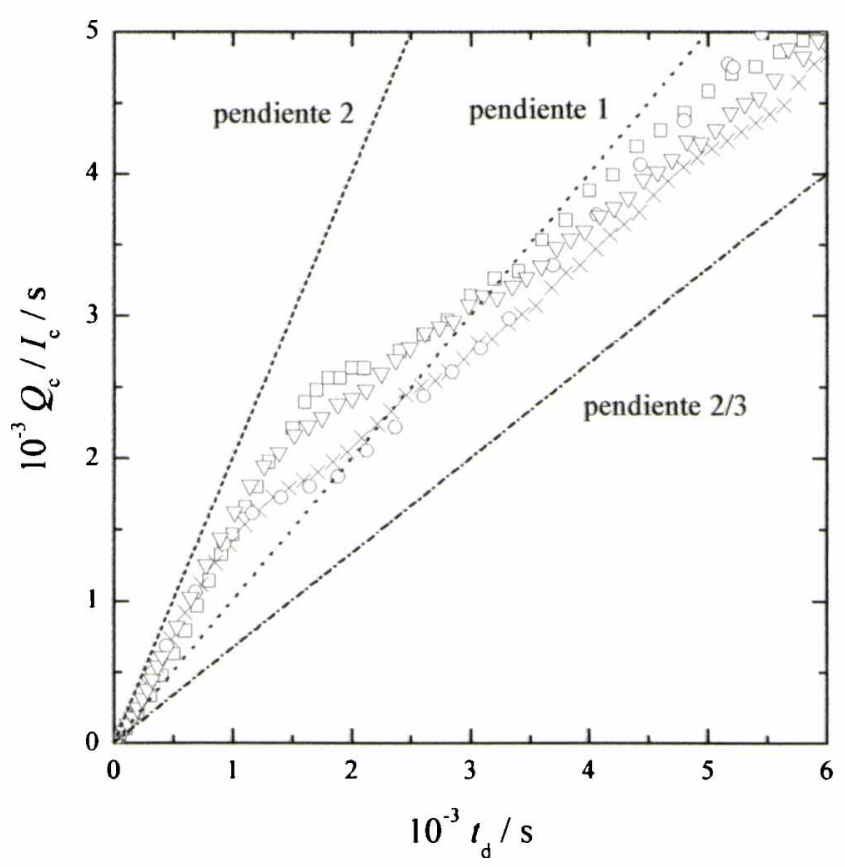

Figura 10.5. Representaciones de los transitorios de corriente de la figura 10.4 como $Q_{d} / I_{c}$ en función de $t$.

Estos transitorios representados como $Q_{\mathcal{J}} / I_{\mathrm{c}}$ en función del tiempo (figura 10.5) muestran tres regiones lineales con pendientes características.

En ausencia de agarosa, para $t<200 \mathrm{~s}$ se aproximan a una recta con pendiente 1; para $200 \mathrm{~s}<t<750 \mathrm{~s}$ se obtiene la pendiente 2; finalmente, para $1500 \mathrm{~s}<t<3500 \mathrm{~s}$, 
resulta la pendiente $2 / 3$. De acuerdo con las relaciones teóricas de $Q_{\mathrm{d}} / I_{\mathrm{c}}$ reunidas en la Tabla 4.9 del Capítulo 4, estas pendientes se pueden asociar a los mecanismos de difusión sin aumento de área (pendiente 2 para $t<750 \mathrm{~s}$ ), y difusión con aumento lineal de área (pendiente $2 / 3$ para $1500 \mathrm{~s}<t<3500 \mathrm{~s}$ ).

Análogamente, para los electrodepósitos obtenidos en soles y geles, las representaciones de $Q_{\mathrm{d}} I_{\mathrm{c}}$ en función del tiempo muestran dos regiones lineales. Para $t<$ $1000 \mathrm{~s}$, la pendiente tiende a 2 , mientras que para $t>1000 \mathrm{~s}$ la pendiente es $2 / 3$.

\subsubsection{Características morfológicas de los electrodepósitos}

En la figura 10.6 se muestran fotografias de electrodepósitos de plata obtenidos en las condiciones descriptas en la sección anterior para $t=47 \min$ y la concentración de agarosa variable entre $0 \leq c_{\text {aga }} \leq 1.3$.

( a )

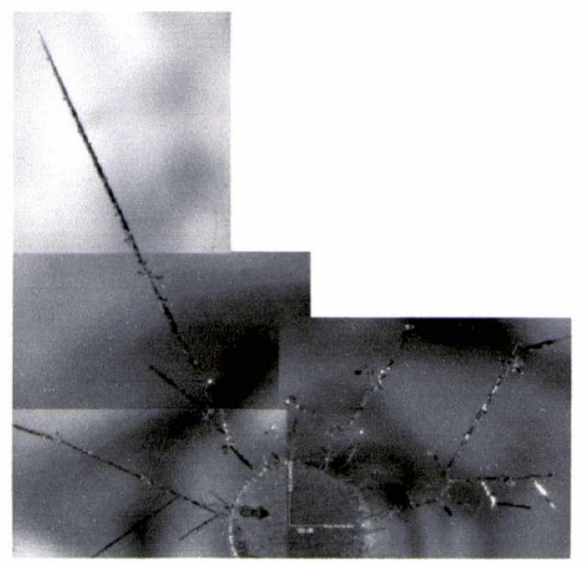

(c)

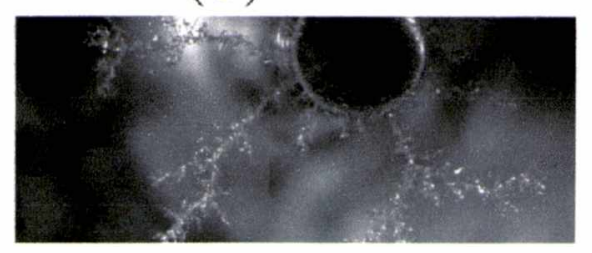

( b )

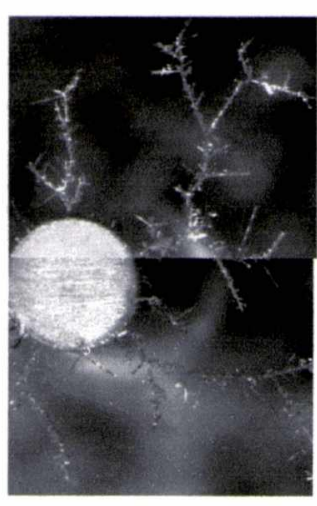

(d)

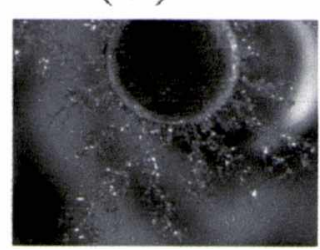

Figura 10.6. Imágenes de los electrodepósitos de plata obtenidos en la celda quasi $2 \mathrm{D}$ circular $\mathrm{A}$, a $\Delta \mathrm{E}_{\text {efectivo }}=-0,18 \mathrm{~V}$, empleando solución II + agarosa (a) $0 \%$; (b) $0,2 \% \mathrm{p} / \mathrm{v}$; (c) $0,35 \% \mathrm{p} / \mathrm{v}$; (d) $0,5 \% \mathrm{p} / \mathrm{v}$ (preparación “in situ”). $298 \mathrm{~K}$. A medida que se incrementa la concentración de agarosa el electrodepósito se hace más denso.

En ausencia de agarosa el electrodepósito está dominado por crecimientos aciculares aparecen luego de la formación de una película compacta de plata de 
aproximadamente 7000 monocapas $\left(Q_{\mathrm{c}}=1.1 \mathrm{mC} \mathrm{cm}^{-2}\right)$. Se observan sitios que reflejan la luz, distribuidos aleatoriamente entre las ramas secundarias. Este efecto se debe a caras facetadas del electrodepósito en posición adecuada para la reflexión de la luz.

Los crecimientos aciculares (Capítulo 4), crecen a una velocidad máxima constante $\left(V_{M}\right)$ y preservan la forma de la punta (ápice) (figura 10.6a). Partiendo de un sol con $c_{\text {aga }}=$ $0.02 \% \mathrm{p} / \mathrm{v}$, la morfología de los electrodepósitos es predominantemente dendrítica. Se distinguen crecimientos con eje central, del que salen ramas laterales formando un ángulo de 30 y $60^{\circ}$. Para $c_{\text {aga }}=0.35 \% \mathrm{p} / \mathrm{v}$, la bifurcación de puntas aumenta y los crecimientos con eje central alcanzan aproximadamente $2 \mathrm{~mm}$. Finalmente, para $c_{\mathrm{aga}}=0.5 \% \mathrm{p} / \mathrm{v}$ (gel), el electrodepósito está formado por ramas pequeñas con bifurcación de las puntas. Se observa también un aumento del número de ramas y un aumento de la densidad aparente de los electrodepósitos.

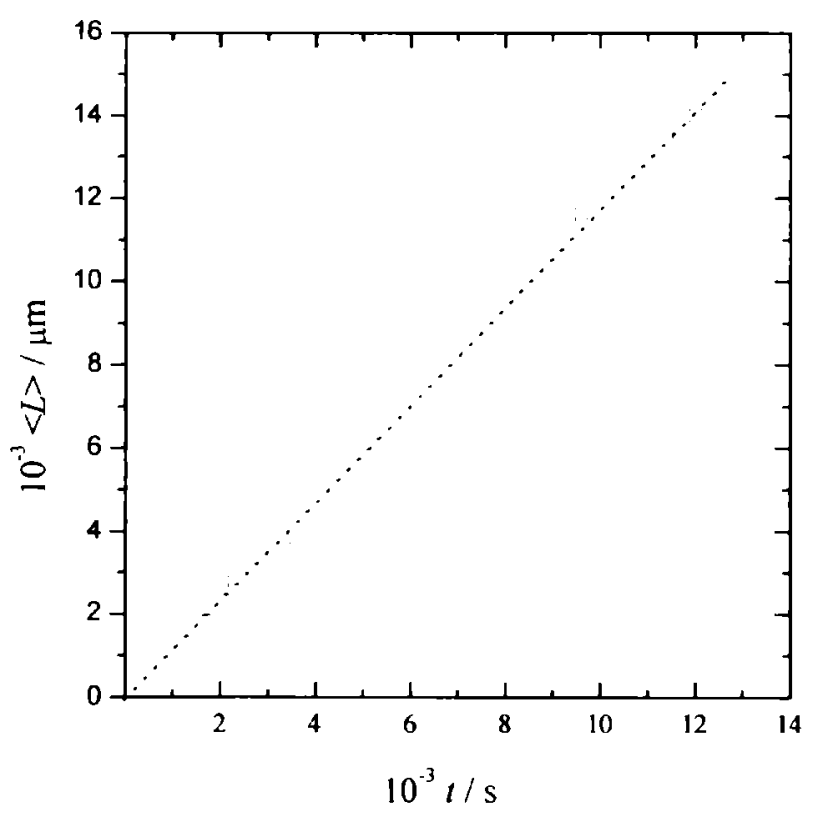

Figura 10.7. Radio del promedio del electrodepósito $\langle L>$ en función del tiempo de electrodeposición $t$ para los experimentos de la figura 10.4. $\Delta \mathrm{E}_{\text {efectivo }}=-0,18 \mathrm{~V}$. Sulfato de plata $0,024 \mathrm{M}+$ agarosa ( ) $0 \% ;(\mathrm{x}) 0,2 \% \mathrm{p} / \mathrm{v} ;(\mathrm{o}) 0,35 \% \mathrm{p} / \mathrm{v} ;(\nabla) 0,5 \% \mathrm{p} / \mathrm{v} .25^{\circ} \mathrm{C}$. La relación lineal entre $\langle L\rangle \mathrm{y} t$ se obtiene en ausencia de agarosa. En presencia de agarosa, a las concentraciones ensayadas, los datos se aproximan a una relación $\left\langle L>\propto t^{1 / 2}\right.$. 
A diferencia de los experimentos realizados en ausencia de agarosa, la velocidad promedio de crecimiento del frente varía y la representación de $\langle L\rangle$ versus $t$ se aproxima a una función del tipo $\langle L\rangle=\mathrm{a} t^{1 / 2}$ (con a $=$ constante), independientemente de la $c_{\text {aga }}$ (figura 10.7). Es interesante notar que la velocidad radial media de los electrodepósitos $<v>$ depende linealmente con $c_{\text {aga }}$ (Fig. 10.8), similar a la relación de Fergunson [221].

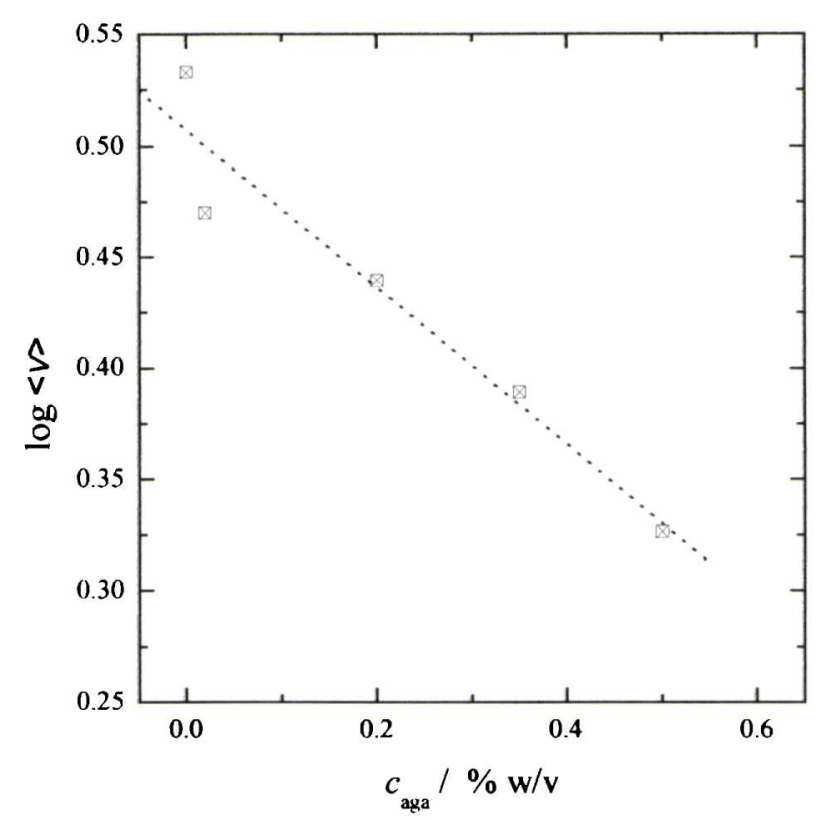

Figura 10.8. Log $<V>$ en función de la concentración de agarosa. Representación de Fergunson.

10.3 Efecto de la agarosa en la electrodeposición de plata en celdas circulares quasi-2D empleando solución I con electrolito soporte

\subsubsection{Transitorios de corriente}

En la figura 10.9 se muestra un transitorio de corriente potenciostático a $\Delta \mathrm{E}_{\mathrm{c}-\mathrm{a}}=-0,580 \mathrm{~V}$ empleando sulfato de plata $0,014 \mathrm{M}+$ sulfato de sodio $0,5 \mathrm{M}+$ ácido sulfúrico 0,01 M (Solución I)+ agarosa $0,6 \% \mathrm{p} / \mathrm{v}$, preparación "in situ". Para $t<100 \mathrm{~s}$, se observa que la corriente decae, y a partir de $t \cong 250 \mathrm{~s}$ aparecen saltos de corrientes con cierta periodicidad. Finalmente, a $t>3000 \mathrm{~s}$, la corriente alcanza un valor estacionario. 


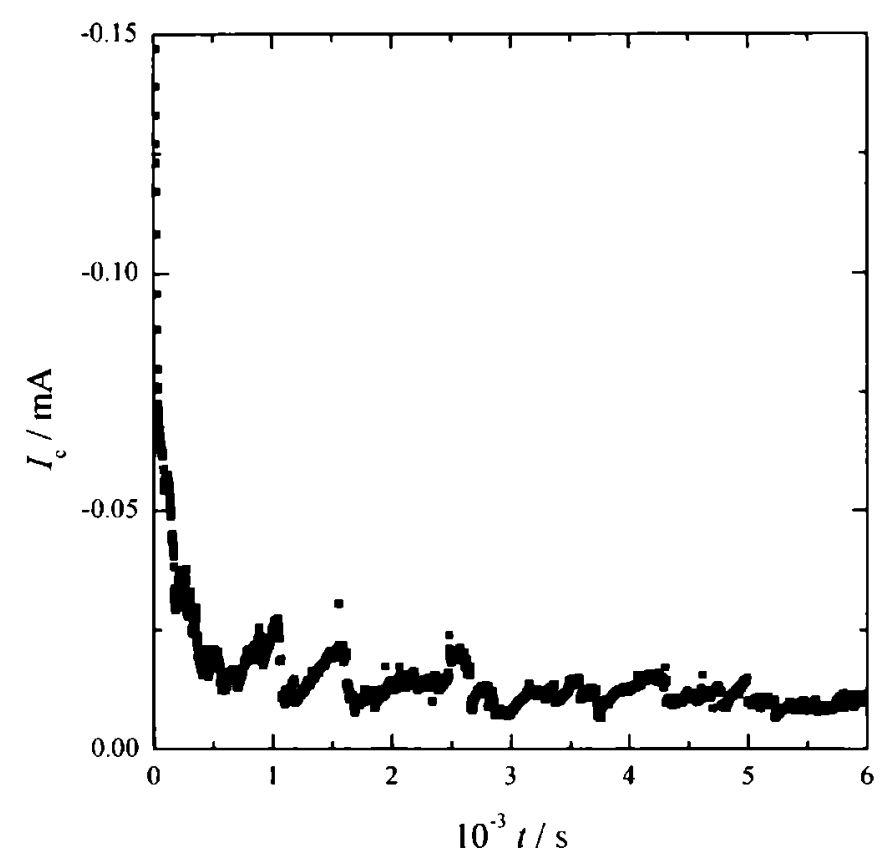

Figura 10.9. Transitorio de corriente potenciostático realizado en la celda circular a $\Delta \mathrm{E}_{\mathrm{c}-\mathrm{a}}=-0,52 \mathrm{~V}$. Solución I + agarosa $0,5 \% \mathrm{p} / \mathrm{v} .25^{\circ} \mathrm{C}$.

Las representaciones de $Q_{\mathrm{c}} / I_{\mathrm{c}}$ (Fig. 10.10) versus $t$ muestran un comportamiento lineal con pendientes que tienden a 2 cuando $t \rightarrow 0$. Luego para $t>100 \mathrm{~s}$ los datos se aproxima a una relación lineal con pendiente 1. Este comportamiento es muy distinto al de los transitorios obtenidos en ausencia de agarosa, en condiciones similares. En este último caso (figura 10.10), las pendientes de la relación lineal $Q_{\mathrm{c}} / I_{\mathrm{c}}$ versus $t$, toma el valor 1 para $t<50 \mathrm{~s}$, y aproximadamente $1 / 2$ para $t>250 \mathrm{~s}$. Estas diferencias se pueden atribuir a variaciones relativas de las contribuciones de los procesos de difusión y la convección en la electrodeposición de plata, de acuerdo a la escala de tiempo, composición de la solución y geometría de la celda (Capítulo 4, Tabla 4.9). En este caso, la pendiente 1/2 es coherente con la preponderancia de la convección libre acoplada con el aumento lineal del área activa del cátodo, como es de esperar para un depósito denso que crece radialmente desde el cátodo hacia el ánodo. La pendiente $\cong 1$, para la electrodeposición a partir de gel, es coherente con el proceso de difusión pura con área constante, para un electrodo de radio inicial de $0,2 \mathrm{~mm}$. 


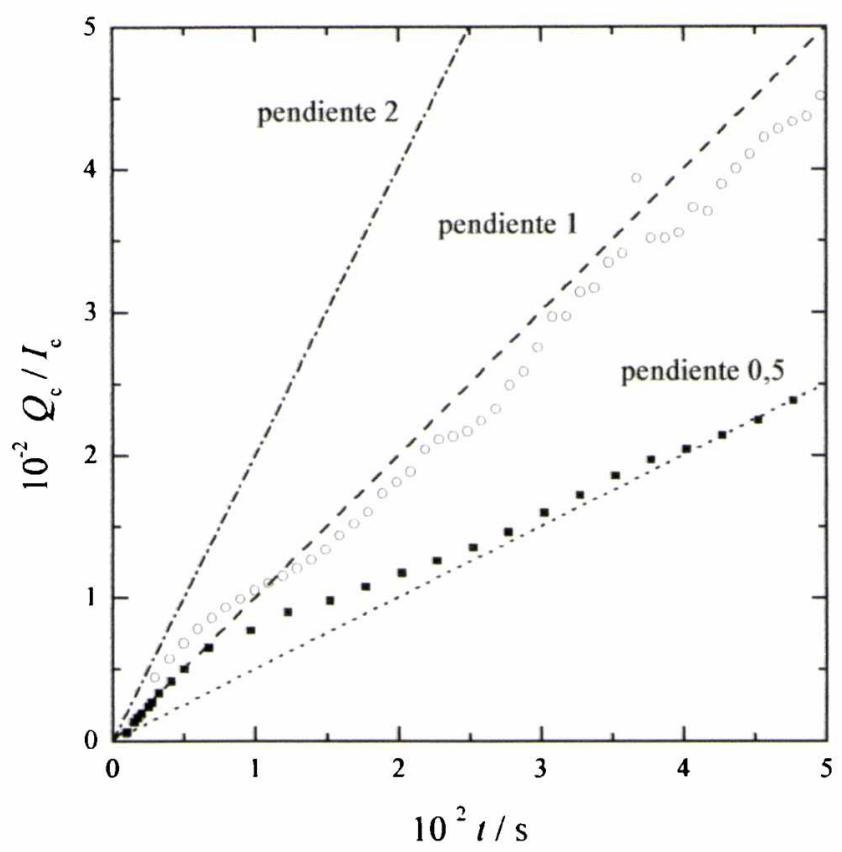

Figura 10.10. Representaciones $Q_{\mathfrak{c}} / I_{\mathfrak{c}}$ para transitorios de corriente obtenidos en la celda circular a $\Delta \mathrm{E}_{\mathrm{c}-\mathrm{a}}=-0,52 \mathrm{~V} ;(\mathbf{a})$ Solución $\mathrm{I}$; (O) gel de sulfato de plata $0,024 \mathrm{M}+$ sulfato de sodio $0,5 \mathrm{M}+$ ácido sulfúrico $0,01 \mathrm{M}+$ agarosa $0,6 \% \mathrm{p} / \mathrm{v}$, el radio del electrodo de trabajo $\left(\mathrm{r}_{\mathrm{c}}\right)$ es de $0,20 \mathrm{~mm}$. $25^{\circ} \mathrm{C}$.

\subsubsection{Características morfológicas de los electrodepósitos}

Los electrodepósitos obtenidos empleando solución $\mathrm{I}$, a $\Delta \mathrm{E}_{\mathrm{c-a}-\mathrm{a}}=-0,52 \mathrm{~V}$, presentan morfología radial densa. Al adicionar agarosa en concentraciones cercanas a las de gelificación, el electrodepósito consiste de ramas individuales densas con predominio de bifurcación en las puntas "tip-splitting”. Si el gel presenta una baja concentración de canales, esto es para $c_{\text {aga }}>0,6 \% \mathrm{p} / \mathrm{v}$, se producen menos ramas incrementándose su espesor. Aparece una relación estrecha entre el tamaño y forma de los aglomerados y canales del gel y las características morfológicas del electrodepósito (figura 10.11).

Las fluctuaciones de corriente en los transitorios potenciostáticos pueden relacionarse con el desorden en la distribución de los obstáculos en el medio que perturban el crecimiento del frente del electrodepósito. Este efecto sugiere la presencia de avalanchas de aglomerados pequeños de agarosa que se producen aleatoriamente en ciertos sitios del frente de crecimiento y producirian inter-conexión entre canales, y asi el crecimiento local súbito del electrodepósito metálico. 
(a)

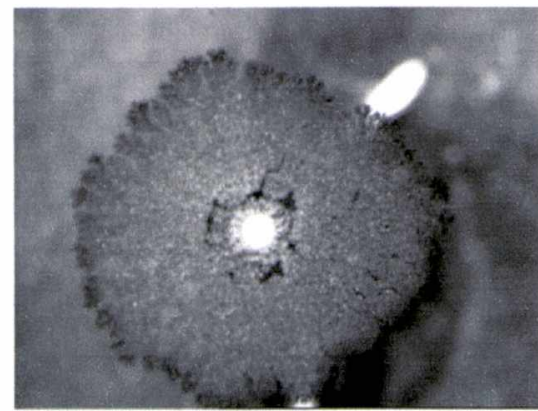

(c)

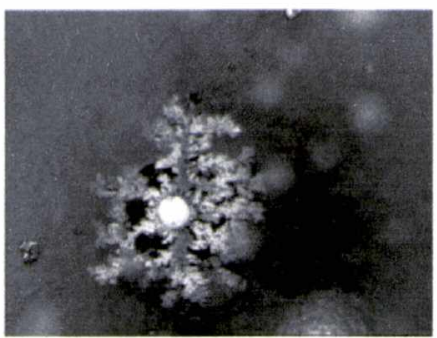

(b)

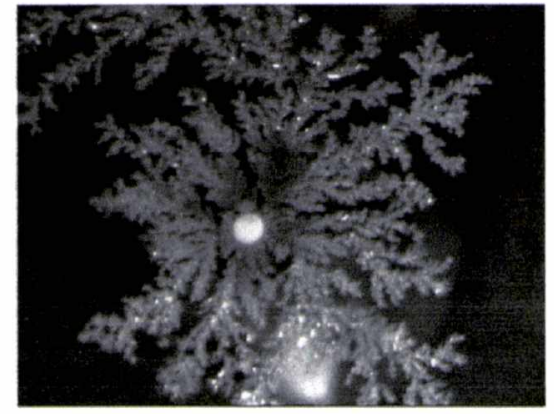

(d)

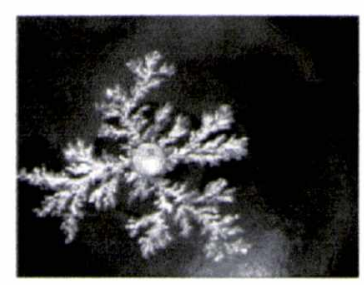

$500 \mu \mathrm{m}$

Figura 10.11. Electrodepósitos de plata obtenidos en la celda circular quasi-2D a $\Delta E_{c-a}=-0,52 \mathrm{~V}$; sulfato de plata $0,014 \mathrm{M}+$ sulfato de sodio $0,5 \mathrm{M}+$ ácido sulfúrico $0,01 \mathrm{M}$ : (a) $\sin$ agarosa, $t=$ $400 \mathrm{~s}$; (b) $c_{\text {aga }}=0,5 \% \mathrm{p} / \mathrm{v}$ (gel), $t=860 \mathrm{~s}$; (c) $c_{\text {aga }}=0,62 \% \mathrm{p} / \mathrm{v}($ gel), $t=1020 \mathrm{~s}$; (d) $c_{\text {aga }}=1.31 \% \mathrm{p} / \mathrm{v}($ gel $), t=727 \mathrm{~s}$. 


\subsection{Experimentos realizados en la celda quasi-2D de geometría rectangular}

\subsubsection{Curvas de polarización}

La curva de polarización catódica para una solución conteniendo sulfato de plata $0,024 \mathrm{M}+$ sulfato de sodio $0,5 \mathrm{M}$ + ácido sulfúrico $0,01 \mathrm{M}$, registrada a $0,2 \mathrm{~V} \mathrm{~s}^{-1}$, tanto en presencia como en ausencia de agarosa, tienen las mismas características (figura 10.12). Así, la inversa de la pendiente de la curva $I_{\mathrm{c}}$ versus $\Delta \mathrm{E}_{\mathrm{c}-\mathrm{a}}$, es decir la resistencia de la solución, para corrientes menores que la corriente límite, resulta en ambos casos de igual magnitud. Cuando estas curvas se corrigen por la caída óhmica, solo difieren en el valor que alcanza la corriente límite. Esta diferencia, en principio, se debe a la eliminación de la convección natural en los geles $[198,199]$. Posiblemente exista además una disminución en el valor del coeficiente de difusión como consecuencia del aumento en las interacciones originadas en la formación de puentes de hidrógeno entre la agarosa y la esfera de solvatación de los iones $\mathrm{Ag}^{+}$[57].

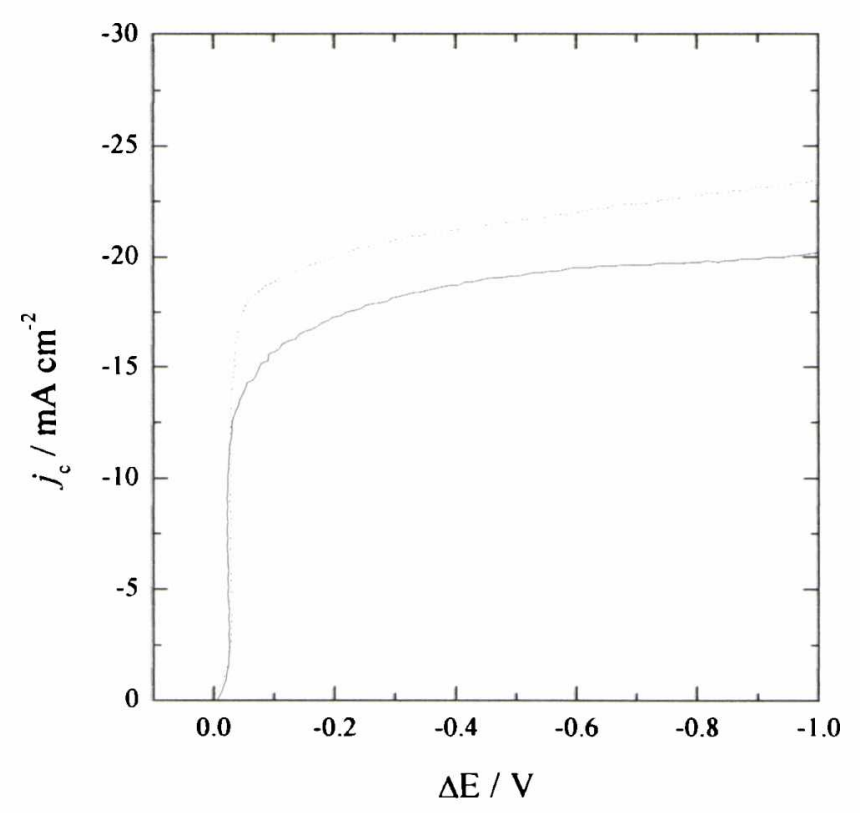

Figura 10.12. Curvas de polarización corregidas por la caida óhmica en la celda rectangular. La línea punteada corresponde al sulfato de plata $0,024 \mathrm{M}+$ sulfato de sodio $0,5 \mathrm{M}+$ ácido sulfúrico $0,01 \mathrm{M}$; La línea continua corresponde al gel de sulfato de plata $0,024 \mathrm{M}+$ sulfato de sodio $0,5 \mathrm{M}$ + ácido sulfúrico $0,01 \mathrm{M}+0.6 \% \mathrm{p} / \mathrm{v} .25^{\circ} \mathrm{C}$.

Las caracteristicas que muestran las curvas de polarización, tanto en solución como en gel, indican que la cinética de la reacción de electrodeposición de plata es un proceso 
controlado por transporte de materia, difusión y migración, o difusión, migración y convección, respectivamente.

\subsubsection{Transitorios de corriente}

La representación de los transitorios de corriente como $Q_{d} I_{\mathrm{c}}$ versus $t$ para la electrodeposición de plata, muestran comportamientos diferentes para $t<200 \mathrm{~s}$, en geles de agarosa de preparación "in situ" y preparación "ex situ" (figura 10.13 y 10.14, respectivamente) y distintas concentraciones de sulfato de plata.
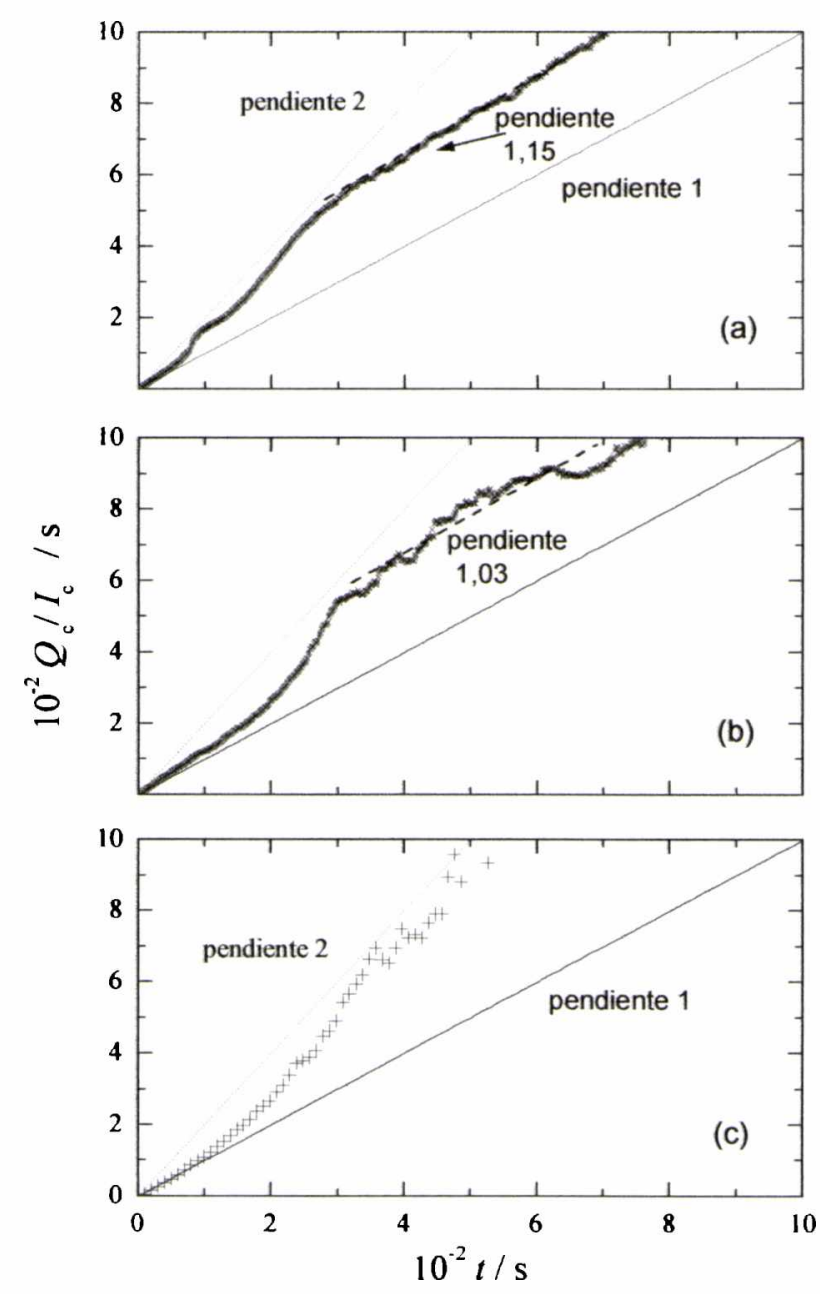

Figura 10.13. Representaciones de $Q d I_{c}$ versus $t$ de los transitorios realizados en celdas rectangulares quasi-2D a $\Delta \mathrm{E}_{\mathrm{c}-\mathrm{a}}=-1,2 \mathrm{~V}$, empleando geles "in situ": sulfato de plata y $\mathrm{M}+$ sulfato de sodio $0,5 \mathrm{M}+$ ácido sulfúrico $0,01 \mathrm{M}+$ agarosa $0,6 \% \mathrm{p} / \mathrm{v}$; (a) $\mathrm{y}=0,016$; (b) $\mathrm{y}=0,018$; (c) $\mathrm{y}=0,024 ; 25^{\circ} \mathrm{C}$. 

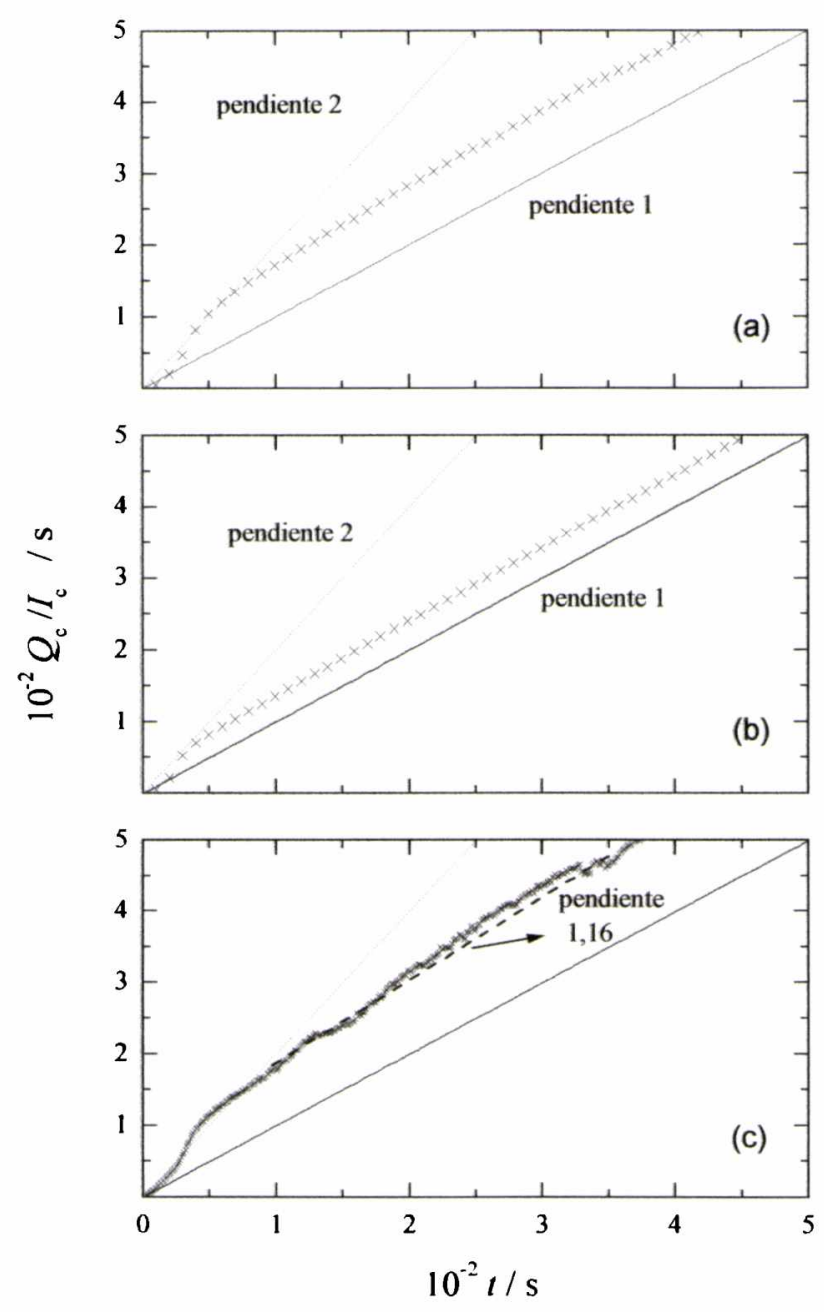

Figura 10.14. Representaciones de $Q_{\mathrm{d}} I_{\mathrm{c}}$ versus $t$ de los transitorios realizados en celdas rectangulares quasi-2D a $\Delta E=-1,2 \mathrm{~V}$, empleando geles "ex situ": sulfato de plata y $\mathrm{M}+$ sulfato de sodio $0,5 \mathrm{M}+$ ácido sulfúrico $0,01 \mathrm{M}+$ agarosa $0,6 \% \mathrm{p} / \mathrm{v}$; (a) $\mathrm{y}=0,008$; (b) $\mathrm{y}=0,012$; (c) $\mathrm{y}=0,018 ; 25^{\circ} \mathrm{C}$.

Los gráficos $Q_{\mathrm{d}} I_{\mathrm{c}}$ versus $t$ a $-1,20 \mathrm{~V}$, para geles "in-situ", y distintas concentraciones sulfato de plata (figura 10.13) son lineales con pendiente 1 para $t<100 \mathrm{~s}$, mientras que la misma pendiente aparece para geles "ex situ" para $t<15 \mathrm{~s}$ (figura. 10.14). Este comportamiento es consistente con la mayor velocidad de desplazamiento del frente de crecimiento del electrodepósito en geles "in situ", cuya estructura de islas y canales es más abierta. En este caso, la pendiente 1 reflejaría una muy fuerte contribución de "advection", ya que el la estructura del gel impide el movimiento macroscópico del fluido.

Se observa que tanto para geles "in situ" como para geles "ex situ", los datos experimentales se aproximan a una relación lineal con pendiente 2 para $100<t<300 \mathrm{~s}$ y $15 \leq t \leq 100 \mathrm{~s}$, respectivamente. Este comportamiento es coherente con el mecanismo de difusión pura, que tiene lugar cuando el frente del electrodepósito es frenado por la 
estructura percolada de los aglomerados inmóviles de agarosa. Estos cambios de comportamiento en los transitorios de corriente confirman la contribución relevante de los distintos fenómenos de transporte. Estas conclusiones, sin embargo, pueden estar afectadas, por la variación del área activa del electrodepósito.

\subsubsection{Características morfológicas de los electrodepósitos}

Los electrodepósitos a $\Delta \mathrm{E}_{\mathrm{c}-\mathrm{a}}=-1,20 \mathrm{~V}$ obtenidos a partir de la solución I, sin agarosa, con la celda BV (figura 10.15) presentan una capa quasi-compacta de plata cuyo espesor es de $0,05 \mathrm{~mm}$. Este depósito se forma durante los primeros $15 \mathrm{~s}$. Luego aparece una segunda capa de ramificado, de alredesor de $0,20 \mathrm{~mm}$ de espesor, entre $15 \leq t \leq 30 \mathrm{~s}$. La morfología de los electrodepósitos presenta protuberancias que a mayor $t$ se convierten en árboles que crecen en la dirección del campo eléctrico. A $t>30 \mathrm{~s}$, los árboles compiten con sus vecinos produciendo un electrodepósito denso. Esta descripción es la misma que la dada en el capítulo 7, cuando se estudió la estadística de ramas en el crecimiento del electrodepósito.

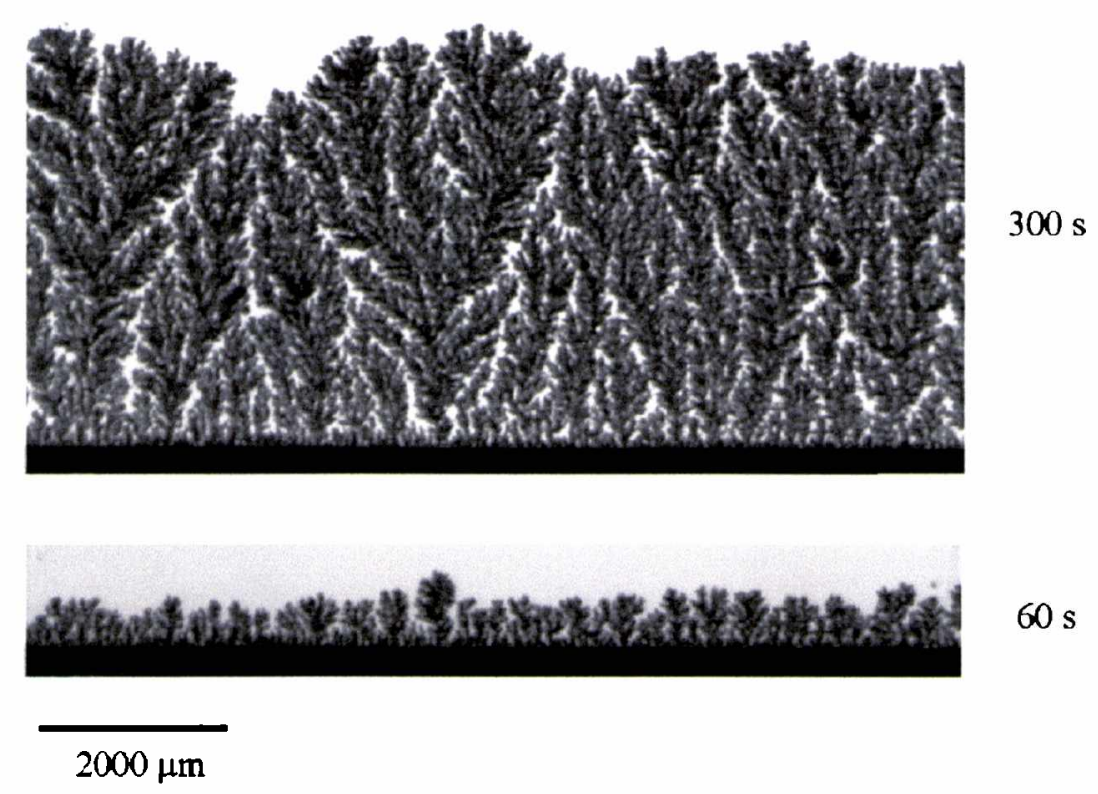

Figura 10.15. Secuencia de fotografías de un electrodepósito obtenidos a partir de la solución I, sin agarosa, con celda rectangular quasi-2D, a $\Delta \mathrm{E}_{\mathrm{c}-\mathrm{a}}=-1.2 \mathrm{~V}$. 

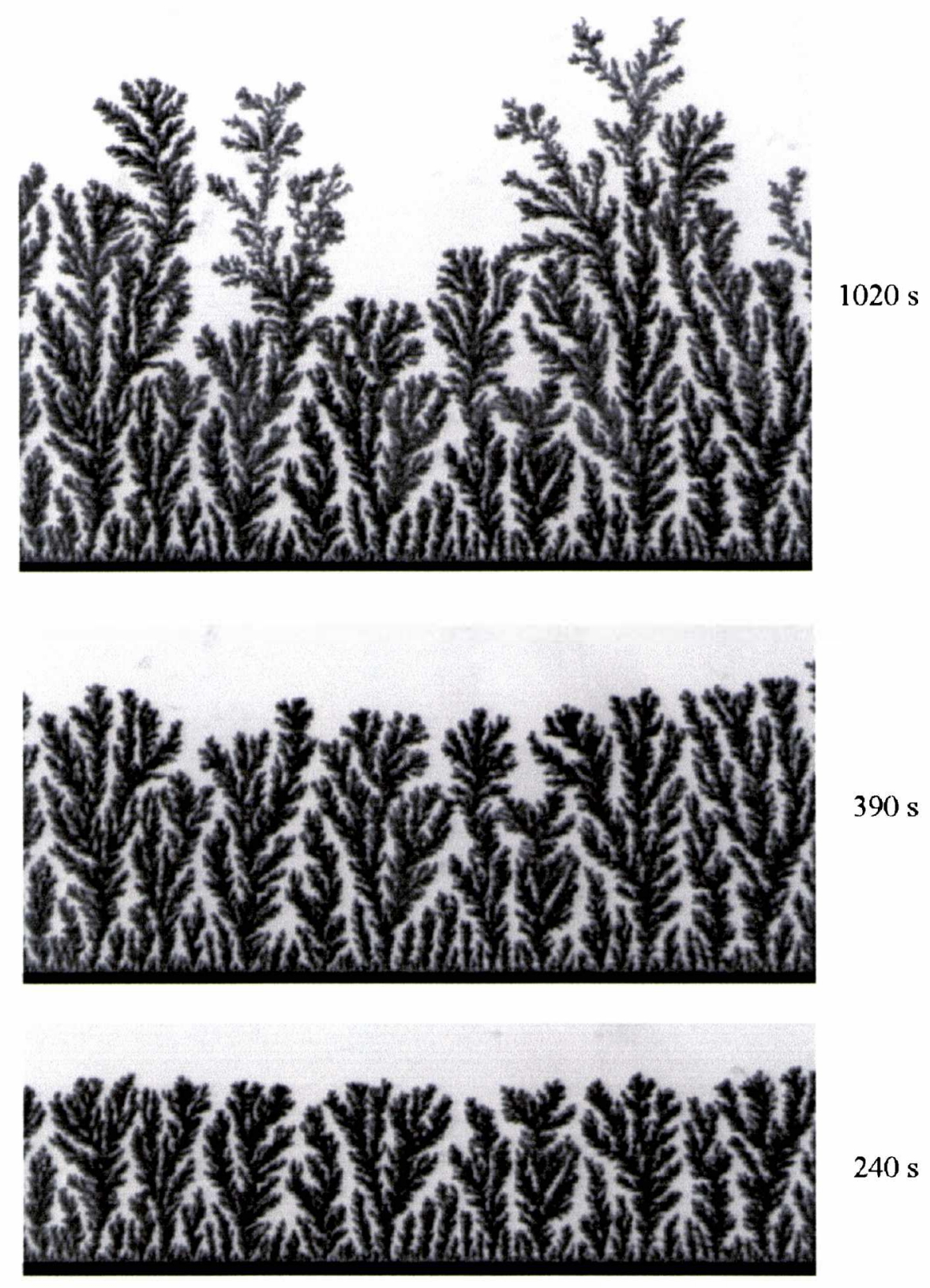

$240 s$

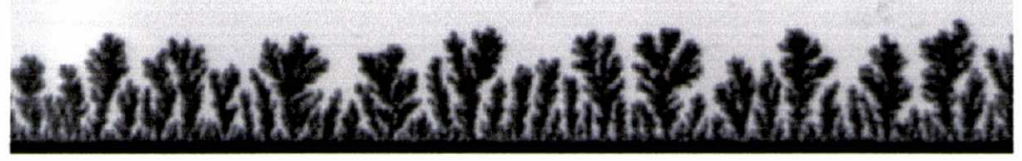

$120 \mathrm{~s}$

$2000 \mu \mathrm{m}$

Figura 10.16. Secuencia de fotografias de un electrodepósito obtenido en sulfato de plata 0,024 $\mathrm{M}+$ sulfato de sodio $0,5 \mathrm{M}+$ ácido sulfúrico $0,01 \mathrm{M}+$ agarosa $0,6 \% \mathrm{p} / \mathrm{v}$ (gel "in situ"), con la celda rectangular quasi-2D, a $\Delta \mathrm{E}_{\mathrm{c}-\mathrm{a}}=-1.2 \mathrm{~V} .25^{\circ} \mathrm{C}$.

La evolución de los electrodepósitos producidos empleando solución de sulfato de plata $0,024 \mathrm{M}+$ sulfato de sodio $0,5 \mathrm{M}$ + ácido sulfúrico $0,01 \mathrm{M}+$ agarosa $0,6 \% \mathrm{p} / \mathrm{v}$ (gel 
"in situ") de la figura 10.16, muestra la formación de una capa compacta a tiempos cortos y la aparición de protuberancias que son origen de los árboles, a $t>15 \mathrm{~s}$. En este caso, la separación entre las ramas es mayor que la observada en electrodepósitos obtenidos en ausencia de agarosa. Por otro lado en el rango $45 \leq t \leq 1275 \mathrm{~s}$, se aprecia la influencia de los obstáculos del medio (aglomerados de agarosa) perturbando el movimiento del frente del electrodepósito ("pinning"). El frenado de algunos árboles se debe no solo a la competencia con algunos vecinos, sino a la presencia de obstáculos. Finalmente, a $t>1300 \mathrm{~s}$, solo unas pocas ramas continúan creciendo.
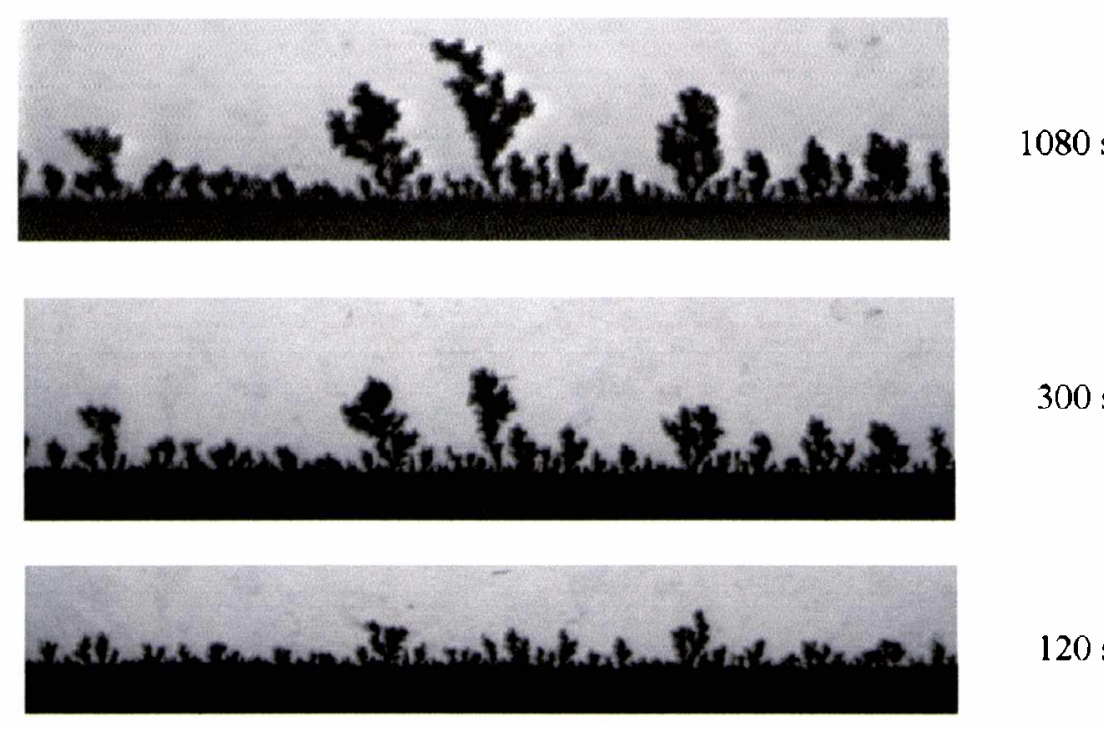

$120 \mathrm{~s}$

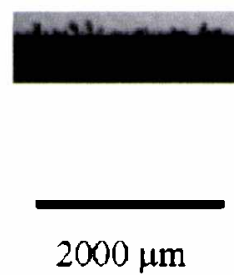

$60 \mathrm{~s}$

Figura 10.17. Secuencia de fotografias del electrodepósito obtenido en solución de sulfato de plata $0,024 \mathrm{M}+$ sulfato de sodio $0,5 \mathrm{M}+$ ácido sulfúrico $0,01 \mathrm{M}+$ agarosa $0,6 \% \mathrm{p} / \mathrm{v}$ (gel "ex situ"), con la celda rectangular quasi-2D, a $\Delta \mathrm{E}_{\mathrm{c}-\mathrm{a}}=-1,2 \mathrm{~V}$.

Experimentos similares, utilizando gel "ex situ" (Fig. 10.17) muestran el origen de un número grande de protuberancias sobre la capa compacta de plata formada en los primeros estadios del crecimiento. El número disminuye rápidamente con $t$ debido a la coalescencia de protuberancias vecinas que evitan su crecimiento individual posterior. A tiempos mayores a los $200 \mathrm{~s}$ se observa que el crecimiento del electrodepósito está gobernado solo por algunos árboles. Finalmente, a $t>500 \mathrm{~s}$, la velocidad de crecimiento de 
estas ramas en la dirección perpendicular al electrodo, disminuye al tiempo que su espesor aumenta.

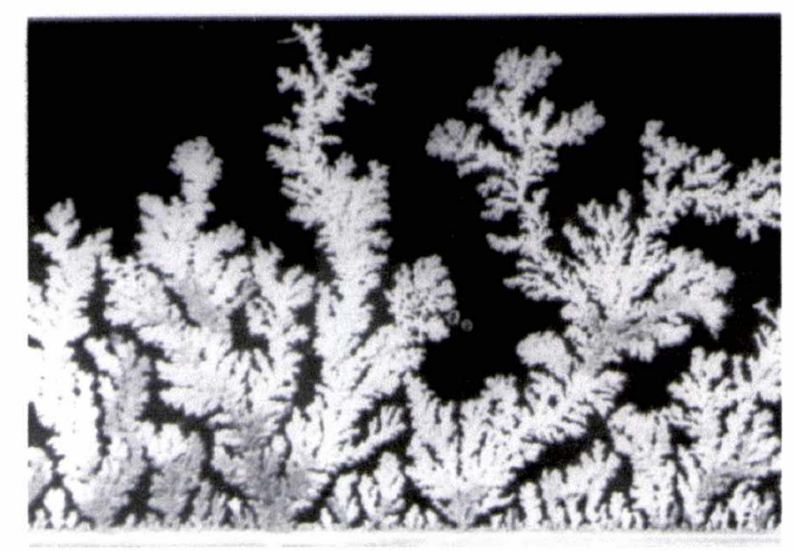

$330 \mathrm{~s}$

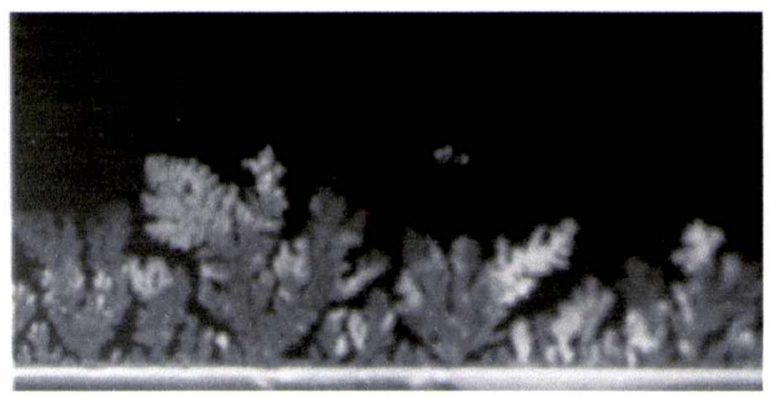

$180 \mathrm{~s}$

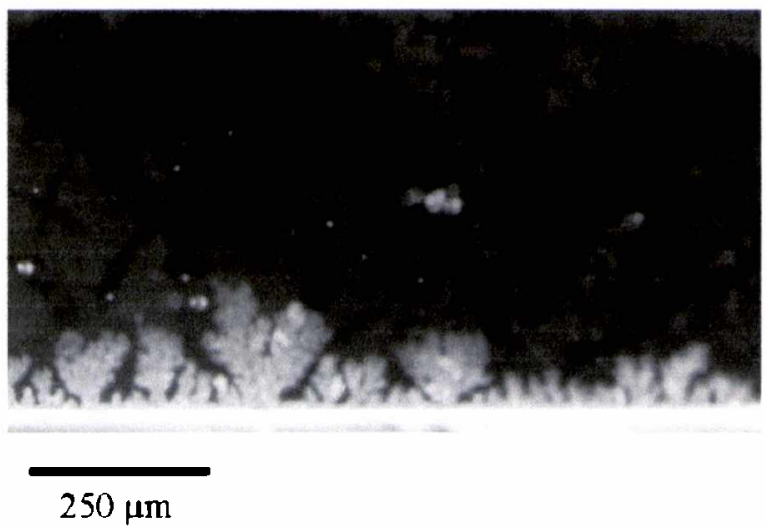

$90 \mathrm{~s}$

Figura 10.18. Secuencia fotográfica de imágenes del crecimiento en gel "in situ". Sulfato de plata $0,024 \mathrm{M}+$ sulfato de sodio $0,5 \mathrm{M}+$ ácido sulfúrico $0,01 \mathrm{M}+$ agarosa $0,6 \% \mathrm{p} / \mathrm{v}$. Se aprecia la influencia de la estructura del gel en la morfologia de los electrodepósitos.

La morfología de los electrodepósitos está fuertemente influenciada por la estructura del gel de agarosa, como se ve en la figura 10.18 y las descripciones de los electrodepósitos dada en los párrafos anteriores. El electrodepósito crece con mayor velocidad por los canales del medio que se encuentran entre los aglomerados de la estructura de agarosa percolada. En estos canales, como se dijo en la primera sección de 
este capítulo, se encuentra un gran número de pequeños aglomerados de agarosa, dotados de movimiento aleatorio. Este movimiento es mayor cuanto menor es el radio medio del aglomerado.

\subsection{Movilidad de los pequeños aglomerados de agarosa}

Para constatar la hipótesis de la existencia de aglomerados de agarosa dotados de movimiento, se realizó una electrodeposición en un gel con manchas de colorante y se observó como se modifican cuando el electrodepósito las alcanza. Se utiliza gel "ex situ" que contiene manchas de azul de metileno. Se comparan las imágenes en tonos de grises de una región conveniente del gel antes y después de la electrodeposición, lo que permite detectar cambios en la distribución de las manchas de azul de metileno como consecuencia del avance del frente del electrodepósito.

En un experimento típico en una imagen del gel con manchas de azul de metileno se selecciona una caja rectangular (rectángulo negro vacio dibujado en la figura 10.19) de manera que la mitad de una mancha de colorante esté ubicada dentro de la caja, y el resto de la mancha entre el electrodo de trabajo y la caja. Luego se construye un histograma de tonos de grises que contiene la caja (blanco) para tener conocimiento de la distribución de los aglomerados coloreados dentro de la caja dibujada. Seguidamente se inicia la electrodeposición de plata hasta que el frente de crecimiento atraviese la mitad de la mancha de colorante que se encuentra fuera del la caja, y alcance el límite de la caja dibujada sobre la imagen del gel. Se construye otro histograma de tonos de grises contenidos en la misma caja y se compara con el blanco para evaluar los cambios en la distribución de los aglomerados coloreados por el azul de metileno. Después de la electrodeposición se observa que el histograma cambia su forma, se aplana, obteniéndose cuentas para tonos de grises menores que en el blanco. El máximo, aunque corresponde al mismo tono de gris tiene menos cuentas (figura 10.19a y 10.19b). Estos resultados sugieren que los aglomerados coloreados son empujados por el electrodepósito que avanza.

A partir de estos resultados, se concluye que es lícito postular la presencia de aglomerados de agarosa de tamaño pequeño que pueden moverse e interfieren en el proceso de crecimiento y arrugosado del electrodepósito de plata. 
a)
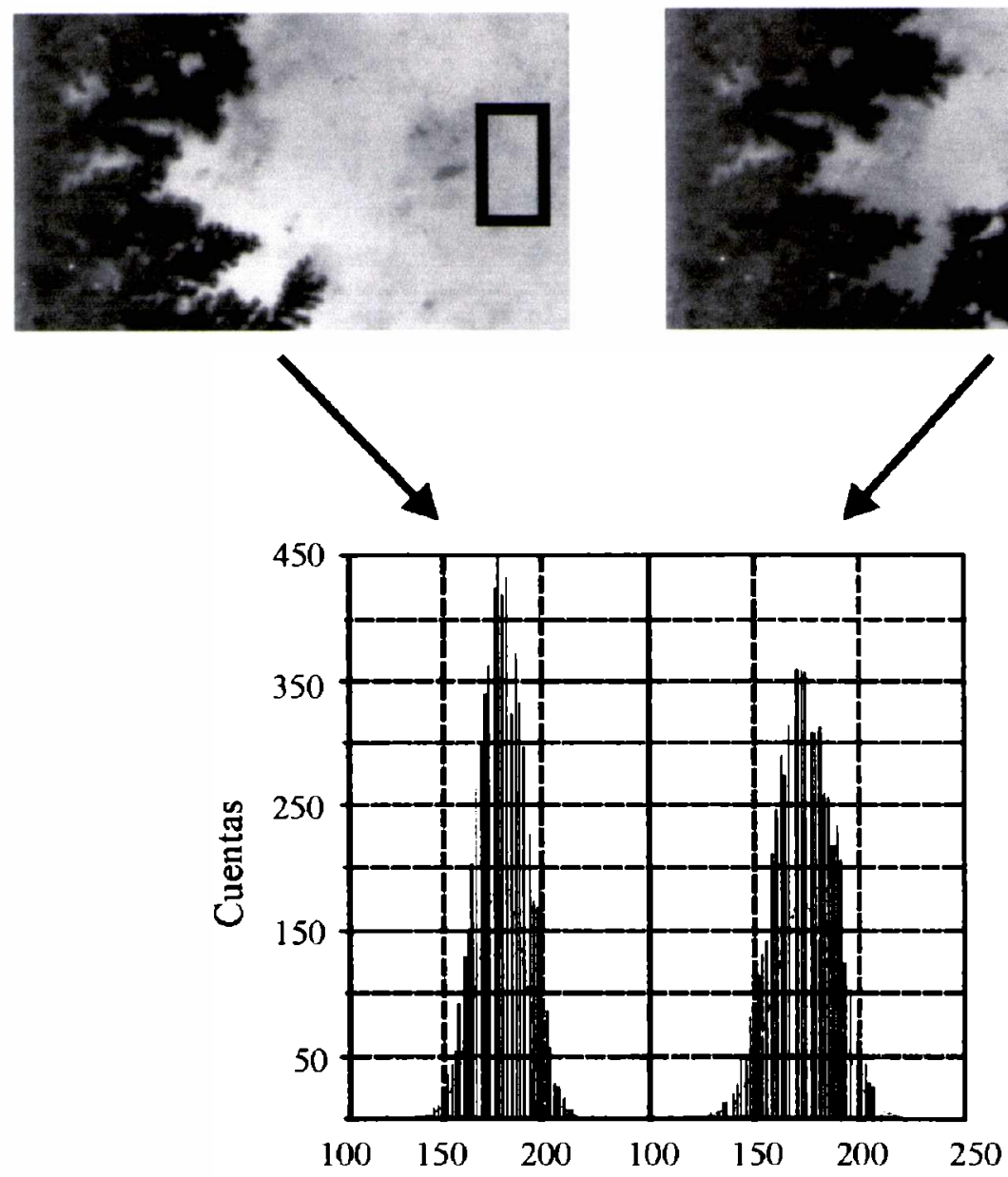

Tonos de grises

b)

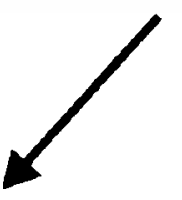

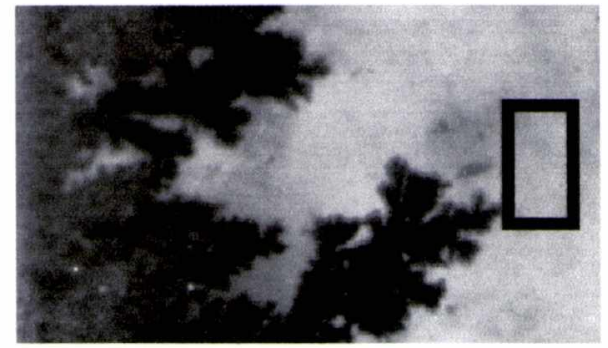
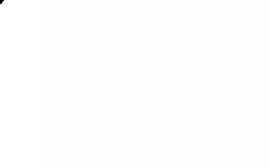
10.6 Influencia de la concentración de la especie electroactiva en la velocidad de movimiento del frente del electrodepósito

En las condiciones experimentales de este trabajo, la fuerza impulsora del proceso de formación del electrodepósito de plata es el gradiente de concentración (más exactamente el gradiente de potencial electroquímico) ya que el proceso está controlado por transferencia de materia. Se trabaja además a un potencial correspondiente a la región de corriente límite. En esta sección se estudia el efecto de la variación de la concentración de la especie electroactiva. Se determina la velocidad de crecimiento de electrodepósitos de plata obtenidos en geles de $0,6 \% \mathrm{p} / \mathrm{v}$ de agarosa con $0,008 \leq c_{\mathrm{Ag}_{2} \mathrm{SO}_{4}} \leq 0,024 \mathrm{M}$. Este límite superior, es la máxima concentración de sulfato de plata que puede disolverse en agua a $25^{\circ} \mathrm{C}$.

Las representación de la velocidad promedio y máxima de desplazamiento del frente, $\langle\boldsymbol{v}\rangle$ y $V_{\mathrm{M}}$, respectivamente, en función de $c_{\mathrm{Ag}_{2} \mathrm{SO}_{4}}$ se muestran en la figura 10.20a y 10.20b. Para soluciones sin agarosa se obtiene una relación lineal entre $\langle\boldsymbol{V}\rangle$ y $v_{\mathrm{M}}$ con $c_{\mathrm{Ag}_{2} \mathrm{SO}_{4}}$. Por el contrario, para geles "in situ" y "ex situ" y $c_{\mathrm{Ag}_{2} \mathrm{SO}_{4}}<1,7 \times 10^{-2} \mathrm{M},<\boldsymbol{V}>$ y $v_{\mathrm{M}}$ muestran un aumento muy lento y valores muchos menores que para las soluciones sin agarosa. A partir de $1,7 \times 10^{-2} \mathrm{M}$ aumenta rápidamente. Existe una concentración crítica de sulfato de plata, $c^{*}{ }_{\mathrm{Ag}_{2} \mathrm{SO}_{4}} \approx 1.7 \times 10^{-2} \mathrm{M}$, que está asociada con el aumento brusco en la velocidad de desplazamiento del frente, aproximándose al valor en ausencia de agarosa. Esta transición abrupta en la velocidad de desplazamiento del frente a partir de $c^{*}{ }_{\mathrm{Ag}_{2} \mathrm{SO}_{4}} \approx$ $1.7 \times 10^{-2} \mathrm{M}$, indica que la fuerza impulsora de la reacción electroquímica es mayor que la fuerza de fricción causada por la presencia de los obstáculos de la estructura de agarosa. Este fenómeno es similar a las transiciones "pinning-depinning" observadas en los modelos de crecimiento de una fase sólida en un medio poroso. 

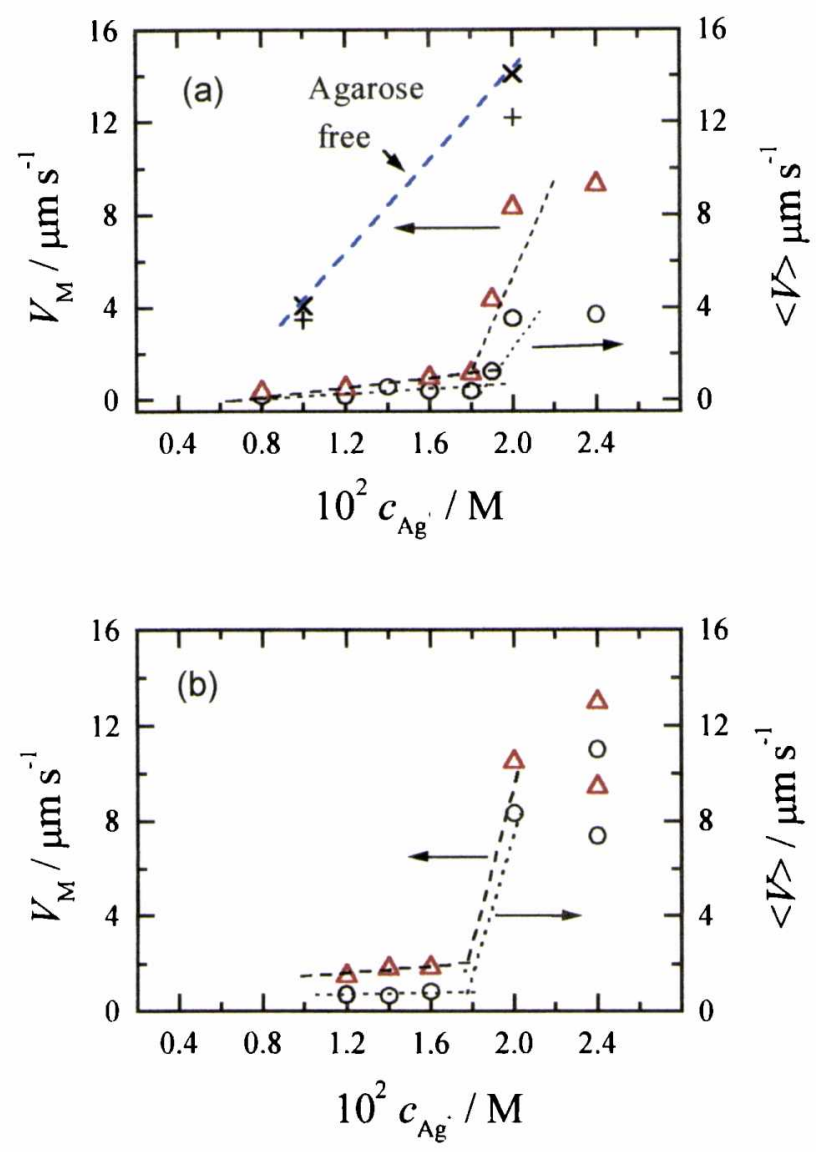

Figura 10.20. Gráfico de la velocidad de avance del frente promedio (o) y máxima $(\Delta),\langle V\rangle$ y $V_{\mathrm{M}}$ respectivamente, en función de $c \mathrm{Ag}_{2} \mathrm{SO}_{4}$, para electrodepósitos obtenidos en soluciones con distintas concentraciones de sulfato de plata + sulfato de sodio $0,5 \mathrm{M}+$ ácido sulfürico $0,01 \mathrm{M}$. $\Delta \mathrm{E}_{\mathrm{c}-\mathrm{a}}=-1,2 \mathrm{~V},(+)$ solución sin agarosa; a) gel "ex situ", $0,6 \% \mathrm{p} / \mathrm{v}$ de agarosa,; b) gel "in situ", $0,6 \% \mathrm{p} / \mathrm{v}$ de agarosa $.25^{\circ} \mathrm{C}$. 


\subsection{Interpretación de los resultados}

La presencia de agarosa en las soluciones empleadas para la electrodeposición de plata produce, como es de esperar, cambios en las propiedades de transporte durante el proceso de electrodeposición. Así, los transitorios de corriente representados como $Q_{\mathrm{d}} I_{\mathrm{c}}$ en función de $t$, en especial para los experimentos realizados con exceso de electrolito soporte, indican que en los geles empleados para la electrodeposición de plata el transporte de materia es predominantemente difusivo, en tanto que en soluciones acuosas la convección es determinante. Para la electrodeposición en la celda rectangular quasibidimensional a $t<700 \mathrm{~s}$, los gráficos $Q_{\mathrm{d}} / I_{\mathrm{c}}$ para gel "in situ" muestran un comportamiento lineal con pendiente cercana a 1 en tanto que para el gel "ex situ" tiende a 2 . Este comportamiento se asocia al proceso de "advection" y difusión pura, respectivamente. Luego, a tiempos mayores, en ambos geles, $Q_{d} / I_{\mathrm{c}}$ se aproxima a 1 , pendiente correspondiente a "advection" producido por el crecimiento rápido de algunas ramas a través de la estructura de islas y canales del medio (figuras 10.13 y 10.14). En estos, a medida que se aumenta la concentración de la especie electroactiva, resultan más marcadas las diferencias de los distintos mecanismos de transporte.

En la Tabla 4.9, se incluyeron los posibles valores que puede tomar la pendiente del gráfico $Q_{\mathcal{J}} I_{\mathrm{c}}$ versus $t$ para diversos mecanismos de transporte, con y sin variación del área activa del electrodepósito y distinta geometría de las celdas electroquímicas. Se observó que los resultados para convección libre y "advection" eran ambiguos. En el párrafo anterior se ha preferido "advection" debido al fundamento que se da a continuación, basado en el cálculo del número de Grashof en geles.

A partir de una cierta concentración crítica de agarosa los soles forman geles que se comportan como plásticos de Bingham [196]. A partir de esa concentración de agarosa se obtiene una estructura percolada que elimina la convección libre. En condiciones estacionarias, la contribución de la convección libre se puede estimar a través del número de Grashof $(G r)$, que indica la relación entre las fuerzas gravitacionales y las fuerzas viscosas:

$$
G r=\alpha^{\prime} \mathrm{g} L^{3} / v^{2}
$$

donde $\alpha^{\prime}=\left(c_{\mathrm{i}}^{0} / \rho\right)(\partial \rho / \partial c)$ es el coeficiente de densificación, $\boldsymbol{c}_{\mathrm{i}}^{0}$ la concentración del reactivo en el seno de la solución, $\rho$ y $v$ son las densidad y la viscosidad cinemática de los soles, respectivamente, $\mathrm{g}$ es aceleración de la gravedad, y $L$ es la longitud característica del sistema. Para la convección libre, $L$ es la altura del electrodo de trabajo, para $L \ll$ distancia ánodo-cátodo, y para geles con estructura percolada $L$ se puede relacionar 
con el tamaño de los poros, el cual es una función de potencia de la concentración de agarosa, o mejor con el radio promedio de los pequeños aglomerados. En este caso, para soluciones de electrodeposición sin agarosa (canales), tomando $v=1.6 \times 10^{-2} \mathrm{~cm}^{2} \mathrm{~s}^{-1}$, $0,1 \leq L \leq 10 \mu \mathrm{m}, \mathrm{g}=980 \mathrm{~cm} \mathrm{~s}^{-2}$, y $\alpha^{\prime}=0,004$ [196], resulta $G r($ sol) cuyo valor mucho menor que 1. Por lo tanto la convección libre no puede desarrollarse. En esta situación la contribución de "advection" podría ser significativa, como es el caso para el crecimiento del electrodepósito en los canales del gel. Por otro lado, a $t \rightarrow 0$, cuando se establece la capa de difusión, el transporte por difusión es importante [78].

Las secuencias de imágenes de electrodepósitos muestran que su morfología está relacionada con la estructura de los geles. La velocidad de avance del frente disminuye con la concentración de agarosa y el ancho de las ramas aumenta. La velocidad de avance del frente sufre cambios abruptos en ciertas regiones, originando avalanchas o crecimiento rápido del electrodepósito, por desplazamiento de los obstáculos proporcionados por el gel.

Al aumentar la concentración de sulfato de plata en los geles de agarosa, se incrementa la fuerza impulsora para la electrodeposición de la plata. Se observa un aumento gradual de la velocidad de avance del electrodepósito por debajo de una cierta concentración crítica, i.e, sulfato de plata $0,017 \mathrm{M}$. Por encima de esta concentración se produce un aumento brusco de la velocidad de avance de la interfase, similar al producido en las transiciones "pinning - depinning" (boqueo - desbloqueo), observadas en varios modelos de crecimiento $[62,63,71-73]$.

El bloqueo al avance de la interfase, similar a un efecto de "pinning", depende de la presencia de una estructura desordenada en los soles y geles (Fig. 10.1a, b), que depende del procedimiento de preparación. Los geles pueden describirse como estructuras quasiestacionaria que percolan el sistema y pequeños aglomerados móviles, cuya velocidad es inversamente proporcional a su tamaño. El cociente entre la velocidad de desplazamiento de pequeños aglomerados y la velocidad promedio de avance del electrodepósito resulta entonces una magnitud decisiva para determinar el comportamiento del sistema. En las condiciones de este trabajo, la velocidad de electrodeposición depende de la concentración de los iones plata en la solución. En principio, la influencia del gel en la estructura de los electrodepósitos se puede explicar a partir del efecto de bloqueo o "pinning" que produce el medio en el frente de crecimiento.

En la figura 10.21 se muestra un esquema del modelo propuesto para describir el gel, en el cual se produce el avance del frente de crecimiento del electrodepósito de plata.

El estudio de la dinámica de la interfase del electrodepósito por medio de las técnicas de escalado dinámico permite obtener información acerca de la evolución de la 
rugosidad de la interfase en un proceso, en el cual además de modificarse las propiedades de transporte, existen obstáculos distribuidos aleatoriamente. Se plantea la pregunta de saber si la ecuación de KPZ sigue siendo apropiada para describir el movimiento de la interfase.

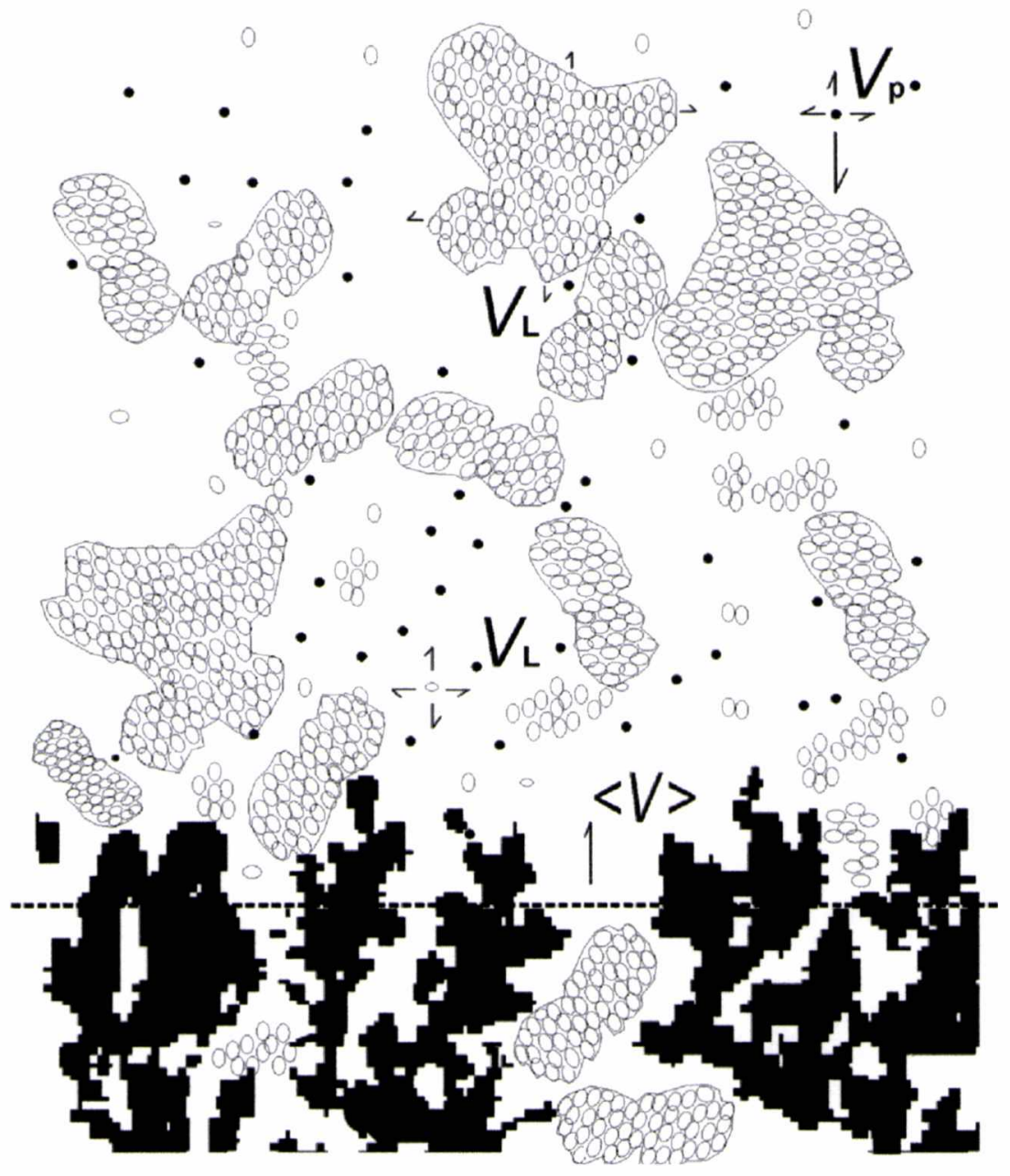

Figure 10.21. Esquema de la electrodeposición de plata en gel de agarosa. Partículas caracterizadas por una amplia distribución de tamaños y velocidades. $\langle\boldsymbol{v}\rangle$ es la velocidad promedio de desplazamiento del frente; $V_{\mathrm{p}}$ es la velocidad de los iones reactivos; $V_{\mathrm{L}}$ indica la velocidad de los aglomerados de agarosa. La línea de trazos indica la altura promedio del frente.

En la figura 10.22 se representan en gráfico doble logarítmico, el ancho de la interfase en función del tiempo y en función del tamaño del sistema, más precisamente, en función del lado de la caja seleccionada dentro de la cual se mide el ancho de la interfase. Se realiza el análisis de escalado dinámico tanto en el gel de preparación "in situ" como "ex situ". En ambos casos se observan comportamientos similares. Los exponentes que resultan de las regiones lineales, son $\beta=1,25 \pm 0,15$ y $\alpha=0,8 \pm 0,1$. 
(a)
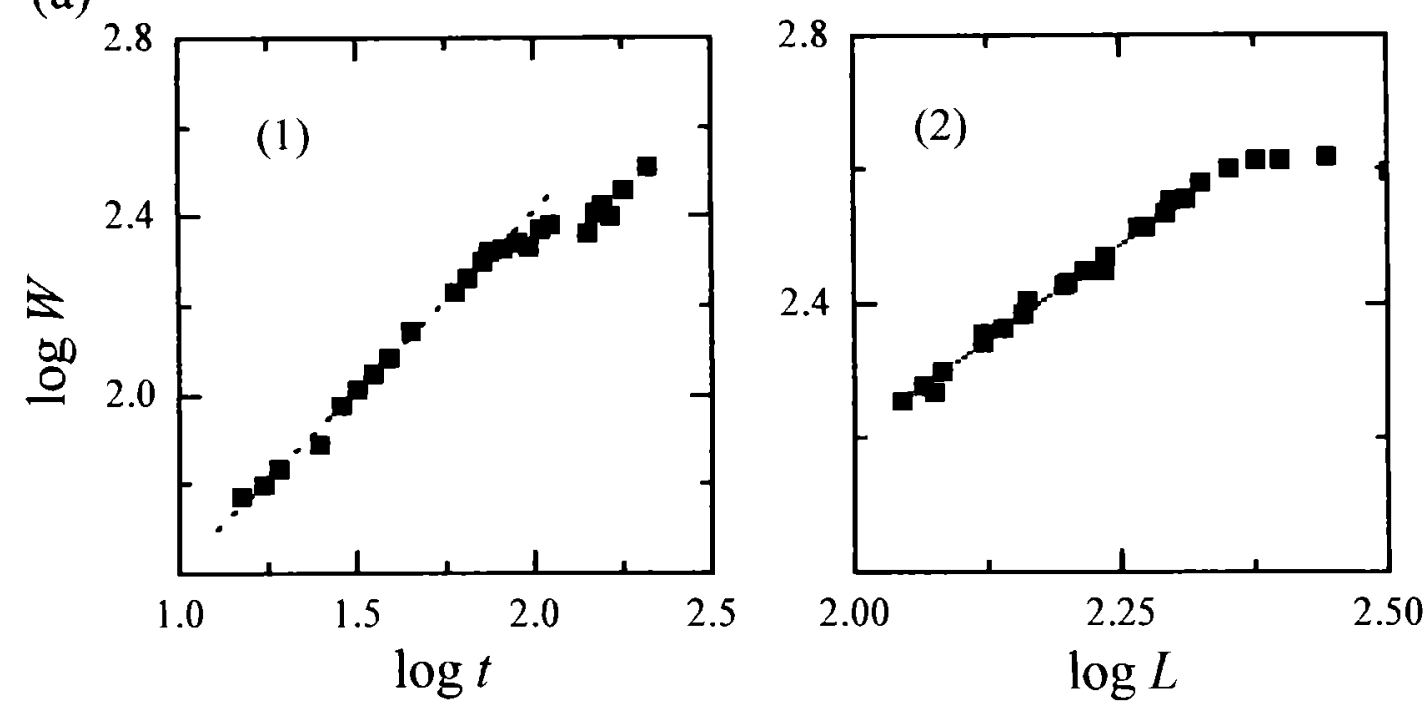

(b)
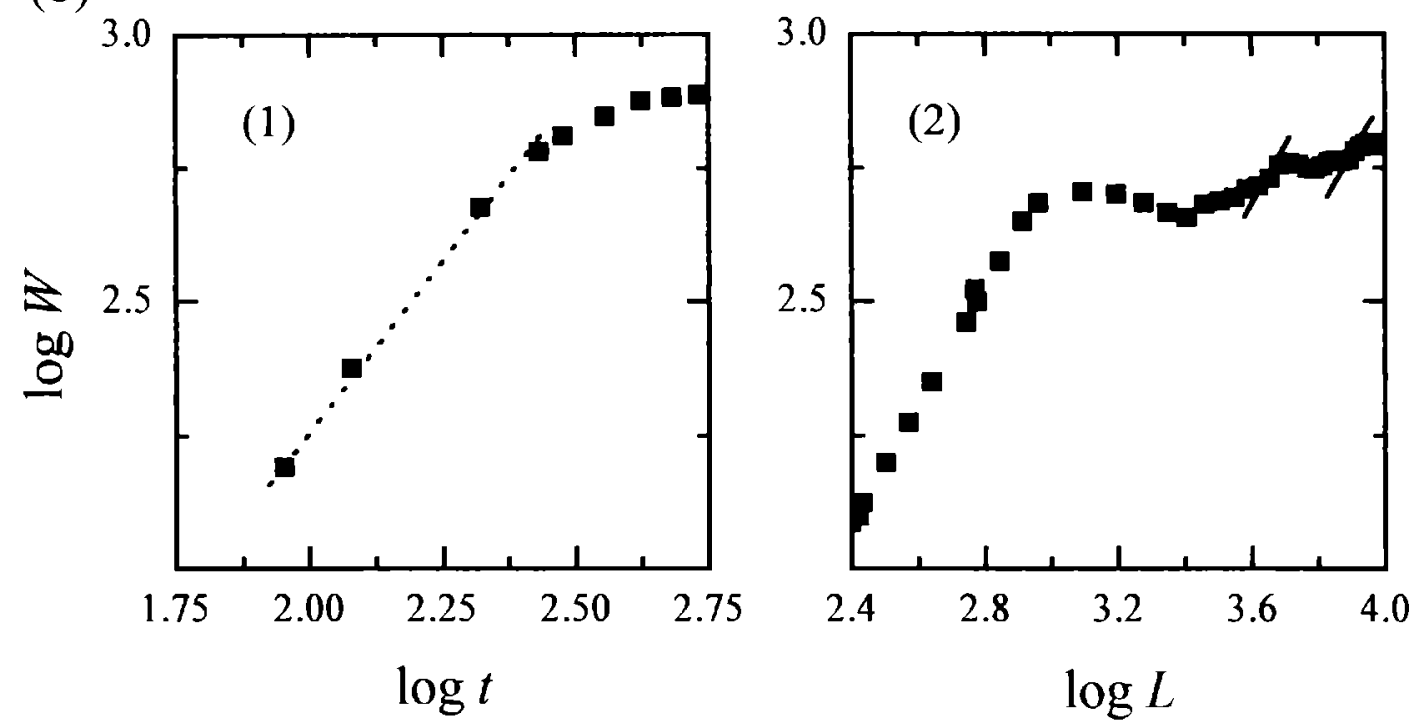

Figura 10.22. Escalado dinámico para electrodepósitos obtenidos en la celda rectangular BV, empleando geles compuestos por sulfato de plata $0,024 \mathrm{M}+$ sulfato de sodio $0,5 \mathrm{M}+$ ácido sulfúrico 0,01 M a $\Delta \mathrm{E}_{\mathrm{c}-\mathrm{a}}=-1,2 \mathrm{~V}$. a) Gel "in situ" . b) Gel "ex situ". 1) Representaciones de $\log W$ versus $\log t$.2) Representaciones de $\log W$ versus $\log L$.

Se desarrollaron un gran número de modelos para describir el avance de la interfase en un medio que presenta obstáculos distribuidos aleatoriamente. En la Tabla 10.2, se resumen los exponentes de escalado para varias dimensiones. La Tabla, que se extrajo de [18] 
Tabla 10.2

Estimaciones numéricas de los exponentes de escalado para el rugosado de la interfase con ruido "congelado" (obstáculos fijos aleatorios). La segunda columna indica la clase de universalidad del modelo. I indica modelo con ruido isotrópico, y DP significa los modelos pertenecientes a la clase de universalidad del modelo de percolación dirigida. Los exponentes pertenecientes a los modelos de "DPD - directed percolation depinning " corresponden a la interfase quieta, estos modelos para la interfase en movimiento dan $\alpha=0,7$.

\begin{tabular}{|c|c|c|c|c|c|c|c|}
\hline Modelo & UC & $d$ & $\alpha$ & $\beta$ & $Z$ & $v$ & $\theta$ \\
\hline DPD & DP & 1 & 0,63 & 0,63 & 1 & 1,733 & 0,636 \\
\hline DPD & DP & 1 & 0,63 & 0,63 & 1 & 1,733 & 0,636 \\
\hline DPD & DP & 1 & 0,63 & - & - & - & - \\
\hline Resistor & DP & 1 & 0,63 & 0,63 & 1,01 & 1,73 & - \\
\hline Parisi & DP & 1 & - & 0,75 & - & - & - \\
\hline RFIM-SS & I & 1 & 1 & - & 1,16 & 1,33 & 0,22 \\
\hline MCR & I & 1 & 0,81 & - & - & 1,30 & - \\
\hline String & I & 1 & 0,97 & - & - & 1,05 & 0,24 \\
\hline Automaton & I & 1 & 1,25 & 0,88 & 1,42 & - & 0,25 \\
\hline Eq. & I & 1 & 0,75 & - & - & - & - \\
\hline Eq. & I & 1 & 1,25 & 0,88 & - & - & - \\
\hline Eq. & I & 1 & 0,72 & 0,61 & 1,16 & - & 0,50 \\
\hline DPD & DP & 2 & 0,48 & 0,41 & 1,16 & 1,06 & - \\
\hline RFIM-SA & I & 2 & 0,67 & - & 1,9 & 0,75 & - \\
\hline RFIM-SS & I & 2 & 1 & - & - & 0,9 & - \\
\hline Automaton & I & 2 & 0,75 & 0,47 & 1,58 & - & 0,65 \\
\hline DPD & DP & 3 & 0,38 & 0,28 & 1,32 & - & - \\
\hline Automaton & I & 3 & 0,35 & 0,2 & 1,75 & - & 0,84 \\
\hline DPD & DP & 3 & 0,27 & 0,18 & 1,50 & - & - \\
\hline
\end{tabular}

Considerando la interfase en movimiento, esto es cuando la fuerza impulsora es mayor que la fuerza de roce proporcionada por los obstáculos distribuidos aleatoriamente, existen cuatro exponentes que caracterizan la interfase. Estos son: el exponente de velocidad $\theta$, el exponente de correlación $v$, el esponente de rugosidad $\alpha$ y el exponente dinámico $Z$. Las leyes de potencia en las que intervienen $\alpha$ y $\beta$ ya fueron mostradas y utilizadas en los capítulos 2 y 8 . Los primeros dos exponentes son característicos del movimiento de una interfase en un medio desordenado. Se tiene que la velocidad de la interfase sigue la ley:

$$
v \propto f^{\theta} \quad, \quad \text { con } f=F_{\mathrm{c}}-F / F_{\mathrm{c}}
$$


siendo $F$ la fuerza impulsora y $F_{\mathrm{c}}$ la fuerza impulsora crítica, por encima de la cual la interfase avanza y debajo de la cual permanece quieta.

Cerca de la transición "pinning - depinning" se define la longitud de correlación $\xi$, como el tamaño característico de los dominios bloqueados por los obstáculos. A medida que la fuerza impulsora se acerca a su valor crítico, $F \rightarrow F_{\mathrm{c}}$, el tamaño de la región bloqueada diverge según:

$$
\xi \propto\left(F-F_{\mathrm{c}}\right)^{-v}
$$

donde $v$ es el exponente de la ley de potencia de la longitud de correlación.

En realidad, el número de exponentes independientes es de tres, pues vale la relación:

$$
0=(Z-\alpha) v
$$

En este trabajo se determinan los exponentes $\alpha$ y $\beta$, que por comparación con aquellos mostrados en la tabla 2 , permiten decir que el avance del electrodepósito de plata en condiciones de corriente límite en geles de agarosa, podría ser descriptos en 2 dimensiones por el modelo del autómata celular o la ecuación KPZ con ruido "congelado" isotérmico.

Si bien, estos experimentos constituyen la primera evidencia experimental de un sistema electroquímico que presenta transición "pinning-depinning", se requiere incrementar la estadística, para confirmar esta interesante conclusión. De esta manera los datos pueden ser útiles en los estudios teóricos relacionados con el movimiento de interfases en medios desordenados. 


\section{CAPITULO 11}

\section{Conclusiones generales}

La electrodeposición de plata en celdas electroquímicas quasi-bidimensionales permite obtener distintas morfologías, según sean las condiciones experimentales, esto es, potencial aplicado, concentración de la especie electroactiva $\mathrm{Ag}^{+}$, concentración y tipo de electrolito soporte, temperatura, condiciones hidrodinámicas y agregado de aditivos.

Los electrodepósitos de plata obtenidos en este trabajo, se pueden clasificar de acuerdo a su morfología en: 1) morfología "tip-splitting"; 2) electrodepósitos aciculares; 3) dendríticos y 4) estructuras densas. Encuentran buen acuerdo con los diagramas morfológicos para el cinc y cobre, que se encuentran en literatura.

La reacción de electrodeposición de plata es una de las reacciones más rápidas conocidas. En las condiciones de este trabajo, la electrodeposición es controlada por transporte de materia, a través de los mecanismos de difusión, migración y convección. La preponderancia de uno u otro mecanismo de transporte es afectada por el agregado o no de electrolito soporte, de aditivos que modifican la estructura del electrolito y por las longitudes características presentes en los electrodepósitos, según estén formados por crecimientos aciculares o estructuras densas con frentes de crecimiento bien definidos.

Las representaciones de los transitorios potenciostáticos de corriente representados como $Q_{d} / I_{\mathrm{c}}$ permiten ver la contribución de los distintos mecanismos de transporte de materia. Esto es válido siempre que se pueda prescindir del conocimiento del área activa del electrodepósito o se conozca la ley de crecimiento de la superficie.

Los electrodepósitos dendríticos y aciculares presentan una punta que puede ser descripta por un paraboloide de revolución que mantiene su forma invariable mientras crece a velocidad constante y no se producen ramificaciones laterales. La corriente en los crecimientos aciculares es inhomogénea, siendo mucho mayor en el ápice que en las caras laterales de la punta. En el ápice de la punta se observan cristales que aparecen y desaparecen continuamente durante el crecimiento. Para las caras laterales vale una descripción similar pero con una población de nuevos cristales considerablemente menor. 
La aplicación de la teoría de estabilidad lineal sugiere que la punta del crecimiento acicular se encuentra en un régimen marginalmente estable, a diferencia de los primeros estadios del crecimiento ramificado, para los que predice un crecimiento inestable.

Las características observadas del crecimiento acicular permiten proponer un mecanismo de electroformación donde luego de una rápida electrodeposición en el ápice, los adiones difunden rápidamente hacia la base de la punta.

Para celdas electroquímicas con $l_{\mathrm{s}}$ (altura del electrodo) $\cong 250 \mu \mathrm{m}$ y para la electrodeposición de plata a potenciales de corriente límite, donde se generan electrodepósitos densos, se prueba la presencia de fenómenos convectivos, con la posible interferencia del avance del frente de crecimiento dentro de la solución electrolítica, causante del proceso de "advection" o en términos más generales, el efecto "Stefan". Se comprueba la validez de la correlación general deducida de la solución de la ecuación de difusión convectiva en coordenadas cartesianas, para situaciones isotérmicas y no isotérmicas. Los datos de este trabajo se comparan con los de la electrodeposición de cobre en medio ácido y con el proceso redox ferri/ferrocianuro de potasio en hidróxido de sodio. Con el uso de celdas tridimensionales y quasi-bidimensionales rectangulares se extiende la validez de la correlación general en más de dos órdenes de magnitud en el número de $G r^{*}$ y $S h$.

Los fenómenos convectivos presentes en la electrodeposición cambian las condiciones de estabilidad del proceso de formación del electrodepósito, favoreciendo la producción de distintos tipos de morfologías y la presencia de transiciones en el modo de crecimiento. Así se encuentra que la aplicación de gradientes de temperatura que pueden generar convección induce $o$ al menos favorece la ocurrencia de transiciones morfológicas.

La incorporación de agarosa en las soluciones de electrodeposición produce cambios significativos en la morfología de los electrodepósitos. La agarosa no modifica la velocidad de la reacción de electrodeposición puesto que prácticamente no se adsorbe sobre la superficie de plata. La acción de la agarosa se puede analizar en términos de dos efectos relevantes. El primer efecto, que es más común, se relaciona con las propiedades hidrodinámicas del sistema. A medida que la concentración de agarosa se incrementa, la viscosidad del medio aumenta y a partir de una cierta concentración se obtienen geles donde la convección natural se elimina. Según se observa en las representaciones $Q_{d} / I_{\mathrm{c}}$ versus $t$. El segundo efecto surge como consecuencia de la estructura desordenada del gel. El electrodepósito crece en un medio desordenado, donde los aglomerados del gel impiden 
el libre desplazamiento del frente de crecimiento. El estudio de la velocidad de desplazamiento del frente del electrodepósito en la electrodeposición en geles preparados con distintas concentraciones de sulfato de plata permite distinguir a una cierta concentración crítica una transición bloqueo-desbloqueo ("pinning-depinning"). En esta transición, la velocidad del frente aumenta abruptamente, acercándose a los valores que se obtienen en la electrodeposición en ausencia de agarosa.

Los electrodepósitos de plata obtenidos en celdas rectangulares quasibidimensionales de geometría rectangular pueden ser caracterizados por la técnica de escalado dinámico y el análisis estadístico de la estructura interna. Para los electrodepósitos densos, se obtiene buen acuerdo entre los dos métodos y permiten asociar al proceso de electroformación el modelo de crecimiento de Kardar-Parisi-Zhang (KPZ) que a través del mapeo a la ecuación hidrodinámica de Burgers, permite ver la importancia de las distintas componentes de velocidad del electrolito en la selección de la morfología.

La reacción de electrodeposición de plata en celdas quasi-bidimensionales es un sistema útil para estudiar la formación de una fase sólida ramificada y estudiar el papel de los mecanismos de transporte y contrastar teorías y modelos de crecimiento. 


\section{BIBLIOGRAFIA}

1. A. J. Bard, L. R. Faulkner, "Electrochemical Methods. Fundamentals and Applications", J. Wiley \& Sons, USA (1980).

2. P. Gallone, "Trattato di Ingegneria Electrochimica" Tamburini Editore, Milano (1973).

3. E. Walsh, M.E. Herren, J Phys. D . Aplied Physics 24, 217 (1991).

4. W. Forker, Elektrochemische Kinetik, Akademie-Verlag-GmbH, Berlin (1976).

5. J. O’M. Bockris, A. K. N. Reddy. “Electroquimica Moderna”, Reverté, España (1980).

6. J. S. Newman, "Electrochemical Systems" segunda ed, Prentice Hall, New Yersey (1991).

7. E. Budevski, G. Staikov, W. J. Lorenz, "Electrochemical Phase Formation and Growth. An Introduction to the initial Stage of Metal Deposition" VCH, New York (1996).

8. R.Winand, P. Van Ham, R. Colin, D. Milojevic, J. Electrochem. Soc. 144, 428 (1997).

9. H. J. Pick, Nature, London, 176, 693 (1955).

10. H. Seiler, H. Fischer, H. Albert, Natuwissensch 45, 127 (1958).

11. M. Pourbaix, "Atlas d'Equilibres Electrochimiques" Gauthier-Villans, Paris, 393 (1963)

12. W. M. Latimer, "The Oxidation State of the Elements and their potentials in Aqueous Solutions", segunda edición, Prentice Hall, New York (1952).

13. A. J. Bard "Encyclopedia of Electrochemistry of the Elements", Marcel Dekker Inc., New York, Vol. VIII (1978).

14. F. Finda, K. Negel, Z. Elecktrochem. 57, 913 (1953).

15. W. Lorenz, Z. Elecktrochem. 59, 730 (1955).

16. H. Gerischer, R. P. Tischer, Z. Elektrochem. 61, 1159 (1957).

17. E. Budevski, W. Bostanov, T,. Vitanov, Z. Stoinov, A. Kotzewa, R. Kaischev, Phys. Status Solidi 13, 577 (1966)

18. A. L. Barabasi, H. E. Stanley, "Fractal Concepts in Surface Growth", Cambridge University Press, Cambridge, England (1995).

19. M. Sander en "Solids far from Equilibrium", C. Godrèche, ed., Cambridge University Press, Cambridge, England (1992).

20. E. Ben-Jacob, P. Garik, T. Mueller, D. Grier, Phys. Rev. A 38, 1370 (1988).

21. L. Niemeyer, L. Pietronero, H. J. Wiesmann, Phys. Rev. Lett. 52, 1033 (1984). 
22. R. Tamamushi, H. Koneko, J. Electrochem. Soc. ， 391 (1980).

23. P.P. Trigueros, F. Sagués, J. Claret, Phys. Rev. E. 49, 4328 (1994).

24. Y. Sawada, A. Dougherty, J. P. Gollub, Phys Rev. Lett. 56, 1260 (1986).

25. D. G. Grier, D. A. Kessler, L. M. Sander, Phys. Rev. Lett. 59, 2315 (1987).

26. D. P. Barkey, P. Garik, E. Ben-Jacob, B. Miller, B. Orr, J. Electrochem. Soc. 139, 1044 (1992).

27. P. L. Schilardi, Tesis Doctoral, Universidad Nacional de La Plata, (1996).

28. M. Matsushita, Y. Hayakawa, H. Honjo Y. Sawada, Phys. Rev. Lett. 53, 286 (1984).

29. R. Messier, J. E. Yehoda, J. Appl. Phys. 58, 3739 (1985).

30. T. M. Mayer, E. Chasar, A. J. Howard, J. Appl. Phys. 76, 1633 (1994).

31. P. Hensen, A. -L. Barabási, H. Larralde, S. Havlin, H. E. Stanley, Phys. Rev. E 50, 618 (1994).

32. S. V. Buldyrev, A. Goldeberger, S. Havlin, C. K. Peng, H. E. Stanley, "Fractals in Biology and Medicine. From DNA to the Heartbeat" en "Fractal Science", A. Bunde, S. Havlin, ed., Springer-Verlag, Berlin, 1994.

33. F. Family, T. Vicsek, J. Phys. A 18, L75 (1985).

34. H. J. Herrmann, H. E. Stanley, J. Phys. A. 21, L829 (1988).

35. F. Family, J. Phys. A 168, 561 (1992).

36. T. Hwa, M. Kardar, Phys. Rev. A 75, 7002 (1992).

37. S. F. Edwards, D. R. Wilkinson, Proc. R. Soc. London A 309, 17 (1982).

38. M. Kardar, G. Parisi, Y. -C. Zhang, Europhys Lett. 56, 889 (1986).

39. T. A. Witten, L. M. Sander, Phys. Rev. Lett. 47, 1400 (1984).

40. P. Meakin, J. Phys. A 18, L661 (1985).

41. R. C. Ball, M. M. Brady, J. Phys. A 18, L809 (1985).

42. Y. Hayakawa, H. Kondo, M. Matsushita, J. Physical Soc. of Japan 55, 2479 (1986).

43. F. Sagués, F. Mas, M. Vilarrasa, J. M. Costa, J. Electroanal. Chem. 278, 351 (1990).

44. D. Grier, E. Ben-Jacob, R. Clarke, L. M. Sander, Phys. Rev. Lett. 66, 177 (1991).

45. J. Nittman, G. Daccord, H. E. Stanley, Nature 314, 141 (1985).

46. E. Ben- Jacob, R. Godbey, N. D. Goldenfeld, J. Koplik, H. Levine, T. Mueller, L. M. Sander, Phys. Rev. Lett. 55, 1315 (1985).

47. A. Buka, J. Kertez, T. Vicsek, Nature 323, 424 (1986).

48. S. N. Rauseo, P. D. Barnes, J. U. Maker, Phys. Rev. A 35, 1245 (1987).

49. B. B. Mandelbrot, "The Fractal Geometry of Nature", Freeman, New York (1975).

50. A. Bunde, S. Havlin, "Fractals and Disordered Systems" Springer-Verlag (1991). 
51. D. Avnir, "The Fractal Approach to the Hetorogeneous Chemistry" J. Wiley \& Sons, New York (1989).

52. J. A. Koanorp, "Fractal modelling. Growth and Form in Biology" Springer-Verlag (1994).

53. H. A. Makse, S. Havlin, H. E. Stanley, "Modelling Urban Growth Patterns" Nature 377,608 (1995).

54. E. Maletsky, T. Perciante, L. Yunker, "Fractalsfor the classroom". Part one "Introduction to Fractals and Chaos", Springer - Verlag, USA, (1992).

55. J. Saimos, P. Pfeifer, V. Mittag, M. Obert, T. Dorfmueller, Chemical Phys. Lett. 128, 545 (1986).

56. M. Matsushita, Y. Hayakawa, Y. Sawada, Phys. Rev. A 32, 3814 (1985).

57. R. J. Lead, K. Starckev, J. K. Wilkinson, Environ. Sci. Technol. 37, 482 (2003).

58. M. Ferree, D. H. Smith, Phys. Rev. E 49, 4114 (1994).

59. M. A. Rubio, C. A. Edwards, A. Dougherty, J. P. Gollub, Phys. Rev. Lett. 63, 1685 (1989).

60. S. He, G. L. M. K. S. Kahanda, P-Z Wong, Phys. Rev. Lett. 69, 3731 (1992).

61. P. Meakin, A. Birovljev, V. Frette, J. Feder, T. Jossang, Physica A 191, 227 (1992).

62. S. V. Buldyrev, A.-L. Barabási, S. Havlin, J. Kertész, H. E. Stanley, H. S. Xenias, Physica A 191, 220 (1991).

63. S.V. Buldyrev, A.-L. Barabási, F. Caserta, S. Havlin, H.E. Stanley, T. Vicsek, Phys. Rev. $A$ 45, $\mathrm{R} 8313$ (1992).

64. J. Zhang, Y.-C. Zhang, P. Alstrom, M. T. Levinsen, Physica A 189, 383 (1992).

65. R. Bruinsma, G. Acppli, Phys. Rev. Lett. 52, 1547 (1984).

66. E. Medina, T. Hwa, M. Kardar, Y. -C. Zhang, Phys. Rev. A 39, 3053 (1989).

67. C.-H. Lam, L. M. Sander, Phys. Rev. Lett. 69, 3338 (1992).

68. H. Horváth, F. Family, T. Vicsek, J. Phys. A 24, L 25 (1991).

69. L-H. Tang, M. Kardar, D. Dhar, Phys. Rev. Lett. 74, 920 (1995).

70. W. Kinzel in "Fractals and Disordered Systems", A. Bunde, S. Havlin, eds., Springer, Heidelberg (1991).

71. L. -H. Tang, H. Leschhorn, Phys. Rev. A 45, R8309 (1992).

72. H. Leschhorn, L-H Tang, Phys. Rev. E 49, 1238 (1994).

73. Z. Olami, I. Procaccia, R. Zeitak, Phys. Rev. E 49, 1232 (1994).

74. R. M. Brady, R. C. Ball, Nature 309, 225 (1984).

75. G. L. M. K. S. Kahanda, M. Tomkiewicz, J. Electrochem. Soc. 136, 1497 (1990). 
76. G. L. M. K. S. Kahanda, M. Tomkiewicz, J. Electrochem. Soc. 137, 3423 (1990).

77. Chao-Peng Chen, J. Jorné, J. Electrochem. Soc. 137, 2047 (1990).

78. D. P. Barkey, en "Advances in Electrochemical Science and Engineering", R. C. Alkire, D. M. Kolb, Wiley-VHC-Verlag, Germany, Vol 7, (2002).

79. D. P. Barkey, P. D. La Porte, J. Electrochem. Soc. 137, 1655 (1990).

80. D. P. Barkey, J. Electrochem. Soc. 137, 1655 (1990).

81. E. Ben-Jacob, P. Garik, D. Grier, Superlattice Microestruct. 3, 599 (1987).

82. Y. Sawada, H. Hyosu, Physica D, 38, 299 (1989).

83. V. Fleury, M. Rosso, J. -N. Chazalbiel, B. Sapoval, Phys. Rev. A 44, 6693 (1991).

84. D. G. Grier, D. A. Kessler, L. M. Sander, Phys. Rev. Lett. 59, 2315 (1987).

85. L. M. Sander en "The Physics of Structure Formation" W. Guttinger, G. Dangelmayer Eds., Springer Verlag, Berlin (1987).

86. J. R. Melrose, D. B. Hibbert, R. C. Ball, Phys. Rev. Lett. 65, 3009 (1990).

87. F. Argoul, A. Arneodo, J. Elesgaray, A. Kuhn, Fractals 5, 75 (1997).

88. P. Garik, D. Barkey, E. Ben-Jacob, E. Bochner, N. Broxholm, B. Miller, B. Orr, R. Zamir, Phys. Rev. Lett. 62, 2703 (1989).

89. Y. Fukunaka, T. Yamamoto, Y. Kondo, J. Electrochem. Soc. 136, 3630 (1989).

90. R. H. Cork, D. C. Pritchard, W. Y. Tam, Phys. Rev. A 44, 6940 (1991).

91. D. P. Barkey, D. Watt, Z. Liu, S. Raber, J. Electrochem. Soc. 141, 1206 (1994).

92. M. Rosso, J. -N. Chalzabiel, V. Fleury, E. Chassaing, Electrochim. Acta 39, 507 (1994).

93. J. M. Huth, H. L. Swinney, W. D. McCormick, A. Kuhn, F. Argoul, Phys. Rev. E 51, 3444 (1994).

94. P. Bruinsma, S. Alexander, J. Chem. Phys. 92, 3074 (1990).

95. V. Fleury, J. H. Kaufman, D. B. Hibbert, Nature 367, 435 (1994).

96. V. Fleury, J.-N. Chazalbiel, M. Rosso, Phys. Rev. E 48, 1279 (1993).

97. J. M. Huth, H. L. Swinney, Y. William, D. MacCormick, Phys. Rev. E 51, 3444 (1995).

98. F. Argoul, E. Freysy, A. Kuhn, C. Léger, L. Potin, Phys. Rev. E 53, 1777 (1996).

99. G. Marshall, P. Mocskos, Phys. Rev. E. 55, 549 (1997).

100. M. Wang, W. J. P. Van Enckevort, N. -ben Ming, P. Bennema, Nature 367, 438 (1996).

101. K. -Q. Zhang, M. Wang, S. L. Zhang, G. -Xin Chen, N.-ben Ming, Phys. Rev E 61, $5512(2000)$.

102. C. Léger, J. Elesgaray, F. Argoul, Phys. Rev. Lett. 78, 5010 (1997). 
103. J. Elesgaray, C. Léger, F. Argoul, Phys. Rev. Lett. 84, 3129 (2000).

104. J. R. De Bruyn, Phys. Rev. E 53, R 5561 (1996).

105. J. Elesgaray, C. Léger, F. Argoul, J. Electrochem. Soc. 145, 2016 (1998).

106. M. Schroter, K. Kassner, I. Rehberg, J. Claret, F. Sagués, Phys. Rev. E 65, 041607 (2002).

107. M. Wang, S. Zhong, X. -B. Yin, J. -M. Zhu, R. -W. Peng, Y. Wang, K. -Q. Zhang, N. -B. Ming, Phys. Rev. Lett. 17, 3827 (2001).

108. M. E. Cliksman, M. B. Koss, E. A. Winsa, J.O.M (The Minerals, Metals and materials Society) 47, 49 (2001).

109. M. Wang, N. -B Ming, Phys. Rev Lett. 71, 113 (1993).

110. D. B. Hibbert, J. R. Melrose, Phys. Rev. A 38, 1036 (1988).

111. N. Ibl, O. Dossenbach, in "Comprehensive Treatise of Electrochemistry", E. Yeager, J. O’M. Bockris, B. E. Conway, R. Sarangapani, eds., Plenum Press, Vol. 6, Ch. 3, New York (1983).

112. D. A. Vermilyea, Nature 1, 814 (1957).

113. P. B. Price, D. A. Vermilyea, M. B. Webb, Acta Metallurgica 6, 524 (1958).

114. R. V. Coleman, Met. Rev. 9, 261 (1964).

115. R. H. Doremus, B. W. Roberts, D. Turnbul, "Growth and Perfection Crystals" J. Wiley, New York, p. 85 (1958).

116. A. V. Bondarenko, Electrochim. Acta 29, 87 (1984).

117. M. I. Shihara, H. Yumoto, K. Akashi, K. Kamei, Mat. Science and Engineering D38, 150 (1996).

118. J. Franks, Nature 6, 1777 (1976).

119. K. J. Vetter, "Electrochemical Kinetics. Theoretical and experimental aspects", Academic Press, London (1964).

120. M. A. Pasquale, S. L. Marchiano, J. M. Vicente, A. J. Arvia, (enviado para ser publicado en el J. of Physical Chemistry B).

121. P. Delahay "New Instrumental Methods in Electrochemistry", 3ra. Edición, Interscience, New York (1961).

122. D. Kinderlehrer, L. Nirenberg en "Moving Boundary Problems" P.G. Wilson, A. D. Solomon, P. T. Boggs Eds., Ac. Press, New York, (1978).

123. J. W. Diggle, A. R. Despic, O’ M. Bockris, J. Electrochem. Soc. 116, 1503 (1969).

124. W. W. Mullins, R. F. Sekerka, J. Appl. Phys. 34, 323 (1963).

125. W. W. Mullins, R. F. Sekerka, J. Appl. Phys. 35, 444 (1964). 
126. J. A. Mc Geough, H. Rasmussen, J. Mech. Eng. Sci. 18, 271 (1976).

127. R. Aogaki, K. Kitazawa, Y. Kose, K. Fukei, Electrochim. Acta 25, 965 (1980).

128. R. Aogaki, T. Makino, Electrochim. Acta 26, 1509 (1981).

129. R. Aogaki, T. Makino, J. Electrochem. Soc. 129, 442 (1982).

130. R. Aogaki, T. Makino, J. Electrochem. Soc. 129, 2447 (1982).

131. Ch. P- Chen, J. Jorne, J. Electrochem. Soc. 138, 3305 (1991).

132. T. Makino, R. Aogaki, E. Niki, J. Chem. Phys. 81 , 5145 (1984).

133. U. Landau, EPRI Report EM-2393, EPRI, Research Report Center, Palo Alto, California, (1982).

134. D. P. Barkey, R. H. Muller, C. W. Tobias, J. Electrochem Soc. 136, 2199 (1989).

135. D. P. Barkey, R. H. Muller, C. W. Tobias, J. Electrochem Soc. 136, 2207 (1989).

136. S. R. Corriel, G. B. McFadden, "Morphological Stability" en "Handbook of Crystal Growth" D. Hurle Ed., Cap. 12, (1993).

137. D. W. Hoffman, Y. Cahn, Surf. Sci. 31, 368 (1972).

138. W. Oldfield, mater Sci. Eng. 11, 211 (1973).

139. J. S. Langer, H. Mueller-Kumbhaar, J. Cryst. Growth 42, 11 (1977).

140. J. S. Langer, H. Mueller-Kumbhaar, Acta Metall. 26, 1681 (1978).

141. J. S. Langer, H. Mueller-Kumbhaar, Acta Metall. 26, 1689 (1978).

142. J. S. Langer, Rev. Modern. Phys. 52, 1 (1980).

143. J. A. Warren, J. S. Langer, Phys. Rev. A 42, 2702 (1990).

144. J. A. Warren, J. S. Langer, Phys. Rev. E 47, 3518 (1993).

145. S. R. Corriel, G. B. McFadden, P. W. Voorhees, R. F. Sekerka, J. Crystal Growth 82, 295 (1987).

146. G. P. Ivantsov, Dokl. Akad. Nauk. S.S.S.R. 558, 567 (1947).

147. M. E. Glicksman, S. P. Marsh, "The Dendrite" en "Handbook of Crystal Growth", D. T. J. Hurle, ed., Cap. 15 (1993).

148. D. E. Temkin, Dokl. Akad. Nauk. S.S.S.R. 132, 1307 (1960).

149. G. B. McFadden, S. R. Corriel, R. F. Sekerka, Acta Mater. 48, 3177 (2000).

150. S. -C. Huang, M. E. Glicksman, Acta Mettallurgica 29, 701 (1981).

151. D. A. Kessler, J. Koplik, H. Levine, Adv. Phys. 37, 255 (1988).

152. T. Kuroda, R. Lacmam, J. of Crystal Growth 56, 189 (1982).

153. M. Muschol, D. Liu, H. Z. Cummins, Phys. Rev. A 46, 1038 (1992).

154. R. Trivedi, J. of Crystal Growth 48, 93 (1980).

155. W. D. Luedtke, U. Landman, J. Phys. Chem. 32, 13324 (1996). 
156. S. C. Wang, U. Kurpick, G. Ehrlich, Phys. Rev. Lett. 22, 4923 (1998).

157. Z. Karaoglanoff, Z. Electrochem. 12, 5 (1906).

158. S. L. Marchiano, A. J. Arvia, Electrochim. Acta 13, 1657 (1968).

159. A. J. Arvia, S. L. Marchiano, "Los Fenómenos de transportes en electroquímica" UNLP, (1972).

160. M. Orlik, Phys. Chem. Chem. Phys. 1, 5359 (1999).

161. A. P. Grigin, A. D. Davydov, Russian J. of Electrochemistry 34, 111 (1998).

162. A. P. Grigin, A. D. Davydov, Russian J. of Electrochemistry 34, 68 (1998).

163. C. Wagner, J. Electrochem. Soc. 104, 129 (1957).

164. V. G. Levich, "Physicochemical Hydrodynamics" Prentice Hall, Englewood Cliff (1962).

165. F. Alavyoon, Electrochim. Acta 37, 333 (1992).

166. F. H. Bark, F. Alavyoon, Appl. Sci. Res.53, 11 (1994).

167. Y. Fukunada, Y. Kondo, Electrochim. Acta, 26, 1537 (1981).

168. V. M. Volgin, A. D. Davydov, Russian J. of Electrochemistry 37, 1197 (2001).

169. J. Leddy, C. G. Zoski, J. Electroanal. Chem. 543, 13 (2003).

170. E. Somers, J. Appl. Mech. 23, 205 (1956).

171. S. R. De Groot, P. Mazur, "Non-equilibrium Thermodynamics", North Holland, Amsterdam (1962).

172. G. R. Engelhardt, S. Nilvov, D. D. McDonald, J. Electrochem. Soc. 429, 193 (1997).

173. W. G. Mathers, A. J. Madden, E. L. Piret, Ind. Eng. Chem. 49, 961 (1957).

174. F. H. Bark, Y. I. Kahrkats, R. Wedia, Russian J. of Electrochemistry 34, 393 (1998).

175. J. S. Newman, W. Tiedemann, J. Electrochem. Soc. 142, 1054 (1995).

176. J. L.Valdes, B. Miller, J. Phys. Chem. 92, 525 (1988).

177. G. C. Barker, A. W. Gardner, J. Electroanal. Chem. 65, 95 (1975).

178. Y. Harima, S. Aoyagui, J. Electroanal. Chem.69, 419 (1976).

179. Y. Harima, S. Aoyagui, J. Electroanal. Chem. 81, 47 (1977)

180. S. L. Marchiano, A. J. Arvia, Electrochim. Acta 14, 741 (1969).

181. I. Citti, O. Aaboubi, J. P. Chopart, E. Merienne, A. Olivier, Electrochim. Acta 41, 2731 (1996).

182. Z. A. Rotenberg, E. O. Zonina, Russ. J. Electrochem. 35, 395 (1999).

183. C. Gabrielli, M. Keddam. J. F. Lizee, J. Electroanal. Chem. 148, 293 (1983).

184. "International Critical Tables", Vol. III and V. McGraw-Hill, New York (1928). 
185. J. A. De Leeuw den Bouter, B. De Munnik, P. M. Heerties, Chem. Eng. Sci. 23 (1968) 1185.

186. P. Novak, I. Rousar, Collect. Czech. Chem. Commun. 48, 2213 (1979).

187. W. Huang, D.B. Hibbert, Phys. Rev. E 53, 727 (1996).

188. P. L. Schilardi, R. C. Salvarezza, A. J. Arvia, Phys. Rev. B 59, 4639 (1999).

189. P. Meakin, Phys. Rev. B. 30, 4207 (1984).

190. M. Matsushita, P. Meakin, Phys. Rev. A 37, 3645 (1988).

191. F. Romá, C. M. Horowitz, E. V. Albano, Phys. Rev. E 66, 066115 (2002).

192. Z. Racz, T. Vicsek, Phys. Rev. Lett. 51, 2382 (1983).

193. D. A. Rees, E. D. Morris, D. Thon, J. K. Madden en "The Polysaccharides"; G.O. Aspinall ed., Academic Press, New York, Vol I, Ch. 5, p. 195 (1982).

194. S.Arnott, A. Fulmer, W. E. Scott, J. Mol. Biol. 90, 269 (1974).

195. D. A. Rees, E. J. Welsh, Angew. Chem. Int. Eng. Edition 16, 214 (1977).

196. J. M. Gavira Ruiz, M. L. Novella, R. Moreno, J. A. Gavira, J. Crystal Growth 232, 165 (2001).

197. P. Carro, S. L. Marchiano, A. Hernandez Creus, S. Gonzáles, R. C. Salvarezza, A. J. Arvia, Phys, Rev. E. 48, R2374 (1993).

198. A. Hernandez Creus, P. Carro, S. Gonzáles, S. L. Marchiano, R. C. Salvarezza, A. J. Arvia, Fractals in the Natural and Applied Sciences A-41, 141 (1994).

199. P. Carro, S. Ambrosolio, S. L. Marchiano, A. Hernandez Creus, R. C. Salvarezza, A. J. Arvia, J. Electroanal. Chem. 396, 183 (1995).

200. A. Bewick, B. Thomas, J. Electroanal Chem. 150, 59 (1977).

201. J. A. Bort, K. Juettner, W. J. Lorenz, E. Schmidt, J. Electroanal. Chem. 90, 413 (1978)

202. K. Juettner, Electrochim. Acta 31, 917 (1986).

203. E. Schmidt, H. Siegenthaler, J. Electroanal. Chem. 150, 59 (1983).

204. A. Popov, N. Dimitrov, O. Velev, I. Vitanov, E. Budevski, E. Schmidt, H. Siegenthaler, Electrochim. Acta 334, 265 (1989).

205. A. H. Creus, P. Carro, S. Gonzáles, R. C. Salvarezza, A. J. Arvia, J. Electrochem. Soc. $142,3806(1995)$.

206. A. S. Perlin and B. Casu, en "The Polysaccharides", G. O. Aspinall, ed., Academic Press, New York, Vol. I, Ch.4, p. 182 (1982).

207. B. Casu, M. Reggiani, G. G. Gallo, A. Vigevani, Tetrahedron 22, 3061 (1966). 
208. Billingham "Molar Mass Measurement in Polymer Science", Kogan Page, London (1977).

209. H. Lerner, J. Giner, J. Soeldner, C. Colton, J. Electrochem. Soc. 126, 237 (1979).

210. A. E. M. Skour, Electrochim. Acta 22, 313 (1977).

211. J. J. Christensen, J. Howard Rytting, R. M. Izett, J. Chem. Soc. London B 1646 (1970).

212. M. L. B. Rao, R. F. Drake, J. Electrochem. Soc. 116, 334 (1969).

213. S. Ernst, J. Heitbaum, C. Hamann, J. Electroanal. Chem. 100, 173 (1979).

214. M. F. L. de Mele, H. A. Videla, A. J. Arvia, J. Electrochem. Soc. 129, 2207 (1982).

215. D. A. Rees, E. D. Morris, D. Thom, J. K. Madden, en "The Polysaccharides", G. O. Aspinall ed., Academic Press, New York, Vol I, Ch. 5, 195 (1982).

216. M. F. L. de Mele, H. A. Videla, A. J. Arvia, Bioelectrochem. Bioenerg. 9, 469 (1982).

217. G. A. Griess, E. T. Moreno, R. A. Eason, P. Serwer, Biopolymers 28, 1475 (1989).

218. T. K. Attwood, B. J. Nelmes, D. B. Sellen, Biopolymers 27, 201 (1988).

219. G. A. Griess, Biopolymers 28, 1475 (1989).

220. K. Starchev, J. Sturm, G. Weill, C.-H. Brogen, J. Phys. Chem. B 101, 5659 (1997).

221. K. A. Fergunson, Metabolism 13, 985 (1964). 


\section{$\underline{\text { Apéndice A }}$}

Ecuaciones para el diagrama de Pourvaix

1. $\mathrm{Ag}^{+}+\mathrm{H}_{2} \mathrm{O}=\mathrm{AgO}^{-}+2 \mathrm{H}^{+}$

$\log \left(\left[\mathrm{AgO}^{-} / \mathrm{Ag}^{+}\right]\right)=-24,04+2 \mathrm{pH}$

2. $\mathrm{Ag}^{2+}+\mathrm{e}=\mathrm{Ag}^{+}$

$\mathrm{E}^{\circ}=1,980+0,0591 \log \left(\left[\mathrm{Ag}^{2+} / \mathrm{Ag}^{+}\right]\right)$

3. $\mathrm{AgO}^{+}+2 \mathrm{H}^{+}+2 \mathrm{e}=\mathrm{Ag}^{+}+\mathrm{H}_{2} \mathrm{O}$

$\mathrm{E}^{\circ}=1,998+0,0591 \mathrm{pH}+0,0295 \log \left(\left[\mathrm{AgO}^{+} / \mathrm{Ag}^{+}\right]\right)$

4. $\mathrm{AgO}^{+}+2 \mathrm{e}=\mathrm{AgO}^{-}$

$\mathrm{E}=1,288+0,0295 \log \left(\left[\mathrm{AgO}^{+} / \mathrm{AgO}^{-}\right]\right)$

5. $\mathrm{AgO}^{+}+2 \mathrm{H}^{+}+\mathrm{e}=\mathrm{Ag}^{2+}+\mathrm{H}_{2} \mathrm{O}$

$\mathrm{E}=2,016-0,1182 \mathrm{pH}+0,0591 \log \left(\left[\mathrm{AgO}^{+} / \mathrm{Ag}^{+}\right]\right)$

1'. $\mathrm{Ag}^{+} / \mathrm{AgO}^{-} \quad \mathrm{pH}=12,02$

2'. $\mathrm{Ag}^{+} / \mathrm{Ag}^{+} \quad \mathrm{E}=1,980$

3'. $\mathrm{Ag}^{+} / \mathrm{AgO}^{+} \quad \mathrm{E}=1,998-0,0591 \mathrm{pH}$

4'. $\mathrm{AgO}^{-} / \mathrm{AgO}^{+} \quad \mathrm{E}=1,288$

5'. $\mathrm{Ag}^{2+} / \mathrm{AgO}^{+} \quad \mathrm{E}=2,016-0,1182 \mathrm{pH}$

6. $\mathrm{Ag}_{2} \mathrm{O}+2 \mathrm{H}^{+}+2 \mathrm{e}=2 \mathrm{Ag}+\mathrm{H}_{2} \mathrm{O}$

a. $\mathrm{E}^{\circ}=1,173-0,0591 \mathrm{pH}$

b. $\mathrm{E}^{\circ}=1,505-0,0591 \mathrm{pH}$

7. $2 \mathrm{AgO}+2 \mathrm{H}^{+}+2 \mathrm{e}=\mathrm{Ag}_{2} \mathrm{O}+\mathrm{H}_{2} \mathrm{O}$

a. $\mathrm{E}^{\circ}=1,398-0,0591 \mathrm{pH}$

b. $E^{\circ}=1,066-0,0591 \mathrm{pH}$

8. $\mathrm{Ag}_{2} \mathrm{O}_{3}+2 \mathrm{H}^{+}+2 \mathrm{e}=2 \mathrm{AgO}+\mathrm{H}_{2} \mathrm{O}$

$\mathrm{E}^{\circ}=1,569-0,0591 \mathrm{pH}$

9. $2 \mathrm{Ag}^{+}+\mathrm{H}_{2} \mathrm{O}=\mathrm{Ag}_{2} \mathrm{O}+2 \mathrm{H}^{+}$

a. $\log \left[\mathrm{Ag}^{+}\right]=6,33-\mathrm{pH}$

b. $\log \left[\mathrm{Ag}^{+}\right]=11,95-\mathrm{pH}$

10. $\mathrm{Ag}_{2} \mathrm{O}+\mathrm{H}_{2} \mathrm{O}=2 \mathrm{AgO}^{-}+2 \mathrm{H}^{+}$

a. $\log \left[\mathrm{AgO}^{-}\right]=-17,72+\mathrm{pH}$

b. $\log \left[\mathrm{AgO}^{-}\right]=-12,10+\mathrm{pH}$ 
11. $\mathrm{Ag}^{2+}+\mathrm{H}_{2} \mathrm{O}=\mathrm{AgO}+2 \mathrm{H}^{+}$

$\log \left[\mathrm{Ag}^{2+}\right]=-3,53-\mathrm{pH}$

12. $2 \mathrm{AgO}^{+}+\mathrm{H}_{2} \mathrm{O}=\mathrm{Ag}_{2} \mathrm{O}_{3}+2 \mathrm{H}^{+}$

$\log \left[\mathrm{AgO}^{+}\right]=-11,10-\mathrm{pH}$

13. $\mathrm{Ag}^{+}+\mathrm{e}=\mathrm{Ag}$

$\mathrm{E}^{\circ}=1,569-0,0591 \log \left[\mathrm{Ag}^{+}\right]$

14. $\mathrm{AgO}^{-}+2 \mathrm{H}^{+}+\mathrm{e}=\mathrm{Ag}+\mathrm{H}_{2} \mathrm{O}$

$\mathrm{E}^{0}=2,220-0,1182 \mathrm{pH}+0,0591 \log \left[\mathrm{AgO}^{-}\right]$

15. $\mathrm{AgO}+2 \mathrm{H}^{+}+\mathrm{e}=\mathrm{Ag}^{+}+\mathrm{H}_{2} \mathrm{O}$

$\mathrm{E}^{0}=1,772-0,1182 \mathrm{pH}+0,0591 \log \left[\mathrm{Ag}^{+}\right]$

16. $\mathrm{AgO}+\mathrm{e}=\mathrm{AgO}^{-}$

$\mathrm{E}^{0}=0,351-0,0591 \log \left[\mathrm{AgO}^{-}\right]$

17. $\mathrm{Ag}_{2} \mathrm{O}_{3}+6 \mathrm{H}^{+}+4 \mathrm{e}=2 \mathrm{Ag}^{+}+3 \mathrm{H}_{2} \mathrm{O}$

$\mathrm{E}^{0}=1,670-0,0886 \mathrm{pH}-0,0295 \log \left[\mathrm{Ag}^{+}\right]$.

18. $\mathrm{Ag}_{2} \mathrm{O}_{3}+2 \mathrm{H}^{+}+4 \mathrm{e}=2 \mathrm{AgO}^{-}+\mathrm{H}_{2} \mathrm{O}$

$\mathrm{E}^{0}=0,960-0,0295 \mathrm{pH}-0,0295 \log$ [AgO'].

19. $\mathrm{Ag}_{2} \mathrm{O}_{3}+6 \mathrm{H}^{+}+2 \mathrm{e}=2 \mathrm{Ag}^{2+}+3 \mathrm{H}_{2} \mathrm{O}$

$\mathrm{E}^{0}=1,360-0,1773 \mathrm{pH}-0,0591 \log \left[\mathrm{Ag}^{2+}\right]$. 


\section{Apéndice B}

\section{$\underline{\text { Sensores de temperatura }}$}

Los sensores de temperaturas son transductores que ante un cambio de temperatura, producen una variación en alguna magnitud que se puede medir electrónicamente, como la resistencia o voltage de salida. Los sensores de temperatura más comunes son:

I) Resistencias detectoras de temperatura

II) Termistores NTC

III) Termocuplas

IV) Sensores a base de semiconductores de silicio.

Resistencias detectoras de temperatura RTD: pueden ser cables o láminas metálicas que presentan cambios en la resistencia cuando varía la temperatura. Dentro de esta categoría se encuentran metales como el cobre, níquel o níquel-acero y platino. Este último es el más conveniente debido a su respuesta lineal, reproducibilidad y estabilidad. Incluso las resistencias de platino constituyen los sensores utilizados como instrumentos de transferencia de los valores térmicos de referencia internacionales.

En los últimos años se ha mejorado la tecnología de los cubrimientos inertes que protegen a los sensores de posibles contaminaciones en ambientes químicamente agresivos que deteriorarían la estabilidad de las termoresistencias. Esto los convierte en los sensores más apropiados en muchas situaciones.

Termistores: son compuestos cerámicos de óxidos metálicos, son de bajo costo y son los instrumentos más sensibles a las variaciones de temperatura. Sin embargo, son sensores que no poseen una respuesta lineal con la temperatura y tienen un coeficiente de temperatura negativo. Los termistores se presentan en distintos tamaños, distintas resistencias de base y provistos de curvas de calibración intercambiables para cada familia de termistores. La intercambiabilidad de un sensor indica que tan bien se ajustan a la curva de calibración establecida para un determinado tipo de sensor. Los termistores de calidad poseen una tolerancia de intercambiabilidad de $\pm 0,2$ a $0,05{ }^{\circ} \mathrm{C}$ y depende de la temperatura a la que se encuentran. Sin embargo, estos termistores en particular, son más caros que las termoresistencias de platino.

Los termistores aprovechan propiedades eléctricas reproducibles de estructuras moleculares sólidas como la espinela. Se obtienen mezclando proporciones variables de 
óxidos metálicos para obtener la resistencia apropiada. Los termistores de YSI, pueden ser de tres tipos: B, que poseen la composición básica constituida por dos óxidos y permiten obtener resistencias de base a $25^{\circ} \mathrm{C}$ que van entre los 2000 y $10000 \mathrm{ohm}$; L, son mezclas de baja resistencia, que resultan en resistencia de base de 100,300 y $1000 \mathrm{ohm}$ a $25^{\circ} \mathrm{C}$; $\mathrm{H}$, son mezclas de óxidos que permiten obtener resistencias de base mayores a los 10 kohm.

Termocuplas: Consisten de dos junturas formadas por dos hilos metálicos distintos. Una juntura es la que se usa cono punta sensora y la otra es de referencia y se sumerge en un baño de hielo. La diferencia de temperatura entre las juntas produce un potencial termoeléctrico entre los dos cables. Las termocuplas tienen rangos de temperatura de operación grandes y pueden construirse de muy pequeño tamaño. Sin embargo tienen la dificultad de poseer potenciales de salida bajos y ser muy susceptibles a los ruidos.

Sensores de silicio: Son utilizados generalmente a temperaturas relativamente bajas. Pueden disponerse de distintos tamaños y diversos encapsulados protectores. La tolerancia de intercambiabilidad que puede alcanzarse es de 1-5\%. No posee respuesta lineal con la temperatura.

En la tabla $\mathrm{B} 1$ se consignan las propiedades más distintivas de los sensores mencionados.

Tabla B1. Tabla comparativa de sensores térmicos.

\begin{tabular}{|c|c|c|c|c|c|}
\hline Características & Pt RTD, láminas & Pt RTD alambres & Termistores & Termocuplas & $\begin{array}{c}\text { Sensores de } \\
\text { Silicio }\end{array}$ \\
\hline Material activo & Lámina de Pt & Alambre de Pt & $\begin{array}{c}\text { Oxidos } \\
\text { metálicos } \\
\text { cerámicos }\end{array}$ & $\begin{array}{c}\text { Dos metales } \\
\text { distintos }\end{array}$ & $\begin{array}{c}\text { Transistor de } \\
\text { silicio }\end{array}$ \\
\hline Costo relativo & Bajo o moderado & Moderado & Bajo o & Bajo & Bajo \\
\hline $\begin{array}{c}\text { Costo del sistema a } \\
\text { implementar }\end{array}$ & Moderado & Moderado & Bajo o & Alto & Bajo \\
\hline Rango de temperatura & $-200-750^{\circ} \mathrm{C}$ & $-220-850{ }^{\circ} \mathrm{C}$ & $-100-500{ }^{\circ} \mathrm{C}$ & $-270-1700{ }^{\circ} \mathrm{C}$ & $-40-125^{\circ} \mathrm{C}$ \\
\hline Parámetro medido & Resistencia & Resistencia & Resistencia & Voltage & Voltage \\
\hline Valor de base & $100-2000 \mathrm{ohm}$ & $100 \mathrm{ohm}$ & $1 \mathrm{Kohm}-1$ & $<10 \mu \mathrm{V}$ & $750 \mathrm{mV}$ \\
\hline Intercambiabilidad & $\pm 0,1 \%- \pm 0.3 \%$ & $\pm 0,06 \%- \pm 0,2 \%$ & $\pm 10 \%- \pm 0,1 \%$ & $\pm 0,5 \% \pm 2 \%$ & $\pm 1 \%- \pm 5 \%$ \\
\hline Estabilidad & Excelente & Excelente & Moderada & Pobre & Moderada \\
\hline Sensibilidad & $0,39 \% /{ }^{\circ} \mathrm{C}$ & $0,39 \% /{ }^{\circ} \mathrm{C}$ & $-4 \% /{ }^{\circ} \mathrm{C}$ & $40 \mu \mathrm{V} /{ }^{\circ} \mathrm{C}$ & $10 \mathrm{mV} /{ }^{\circ} \mathrm{C}$ \\
\hline
\end{tabular}


Continuación Tabla B.1

\begin{tabular}{|c|c|c|c|c|c|}
\hline Sensibilidad relativa & Moderada & Moderada & La más alta & Pobre & Moderada \\
\hline Pendiente & Positiva & Positiva & Negativa & Positiva & Positiva \\
\hline $\begin{array}{c}\text { Susceptibilidad al } \\
\text { ruido }\end{array}$ & Baja & Baja & Baja & Alta & Baja \\
\hline $\begin{array}{l}\text { Error por cables } \\
\text { conectores }\end{array}$ & Baja & Baja & Baja & Alta & Baja \\
\hline $\begin{array}{c}\text { Tamaño mínimo punta } \\
\text { de prueba } \\
\text { / pulgadas }\end{array}$ & 0,08 & 0,08 & 0,065 & 0,025 & 0,08 \\
\hline $\begin{array}{l}\text { Requerimientos } \\
\text { adicionales }\end{array}$ & --- & $\begin{array}{l}\text { Compensación de } \\
\text { cables conectores }\end{array}$ & Linearización & $\begin{array}{l}\text { Juntura de } \\
\text { referencia }\end{array}$ & --- \\
\hline
\end{tabular}

Termocuplas, termistores, y transistores LM 35

\section{Circuito termoeléctrico}

En la figura BI, se representa un circuito eléctrico de un par termoeléctrico, que constituye el fundamento de las termocuplas utilizadas para medir temperatura.

Cuando se sueldan dos hilos de metales distintos formando un circuito cerrado, se origina en este una fuerza electromotriz siempre que las soldaduras A y B estén a diferente temperatura. La fuerza electromotriz, para un par de metales dado, depende de la diferencia de temperatura entre sus soldaduras. El par termoeléctrico puede utilizarse como termómetro colocando una soldadura en contacto con el cuerpo cuya temperatura se quiere medir y manteniendo la otra a una temperatura conocida (generalmente $0^{\circ} \mathrm{C}$ ). La fuerza electromotriz (fem) en $\mathrm{C}$ es proporcional a la diferencia de temperatura entre las distintas soldaduras. 


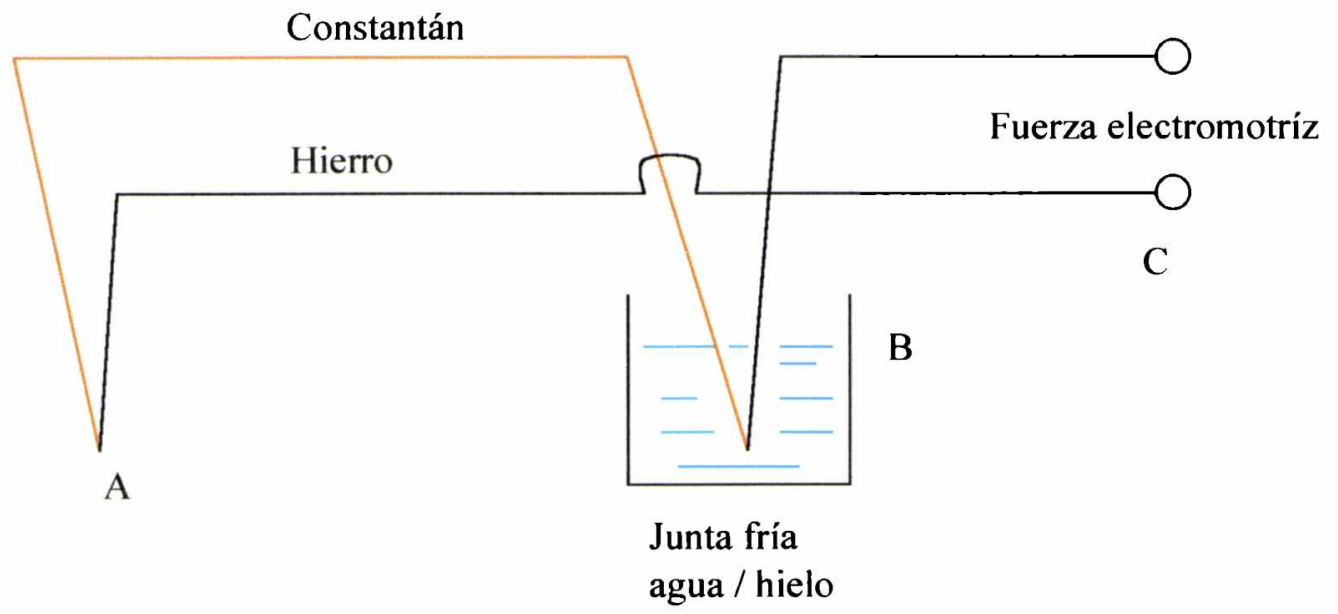

Figura B1. Circuito termoeléctrico utilizado para medir temperatura.

La curva de respuesta, temperatura - diferencia de potencial, de la termocupla tipo $\mathrm{J}$ de $\mathrm{Fe} /$ Constantán se muestra en la figura B2 para distintas temperaturas comprendidas entre 0 y $100^{\circ} \mathrm{C}$. Los datos fueron tomados de la norma ASTM E 230. La temperatura máxima recomendada es de $760^{\circ} \mathrm{C}$.

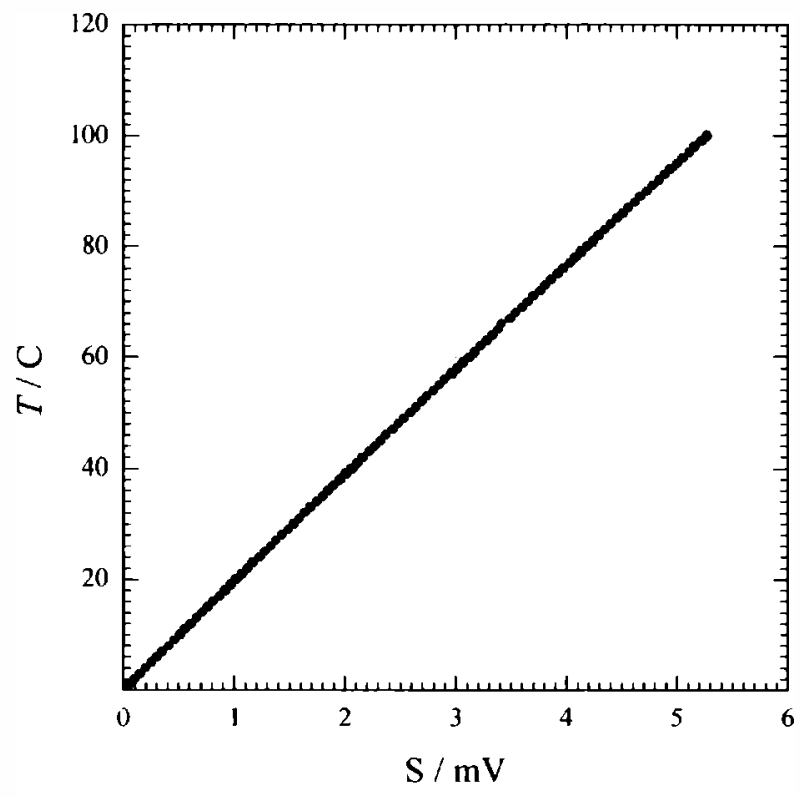

Figura B2. Curva de temperatura versus diferencia de potencial $\mathrm{S}$ en $\mathrm{mV}$.

\section{Termistor YSI}

El termistor de precisión YSI 44001 A se puede utilizar en el rango de temperaturas comprendidos entre $-80^{\circ} \mathrm{C}$ y $100^{\circ} \mathrm{C}$. La curva de respuesta, temperatura resistencia, se muestra en la figura $\mathrm{B} 3$ para el rango que va desde -20 a $100^{\circ} \mathrm{C}$. 


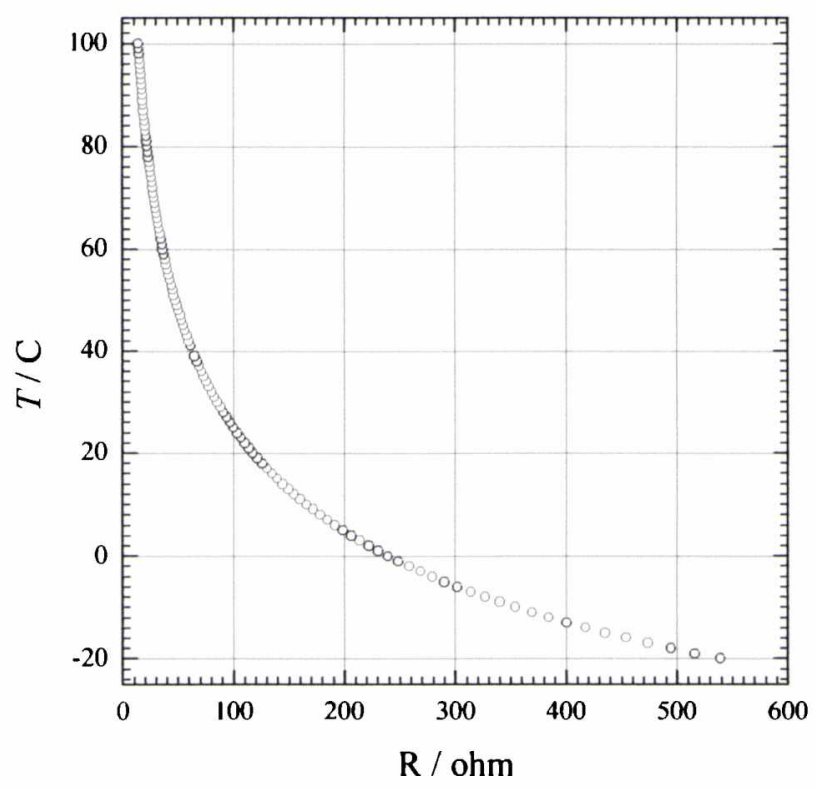

Figura B3. Curva Temperatura - resistencia para el termistor YSI $44001 \mathrm{~A}$

En la figura B4 se muestra un termistor YSI 44001 A. Se aprecia el pequeño tamaño del sensor.

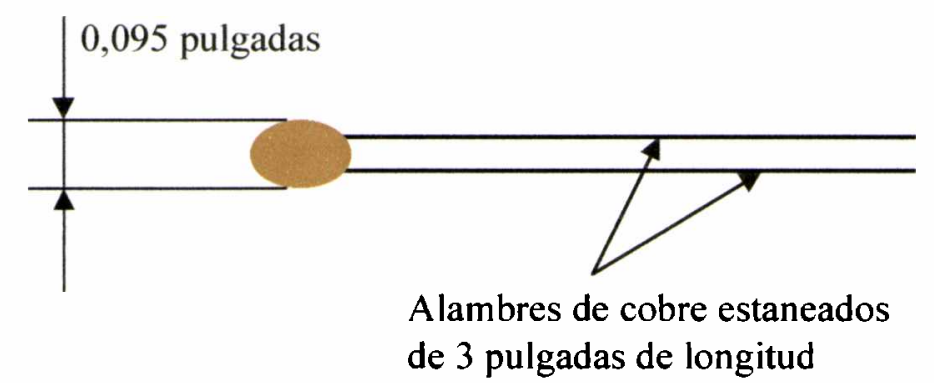

Figura B4. Termistor YSI $44001 \mathrm{~A}$.

\section{Sensores LM 35}

Los transistores LM 35 son sensores de temperatura de alta precisión, que posen una salida de voltage que es linearmente proporcional a la temperatura. El factor de escala es de $10 \mathrm{mV} /{ }^{\circ} \mathrm{C}$ y alcanzan una precisión de $1 / 4$ de ${ }^{\circ} \mathrm{C}$ a $25^{\circ} \mathrm{C}$. Pueden ser alimentados con fuentes de 4 a $30 \mathrm{~V}$. En la figura B6 se muestra un esquema del sensor LM 35 y un circuito de conexión posible para su empleo. 
a)

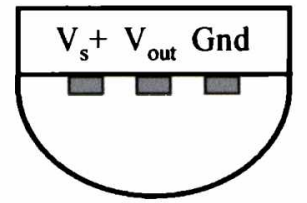

LM 35

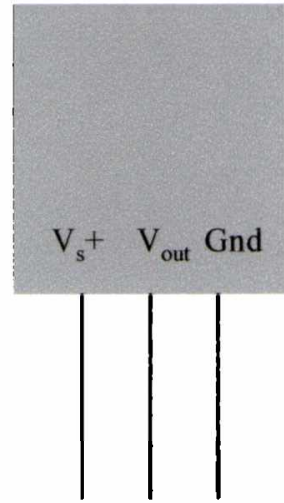

b)

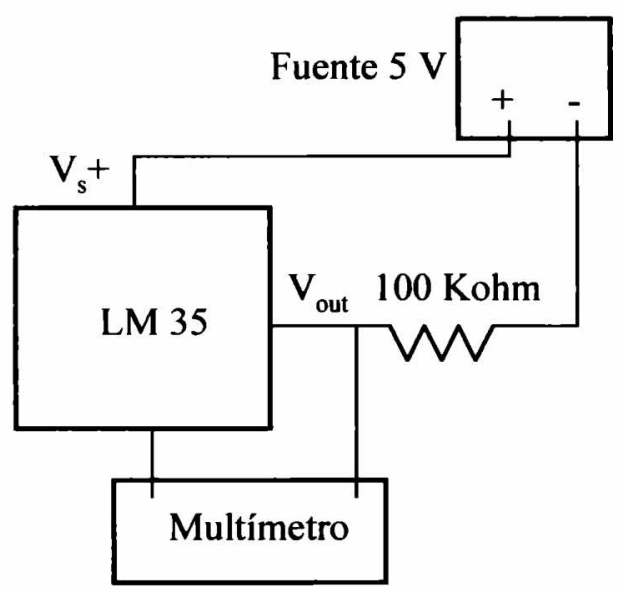

Figura B6. a) Esquema del sensor de temperaturas LM 35; b) Circuito de conexión empleado para la utilización del sensor. $V_{s}$ : voltage de alimentación; $V_{\text {out }}$ señal de salida; Gnd : tierra. 


\section{Apéndice C}

Problema de frontera móvil con solución explícita

Planteo general para una sola fase:

$$
\begin{aligned}
& \left\{\begin{array}{l}
a^{2} \begin{array}{l}
\partial \theta \\
\partial x^{2}
\end{array}=\begin{array}{l}
\partial \theta \\
\partial t
\end{array} S(t)<x ; t>0 \\
\theta(x, 0)=\mathrm{h}(x) \quad x>0=S(0) \\
\theta(S(t), t)=\psi(t) t>0
\end{array}\right. \\
& S=S(t) \text { es la frontera, con } \mathrm{S}(0)=0 .
\end{aligned}
$$

Se considera:

$\mathrm{h}(x)=0 ; S(t)=\beta t ; \psi(t)=$ Constante $; \theta=c_{\mathrm{i}}$ ( concentración de la especie i $)$; $\beta$ es la velocidad $(d S(t) / d t=\beta)$.

La solución propuesta por Tarzia y adaptada por Vicente es:

$$
\begin{aligned}
& \theta\left(a, c_{\mathrm{i}}, \beta, x, t\right)=c \cdot \exp \left(-\frac{\beta}{a^{2}}(x-\beta t)\right) \gamma\left(\begin{array}{c}
x-\beta t \\
2 a t
\end{array}+\begin{array}{c}
\beta \\
2 a
\end{array}\right)+ \\
& +\exp \left(\begin{array}{c}
\beta(x-\beta t) \\
a^{2}
\end{array}\right) \gamma\left(\begin{array}{c}
x-\beta t \\
2 a t
\end{array}+\begin{array}{c}
\beta, t \\
2 a
\end{array}\right)
\end{aligned}
$$

con $\gamma(r)=\frac{1-\operatorname{ERF}(r)}{2} ; \mathrm{a}=D_{\mathrm{i}}^{1 / 2}$ es el coeficiente de difusión de la especie i.

Redefiniendo $\mathrm{u}(x, t)=c-\theta(x, t)$ se tiene :

$$
\begin{aligned}
& \mathrm{u}\left(a, c_{\mathrm{i}}, \beta, x, t\right)={ }_{2}^{c} \cdot \exp \left(\begin{array}{c}
\beta^{2} t \\
a^{2}-\frac{\beta x}{a^{2}}
\end{array}\right)\left(\operatorname{ERF}\left(\begin{array}{c}
x+\beta, t \\
2 a t \\
a
\end{array}\right)-1\right)+ \\
& +{ }_{2}^{c} \mathrm{ERF}\left(\left(\begin{array}{c}
x \\
2 a t
\end{array}\right)+1\right)
\end{aligned}
$$

Luego la corriente se calcula a partir de $d u /\left.d x\right|_{x=\beta+}$ y multiplicando por las constantes adecuadas. 


\section{Apéndice D}

Resolución de la ecuación de difusión - convectiva con efecto combinado de los gradientes de concentración y térmico

Se debe resolver simultáneamente las ecuaciones de transferencias de momento, de materia y de energía.

Para el caso de un electrodo vertical bajo la acción de la fuerza gravitatoria, la ecuación de transferencia de momento es:

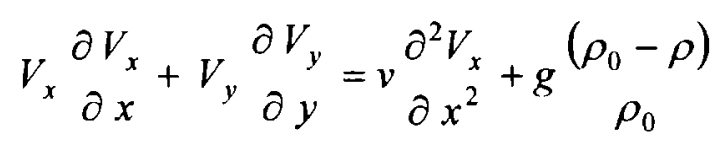

donde $x$ e $y$ son las coordenadas definidas sobre el electrodo (con origen en la parte más baja del electrodo) y en la dirección perpendicular del electrodo respectivamente, $V_{x}$ y $V_{y}$ son las componentes de la velocidad del líquido, $v$ la viscosidad cinemática, $g$ la constante gravitatoria, $\rho_{0}$ la densidad de referencia (del seno de la solución) y $\rho$ la densidad de la solución, que es función de la concentración y de la temperatura.

Las ecuaciones de transferencia de masa y de energía son respectivamente:

$$
\begin{aligned}
& V_{x}{ }_{\partial x}^{\partial c_{\mathrm{i}}}+V_{y} \partial c^{\partial c_{\mathrm{i}}}=D \begin{array}{l}
\partial^{2} c_{\mathrm{i}} \\
\partial x^{2}
\end{array}
\end{aligned}
$$

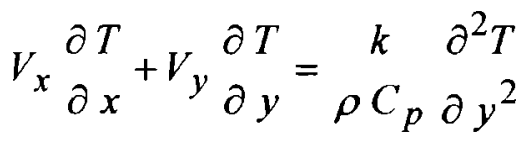

donde $c_{\mathrm{i}}$ es la concentración de las especies que difunden, $D$ el coeficiente de difusión, $T$ la temperatura, $k$ la conductividad térmica y $C_{p}$ la capacidad calorífica a presión constante.

Las condiciones de contorno para este conjunto de ecuaciones diferenciales son:

$$
\begin{aligned}
& y=0 ; V_{x}=V_{y}=0 ; c_{\mathrm{i}}=0 ; T=T_{\mathrm{c}} \\
& y=\infty ; V_{x}=V_{y}=0 ; c_{\mathrm{i}}=c_{\mathrm{i}} ; T=T_{0}
\end{aligned}
$$

Se considerando que la densidad no varía demasiado con la concentración y la temperatura, se puede escribir:

$$
\rho=\rho_{0}+\frac{\partial \rho}{\partial c}\left(c-c_{\mathrm{i}}^{0}\right)+\frac{\partial \rho}{\partial T}\left(T-T_{0}\right)
$$


Para resolver las ecuaciones (D1), (D2) y (D3) se las transforma en un conjunto de ecuaciones diferenciales totales.

Resulta conveniente definir en este momento los coeficientes de densificación $\alpha$ y $\beta$ :

$$
\begin{array}{r}
\alpha=\begin{array}{l}
C_{0} \partial \rho \\
\rho_{0} \partial c
\end{array} \\
\beta=\begin{array}{r}
\Delta T^{\prime} \partial \rho \\
\rho_{0} \partial T
\end{array}
\end{array}
$$

donde $\Delta T^{\prime}=T_{0}-T_{\mathrm{c}} ; T_{0}=T_{\mathrm{a}}-T_{\mathrm{c}}$ (temperatura del ánodo y del cátodo respectivamente).

Siguiendo el mismo procedimiento usado para resolver la ecuación de transferencia de masa en condiciones de convección natural en condiciones isotérmicas (difusión convectiva) [Levich] se define una nueva variable adimensional $\mu$ :

$$
\mu=\left(\frac{g}{4 v^{2}}\right)^{1 / 4} x^{1 / 4}
$$

Se definen además la concentración $\varphi$ y la temperatura $\tau$ adimensional:

$$
\begin{gathered}
\varphi=\begin{array}{c}
c^{0}-c \\
c^{0}
\end{array} \\
\tau=\begin{array}{l}
T_{0}-T \\
T_{0}-T_{1}
\end{array}
\end{gathered}
$$

la función de corriente se define [164]:

$$
\psi=4 v\left(\begin{array}{c}
g \\
4 v^{2}
\end{array}\right)^{1 / 4} x^{3 / 4} f(\mu)
$$

$\mathrm{Y}$ las componentes de la velocidad pueden expresarse:

$$
\begin{gathered}
V_{x}=\frac{\partial \psi}{\partial y}=4 v\left(\begin{array}{c}
g \\
4 v^{2}
\end{array}\right)^{1 / 2} x^{1 / 2} f^{\prime}(\mu) \\
V_{y}=-\frac{\partial \psi}{\partial x}=v\left(\begin{array}{c}
g \\
a v^{2}
\end{array}\right)^{1 / 4}\left(\begin{array}{c}
\mu f^{\prime}(\mu)-3 f(\mu) \\
x^{1 / 4}
\end{array}\right)
\end{gathered}
$$

donde $f(\mu)$ y $f^{\prime}(\mu)$ son funciones de la variable $\mu$ y su primera derivada, que satisfacen:

$$
f^{\prime \prime}+3 f f^{\prime \prime}-2(f)^{2}+\alpha \beta+\beta \tau=0
$$


Similarmente, las ecuaciones diferenciales totales para la transferencia de materia y energía, en término de $\varphi$ y $\tau$, son respectivamente

$$
\begin{gathered}
\varphi^{\prime \prime}+3 \operatorname{Sc} f \varphi^{\prime}=0 \\
\tau^{\prime \prime}+3 \operatorname{Pr} f \tau^{\prime}=0
\end{gathered}
$$

donde $S c$ es en número de Schmidt definido por:

$$
\mathrm{Sc}=v / D
$$

Y Pr el número de Prandlt:

$$
\operatorname{Pr}=v \rho C_{\mathrm{p}} / k
$$

Las condiciones de contorno para (D.13-D.15) son:

$$
\mu=0\left\{\begin{array}{l}
f=f^{\prime}=0 \\
\varphi=1 \\
\tau=1
\end{array} ; \quad \mu=\infty\left\{\begin{array}{l}
f^{\prime}=0 \\
\varphi=0 \\
\tau=0
\end{array}\right.\right.
$$

\section{Funciones de distribución}

Para obtener las funciones de distribución relacionadas con la transferencia de materia en condiciones no isotérmicas, se consideran primero los siguientes casos límite:

1) Convección libre isotérmica, $\Delta T=0$

El conjunto de ecuaciones diferenciales se reduce a la (D.13) y la (D.14).

Para establecer la distribución de concentración Levich consideró que $f$ puede expresarse en serie de potencia de $\eta$

$$
f(\eta)={ }_{2}^{A_{\eta}} \eta^{2}-\eta^{3}+\left(\begin{array}{c}
A_{\eta} S c \\
2
\end{array}\right)^{1 / 3} \begin{gathered}
\eta^{4} \\
24 \times 0,89
\end{gathered}
$$

donde

$$
\eta=\left(\begin{array}{c}
g \alpha \\
4 v^{2}
\end{array}\right)^{1 / 4} \quad x^{1 / 4}
$$

A partir de las condiciones de contorno, se tiene para $A_{\eta}$ 


$$
A_{\eta}=\begin{gathered}
0,48 \\
S c^{1 / 4}
\end{gathered}
$$

y la distribución de concentraciones resulta

$$
\varphi=1-{ }_{0,89}^{\left(\begin{array}{c}
0,48 \\
2
\end{array}\right)^{1 / 3} S c^{1 / 4} \eta}
$$

2) Convección originada únicamente por gradientes térmico

El conjunto de ecuaciones se reduce ahora al problema de transferencia de calor por convección. Se trata en forma similar al caso 1).

$f$ puede expresarse en serie de potencia de $\lambda$

$$
f(\lambda)={ }_{2}^{A_{\lambda}} \lambda^{2}-\frac{\lambda^{3}}{6}+\left(\begin{array}{c}
A_{\lambda} S c \\
2
\end{array}\right)^{1 / 3} \begin{gathered}
\lambda^{4} \\
24 \times 0,89
\end{gathered}
$$

donde

$$
\lambda=\left(\begin{array}{c}
g \beta \\
4 v^{2}
\end{array}\right)^{1 / 4} x^{1 / 4}
$$

A partir de las condiciones de contorno, se tiene para $A_{\lambda}$

$$
A_{\lambda}=\begin{gathered}
0,48 \\
\operatorname{Pr}^{1 / 4}
\end{gathered}
$$

y la distribución de temperaturas resulta

$$
\tau=1-{ }_{0,89}^{\left(\begin{array}{c}
0,48 \\
2
\end{array}\right)^{1 / 3} \operatorname{Pr}^{1 / 4} \lambda}
$$

3) Se ataca el problema de las contribuciones combinadas de los gradientes de concentración y de temperatura que modifican la densidad del fluido. De acuerdo a (D.10), (D.19) y (D.23) se tiene

$$
\varphi=4 v\left(\begin{array}{c}
g \\
4 v^{2}
\end{array}\right)^{1 / 4} x^{3 / 4}\left\{\begin{array}{l}
{\left[A_{\eta} \alpha^{3 / 4} \pm A_{\lambda} \beta^{3 / 4}\right]_{2}^{\mu^{2}}-\alpha \pm \beta} \\
{\left[\left(A_{\eta} S c\right)^{1 / 3} \alpha^{5 / 4} \pm\left(A_{\eta} \operatorname{Pr}\right)^{1 / 3} \beta^{5 / 4}\right]_{2^{1 / 3} \times 24 \times 0,89}}
\end{array}\right\}
$$

Finalmente con (D.13) y (D.14) se calculan las componentes de la velocidad del fluido $V_{x}$ y $V_{y}$. 


\section{Apéndice E}

Programa para simular crecimientos fractales

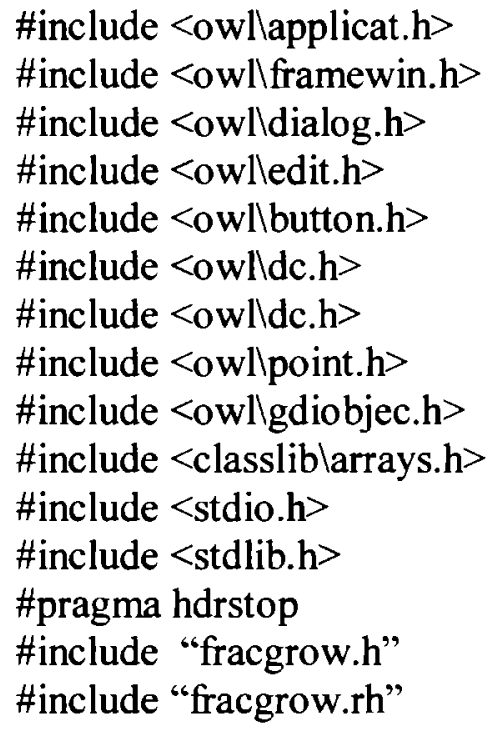

//Enable data transfers between options buffer and controls SetTransferBuffer (.options); 
public:

TfracWin (Twindow* pare, const char far* name);

Buffer options;

// Data transfer buffer

Protected:

// void SetupWindow ( );

// void SetMaxCoordinates ( );

$/ /$ void EvSize (UINT sizeType, TSize\& size);

$/ /$ void Paint (TDC\& dc, BOOL erase, TRect\& rect);

void CmOpts ( );

void CmRun ( );

BOOL Empty (TDC \& dc, TPoint p);

Private:

int $\mathrm{Vx}, \mathrm{Vy}, \mathrm{Ey}$;

int Px1, Pxr, Pyu, Pyd;// Cumulativve probabilities of movement long Npix;

int Big;

int Max y[playing Field];

TArrayAsVector <TPoint $>$ PlayingFielf;

TRect * Playing Area;

DECLARE_RESPONSE_TABLE (TFracWin);

\}

DEFINE_RESPONSE_TABLE1 (TfracWin,TFrameWindow)

EV_COMMAND (CM_OPTIONS, CmOpts),

EV_COMMAND (CM_RUN, CmRun),

END_RESPONSE_TABLE;

TFracWin: : TFracWin (Twindow* pare, const char far* name)

:TfracWindow (pare, name), Twindow (pare, name),

PlayingField(DEFAULT PARTICLES, 0 , DEFAULT_ADD_PARTICLES)

\{

$\operatorname{char}^{*} \operatorname{str}=" 0 "$

randomize;

strcpy (options.Vx_C, str);

strcpy (options. Vy_C, str);

strcpy (options. Ey_C, str);

strcpy (options. Npix_C, DEFAULT_PARTICLEZ_C);

Big = DEFAULT_BIG;

$\mathrm{Vx}=$ DEFAULT_VX;

$\mathrm{Vy}=$ DEFAULT_VY;

Ey $=$ DEFAULT_EY;

Npix = DEFAULT_PARTICLES;

$\mathrm{Px} 1=$ (int) $\left(\mathrm{Big}^{*}(1.0+\mathrm{Vx} / 2) /(4+\mathrm{Vx}+\mathrm{Vy}+\mathrm{Ey})\right)$;

$\mathrm{Pxr}=\mathrm{Pxl}+($ int $)\left(\mathrm{Big}^{*}(1.0+\mathrm{Vx} / 2) /(4+\mathrm{Vx}+\mathrm{Vy}+\mathrm{Ey})\right)$ 


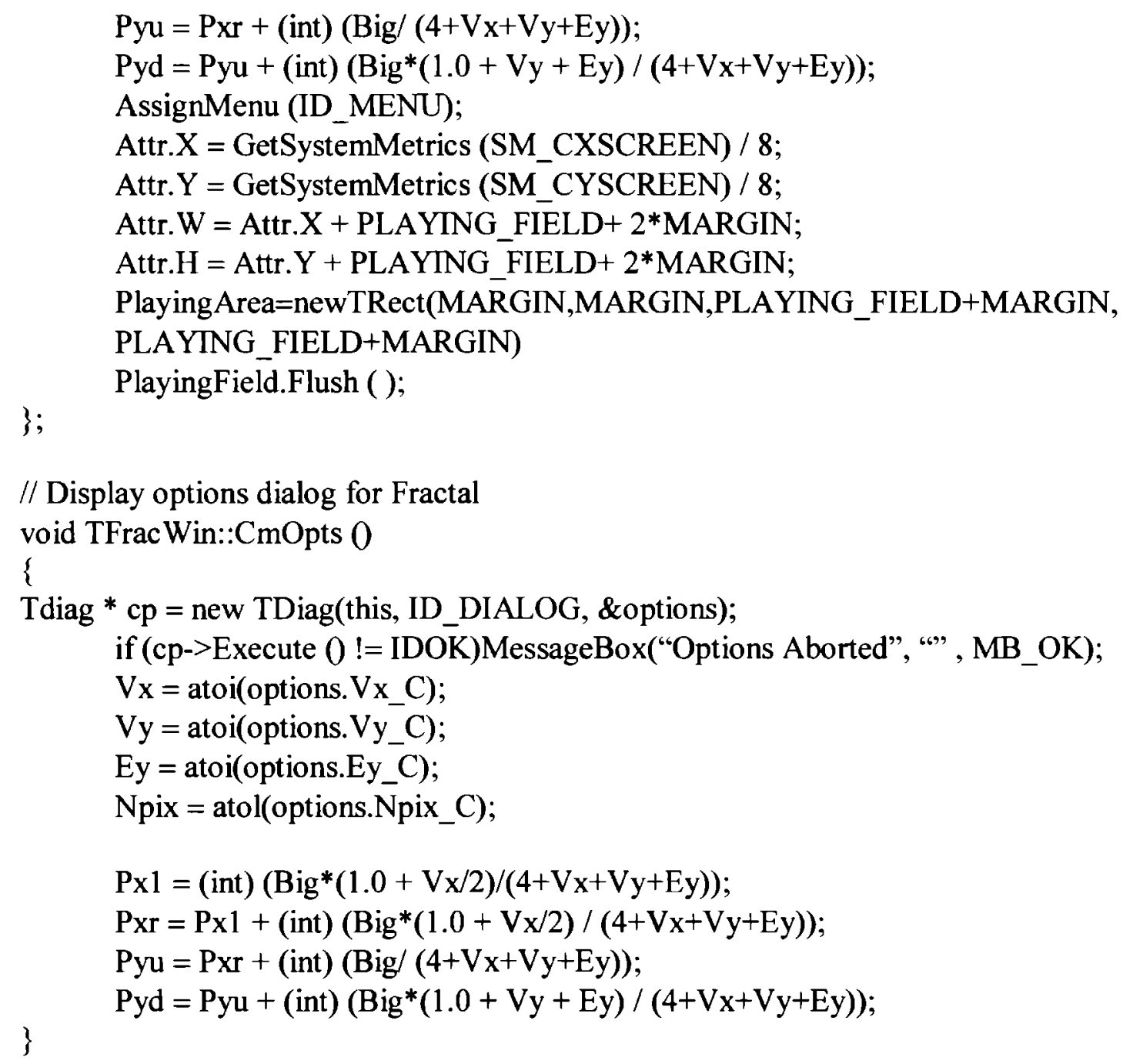

BOOL TFracWin: : Empty (TDC \& dc, Tpoint p)

Tcolor $\operatorname{red}(255,0,0)$;

Return ( (dc.GetPixel (p.x,p.y+1) !=red) \&\& (dc.GetPixel(p.x,p.y-1)) !=red) $\& \&$ (dc.GetPixel(p.x+1,p.y)) !=red) $\& \&$ (dc.GetPixel(p.x-1,p.y)) !=red)

$\& \&$ (dc.GetPixel(p.x+1,p.y+1)) !=red)

$\& \&($ dc.GetPixel(p.x-1,p.y+1)) !=red)

$\& \&($ dc.GetPixel(p.x+1,p.y-1)) !=red)

$\& \&($ dc.GetPixel(p.x-1,p.y-1)) !=red) )

void TFracWin::CmRun 0 \{

;\}

long $\mathrm{p}$;

int $\mathrm{R}, \mathrm{i}$; 
Tpoint pix, jump, zero $(0,0)$;

BOOL Lost;

TclientDC dc(HWindow);

Tcolor red $(255,0,0)$, blue $(0,0,255)$;

Tpen bluepen (blue);

Tpen redpen (red);

dc.SelectObject (bluepen);

dc.Rectangle (*PlayingArea);

dc. RestorePen 0 ;

dc.SelectObject (redpen);

dc.MoveTo (MARGIN, PLAYING_FIELD + MARGIN);

dc.LineTo (PLAYING_FIELD + MARGIN, PLAYING_FIELD + MARGIN);

dc.RestorePen 0 ;

$\mathrm{p}=0$;

for $(\mathrm{i}=0 ; \mathrm{i}<$ PLAYING_FIELD; $\mathrm{i}++)$ Max_y[i] = PLAYING_FIELD + MARGIN;

Max_y[0] = PLAYING_FIELD + MARGIN;

While ( $\mathrm{p}<\mathrm{Npix})$;

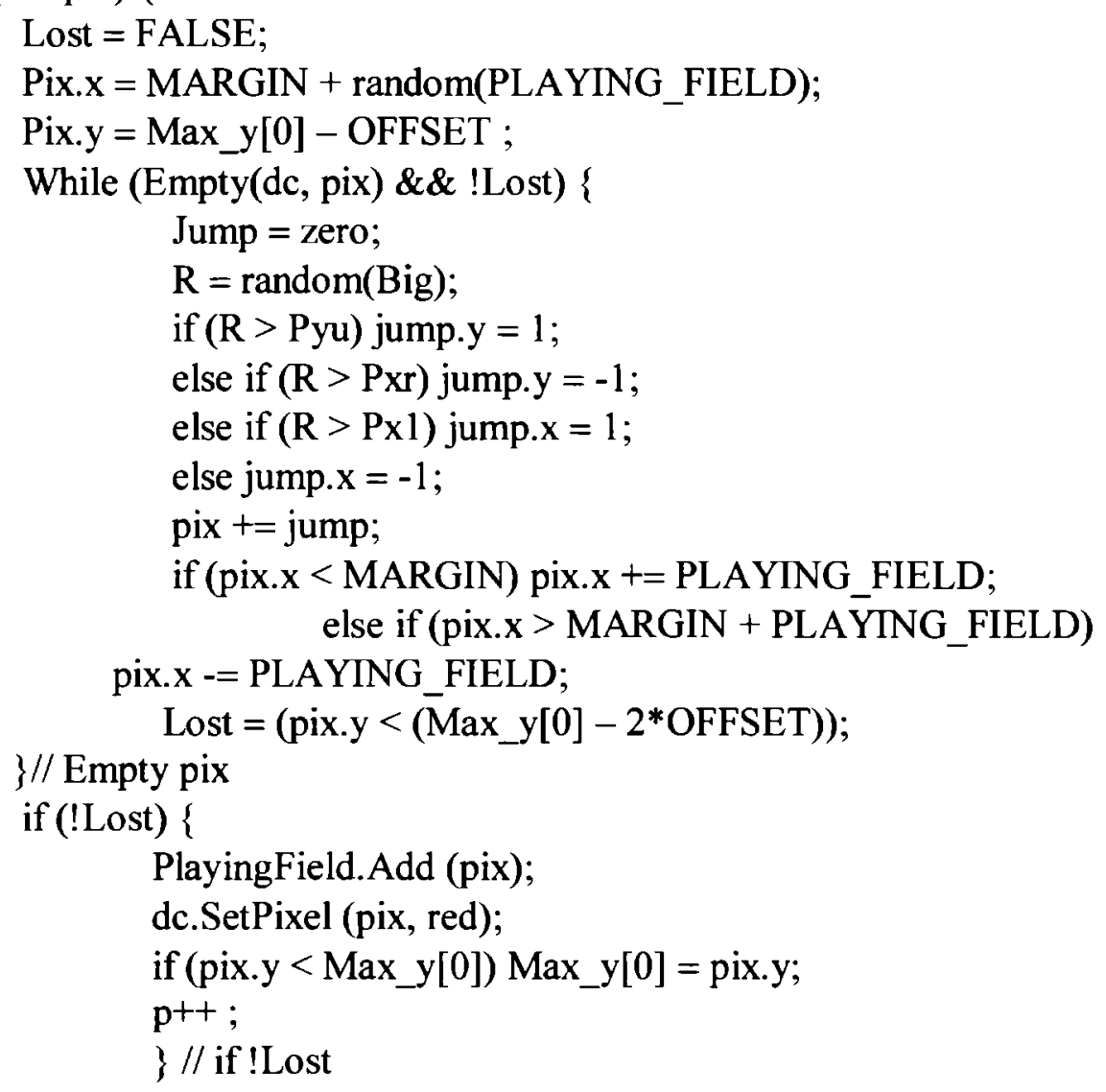

\} //while $\mathrm{p}<$ Npix

MessageBox ( "Hello Edward”, “”, MB_OK); 


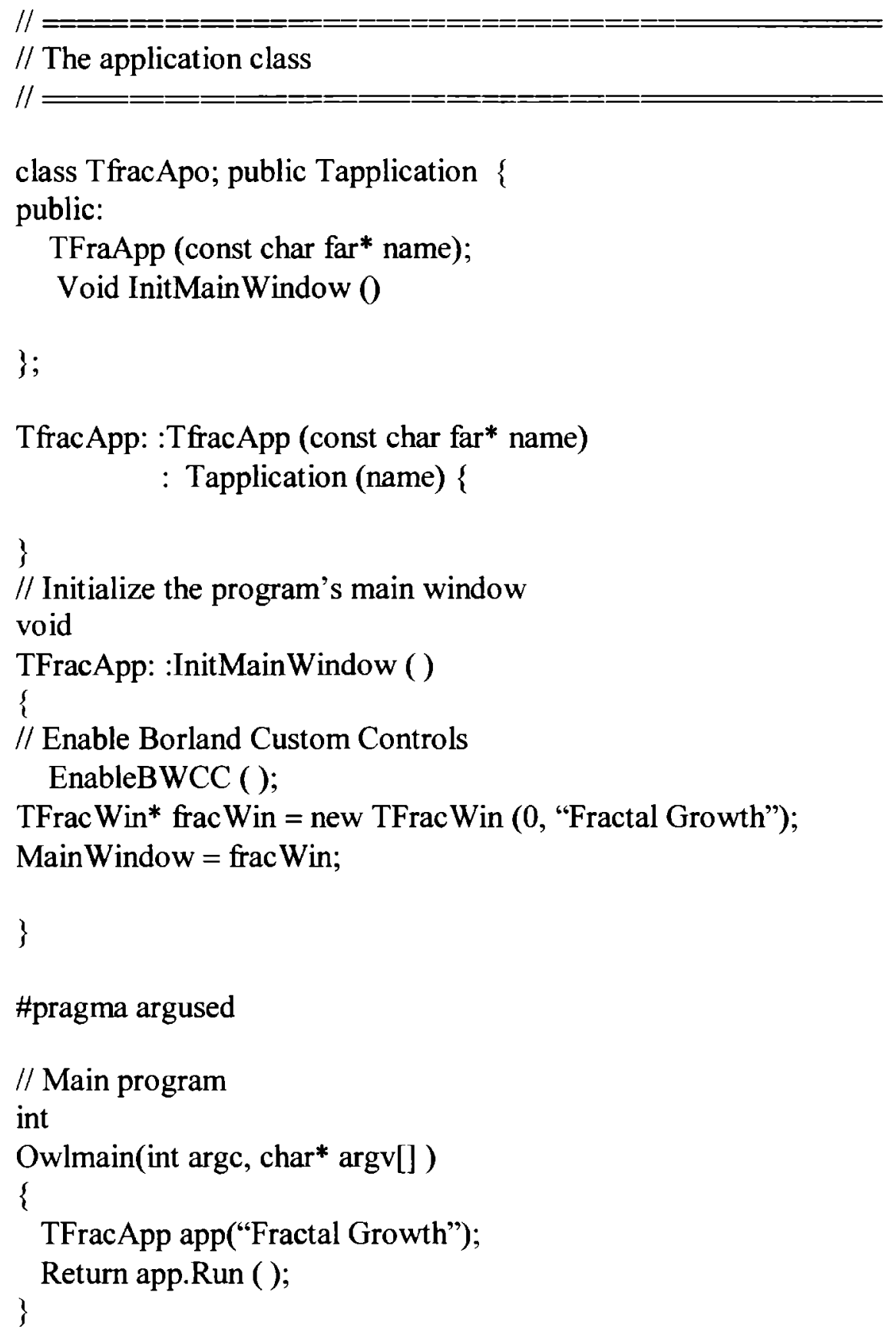


El presente trabajo de Tesis ha originado las siguientes publicaciones en revistas internacionales:

* "Transitions in the growth mode of branched silver electrodeposits under isothermal and non-isothermal ionic mass transfer kinetics" M.A. Pasquale, S.L. Marchiano And A.J. Arvia, J. Electroanal. Chem., 532 (2002) 255.

* "Stability analysis of branched silver electrodeposits: Solid phase growth under a marginally stable regime". M.A. Pasquale, S.L. Marchiano, P.L. Schilardi, R.C. Salvarezza and A.J. Arvia, Physical Review E, 65 (2002) 041608.

* "Non-isothermal ionic mass transfer at vertical parallel plate electrodes under natural convection. Comparison and validity range of dimensionless correlations", M.A. Pasquale, S.L. Marchiano And A.J. Arvia, Electrochim. Acta, 48 (2002) 153.

* "Influence of agarose on the electrochemical behaviou of the silver and platinum aqueous acid electrolyte interface". M. A. Pasquale, S. L. Marchiano, A.E. Bolzán and A.J. Arvia, J. appl. Electrochim., 33 (2003) 431.

* "Comparative dynamic scaling analysis of quasi-2D electrodeposited silver patterns under localized and non-localized random quenched noise". M.A. Pasquale, S.L. Marchiano and A.J. Arvia. En "Thinking in Patterns. Fractals and Related Phenomena in Nature", M. M. Novak ed., Vancouver, Canada, (2004).

* "Experimental evidence on the development of scale invariance in the internal structure of self-affine aggregates". C.M. Horowitz, M.A. Pasquale, E.V. Albano and A.J. Arvia. Enviado al Physical Review B.

* "Sieving effect of agarose on quasi 2D silver patterns electroformation. A pinningdepinning-like transition resulting from gelled plating baths". M. A. Pasquale, S. L. Marchiano and A.J. Arvia. Aceptado para ser publicado en el Journal of Chem. Phys.

* "Solution of the Stefan problem: silver electrodeposition under mass transfer control. The transition from diffusion to advection regime". M.A. Pasquale and S.L. Marchiano, J. M. Vicente and A. J. Arvia. Enviado al Journal of Chem. Phys. 